\section{MICROBIAL SIZE SPECTRA FROM DIVERSE MARINE ECOSYSTEMS}

by

\author{
Karina Y. H. Gin \\ B.Eng. Civil Engineering (1988) \\ University of Melbourne \\ M.Eng. Civil Engineering (1991) \\ National University of Singapore \\ Submitted in Partial Fulfillment of the Requirements of \\ DOCTOR OF SCIENCE \\ in Aquatic Science and Environmental Engineering \\ at the \\ MASSACHUSETTS INSTITUTE OF TECHNOLOGY \\ and the \\ WOODS HOLE OCEANOGRAPHIC INSTITUTION \\ June 1996 \\ (C) 1996 Karina Y. H. Gin \\ All rights reserved
}

\begin{tabular}{c} 
MARINE \\
BIOLOGICAL \\
LABORATORY \\
\hline LIB RARY \\
\hline $\begin{array}{c}\text { WOODS HOLE, MASS. } \\
\text { W. H. O. I. }\end{array}$ \\
\hline
\end{tabular}

The author hereby grants to MIT and WHOI permission to reproduce and to distribute publicly paper and electronic copies of this thesis document in whole or in part.

Signature of

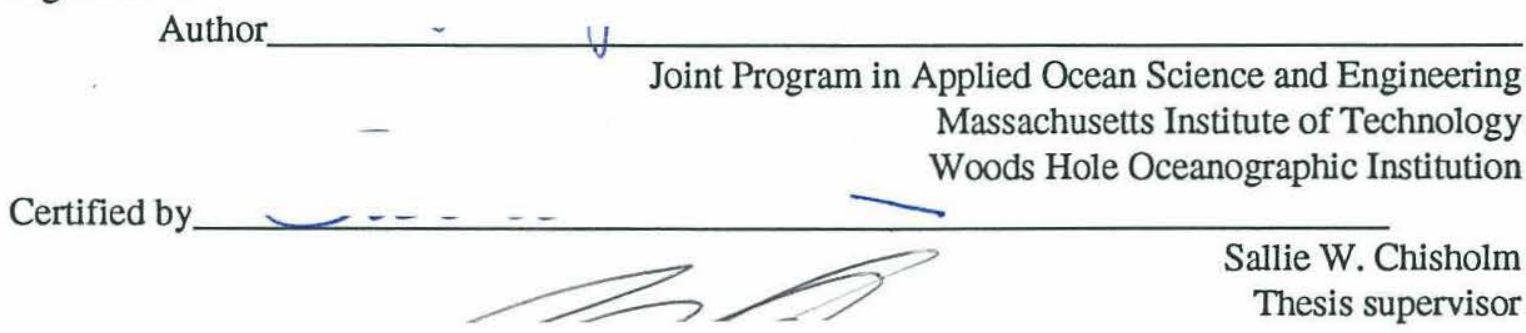

Accepted by

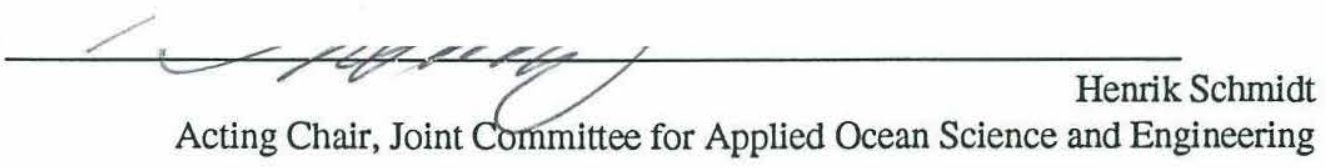




\title{
MICROBIAL SIZE SPECTRA \\ FROM DIVERSE MARINE ECOSYSTEMS
}

by

\author{
Karina Y. H. Gin \\ Submitted in partial fulfillment of the \\ requirements for the Degree of Doctor of Science \\ at the Massachusetts Institute of Technology \\ and the Woods Hole Oceanographic Institution \\ June 1996
}

\begin{abstract}
Characteristics of microbial size spectra (bacteria and phytoplankton) were examined in relation to changes in ecosystem productivity and environmental perturbations. Samples were obtained from productive coastal waters in Massachusetts and Cape Cod Bays, oligotrophic waters in the Sargasso Sea and high nutrient, low chlorophyll waters in the equatorial Pacific. In general, a relative predominance of larger bacteria and phytoplankton cells was observed in early spring, where low temperatures resulted in wellmixed waters and high nutrient concentrations. Seasonal succession was accompanied by a shift in the size spectrum to smaller cells, coinciding with rising temperatures, stratification of the water column and diminishing nutrient concentrations. In stratified waters, larger mean bacteria and phytoplankton sizes were observed in surface and deep waters, whereas smaller sizes were observed around the chlorophyll maximum. Bacteria and phytoplankton growth were well correlated with mean bacteria sizes varying positively with mean phytoplankton sizes. Data pooled from all locations showed that the size spectral characteristics most sensitive to environmental change were the mean cell size, bacteria intercept and phytoplankton slope of the normalized concentration size spectrum. Increases in ecosystem productivity, chlorophyll, particulates and nutrients were generally accompanied by shifts in the size spectra to larger bacteria and phytoplankton.
\end{abstract}

Thesis supervisor: Prof. Sallie. W. Chisholm

Title: Professor of Civil and Environmental Engineering, and Biology 


\title{
MICROBIAL SIZE SPECTRA \\ FROM DIVERSE MARINE ECOSYSTEMS
}

\author{
by \\ Karina Y. H. Gin \\ Submitted in partial fulfillment of the requirements \\ for the Degree of Doctor of Science \\ in Aquatic Science and Environmental Engineering \\ at the Massachusetts Institute of Technology \\ and the Woods Hole Oceanographic Instituition \\ June 1996
}

\begin{abstract}
Microbial size spectra serve as synoptic pictures of the organization of the pelagic food web. However, field data sets are limited and the range and variability of size spectra are still relatively unexplored. In this thesis, we examined how the characteristics of microbial size spectra varied with ecosystem productivity, and how size spectra responded to environmental perturbations. Flow cytometry was used to generate size spectra and to study the temporal and spatial dynamics of bacteria and phytoplankton from high nutrient, productive coastal waters in Massachusetts and Cape Cod Bays, and low nutrient, low productivity waters in the oligotrophic Sargasso Sea. Additional data was collected from the equatorial Pacific - a high nutrient, low chlorophyll region.

In general, a spectrum reflecting the predominance of larger bacteria and phytoplankton cells was observed in winter and early spring, where low temperatures resulted in wellmixed waters and high nutrient concentrations. Seasonal succession was accompanied by a distinct shift in the size spectrum to smaller cells, coinciding with rising temperatures, stratification of the water column and diminishing nutrient concentrations. In stratified waters, larger mean bacteria and phytoplankton sizes were observed in surface and very deep waters, whereas the smallest sizes were typically seen around the chlorophyll maximum. In the fall, decreasing temperatures destabilized the water column, replenishing nutrients which in certain cases triggered a fall bloom and a subsequent shift in the spectrum to larger sizes. Bacteria growth was generally well correlated with phytoplankton growth, with mean bacteria sizes varying positively with mean phytoplankton sizes.

Data pooled from all locations showed that the size spectral characteristics most sensitive to environmental change were the mean cell size, bacteria intercept and phytoplankton slope of the corresponding normalized concentration size spectrum. Increases in
\end{abstract}


ecosystem productivity, chlorophyll, particulates and nutrients (especially silicate) were generally accompanied by shifts in the size spectra to larger bacteria and phytoplankton. For phytoplankton, slope values ranged from about -1.8 (oligotrophic oceanic waters) to about -1.3 (eutrophic coastal waters). For bacteria, the growing importance of large bacteria in productive waters was reflected by an increase in the bacteria intercept from 2 to 4.4 cells $\mathrm{ml}^{-1} \mu \mathrm{m}^{-3}$.

Thesis supervisor: Prof. Sallie. W. Chisholm

Title: Professor of Civil and Environmental Engineering, and Biology 


\section{ACKNOWLEDGEMENTS}

I would like to acknowledge and thank all the people who assisted and encouraged me during my thesis.

My thesis supervisor, Penny Chisholm provided the resources and direction which made this work possible and I am grateful for her encouragement and support. I also thank members of my thesis committee: Rob Olson and Eric Adams for their assistance. The work was partially funded by the National Science Foundation (JGOFS) OCE9022285, OCE-9302529, OCE-9012117; NOAA Sea Grant (MIT); the Massachusetts Water Authority contract \# S179; and fellowship funding from the National University of Singapore Overseas Scholarship.

Many thanks to Keith Lichten and Laurel Schaider for helping to collect samples despite harsh weather conditions. Their enthusiasm and cheerful companionship were always a great source of encouragement. I also thank past and present members of Penny's lab. group especially Sheila Frankel for her friendship and support, Lisa Moore, Brian Binder, Ena Urbach, Kent Bares, Nicole Poulton, Carol Duval, Liz Mann, Lana Aref, Jeff Dusenberry, Gabrielle Rocap as well as Erik Zettler and Michelle DuRand from Rob's group.

I also wish to acknowledge many people outside MIT who assisted me through my thesis: Mike Conner and Mike Michelson from the Massachusetts Water Authority was most helpful in providing Boston Harbour data as and when I needed it; Dave Borkman and Toni Chute for their kind assistance in collecting samples and the crews of R/V Marlin, Iselin and the Endeavour.

Special thanks to those who helped me when I lost the use of my hands: Steven Tay, Francis Tay and their families for always being there as well as providing me delicious home-cooked meals, Aaron Frankel and xyz for helping me finish up the lab. experiments and Jennifer Guo for helping me 'cut and paste' the figures.

I am especially indebted to my dad, who typed most of this thesis and helped me to generate all the graphs. He was always willing to put aside all his other activities to help me. I thank him and my mum for their generous love and support all these years.

To my husband Eng-Soon, I am most grateful for his insightful comments on my work and especially appreciative of his constant love and encouragement. Without his support, I would not have been able to complete this thesis.

Finally, my deepest gratitude to Almighty God who has given me all things and inspired me with His creation. To Him, I owe everything. 


\section{TABLE OF CONTENTS}

$\begin{aligned} \text { Page } & \\ & \end{aligned}$

List of Figures...................................................................................................... 11

List of Tables........................................................................................................ 23

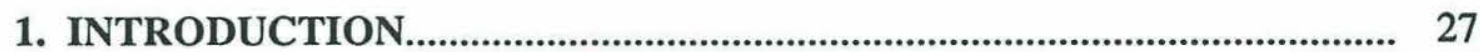

Patterns in the size spectra of pelagic organisms......................................... 27

Field observations of the overall community size spectrum............................ 28

Theoretical aspects of size spectra and their limitations................................ 30

Relationships between size spectra of component groups of organisms and the overall community size spectrum.......................................... 32

Size spectra of phytoplankton...................................................................... 33

Patterns of size-fractionated chlorophyll....................................................... 34

Maximum concentration size spectra of phytoplankton and selfregulation of the phytoplankton community..................................... 35

Phytoplankton cell size and nutrient uptake............................................... 37

Effects of predation on phytoplankton size structure................................... 39

Influence of bottom-up and top-down controlling factors on phytoplankton

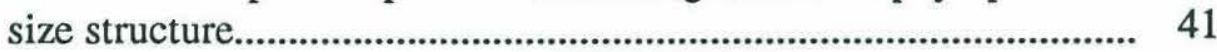

Size spectra of bacterioplankton..................................................................... 43

Importance of bacteria size on food web dynamics...................................... 44

Influence of grazing on bacteria community structure..................................... 44

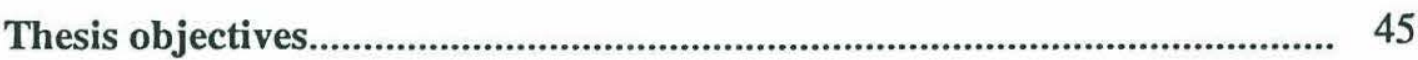

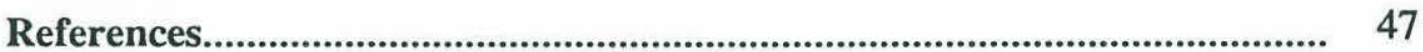

2. TEMPORAL AND SPATIAL VARIATION IN MARINE MICROBIAL SIZE SPECTRA: I. MASSACHUSETTS \& CAPE COD BAYS................ 53

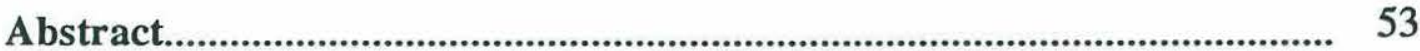

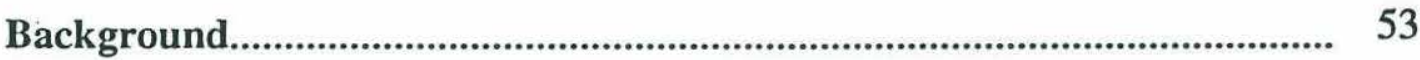

Methods.......................................................................................... 56

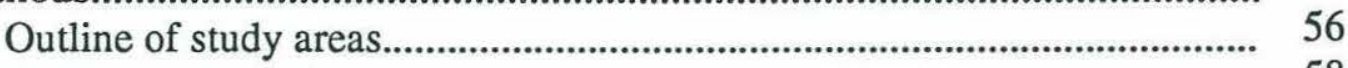

Field sampling scheme............................................................................... 58

Flow cytometric analysis............................................................................... 60

Merging the picoplankton and nano/microplankton to form a continuous 


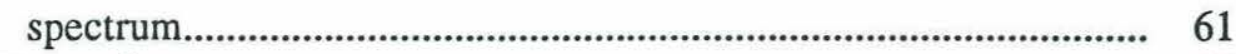

Data Processing.............................................................................................. 66

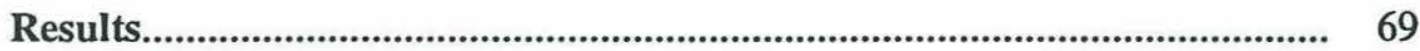

Depth variation of size spectra................................................................. 69

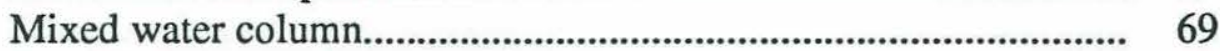

Stratified water column.................................................................. 72

Seasonal variation of size spectra............................................................ 79

Spatial variation of size spectra from the Massachusetts and Cape Cod

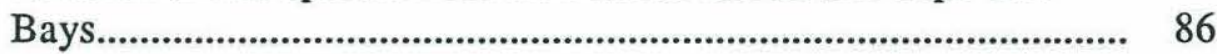

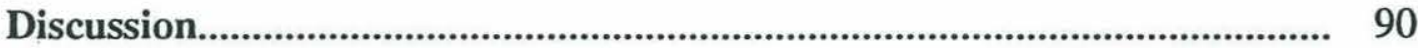

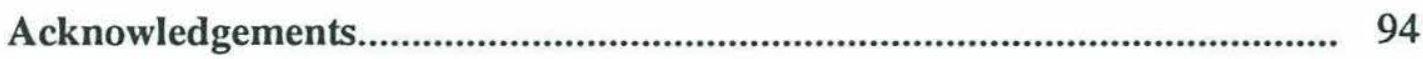

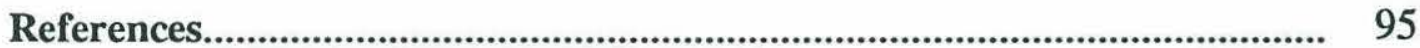

3. TEMPORAL AND SPATIAL VARIATION IN MARINE MICROBIAL SIZE SPECTRA: II. THE BERMUDA ATLANTIC TIME SERIES STATION.............................................................................................. 100

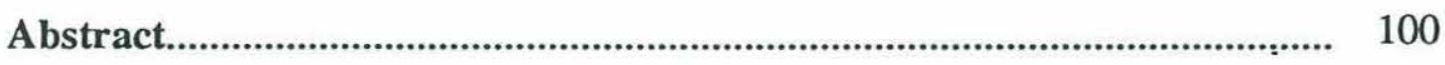

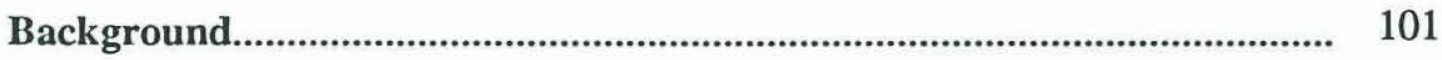

Methods...................................................................................................... 103

Field sampling scheme.......................................................................... 103

Flow cytometric analysis........................................................................ 105

Merging the picoplankton and nano/microplankton to form a continuous

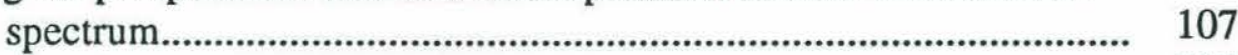

Data Processing...................................................................................... 110

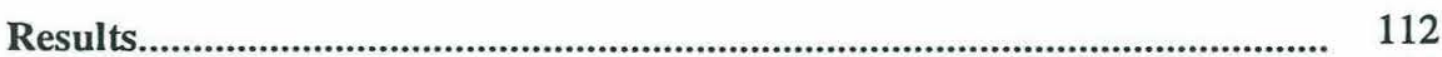

Depth variation of size spectra.................................................................. 112

Seasonal variation of size spectra............................................................ 120

Relationships between microbial size structure and environmental measurements................................................................................ 125

Discussion.......................................................................................... 130

Relationships between flow-cytometric measurements and standard environmental measurements....................................................... 130

Overall characteristics of size spectra from the Sargasso Sea......................... 135

The response of microbial size spectra to environmental perturbations......... 138 
Conclusions.............................................................................................. 140

Acknowledgements........................................................................................ 141

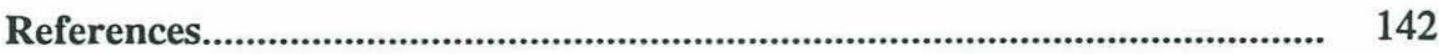

4. TEMPORAL AND SPATIAL VARIATION IN MARINE MICROBIAL SIZE SPECTRA: III. COMPARISON OF HIGH AND LOW PRODUCTIVITY ECOSYSTEMS............................................................... 148

Abstract........................................................................................... 148

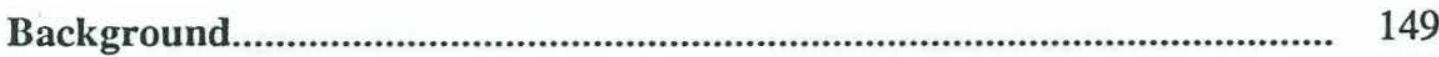

Methods..................................................................................... 151

Field sampling scheme.............................................................................. 151

Flow cytometric analysis....................................................................... 154

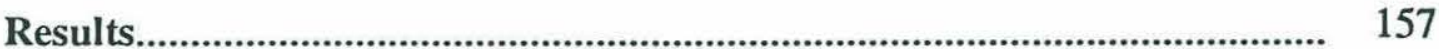

A comparison of the histogram size spectra for ecosystems of different trophic states........................................................................... 157

A comparison of the normalized size spectral characteristics for ecosystems of different trophic states.............................................................. 161

Variation of spectral characteristics with indicators of trophic state.............. 165

Relationships with biological measurements.................................... 165

Relationships with chemical and physical measurements................... 174

Discussion.................................................................................................. 176

The range and variability of microbial size spectra......................................... 176

Environmental regulation of size spectra.................................................... 177

A comparison of field measurements and steady state models of the size spectrum 180

Explanation of dynamic changes in the size spectrum based on nutrient uptake kinetics.

Explanation of dynamic changes in the size spectrum based on grazing mechanisms.

Conclusions

Acknowledgements.

References. 


\section{A STUDY OF THE SIZE SPECTRAL RESPONSE OF}

PICOPLANKTON TO NUTRIENT ENRICHMENT AND GRAZING...... 201

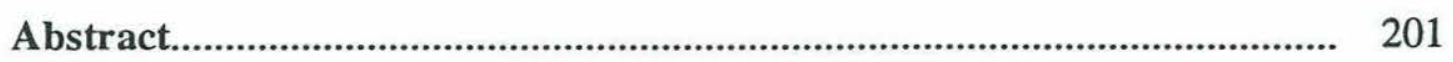

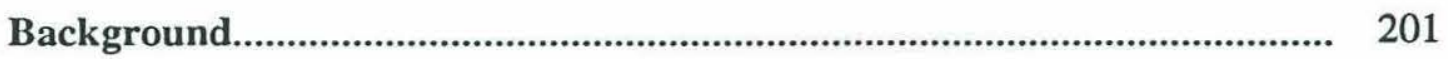

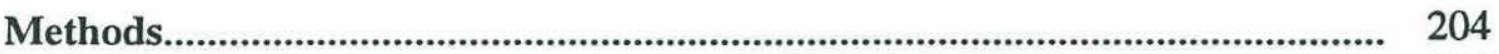

Experimental design............................................................................. 204

Sampling scheme..................................................................................... 207

Flow cytometric analysis............................................................................. 208

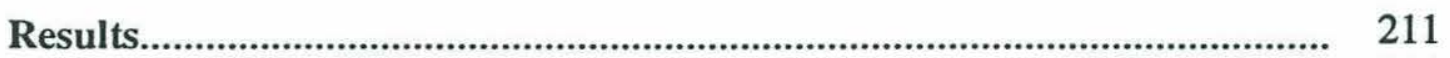

Coastal waters of Massachusetts Bay....................................................... 211

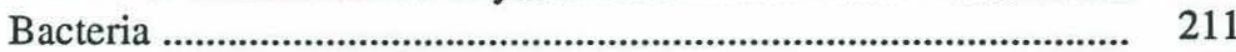

Picophytoplankton..................................................................... 223

The Sargasso Sea................................................................................. 229

Bacteria ............................................................................ 229

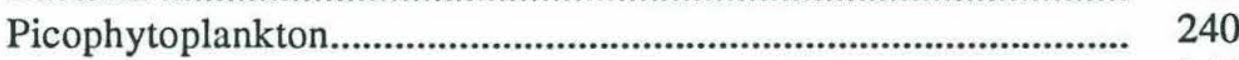

Grazing rates........................................................................................... 245

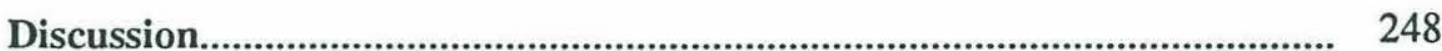

Nutrient effects............................................................................. 248

Effects of predation................................................................................ 250

Combined effects of predation and nutrient enrichment............................... 251

A comparison of size spectra from coastal and oceanic waters and the results of the incubation experiments............................................... 252

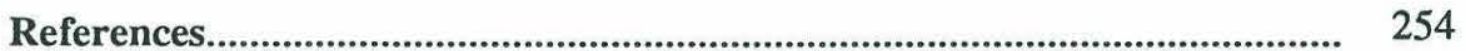

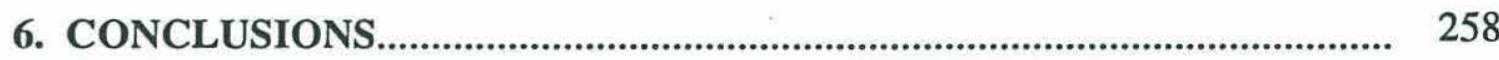

APPENDIX A Discrete and continuous functions of size spectra............ 263

APPENDIX B Sample preservation......................................................... 266

Comparison of different preservation fixatives.............................................. 266

Preservation effects on sub-populations...................................................... 270

APPENDIX C $\quad$ Flow cytometric analysis.................................................. 279

Discrimination of bacteria and phytoplankton from other particles................. 279

Different instrument configurations............................................................. 280

Protocol for analyzing picoplankton on the flow cytometer ('pico' settings) 
Protocol for analyzing nano/microplankton on the flow cytometer

('nano/micro' settings)................................................................. 285

Identification of cell populations................................................................ 285

APPENDIX D Sizing the micro-organisms using flow cytometry............ 290

The picoplankton calibration equation................................... 290

The nano/microplankton calibration equation........................ 293

Merging the picoplankton and nano/microplankton to form a continuous spectrum................................................. 293

APPENDIX E Size spectra of fluorescence........................................... 299

Differences in fluorescence yield due to different instrument configurations................................................................... 300

Trends in fluorescence size spectra with chlorophyll............. 302

APPENDIX F Additional Figures of Size spectra from Boston Harbour, Massachusetts and Cape Cod Bays.................. 308

APPENDIX G Additional Figures of Size spectra from the Sargasso

Sea.

APPENDIX H Additional Figures of Size spectra from the Equatorial Pacific

REFERENCES (Appendices). 


\section{LIST OF FIGURES}

Fig. 2.1. Location of sampling stations in temperate coastal waters in Boston Harbour ( $42^{\circ} 20.4^{\prime} \mathrm{N}, 70^{\circ} 56.5^{\prime} \mathrm{W}$ - F23P), Massachusetts Bay $\left(42^{\circ} 28.4^{\prime} \mathrm{N}, 70^{\circ} 37.1^{\prime} \mathrm{W}-\mathrm{F} 22\right)$ and Cape Cod Bay $\left(41^{\circ} 54.5^{\prime} \mathrm{N}, 70^{\circ} 13.7^{\prime} \mathrm{W}-\right.$ F2P). Depth contours are in metres. Taken from Kelly et. al., 1994a.

Fig. 2.2. Flow cytometric signatures of bacteria and picophytoplankton for surface samples in June, 1993 for Boston Harbour (a, b respectively), Cape Cod Bay (c, d) and Massachusetts Bay (e, f). Bacteria were discriminated on the blue fluorescence versus forward light scatter scattergram whilst picophytoplankton were discriminated on red fluorescence versus forward light scatter. Each data parameter was collected in relative units covering three logarithmic decades. These picoplankton samples were captured using dual-beam analysis on the 'pico' settings of an Epics 753 flow cytometer. Standard calibration beads of $0.46 \mu \mathrm{m}$ (Bd1) and $0.57 \mu \mathrm{m}$ $(\mathrm{Bd} 2)$ were also added for reference.

Fig. 2.3. Flow cytometric signatures of nanno and microphytoplankton for surface samples in June, 1993 for Cape Cod Bay (a), Massachusetts Bay (b) and Boston Harbour (c). Phytoplankton were analyzed using the 'nanno/micro' settings on an Epics V flow cytometer and discriminated from other particles on the red fluorescence versus forward light scatter scattergram. Each data parameter was collected in relative units covering three logarithmic decades. Standard calibration beads of $2.02 \mu \mathrm{m}$ (Bd1) and $5.79 \mu \mathrm{m}(\mathrm{Bd} 2)$ were also added for reference.

Fig. 2.4. Empirical size calibration equations for converting forward light scatter to volumetric size. The picoplankton calibration was obtained by filtering Gulf Stream seawater samples through various Poretics polycarbonate filters and analyzing the filtrates on an Epics 753 flow cytometer using 'pico' settings. The calibration for nanno/microplankton greater than $10 \mu \mathrm{m}^{3}$, was obtained by sizing a variety of phytoplankton cultures with a Coulter Counter and analyzing the same samples on an Epics $\mathrm{V}$ flow cytometer using the 'nanno/micro' settings. The nanno/microplankton calibration was modified for sizes less than $10 \mu \mathrm{m}^{3}$ to ensure that overlapping populations (measured on both settings) merged correctly. This was achieved by setting the nanno/microplankton calibration slope equal to the value of the slope of the picoplankton calibration. The dashed lines indicate an estimate of the errors in the calibration equations.

Fig. 2.5. Differences between normalized and modified normalized concentration size spectra for Boston Harbour taken from surface waters on February 23, 1993. 
The complete normalized spectrum (a) was obtained by dividing the raw data by the width of the corresponding size class, whilst the modified normalized spectrum (b) was obtained by excluding data points to the left of the maximum of the normalized data in (a). The coefficents of regression are also shown: intercept $(\mathrm{Y})$, slope $(\mathrm{S})$ and variance $(\mathrm{R})$ for bacteria, phytoplankton and total (bacteria + phytoplankton) community.

Fig. 2.6. Depth profiles of flow cytometrically generated size spectra for the station in Boston Harbour on October 15, 1992, under fully mixed conditions. Histogram size spectra of concentration and biomass for bacteria (open circles), phytoplankton (closed circles) and combined bacteria plus phytoplankton (open triangles) are shown in panels $\mathrm{a}$ and $\mathrm{b}$ respectively. Corresponding depth profiles of temperature (open squares), extracted chlorophyll (open diamonds) and nitrate concentration (closed diamonds) are also shown in panels $\mathrm{c}$ and d. Environmental measurements were taken from Kelly et. al., 1993.

Fig. 2.7. Depth profiles of size spectral characteristics for Boston Harbour on October 15, 1992, corresponding to the size spectra and environmental conditions shown in Fig. 2.6: a) bacteria biomass, b) bacteria cell concentration, c) mean bacteria size, d) intercept of normalized bacteria spectrum, e) slope of normalized bacteria spectrum, f) phytoplankton biomass, g) phytoplankton cell concentration, h) mean phytoplankton size, i) intercept of normalized phytoplankton spectrum and j) slope of normalized phytoplankton spectrum. (Error bars correspond to one standard deviation:- those without error bars have small standard deviations which fall within the symbols.)

Fig. 2.8. Depth profiles of histogram size spectra together with corresponding environmental measurements for the station in Massachusetts Bay on June 22, 1993 at $1620 \mathrm{hr}$, under stratified conditions.

Fig. 2.9. Depth profiles of size spectral characteristics for Massachusetts Bay on June 22, 1993 at $1620 \mathrm{hr}$, corresponding to the size spectra and environmental conditions shown in Fig. 2.8.

Fig. 2.10. Depth profiles of histogram size spectra together with corresponding environmental measurements for the station in Cape Cod Bay on June 24, 1993 at $0815 \mathrm{hr}$, when a shallow mixed layer is formed.

Fig. 2.11. Depth profiles of size spectral characteristics for Cape Cod Bay on June 24,1993 at $0815 \mathrm{hr}$, corresponding to the size spectra and environmental conditions shown in Fig. 2.10. 
Fig. 2.12. Depth variation of histogram size spectra of concentration and biomass plotted on log scales for mixed conditions in the Boston Harbour station in October, 1992 (a, b respectively), stratified conditions in Massachusetts Bay in June, 1993 (c, d) and a shallow mixed layer in Cape Cod Bay in June, 1993 (e, f). Size spectra of bacteria (open symbols) and phytoplankton (closed symbols) were measured at the surface (circles), intermediate surface (inverted triangles), chlorophyll maximum (squares), intermediate bottom (upright triangles) and bottom waters (diamonds). Note that the arrows point in the direction of increasing depth. Standard deviations are reflected by the size of the symbols.

Fig. 2.13. Seasonal variation of histogram size spectra of concentration and biomass taken from the surface of Boston Harbour ( $a, b$ respectively), Cape Cod Bay (c, d) and Massachusetts Bay (e, f). Bacteria (open symbols) and phytoplankton (closed symbols) samples were collected on October 15, 1992 (diamond), February 23, 1993 (circle), April 6, 1993 (inverted triangle), June 25, 1993 (square) and August 27, 1993 (upright triangle). Samples for the other two stations were also obtained at around the same times. Note that the arrows point in the direction of seasonal succession. Standard deviations fall within the size of the symbols.

Fig. 2.14. Seasonal variation of size spectral characteristics at the surface for the Boston Harbour station, corresponding to the histograms in Fig. 2.13. Mean cell sizes, intercepts and slopes of the normalized concentration size spectra for phytoplankton (open circles) and bacteria (closed circles) are illustrated together with environmental measurements of temperature, nitrate, ammonium, chlorophyll, beam attenuation and integrated biomass (obtained flow-cytometrically). Error bars reflect the standard deviation from the mean.

Fig. 2.15. Seasonal variation of size spectral and environmental characteristics from the surface of the Cape Cod Bay station, corresponding to the histograms in Fig. 2.13.

Fig. 2.16. Seasonal variation of size spectral and environmental characteristics from the surface of the Massachusetts Bay station, corresponding to the histograms in Fig. 2.13.

Fig. 2.17. Spatial variation of histogram size spectra of concentration and biomass (a, b respectively) for averaged surface spectra for Boston Harbour (circles), Cape Cod Bay (triangles) and Massachusetts Bay (squares) in spring, 1993. Averaged values of mean bacteria and phytoplankton cell sizes (c), biomass and chlorophyll (d) at each station are also shown. Averages were computed from surface data for 
February and March, 1993.

Fig. 2.18. Spatial variation of histogram size spectra of concentration and biomass ( $\mathrm{a}, \mathrm{b}$ respectively) for averaged surface spectra for Boston Harbour (circles), Cape Cod Bay (triangles) and Massachusetts Bay (squares) in summer, 1993. Averaged values of mean bacteria and phytoplankton cell sizes (c), biomass and chlorophyll (d) at each station are also shown. Averages were computed from surface data for June and August, 1993.

Fig. 3.1. Flow cytometric signatures of bacteria (a), picophytoplankton (b,c) and nano/microphytoplankton (d) for surface samples of the BATS station, Sargasso Sea on February 9, 1993 at 0815 hrs. Bacteria were captured using dual-beam analysis on the 'pico' settings of an Epics 753 flow cytometer. Bacteria were discriminated on the blue fluorescence versus forward light scatter scattergram (a) whilst picophytoplankton were generally discriminated on red fluorescence versus forward light scatter (c). Synechococcus could be further resolved from Prochlorococcus because the former fluoresces orange but not the latter (b). $\mathrm{Nano/microphytoplankton} \mathrm{were} \mathrm{analysed} \mathrm{on} \mathrm{red} \mathrm{fluorescence} \mathrm{versus}$ forward scatter (d) and captured using the 'nano/micro' settings. Standard calibration beads of $0.46 \mu \mathrm{m}(\mathrm{Bd} 1), 0.57 \mu \mathrm{m}(\mathrm{Bd} 2), 2.02 \mu \mathrm{m}(\mathrm{Bd} 3)$ and $3.79 \mu \mathrm{m}(\mathrm{Bd} 4)$ were also added for reference. Flow cytometric data were recorded in relative units on a scale of 256 channels representing 3 logarithmic decades.

Fig. 3.2. Differences between normalized and modified normalized concentration size spectra for the BATS station taken from surface waters in February. The complete normalized spectrum (a) was obtained by dividing the raw data by the width of the corresponding size class, whilst the modified normalized spectrum (b) was obtained by excluding data points to the left of the maximum of the normalized data in (a). The coefficents of regression are also shown: intercept $(\mathrm{Y})$, slope (S) and correlation coefficient $(r)$ for bacteria, phytoplankton and total (bacteria + phytoplankton) community.

Fig. 3.3. Depth profiles of flow cytometrically generated size spectra for the BATS station in the Sargasso Sea on May 19, 1992 at $1240 \mathrm{hr}$, under stratified conditions. Histogram size spectra of concentration and biomass for bacteria (open circles) and phytoplankton (closed circles) are shown in panels $\mathrm{a}$ and $\mathrm{b}$ respectively. Corresponding depth profiles of temperature (open squares), primary productivity PP (open circles), particulate organic carbon POC (closed circles), extracted chlorophyll (open diamonds) and nitrate concentration (closed 
diamonds) are also shown in panels $\mathrm{c}$ and $\mathrm{d}$. Environmental measurements were taken from Knap et. al., 1995a.

Fig. 3.4. Depth profiles of size spectral characteristics for the BATS station on May 19, 1992 at $1240 \mathrm{hr}$, corresponding to the size spectra and environmental conditions shown in Fig. 3.3: a) Bacteria biomass (measured flow cytometrically), b) bacteria cell concentration, c) mean bacteria size, d) bacteria intercept, e) bacteria slope, f) phytoplankton biomass, $g$ ) phytoplankton cell concentration, $h$ ) mean phytoplankton size, i) phytoplankton intercept and j) phytoplankton slope.

Fig. 3.5. Depth profiles of histogram size spectra together with corresponding environmental measurements for the BATS station on March 10, 1993 at $1407 \mathrm{hr}$, under fully mixed conditions. Environmental measurements were taken from Knap et. al., 1995 b.

Fig. 3.6. Depth profiles of size spectral characteristics for the BATS station on March 10, 1993 at $1407 \mathrm{hr}$, corresponding to the size spectra and environmental conditions shown in Fig. 3.5.

Fig. 3.7. Depth variation of histogram size spectra of concentration and biomass plotted on log scales for the BATS station under stratified conditions in May, 1992 (a, b respectively), and under fully mixed conditions in March, 1993 (e, f). Size spectra of bacteria (open symbols) and phytoplankton (closed symbols) were taken from depths of $2 \mathrm{~m}$ (circles), $40 \mathrm{~m}$ (inverted triangles), $80 \mathrm{~m}$ (squares), $120 \mathrm{~m}$ (upright triangles) and $200 \mathrm{~m}$ (diamonds). Note that standard deviations fall within the actual size of the symbols used and that the arrows point in the direction of increasing depth.

Fig. 3.8. Seasonal variation of histogram size spectra of concentration and biomass at the BATS station taken from surface waters ( $\mathrm{a}, \mathrm{b}$ respectively) and the chlorophyll maximum (c,d). Bacteria (open symbols) and phytoplankton (closed symbols) samples were collected on February 9, 1993 (circle), March 10, 1993 (inverted triangle), May 19, 1992 (square), July 14, 1992 (upright triangle) and September, 1992 (diamond). Standard deviations fall within the actual size of the symbols used.

Fig. 3.9. Seasonal variation of size spectral characteristics at the surface for the 123 BATS station, corresponding to the histograms in Fig. 3.8a and b. Mean cell sizes, intercepts and slopes of the normalized concentration size spectra for phytoplankton (open circles) and bacteria (closed circles) are illustrated together with environmental measurements of temperature, $\mathrm{NO}_{3}, \mathrm{POC}, \mathrm{PON}$, chlorophyll and integrated biomass (obtained flow-cytometrically). Environmental measurements were taken from Knap et. al., 1995a, b. 
Fig. 3.10. Seasonal variation of size spectral characteristics at the chlorophyll maximum for the BATS station, corresponding to the histograms in Fig. 3.8c and d.

Fig. 3.11. Relationships between mean bacteria size (a, b, c) and bacteria slope $(\mathrm{d}, \mathrm{e}, \mathrm{f})$ with selected bulk environmental measurements of extracted chlorophyll, particulate organic carbon and nitrate concentration. Data were pooled from all depths in the Sargasso Sea BATS station.

Fig. 3.12. Relationships between mean phytoplankton size (a, b, c) and 129 phytoplankton intercept $(\mathrm{d}, \mathrm{e}, \mathrm{f})$ with selected bulk environmental measurements of extracted chlorophyll, particulate organic carbon and nitrate concentration. Data were pooled from all depths in the Sargasso Sea BATS station.

Fig. 3.13. Relationships between extracted chlorophyll and integrated (flow cytometric) biomass (a) and between integrated biomass and particulate organic carbon, POC (b). In (b), integrated biomass was calculated using the low biomass-size conversion factor of $80 \mathrm{fgC} \mu \mathrm{m}^{-3}$ for nano/microplankton (closed circles), the high factor of $220 \mathrm{fgC} \mathrm{m}^{-3}$ (open triangles) and that from Verity et. al. (1992) (open circles) which was the one actually used in this study.

Fig. 3.14. Comparison of normalized biomass size spectra using different biomass-size conversion factors for the nano/microplankton range. Actual conversion factors used in this study resulted in a size spectrum (open circles, solid line) that was closer to that using the higher conversion factor of $220 \mathrm{fgC \mu m}^{-3}$ (open diamonds, small dashed line) rather than the smaller

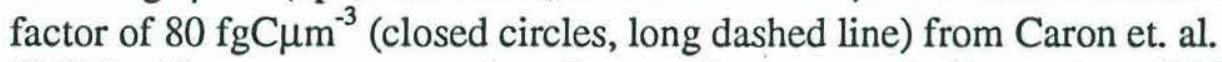
(1994). Size spectra were taken from surface waters in September, 1992.

Fig. 3.15. Relationship between bacteria counts by epifluorescence microscopy $(\mathrm{M})$ and flow cytometry $(\mathrm{FC})$. The dashed line shows where counts from both techniques are equal.

Fig. 4.1. Comparison of concentration and biomass size spectra (histograms) of 158 surface bacteria (open symbols) and surface phytoplankton (closed symbols) from Boston Harbour (circle), Cape Cod Bay (inverted triangle), Massachusetts Bay (square) and the Sargasso Sea (upright triangle) in winter (a, b respectively) and summer (c, d). Winter samples were collected in February, 1993 (1992 for Sargasso Sea), whilst summer samples were collected in August, 1993 (coastal stations) and September, 1992 (Sargasso Sea). 
Fig. 4.2. Flow cytometric signatures of relative forward scatter vs. blue

fluorescence from the DNA stain, Hoescht, of bacteria from surface waters of (a)

Boston Harbour (June, 1993) and (b) the BATS station (February, 1993). Flow

cytometric data were recorded in relative units on a scale of 256 channels

representing 3 logarithmic decades and scaled relative to $0.46 \mu \mathrm{m}$ standard

calibration beads $(\mathrm{Bd})$.

Fig. 4.3. Comparison of a) concentration and b) biomass size spectra

162

(histograms) of surface bacteria (open symbols) and surface phytoplankton

(closed symbols) from the equatorial Pacific (latitude $140^{\circ} \mathrm{W}$; longitude

$12^{\circ} \mathrm{S}$-circle, $4^{\circ} \mathrm{S}$-inverted triangle, $0^{\circ}$-square) and the Sargasso Sea BATS

station (dashed line). Samples for the equatorial Pacific were collected on

September 25,29 and October 3,1992 (for $12^{\circ} \mathrm{S}, 4^{\circ} \mathrm{S}$ and $0^{\circ}$ respectively)

and on September 15, 1992 for the BATS station.

Fig. 4.4. Seasonal-depth averaged characteristics of the modified

163

normalized concentration size spectra for a) phytoplankton, b) bacteria and

c) total (bacteria plus phytoplankton) community. The spectra were

regenerated from the seasonal-depth averaged Y-intercept and slope of the normalized concentration size spectra for the equatorial Pacific (open square), the Sargasso Sea (open circle), Boston Harbour (closed circle), Cape Cod Bay (inverted closed triangle) and Massachusetts Bay (closed triangle). In a) the size spectrum of maximum phytoplankton concentration in culture is also illustrated for comparison (extrapolated from Agusti \& Kalff, 1989). This was obtained by measuring the maximum cell concentration achieved in culture for a number of phytoplankton species.

Fig. 4.5. Relationships between mean bacteria size (a, b, c) and mean phytoplankton size (d, e, f) with the bulk environmental measurements of extracted chlorophyll, particulate organic carbon and particulate organic nitrogen. Data were pooled from all depths in the Sargasso Sea BATS station (excluding oceanic samples greater than $160 \mathrm{~m}$ depth where total cell counts were generally less than $100 \mathrm{ml}^{-1}$ ) and the $12^{\circ} \mathrm{S}$ and $4^{\circ} \mathrm{S}$ equatorial Pacific stations. For the coastal stations, chlorophyll measurements were pooled from all depths at the three locations in Boston Harbour, Massachusetts and Cape Cod Bays, whilst POC and PON data were only available for surface and chlorophyll maximum samples at the Boston Harbour and Cape Cod Bay stations.

Fig. 4.6. Relationships between a) mean bacteria size and bacteria biomass and b) fraction of bacteria biomass in the size fraction 0.2 to $0.8 \mu \mathrm{m}$ (open circle), and size fraction greater than $0.8 \mu \mathrm{m}$ (closed circle). Similar relationships for phytoplankton are also shown in c) and d) respectively, where the size classes in d) consist of the 
pico (0.2-2 $\mu \mathrm{m}$ : open circle), nano ( $2-20 \mu \mathrm{m}$ : closed circle) and micro ( $>20$ $\mu \mathrm{m}$ : open triangles) fractions. Data were pooled from all locations (ie. Boston harbour, Massachusetts Bay, Cape Cod Bay, Sargasso Sea and equatorial Pacific), except for the deepest oceanic samples greater than $160 \mathrm{~m}$.

Fig. 4.7. Variation of the bacteria intercept (a, b, c) and bacteria slope (d, e, 169 f) with integrated bacteria biomass, particulate organic carbon and chlorophyll. The intercept and slope values were calculated from linear regressions of the modified normalized concentration size spectra of bacteria pooled from all locations (ie. Boston harbour, Massachusetts Bay, Cape Cod Bay, Sargasso Sea and equatorial Pacific), except for the deepest oceanic samples greater than $160 \mathrm{~m}$. Note that only POC data were available for surface and mid-depth samples at the Boston Harbour and Cape Cod Bay stations. Corresponding coefficients of regression are found in Table 4.3.

Fig. 4.8. Correlations of the phytoplankton intercept $(\mathrm{a}, \mathrm{b}, \mathrm{c})$ and phytoplankton slope (d, e, f) with integrated phytoplankton biomass, particulate organic carbon and chlorophyll. The intercept and slope values were calculated from linear regressions of the modified normalized concentration size spectra of bacteria pooled from all locations (ie. Boston harbour, Massachusetts Bay, Cape Cod Bay, Sargasso Sea and equatorial Pacific), except for the deepest oceanic samples greater than $160 \mathrm{~m}$. Note that for the coastal stations, POC data were only available for surface and mid-depth samples at the Boston Harbour and Cape Cod Bay stations. Corresponding coefficients of regression are found in Table 4.4.

Fig. 4.9. Relationships between primary productivity and the characteristics of size spectra. In general, good correlations were found between primary productivity and mean bacteria size (a), bacteria intercept (b) but not the bacteria slope (c). In contrast, good correlations exist for mean phytoplankton size (d) and phytoplankton slope (f) but not phytoplankton intercept (e). Data were pooled from the Sargasso Sea (excluding oceanic samples greater than $100 \mathrm{~m}$ ) and the surface and mid-depths of Boston Harbour and Cape Cod Bay. Corresponding coefficients of regression are found in Tables 4.3 and 4.4.

Fig. 4.10. Relationships between mean bacteria size (a, b, c) and mean phytoplankton size (d, e, f) with beam attenuation, temperature and silicate. Data were pooled from all samples excluding the deepest oceanic samples greater than $160 \mathrm{~m}$. Corresponding coefficients of regression are found in Tables 4.3 and 4.4. 
Fig. 4.11. Positive correlation relationships between a) mean bacteria population size and mean phytoplankton population size and b) total bacteria biomass and total phytoplankton biomass. Data were pooled from all locations excluding the deepest oceanic samples greater than $160 \mathrm{~m}$. Corresponding coefficients of regression are found in Table 4.5.

Fig. 4.12. Fraction of bacteria by biomass in total community plotted on 186 linear and log scales for Boston Harbour (open circle), Cape Cod Bay (closed circle), Massachusetts Bay (open triangle), the Sargasso Sea (closed triangle) and the equatorial Pacific (square), excluding the deepest oceanic samples greater than $160 \mathrm{~m}$.

Fig. 5.1. Summary of the experimental design used to study the effects of nutrient enrichment and grazing on the picoplankton size spectrum. B and $G$ represent the controls for the enriched and unenriched treatments respectively, whilst $\mathrm{C}(1: 3), \mathrm{D}(1: 1), \mathrm{E}(3: 1)$ are the enriched dilution treatments and $\mathrm{H}(1: 3), \mathrm{I}(1: 1), \mathrm{J}(3: 1)$ are the unenriched dilution treatments. The ratio given is the ratio of filtered seawater (through $0.22 \mu$ m) to pre-screened seawater (through $64 \mu \mathrm{m}$ mesh).

Fig. 5.2. Flow cytometric signatures of bacteria and picophytoplankton analyzed on the 'pico' settings of an Epics 753 flow cytometer. In the coastal incubation experiment, bacteria (a) and picophytoplankton (b) could be easily discriminated from each other because the red fluorescence of the picophytoplankton was well above the baseline. In the oceanic incubation experiments, however, the red fluorescence of Prochlorococcus (window 3) was close to the baseline (d) and had to be separated from bacteria on blue fluorescence versus forward scatter (c), where the population was gated out from the bitmap defining bacteria (bitmap 4). In this way, bacteria was discriminated for analysis. When analyzing for picophytoplankton, the bitmaps (bitmap 3) were drawn on blue (e) and red (f) fluorescence versus forward scatter, as shown. Reference beads of $0.46 \mu \mathrm{m}$ (Bd1) and $0.57 \mu \mathrm{m}$ $(\mathrm{Bd} 2)$ were also run to provide a reference frame for analysis.

Fig. 5.3. Histogram concentration size spectra of bacteria (open circle) and picophytoplankton (closed circle) for the coastal incubations (Massachusetts Bay) at the beginning of the experiment. The letter designation corresponds to the treatments listed in Table 4.1 and the number indicates the replicate bottle. The left hand panel of graphs represent the treatments enriched with inorganic nutrients whilst the unenriched treatments are shown in the right hand panel.

Fig. 5.4. Histogram concentration size spectra of bacteria (open circle) and 
picophytoplankton (closed circle) for the coastal experiment after incubating samples for 1 day in simulated field conditions.

Fig. 5.5. Histogram concentration size spectra of bacteria (open circle) and picophytoplankton (closed circle) for the coastal experiment after incubating samples for 2 days in simulated field conditions.

Fig. 5.6. Histogram concentration size spectra of bacteria (open circle) and picophytoplankton (closed circle) for the coastal experiment after incubating samples for 3 days in simulated field conditions.

Fig. 5.7. Histogram concentration size spectra of bacteria (open circle) and picophytoplankton (closed circle) for the coastal experiment after incubating samples for 4 days in simulated field conditions.

Fig. 5.8. Evolution of the normalized difference spectra for unenriched bacteria in the coastal incubation experiment. Normalized difference spectra were computed by taking the difference between the spectra of a treated sample at some specified time and its corresponding initial (C-Co), and dividing the difference by the total initial bacteria concentration $\left(\mathrm{Co}_{\mathrm{T}}\right)$. G represents the unenriched control treatment while $\mathrm{H}$ (1:3), I (1:1) and J (3:1) are the unenriched dilution treatments. Replicate time courses are shown in (a) and (b).

Fig. 5.9. Evolution of the normalized difference spectra for bacteria enriched with inorganicnutrients in the coastal incubation experiment. B represents the enriched control treatment while C (1:3), D (1:1) and E (3:1) are the enriched dilution treatments. Replicate time courses are shown in (a) and (b).

Fig. 5.10. Evolution of the normalized difference spectra for unenriched picophytoplankton in the coastal incubation experiment. $\mathrm{G}$ represents the unenriched control treatment while $\mathrm{H}(1: 3), \mathrm{I}(1: 1)$ and $\mathrm{J}(3: 1)$ are the unenriched dilution treatments. Replicate time courses are shown in (a) and (b).

Fig. 5.11. Evolution of the normalized difference spectra for picophytoplankton enriched with inorganic nutrients in the coastal incubation experiment. B represents the enriched control treatment while $\mathrm{C}$ (1:3), D (1:1) and E (3:1) are the enriched dilution treatments. Replicate time courses are shown in (a) and (b).

Fig. 5.12. Histogram concentration size spectra of bacteria (open circle) 
and picophytoplankton (closed circle) for the oceanic incubations (Sargasso Sea) at the beginning of the experiment. The letter designation corresponds to the treatments listed in Table 4.1 and the number indicates the replicate bottle. The left hand panel of graphs represent the treatments enriched with inorganic nutrients whilst the unenriched treatments are shown in the right hand panel.

Fig. 5.13. Histogram concentration size spectra of bacteria (open circle) and pico-phytoplankton (closed circle) for the oceanic experiment after incubating samples for 1 days in simulated field conditions.

Fig. 5.14. Histogram concentration size spectra of bacteria (open circle) and picophytoplankton (closed circle) for the oceanic experiment after incubating samples for 2 days in simulated field conditions.

Fig. 5.15. Histogram concentration size spectra of bacteria (open circle) and picophytoplankton (closed circle) for the oceanic experiment samples for 3 days in simulated field conditions.

Fig. 5.16. Histogram concentration size spectra of bacteria (open circle) and picophytoplankton (closed circle) for the oceanic experiment after incubating samples for 4 days in simulated field conditions.

Fig. 5.17. Evolution of the normalized difference spectra for unenriched bacteria in the oceanic incubation experiment. $G$ represents the unenriched control treatment while $\mathrm{H}(1: 3), \mathrm{I}(1: 1)$ and $\mathrm{J}(3: 1)$ are the unenriched dilution treatments. Replicate time courses are shown in (a) and (b).

Fig. 5.18. Evolution of the normalized difference spectra for bacteria enriched with inorganic nutrients in the oceanic incubation experiment. B represents the enriched control treatment while C (1:3), D (1:1) and E (3:1) are the enriched dilution treatments. Replicate time courses are shown in (a) and (b).

Fig. 5.19. Evolution of the normalized difference spectra for unenriched picophytoplankton in the oceanic incubation experiment. $G$ represents the unenriched control treatment while $\mathrm{H}(1: 3), \mathrm{I}(1: 1)$ and $\mathrm{J}(3: 1)$ are the unenriched dilution treatments. Replicate time courses are shown in (a) and (b).

Fig. 5.20. Evolution of the normalized difference spectra for picophytoplankton enriched with inorganic nutrients in the oceanic incubation experiment. B represents the enriched control treatment while 
C (1:3), D (1:1) and E (3:1) are the enriched dilution treatments. Replicate time courses are shown in (a) and (b).

Fig. 5.21. Apparent growth rates as a function of the dilution factor for the

oceanic $(a, b)$ and coastal (c, d) incubation experiments. Intrinsic growth rates and grazing mortality rates for bacteria and picophytoplankton were estimated from the coefficients of the linear regressions to the data for the enriched dilutions (circles, solid line). For comparison, regressed data from the unenriched dilutions are also shown (squares, dashed line). 


\section{LIST OF TABLES}

Page

Table. 2.1. Characteristics of the normalized concentration size spectra of bacteria and phytoplankton for the stations in Boston Harbour, Massachusetts and Cape Cod Bays. The intercepts and slopes were averages of values at the surface for February and March, 1993 for spring and June and August, 1993 for summer. Numbers in parenthesis are the standard deviations.

Table 3.1. Linear regression coefficients for characteristics of bacteria size spectra (Y-intercept, S-slope, r-correlation coefficient) with standard measurements of the environment $\left(\mathrm{NO}_{3}\right.$-nitrate $\mu \mathrm{M}, \mathrm{SiO}_{4}$-silicate $\mu \mathrm{M}, \mathrm{PO}_{4}$ phosphate $\mu \mathrm{M}$, POC-particulate organic carbon $\mu \mathrm{M}$, PON-particulate organic nitrogen $\mu \mathrm{M}, \mathrm{CHL}$-chlorophyll $\mu \mathrm{gl}^{-1}$, BIO-integrated flowcytometric biomass $\mathrm{pgCml}^{-1}, \mathrm{PP}$-primary production $\mathrm{mgCm}^{-3} \mathrm{day}^{-1}$, BEAMbeam attenuation $\mathrm{m}^{-1}$, TEMP-temperature $\left.{ }^{\circ} \mathrm{C}\right)$. Data were pooled from all depths $(250 \mathrm{~m})$ and all seasons for the BATS station in the Sargasso Sea.

Table 3.2. Linear regression coefficients for characteristics of phytoplankton 128 size spectra (Y-intercept, S-slope, r-correlation coefficient) with standard measurements of the environment $\left(\mathrm{NO}_{3}\right.$-nitrate $\mu \mathrm{M}, \mathrm{SiO}_{4}$-silicate $\mu \mathrm{M}, \mathrm{PO}_{4}$ phosphate $\mu \mathrm{M}$, POC-particulate organic carbon $\mu \mathrm{M}$, PON-particulate organic nitrogen $\mu \mathrm{M}, \mathrm{CHL}$-chlorophyll $\mu \mathrm{gl}^{-1}$, BIO-integrated flowcytometric biomass $\mathrm{pgCml}^{-1}, \mathrm{PP}$-primary production $\mathrm{mgCm}^{-3} \mathrm{day}^{-1}, \mathrm{BEAM}-$ beam attenuation $\mathrm{m}^{-1}$, TEMP-temperature ${ }^{\circ} \mathrm{C}$ ). Data were pooled from all depths $(250 \mathrm{~m})$ and all seasons for the BATS station in the Sargasso Sea.

Table 4.1. Selected environmental characteristics used to indicate the trophic states of the 5 locations ie. the low nutrient, low chlorophyll Sargasso Sea; the high nutrient, low chlorophyll equatorial Pacific and high nutrient, high chlorophyll areas in Massachusetts and Cape Cod Bays. These include measurements of chlorophyll (CHL), primary productivity (PP), total dissolved inorganic nitrogen plus particulate nitrogen (TN), dissolved inorganic nitrogen (DIN), particulate organic carbon (POC) and beam attenuation (BEAM). Values given for the Sargasso Sea and coastal locations are seasonal-depth averages (standard deviation in parentheses) collected over the 1 year sampling period (see text), whereas the values for the equatorial Pacific are taken from a depth profile at $\left(0^{\circ}, 140^{\circ} \mathrm{W}\right)$, taken in October, 1992. Measurements were compiled from Knap et. al., 1994, 1995 and Kelly et. al., 1993, 1994a,b,c,d, 1995. 
Table 4.2. Spatially and temporally averaged spectral characteristics for the coastal and oceanic locations. The intercept (Y), slope (S) and correlation coefficient ( $r$ ) were calculated from linear regressions of the normalized concentration size spectra of the bacteria, phytoplankton and total (bacteria plus phytoplankton) communities.

Table 4.3. Correlations between environmental indicators of trophic state 168 and characteristics of the normalized concentration size spectra of bacteria. The intercept (Y), slope (S) and the correlation coefficient (r) were computed from the linear regression of selected environmental characteristics and the mean bacteria size, bacteria slope and bacteria intercept pooled from all the sampling locations (excluding samples greater than $160 \mathrm{~m}$ from the open oceans, and also excluding the equatorial Pacific samples for the nutrient regressions). These environmental measurements included dissolved inorganic nitrogen (DIN), total nitrogen ( $\mathrm{TN}=\mathrm{DIN}+\mathrm{PON})$, silicate, phosphate, particulate organic carbon (POC), particulate organic nitrogen (PON), chlorophyll (CHL- $\left.\mu \mathrm{gl}^{-1}\right)$, total biomass (bacteria+phytoplankton biomass-pgCml ${ }^{-1}$ ), bacteria biomass (BBIO), primary productivity (PP), bacteria cell concentration (BNOS-cells $\mathrm{ml}^{-1}$ ), beam attenuation $\left(\mathrm{BEAM}-\mathrm{m}^{-1}\right)$ and temperature $\left(\right.$ TEMP- $\left.{ }^{\circ} \mathrm{C}\right)$. Biomass measurements were obtained by integrating the flow cytometrically derived biomass size spectra. All nutrient measurements are in $\mu \mathrm{M}$ unless otherwise indicated.

Table 4.4. Correlations between environmental indicators of trophic state 170 and characteristics of the normalized concentration size spectra of phytoplankton. The intercept (Y), slope (S) and the correlation coefficient (r) were computed from the linear regression of selected environmental characteristics (as in Table 4.3) and the mean bacteria size, bacteria slope and bacteria intercept pooled from all the sampling locations (excluding samples greater than $160 \mathrm{~m}$ from the open oceans).

Table 4.5. Linear regression coefficients (Y-intercept, S-slope, r-correlation coefficient) of the bulk environmental measurements of particulate organic carbon (POC- $\mu \mathrm{M})$ and chlorophyll (CHL- $\left.\mu \mathrm{gl}^{-1}\right)$ with total (bacteria+phytoplankton) biomass (TBIO-pgCml ${ }^{-1}$ ). The results for the linear regression between bacteria biomass (BBIO- $\mathrm{pgCml}^{-1}$ ) and phytoplankton biomass (PBIO) together with the relation between mean bacteria size (BSIZE- $\mu \mathrm{m}^{3}$ ) and mean phytoplankton size (PSIZE) are also given.

Table 5.1. Summary of treatments for incubation bottle experiments to test the effects of grazing pressure and nutrient enrichment. Changes in grazing pressure 
were carried out by dilution with filtered seawater, where the ratio given is the ratio of filtered seawater $(0.22 \mu \mathrm{m})$ to pre-screened sample seawater $(64 \mu \mathrm{m})$. Each treatment is given a letter designation followed by a number that indicates the replicate. In total, $8 \times 2$ treatments were performed for each of the coastal and oceanic incubation experiments.

Table 5.2. Initial concentrations of bacteria and picophytoplankton for the coastal incubation bottles. Samples were taken from Massachusetts Bay on July 28th and analyzed flow cytometrically. Note that initial concentrations for $\mathrm{A}$ and $\mathrm{F}$ treatments were not measured, but were assumed to be close to the $\mathrm{B}$ and $\mathrm{G}$ treatments (ie. only difference is that copepods were added to the $\mathrm{A}$ and $\mathrm{F}$ bottles). Concentrations are given as no. of cells $\mathrm{ml}^{-1}$.

Table 5.3. Initial concentrations of bacteria and picophytoplankton for the oceanic incubation bottles. Samples were taken from the Sargasso Sea on July 8th and analyzed flow cytometrically. Concentrations are given as no. of cells $\mathrm{ml}^{-1}$.

Table 5.4. Linear regression coefficients for the apparent growth rates of bacteria and picophytoplankton as a function of the dilution factor, corresponding to Fig. 5.21. Y-intercept (Y), slope (S) and correlation coefficient $(r)$ were calculated for both enriched and unenriched samples. 


\section{Chapter One}

\section{INTRODUCTION}

\section{PATTERNS IN THE SIZE SPECTRA OF PELAGIC ORGANISMS}

The extent to which an ecosystem can sustain life depends on the overall biomass (ie. energy) of primary producers and the efficiency with which this energy can be transfered to other trophic levels. Traditional methods of visualizing energy flow in a system are based on a linear food chain. However, more recent evidence points to the existence of a microbial loop in which a substantial portion of the system energy is efficiently recycled through bacteria (Azam et. al., 1993). The relative importance of these different energy pathways has been linked to the trophic state of an aquatic ecosystem, typically described by levels of primary productivity, chlorophyll and nutrients. While these measurements are useful indicators of the overall capacity of the ecosystem, they do not reveal much in terms of the structure and organisation of the pelagic food web. An alternative to studying such bulk parameters is to look at the size spectrum of the biological community. This not only provides a concise overview picture of the community but also reflects functional changes at the cellular level. Empirical size-based relationships of metabolic processes, such as respiration and growth rates, have been demonstrated from species to community level (Ahrens and Peters, 1991a). In the marine pelagial, size is also coupled to trophic or energy transfer since larger organisms generally eat smaller organisms. The use of size to describe trophodynamics becomes more relevant where microorganisms are concerned. In these situations, trophic levels become less distinguishable and species-level taxonomy becomes increasingly diffficult. Studies also indicate that size spectra could potentially be used to assess ecosystem health or trophic state (Sprules \& Munawar, 1986, Ahrens \& Peters, 1991a, b), which would have useful application in the management of marine resources, such as fisheries and aquaculture. For example, size spectra have been used effectively to predict fish stocks from phytoplankton 
standing stocks (Sprules and Munawar, 1986). The resolution of the biological community through size spectra is also important in the area of satellite imagery and remote sensing. Remote sensing measurements provide only a bulk assessment of system properties whereas size spectra can reveal how light scattering and fluorescence is distributed among particles of different size, shape and pigment composition. Currently, knowledge of size spectral information in the world's oceans is limited but studies show that the microbial community, particularly bacteria and phytoplankton, are major contributers and therefore influential in biogeochemical processes (Stramski and Kiefer, 1991).

In the past, studies of size spectra have been hampered because of the tedious and time-consuming methods of enumeration (eg. microscopy) that were used. With advances in technology, however, new automated tools such as image analysis, electronic particle counters and flow cytometry, are available which can speed up the process. These methods are particularly suitable for the enumeration of natural microbial populations in the size range from about $1 \mu \mathrm{m}$ to $100 \mu \mathrm{m}$ : at the large end of the scale, enumeration of large organisms is hampered by their relative scarcity; at the small end, technology is pushed to detect the smallest organisms, namely, bacteria and viruses. The challenge is to have as wide a size range as possible and yet still make analysis of an ecosystem practical and efficient.

\section{Field Observations of the Overall Community Size Spectrum}

Accumulated empirical evidence shows that there is a fundamental regularity in which particles are distributed in pelagic waters such that there is a sharp, continuous decrease in particle concentration with increasing size. This characteristic feature of total particulates is also typical of living particles where it has been found that smaller organisms constitute much greater numbers than larger organisms (Sprules and Munawar, 1986, Rodriguez and Mullin, 1986). In these studies, size spectra have either been given in the form of cell concentration size spectra, biomass size spectra or normalized biomass 
size spectra. These distributions are mathematically related (see Appendix A) and can be described as power functions:

$\mathrm{F}=\mathrm{aWb}$

where $\mathrm{F}$ is the concentration, biomass or normalized biomass size spectra (given by the total biomass of organisms in weight class, $\mathrm{W}$, divided by the weight class range, $\Delta \mathrm{W}$ ) and $\mathrm{a}$ and $\mathrm{b}$ are constants. Actual data is usually logarithmically transformed so that the $\mathrm{Y}$ intercept is given by $\log a$ and the slope of the function is given by $b$.

The first biomass size spectra were obtained by Sheldon et. al. (1972) in marine waters and covered extensive regions in the Atlantic and Pacific oceans. Using an electronic particle counter, the authors measured surface and deep particles in the size range 1 to $100 \mu \mathrm{m}$ and found that there were approximately 'similar amounts of material in logarithmically equal sized categories'. Later studies were able to distinguish between living and nonliving particles (using microscopy) as well as to extend the size range of particles analyzed. Most, however, were confined to freshwater environments but results are similar ie. flat biomass spectra or normalized biomass slopes of -1 (Rodriguez et. al. 1990, Gaedke, 1992). In contrast, marine data sets are scarce. One such study of the oligotrophic North Pacific Central Gyre showed that the average biomass size spectrum (1 - $200 \mu \mathrm{m}$ ) had a slope of -0.17 (Rodriguez and Mullin, 1986) as opposed to the flat spectra of Sheldon et. al., 1972. The slope of the normalized size spectrum also became less steep with depth, reflecting the importance of larger organisms. This trend in slope was also seen with the progression of seasonal changes from winter to summer and was also observed in lake systems (Gaedke, 1992) of increasing eutrophy (Sprules and Munawar, 1986, Ahrens and Peters, 1991a,b). External disturbances were hypothesized to cause a shift in the size spectrum (eg. steeper slopes) with the result that energy was transferred to larger organisms as the system recovered (Gaedke, 1992). These results 
suggested that external perturbations and size and depth of the pelagic zone were important factors in influencing the shape of the size spectrum.

Although characteristics of the entire size spectrum, such as Y-intercept and slope, are useful parameters in depicting overall changes in the community, they do not reveal the finer details of structure which may be important in decribing the internal dynamics of a system. In a survey of freshwater lakes, Sprules and Munawar (1983), found characteristic peaks in the biomass size spectra at approximately $10 \mu \mathrm{m}$ and $500 \mu \mathrm{m}$, corresponding to the main phytoplankton and zooplankton assemblages respectively. These 'jagged' spectra with distinct peaks at well-separated average body sizes were similar to those observed in pulsed, productive marine ecosystems at high latitudes but different from the 'flat' spectra observed in equatorial and subtropical oceanic waters (Sheldon et. al. 1972).

\section{Theoretical Aspects of Size Spectra and their Limitations}

Field observations provided the framework for developments in theoretical explanations of the regularity in the size spectrum. Models of size spectra are principally based on a conservation of energy or biomass approach. Earlier studies made use of empirical, allometric rules governing metabolic and growth rates (Platt and Denman, 1977, 1978):

$\mathrm{R}=\mathrm{AW} \mathrm{B}^{\mathrm{B}}$

where $\mathrm{R}$ refers to specific growth rate (or respiration or photosynthetic rate), $\mathrm{W}$ is a measure of the mass or size of the organism and A and B are constants. The constant, A, was highly variable and could be used to differentiate major groups of organisms (Fenchel, 1974). On the other hand, the exponent, B, was relatively constant and roughly equal to 0.25 (Laws, 1975, Banse, 1976, Peters, 1983). However, there is increasing evidence which shows that growth rates for microorganisms may be less likely to be tightly related 
to size. In a recent study, Joint (1991) showed that productivity measurements of picoplankton more closely followed the allometric equations when B was approximately equal to -0.15 , as opposed to the more generally accepted value of -0.25 . When the value of -0.25 was applied to bacteria, the allometric relationship predicted unrealistically high rates of growth. For phytoplankton, the growth rates of many larger species have been found to be comparable or even faster than that of smaller species (Banse, 1982). Nevertheless, the allometric models did reproduce fairly well the main features of the experimental data sets taken from the subtropical oceans ie. slope of the normalized biomass spectrum -1 (Kerr, 1974, Platt and Denman, 1977, 1978). It may be that the general allometric rule is applicable to the broad spectrum of organisms but less so when considering particular sub-groups of organisms (see later).

Alternative theoretical models which place more emphasis on predator-prey relationships are equally successful in explaining the measured particle size distributions at sea (Boudreau et. al., 1991, Silvert and Platt, 1980, Borgman, 1982, Kiefer and Berwald, 1991). The advantage of these models is that they provide insight into the internal dynamics of the food web by taking into account the dependency of biomass flow on the size of predator and prey cells as well as the assimilation and capture efficiencies of predators. However, the trophic structure of the plankton community at the lower end of the size range differs in principle from that at the higher end where it is assumed that the main flux of biomass is towards larger organisms. Pelagic bacteria live predominantly on organic matter originating from larger organisms, mainly in the form of exudates from phytoplankton (Azam et. al., 1983). Hence, a more accurate description of energy flow within the system would need to consider two pathways: firstly, through grazing, which conforms to the concept of a biomass flux up the spectrum and secondly, through release of organic substrates which implies transfer of organic matter to smaller organisms (Gaedke, 1993). At the same time, the creation of new organic matter through primary production is of considerable importance in determining how much energy is available for transfer up the food chain. Recently, the size-based dynamics of plankton food webs 
involving coupled interactions between bacteria, phytoplankton and zooplankton, and incorporating external nutrient inputs and physical mechanisms have been modelled successfully and applied to the Southern Benguela region (Maloney \& Field, 1991a, b) and the Sargasso Sea (Hurtt \& Armstrong, 1995).

\section{Relationships Between Size Spectra of Component Groups of Organisms and the Overall Community Size Spectrum}

The entire biomass size spectrum has been shown to be comprised of a series of overlapping parabolic size distributions, each of which corresponds to a particular group of organisms (Gasol et. al. 1991, Gaedke, 1992). The effect of these small-scale distributions is to increase the amount of residual variation in the overall size spectrum. Dickie et. al., (1987) explain this variability on the basis of two allometric scalings of body size. The primary scaling reflects the common metabolic properties of living organisms and is indexed by the slope of the overall, normalized biomass spectrum (ie. slope -1). This physiological scaling appears to be a general regulatory mechanism by which energy is transferred through organisms, particularly with respect to steady state systems, as in the oligotrophic open oceans (Platt and Denman, 1977, 1978). The secondary scaling is an ecological scaling factor which allows for population density adjustments so that organisms can satisfy their individual food requirements. This arises from the demonstration that within quasi-taxanomic groups, production efficiency, measured as the ratio of production, $\mathrm{P}$, to respiration per unit area, $\mathrm{R}$, is constant (Humphreys, 1979) ie.

$\mathrm{P} / \mathrm{R}=\mathrm{P} / \mathrm{B} \times \mathrm{B} / \mathrm{R}=$ constant $\quad(3)$

and B is biomass. Using this assumption, it can be shown that the secondary or ecological scaling results in a sharp increase in biomass with increase in body size, as demonstrated in the field results of Rodriguez et. al. (1990). In this particular ecosystem (oligotrophic lake), the overall biomass size spectrum had a flat slope (close to zero) but the linear 
regressions fitted within the sub-groups of pico, nano, micro/mesoplankton were +0.44 , +0.36 and +1.16 respectively. Ecological relationships were postulated to be fundamental in controlling the size structure and dynamics of the planktonic community. In contrast, a study of Lake Constance, Germany, showed that the slope of the phytoplankton community did not deviate significantly from the overall slope, which was also close to zero (Gaedke, 1992), implying that physiological factors were the primary scaling factors in this example. These findings together with the extensive marine data set collected by Sheldon et. al. (1972) suggest that the overall primary scaling, given by a normalized biomass slope of approximately -1 , is a fairly robust feature of steady-state ecosystems. The departure of component groups of organisms from the primary scaling was postulated to reflect the effects of the population's response to external perturbations to the system (eg. nutrient inputs) or to food web interactions (eg. grazing) (Boudreau et. al., 1991, Rodriguez et. al., 1990). However, this simplified approach is complicated by several factors. Firstly, real systems are dynamic and those which undergo major seasonal changes have been known to show a systematic increase in the overall slope with season (Gaedke, 1992). Secondly, different sized organisms have different reaction times which must be taken into consideration during sampling procedures, especially when considering the overall spectrum. Thirdly, the -1 slope has also been explained theoretically using predator-prey concepts so the mechanisms behind the primary scaling are still debatable (Kiefer and Berwald, 1991).

\section{SIZE SPECTRA OF PHYTOPLANKTON}

In this thesis, we focus on bacteria and phytoplankton as subgroups of the larger pelagic community. The phytoplankton community is a suitable component group of the entire size spectrum to investigate the impact of second order scaling factors and hence, ecological impacts in the system:- the group extends over a very large size range and cell size is an important selection criterion for phytoplankton species (Stein et. al., 1988). In addition, phytoplankton are numerically abundant and have fairly rapid response times in 
the order of hours/days. In terms of ecosystem function, phytoplankton play key roles in being the primary source of food in the food chain and hence, the starting point of energy transfer to higher organisms. Their community structure and function is also important in influencing turnover rates of nutrients and carbon within the ecosystem (Maloney and Field, 1991). By studying how the size spectrum of this component group deviates from the overall primary, scaling of the spectrum, it may be possible to assess the effects of external perturbations to the system with subsequent ecological shifts in the spectrum (Dickie et. al., 1987, Boudreau et. al., 1991). Further research is required to study and quantify these effects, particularly in marine environments.

\section{Patterns of Size-Fractionated Chlorophyll}

Phytoplankton abundance is commonly expressed in terms of extracted chlorophyll and size-fractionated chlorophyll is a convenient measure of large phytoplankton size classes. When total chlorophyll concentrations are high, microplankton $(>20 \mu \mathrm{m})$ form the major fraction of the phytoplankton community whereas at low total chlorophyll levels, picoplankton (0.2-2 $\mu \mathrm{m})$ dominate (Hopcroft and Roff, 1990). In coastal, eutrophic systems, the picoplankton size fraction has been shown to remain fairly stable so that the variability associated with changes in total chlorophyll can be traced to the nano and in particular, the microplankton size fractions (Robles-Jarero and Lara-Lara, 1993, Hopcroft and Roff, 1990). As with the biomass or concentration size spectra, the patterns arising from size-fractionated chlorophyll also point to a regularity in the structure of the phytoplankton community. It appears that the total amount of chlorophyll in each size fraction has an upper limit and that beyond these thresholds, further additions of chlorophyll to the system are only achieved by larger cells (Raimbault, 1988, Chisholm, 1992). Hence, as one progresses from an oligotrophic to eutrophic system, one observes a decreasing proportion of small cells in relation to large cells. External disturbances to the system (eg. from nutrients and/or changes in hydrographic regimes) are believed to be 
the causes of the greater variability of these fractions (Robles-Jarero and Lara-Lara, 1993, Hopcroft and Roff, 1990).

A new method of analyzing phytoplankton size distributions is flow cytometry (Chisholm, 1992, Li, 1994, Binder et. al., 1996). This technique not only enables rapid enumeration of particle abundance but also has the capability to capture the fluorescent properties of pigment-containing cells. A study of phytoplankton size spectra in the Sargasso Sea using this technique confirms the trend of decreasing cell concentration with increasing cell size (Chisholm, 1992). At the same time, the study shows that the size distribution of chlorophyll fluorescence is bimodal, with a sizeable fraction coming from larger cells contrary to expectations from extracted chlorophyll measurements. The question remains therefore, as to whether size-fractionated fluorescence yield (in-vivo measurement) is actually compatible with extracted chlorophyll measurement. Nevertheless, flow cytometry remains a potentially powerful tool to analyze microbial size spectra because of its discriminatory powers and rapid counting ability.

\section{Maximum Concentration Size Spectra of Phytoplankton and Self-regulation of the Phytoplankton Community}

In a study of published literature values, Duarte et. al. (1987) found that the maximum achievable concentration by aquatic organisms, ranging from bacteria to fish, is an inverse function of their body size:

$\log \left(\mathrm{C}_{\max }\right)=8.53-0.95 \log \mathrm{V}$

where $\mathrm{C}_{\max }$ is the maximum concentration achievable in culture (given optimum growing conditions) and $\mathrm{V}$ is the volume of the individual organism. The existence of a relationship between maximum concentration and organism size is of interest because it implies that natural populations growing at or close to their maximum concentration in culture are unlikely to be affected by external controls, such as nutrient addition or 
removal (Agusti et. al., 1990). Conversely, significant deviations between maximum achievable concentrations in culture and those observed in nature could reflect the magnitude of the external, ecological controlling factors. Such information would have useful applications in the management of experimental and commercial aquaculture which seek to maximize stock size before harvest (Duarte et. al., 1987).

The slope of equation (4), which corresponds to a limiting case of concentration size spectra, is very close to -1 suggesting that the size distributions of the field populations taken from Sheldon et. al. (1972) are close to the size distribution of the maximum achievable concentration in culture. (Note that the slopes of concentration size spectra are directly comparable to the slopes of normalized biomass spectra - Appendix A). If one computes the volume per capita as the inverse of the maximum concentration and then calculates the average distance between neighbouring cells, it is found that the inter-organism distance is proportional to body length. This suggests that space restrictions, rather than metabolic constraints, may be determining the upper limit to abundance for aquatic organisms (Duarte et. al., 1987).

In contrast to the distribution obtained over the entire spectrum of organisms, a compilation of literature data for freshwater phytoplankton cultures alone gave a slope value of -1.27 (Agusti et. al. 1987). This implied that under optimal conditions, larger algae were able to support lower biomasses and less dense populations than small algae (ie. biomass $\sim$ size $^{-0.32}$ ). Self-shading of the phytoplankton was suggested to be the probable determinant of the maximum concentration but this was refuted in a later study, which did not show significant differences in the size spectra between cultures grown under low and high light conditions (Agusti and Kalff, 1989). In the later study, however, the experimental slope was significantly higher $(-0.79)$ than that compiled from literature. The authors attributed this difference to the variance introduced in pooling data from a wide variety of cultures grown under very different conditions (in the case of the literature survey) whereas the later study was restricted to a narrow taxonomic range and grown under similar conditions (size range between 2 to $5 \times 10^{6} \mu \mathrm{m}^{3}$ or 1.6 to $200 \mu \mathrm{m}$ ). Since the 
slope value of the maximum concentration size spectrum in this case was close to the 0.75 power rule that describes the effect of cell size on metabolic processes (Peters, 1983), it was suggested that physiological constraints were responsible for the existence of the sizedependent concentration maximum. Whether the maximum achievable concentration is constrained by physiological or geometric factors is still uncertain.

In a field study of Florida lakes, Agusti et. al. (1990) found that a significant proportion of phytoplankton had populations that were at or close to their maximal achievable densities. Such communities were characterized by large-celled blue-green algae whereas communities that had cell concentrations much less than their maximum were typified by small-celled diatoms and green algae. This change in community structure of phytoplankton populations in very eutrophic systems has been described as a 'self-regulatory' mechanism of the algal community in response to a deterioration in growth conditions (eg. self-shading, abrupt changes in $\mathrm{pH}$, etc) when phytoplankton populations become very dense (Agusti et. al., 1990, Duarte and Agusti, 1990). The mechanism is thought to be triggered when phytoplankton crops have reached the ceiling imposed by physical and chemical constraints, notably light and nutrient limitation (Agusti et. al., 1992). Under these harsh conditions, autogenic factors (or non-nutrient constraints) operate to modify the phytoplankton community such that only few taxa can compete and survive.

\section{Phytoplankton Cell Size and Nutrient Uptake}

When natural phytoplankton populations exist below their maximum concentration, other external constraints such as resource availability and/or predation may be limiting their abundance and regulating community structure. The influence of nutrient uptake on phytoplankton size is a subject that has received much attention over the years because of its application to the management of ecosystem eutrophication. Lake studies covering a wide variety of trophic states have shown that as total phosphorus (and hence, total community biomass) increases, the proportion of larger phytoplankton cells 
increase together with a shift in taxonomic composition of the community to one or a few taxa (Ahrens and Peters, 1991b, Agusti et. al. 1990, 1991). The dominance of large cells is probably a reflection of the important adaptive value of cell size to changes in environmental conditions. Large cells, for example, would generally have slower growth rates but a higher capacity for luxuriant nutrient uptake, a property that is advantageous when nutrients are abundant (ie. eutrophic systems). On the other hand, small cells with their higher surface area to volume ratios as well as lower subsistence quotas and high growth rates, would thrive better in nutrient-poor environments (Agusti et. al. 1990, Chisholm 1992). This is indeed the case for the oligotrophic oceans where picoplankton dominate the phytoplankton community (Chisholm et. al. 1988). These results have also been shown in controlled experiments where the phytoplankton comunity shifts towards picoplankton in nutrient-poor incubations and conversly, to larger nanoplankton in enriched environments (Graneli et. al. 1993).

The dominance of picoplankton in oligotrophic environments has been explained on the basis of diffusion limitation (Hudson and Morel, 1991, Chisholm, 1992). For a cell to survive, the supply of nutrients to the cell, J, must be at least equal to or greater than the cell's requirements for the limiting nutrient ie.

$\mathrm{J}=4 \pi \mathrm{rDS} \geq \mu \mathrm{Q}$

where $\mathrm{r}$ is the cell radius, $\mathrm{D}$ is the molecular diffusion coefficient, $\mathrm{S}$ is the ambient concentration of nutrient, $\mu$ is the specific growth rate and $Q$ is the cell quota for the limiting nutrient. Knowing $\mathrm{Q}$ and $\mathrm{D}$, one can calculate, for a range of cell sizes and growth rates, the ambient concentration at which diffusion would limit the growth of phytoplankton cells of different sizes (Chisholm, 1992). Using this approach, it was shown that small cells growing at the same rate as larger cells, are only diffusion limited at very low nutrient concentrations whereas larger cells approach diffusion limitation at higher concentrations. In oligotrophic environments where concentrations of $\mathrm{NO}_{3}{ }^{-}$and 
$\mathrm{NH}_{4}{ }^{+}$are typically in the nano-molar range, small cells are thus favoured relative to larger cells.

\section{Effects of Predation on Phytoplankton Size Structure}

Phytoplankton community structure is also regulated by predators. Here, size plays a very important role in determining grazing patterns since predators generally eat prey smaller or at least as big as themselves. Being very large gives prey organisms the advantage of avoiding predation, at least until grazers are given sufficient time to adjust to larger prey sizes. For example, in nutrient-rich systems, large algal species (often in colonial form) dominate, decreasing the ability of zooplankton to graze them (Graneli et. al., 1993, Elser and Goldman, 1991). On the other hand, being very small also has the advantage of providing refuge from grazers. For filter feeders, the prey size range is set by the mesh size of the filtering apparatus. For raptorial feeders, theoretically no minimum prey size exists but the encounter rate between predator and prey is predicted to be proportional to the linear dimensions of the prey (Monger and Landry, 1990). Experimental studies, however, have shown that the size selectivity spectrum of prey sizes actually corresponds to a quasi-normal distribution in which an optimum prey size exists and the clearance rate is maximized (Boudreau et. al., 1991, Kiefer and Berwald, 1991, Hansen et. al., 1994). The ratio between optimum predator size and prey size is generally assumed to be a fixed ratio in size spectra modelling studies (Silvert and Platt, 1980, Kiefer and Berwald, 1991), but recent work has shown that such ratios can vary significantly between taxonomic groups, from about 1:1 for dinoflagellates to $18: 1$ for rotifers and copepods (Hansen et. al., 1994).

Recently, models of particle encounter efficiency borrowed from aerosol filtration theory have revolutionised ideas about mechanisms of planktonic feeding. These models propose four mechanisms in which predator particles can encounter prey particles: 1) direct interception, 2) inertial impaction, 3) gravitational deposition and 4) diffusional deposition (Shimeta and Jumars, 1991). Particle capture can be visualized by separating 
capture conceptually into the encounter event and the retention probability. The encounter event is described by the encounter rate and encounter efficiency whilst the retention probability gives the proportion of encountered particles actually captured. Current models on size spectra which focus on predator-prey mechanisms typically assume direct interception to be the dominant mechanism of predator-prey encounter (Kiefer and Berwald, 1991).

The relative importance of the four mechanisms is dependent on the size of the particles concerned. In general, total encounter rate can be obtained by summing up the individual encounter rates for the individual mechanisms. For the most part, the phytoplankton size spectra would be largely influenced by the mechanism of direct interception. However, in the case of very small particle sizes, diffusional processes would become more important in governing the encounter rate. This would be applicable in the case of small protozoans feeding on picoplankton but as yet, most size spectral models only consider direct interception as the mechanism of encounter. Encounter efficiencies are also dependent on particle size and may work in direct opposition to encounter rates. For example, theory predicts that a smaller predator radius increases encounter as well as capture efficiency for most mechanisms, but it either decreases or does not change encounter rate (Shimeta and Jumars, 1991). The counteracting effects of rates and efficiencies may be the cause of the observed quasi-normal distribution of prey captured. These processes are in turn, affected by fluid dynamics and the nature of the flow regime. The incorporation of these factors into models of biomass size spectra together with additional field data would improve our current understanding of the size structure and function of the microbial community.

In real systems, the abundance and community structure of phytoplankton is modulated by the chain of predatory interactions within the pelagic food web ('cascading trophic interactions'). Many lake studies have demonstrated 'top-down' control of phytoplankton in which the effects of size-selective fish predation on zooplankton had subsequent ramifications on size-selective zooplankton grazing on phytoplankton 
(Mazumder et. al., 1990, Vanni et. al., 1990, Elser and Goldman, 1991). Studies in the marine pelagial, however, are few owing to difficulties in large-scale experimentation, but similar results illustrating 'cascading trophic interactions' have been observed in some coastal waters (Graneli et. al., 1993). The importance of 'top-down' regulation in lake systems has been shown to depend on trophic state (Elser and Goldman, 1991) and it is likely that similar mechanisms operate in marine systems.

\section{Influence of Bottom-Up and Top-Down Controlling Factors on Phytoplankton Size Structure}

As discussed earlier, oligotrophic and eutrophic systems show very different community size structures. Consequently, one can expect differences to exist in how the community responds to grazing and nutrients. Both these mechanisms influence the size spectrum of phytoplankton but their relative contribution will vary depending on the trophic state of the ecosystem. In oligotrophic systems where nutrients are relatively scarce, 'bottom-up' control mechanisms are generally believed to be important in structuring the phytoplankton communities which are predominantly small-celled. However, it has also been argued that significant grazing pressure exists to maintain the sparse populations and efficient recycling necessary to prevent nutrient limitation in these waters (Agusti et. al., 1992). As nutrient supply increases towards mesotrophic systems, phytoplankton may face a tradeoff between the advantages of large size as a defence against grazing and its disadvantages in nutrient acquisition. At the same time, grazing pressure may be less efficient at recycling nutrients, so that nutrient-limited phytoplankton communities may result, which reflect the impacts of both zooplankton grazing and nutrient regeneration (Elser and Goldman, 1991). In the case of eutrophic systems, zooplankton grazing may be insufficient to prevent the high phytoplankton biomass characteristic of these systems. Here, colonial and other large algae dominate, which may be triggered by self-regulatory processes (Agusti et. al., 1992). Although these mechanisms are important in determining phytoplankton community structure, they are not 
easily differentiated in natural systems because of the interplay and feedback effects which operate between them. Nevertheless, a consideration of these factors in concert is necessary for more realistic and accurate predictions in ecological modelling.

Since the response of the community is dependent on the trophic state or productivity of the ecosystem, more recent studies have conducted experiments which cover a wide range in ecosystem trophy (Graneli et. al., 1994, Elser and Goldman, 1991). These studies (mainly from lakes) show that certain characteristics of the community size spectrum can be correlated to specific indicators of trophic state. For lake systems, total phosphorus concentration was shown to be well correlated with characteristics of the normalized biomass size spectrum (Ahrens and Peters, 1991b, Sprules and Munawar, 1986):- As total phosphorus increased, the slope became less negative indicating that larger organisms increased disproportionately. The Y-intercept of the spectrum, representing the biomass at $1 \mu \mathrm{m}^{3}$, also increased with total phosphorus, reflecting a tendency for biomass to increase in all size classes as phosphorus concentration in lakes increased (Ahrens and Peters, 1991b). The pattern of residuals around the regressions have also been used to describe progressive departure from the steady state (eg. oligotrophic system) with increasing ecosystem productivity (Sprules and Munawar, 1986).

For marine waters, the study carried out by Sheldon et. al. (1972) provided the only extensive data set of total particulates (biological particles were not distinguishable), spanning coastal to oceanic regions in the Atlantic and Pacific. The form of the size spectrum was shown to vary predictably both geographically and with depth (eg. temperate and polar regions above $40^{\circ}$ latitude had jagged size distributions whereas subtropical regions had smooth, flat spectra), but attempts were not made to correlate these differences with changes in environmental measurements. Other marine studies were generally confined to one particular type of ecosystem (Bode et. al., 1990, Rodriguez and Mullin, 1986, Warwick and Joint, 1987) because of the difficulty in accessing a large range of ecosystems. Nevertheless, these investigations together with the lake studies, 
suggest that trophic state, size and type of ecosystem are important determinants of microbial size spectra. Data so far from the marine environment, however, are not sufficiently comprehensive to attribute specific patterns of the shape of the size spectrum to environmental characteristics of the ecosystem. Nor is it clear how the relative strengths of nutrient or predatory effects on phytoplankton size spectra varies as a function of trophic state in marine environments: These questions adressed at both the mechanistic and ecosystem level will have to be resolved for a better understanding of ecosystem function and community structure.

\section{SIZE SPECTRA OF BACTERIOPLANKTON}

In recent years, increasing emphasis is being placed on the important role of bacteria in pelagic food webs. The microbial loop pathway, in which dissolved organic matter is taken up by bacteria and subsequently ingested by protozoa and metazoa (Azam et. al., 1983), is another major route for the flows of material and energy in the system. Their presence is an indication of ecosystem efficiency because nutrients are recycled that would otherwise be lost in settling. The sequestration of nutrients is a consequence of the fact that bacteria, being very small, sink very slowly compared to larger particles and therefore can maintain significant steady-state concentrations in the euphotic zone. In coastal systems, bacteria commonly make up 5 to $20 \%$ of the microbial biomass but in oligotrophic environments, bacteria may comprise more than $70 \%$ of the microbial organic carbon and more than $90 \%$ of the biological surface area (Fuhrman et. al., 1989). Since bacteria have such a large biomass and surface area, their potential accessibility to dissolved nutrients or substances that can adsorb to surfaces is very great (Cho and Azam, 1988). Bacteria could easily outcompete phytoplankton for limiting nutrients and hence regulate the major $\mathrm{C}$ supply for the system. This is especially important in oligotrophic environments where the relative proportion of bacteria to phytoplankton has been shown to increase dramatically (Cho and Azam, 1990). Bacteria may also be the major particulate reservoirs of limiting nutrients since the carbon to nitrogen ratio of natural 
bacteria assemblages is less than 4 (Lee and Fuhrman, 1987) while that of phytoplankton is approximately 6 to 7 (Cho and Azam, 1990).

\section{Importance of Bacteria Size on Food Web Dynamics}

Most studies of bacteria focus on the total biomass or abundance of these organisms in their natural environments. However, whole community measurements would tend to mask the trophic links between bacteria and other organisms when studying the dynamics of the food web. A study of a mesotrophic lake by Letarte and Pinel-Alloul (1991) highlighted the importance of considering bacterial size by showing that while bacterial production was well correlated with the small bacteria fraction $(<1 \mu \mathrm{m})$ and not the large size fraction $(1-3 \mu \mathrm{m})$, primary production correlated well with the larger bacteria size fraction but not the smaller fraction. More effort is required to study bacteria and phytoplankton taking into account cell size since different sized fractions may play very different ecological roles. In the marine environment, studies show that there is a shift from large bacteria $(>1 \mu \mathrm{m})$ to small bacteria $(<1 \mu \mathrm{m})$ as one proceeds along a nearshore to offshore transect (Griffith et. al., 1990, Wiebe, 1984). This is in accord with the general observation that as one approaches more eutrophic environments, the size spectrum shifts from predominantly small-celled to large-celled organisms.

\section{Influence of Grazing on Bacteria Community Structure}

As with phytoplankton, the main mechanisms underlying bacterial size spectra are likely to be grazing and nutrient effects. In the case of grazing, considerable evidence exist which points to the size-selective predation of bacteria by small protists (Chrzanowski and Simek, 1990). Size-selective predation is an important factor in controlling bacterial size and hence, in structuring bacterial communities. A recent study by Simek and Chrzanowski (1992) shows that larger bacterial cells are preferentially ingested by flagellates so that in the absence of flagellate grazing, the size structure of the bacterial population shifts to larger cells. Predation appears to vary as a function of prey 
size but the nature of this relationship is still uncertain: some have modelled clearance rates to be proportional to the square of the radius of the prey (Fenchel, 1982, 1984) whilst others have modelled clearance rates that vary in direct proportion to the prey radius (Monger and Landry, 1990, 1991). The discrepancy could lie in the different mechanisms at work as diffusional processes tend to dominate over direct interception processes for smaller organisms (Shimeta \& Jumaars, 1991). Since larger cells are preferentially grazed upon, being very small could also provide refuge from predators (Chrzanowski and Simek, 1990, Jurgens et. al., 1994). However, the extent to which this is true has been questioned (Simek and Chrzanowski, 1992). Part of the problem lies in the difficulty of measuring very minute bacteria in their natural environments.

\section{THESIS OBJECTIVES}

These patterns in size spectra observed in aquatic environments suggest that there is a characteristic way in which the biological community is structured according to the trophic state or productivity of the ecosystem. At the level of the entire community, an overall primary scaling exists in the size spectrum which is fairly robust and well studied in terms of modelling. However, at the level of ecological scaling of subgroups of the entire community, the spectrum appears to be more variable and susceptible to disturbances in the environment. The nature and degree of this interaction is still unclear, particularly with regard to the very small picoplankton end of the size spectrum in marine waters. While size-fractionated chlorophyll studies have shown a systematic pattern in the way chlorophyll is distributed with changes in ecosystem productivity, few studies have addressed this from the size spectral point of view, which gives direct information on cell numbers as well as biomass. With new and faster methods of analysis now available, it is timely to revisit size spectra especially as a means to study the dynamics of microbial communities in pelagic waters. In this thesis, we ask the following questions:- 
1) What are the temporal and vertical spatial variability in phytoplankton and bacteria size spectra from temperate coastal waters and subtropical open ocean waters?

2) How do the characteristics of microbial size spectra vary with eutrophication and ecosystem productivity?

3) How do variations in size spectra correlate with bulk environmental measurements of the ecosystem ?

4) Are there upper and lower bounds to microbial size spectra and why ?

5) What are the dominant environmental factors that influence microbial size spectra?

6) How do nutrients and predation affect the size structure of bacteria and phytoplankton communities?

To address questions $1,2 \& 3$, we explore the range and variability of microbial size spectra from diverse marine ecosystems, including coastal waters in Massachusetts and Cape Cod Bays (chapter 2), open ocean waters in the Sargasso Sea (chapter 3) and equatorial Pacific. Variability in the size spectra is examined in terms of seasonal changes as well as changes in water column structure. The oligotrophic open oceans and more eutrophic coastal waters of Massachusetts and Cape Cod Bays can be said to represent two very diverse environments and hence, a comparison of size spectra from these regions will give some idea of the range and bounds to microbial size spectra (question 4, chapter 4). At the same time, correlation of size spectra with bulk environmental measurements will help to identify some of the dominant factors underlying the size spectrum (question 5 , chapter 4). However, field measurements are complicated by the interaction of a number of influencing factors, which are not easily isolated. To study the effects of selected mechanisms (ie. nutrients and predation) on the microbial size spectrum, incubation experiments were also conducted whereby samples were systematically manipulated, keeping all other factors constant (question 6, chapter 5). The combination 
of these field and incubation experiments should thus assist in furthering our understanding of how environmental perturbations in the ecosystem affect the characteristics of microbial size spectra (chapter 6).

Note. Chapters two to four in this thesis are written as papers independent of the thesis. As such, there are some repeated texts and cross-referencing between these three chapters.

\section{REFERENCES (chapter 1)}

Agusti, S., Duarte, C.M. and Kalff, J., 1987. Algal call size and the maximum density and biomass of phytoplankton. Limnol. Oceanogr. 32 (4): 983-986.

Agusti., S. and Kalff, J. 1989. The influence of growth conditions on the size dependence of maximal algal density and biomass. Limnol. Oceanogr. 34 (6): 1104-1108.

Agusti, S., Duarte, C.M. and Canfield, D.E. 1990. Phytoplankton abundance in Florida lakes: Evidence for frequent lack of nutrient limitation. Limnol. Oceanogr. 35 (1): 181188.

Agusti, s., Duarte, C.M. and Canfield, D.E. 1991. Biomass partitioning in Florida phytoplankton communities. Journal of Plankton Research 13 (1): 239-245.

Agusti, S., Duarte, C.M. and Canfield, D.E. 1992. Self-regulation, bottom-up, and topdown control of phytoplankton communities: A reply to the comment by Kamenir. Limnol. Oceanogr. 37 (3): 683-687.

Ahrens, M.A. and Peters, R.H., 1991a. Plankton community respiration: relationships with size distribution and lake trophy. Hydrobiologia 224: 77-87.

Ahrens, M. and Peters, R. 1991b. Patterns and limitations in limnoplankton size spectra. Can J. Fish. Aquat. Sci. Vol 48: 1967-1978.

Azam, F., Fenchel, T., Field, J.G., Gray, J.S., meyer-Reil, L.A. and Thingstad, F., 1983. The ecological role of microbes in the sea. Mar. Ecol. Prog. Ser. 10: 257-263.

Banse, K., 1976. Rates of growth, respiration and photosynthesis of unicellular algae as related to cell size. A review. J. Phycol. 12: 135-140. 
Banse, K., 1982. Cell volumes, maximal growth rates of unicellular algae and ciliates and the role of ciliates in the marine pelagial. Limnol. Oceanogr. 27: 1059-1071.

Binder, B., Chisholm, S.W., Olson, R.J., Frankel, S.L. and Worden, A.Z., 1996. Dynamics of pico-phytoplankton, ultra-phytoplankton and bacteria in the central equatorial Pacific. Deep Sea Res. (in press).

Bode, A. Fernandez, E., Botas, A. and Anadon, R., 1990. Distribution and composition of suspended particulate matter related to a shelf-break saline intrusion in the Cantabrian Sea (Bay of Biscay). Oceanol. Acta 13(2): 219-228.

Borgman, E., 1982. Particle-size-conversion efficiency and total animal production in pelagic ecosystems. Can. J. Fish. Aquat. Sci. 39: 668-674.

Boudreau, P.R., Dickie, L.M. and Kerr, S.R., 1991. Body-size spectra of production and biomass as system-level indicators of ecological dynamics. J. Theor. Biol. 152: 329-339.

Chisholm, S.W., Olson, R.J., Zettler, E.R, Goericke, R., Waterbury, J. and Welschmeyer, N., 1988. A novel free-living prochlorophyte abundant in the oceanic euphotic zone. Nature 334: 340-343.

Chisholm, S.W., 1992. Phytoplankton size. in P. Falkowski (ed.) Primary production and biogeochemical cycles in the sea, Brookhaven Syposium on Biology, \#37.

Cho, B. C., Azam, F. (1988). Major role of bacteria in biogeochemical fluxes in the ocean's interior. Nature, Lond. 332: 441-443.

Cho, B. C., Azam, F. (1990). Biogeochemical significance of bacterial biomass in the ocean's euphotic zone. Mar. Ecol. Prog. Ser. 63: 253-259.

Chrzanowski, T. H. and Simek, K., 1990. Prey-size selection by freshwater flagellated protozoa. Limnol. Oceanogr. 35: 1429-1436.

Duarte, C.M., Agusti, S. and Peters, H. 1987. An upper limit to the abundance of aquatic organisms. Oecologia (Berlin) 74: 272-276.

Dickie, L.M., Kerr, S.R. and Boudreau, P. R., 1987. Size-dependent processes underlying regularities in ecosystem structure. Ecol. Mono. 57(3): 233-250.

Duarte, C.M., Agusti, S. and Canfield, D.E. 1990. Size plasticity of freshwater plankton: Implications for community structure. Limnol. Oceanogr. 35 (8): 1846-1851. 
Elser, J.J. and Goldman, C.R., 1991. Zooplankton effects on phytoplankton in lakes of contrasting trophic state. Limnol. Oceanogr. 36(1): 64-90.

Fenchel, T., 1982. Ecology of heterotrophic microflagellates. I. Some important forms and their functional morphology. Mar. Ecol. Prog. Ser. 8: 211-223.

Fenchel, T., 1984. Suspended marine bacteria as a food source. In: Fasham, M.J. (ed) Flows of energy and materials in marine ecosystems. Plenum Press, New York.

Fuhrman, J.A., Sleeter, T.D., Carlson, C.A., Proctor, L.M. (1989) Dominance of bacterial biomass in the Sargasso Sea and its ecological implications. Mar. Ecol. Prog. Ser. 57: 207-217.

Gaedke, U., 1992. The size distribution of plankton biomass in a large lake and its seasonal variability. Limnol. Oceanogr. 37(6): 1202-1220.

Gaedke, U., 1993. Ecosystem analysis based on biomass size distributions: A case study of a plankton community in a large lake. Limnol. Oceanogr. 38(1): 112-127.

Gasol, J.M., Guerrero, R., Pedros-Alio, C., 1991. Seasonal dominance in size structure and procaryotic dominance in sulfurous Lake Ciso. Limnol. Oceanogr. 36(5): 860-872.

Graneli. E., Olsson, P., Graneli, W. and Nylander, C., 1993. Weak 'top-down' control of dinoflagellate growth in the coastal Skagerrak. J. Plankton Res. 15(2): 213-237.

Griffith, P.C., Douglas, D.J. and Wainright, S.C., 1990. Metabolic activity of sizefractionated microbial plankton in estuarine, nearshore, and continental shelf waters of Georgia. Mar. Ecol. Prog. Ser. 59: 263-270.

Hansen, B., Bjornsen, P.K. and Hansen, P.J., 1994. The size ratio between planktonic predators and their prey. Limnol. Oceanogr. 39(2): 395-403.

Hopcroft, R.R. and Roff, J.C., 1990. Phytoplankton size fractions in a tropical neritic ecosystem near Kingston, Jamaica. J. Plankton Res. 12(5): 1069-1088.

Hudson, R.J. and Morel, F.M.M., 1991. Trace metal transport by marine microorganisms: Implications of metal coordination kinetics. Deep Sea Res. 40: 129-150.

Humphreys, W.F., 1979. Production and respiration in animal populations. Journal of Animal Ecology 50: 543-561.

Hurtt, G.C. and Armstrong, R.A., 1995. A pelagic ecosystem model calibrated with BATS Data. Deep Sea Res. (in press). 
Joint, I. 1991. The allometric determination of pelagic production rates. J. Plankton Res. 13: 69-81.

Jurgens, K., Arnddt, H. and Rothhaupt, K.O., 1994. Zooplankton-mediated changes of bacterial community structure. Microb. Ecol. 27:27-42.

Kerr, S.R., 1974. Theory of size distribution in ecological communities. J. Fish. Res. Bd. Can. 31: 1859-1862.

Kiefer, D.A and Berwald, J., 1991. A random encounter model for the microbial planktonic community. Limnol. Oceanogr. (3): 457-467

Laws, E. A., 1975. The importance of respiration losses in controlling the size distribution of marine phytoplankton. Ecology 56: 419-426.

Lee, S. and Fuhrman, J.A., 1987. Relationship between biovolume and biomass of naturally derived marine bacteria plankton. Appl. Envir. Micro. 53: 1298-1303.

Letarte, Y. and Pinel-Alloul, B., 1991. Relationships between bacterioplankton production and limnological variables: Necessity of bacterial size considerations. Limnol. Oceanogr. 36(6): 1208-1216.

Li, W.K.W., 1994. Phytoplankton biomass and chlorophyll concentration across the North Atlantic. Sci. Mar. 58(1-2): 67-79.

Maloney, C.L. and Field, J.G., 1991. The size-based dynamics of plankton food webs. I. A simulation model of carbon and nitrogen flows. J. Plankton Res. 13(5): 1003-1038.

Mazumder, A., Taylor, W.D. McQueen, D.J., Lean, D.R.S. and Lafontaine, N.R., 1990. A comparison of lakes and lake enclosures with contrasting abundances of planktivorous fish. J. Plankton Res. 12: 109-124.

Monger, B.C. and Landry, M.R., 1990. Direct interception feeding by marine zooflagellates: The importance of surface and hydrodynamic forces. Mar. Ecol. Prog. Ser. 65: 123-140.

Monger, B.C. and Landry, M.R., 1991. Prey size dependency of grazing by free-living marine flagellates. Mar. Ecol. Prog. Ser. 74:239-248.

Peters, R. H., 1983. The Ecological Implications of Body Size. Cambridge: Cambridge University Press. 
Platt, T. and Denman, K.L., 1977. Organization in the pelagic ecosystem. Helogol. Wiss. Meeresunters 30: 575-581.

Platt, T. and Denman, K.L., 1978. The structure of pelagic marine ecosystems. Rapp. P.V. Reun. Cons. Int. Explor. Mer 173: 60-65.

Raimbult, P., Rodier, M. and Taupier-Letage, I., 1988. Size fraction of phytoplankton in the Ligurian Sea and the Algerian Basin (Mediterranean Sea): Size distribution versus total concentration. Mar. Microb. Food Webs 3:1.

Robles-Jarero, E.G. and Lara-Lara, J. R., 1993. Phytoplankton biomass and primary productivity by size classes in the Gulf of Tehuantepec, Mexico. J. Palnkton Res. 15(12): 1341-1358.

Rodriguez, J. and Mullin, M. 1986. Relation between biomass and body weight of plankton in a steady state oceanic ecosystem. Limnol. Oceanogr. 31 (2): 361-370.

Rodriguez, J., Echevarria, F.and Jimenez-Gomez, F. 1990. Physiological and ecological scalings of body size in an oligotrophic, high mountain lake (La Caldera, Sierra Nevada, Spain). J. Plankton Res. 12(3): 593-599.

Sheldon, R., Prakash, A. and Sutcliff, W. 1972. The size distribution of particles in the ocean. Limnol. Oceanogr. 17: 327-340.

Shimeta, J. \& Jumaars, P.A., 1991. Physical mechanisms and rates of particle capture by suspension feeders. Oceanogr. Mar. Biol. Annu. Rev. 29: 191-257.

Silvert, W. and Platt, T., 1980. Dynamic energy-flow model of the particle size distribution in pelagic ecosystems. In W. Charles Kerfoot (ed) Evolution and ecology of zooplankton communities. The University Press of New England.

Simek, K. and Chrzanowski, T.H., 1992. Direct and indirect evidence of size-selective grazing on pelagic bacteria by freshwater nanoflagellates. Appl. Environ. Micro. 58(11): 3715-3720.

Sprules, W.G., Casselman, J.M. and Shuter, B.J., 1983. Size distribution of pelagic particles in lakes. Can. J. Fish. Aquat. Sci. 40: 1761-1769

Sprules, W.G. and Munawar, M. 1986. Plankton size spectra in relation to ecosystem productivity, size and perturbation. Can. J. Fish. Aquat. Sci. Vol. 43: 1789-1794. 
Stein, R.A., Threlkeld, S.T., Sandgren, C.D., Sprules, W.G., Persson, L., Werner, E.E., Neill, W.E. and Dodson, S.I. 1988. Size structured interactions in lake communities. in S.R. Carpenter (ed) Complex interactions in lake communities. Springer-Verlag.

Stramski, D. and Kiefer, D.A., 1991. Light scattering by microorganisms in the open ocean. Prog. Oceanogr. 28: 343-383.

Vanni, M.J., Luecke, C., Kitchell, J.F., Allen, E., Tempte, J. and Magnuson, J.J., 1990. Effects on lower trophic levels of massive fish mortality. Nature 344: 333-335.

Warwick, R.M. and Joint, I.R., 1987. The size distribution of organisms in the Celtic Sea: from bacteria to metazoa. Oecologia (Berlin) 73: 185-191.

Wiebe, W.J., 1984. Physiological and biochemical aspects of marine bacteria. in J.E. Hobbie and P.J. leB William (eds), Heterotrophic activity in the sea. Plenum. 


\title{
Chapter Two
}

\section{TEMPORAL AND SPATIAL VARIATION IN MARINE MICROBIAL SIZE}

\section{SPECTRA: I. MASSACHUSETTS \& CAPE COD BAYS}

\begin{abstract}
Microbial size spectra in aquatic ecosystems are a function of various environmental parameters. In this study, we seek to understand how plankton community size structure is influenced by perturbations in the coastal environment, with a focus on the spatial and temporal dynamics of bacteria and phytoplankton (ie. $0.2 \mu \mathrm{m}$ to $70 \mu \mathrm{m}$ ) size spectra from the Massachusetts and Cape Cod Bay regions. In general, depth variations in the size spectra could be correlated to the physical structure of the water column. Size spectra in mixed waters typically showed uniform characteristics within the mixed layer. In stratified waters, spectral changes were depicted by relatively greater abundances of larger cells near the surface, a shift towards smaller cells at some intermediate depth near the chlorophyll maximum, followed by a gradual increase in mean cell size at lower depths. In terms of seasonal changes, large cells dominated the size spectrum in late winter/early spring where mixed conditions prevailed. As the growing season developed into summer stratified conditions, a relative increase in the pico and nanoplankton was observed with little change in the larger microplankton fractions. A comparison of size spectra from three different locations in the Massachusetts and Cape Cod Bay areas confirmed that the size structures of both bacteria and phytoplankton were skewed towards larger size classes for shallow coastal waters, especially in Boston Harbour near the location of a sewer outfall. In contrast, offshore waters in Massachusetts Bay were generally characterized by a greater relative proportion of small bacteria and small phytoplankton. Overall, the phytoplankton size spectrum could be characterized by the slope of the normalized concentration spectrum, which ranged from about -1.75 to -1.35 for these coastal eutrophic waters. We hypothesize that these represent lower and upper bounds for nutrient limited and nutrient replete systems respectively.
\end{abstract}

\section{BACKGROUND}

The analysis of the size spectra of planktonic communities is becoming increasingly popular as a tool to study the structure and function of pelagic ecosystems. Traditional methods relied on Coulter Counters for enumerating particles, typically in the range of 1 to $100 \mu \mathrm{m}$. However, these techniques were limited in that biological particles were not able to be discriminated from other particles. Nevertheless, the results revealed a strikingly regular distribution of particles in the oceans such that biomass was roughly 
equally distributed over logarithmic size classes (Sheldon et. al. 1972). This discovery led to the formulation of theoretical models to explain the allometric relationship between size and biomass of pelagic organisms (Platt and Denman, 1977, 1978). Whilst these models were based primarily on rules governing the physiological behaviour of cells, later models were also able to reproduce similar results using grazing hypotheses (Silvert and Platt, 1980, Kiefer and Berwald, 1991). Both these types of models focused on the flow of energy (or biomass) from smaller to larger organisms. However, it is now known that a substantial portion of system energy and carbon is recycled through the microbial loop, providing a backflow to the classical propogation of energy through the system (Azam et. al., 1983). To date, this issue has not been sufficiently addressed in the theoretical analyses of size spectra.

Compared to theoretical studies, field studies on size spectra are few. This is partly due to the tedious and time consuming methods of enumerating biological particles using microscopy. Most studies focus on the overall size spectrum of the plankton community and generally confirm the findings from Sheldon et. al.'s (1972) extensive survey, where the slope of the normalized biomass spectrum is approximately equal to - 1 or a flat biomass spectrum with slope equal to 0 (Sprules et. al., 1983, Rodriguez and Mullin, 1986). Since the overall spectrum is fairly robust over a wide range of ecosystems, it has been described as a primary or physiological scaling, reflecting the metabolic constraints of organisms with size (Dickie et. al. 1987, Boudreau et. al., 1991). When the size range is limited to a component group of organisms with similar functional characteristics, eg. phytoplankton, the variability in the size spectrum appears to be more sensitive to changes in the environment. This secondary scaling is postulated to reflect ecological factors which allow for population density adjustments so that individuals can satisfy their food requirements. Generally, this results in a biomass size spectrum which increases substantially with organism size, leading to positive sloping biomass spectra (Gilabert et. al. 1990, Rojo and Rodriguez, 1994) as opposed to the flat biomass spectrum of Sheldon et. al. (1972). The difference between slopes at the secondary level of scaling 
relative to the primary scaling is postulated to be an indication of the extent of perturbation to the system (Gaedke, 1992). In this study, the focus is on size spectra of microorganisms (ie. phytoplankton and bacteria) as subcomponents of the larger pelagic community. These organisms were chosen because they are the primary source of food in the food chain and are also important in influencing the turnover rates of nutrients and carbon within the ecosystem. They also respond rapidly to external disturbances compared with larger organisms, making them suitable indicators of perturbations to the system.

Most environmental studies focus on bulk measurements of biomass and concentration which, although useful, do not necessarily draw out the trophic relationships between microorganisms and other organisms higher up the food chain. For example, changes in community structure and diversity may alter the food value even though the total productivity of the system may remain the same. Organism size plays an important ecological role in these processes because grazing is dependent on prey size, both for bacteria (Letarte and Pinel-Alloul, 1991, Simek and Chrzanowski, 1992) and phytoplankton (Kiefer and Berwald, 1991). In the case of freshwater studies, the dynamics of microbial size spectra have been described for oligotrophic (Rodriguez et. al., 1990), eutrophic (Gaedke, 1993, Echevarria and Rodriguez, 1993) and hypereutrophic lakes (Rojo and Rodriguez, 1994). These studies show that there is a systematic increase in the slope of the normalized biomass spectrum, ranging from an average of - 0.64 to 0.41 , with increased system trophy. This is a reflection of the relative importance of larger phytoplankton as the system becomes more eutrophic. In the case of marine environments, however, fewer field data on size spectra are available. Most studies use measurements of size-fractionated chlorophyll-a to describe community structure but this is limited in resolution because the size classes depend on available filter sizes (Hopcroft and Roff, 1990). Furthermore, size fractionated chlorophyll measurements do not reveal actual cell numbers nor biomass. The range and variability of microbial size spectra in marine environments are still relatively unexplored, particularly with respect to the 
picoplankton end of the spectrum. With the introduction of new technology to analyze particles more rapidly, it is timely to explore the realm of microbial size spectra from natural habitats and to seek an understanding of how the size structure of the microbial community responds to changes in the environment.

To address this question, we examine the range and variability of size spectra in relation to perturbations in a eutrophic coastal environment. In particular, seasonal and depth characteristics of bacteria and phytoplankton size spectra (ie. $0.2 \mu \mathrm{m}$ to $70 \mu \mathrm{m}$ ) from the Massachusetts and Cape Cod Bay regions were studied using flow cytometry. This technique is suitable for rapid enumeration of particles and also has the ability to discriminate phytoplankton and bacteria cells from other particles on the basis of a cell's fluorescence and light scattering properties. By using empirical calibrations to convert forward light scatter to volume, size spectra of these trophic subgroups were generated. Biomass, which reflects the distribution of energy in the system, was estimated from concentration and cell size and also analyzed as a function of size. Size spectral trends and patterns were examined to formulate hypotheses about relationships between size spectra and environmental factors, community succession and the role of perturbations in the ecosystem.

\section{METHODS}

\section{Outline of Study Area}

The study encompasses coastal waters in Massachusetts and Cape Cod Bays which show substantial seasonal fluctuations, typical of temperate coastal waters. Three stations were chosen to cover a broad range of water characteristics:- in Boston Harbour ( $42^{\circ} 20.4^{\prime} \mathrm{N}, 70^{\circ} 56.5^{\prime} \mathrm{W}$ - station F23P), Cape Cod Bay ( $41^{\circ} 54.5^{\prime} \mathrm{N}, 70^{\circ} 13.7^{\prime} \mathrm{W}$ - station F2P) and Massachusetts Bay (42²8.4'N, 70³7.1'W - station F22) (Fig. 2.1). Sampling was part of a larger ongoing project by the Massachusetts Water Resources Authority (MWRA) to provide baseline water quality measurements of the Massachusetts and Cape Cod Bay areas. The aim of the project was to determine conditions prior to diversion of 


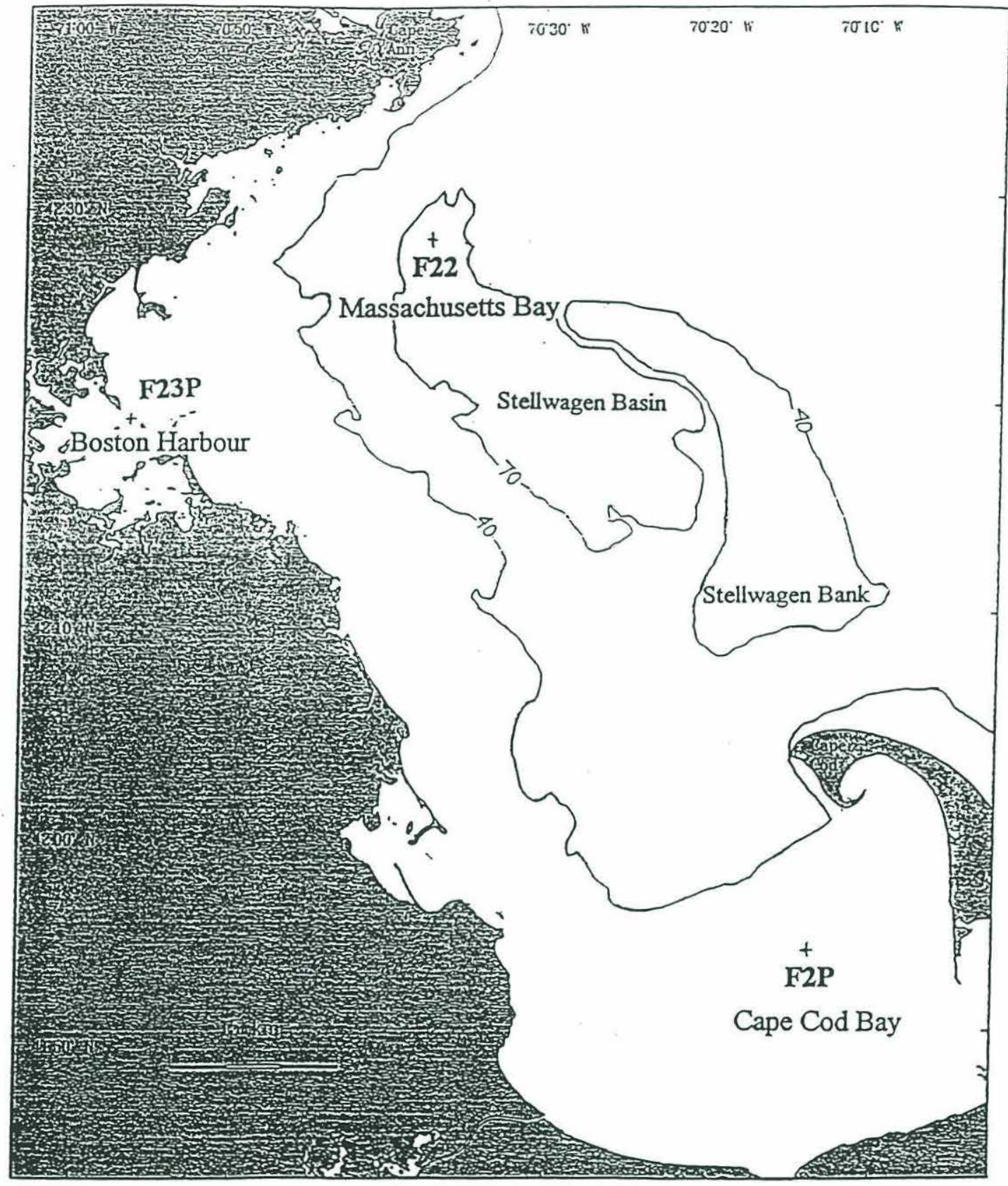

Fig. 2.1. Location of sampling stations in temperate coastal waters in Boston Harbour $\left(42^{\circ} 20.4^{\prime} \mathrm{N}, 70^{\circ} 56.5^{\prime} \mathrm{W}\right.$ - F23P), Massachusetts Bay $\left(42^{\circ} 28.4^{\prime} \mathrm{N}, 70^{\circ} 37.1^{\prime} \mathrm{W}-\mathrm{F} 22\right)$ and Cape Cod Bay $\left(41^{\circ} 54.5^{\prime} \mathrm{N}, 70^{\circ} 13.7^{\prime} \mathrm{W}\right.$ - F2P). Depth contours are in metres. Taken from Kelly et. al., 1994a. 
MWRA effluent from Boston Harbour, through a proposed outfall located about $15 \mathrm{~km}$ from the existing Deer Island Treatment Plant, directly into western Massachusetts Bay. The study was initiated in 1991 to verify compliance with regulation standards and to assess the environmental impact of effluent discharge into Massachusetts Bay.

Boston Harbour is an estuarine outlet and is subject to strong tidal fluctuations and freshwater discharges (depth 26m). Being situated near Boston city, the station is under the influence of significant anthropogenic inputs, including effluent from the nearby Deer Island treatment plant and untreated combined sewer overflows (CSO) into the harbour. Winter nutrient concentrations are high (eg. $10 \mu \mathrm{M} \mathrm{NO}_{3}$ ) leading to a highly pulsed and productive ecosystem (Kelly et. al., 1994a). Chlorophyll levels range from $0.2 \mu \mathrm{g}^{-1}$ (early spring) to $8 \mu \mathrm{g}^{-1}$ (late summer) and the level of particulates is generally high in the water column (beam attenuation $\sim 4 \mathrm{~m}^{-1}$ ) (Kelly et. al., 1994a, d). Cape Cod Bay is of similar water depth to Boston Harbour (32m) but is less influenced by anthropogenic discharges. It lies within a shallow bay protected from the general oceanic circulation by the Cape Cod peninsular. Chlorophyll measurements reach a maximum of about $5 \mu \mathrm{g} \mathrm{l}^{-1}$ in the spring and turbidity is generally lower than at Boston Harbour (Kelly et. al., 1994a). Further offshore in Massachusetts Bay, oceanic currents play a major role in influencing the characteristics of the water body. The station is located in the deep channel of Stellwagen Basin (depth $80 \mathrm{~m}$ ) and provides a contrast to the other two shallow coastal stations.

\section{Field Sampling Scheme}

The emphasis in this study is on capturing size spectral characteristics and examining them in the context of measured environmental variables. Sampling was limited to depth profiles in selected months in order to detect the main seasonal trends at each of the three locations ie. in October 1992, February 1993, March, April, June and August 1993 in connection with the farfield surveys conducted by MWRA (Kelly et. al., 1993, 1994a, b, c, d). Seawater was collected in 51 Niskin bottles at discrete depths based on 
CTD (conductivity-temperature-depth) measurements ie. at the surface, intermediate surface, chlorophyll maximum (or mid-depth for deep mixed layers), intermediate bottom and bottom. $200 \mathrm{ml}$ glutaraldehyde (Tousimis - 25\% stock solution) was pipetted into sterile $50 \mathrm{ml}$ centrifuge tubes and seawater from each depth was added up to the $50 \mathrm{ml}$ level to obtain a final concentration of $0.1 \%$ (Gin, 1996). A surface sample at each station was also filtered $(0.2 \mu \mathrm{m}$ for nano/microplankton analysis; $0.02 \mu \mathrm{m}$ for picoplankton analysis) and treated in the same manner as the actual samples to act as reference controls for background fluorescence and scattering. Each sample was well mixed and then two aliquots (replicates) of $2 \mathrm{ml}$ were withdrawn each into $2 \mathrm{ml}$ cryovials for picoplankton analysis. The remainder of the samples in the centrifuge tubes (for nano/microplankton analysis) together with the picoplankton samples were then left in the dark for 10 to 15 minutes. After this time, the samples were immersed into liquid nitrogen for storage (Vaulot et. al., 1989). (Note that $1 \mathrm{~mm}$ holes were made in the caps of the centrifuge tubes because the tubes had a tendency to crack when frozen samples were thawed due to the pressure buildup behind the caps.) For long term storage, nano/microplankton samples were subsequently transferred to a $-40^{\circ} \mathrm{C}$ freezer due to limited liquid nitrogen storage space for the $50 \mathrm{ml}$ centrifuge tubes (Gin, 1996). Picoplankton samples, being smaller, were stored for the long term in liquid nitrogen before flow cytometric analysis.

In addition, standard measurements of chlorophyll a, transmissometry, temperature, salinity, irradiance as well as measurements of dissolved ammonia, nitrate, nitrite, phosphate and silicate were made at the same time as samples for flow cytometry were collected (Kelly et. al., 1993, 1994a, b, c, d). At the Boston Harbour (F23P) and Cape Cod stations (F2P), additional samples were taken at the surface and mid-depth for laboratory measurements of biology/productivity. These included measurements of particulate organic carbon and nitrogen, total suspended solids, extracted chlorophyll-a, phytoplankton and zooplankton identification and enumeration using microscopy and water column production using C-14 methods. Details of measurement methods may be found in Albro et. al., 1993. 


\section{Flow Cytometry Analysis}

Samples were analyzed on flow cytometers using two main instrument configurations. The first configuration ('pico' settings) was designed to analyze heterotrophic bacteria and picophytoplankton in the size range 0.2 to $2.0 \mu \mathrm{m}$ using dualbeam flow cytometery on an EPICS 753 instrument (Duval, 1993, Binder et. al., 1996). In this set-up, a spherical lens was used to focus blue (488nm) and UV $(355-356 \mathrm{~nm})$ laser beams to a tight spot, measuring approximately $20 \mu \mathrm{m}$ in diameter. Immediately following sample thawing in a water bath $\left(25^{\circ} \mathrm{C}\right), 0.5 \mathrm{ml}$ aliquots were stained with the DNA-specific fluorochrome Hoechst-33342 to give a final concentration of $0.5 \mu \mathrm{g} \mathrm{ml}^{-1}$ (Monger and Landry, 1993). Samples were then incubated in the dark for 1 hour at room temperature before dual beam analysis. Excitation with blue light causes chlorophyll-containing cells to fluorescence red whereas UV excitation causes DNA-containing cells stained with Hoechst to fluoresce blue. In this way, phytoplankton (with both DNA and chlorophyll) and bacteria (only DNA) could be easily discriminated (Gin, 1996). Just prior to flow cytometric analysis, known volumes of two standard bead stocks were also added to the sample: $0.57 \mu \mathrm{m}$ blue-excitable beads ("Fluoresbrite YG", Polysciences, Inc.) and $0.46 \mu \mathrm{m}$ UV-excitable beads ("Fluoresbrite BB"). These beads were used as reference fluorescence and light scatter standards and also to determine cell abundance (Olson et. al., 1993). By calibrating the flow rate each day using standard beads, the actual volume analyzed per sample could be calculated from the number of beads counted within each sample. In general, the day-to-day variation in bead calibrations was less than $5 \%$.

Nano/microplankton from about 2 to $70 \mu \mathrm{m}$ were analyzed on an EPICS V flow cytometer using a different configuration from the picoplankton analysis ie. 'nano/micro' settings. In this set-up, a single blue laser line was focused through both a $150 \mathrm{~mm}$ and $40 \mathrm{~mm}$ lens for cell excitation (Olson et. al., 1989). Since the abundance of larger phytoplankton is of several orders of magnitude less than that of picoplankton, larger volumes of sample have to be analyzed before reasonable statistical cell counts can be 
made. To achieve this, larger sized sample tubing and needles were used to process larger volumes with flow rates of about $2-4 \mathrm{ml} \mathrm{min}{ }^{-1}$ compared to $5 \times 10^{-3} \mathrm{ml} \mathrm{min}^{-1}$ for 'pico' settings. Following sample thawing in a water bath $\left(25^{\circ} \mathrm{C}\right), 45 \mathrm{ml}$ aliquots were withdrawn and known volumes of beads (blue-excitable "Fluoresbrite YG") were added ( 2.02 and $5.95 \mu \mathrm{m}$ ). Mixes of different sized beads in $0.2 \mu \mathrm{m}$ filtered seawater were also run on both configurations to provide a reference frame for analysis.

\section{Merging the Picoplankton and Nano/Microplankton to Form a Continuous Spectrum}

Software (CytoPC) provided by D. Vaulot (Station Biologique, Roscoff, France) was used to analyze the data and discriminate bacteria and phytoplankton from other particles (Gin, 1996). Bacteria were identified as a cluster of cells that contained significant blue fluorescence relative to standard $0.46 \mu \mathrm{m}$ beads (Fig. 2.2).

Picophytoplankton could be distinguished from bacteria and other particles because of their high red fluorescence relative to standard $0.57 \mu \mathrm{m}$ beads. Generally, picophytoplankton signatures emerged as a continuous cluster of cells which had increasing red fluorescence with increasing forward light scatter. For the examples taken in June, these clusters were comprised of smaller Synechoccus (discriminated using orange fluorescence) and slightly larger ultraplankton, with the picophytoplankton at Cape Cod being smaller (lower forward scatter) and more abundant than the other two stations. A similar sweep of cells on the red fluorescence versus forward scatter scattergram was also observed for the larger nano/microphytoplankton obtained from the 'nano/micro' instrument configuration (Fig. 2.3).

The identified populations were projected from the fluorescence vs forward scatter scattergram and modified to remove background fluorescence and scattering. Two sets of data, one from each of the 'pico' and 'nano/micro' settings were obtained and merged to form the overall size spectrum. The data sets were aligned using the forward light scatter signals from standard beads which could be seen on both configurations (eg. $0.75 \mu \mathrm{m}$ 

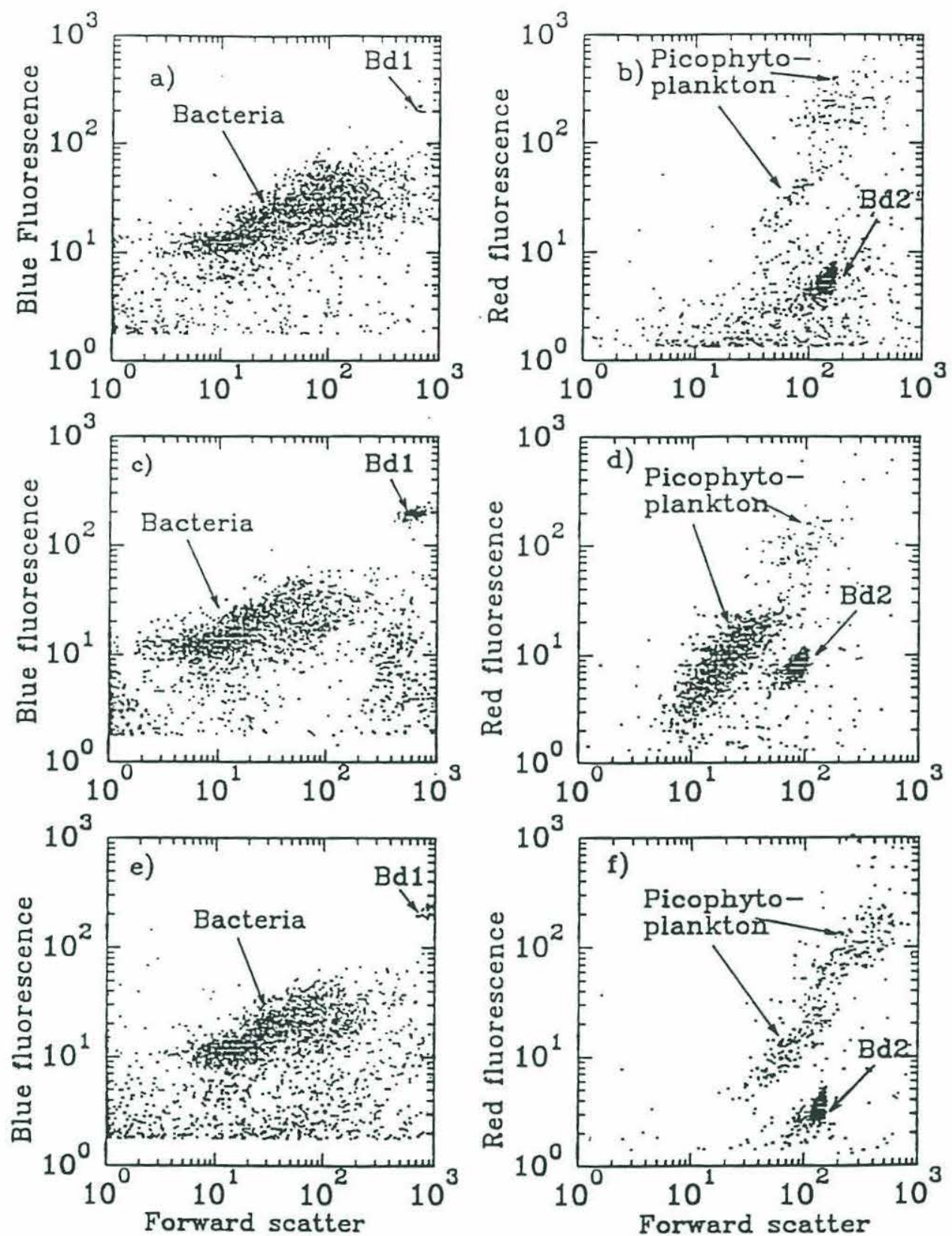

Fig. 2.2. Flow cytometric signatures of bacteria and picophytoplankton for surface samples in June, 1993 for Boston Harbour (a, b respectively), Cape Cod Bay (c, d) and Massachusetts Bay (e, f). Bacteria were discriminated on the blue fluorescence versus forward light scatter scattergram whilst picophytoplankton were discriminated on red fluorescence versus forward light scatter. Each data parameter was collected in relative units covering three logarithmic decades. These picoplankton samples were captured using dual-beam analysis on the 'pico' settings of an Epics 753 flow cytometer. Standard calibration beads of $0.46 \mu \mathrm{m}(\mathrm{Bd} 1)$ and $0.57 \mu \mathrm{m}(\mathrm{Bd} 2)$ were also added for reference. 


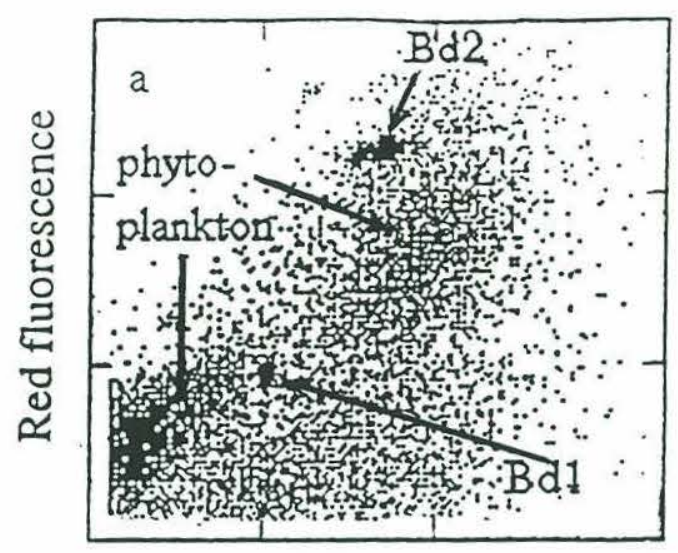

Forward scatter

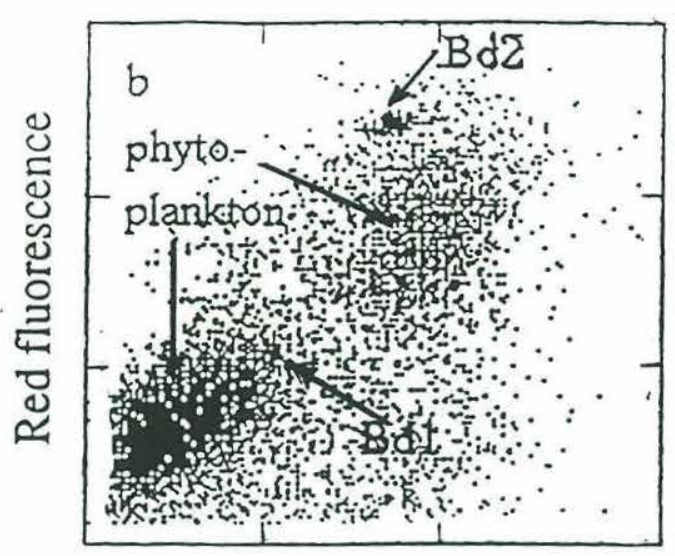

Forward scatter

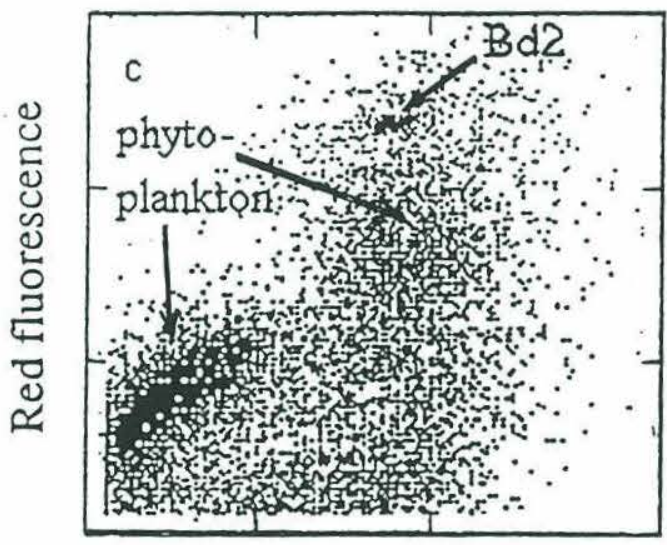

Forward scatter

Fig. 2.3. Flow cytometric signatures of nanno and microphytoplankton for surface samples in June, 1993 for Cape Cod Bay (a), Massachusetts Bay (b) and Boston Harbour (c). Phytoplankton were analyzed using the 'nanno/micro' settings on an Epics V flow cytometer and discriminated from other particles on the red fluorescence versus forward light scatter scattergram. Each data parameter was collected in relative units covering three logarithmic decades. Standard calibration beads of $2.02 \mu \mathrm{m}(\mathrm{Bd} 1)$ and $5.79 \mu \mathrm{m}(\mathrm{Bd} 2)$ were also added for reference. 
beads). For the purposes of this study, we chose to convert forward light scatter to volumetric size by applying empirical size-scatter calibrations measured on both the 'pico' and 'nano/micro' settings (Fig. 2.4). While these calibrations do not account for odd cell shapes and changes in refractive index, we feel that as a first approximation, the use of size is valid because of the good correlation between forward scatter and cell size as well as the large size range (about 7 log decades) considered in this study, which would tend to mask details at the cellular level.

The nano/microplankton calibration was obtained by sizing phytoplankton cultures with a Coulter counter and analyzing the relative forward light scatter of the same cells on a flow cytometer (DuRand, 1995, Gin, 1996). For the picoplankton calibration equation, seawater samples were first preserved with $0.1 \%$ glutaraldehyde and then filtered through Poretics polycarbonate filters of sizes $0.4,0.6,0.8$ and $1.0 \mu \mathrm{m}$ using gentle pressure on a $10 \mathrm{ml}$ syringe (Brian Binder, pers. comm.) or by gravity (Aref, 1996). The filtrates were then analyzed for bacteria and picophytoplankton on an Epics 753 using the 'pico' configuration. The concentration distributions (as a function of forward scatter relative to $0.46 \mu \mathrm{m}$ beads) were then expressed as a fraction of the unfiltered concentration distribution, and the $50 \%$ retention value of forward scatter was obtained for each filtrate. This gave an average value for the forward scatter corresponding to the filter size used. Recent experiments using these filtration methods show that the picoplankton calibration equation is, in fact, quite stable for different water types (Gin, 1996) and different times of the year (Aref, 1996).

To ensure a smooth transition of the spectrum from pico to nano/micro scales, the nano/microplankton calibration was modified (ie. set at the same slope value as the picoplankton calibration) where actual calibration data was unavailable (less than $10 \mu \mathrm{m}^{3}$ ). This resulted in a fairly good fit of the overlapping populations captured on both the 'pico' and 'nano/micro' settings (Gin, 1996). Although these empirical calibrations are only approximate and should be further refined in future applications, we chose to use physical size units rather than forward light scatter because it enables the rough estimation of cell 


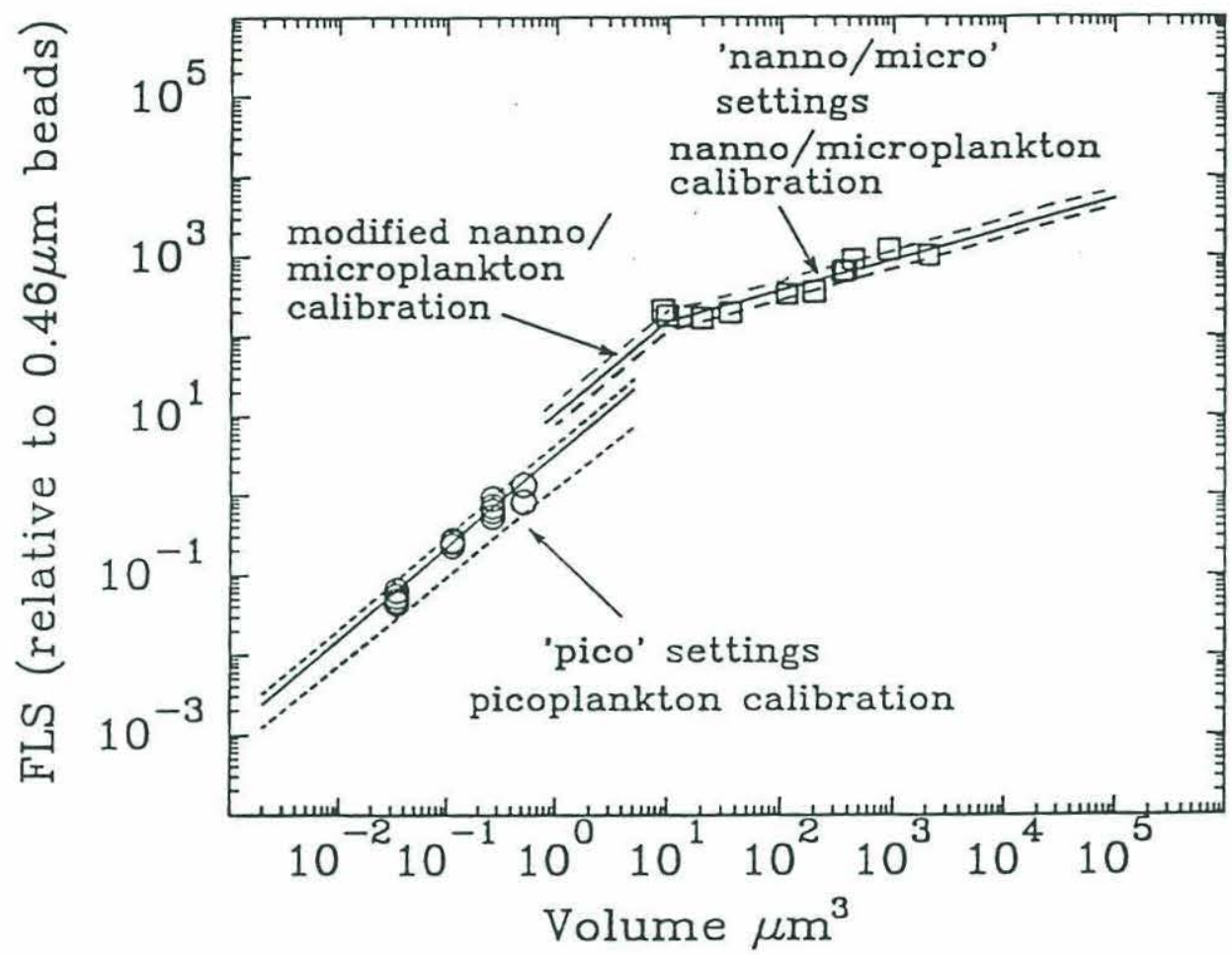

Fig. 2.4. Empirical size calibration equations for converting forward light scatter to volumetric size. The picoplankton calibration was obtained by filtering Gulf Stream seawater samples through various Poretics polycarbonate filters and analyzing the filtrates on an Epics 753 flow cytometer using 'pico' settings. The calibration for nanno/microplankton greater than $10 \mu \mathrm{m}^{3}$, was obtained by sizing a variety of phytoplankton cultures with a Coulter Counter and analyzing the same samples on an Epics V flow cytometer using the 'nanno/micro' settings. The nanno/microplankton calibration was modified for sizes less than $10 \mu \mathrm{m}^{3}$ to ensure that overlapping populations (measured on both settings) merged correctly. This was achieved by setting the nanno/microplankton calibration slope equal to the value of the slope of the picoplankton calibration. The dashed lines indicate an estimate of the errors in the calibration equations. 
biomass. Individual cell biomass was estimated from cell size, $\mathrm{V}$ (in $\mu \mathrm{m}^{-3}$ ), through empirical carbon-size relationships taken from the literature: bacteria - $350 \mathrm{fgC} \mu \mathrm{m}^{-3}$ (Lee and Fuhrman, 1987); picophytoplankton - $470 \mathrm{fgC} \mu \mathrm{m}^{-3}$ (Verity et al., 1992); nanoplankton - $C(p g)=0.433 V^{0.863}$ (Verity et. al., 1992); microplankton - $C(p g)=0.347 \log V^{0.866}$ (Strathman, 1967). Biomass for each size category was calculated by multiplying cell concentration by cell biomass, thus generating size spectra of biomass.

\section{Data Processing}

The size spectra were analyzed in two ways:- as histograms where the original data was reclassified into logarithmic size classes of equal width; and as normalized spectra where the original data was divided by the original size class width to make the spectra independent of size class (Platt and Denman, 1977, 1978, Rodriguez and Mullin, 1986, Sprules and Munawar, 1986). (Note that the original logarithmic size classes from the pico and nano/microplankton ends of the spectrum are different due to the different forward scatter-size calibration equations.) Normalization allows for comparison of size spectra from different sources, including theoretical models. These normalized spectra are typically characterized by the intercept and slope of the log-transformed data (see Appendix). For this analysis, regressions were calculated for the normalized concentration

size spectra alone but these can be extrapolated to normalized biomass spectra through the relationships given in the Appendix. The intercept and slope are important because they define the shape of the size spectrum whereas parameters such as mean cell size average out changes in the spectrum. This means that biomass or energy flow considerations of different sized fractions can be more easily visualised and quantified using the intercept and slope, whereas the mean cell size is limited in this respect. However, for a more complete description of changes in the microbial community, it is necessary to analyze all three parameters since not all changes may be depicted with just one or two of these measurements. An example of this is when the size spectrum shifts along itself so that the intercept and slope remain unchanged but the mean size changes. 
In the case of the normalized concentration size spectrum, the intercept, by definition, is the abundance of cells of $1 \mu \mathrm{m}^{3}$ (1.2 $\mu \mathrm{m}$ diameter) but is also used in a more general way, to reflect the total numerical abundance of organisms or the resource level of the system (Sprules and Munawar, 1986). (Note that the intercept of the normalized bacteria spectrum actually portrays the abundance of large bacteria whereas for the normalized phytoplankton spectrum, the intercept represents the abundance of small cells ie. picophytoplankton.) The slope is a useful measure of the overall distribution of cells and changes in the slope reflect the relative importance of the various size classes. A slope of -2 for the normalized concentration size spectrum corresponds to the flat biomass spectrum where equal amounts of material exist in equal sized logarithmic classes. Higher slope values imply a disproportionate increase in the biomass of larger organisms while lower slopes indicate a relative biomass increase in smaller organisms. However, slope changes are only meaningful when there is a good fit of data to the linear regression and hence, calculations were based only on the steadily decreasing function to the right of the maximum, for which the correlation coefficient is generally greater than 0.97 ('modified' normalized spectrum) (Fig. 2.5). The front end of the spectrum, which represents the tail end of a normally distributed population of the smallest bacteria or phytoplankton, is neglected as these small and less abundant cells would probably also be undetectable using conventional microscopy. At any rate, the information is not lost since the size spectrum is still analyzed through histograms as well as changes in mean cell size.

When considering the modified normalized spectra, variations in the intercepts and slopes for replicate spectra were typically less than $5 \%$ for bacteria, $1 \%$ for phytoplankton and $2 \%$ for total bacteria plus phytoplankton. Similar variations were also found between the spectral characteristics (ie. intercept and slope) of live and preserved size spectra, even though cell counts of specific populations could vary by up to $30 \%$ for live and preserved samples (Gin, 1996). The smaller differences for the normalized spectra arose because these were based on log scales which covered a broad range in abundance and size. On 

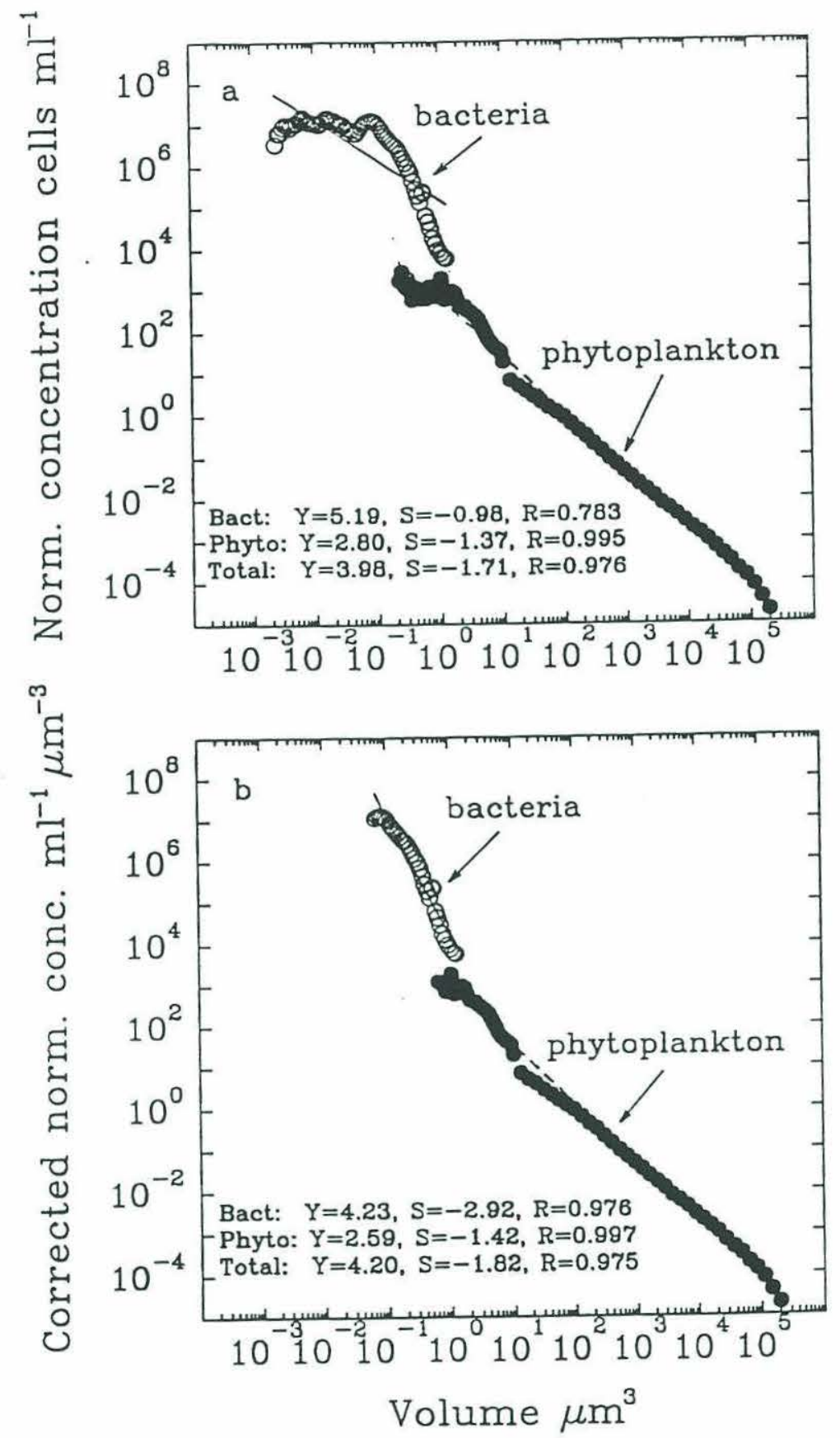

Fig. 2.5. Differences between normalized and modified normalized concentration size spectra for Boston Harbour taken from surface waters on February 23, 1993. The complete normalized spectrum (a) was obtained by dividing the raw data by the width of the corresponding size class, whilst the modified normalized spectrum (b) was obtained by excluding data points to the left of the maximum of the normalized data in (a). The coefficents of regression are also shown: intercept (Y), slope (S) and variance (R) for bacteria, phytoplankton and total (bacteria + phytoplankton) community. 
the whole, $5 \%$ provides a reasonable estimate of the analytical errors involved in this study.

\section{RESULTS}

\section{Depth Variation of Size Spectra}

\section{Mixed Water Column}

In general, variations in the size spectrum can be correlated to the physical structure of the water body. Mixed conditions typically occur in the winter, early spring and fall where storm events are frequent and cold temperatures at the surface enhance convective exchange. Within the mixed layers of the water column, the physical, chemical and associated biological characteristics are generally uniform with depth (Fig. 2.6). For example, the shallow coastal station in Boston Harbour in October shows a fully-mixed water column with temperatures of about $12^{\circ} \mathrm{C}$, chlorophyll levels of $2 \mu \mathrm{g} \mathrm{l} 1^{-1}$ and nitrate concentrations of $4 \mu \mathrm{M}$ (Kelly et. al., 1993). The depth profiles illustrate that on linear scales, the size spectra are not the same for concentration and biomass:- While the concentration spectrum is characterized by a unimodal distribution dominated by bacteria cells, the biomass spectrum from these coastal waters is skewed heavily towards the larger nano and microplankton. Bacteria and phytoplankton abundance together with their corresponding size spectral characteristics (eg. mean cell size, intercept and slope of the normalized concentration size spectrum) are generally similar with depth (Fig. 2.7). (Note that independent phytoplankton cell counts using microscopy from Kelly et. al., 1993 were consistently lower by one order of magnitude, probably because the smaller but numerically more abundant Synechococcus cells were not measured in their studies. However, our flow cytometric measurements could not detect very large cells greater than about $70 \mu \mathrm{m}$.) On the whole, the waters of Boston Harbour are well-mixed and show less vertical variation in spectral characteristics throughout the year because of strong tidal currents and its shallow depth. Size spectral characteristics in Cape Cod Bay and the offshore Massachusetts Bay station also show fairly uniform structures with depth in the 

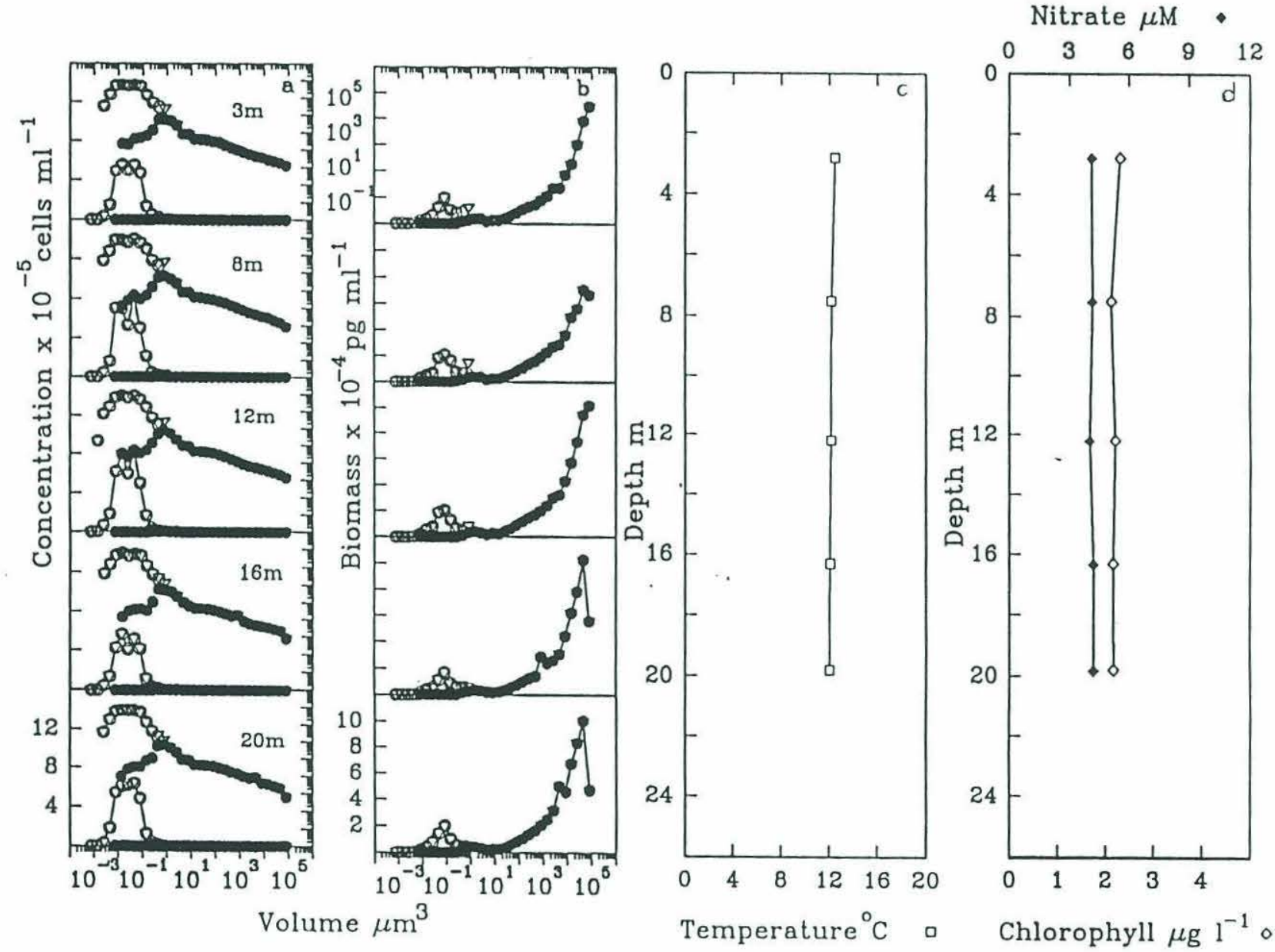

Fig. 2.6. Depth profiles of flow cytometrically generated size spectra for the station in Boston Harbour on October 15, 1992, under fully mixed conditions. Histogram size spectra of concentration and biomass for bacteria (open circles), phytoplankton (closed circles) and combined bacteria plus phytoplankton (open triangles) are shown in panels a and b respectively. Corresponding depth profiles of temperature (open squares), extracted chlorophyll (open diamonds) and nitrate concentration (closed diamonds) are also shown in panels c and d. Environmental measurements were taken from Kelly et. al., 1993. 


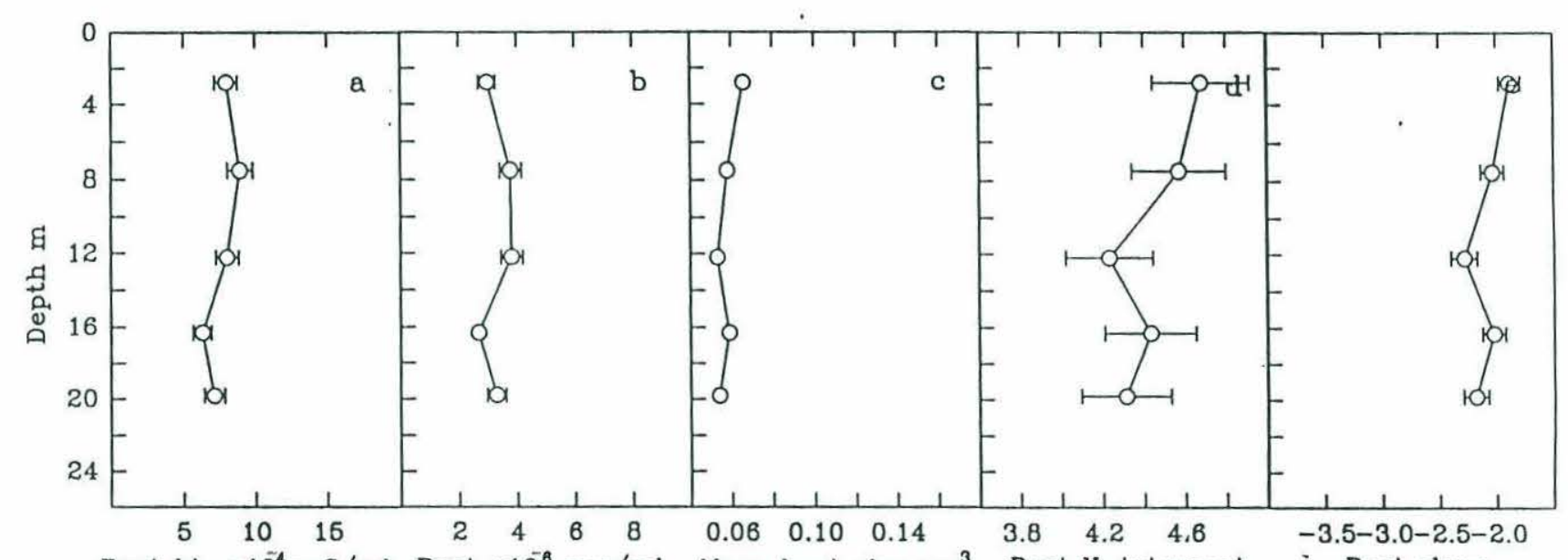

Bact bio $\times 10^{-4} \mathrm{pgC} / \mathrm{ml}$ Bact $\times 10^{-8} \mathrm{nos} / \mathrm{ml}$ Mean bact size $\mu \mathrm{m}^{3}$ Bact $\mathrm{Y}$-intercept Bact slope

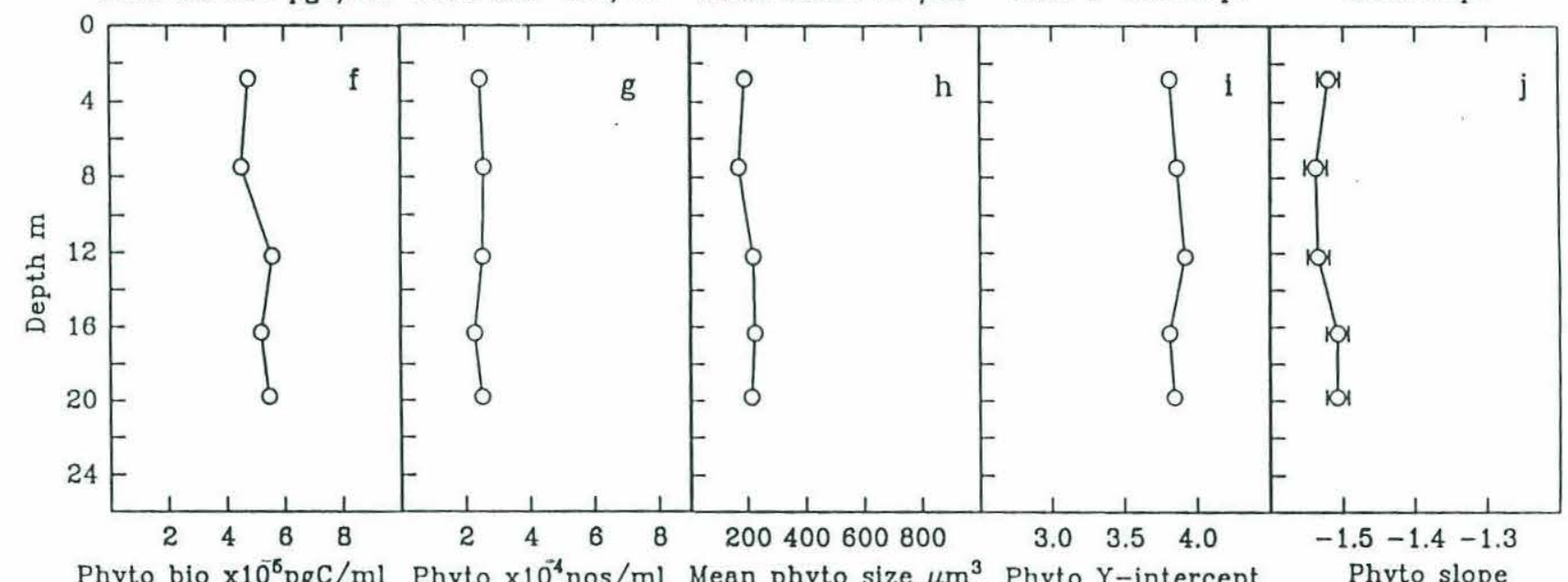

Fig. 2.7. Depth profiles of size spectral characteristics for Boston Harbour on October 15, 1992, corresponding to the size spectra and environmental conditions shown in Fig. 2.6: a) bacteria biomass, b) bacteria cell concentration, c) mean bacteria size, d) intercept of normalized bacteria spectrum, e) slope of normalized bacteria spectrum, f) phytoplankton biomass, g) phytoplankton cell concentration, h) mean phytoplankton size, i) intercept of normalized phytoplankton spectrum and j) slope of normalized phytoplankton spectrum. (Error bars correspond to one standard deviation:- those without error bars have small standard deviations which fall within the symbols.) 
mixed layer, with occasionally greater biomass and slightly larger cells in the $5 \mathrm{~m}$ surface layer (Gin, 1996).

\section{Stratified Water Column}

When stratification of the water column occurs during warm, summer conditions, the depth variation of size spectra becomes pronounced. In deep, strongly stratified waters, a distinct chlorophyll maximum usually develops at the bottom of the stratified layer below the surface (eg. 13m for Massachusetts Bay in June in Fig. 2.8). Above this depth, the biomass size spectra are dominated by larger cells, with the largest cells and greatest biomass at the surface (ie. in the upper $5 \mathrm{~m}$ ). Conversely, associated nutrient levels are often low due to drawdown from high primary production and the absence of physical transport mechanisms to replace nutrients. The smallest mean population sizes are generally observed near or at the chlorophyll maximum, coinciding with slightly elevated nutrient levels (Fig. 2.8, 2.9). Below the chlorophyll maximum where light levels diminish even further, a significant drop in cell concentration and biomass occurs for the whole spectrum, whilst nutrient concentrations steadily increase. At these lower depths, mean sizes of both bacteria and phytoplankton populations increase. Note that in spite of the changes in community size structure and cell abundance with depth, the bulk measurement of beam attenuation remains fairly constant with depth for this stratified profile.

These changes in the histogram size spectra are also reflected in changes in the slope of the normalized concentration size spectra (Fig. 2.9). For phytoplankton, the slope at the surface is usually the shallowest and highest in value, indicating the greater relative importance of large cells in surface waters. The slope gradually steepens with depth until it reaches a minimum value near the chlorophyll maximum, where small cells play a more significant role. The corresponding depth profile of the Y-intercept forms an opposite trend to that of the phytoplankton slope, with generally higher values in the upper stratified layer but lower values at depth. The higher intercept values near the 


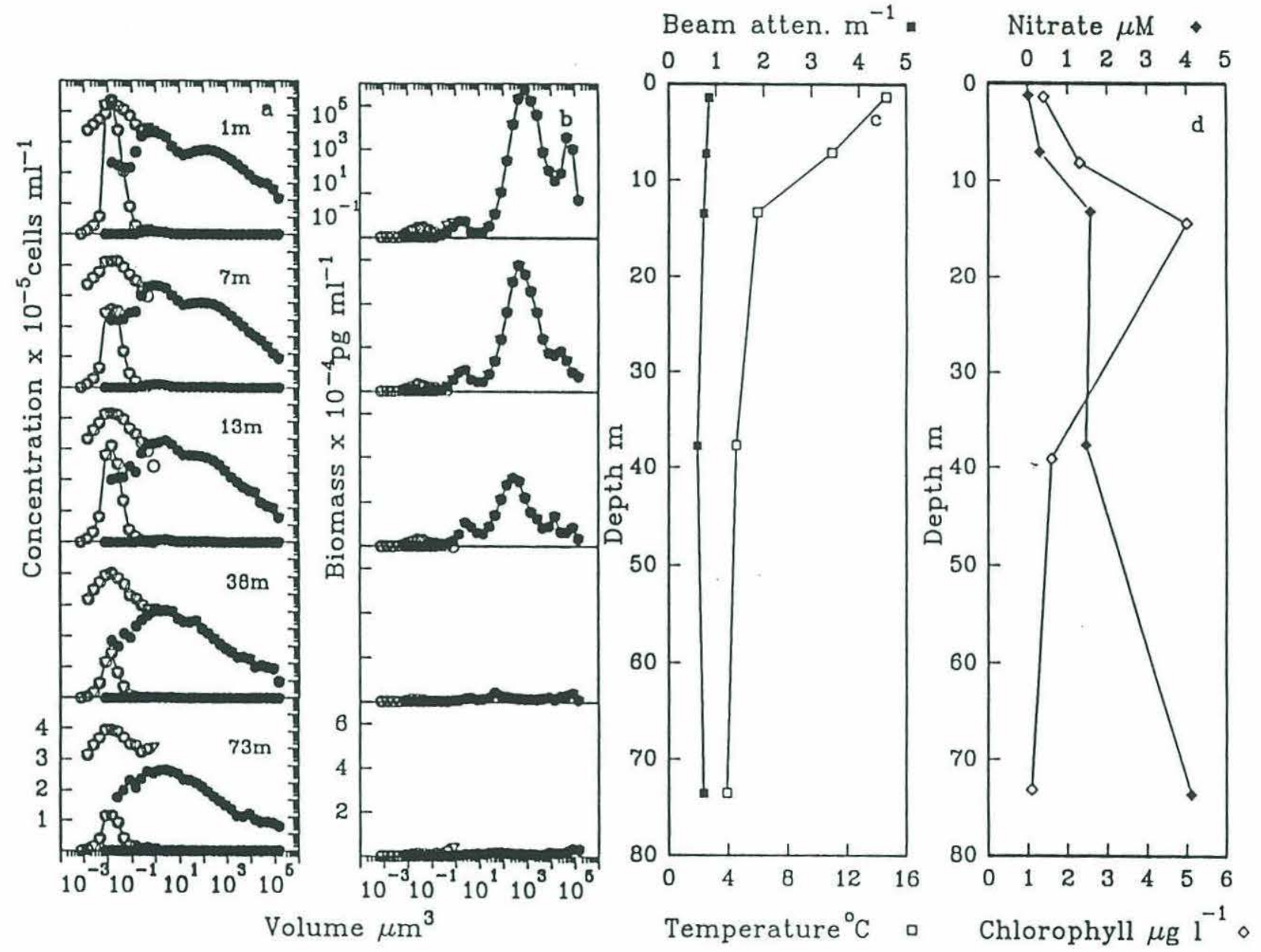

Fig. 2.8. Depth profiles of histogram size spectra together with corresponding environmental measurements for the station in Massachusetts Bay on June 22, 1993 at $1620 \mathrm{hr}$, under stratified conditions. 

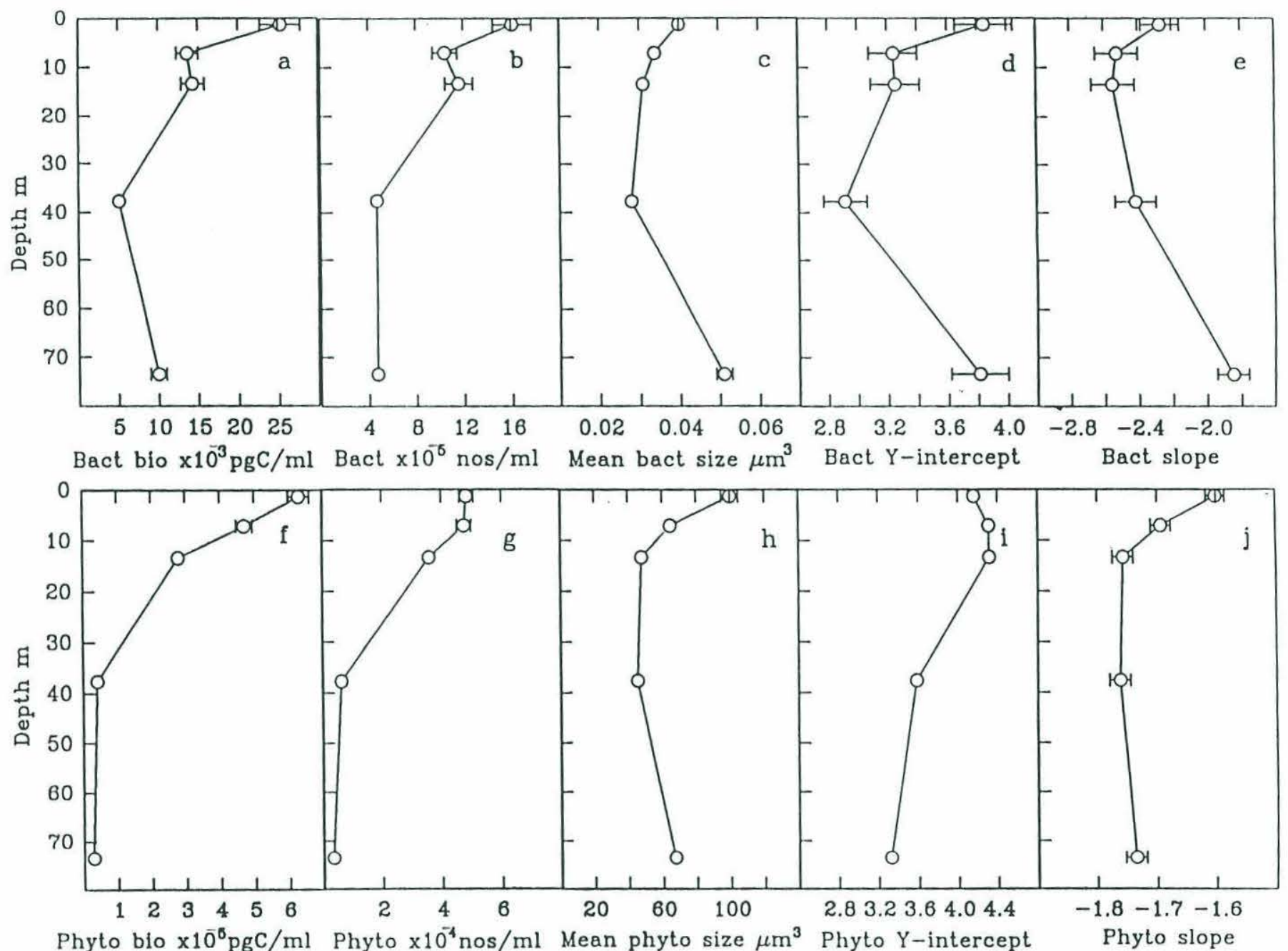

Fig. 2.9. Depth profiles of size spectral characteristics for Massachusetts Bay on June 22, 1993 at $1620 \mathrm{hr}$, corresponding to the size spectra and environmental conditions shown in Fig. 2.8. 
surface indicate higher concentration and biomass levels whereas the lower values at depth reflect the dramatic fall in phytoplankton abundance. In the case of bacteria, similar trends in total bacteria abundance, mean size and slope of the normalized spectrum are found, suggesting that bacteria growth is closely coupled to phytoplankton growth. (Note that the intercept for bacteria follows an opposite trend to that of phytoplankton because it reflects the abundance of large bacteria.) In addition, bacteria in bottom waters are skewed to larger sizes and may be as big, if not bigger than surface bacteria.

In between the fully mixed and strongly stratified structure of the water column lies a range of depth profiles covering the weakly stratified and shallow mixed water columns. On the whole, distinct variations in spectral characteristics are often observed where the density or temperature gradient begins to change rapidly in the water column ie. at the thermocline. This can also be seen for a shallow mixed layer at the Cape Cod station in June (Fig. 2.10). Within the mixed layer, fairly uniform spectral characteristics are observed for bacteria and phytoplankton, with a tendency towards slightly larger cells at the surface (1m) (Fig. 2.11). At the chlorophyll maximum near the thermocline $(20 \mathrm{~m})$, however, smaller phytoplankton and bacteria play a more significant role, as with the chlorophyll maximum of the stratified example in Massachusetts Bay. At lower depths, the change is much more dramatic as mean sizes of both bacteria and phytoplankton increase (ie. picoplankton abundance drops), in association with elevated nutrient concentrations. Beam attenuation also increases by about a factor of two at these lower depths.

The depth variation of size spectra from bacteria to phytoplankton is more clearly illustrated when the concentration and biomass spectra are analyzed on log scales, since bacteria counts typically exceed the largest phytoplankton concentrations by some 5 orders of magnitude (Fig. 2.12). On log scales, the concentration size spectrum is a steadily decreasing function of size whereas the biomass spectrum is generally an increasing function of size (see Appendix for relationships between these two spectra). Within the fully mixed layer of the Boston Harbour station in October, the relative depth 


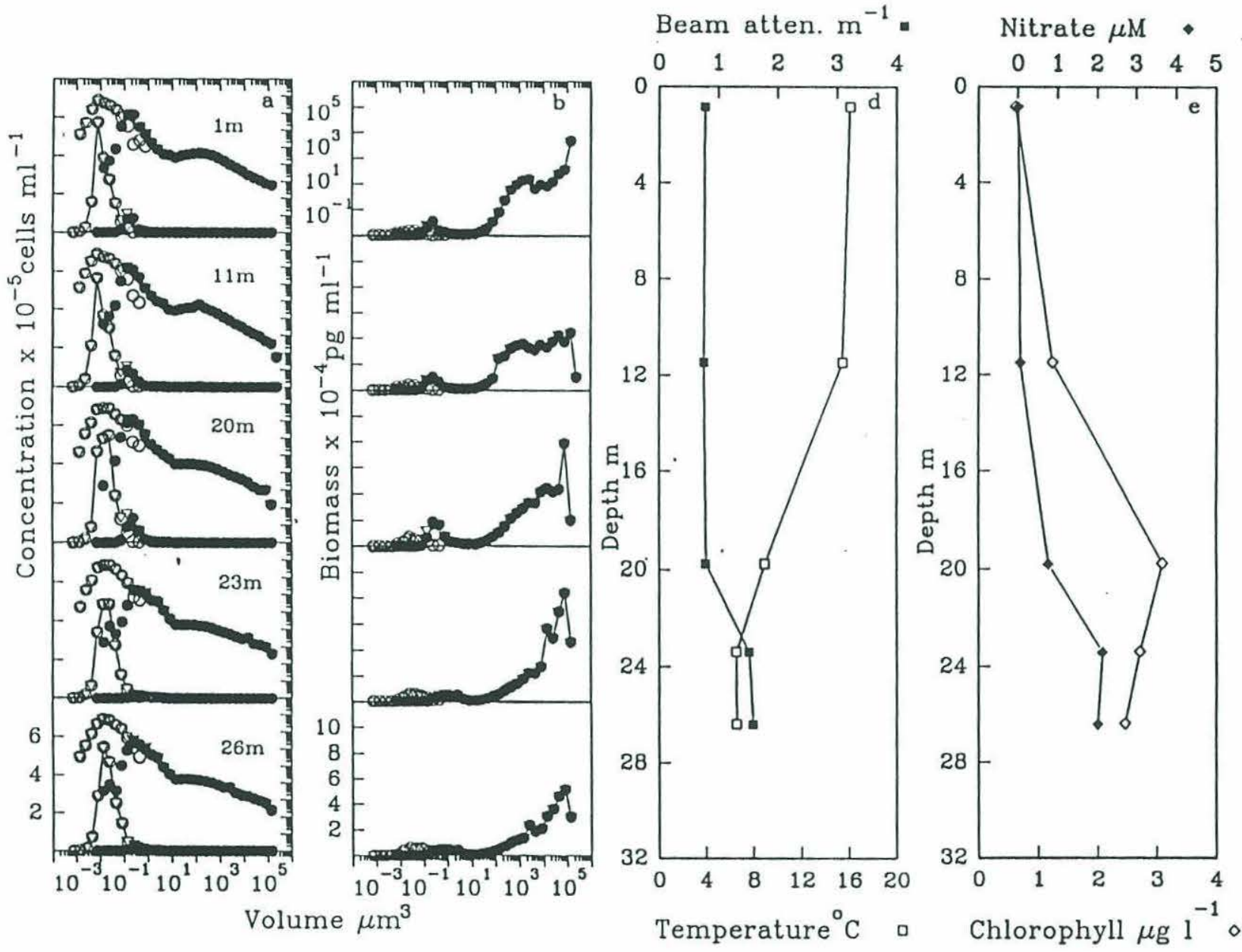

Fig. 2.10. Depth profiles of histogram size spectra together with corresponding environmental measurements for the station in Cape Cod Bay on June 24, 1993 at $0815 \mathrm{hr}$, when a shallow mixed layer is formed. 

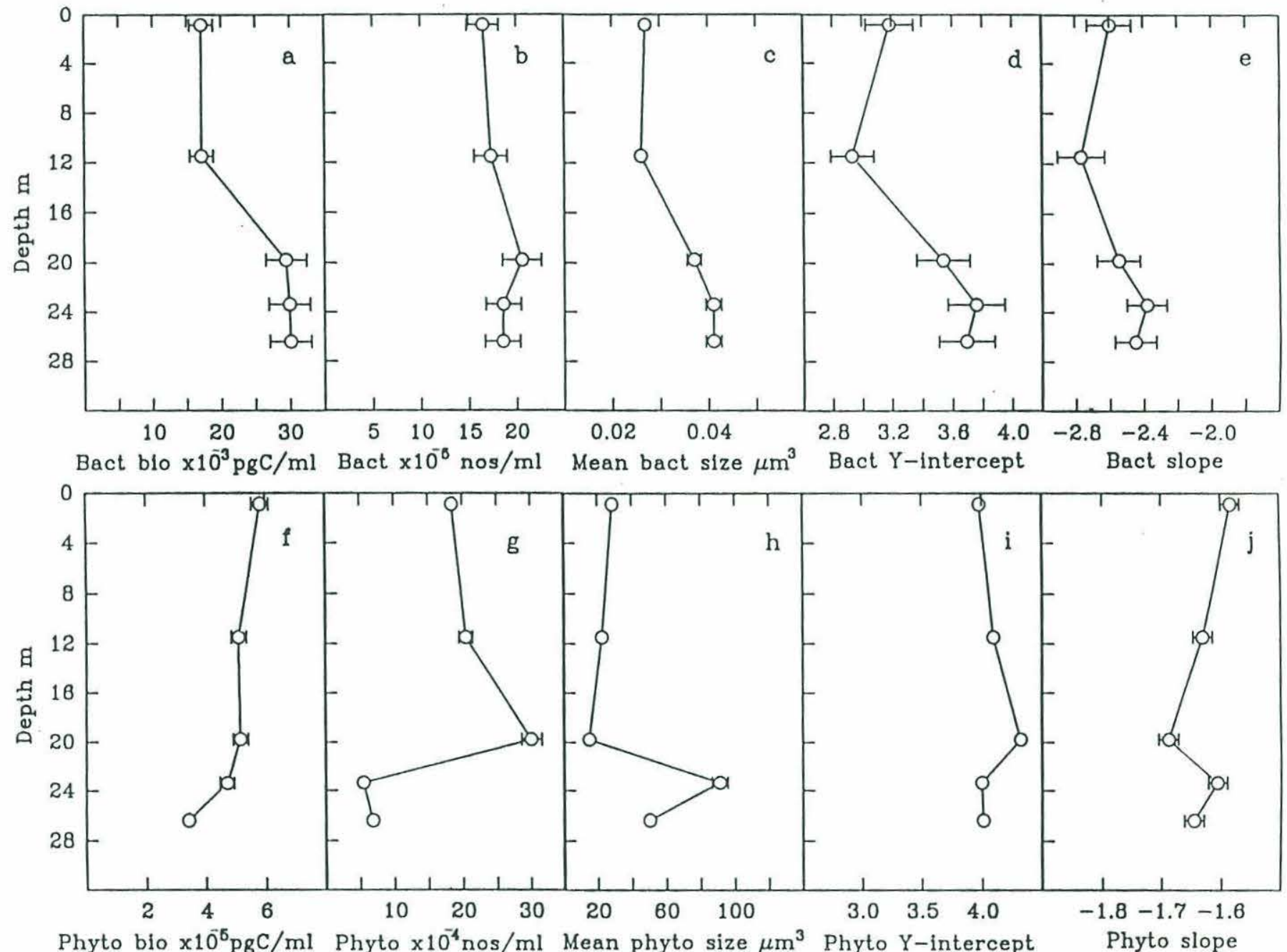

Fig. 2.11. Depth profiles of size spectral characteristics for Cape Cod Bay on June 24, $1993 \mathrm{at} 0815 \mathrm{hr}$, corresponding to the size spectra and environmental conditions shown in Fig. 2.10. 

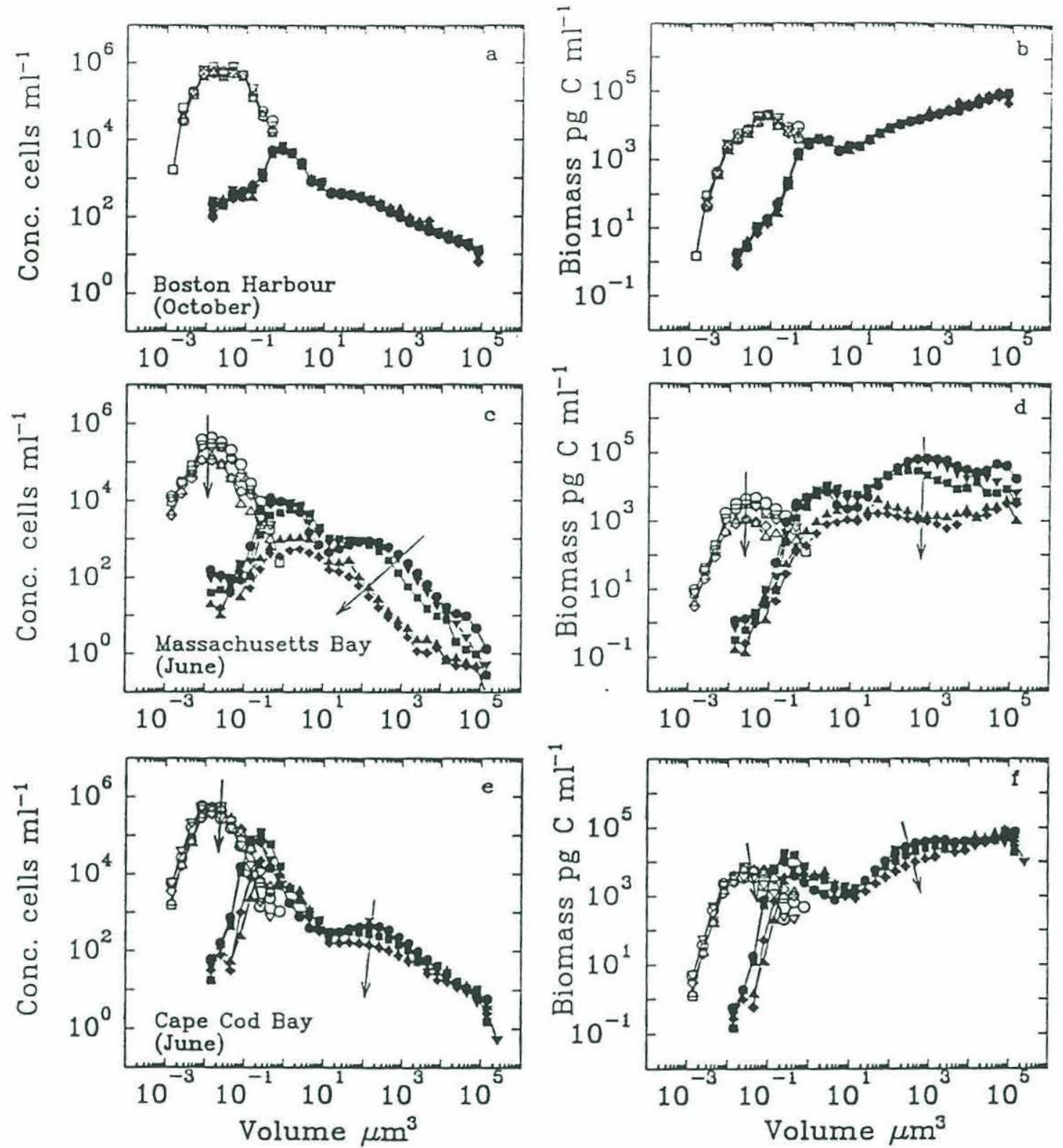

Fig. 2.12. Depth variation of histogram size spectra of concentration and biomass plotted on log scales for mixed conditions in the Boston Harbour station in October, 1992 (a, b respectively), stratified conditions in Massachusetts Bay in June, 1993 (c, d) and a shallow mixed layer in Cape Cod Bay in June, 1993 (e, f). Size spectra of bacteria (open symbols) and phytoplankton (closed symbols) were measured at the surface (circles), intermediate surface (inverted triangles), chlorophyll maximum (squares), intermediate bottom (upright triangles) and bottom waters (diamonds). Note that the arrows point in the direction of increasing depth. Standard deviations are reflected by the size of the symbols. 
differences between size spectra are minimal compared to a strongly stratified profile, such as the Massachusetts Bay station in June. In the latter case, the deeper samples had abundances that were typically one order of magnitude less than surface spectra. For comparison, the depth variation of size spectra for the shallow mixed water column of Cape Cod Bay is also fairly small relative to the deep stratified layer of Massachusetts Bay.

\section{Seasonal Variation of Size Spectra}

The large seasonal environmental perturbations of temperate waters result in corresponding large fluctuations in the size structure of the microbial community. Our data collection for this time series proceeded in the fall of 1992 (October), where the onset of lower temperatures led to a weakening of the stratified layer in the previous summer. In general, the fall period is characterized by increasing storm events which encourage mixing, thereby restoring nutrients back into the water column (Kelly et. al., 1993). This may subsequently trigger a bloom in the phytoplankton community, but as time progresses, decreasing light and temperature will eventually discourage phytoplankton growth and the microbial size spectrum starts to shift toward the characteristics of winter spectra (Fig. 2.13).

In winter/early spring (February), the phytoplankton cell concentration size spectra (log scales) typically form gently sloping distributions, indicating the predominance of large cells by biomass. The emphasis on larger size classes results in shallow slopes (eg. 1.4 in Boston Harbour and Cape Cod Bay) but low values of the intercept (eg. 3 for the same stations) of the normalized concentration size spectrum of phytoplankton compared to summer conditions in June (Figs. 2.14, 2.15, 2.16). These spectral characteristics are often associated with high ambient nutrient levels and cold, turbulent, mixed conditions in the water column. However, in the case of Cape Cod Bay, the spring bloom was more intense than the other two stations, leading to lower levels of ambient nitrate but higher levels of biomass and chlorophyll (Kelly et. al., 1994a). Corresponding particulate levels 

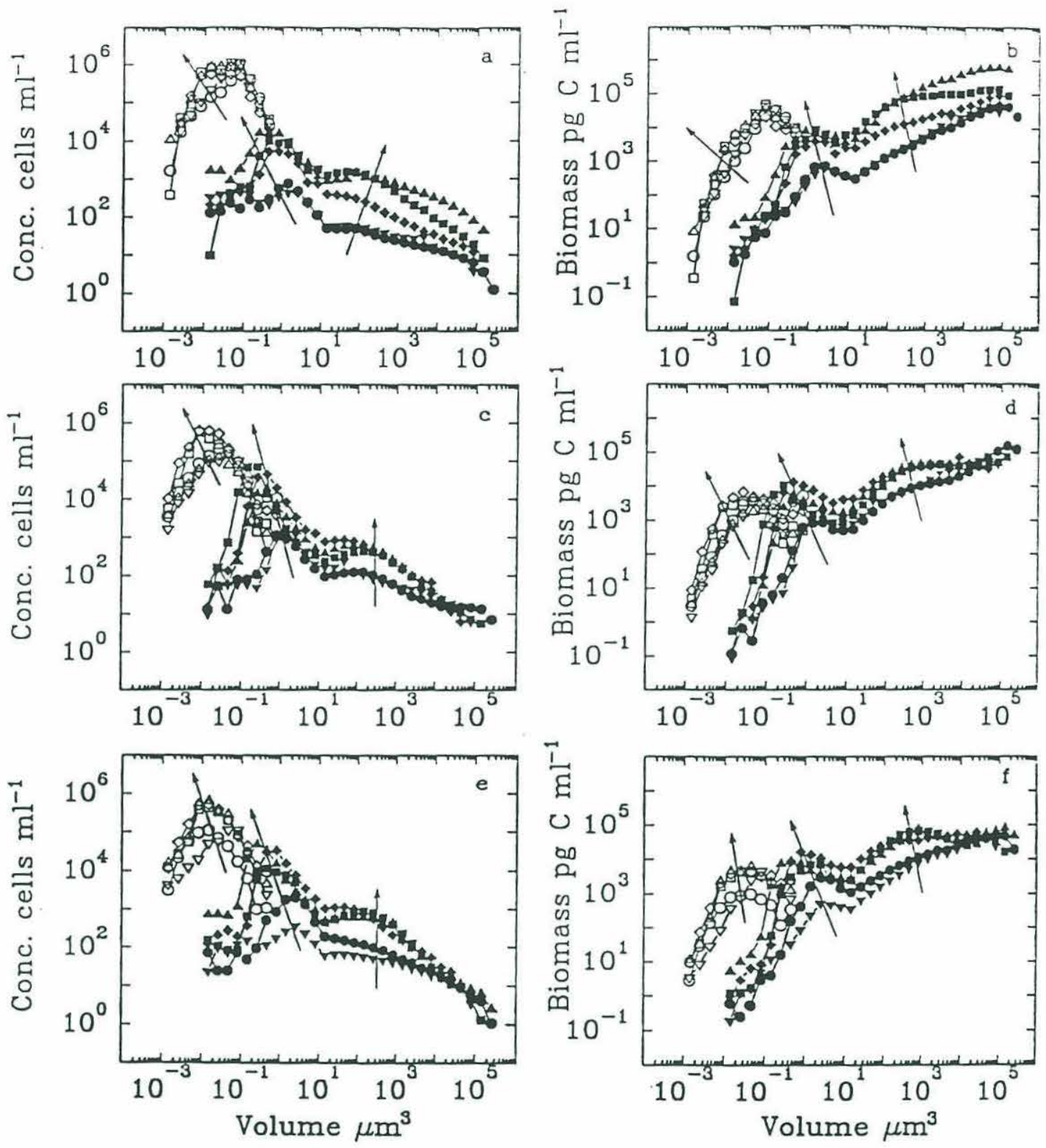

Fig. 2.13. Seasonal variation of histogram size spectra of concentration and biomass taken from the surface of Boston Harbour (a, b respectively), Cape Cod Bay (c, d) and Massachusetts Bay (e, f). Bacteria (open symbols) and phytoplankton (closed symbols) samples were collected on October 15, 1992 (diamond), February 23, 1993 (circle), April 6, 1993 (inverted triangle), June 25, 1993 (square) and August 27, 1993 (upright triangle). Samples for the other two stations were also obtained at around the same times. Note that the arrows point in the direction of seasonal succession. Standard deviations fall within the size of the symbols. 
in the water column are also high in the winter period (eg. $25 \mu \mathrm{M}$ POC at Boston Harbour and Cape Cod Bay) compared to the summer period ( $\sim .8 \mu \mathrm{M}$ POC). While the Boston Harbour and Massachusetts Bay stations show a general decrease in mean bacteria and phytoplankton sizes as the spring bloom progresses, the Massachusetts Bay station shows a sharp increase in cell size at the end of the spring bloom and the onset of early stratification ie. in April (Fig. 2.16). Nitrogen is mainly in the form of ammonium ( $2 \mu \mathrm{M})$ and nitrate concentrations are depleted throughout the water column, signalling the cessation of the spring bloom in Massachussetts Bay (Kelly et. al., 1994b).

As the growing season progresses with increasing stratification of the water column, higher temperature and light levels at the surface favour phytoplankton growth, resulting in further drawdown of nutrients in the upper layers. The result is a steady shift in the community towards smaller size classes both for bacteria and phytoplankton (Fig. 2.13), even though total biomass (and total cell concentration) generally increase during the summer growing period. The growing relative importance of smaller cells during the summer also coincides with increases in zooplankton populations of barnacle nauplii, copepod nauplii, copepods and other mesozooplankton (Kelly et. al., 1994c, d). This suggests that grazing processes may also play an important role in structuring the community, at least for the larger phytoplankton. For bacteria, the shift in the size spectrum is due primarily to a relative increase in small cells of modal size $0.01 \mu \mathrm{m}^{3}(0.3$ $\mu \mathrm{m})$ whilst still maintaining substantial populations of larger bacteria $\left(0.08 \mu \mathrm{m}^{3} \sim 0.5 \mu \mathrm{m}\right)$. This results in a general increase in the intercept of the normalized concentration spectrum and a flattening of the slope to higher values from previous levels in April (Figs. $2.14,2.15,2.16)$. For phytoplankton, the shift in community structure translates into a decrease in the mean or modal class, an increase in intercept of the normalized concentration size spectrum (ie. a greater abundance of picophytoplankton), together with a steepening of the slope to more negative values. (Note that minimum values of -1.8 were encountered at the Massachusetts and Cape Cod Bay stations). While steeper concentration size spectra are generally observed with seasonal succession, the biomass 


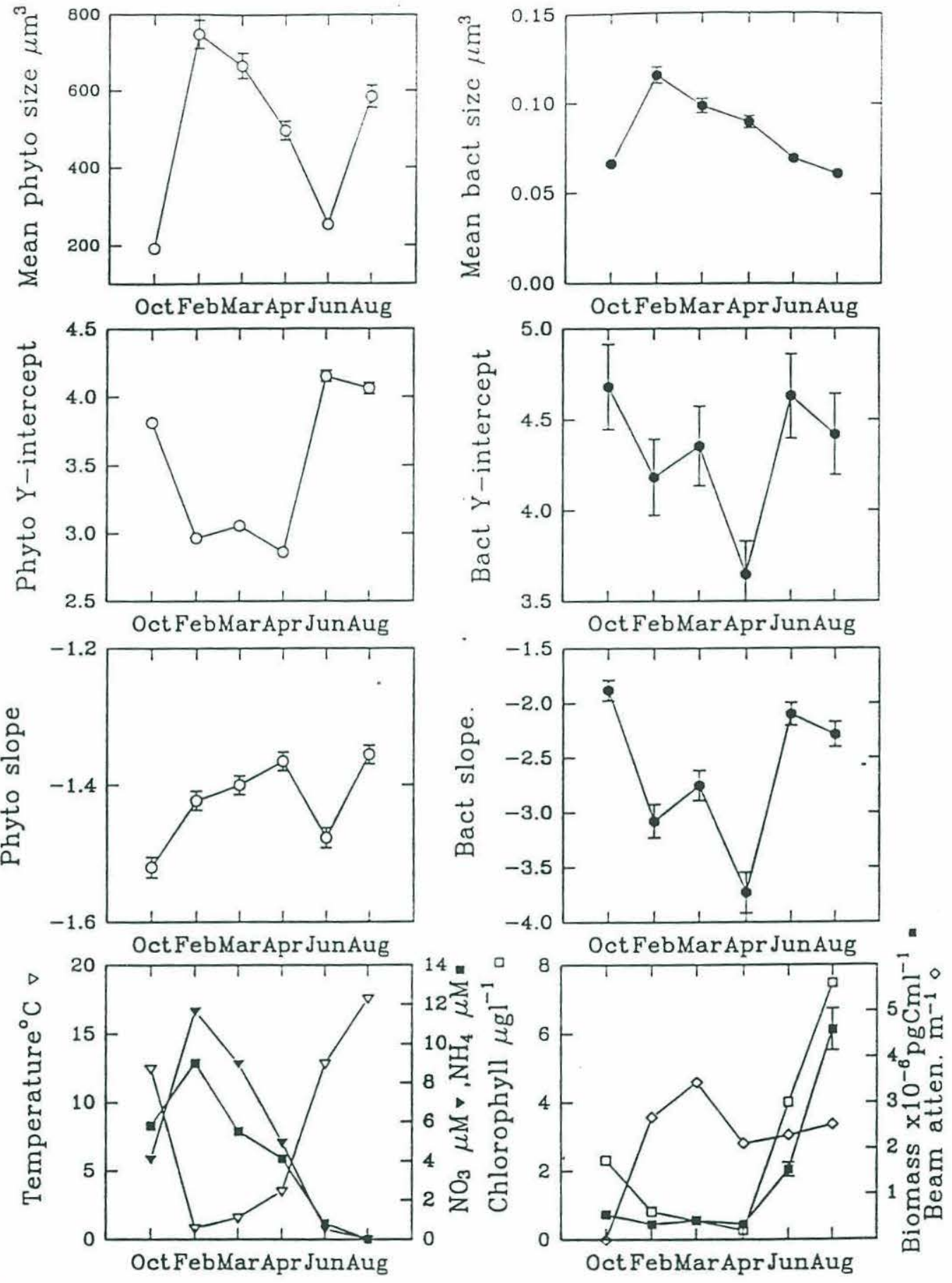

Fig. 2.14. Seasonal variation of size spectral characteristics at the surface for the Boston Harbour station, corresponding to the histograms in Fig. 2.13. Mean cell sizes, intercepts and slopes of the normalized concentration size spectra for phytoplankton (open circles) and bacteria (closed circles) are illustrated together with environmental measurements of temperature, nitrate, ammonium, chlorophyll, beam attenuation and integrated biomass (obtained flow-cytometrically). Error bars reflect the standard deviation from the mean. 

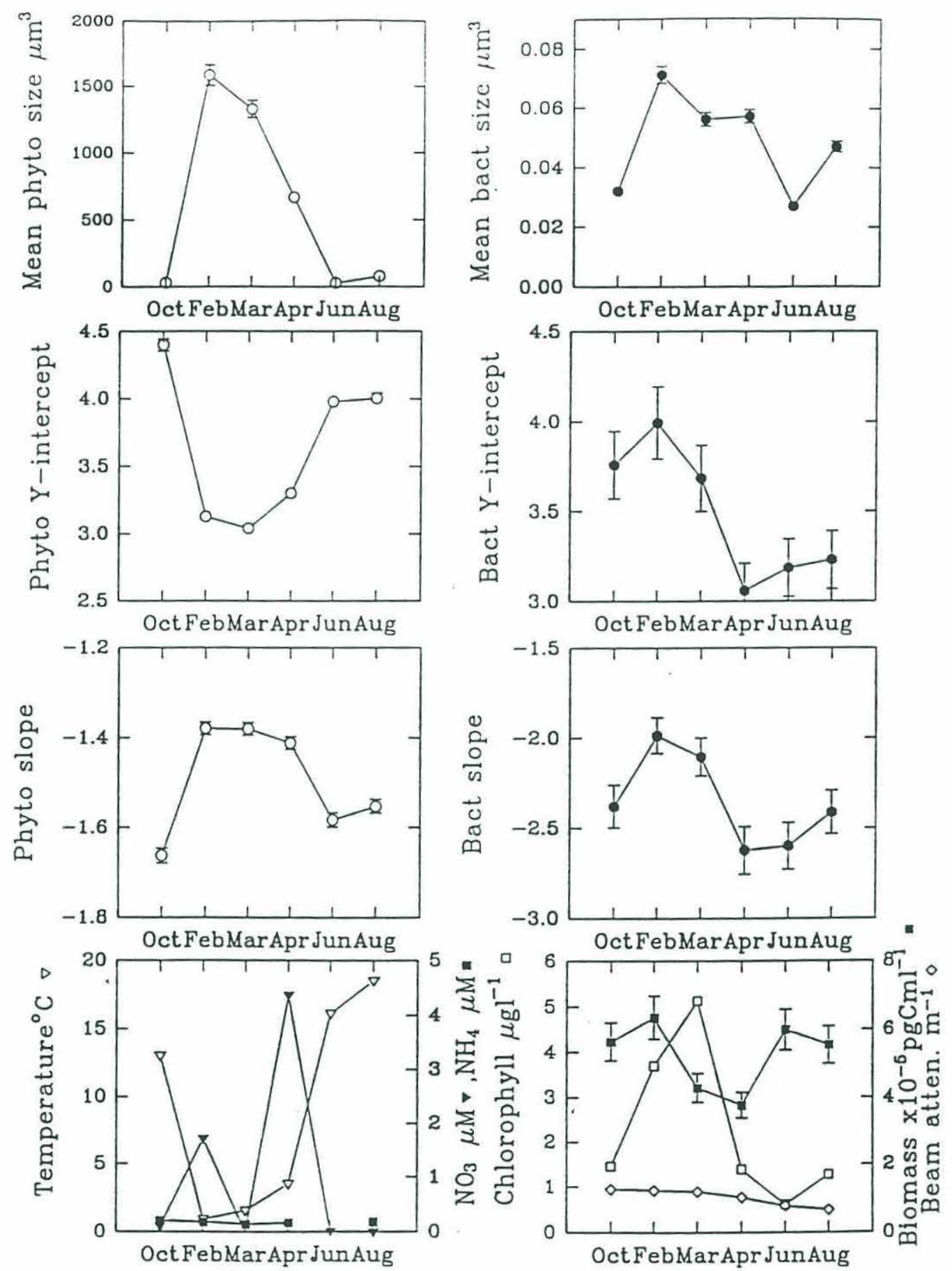

Fig. 2.15. Seasonal variation of size spectral and environmental characteristics from the surface of the Cape Cod Bay station, corresponding to the histograms in Fig. 2.13. 

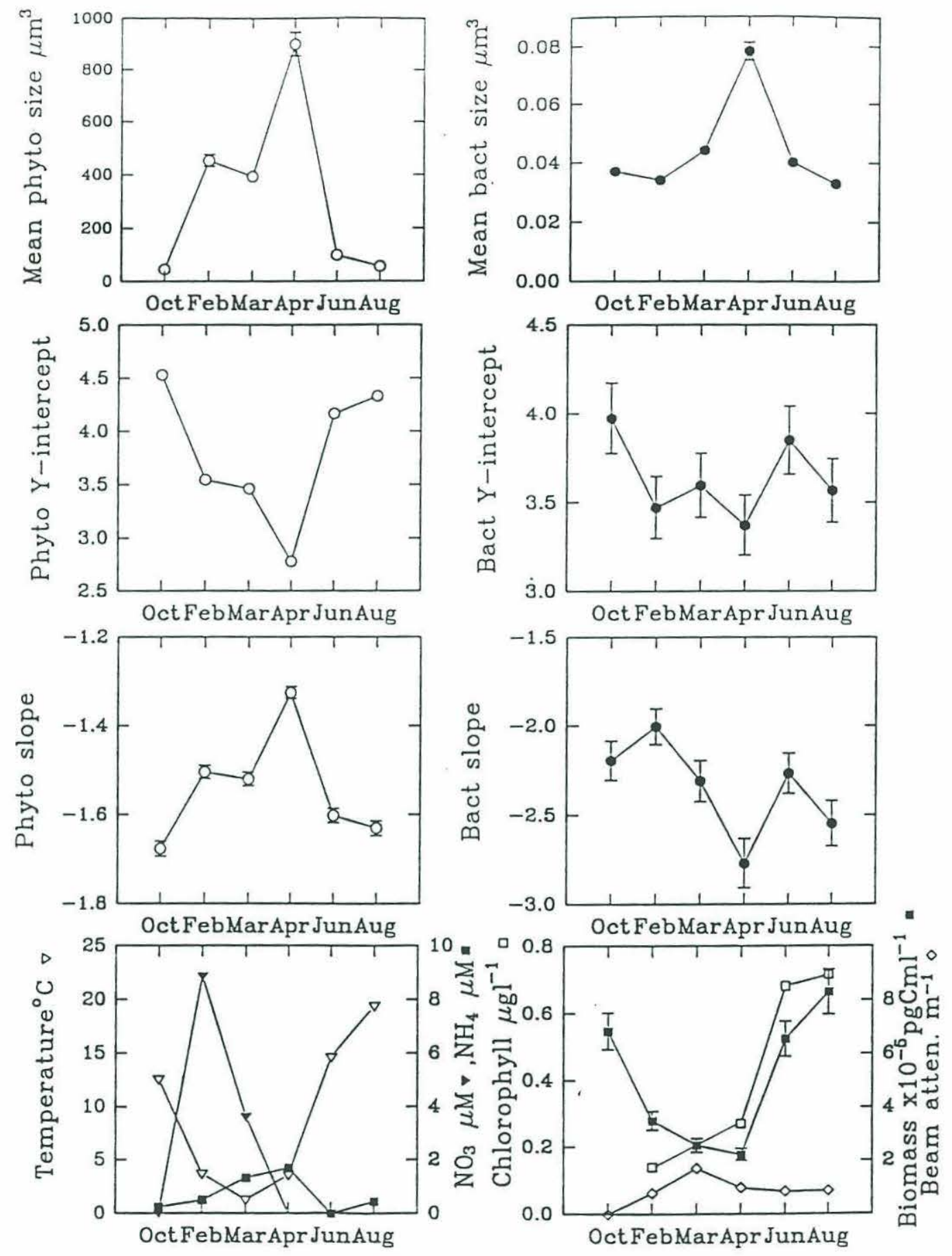

Fig. 2.16. Seasonal variation of size spectral and environmental characteristics from the surface of the Massachusetts Bay station, corresponding to the histograms in Fig. 2.13 . 
size spectrum actually becomes flatter as the season progresses (Fig. 2.13) ie. as nutrient levels diminish, the biomass spectrum approaches the flat distribution observed in steadystate oceanic systems (Sheldon et.al., 1972, Rodriguez and Mullin, 1986). In general, the pico and nanoplankton show the greatest change in abundance, whilst the microplankton show the least change. In late summer (August), size spectra from Boston Harbour show a dramatic shift in the size spectrum of phytoplankton, associated with an increase in chlorophyll to $8 \mu \mathrm{g} \mathrm{l}^{-1}$. This is mainly due to an increase in microplankton abundance since the pico and nanoplankton abundance remain essentially the same as June. The mean size of the phytoplankton community actually doubles, and is accompanied by a flattening of the slope back to original winter values but at a higher value of intercept (Fig. 2.14). This coincides with the initiation of an intense fall bloom of diatoms in western Massachusetts Bay, where chlorophyll concentrations in this region reached high values of about $20 \mu \mathrm{g} \mathrm{l}^{-1}$ in certain locations (Kelly et. al., 1994d).

The seasonal data also show inter-relationships between the different size spectral characteristics. For example, a positive correlation between the mean phytoplankton cell size and the slope of the normalized concentration size spectrum for phytoplankton exists eg. shallow slopes or high slope values are associated with large mean cell sizes (eg. Figs. $2.14,2.15,2.16$ ). On the other hand, mean phytoplankton cell size is negatively correlated with the intercept of the normalized phytoplankton spectrum, such that higher intercept values (indicating a predominance of picophytoplankton) shifts the spectrum to smaller sizes. For bacteria, the relationship between mean cell size and the characteristics of the normalized bacteria spectrum is less well correlated. However, there appears to be a correlation in the seasonal trends of the bacteria intercept and slope, indicating that increases in the intercept (or a predominance of large bacteria) generally lead to a corresponding flattening of the bacteria slope and vice versa. At the same time, the seasonal trends reveal a coupling between surface water temperature and mean cell size, such that large cells are associated with cold water and small cells with warmer waters. These relationships are likely to be a consequence of the higher nutrient concentrations 
found in cold mixed waters compared to negligible nutrient concentrations in warm stratified waters.

\section{Spatial Variation of Size Spectra from Massachusetts and Cape Cod Bays}

While the three chosen locations have similar depth and seasonal trends in size spectra, the actual size characteristics of each station are quite different. These differences are illustrated by comparing the average surface histogram size spectra in spring and in summer. (Averaged spring values refer to surface values averaged over February and March, 1993, whilst averaged summer values are averaged over June and August, 1993.) In spring, the bloom is more intense at the shallow Cape Cod Bay station, where chlorophyll and total biomass levels are higher than the Boston Harbour and Massachusetts Bay stations (Fig. 2.17). The phytoplankton size spectra for this period show that the distributions are roughly similar, with the largest phytoplankton cells (mean size $\sim 1500 \mu \mathrm{m}^{3}$ or $14 \mu \mathrm{m}$ diameter) at the Cape Cod station. In the case of bacteria, small bacteria less than $0.01 \mu \mathrm{m}^{3}(0.3 \mu \mathrm{m})$ have similar abundances at all three location whereas larger bacteria of about $0.1 \mu \mathrm{m}^{3}(0.6 \mu \mathrm{m})$ are considerably more abundant at the Boston Harbour station compared to the other two stations. The large bacteria observed at the Boston Harbour station are probably a consequence of the significant anthropogenic inputs entering the system through general pollution from Boston city and effluent discharges from a nearby sewer outfall.

In summer, at the height of the growing season, biomass and chlorophyll levels at the Boston Harbour station exceed those of the other two stations (Fig. 2.18). Both bacteria and phytoplankton from Boston Harbour are considerably larger, with mean cell sizes of $0.065 \mu \mathrm{m}^{3}(0.5 \mu \mathrm{m})$ and $400 \mu \mathrm{m}^{3}(9 \mu \mathrm{m})$ respectively, compared to $0.038 \mu \mathrm{m}^{3}$ $(0.4 \mu \mathrm{m})$ and $80 \mu \mathrm{m}^{3}(5 \mu \mathrm{m})$ for the other two stations. The corresponding average histogram size spectra of concentration and biomass show that these differences are due to a predominance of cells greater than $1000 \mu \mathrm{m}^{3}(12 \mu \mathrm{m})$ for phytoplankton and greater than $0.02 \mu \mathrm{m}^{3}(0.3 \mu \mathrm{m})$ for bacteria. The other two stations have size spectra which are 

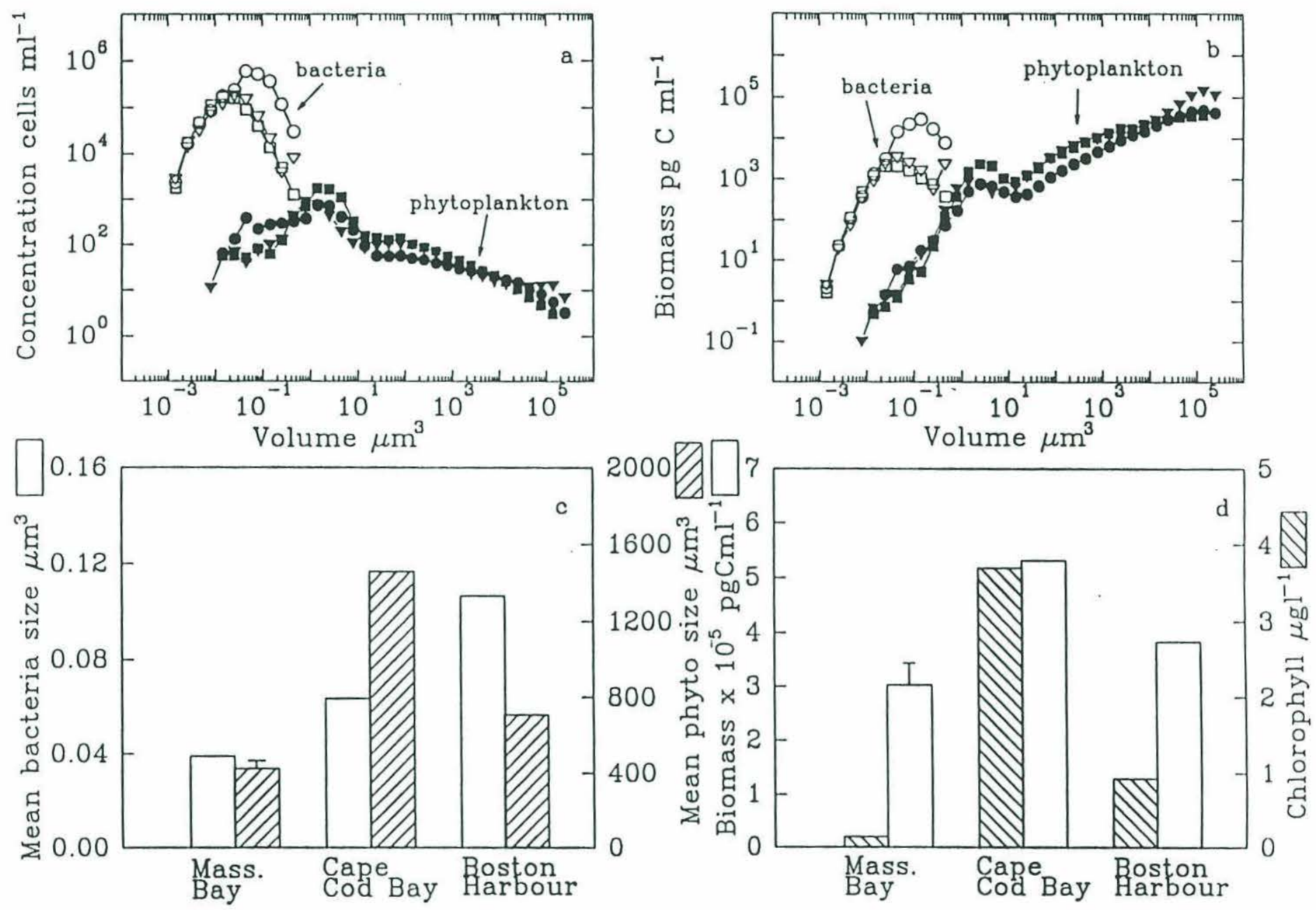

Fig. 2.17. Spatial variation of histogram size spectra of concentration and biomass ( $a, b$ respectively) for averaged surface spectra for Boston Harbour (circles), Cape Cod Bay (triangles) and Massachusetts Bay (squares) in spring, 1993. Averaged values of mean bacteria and phytoplankton cell sizes (c), biomass and chlorophyll (d) at each station are also shown. Averages were computed from surface data for February and March, 1993. 

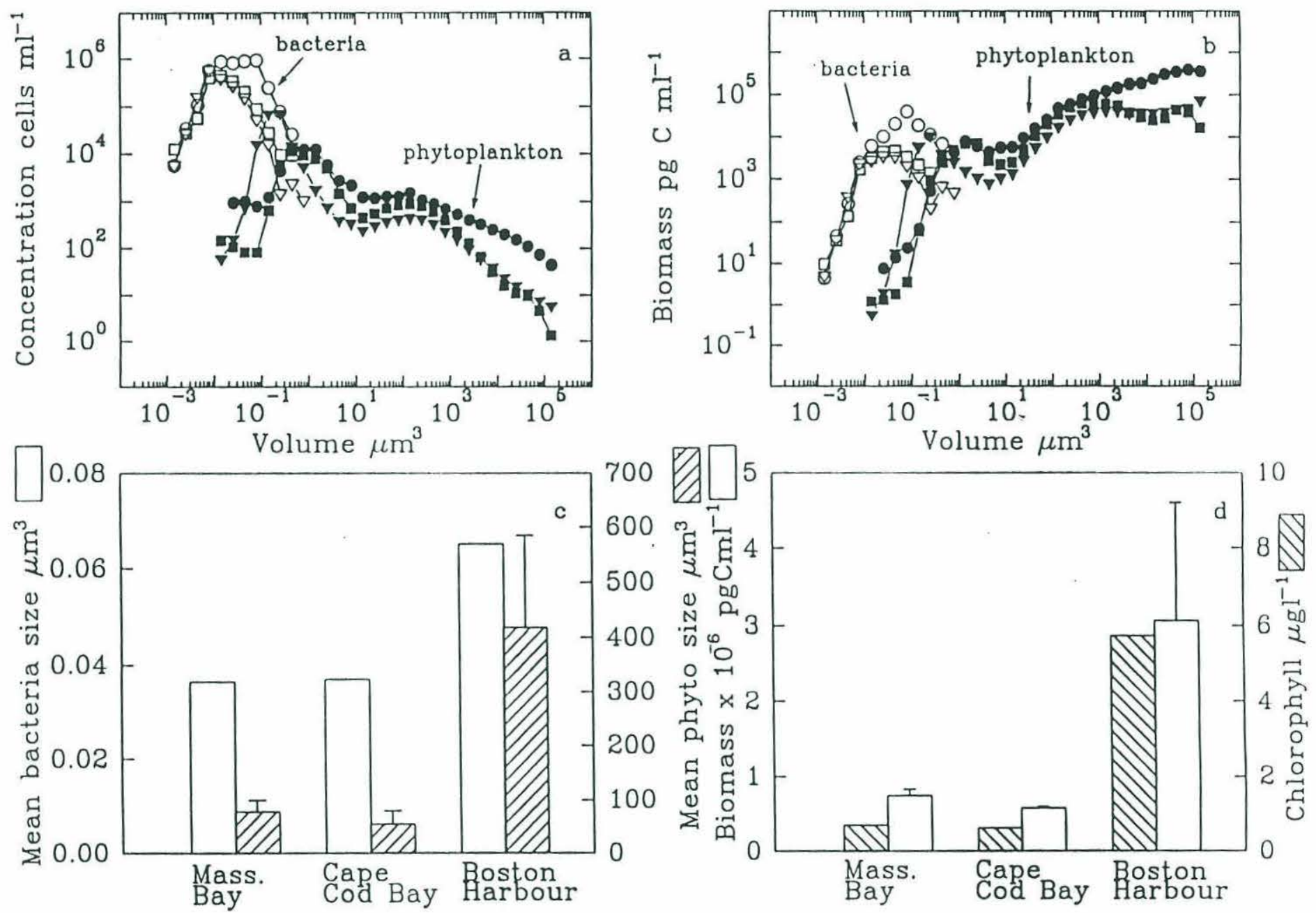

Fig. 2.18. Spatial variation of histogram size spectra of concentration and biomass (a, b respectively) for averaged surface spectra for Boston Harbour (circles), Cape Cod Bay (triangles) and Massachusetts Bay (squares) in summer, 1993. Averaged values of mean bacteria and phytoplankton cell sizes (c), biomass and chlorophyll (d) at each station are also shown. Averages were computed from surface data for June and August, 1993. 
skewed to smaller sizes, particularly for the Cape Cod station, where a significant population of cells less than $0.5 \mu \mathrm{m}^{3}(1 \mu \mathrm{m})$ is observed in summer.

These changes in the histogram size spectra can be summarized by changes in the average intercepts and slopes of the normalized concentration size spectra (Table 2.1). In

\begin{tabular}{llllll}
\hline Season & Location & Bacteria & & \multicolumn{2}{l}{ Phytoplankton } \\
& & Intercept & Slope & Intercept & Slope \\
\hline Spring & Mass. Bay & $3.53(0.06)$ & $-2.16(0.15)$ & $3.50(0.04)$ & $-1.51(0.01)$ \\
& Cape Cod Bay & $3.84(0.15)$ & $-2.04(0.06)$ & $3.08(0.04)$ & $-1.38(0.01)$ \\
& Boston & $4.27(0.09)$ & $-2.92(0.16)$ & $3.01(0.04)$ & $-1.41(0.01)$ \\
& Harbour & & & & \\
Summer & Mass. Bay & $3.71(0.14)$ & $-2.41(0.14)$ & $4.25(0.08)$ & $-1.62(0.01)$ \\
& Cape Cod Bay & $3.21(0.02)$ & $-2.51(0.09)$ & $3.99(0.01)$ & $-1.57(0.02)$ \\
& Boston & $4.52(0.10)$ & $-2.19(0.09)$ & $4.11(0.04)$ & $-1.42(0.06)$ \\
& Harbour & & & & \\
\hline
\end{tabular}

Table. 2.1. Characteristics of the normalized concentration size spectra of bacteria and phytoplankton for the stations in Boston Harbour, Massachusetts and Cape Cod Bays. The intercepts and slopes were averages of values at the surface for February and March, 1993 for spring and June and August, 1993 for summer. Numbers in parenthesis are the standard deviations.

the case of bacteria, the intercepts and slopes of the normalized bacteria spectra for Massachusetts and the Cape Cod Bay stations are generally not significantly different from each other. However, the spectral characteristics at these stations are considerably different from Boston Harbour, which has much higher values of intercepts, indicating the predominance of large bacteria. The corresponding slope for Boston Harbour bacteria is also significantly different from the other two stations but shows opposite trends in the 
spring and summer ie. it is steeper than the other two stations in the spring but shallower in the summer. For phytoplankton in spring, the higher value of intercept but lower slope value (ie. steeper slope) at the offshore Massachusetts Bay station indicate the greater relative importance of picophytoplankton compared to the other two stations. In the summer, however, the phytoplankton intercepts are all similar in magnitude, reflecting the shift to smaller picoplankton cells as the growing season progresses is characteristic of all stations. However, the phytoplankton slope at Boston Harbour is greater in value (ie. shallower slope) than the other two stations, reflecting the importance of larger cells, on average, relative to the other two stations.

\section{DISCUSSION}

The results obtained in this study were consistent with earlier findings pertaining to seasonal succession of phytoplankton in temperate coastal waters and further showed the range and variability of bacteria size spectra to perturbations in the environment. On the whole, size spectra taken from Massachusetts and Cape Cod Bays reflected the eutrophic character of this coastal system, with a predominance of larger bacteria and phytoplankton for shallow inshore waters relative to offshore waters. Bacteria from Boston Harbour were especially large, possibly due to significant anthrogenic inputs from a nearby sewer outfall and discharges from Boston. Size spectra from Boston Harbour, Massachusetts and Cape Cod Bays were characterized by slopes of the normalized concentration size spectrum, which for phytoplankton ranged from about -1.3 to -1.8 depending on the depth and time of year. Size spectra within a mixed layer generally showed similar characteristics but with changes in the temperature profile, significant changes in the size spectrum could be detected. For stratified waters, the greatest biomass and largest cell sizes were usually observed in the upper $5 \mathrm{~m}$ of the surface layer. At lower depths, the occurrence of the chlorophyll maximum generally coincided with a shift in the spectrum to a greater predominance of small cells whereas further down the water column, a shift in the spectrum to larger mean cell sizes was detected. 
That larger cells should dominate near the surface is paradoxical, given the generally low measured nutrient concentrations under stratified conditions. In nutrient poor waters, small cells have been argued to be better competitors than large cells because of their higher surface area to volume ratio (eg. Smetachek, 1985, Kiфrboe, 1993). However, very high light levels at the surface may be inhibiting smaller phytoplankton which do not have the protection from self-shading effects afforded by larger cells (Geider et. al., 1986). Measurements of specific growth rates as a function of light intensity showed that diatoms were capable of growing at maximum rates in high light conditions over a wide range of light intensities whereas cyanobacteria had optimal growth rates at lower light levels (Raven and Richardson 1986). Large cells also have higher cell quotas and a greater storage capacity for nutrients (Droop, 1968, Goldman and McCarthy, 1978), which would be beneficial after nutrients have been depleted in the water column. Prolonged stratification, however, would be detrimental to large cells after the cell's nutrient store is exhausted and also because such cells have a greater tendency to sink (Smayda, 1970). Nevertheless, certain mechanisms do exist which may assist the survival of large cells at the surface:- Flagellated forms which can swim, for example, are common in the late summer period (Kelly et. al., 1994c, d). The relative importance of small cells around the chlorophyll maximum could be due to the greater light harvesting potential of small phytoplankton in light limiting and nutrient limiting conditions (larger cells with larger absorption cross-section have greater self-shading effects). However, far below the chlorophyll maximum where even lower light levels exist, higher nutrient concentrations below the nutricline may be responsible for switching the competitive edge back to larger cells.

The changes in size spectra from this study support previous reports on the seasonal successional changes of phytoplankton, where a steady shift to smaller cells during the growing season is observed. Our study further showed that similar trends in bacteria size occur, complementing the shifts in the phytoplankton spectrum. In a study of summer phytoplankton populations for eutrophic coastal waters off Spain (chlorophyll 
values $\sim 15 \mu \mathrm{g} \mathrm{l}^{-1}$ ), size spectra measurements showed a dominance of nanoplankton, with a progressive displacement towards the smallest size classes in late summer, even at the time scale of days (Ruiz et. al., 1992). While the summer trends in size spectra are similar to our study and support the theoretical predictions regarding phytoplankton succession (Margalef, 1978), the actual slope values of the normalized biomass size spectra for summer phytoplankton in Ruiz et. al.'s study varied widely from -1.32 to -0.58 . The minimum slope value was much lower than that encountered in our study and the range of values was also considerably more variable. (Note that image analysis was used to measure their size spectra.) This could be partly due to a lack of picoplankton measurements in their study, which would offset the slope of the phytoplankton size spectrum, especially in summer when these small cells are likely to proliferate, as demonstrated in our study. The same coastal waters off Spain in winter showed the dominance of large microplankton (Rodriguez et. al., 1987). However, a direct comparison of phytoplankton size spectra for the winter and summer was unavailable due to different size ranges of organisms studied ie. only cells greater than $128 \mu \mathrm{m}^{3}$ were measured in winter. Our study using homogeneous techniques and size ranges confirm the predominance of large microphytoplankton in winter and size spectra characterized by slopes that are less steep than those in summer, with a maximum value of about -1.35 .

In another recent study on the seasonal dynamics of a hypereutrophic lake in Spain (chlorophyll levels ranged from 20 to $860 \mu \mathrm{g} \mathrm{l}^{-1}$ ), the overall normalized biomass size spectrum averaged over the year was characterized by an intercept of $4.2 \mathrm{I}^{-1}$ and slope of 1.41 (Rojo and Rodriguez, 1994). Although these parameters showed variability due to seasonal changes, it is interesting that in spite of the very large values of chlorophyll measured in this highly eutrophic lake (due to excess nutrient inputs), the average slope value is comparable to the winter maximum encountered in our coastal study. It appears that an upper bound value, corresponding to an average slope value of -1.3 to -1.4 , may exist for eutrophic waters in which nutrients are not limiting. In these situations, light may be the limiting factor in structuring the phytoplankton community, perhaps also triggering 
regulation by autogenic factors. In addition, large cells have a greater tendency to form aggregates which can rapidly settle out of the water column (Kiфrboe, 1993). At the other end of the scale, a study of laboratory cultures measured at stationary phase, reported that the maximum concentration achievable by phytoplankton cells was a function of size with a slope of -0.79 (Agusti and Kalff, 1989). This corresponded favourably with the minimum value of slope ( -1.75 for normalized concentration spectrum) obtained in our study of coastal waters under certain conditions in summer. We hypothesize that this slope value could represent the minimum bound of the phytoplankton size spectrum under stressed, nutrient limited conditions.

The availability of light and nutrients is dependent on the physical structure of the water column, and are thus important in determining the characteristics of the microbial size spectrum. From our study of coastal waters, shallow phytoplankton slopes of the normalized spectrum (or the predominance of large cells) were generally identified with winter mixing, whilst steeper phytoplankton slopes evolved in association with stratification of the water column. Similar trends in the phytoplankton size spectrum were observed in the seasonal dynamics of the hypereutrophic lake study in Spain (Rojo and Rodriguez, 1994). During the winter/early spring, the proliferation of large phytoplankton could be explained by turbulent mixing processes which not only physically maintain large cells in the water column but also ensure sufficiently high nutrient concentrations for large cells to thrive. In particular, larger nano and microplankton cells are believed to be better adapted to extreme environmental conditions which have high and variable rates of nutrient input (Munawar et. al., 1978, Hopcroft and Roff, 1990). This was clearly demonstrated in our study of biomass size spectra which showed steep positive slopes favouring the larger nano and microplankton. In addition, our study further shows that size spectra of bacteria were also skewed in favour of larger cells during turbulent winter mixing periods.

In contrast, summer stratification generally led to a shift in the size spectrum to smaller mean cell sizes especially in surface waters. This could be partly explained by the 
sinking of larger phytoplankton cells which have higher settling velocities (Kiфrboe, 1993). At the same time, lower nutrient concentrations have been shown to favour small cells because of their higher nutrient uptake kinetics (Smith and Kalff, 1982). In both cases, the stability of the stratified water column would tend to enhance sinking of large cells and prevent nutrient replenishment to surface waters. Under these conditions, regenerated forms of nitrogen may be a critical source of nutrients for phytoplankton cells even though such nutrients were often below detection levels. In particular, the regeneration of nitrogen could be fuelled by the microbial loop through direct grazing on bacteria by protozoa (Azam et. al., 1983, Goldman et. al., 1984). Previous laboratory studies showed that larger bacteria were preferentially grazed when a variety of different sized bacteria were fed to heterotrophic nanoflagellates (Simek and Chrzanowski, 1992). This would tend to support the shift in our field measurements of size spectra to smaller bacteria during warm stratified conditions. These changes in community structure could easily be overlooked if only bulk environmental measurements were made. Microbial size spectra, on the other hand, easily show changes in the organization of the community and how biomass (or energy) is partitioned in the microbial community. The greater resolution obtained from size spectra thus offers a more detailed framework to explore the mechanisms functioning within the ecosystem and hence theoretical models for carbon and nutrient cycling.

\section{ACKNOWLEDGEMENTS}

We would like to thank Keith Lichten, Laurel Schaider, Dave Borkman and Toni Chute for helping to collect our samples and Sheila Frankel, Brian Binder, Carol Duval and Kent Bares for development of analytical protocols for the flow cytometers. The work was supported by the Massachusetts Water Resources Authority contract \#S179, the National Science Foundation (JGOFS) OCE-9022285, OCE-9012117 and OCE9302529 and fellowship support from the National University of Singapore Overseas Scholarship. 


\section{REFERENCES (chapter 2)}

Agusti., S. and Kalff, J. 1989. The influence of growth conditions on the size dependence of maximal algal density and biomass. Limnol. Oceanogr. 34 (6): 1104-1108.

Albro, C.S., Kelly, J.R., Hennessy, J., Doering, P. and Turner, J., 1993. Combined work/quality assurance project plan for baseline water quality monitoring: 1993-1994. Massachusetts Water Resources Authority, Boston, MA. Miscellaneous Report 14. 73pp.

Azam, F., Fenchel, T., Field, J.G., Gray, J.S., meyer-Reil, L.A. and Thingstad, F., 1983. The ecological role of microbes in the sea. Mar. Ecol. Prog. Ser. 10: 257-263.

Binder, B., Chisholm, S.W., Olson, R.J., Frankel, S.L. and Worden, A.Z., 1996. Dynamics of pico-phytoplankton, ultra-phytoplankton and bacteria in the central equatorial Pacific. Deep Sea Res. (in press).

Cushing, D.H., 1989. A difference in structure between ecosystems in strongly stratified waters and those that are only weakly stratified. J. Plankton Res. 11: 1-13.

Dickie, L.M., Kerr, S.R. and Boudreau, P. R., 1987. Size-dependent processes underlying regularities in ecosystem structure. Ecol. Mono. 57(3): 233-250.

Droop, M.R, 1968. Vitamin $B_{12}$ and marine ecology. 4. The kinetics of uptake, growth, and inhibition in Monochrysis lutherii. J. Mar. Biol. Assoc. U.K. 48: 689-733.

DuRand, M.D., 1995. Phytoplankton growth and diel variations in beam attenuation through individual cell analysis. Ph.D. Thesis. MIT/WHOI: 263pp.

Duval, C., 1993. Phototrophic and Heterotrophic Picoplankton in the Equatorial Pacific: Analysis by Flow Cytometry. MSc thesis. MIT: 127pp.

Echevarria, F. and Rodriguez, J., 1994. The size structure of plankton during a deep bloom in a stratified reservoir. Hydrobiologia 284: 113-124.

Gaedke, U., 1992. The size distribution of plankton biomass in a large lake and its seasonal variability. Limnol. Oceanogr. 37(6): 1202-1220.

Gaedke, U., 1993. Ecosystem analysis based on biomass size distributions: A case study of a plankton community in a large lake. Limnol. Oceanogr. 38(1): 112-127.

Geider, R.J., 1987. Light and temperature dependence of the carbon to chlorophyll a ratio in microalgae and cyanobacteria: implications for physiology and growth of phytoplankton. New. Phytol. 106: 1-34. 
Gilabert, J., Rodriguez, J. and Jimenez-Gomez, F., 1990. The planktonic size-abundance spectrum in an oligotrophic, hypersaline coastal lagoon, the Mar Menor, Murcia, Spain. In Barnes, M. and Gibson, R.N. (eds) Trophic Relationships in the Marine Environment. Aberdeen University Press: 18-27.

Goldman, J.C. \& McCarthy, J.J., 1978. Steady-state growth and ammonium uptake of a fast growing marine diatom. Limnol. Oceanogr. 19: 756-766.

Goldman, J.C., 1984. Conceptual role for microaggregates in pelagic waters. Bull. Mar. Sci. 35: 462-470.

Graneli. E., Olsson, P., Graneli, W. and Nylander, C., 1993. Weak 'top-down' control of dinoflagellate growth in the coastal Skagerrak. J. Plankton Res. 15(2): 213-237.

Hopcroft, R.R. and Roff, J.C., 1990. Phytoplankton size fractions in a tropical neritic ecosystem near Kingston, Jamaica. J. Plankton Res. 12(5): 1069-1088.

Kelly, J., Albro, C., Foster, K., Hennessy, J., Doering, P., Reed, L., Requintina, E., Turner, J. and Borkman, D. 1993. Water quality monitoring in Massachusetts and Cape Cod Bays: annual report for 1992. MWRA Enviro. Quality Dept. Tech. Rpt. Series No. 93-16. Massachusetts Water Resources Authority, Boston, MA: 129.

Kelly, J., Albro, C., Hennessy, J., Turner, J., Borkman, D. and Doering, P., 1994a. Water quality monitoring in Massachusetts and Cape Cod Bays: December 1992, February and March 1993. MWRA Enviro. Quality Dept. Tech. Rpt. Series No. 94-2. Massachusetts Water Resources Authority, Boston, MA: 197.

Kelly, J., Albro, C., Hennessy, J., Turner, J., Borkman, D. and Doering, P., 1994b. Water quality monitoring in Massachusetts and Cape Cod Bays: April and May 1993. MWRA Enviro. Quality Dept. Tech. Rpt. Series No. 94-3. Massachusetts Water Resources Authority, Boston, MA: 143.

Kelly, J., Albro, C., Hennessy, J., Turner, J., Borkman, D. and Doering, P., 1994c. Water quality monitoring in Massachusetts and Cape Cod Bays: June and July 1993. MWRA Enviro. Quality Dept. Tech. Rpt. Series No. 94-11. Massachusetts Water Resources Authority, Boston, MA: 152.

Kelly, J., Albro, C., Hennessy, J., Turner, J., Borkman, D. and Doering, P., 1994d. Water quality monitoring in Massachusetts and Cape Cod Bays: August and September 1993. MWRA Enviro. Quality Dept. Tech. Rpt. Series No. 94-12. Massachusetts Water Resources Authority, Boston, MA: 152. 
Kiefer, D.A and Berwald, J., 1991. A random encounter model for the microbial planktonic community. Limnol. Oceanogr. (3): 457-467.

Kiфrboe, T. 1993. Turbulence, phytoplankton cell size and the structure of pelagic food webs. Adv. in Mar. Bio.29:1-72.

Lee, S. and Fuhrman, J.A., 1987. Relationship between biovolume and biomass of naturally derived marine bacteria plankton. Appl. Envir. Micro. 53: 1298-1303.

Letarte, Y. and Pinel-Alloul, B., 1991. Relationships between bacterioplankton production and limnological variables: Necessity of bacterial size considerations. Limnol. Oceanogr. 36(6): 1208-1216.

Malone, T.C., 1980. Algal Size. in I. Morris (ed.), The Physiological Ecology of Phytoplankton, Univ. Calif.: 443-463.

Margalef, R., 1978. Life-forms of phytoplankton as survival alternatives in an unstable environment. Oceanol. Acta, 1: 493-509.

McCave, I.N., 1975. Vertical flux of particles in the ocean. Deep Sea Res. 22: 491-502.

Monger, B. C. and Landry, M.R., 1993. Flow Cytometric Analysis of Marine Bacteria Using Hoechst 33342. Appl. Env. Microbiology 59: 905-911.

Olson, R.J., Zettler, E.A. and Anderesson, O.K., 1989. Discrimination of eukaryotic phytoplankton cell types from light scatter and autofluorescence properties measured by flow cytometry. Cytometry 10: 636-643.

Olson, R.J., Zettler, E.R. and DuRand, M.D., 1993. Phytoplankton analysis using flow cytometry. In P.F. Kemp, B. F. Sherr, E.B. Sherr and J.J. Cole (eds) Handbook of methods in aquatic microbial ecology. Lewis Publ., Boca Raton: 175-186.

Platt, T. and Denman, K.L., 1977. Organization in the pelagic ecosystem. Helogol. Wiss. Meeresunters 30: 575-581.

Platt, T. and Denman, K.L., 1978. The structure of pelagic marine ecosystems. Rapp. P.V. Reun. Cons. Int. Explor. Mer 173: 60-65.

Psenner, R. and Sommaruga, R., 1992. Are rapid changes in bacterial biomass caused by shifts from top-down to bottom-up control. Limnol. Oceanogr. 37(5): 1092-1100.

Raven, J.A. and Richardson, K., 1986. Marine environments. In N.R. Baker and S.P. Long (eds) Photosynthesis in contrasting environments. Elsevier, Amsterdam: 337-398. 
Rodriguez, J. and Mullin, M. 1986. Relation between biomass and body weight of plankton in a steady state oceanic ecosystem. Limnol. Oceanogr. 31 (2): 361-370.

Rodriguez, J., Jimenez, F., Baustista, B. and Rodriguez, V., 1987. Planktonic biomass spectra dynamics during a winter production pulse in Mediterranean coastal waters. J. Plankton Res. 9(6): 1183-1194.

Rodriguez, J., Echevarria, F.and Jimenez-Gomez, F. 1990. Physiological and ecological scalings of body size in an oligotrophic, high mountain lake (La Caldera, Sierra Nevada, Spain). J. Plankton Res. 12(3): 593-599.

Rojo, C. and Rodriguez, J., 1994. Seasonal variability of phytoplankton size structure in a hypertrophic lake. J. Plankton Res.16(4): 317-335.

Ruiz, J., Guerrero, V., Rodriguez, V. \& Rodriguez, J., 1992. Chlorophyll and size biomass spectrum of phytoplankton. Analysis of fluctuations in eutrophic, coastal waters. In G. Columbo, I. Ferrari, V.U. Ceccherelli \& R. Rossi (eds), Marine eutrophication and population dynamics. Olsen and Olsen, Denmark: 59-62.

Sheldon, R., Prakash, A. and Sutcliff, W. 1972. The size distribution of particles in the ocean. Limnol. Oceanogr. 17: 327-340.

Silvert, W. and Platt, T., 1980. Dynamic energy-flow model of the particle size distribution in pelagic ecosystems. In W. Charles Kerfoot (ed) Evolution and ecology of zooplankton communities. The University Press of New England.

Simek, K. and Chrzanowski, T.H., 1992. Direct and indirect evidence of size-selective grazing on pelagic bacteria by freshwater nannoflagellates. Appl. Environ. Micro. 58(11): 3715-3720.

Smayda, T.J., 1970. The suspension and sinking of phytoplankton in the sea. Ocean. \& Mar. Biol. Ann. Rev. 8:353-414.

Smetachek, V., 1985. Role of sinking in diatom life-history cycles: ecological, evolutionary and geological significance. Marine Biol. 84: 239-251.

Smith, R.E.H. and Kalff, J. 1982. Size-dependent phosphorous uptake kinetics and cell quota in phytoplankton. J. Phycol. 18: 275-284.

Sprules, W.G., Casselman, J.M. and Shuter, B.J., 1983. Size distribution of pelagic particles in lakes. Can. J. Fish. Aquat. Sci. 40: 1761-1769. 
Sprules, W.G. and Munawar, M. 1986. Plankton size spectra in relation to ecosystem productivity, size and perturbation. Can. J. Fish. Aquat. Sci. Vol. 43: 1789-1794.

Strathmann, R.R., 1967. Estimating the organic carbon content of phytoplankon from cell volume or plasma volume. Limnol. Oceanogr. 12: 411-418.

Vaulot, D., Courties, C. and Partensky, F. 1989. A simple method to preserve oceanic phytoplankton for flow cytometry analysis. Cytometry 10: 629-635.

Verity, P.G., Robertson, C.Y., Tronzo, C.R., Andrews, M.G., Nelson, J.R. and Sieracki, M.E., 1992. Relationships between cell volume and the carbon and nitrogen content of marine photosynthetic nannoplankton. Limnol.Oceanogr. 37(7): 1434-1446.

Wheeler, P.A. and Kirchman, D.L., 1986. Utilization of inorganic and organic nitrogen by bacteria in marine systems. Limnol. Oceanogr. 31(5): 998-1009. 


\title{
Chapter Three
}

\author{
TEMPORAL AND SPATIAL VARIATION IN MARINE MICROBIAL SIZE \\ SPECTRA: II. THE BERMUDA ATLANTIC TIME SERIES STATION
}

\begin{abstract}
Microbial size spectra are useful measures of change in community structure and organization. However, field measurements of microbial size spectra from the marine pelagial are relatively few due to time-consuming methods of enumeration in the past. In addition, earlier measurements of size spectra underestimated the picoplankton end of the spectrum, which is now known to be an important component of the food web in open ocean environments. Thus, the range and variability of microbial size spectra in relation to environmental changes are still poorly understood. In this study we report the range and variability of microbial size spectra (bacteria and phytoplankton) in relation to environmental changes for the BATS station in the oligotrophic Sargasso Sea. Dual-beam flow cytometry was used to generate concentration and biomass size spectra of bacteria and phytoplankton. Overall, the size spectra of these organisms have a relative predominace of small cells, with mean mean cell size increasing as nutrients increased with depth and season. The average slope of the normalized concentration size spectrum (ie. cell concentration normalized to the size interval) was -1.9;- close to the theoretical value of -2 which is observed when there is an equal amount of biomass in logarithmically sized intervals. By integrating the flow-cytometrically derived biomass size spectra, it was estimated that approximately $10-20 \%$ of the microbial carbon was comprised of bacteria, which is considerably less than previous measurements of bacteria biomass in open ocean waters based on microscopy. This is partly due to possible double-counting of Prochlorococcus in microscopy and also due to the choice of biomass-size conversion factors taken from the literature, the latter occasionally leading to biomass exceeding particulate organic carbon measurements.
\end{abstract}




\section{BACKGROUND}

In oliogotrophic oceanic environments, microorganisms constitute the majority of living biomass (Cho and Azam, 1988, Fuhrman et. al., 1989). Most studies focus on the abundance and biomass of one or a few of these populations, such as planktonic bacteria (Fuhrman et. al., 1989, Cho and Azam, 1990), cyanobacteria (Waterbury et. al., 1986, Olson et. al., 1990) and prokaryotic/eukaryotic picoplankton ( $\mathrm{Li}, 1994)$. However, there is increasing emphasis on the absolute and relative contributions of the various assemblages to total biomass in the plankton in understanding the biogeochemical cycling of carbon and other nutrients. In particular, food web structure and the size spectrum of organisms are important determinants of what fraction of photosynthetically fixed carbon sinks out of the upper mixed layer (Caron et. al., 1995, Li et. al., 1992, Eppley and Peterson, 1979). Most measurements of community structure use size-fractionated chlorophyll-a to describe the partitioning of biomass in the phytoplankton community (Raimbult et. al., 1988, Hopcropft and Roff, 1990, Jochem et. al., 1993). A compilation of such measurements from a variety of oceanic environments revealed an upper bound fraction to the less than $1 \mu \mathrm{m}$ fraction (roughly $0.5 \mu \mathrm{g} \mathrm{l}^{-1}$ ), regardless of the total chlorophyll concentration (Chisholm, 1992). This limit for the $<1 \mu \mathrm{m}$ fraction can also be extended to other size fractions, and has been measured for the $<3 \mu \mathrm{m}$ and $<10 \mu \mathrm{m}$ fractions (Raimbult, 1988). The pattern that emerges from these studies of sizefractionated chlorophyll is that as total chlorophyll in the system increases, additional chlorophyll is contributed from progressively larger cells. These findings have recently been successfully applied to a pelagic ecosystem model of the Sargasso Sea to predict the seasonal cycles of primary production and nutrients (Hurtt and Armstrong, 1995, Armstrong, 1994). While size-fractionated chlorophyll studies are useful in describing community structure, they are limited in resolution and also do not reveal actual cell numbers or biomass, the latter being important for energy flows. The size spectral approach offers an alternative which not only shows how biomass is distributed in the community but also provides insight into the mechanisms at work through size-based 
relationships with metabolic (Platt and Denman, 1977, 1978) and ecological processes such as predation (Silvert and Platt, 1980, Chrzanowski and Simek, 1990, Jurgens et. al., 1994).

The earliest measurements of size spectra covered extensive regions in the Atlantic and Pacific oceans and revealed biomass size spectra ( 1 to $100 \mu \mathrm{m})$ which had roughly equal amounts of particulate material in equal logarithmic size classes (Sheldon et. al., 1972). When normalized to the width of the size class, the resulting normalized biomass size spectrum gave slope values of about -1. (Alternatively, the size spectrum can be expressed in terms of cell concentration instead of biomass, which when normalized to the size class width will give equivalent slopes of -2 (Gin and Chisholm, 1996).) These measurements were made using a Coulter counter and so it was not possible to discriminate between biological and non-biological particles. In a later study of the North Pacific Ocean, microscopy was used to measure size spectra (phytoplankton of $10 \mu \mathrm{m}$ to macrozooplankton of $200 \mu \mathrm{m}$ ) where the corresponding slopes of the normalized biomass spectrum ranged between -1 and -1.2 (Beers et. al., 1982, Rodriguez and Mullin, 1986). Although microscopy allowed discrimination of organisms from other particles, the method was tedious and time-consuming when it came to measuring more than one population of the microbial community. Recent advances in technology (eg. flow cytometry), however, have resulted in more automated means of analysis as well as the discovery of 'new' groups in the plankton, such as Prochlorococcus (Chisholm et. al., 1988). These new methods highlight the relative importance of the pico-sized fractions of the phototrophic community ( $\mathrm{Li}, 1994$, Caron et. al., 1994) as well as the heterotrophic community (Fuhrman et. al., 1989) in open ocean environments.

The dominance of small organisms has important implications for the food web structure, nutrient cycling and sinking flux for oceanic systems. To date, the inclusion of very small phytoplankton, Prochlorococcus, and bacteria has not been done in previous measurements of oceanic size spectra. There is still a need to characterize these communities within the overall spectrum of microorganisms if one is to accurately assess 
the energy and flow of nutrients through populations and through plankton communities in general. In this study, we test whether the addition of picoplankton to microbial size spectra from the Sargasso Sea changes the -1 slope value of the normalized biomass spectrum (-2 if in terms of normalized concentration) reported in previous measurements of size spectra from other open ocean environments. In addition, our previous study on coastal eutrophic waters showed that under stressed, nutrient limited conditions in summer, normalized concentration size spectra of phytoplankton could approach a slope value of about -1.8 (Gin and Chisholm, 1996). Since the Sargasso Sea is a well known example of an oligotrophic, nutrient limited system, we also compare the size spectra from both ecosystems to see if they are similar when nutrients are depleted in the water column. To address these questions, the range and variability of microbial size spectra from the Sargasso Sea are examined in relation to perturbations in the environment and the structure of the water column. The study is confined to phytoplankton and bacteria only, since these organisms are at the base of the food chain and also play a major role in the cycling of carbon and nutrients in the system. Flow cytometry was used to generate size spectra in the range of $10^{-3}$ to $10^{5} \mu \mathrm{m}^{3}(0.2 \mu \mathrm{m}$ to $45 \mu \mathrm{m})$. This method is suitable for rapid enumeration of particles and also has the ability to discriminate phytoplankton and bacteria cells from other particles. By using empirical calibrations to convert forward light scatter to volume, concentration size spectra of these trophic subgroups were generated. Biomass was estimated from concentration and cell size and also analyzed as a function of size.

\section{METHODS}

\section{Field Sampling Scheme}

The Sargasso Sea is a subtropical oceanic gyre in the Atlantic, characterized by low nutrients and low primary production with chlorophyll-a levels typically less than 0.5 $\mu \mathrm{gl}^{-1}$ (Knap et. al., 1994, 1995). The intensity of light remains high year-round and the amounts of particulate and dissolved organic matter are extremely low (eg. beam 
attenuation $\sim 0.5 \mathrm{~m}^{-1}$ ). Samples were collected from the Bermuda Atlantic Time Series (BATS) station which is located off Bermuda near the site of the Ocean Flux Program $\left(31^{\circ} 50^{\prime} \mathrm{N}, 64^{\circ} 10^{\prime} \mathrm{W}\right)$. The study area is part of the Joint Global Ocean Flux Study (JGOFS), and international and interdisciplinary study (International Geosphere Biosphere Program - IGBP) with the goal of understanding the role of oceans in global carbon and nutrient cycles.

Samples from the BATS station were collected in May 1992, July, September, November, February 1993, March and April, 1993. Seawater was collected from 12 depths in the upper $250 \mathrm{~m}$ zone using 12 L Niskin bottles. $200 \mathrm{ml}$ glutaraldehyde (Tousimis - $25 \%$ stock solution) was pipetted into sterile $50 \mathrm{ml}$ centrifuge tubes and seawater from each depth was added up to the $50 \mathrm{ml}$ level to obtain a final concentration of $0.1 \%$ (Gin, 1996), except for the 1992 nano/microplankton samples, which were fixed at $1 \%$ glutaraldehyde concentration. (Previous tests showed that there was not much difference in preservation between 0.1 to $1 \%$ glutaraldehyde for nano/micro phytoplankton - see Gin, 1996). Samples for each depth were divided into two for separate picoplankton and nano/microplankton analysis. A surface sample at each station was also filtered $(0.2 \mu \mathrm{m}$ for nano/microplankton analysis; $0.02 \mu \mathrm{m}$ for picoplankton analysis) and treated in the same manner as the actual samples to act as reference controls for background fluorescence and scattering. Each sample was well mixed and then two aliquots (replicates) of $2 \mathrm{ml}$ were withdrawn each into $2 \mathrm{ml}$ cryovials for picoplankton analysis. The remainder of the samples in the centrifuge tubes (for nano/microplankton analysis) together with the picoplankton samples were then left in the dark for 10 to 15 minutes. After this time, the samples were immersed into liquid nitrogen for storage before flow cytometric analysis (Vaulot et. al., 1989). (Note that $1 \mathrm{~mm}$ holes were made in the caps of the centrifuge tubes because the tubes had a tendency to crack when frozen samples were thawed due to the pressure buildup behind the caps.) Auxillary measurements were also made at the time of sampling and included temperature, salinity, dissolved oxygen, transmissometry, irradiance, nitrate, nitrite, phosphate, silicate, 
particulate organic carbon (POC) and nitrogen (PON), chlorophyll-a, primary production and bacterioplankton abundance (Knapp et. al., 1993, 1994, 1995).

\section{Flow Cytometry Analysis}

Samples were analyzed using two main instrument configurations on the flow cytometer (Gin, 1996). The first configuration (ie. 'pico' settings) was designed to analyze heterotrophic bacteria and picophytoplankton using dual-beam flow cytometry (Binder et. al., 1996, Duval, 1993, Monger and Landry, 1993). In this set-up, a spherical lens was used to focus blue ( $488 \mathrm{~nm})$ and UV (355-356nm) laser beams to a tight spot, measuring approximately $20 \mu \mathrm{m}$ in diameter. Immediately following sample thawing in a water bath $\left(25^{\circ} \mathrm{C}\right), 0.5 \mathrm{ml}$ aliquots were stained with the DNA-specific fluorochrome Hoechst-33342 to give a final concentration of $0.5 \mu \mathrm{g} \mathrm{ml}^{-1}$ (Monger and Landry, 1993). Samples were then incubated in the dark for 1 hour at room temperature before dual beam analysis. Just prior to flow cytometric analysis, known volumes of two standard bead stocks were also added to the sample: $0.57 \mu \mathrm{m}$ blue-excitable beads ("Fluoresbrite YG" by Polysciences, Inc.) and $0.46 \mu \mathrm{m}$ UV-excitable beads ("Fluoresbrite BB"). These beads were used as reference fluorescence and light scatter standards and also to determine cell abundance (Olson et. al., 1993). By calibrating the flow rate each day using standard beads, the actual volume analyzed per sample could be calculated from the number of beads counted within each sample. In general, the day-to-day variation in bead calibrations was less than 5\%. Excitation with blue light causes chlorophyll-containing cells to fluoresce red whereas UV excitation causes DNA-containing cells stained with Hoescht to fluoresce blue (Fig. 3.1). In this way, phytoplankton (fluoresces red and blue) and bacteria (fluoresces blue only) could be discriminated from each other as well as from inorganic particles in the water (Gin, 1996, Binder et. al., 1996). Further identification of sub-populations of phytoplankton such as Synechococcus, could be made because such cells also fluoresce orange with blue excitation due to the prescence of phycoerythrin (Olson et. al., 1990). For surface samples in summer, however, the smallest 

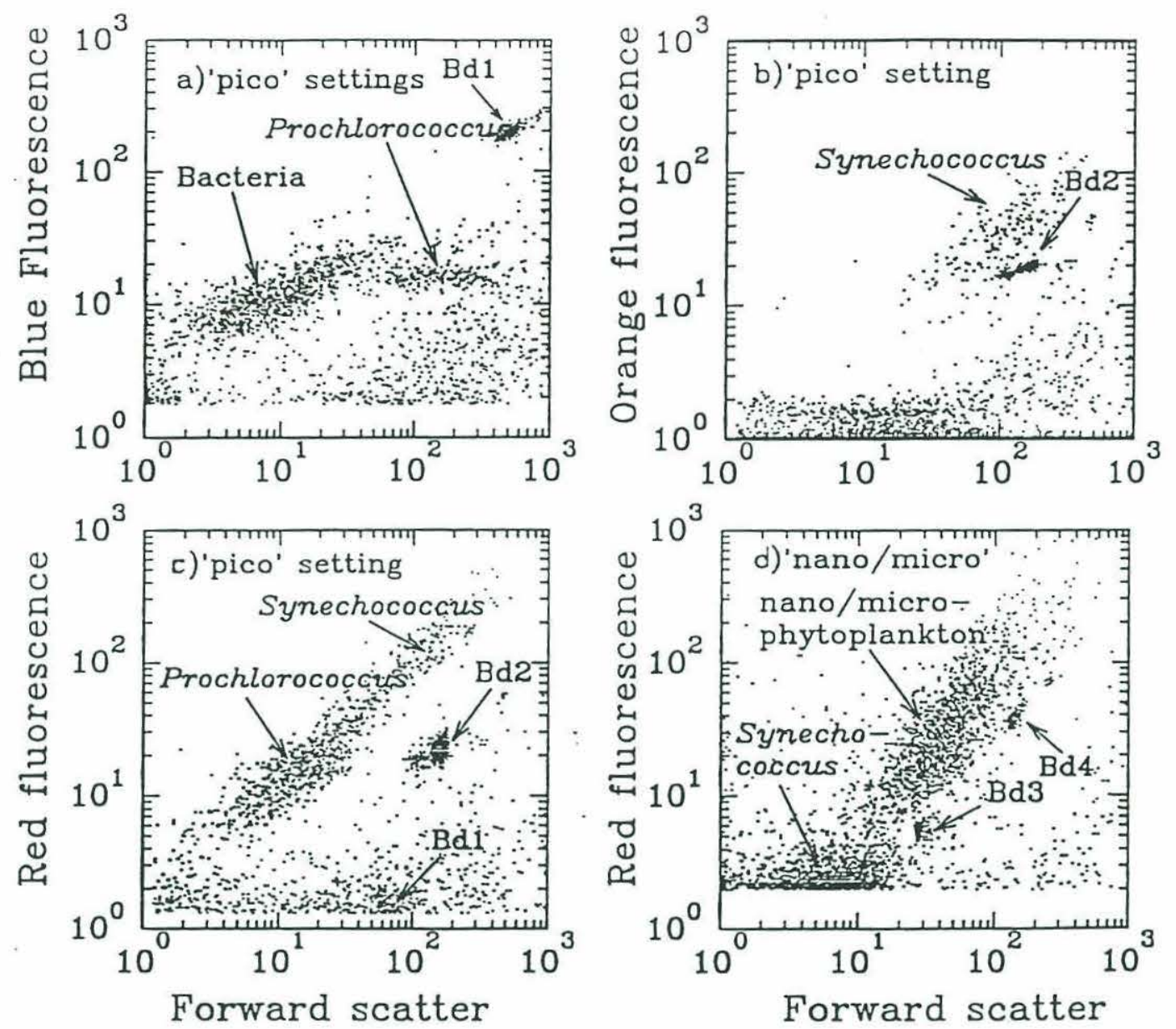

Fig. 3.1. Flow cytometric signatures of bacteria (a), picophytoplankton (b,c) and nano/microphytoplankton (d) for surface samples of the BATS station, Sargasso Sea on February 9, 1993 at 0815 hrs. Bacteria were captured using dual-beam analysis on the 'pico' settings of an Epics 753 flow cytometer. Bacteria were discriminated on the blue fluorescence versus forward light scatter scattergram (a) whilst picophytoplankton were generally discriminated on red fluorescence versus forward light scatter (c). Synechococcus could be further resolved from Proohlorococcus because the former fluoresces orange but not the latter (b). Nano/microphytoplankton were analysed on red fluorescence versus forward scatter (d) and captured using the 'nano/micro' settings. Standard calibration beads of $0.46 \mu \mathrm{m}(\mathrm{Bd} 1), 0.57 \mu \mathrm{m}(\mathrm{Bd} 2), 2.02 \mu \mathrm{m}(\mathrm{Bd} 3)$ and $3.79 \mu \mathrm{m}(\mathrm{Bd} 4)$ were also added for reference. Flow cytometric data were recorded in relative units on a scale of 256 channels representing 3 logarithmic decades. 
phytoplankton, Prochlorococcus, had very low values of red fluorescence which tended to make them difficult to discriminate from bacteria (ie. cells were close to the baseline of red fluorescence). These small phytoplankton were analysed separately using a single blue laser configuration set at higher power in order to increase their red fluorescence for detection.

Nano/microplankton from about 2 to $45 \mu \mathrm{m}$ were analyzed on an EPICS $\mathrm{V}$ flow cytometer using a different configuration from the picoplankton analysis ie. 'nano/micro' settings. Following Olson et. al. (1989), a single blue laser line was focused through both a $150 \mathrm{~mm}$ and a $40 \mathrm{~mm}$ lens for cell excitation. Since the abundance of larger phytoplankton is of several orders of magnitude less than that of picoplankton, larger volumes of sample have to be analyzed before reasonable statistical cell counts can be made. To achieve this, larger sized sample tubing and needles were used to process larger volumes, with flow rates of about $5-10 \mathrm{ml} \mathrm{min}^{-1}$ compared to $5 \times 10^{-3} \mathrm{ml} \mathrm{min}^{-1}$ for 'pico' .settings. Following sample thawing in a water bath $\left(25^{\circ} \mathrm{C}\right), 45 \mathrm{ml}$ aliquots were withdrawn and known volumes of beads (blue-excitable "Fluoresbrite YG") were added (ie. 2.02 and $3.79 \mu \mathrm{m}$ ). Mixes of different sized beads in $0.2 \mu \mathrm{m}$ filtered seawater were also run on both configurations to provide a reference frame for analysis. The upper limit to our size range was partly determined by the forward scatter signals of overlapping beads seen on both settings (which in turn were dependent on the sensitivity of the picoplankton scale), and partly by the relative scarcity of larger cells in our $45 \mathrm{ml}$ sample volumes.

\section{Merging the Picoplankton and Nano/Microplankton to Form a Continuous}

\section{Spectrum}

Software (CytoPC) provided by D. Vaulot (Station Biologique, Roscoff, France) was used to analyse the populations on red fluorescence versus forward scatter (for phytoplankton) and blue fluorescence versus forward scatter (for bacteria). The identified populations were projected from the fluorescence vs forward scatter scattergram and 
modified to remove background fluorescence and scattering. Two sets of data, one from each of the 'pico' and 'nano/micro' settings were obtained and merged to form the overall size spectrum. The data sets were aligned using the forward light scatter signals from standard beads which could be seen on both configurations (eg. $0.66 \mu \mathrm{m}$ beads). Changes in forward light scatter have been traced to changes in particle refractive index, shape and/or size, with particle size being the more important variable (Jerlov, 1976, Gordon et. al., 1984). For the purposes of this study, we have converted forward light scatter to volumetric size by applying empirical size-scatter calibrations measured on both the 'pico' and 'nano/micro' settings (Gin and Chisholm, 1996). These calibrations do not account for odd cell shapes and changes in refractive index, and thus are an approximation only. Given the good correlation between forward scatter and cell size, however, as well as the large size range (about 7 log decades) considered in this study (which would tend to mask details at the cellular level), we feel this is a reasonable approximation.

The nano/microplankton calibration was obtained by sizing phytoplankton cultures with a Coulter counter and analyzing the relative forward light scatter of the same cells on a flow cytometer (DuRand, 1995, Gin, 1996). For the picoplankton calibration equation, seawater samples were first preserved with $0.1 \%$ glutaraldehyde and then filtered through Poretics polycarbonate filters of sizes $0.4,0.6,0.8$ and $1.0 \mu \mathrm{m}$ using gentle pressure on a $10 \mathrm{ml}$ syringe (Brian Binder, pers. comm.) or by gravity (Aref, 1996). The filtrates were then analyzed for bacteria and picophytoplankton on an Epics 753 using the 'pico' configuration. The concentration distributions (as a function of forward scatter relative to $0.46 \mu \mathrm{m}$ beads) were then expressed as a fraction of the unfiltered concentration distribution, and the $50 \%$ retention value of forward scatter was obtained for each filtrate. This gave an average value for the forward scatter corresponding to the filter size used. Recent experiments using these filtration methods show that the picoplankton calibration equation is, in fact, quite stable for different water types (Gin, 1996) and different times of the year (Aref, 1996). The resulting cell sizes estimated from the picoplankton calibration 
were comparable to previous reported measurements of Prochlorococcus $(0.6-0.7 \mu \mathrm{m})$ and Synechococcus $(\sim 1 \mu \mathrm{m})$ (Chisholm et. al., 1988, Morel et. al., 1993).

To ensure a smooth transition of the spectrum from pico to nano/micro scales, the nano/microplankton calibration was modified (ie. set at the same slope value as the picoplankton calibration) where actual calibration data was unavailable (less than $10 \mu \mathrm{m}^{3}$ ). This resulted in a fairly good fit of the overlapping populations captured on both the 'pico' and 'nano/micro' settings (Gin, 1996). Although these empirical calibrations are only approximate and could be further refined, the use of physical size units is preferable to light scatter because it enables the calculation of cell biomass and is less abstract than forward light scatter. Individual cell biomass was estimated from cell size, $\mathrm{V}$ (in $\mu \mathrm{m}^{-3}$ ), through empirical carbon-size relationships taken from the literature: bacteria - 350 $\mathrm{fgC} \mu \mathrm{m}^{-3}$ (Lee and Fuhrman, 1987); picophytoplankton - $470 \mathrm{fgC} \mu \mathrm{m}^{-3}$ (Verity et al., 1992); nanoplankton - C (pg) $=0.433 \mathrm{~V}^{0.863}$ (Verity et. al., 1992); microplankton $\mathrm{C}(\mathrm{pg})=0.347 \log \mathrm{V}^{0.866}$ (Strathman, 1967). Biomass for each size category was calculated by multiplying cell concentration by cell biomass, thus generating size spectra of biomass. However, the range of reported conversion factors is quite considerable and will have an effect on the biomass size spectrum depending on which factors are used. Nevertheless, our measurements of total integrated biomass from flow cytometry (see later) correlated well with measurements of POC, considering the fact that we did not measure detritus or microzooplankton and that our sample volume ( $45 \mathrm{ml}$ compared to 41 for $\mathrm{POC}$ ) was smaller, which may have missed rare but large cells. This will be discussed in more detail in a later section.

In addition to biomass estimation, flow cytometry can also be used to estimate invivo chlorophyll fluorescence, which is another proxy for the abundance of living material. However, preliminary investigations showed that the fluorescence yield measured on the 'pico' settings led to an underestimation of picoplankton fluorescence (roughly about $4 \mathrm{x}$ ) compared to that obtained on the 'nano/micro' configuration for the same population of cells (Michelle DuRand, per. comm., Gin, 1996). This caused a mismatch when the two 
ends of the spectrum were merged and hence, the focus in this study has been on size spectra of concentration and biomass, rather than fluorescence size spectra. (Note that earlier fluorescence size distributions measured by $\mathrm{Li}$ (1994) were concerned only with the picoplankton end of the spectrum, and not the entire range of phytoplankton.)

\section{Data Processing}

The size spectra were analyzed in two ways:- as histograms where the original data was reclassified into logarithmic size classes of equal width; and as normalized spectra where the original data was divided by the original size class width to make the spectra independent of size class (Platt and Denman, 1977, 1978, Rodriguez and Mullin, 1986, Sprules and Munawar, 1986). Normalization allows for comparison of size spectra from different sources, including theoretical models. These normalized spectra are typically characterized by the intercept and slope of the log-transformed data. For the analysis, regressions were calculated for the normalized concentration size spectra alone but these can be extrapolated to normalized biomass spectra through the relationships given in Gin and Chisholm (1996). Patterns and trends in the histograms and normalized spectra were studied on both linear and logarithmic scales in order to extract as much information as possible.

In the case of the normalized concentration size spectrum, the intercept, by definition, is the abundance of cells of $1 \mu \mathrm{m}^{3}$ but is also used in a more general way, to reflect the total abundance of organisms or the resource level of the system (Sprules and Munawar, 1986). (Note that the intercept of the normalized bacteria spectrum actually portrays the abundance of large bacteria whereas for the normalized phytoplankton spectrum, the intercept represents the abundance of small cells ie. picophytoplankton.) The slope is a useful measure of the overall distribution of cells and changes in the slope reflect the relative importance of the various size classes. A slope of -2 for the normalized concentration size spectrum corresponds to the flat biomass spectrum where equal amounts of material exist in equal sized logarithmic classes. Higher slope values imply a 

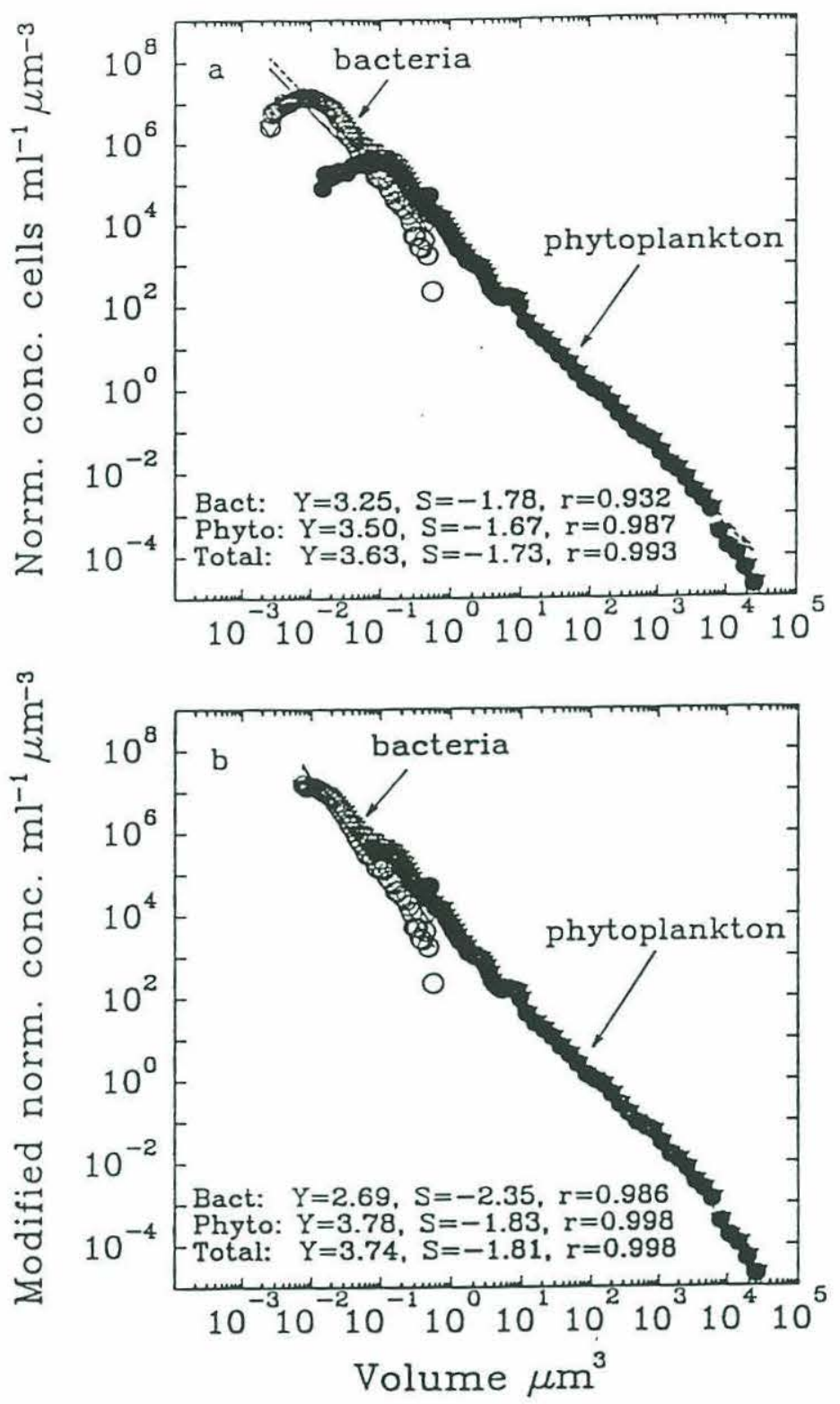

Fig. 3.2. Differences between normalized and modified normalized concentration size spectra for the BATS station taken from surface waters in February. The complete normalized spectrum (a) was obtained by dividing the raw data by the width of the corresponding size class, whilst the modified normalized spectrum (b) was obtained by excluding data points to the left of the maximum of the normalized data in (a). The coefficents of regression are also shown: intercept (Y), slope (S) and correlation coefficient ( $\mathrm{r}$ ) for bacteria, phytoplankton and total (bacteria + phytoplankton) community. 
disproportionate increase in the biomass of larger organisms while lower slopes indicate a relative biomass increase in smaller organisms. One of the objectives of this study is to analyze the variation in slopes to perturbations in the environment. However, changes in slope are only meaningful when there is a good fit of data to the linear regression. For this reason, the main region of interest for normalized spectra is in the steadily decreasing function with size, to the right of the maximum, for which the correlation coefficient, $r$, is generally greater than 0.97 (Fig. 3.2). In this study, calculations of the intercept and slope were based only on the steadily decreasing function of the spectrum (ie. 'modified'

normalized spectrum), neglecting the front end which represents the tail end of a normally distributed population of the smallest bacteria or phytoplankton cells. These cells would probably also be undetectable using conventional microscopy since they are so few and so small. At any rate, the information is not lost since the size spectrum is still analyzed through histograms as well as changes in meản cell size.

When considering the modified normalized spectra, variations in the intercepts and slopes for replicate spectra were typically less than $5 \%$ for bacteria, $1 \%$ for phytoplankton and $2 \%$ for total bacteria plus phytoplankton. Similar variations were also found between the spectral characteristics (ie. intercept and slope) of live and preserved size spectra, even though cell counts of specific populations could vary by up to $30 \%$ for live and preserved samples (Gin, 1996). The smaller differences for the normalized spectra arose because these were based on log scales which covered a broad range in abundance and size. On the whole, $5 \%$ provides a reasonable estimate of the analytical errors involved in this study.

\section{RESULTS}

\section{Depth Variation of Size Spectra}

The depth variation of microbial size spectra is dependent on the physical structure of the water column. In early summer (May), when stratification of the water column occurs, a distinct chlorophyll maximum is observed at about $90 \mathrm{~m}$ depth (Fig. 3.3). Most 

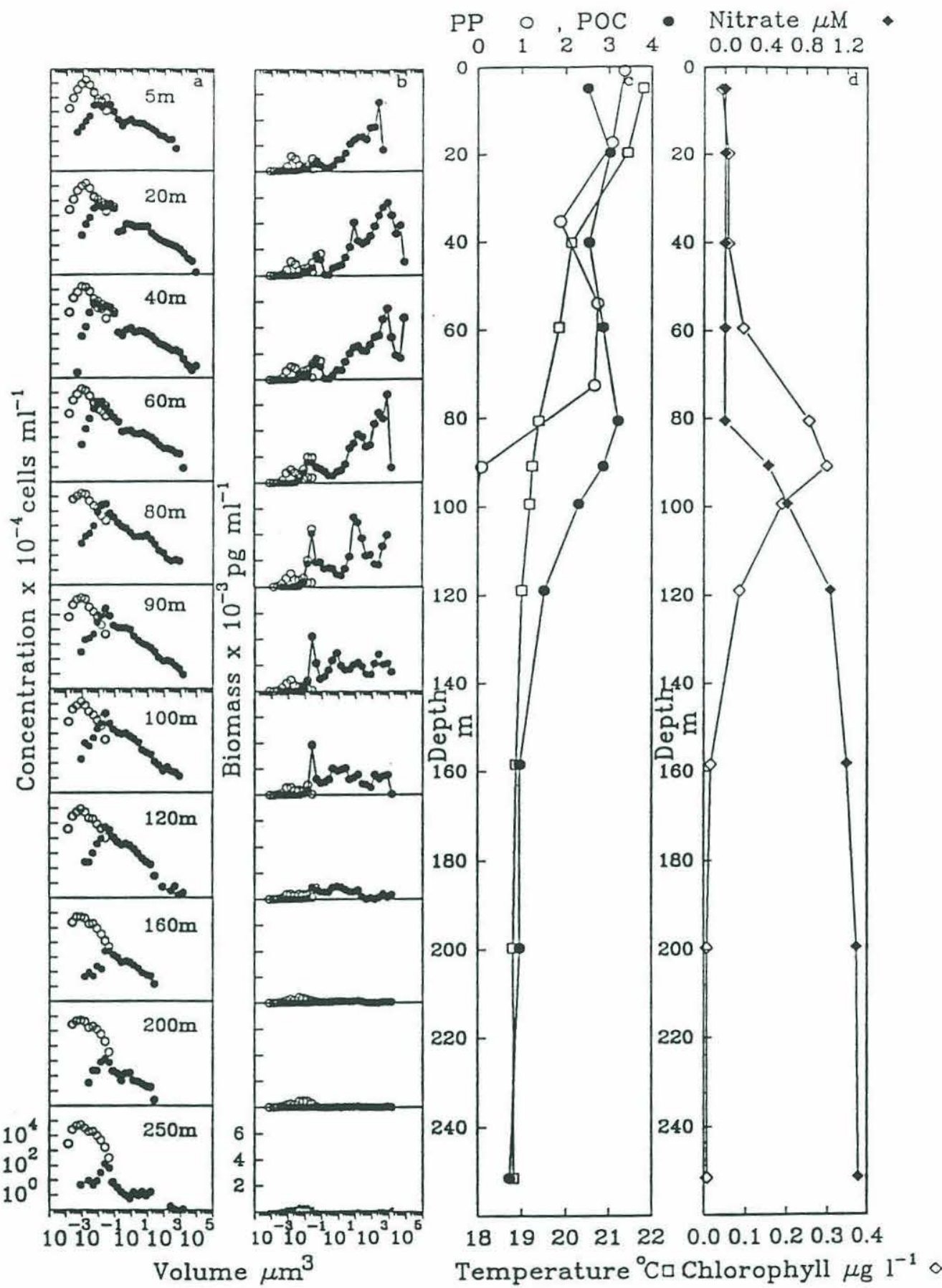

Fig. 3.3. Depth profiles of flow cytometrically generated size spectra for the BATS station in the Sargasso Sea on May 19, 1992 at $1240 \mathrm{hr}$, under stratified conditions. Histogram size spectra of concentration and biomass for bacteria (open circles) and phytoplankton (closed circles) are shown in panels $\mathrm{a}$ and $\mathrm{b}$ respectively.

Corresponding depth profiles of temperature (open squares), primary productivity PP (open circles), particulate organic carbon POC (closed circles), extracted chlorophyll (open diamonds) and nitrate concentration (closed diamonds) are also shown in panels $\mathrm{c}$ and d. Environmental measurements were taken from Knap et. al., 1995a. 

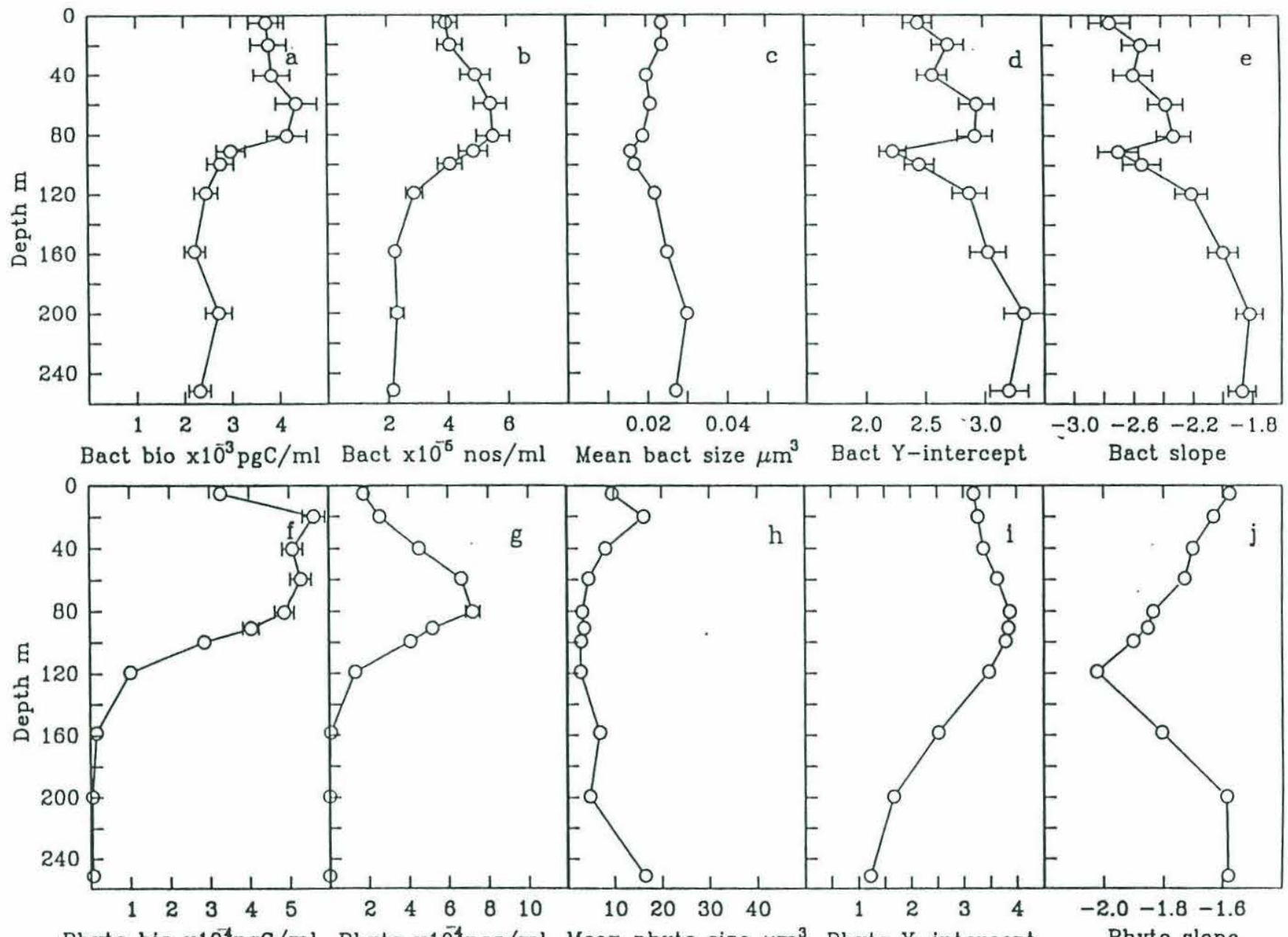

Phyto bio $\times 10^{-4} \mathrm{pgC} / \mathrm{ml}$ Phyto $\times 10^{-4} \mathrm{nos} / \mathrm{ml}$ Mean phyto size $\mu \mathrm{m}^{3}$ Phyto Y-intercept Phyto slope

Fig. 3.4. Depth profiles of size spectral characteristics for the BATS station on May 19, 1992 at $1240 \mathrm{hr}$, corresponding to the size spectra and environmental conditions shown in Fig. 3.3: a) Bacteria biomass (measured flow cytometrically), b) bacteria cell concentration, c) mean bacteria size, d) bacteria intercept, e) bacteria slope, f) phytoplankton biomass, g) phytoplankton cell concentration, h) mean phytoplankton size, i) phytoplankton intercept and j) phytoplankton slope. 
of the primary production takes place above this depth, leading to a depletion of nutrients (eg. nitrate) in the upper $80 \mathrm{~m}$. Chlorophyll, on the other hand, is low in the upper layers at less than $0.1 \mu \mathrm{g} \mathrm{l}^{-1}$, but subsequently rises to a peak of $0.3 \mu \mathrm{g} \mathrm{l}^{-1}$ at the chlorophyll maximum. In general, the concentration size spectra of bacteria, plotted on log scales, show unimodal distributions for bacteria centred at $0.02 \mu \mathrm{m}^{3}(0.34 \mu \mathrm{m}$ diameter). For phytoplankton, the concentration size spectrum peaks at around $0.2 \mu \mathrm{m}^{3}(0.73 \mu \mathrm{m}$ diameter) and then steadily decreases with increasing size. While the cell concentration of bacteria is generally much greater than that of phytoplankton, the biomass of bacteria is often comparable or less than that of phytoplankton depending on depth.

For stratified water columns, the profiles typically show a gradual shift in the relative importance of larger nanoplankton biomass near the surface to smaller picoplankton near the chlorophyll maximum. The shift to smaller sizes from surface waters to the chlorophyll maximum is evident for both bacteria and phytoplankton, as illustrated by the general decrease in mean cell size in Fig. 3.4. Within this upper zone, both the corresponding total concentrations of bacteria and phytoplankton increase with depth to a maximum just above the chlorophyll maximum. In contrast, total bacteria and phytoplankton biomass levels remain fairly constant, at about $4 \times 10^{3} \mathrm{pg} \mathrm{C} \mathrm{ml}^{-1}$ and $5 \times 10^{4}$ pg C ml${ }^{-1}$ respectively. The associated characteristics of the normalized concentration size spectra for bacteria show an overall increase in intercept and slope values (ie. a relative increase in larger bacteria) with depth, except in the vicinity of the chlorophyll maximum, where minimum values coincide with the smallest mean bacteria sizes. In contrast, the intercept and slope of the normalized phytoplankton concentration size spectra form trends which are almost mirror images of each other. For stratified waters, the intercept typically increases from the surface to the chlorophyll maximum, whereas the slope decreases in value (or steepens). Both these changes in size spectral characteristics indicate the growing importance of picophytoplankton for depths near the chlorophyll maximum. (Note that the minimum for the phytoplankton slope ie. -2.0 in this example is actually about $30 \mathrm{~m}$ below the chlorophyll maximum.) Below the chlorophyll maximum, 
there is a sharp decline in both bacteria and phytoplankton abundance, with a consequent increase in nutrient levels from undetectable levels to about $1.3 \mu \mathrm{M}$ nitrate. The associated changes in size spectra reveal a shift to larger cell sizes at these lower depths. (Note that these depth changes in size spectra are similar to the trends observed for stratified coastal waters in Massachusetts and Cape Cod Bays (Gin and Chisholm, 1996).)

In contrast, a well-mixed water column, as observed in March, reveals fairly uniform characteristics with depth (Fig. 3.5). In this example, the deep mixed layer extends to about $130 \mathrm{~m}$, with similar values of particulate organic carbon $(1.2 \mu \mathrm{M})$ and chlorophyll $\left(0.3 \mu \mathrm{g} \mathrm{I}^{-1}\right)$ values within it. The corresponding depth profiles of size spectra also depict similar distributions with uniform bacteria and phytoplankton cell abundances within the mixed layer, at about $3.8 \times 10^{5}$ cells ml-1 and $3.8 \times 10^{4}$ cells $\mathrm{ml}^{-1}$ respectively (Fig. 3.6). Phytoplankton biomass, on the other hand, is uniform in the upper $40 \mathrm{~m}$ or so but then steadily decreases with depth within the mixed layer until just below the thermocline, where it falls dramatically. The decrease in biomass within the mixed layer parallels the trend in primary productivity measurements and is due primarily to an overall decrease in biomass across all size classes, particularly for nanoplankton cells of about $400 \mu \mathrm{m}^{3}$ (10 $\mu \mathrm{m}$ diameter) (see also Fig. 3.5). This results in a decrease in mean phytoplankton cell size from 5 to $2.3 \mu \mathrm{m}^{3}$ (or 2.1 to $1.6 \mu \mathrm{m}$ ) within the mixed layer. The intercept and slope of the normalized bacteria size spectra show a small but steady increase in value with depth in the mixed layer even though the mean bacteria size is unchanged. In the case of normalized phytoplankton spectra, the intercept remains fairly constant within the mixed layer ( 4) whereas the slope is more variable and decreases to a minimum just below the mixed layer, at about $160 \mathrm{~m}$. The mixed layer extends down to the nutricline $(150 \mathrm{~m})$, below which both bacteria and phytoplankton cell abundance decreases substantially whilst nitrate increases steadily to $4 \mu \mathrm{M}$ at about $250 \mathrm{~m}$. At these lower depths, the size spectrum shifts again in favour of larger cells in association with the higher nutrient levels.

These depth changes in size spectra are more clearly illustrated when plotted on a single graph on log scales (Fig. 3.7). In general, the concentration size spectrum is a 


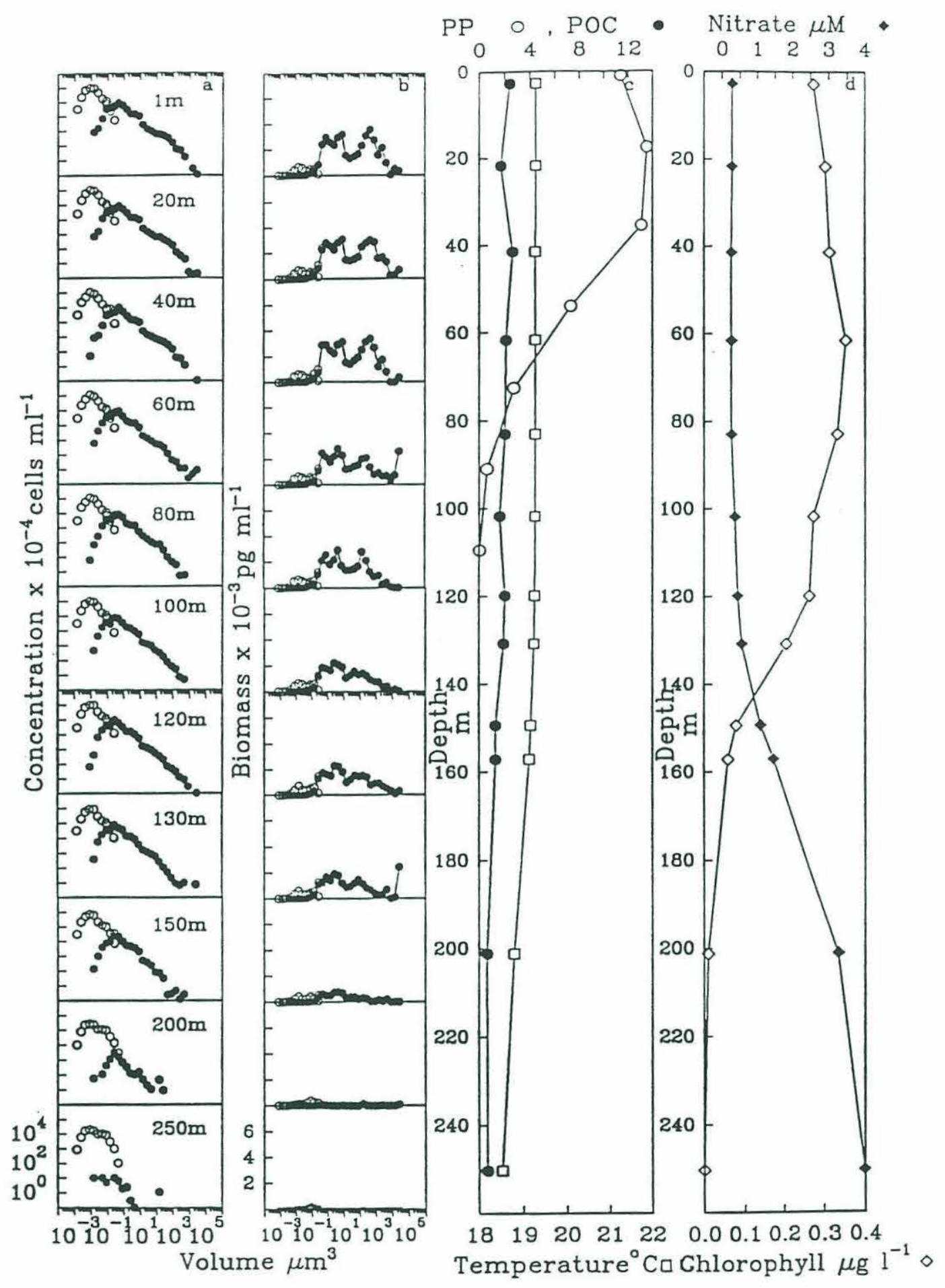

Fig. 3.5. Depth profiles of histogram size spectra together with corresponding environmental measurements for the BATS station on March 10, 1993 at $1407 \mathrm{hr}$, under fully mixed conditions. Environmental measurements were taken from Knap et. al., $1995 \mathrm{~b}$. 


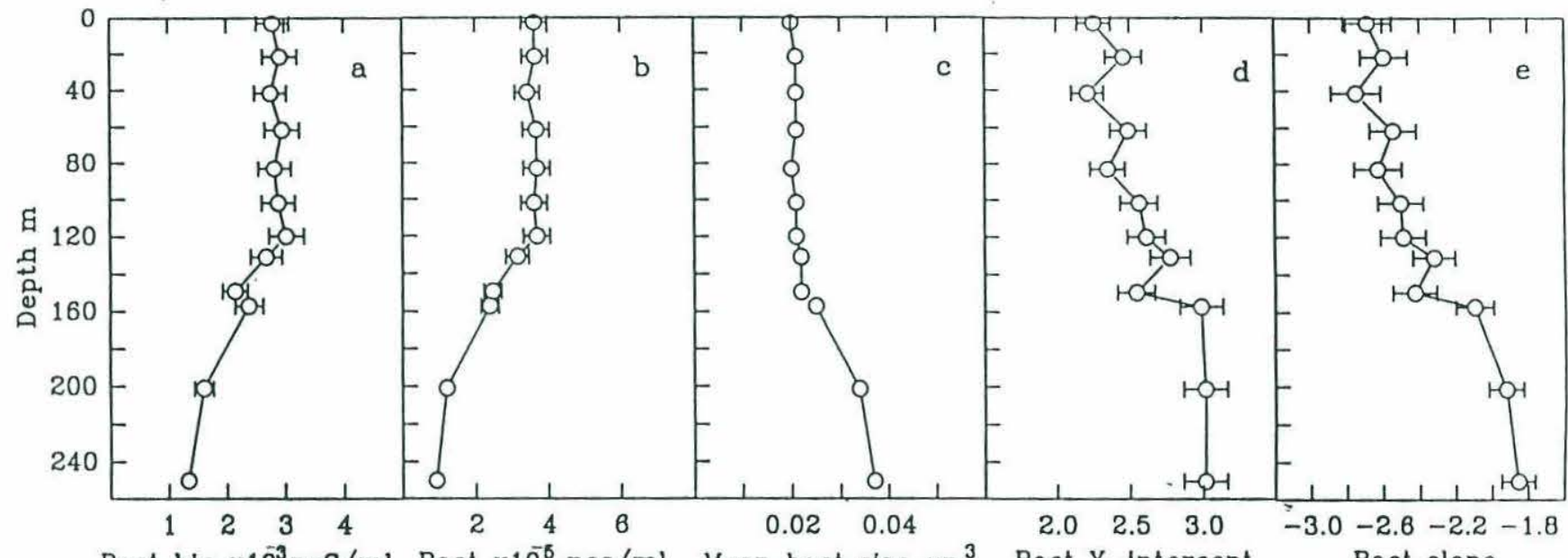

Bact bio $\times 10^{-3} \mathrm{pgC} / \mathrm{ml}$ Bact $\times 10^{-5}$ nos $/ \mathrm{ml}$ Mean bact size $\mu \mathrm{m}^{3}$ Bact Y-Intercept

Bact slope

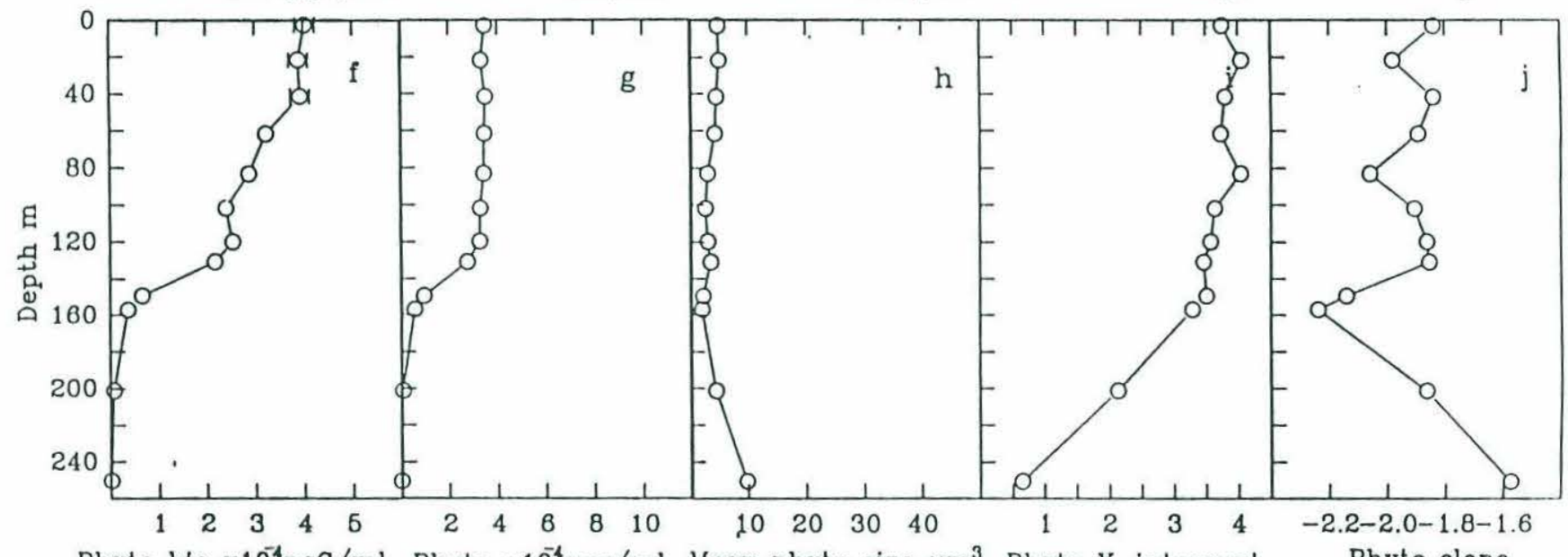

Phyto bio $\times 10^{-4} \mathrm{pgC} / \mathrm{ml}$ Phyto $\times 10^{-4} \mathrm{nos} / \mathrm{ml}$ Mean phyto size $\mu \mathrm{m}^{3}$ Phyto Y-intercept Phyto slope

Fig. 3.6. Depth profiles of size spectral characteristics for the BATS station on March 10, 1993 at $1407 \mathrm{hr}$, corresponding to the size spectra and environmental conditions shown in Fig. 3.5. 

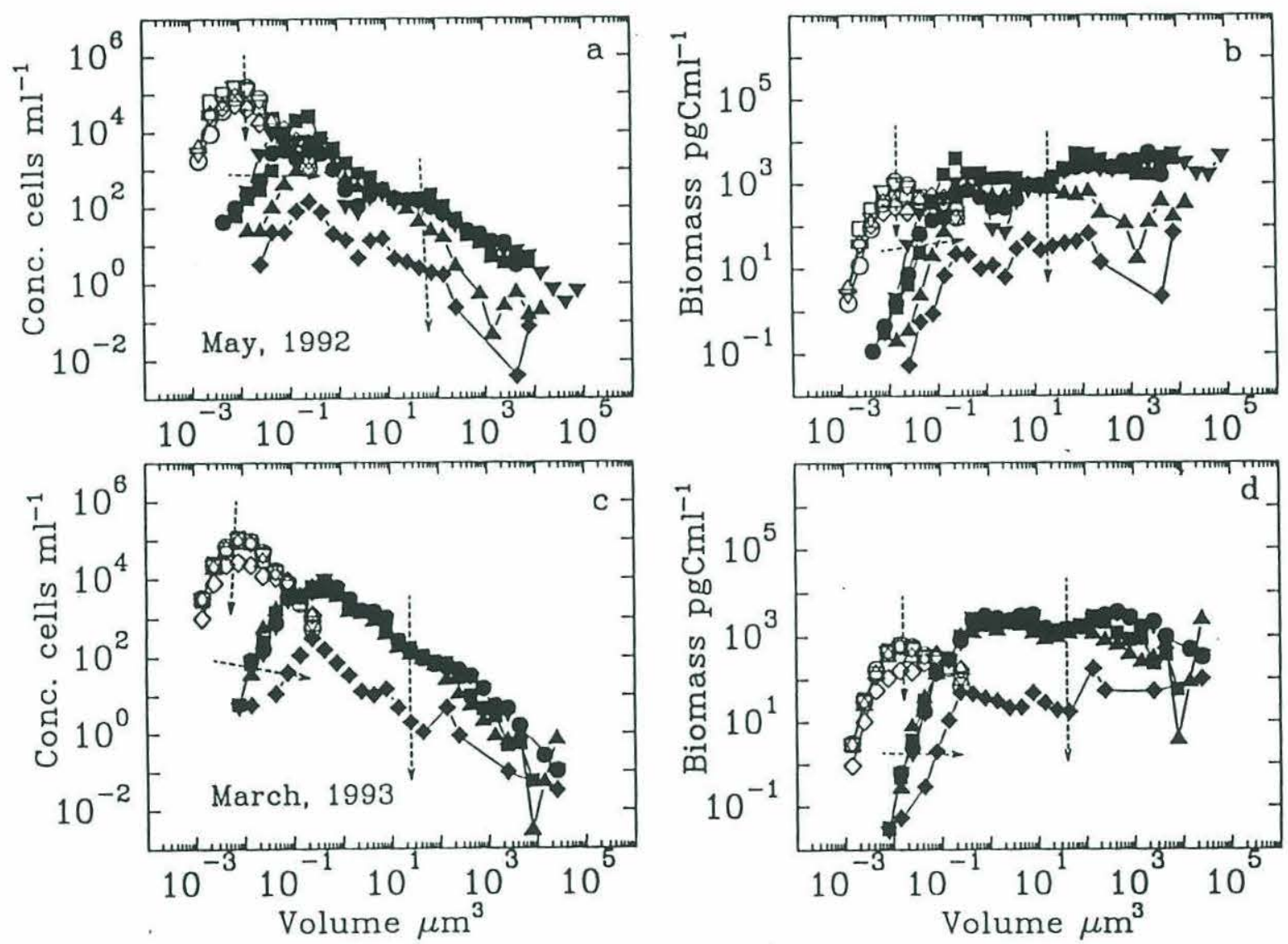

Fig. 3.7. Depth variation of histogram size spectra of concentration and biomass plotted on log scales for the BATS station under stratified conditions in May, 1992 (a, b respectively), and under fully mixed conditions in March, 1993 (e, f). Size spectra of bacteria (open symbols) and phytoplankton (closed symbols) were taken from depths of $2 \mathrm{~m}$ (circles), $40 \mathrm{~m}$ (inverted triangles), $80 \mathrm{~m}$ (squares), $120 \mathrm{~m}$ (upright triangles) and $200 \mathrm{~m}$ (diamonds). Note that standard deviations fall within the actual size of the symbols used and that the arrows point in the direction of increasing depth. 
steadily decreasing function with size, whereas the biomass size spectrum is relatively flat confirming previous measurements of size spectra from oceanic environments (Sheldon et. al., 1972). (Note, however, that their results pertain to total particulates over a larger spectrum (1 to $100 \mu \mathrm{m}$ ), whereas this study is concerned only with bacteria and phytoplankton). For the stratified profile in May, the shift to a relative predominance of smaller phytoplankton at $120 \mathrm{~m}$ relative to surface spectra is evident ie. the size spectrum steepens. In contrast, the deep mixed layer generally has uniform size spectra, with slightly more variability at the microplankton end of the spectrum. Both examples show an overall decrease in abundance at the lower depths, together with a displacement in the size spectrum to the right towards larger sizes.

\section{Seasonal Variation of Size Spectra}

On the whole, the seasonal variation of size spectra from the oligotrophic Sargasso Sea is small relative to temperate coastal systems (Gin and Chisholm, 1996). For bacteria, the variation is particularly small, both for surface waters as well as at the chlorophyll maximum (Fig. 3.8). There is slightly more variability in the phytoplankton size spectra, especially at the surface in the $1-10 \mu \mathrm{m}^{3}(1-2.7 \mu \mathrm{m})$ range, where abundances in early spring are generally higher than those for the rest of the year. (This can be attributed to the growth of Synechococcus and eukaryotic picophytoplankton - data not shown.) In addition, there is a relative decrease in the smallest picophytoplankon, Prochlorococcus, leading to a shift in the mode to larger sizes from February to March. By early summer (May), the surface abundance of Synechococcus and eukaryotic picophytoplankton decreases, coinciding with nutrient depletion in the stratified water column. In July and September, there is a relative increase in Prochlorococcus but a relative decrease in large nanoplankton in the size range 300 to $4000 \mu \mathrm{m}^{3}$ ( 8 to $20 \mu \mathrm{m}$ ), leading to a steepening of the phytoplankton size spectrum. Similar variations in the pico end of the spectrum can also be detected at the chlorophyll maximum but these are to a smaller extent compared with surface variations. The relative predominance of larger picoplankton (ie. 

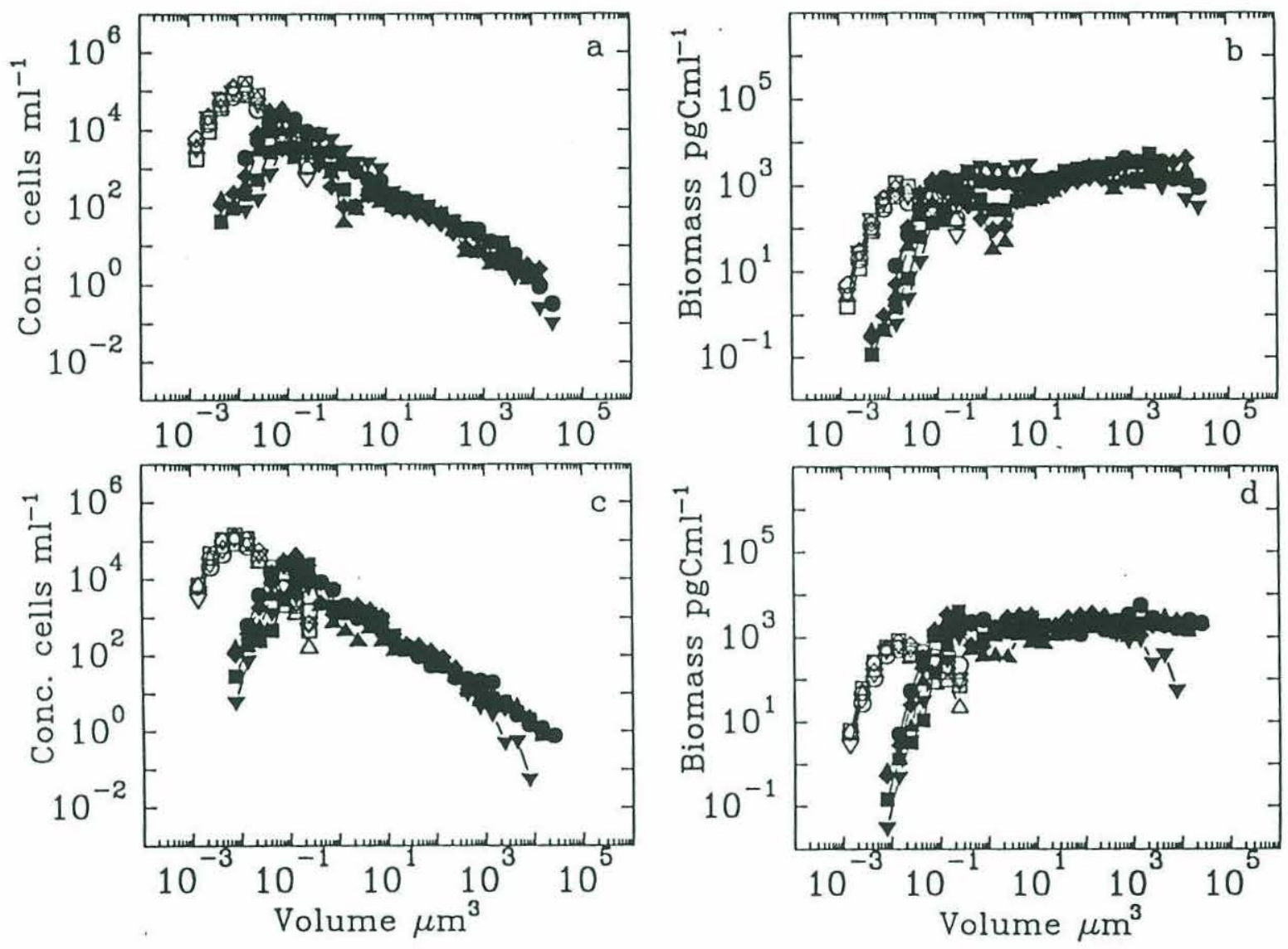

Fig. 3.8. Seasonal variation of histogram size spectra of concentration and biomass at the BATS station taken from surface waters (a, b respectively) and the chlorophyll maximum (c, d). Bacteria (open symbols) and phytoplankton (closed symbols) samples were collected on February 9, 1993 (circle), March 10, 1993 (inverted triangle), May 19, 1992 (square), July 14, 1992 (upright triangle) and September, 1992 (diamond). Standard deviations fall within the actual size of the symbols used. 
Synechococcus and eukaryotic picophytoplankton) in early spring compared to summer and fall periods has also been reported in earlier studies of Synechococcus and Prochlorococcus abundance in the North Atlantic (Olson et. al., 1990a and b, Chisholm, 1992).

The seasonal changes of size spectra can be correlated to changes in the environmental characteristics of the system. During the summer, mean cell sizes of phytoplankton in surface waters decrease with warm surface temperatures and depletion of nitrates (Fig. 3.9). Chlorophyll and total integrated biomass (bacteria plus phytoplankton) are generally low (less than $0.05 \mathrm{gg} \mathrm{l}^{-1}$ and $3 \times 10^{4} \mathrm{pg} \mathrm{C} \mathrm{ml}^{-1}$ respectively) compared to spring values $\left(0.3 \mu \mathrm{g} \mathrm{l}^{-1}\right.$ and $\left.4.5 \times 10^{4} \mathrm{pg} \mathrm{C} \mathrm{ml}^{-1}\right)$. The growing importance of smaller picoplankton cells during the summer and into late fall correspond to an increase in intercept but decrease in slope of the normalized phytoplankton concentration size spectra. In early spring (February, March, 1993), lower surface temperatures coincide with increases in total biomass, chlorophyll and particulate levels and slightly elevated nutrient levels arising from winter mixing processes (eg. in March, surface nitrate is $0.3 \mu \mathrm{M}$ ). The increase in mean phytoplankton cell size observed from February to March is due to a shift in the mode to larger sizes whilst the actual shape of the spectrum remains unchanged (see also Fig. 3.8). Hence, similar high values of intercept and low values of slope of the normalized phytoplankton spectra are found for both February and March. This example illustrates the importance of considering all three spectral characteristics when assessing overall changes in the size spectrum.

The trends in size spectra at the chlorophyll maximum with season are generally less obvious than those at the surface (Fig. 3.10). Overall, however, similar relationships between size spectral characteristics and environmental measurements are also detected at the chlorophyll maximum. For example, temperature is roughly inversely related to mean phytoplankton size and trends in the phytoplankton intercept parallel those of biomass and chlorophyll, except for March. In contrast to phytoplankton, seasonal trends in the bacteria size spectra at the surface and chlorophyll maximum do not appear to be 

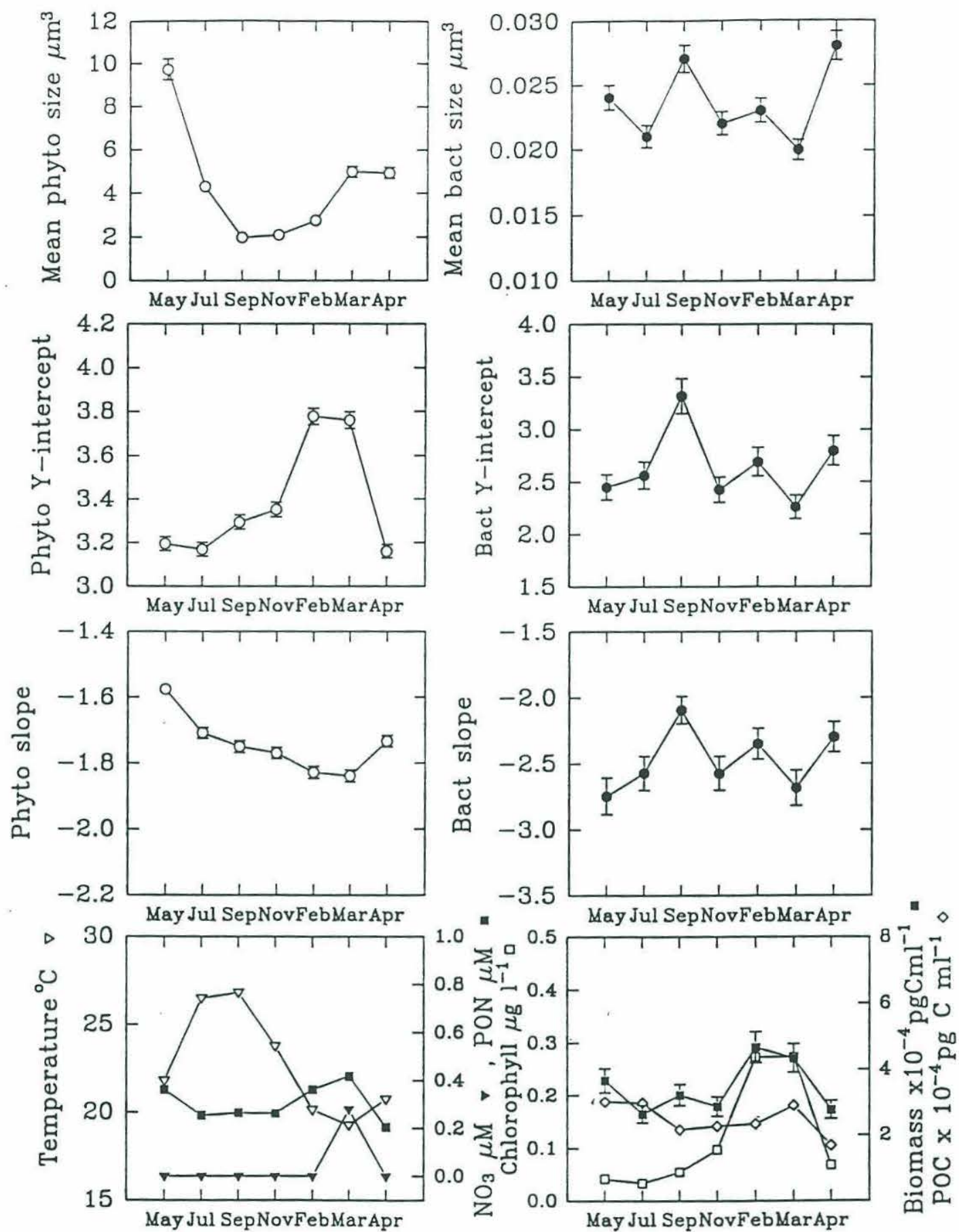

Fig. 3.9. Seasonal variation of size spectral characteristics at the surface for the BATS station, corresponding to the histograms in Fig. 3.8a and b. Mean cell sizes, intercepts and slopes of the normalized concentration size spectra for phytoplankton (open circles) and bacteria (closed circles) are illustrated together with environmental measurements of temperature, $\mathrm{NO}_{3}, \mathrm{POC}, \mathrm{PON}$, chlorophyll and integrated biomass (obtained flow-cytometrically). Environmental measurements were taken from Knap et. al., 1995a, b. 

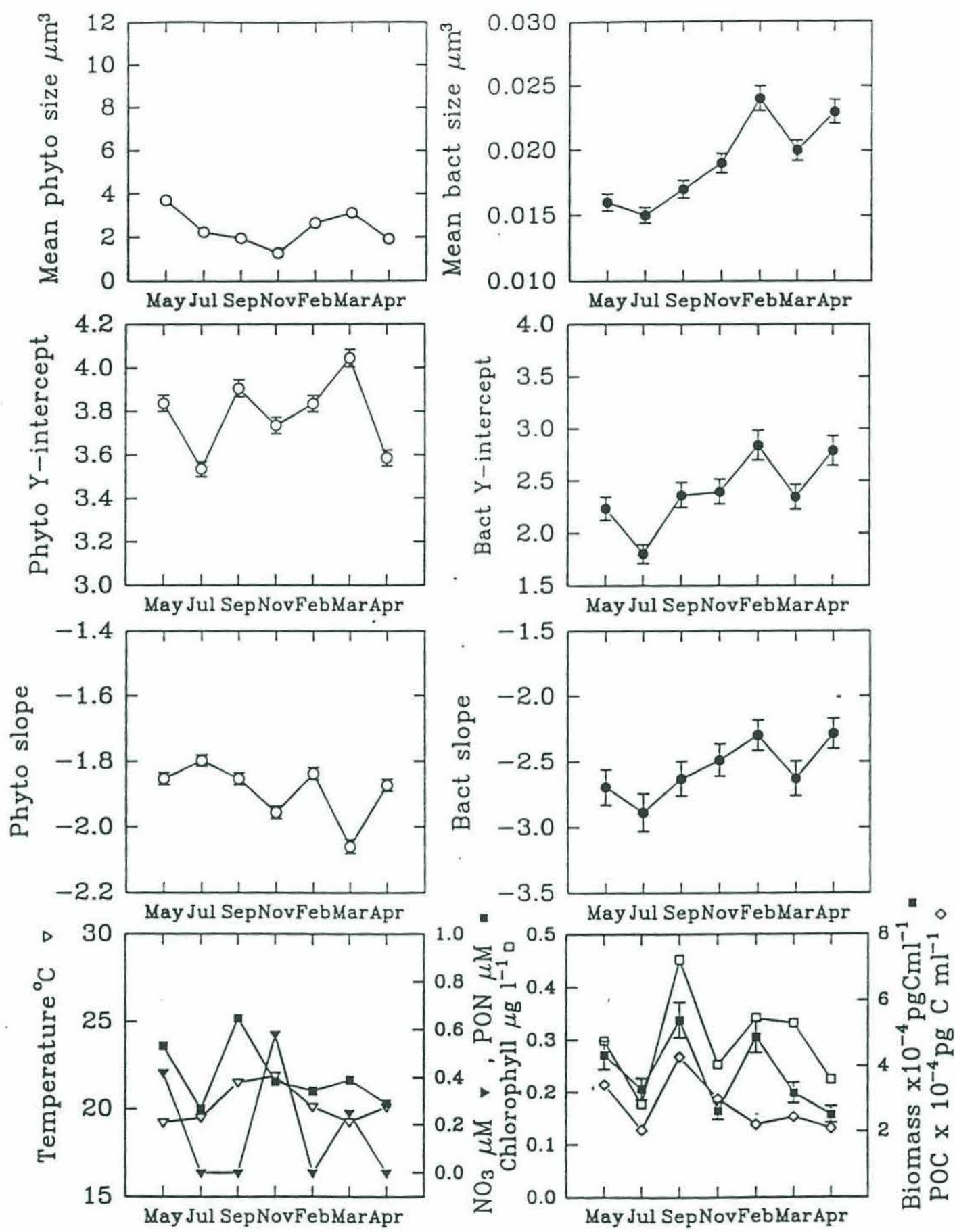

Fig. 3.10. Seasonal variation of size spectral characteristics at the chlorophyll maximum for the BATS station, corresponding to the histograms in Fig. 3.8c and d. 
correlated with changes in the corresponding environmental measurements (Figs. 9, 10). However, a consistent pattern emerged between mean bacteria size, bacteria intercept and slope in that when mean cell size increased, the intercept and slope values also increased.

\section{Relationships Between Microbial Size Structure and Environmental Measurements}

The variations in size spectra with depth and season suggest that overall correlations can be found with selected measurements of the environment (Fig. 3.11, Table 3.1). Data pooled from all depths and all seasons show that mean bacteria size and

\begin{tabular}{llllllllll}
\hline & \multicolumn{3}{l}{ Mean Bacteria Size } & \multicolumn{3}{c}{ Bacteria Slope } & \multicolumn{3}{c}{ Bacteria Intercept } \\
& $\mathrm{Y}$ & $\mathrm{S}$ & $\mathrm{r}$ & $\mathrm{Y}$ & $\mathrm{S}$ & $\mathrm{r}$ & $\mathrm{Y}$ & $\mathrm{S}$ & $\mathrm{r}$ \\
\hline $\mathrm{NO}_{3}$ & -1.59 & 0.22 & 0.73 & -2.13 & 0.59 & 0.70 & 2.85 & 0.54 & 0.56 \\
$\mathrm{SiO}_{4}$ & -1.56 & 0.68 & 0.66 & -2.08 & 1.88 & 0.64 & 2.91 & 1.42 & 0.43 \\
$\mathrm{PO}_{4}$ & -1.14 & 0.36 & 0.62 & -1.18 & 0.70 & 0.55 & 3.59 & 0.52 & 0.32 \\
$\mathrm{POC}$ & -1.57 & -0.35 & 0.73 & -2.09 & -1.06 & 0.77 & 2.91 & -0.86 & 0.55 \\
$\mathrm{PON}$ & -1.86 & -0.37 & 0.72 & -2.92 & -1.07 & 0.72 & 2.23 & -0.87 & 0.51 \\
$\mathrm{CHL}$ & -1.77 & -0.13 & 0.62 & -2.68 & -0.36 & 0.59 & 2.36 & -0.36 & 0.50 \\
$\mathrm{BIO}$ & -0.86 & -0.18 & 0.73 & 0.03 & -0.54 & 0.76 & 4.64 & -0.44 & 0.54 \\
$\mathrm{PP}$ & -1.68 & 0.02 & 0.10 & -2.44 & -0.01 & 0.03 & 2.62 & 0.01 & 0.02 \\
$\mathrm{BEAM}$ & -2.04 & -1.24 & 0.39 & -3.35 & -3.12 & 0.31 & 2.44 & -0.95 & 0.09 \\
TEMP & -0.34 & -0.98 & 0.34 & 1.85 & -3.14 & 0.39 & 5.14 & -1.81 & 0.20 \\
\hline
\end{tabular}

Table 3.1. Linear regression coefficients for characteristics of bacteria size spectra (Yintercept, S-slope, r-correlation coefficient) with standard measurements of the environment $\left(\mathrm{NO}_{3}\right.$-nitrate $\mu \mathrm{M}, \mathrm{SiO}_{4}$-silicate $\mu \mathrm{M}, \mathrm{PO}_{4}$-phosphate $\mu \mathrm{M}, \mathrm{POC}$-particulate

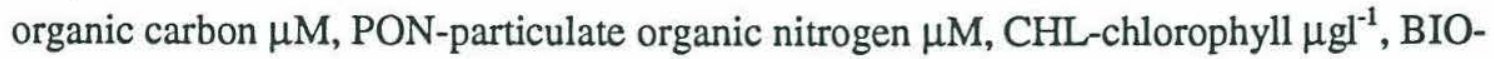
integrated flow-cytometric biomass $\mathrm{pgCml}^{-1}, \mathrm{PP}$-primary production $\mathrm{mgCm}^{-3} \mathrm{day}^{-1}$, 

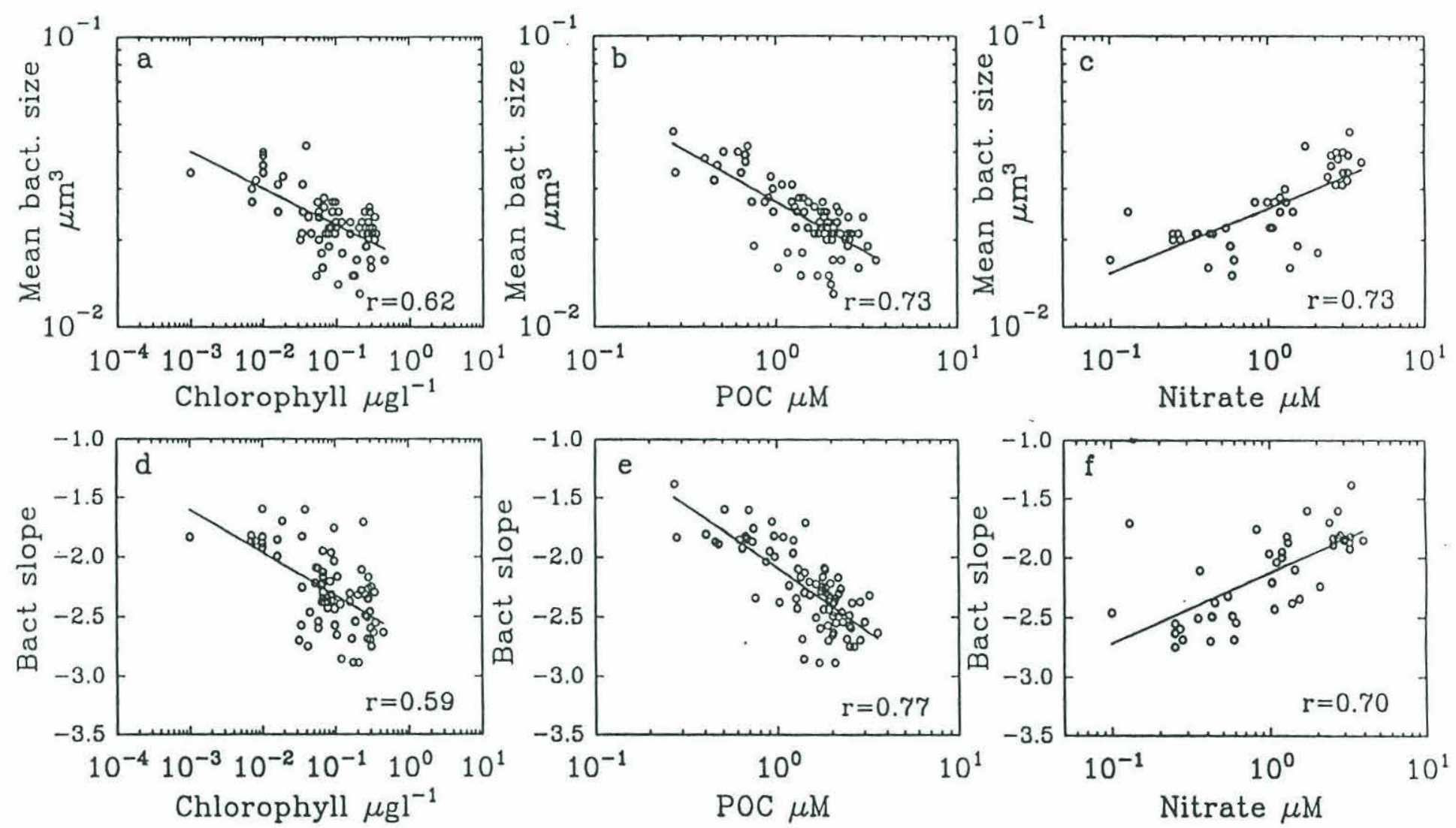

Fig. 3.11. Relationships between mean bacteria size $(a, b, c)$ and bacteria slope $(d, e, f)$ with selected bulk environmental measurements of extracted chlorophyll, particulate organic carbon and nitrate concentration. Data were pooled from all depths in the Sargasso Sea BATS station. 
BEAM-beam attenuation $\mathrm{m}^{-1}$, TEMP-temperature ${ }^{\circ} \mathrm{C}$ ). Data were pooled from all depths $(250 \mathrm{~m})$ and all seasons for the BATS station in the Sargasso Sea.

bacteria slope (of the normalized concentration spectrum) are well correlated with changes in nutrients, particularly with nitrate ( $\mathrm{r} 0.73$ ) and to a smaller extent, silicate ( $\mathrm{r} 0.66)$ and phosphate ( $r \sim 0.62)$. In spite of the extremely low nutrient concentrations, bacteria show a clear increase in mean cell size together with a flattening of the slope for increases in nutrient levels, particularly nitrate. The bacteria intercept also increases somewhat in response to nutrients but the correlation is not as good as for mean bacteria size and slope (eg. $\mathrm{r} \sim 0.56$ for $\mathrm{NO}_{3}$ ). Temperature measurements generally do not correlate as well with bacteria size spectra ( $r \sim 0.3-0.4)$, probably because temperature itself does not vary much in these warm waters. In terms of bulk indicators of biomass, mean bacteria size and bacteria slope also show good inverse correlations with POC and PON ( $r \sim 0.7)$, but slightly less so with chlorophyll ( $r \sim 0.6)$. Total (bacteria plus phytoplankton) biomass was also calculated by integrating the size spectra and gave similar correlation coefficients as POC, PON when regressed against mean bacteria size and slope. These relationships are inverse in that larger values of POC, biomass, etc are generally associated with smaller values of mean bacteria size and steeper slopes ie. a shift in the spectrum to smaller bacteria. Similar inverse correlations are found between beam attenuation and mean bacteria size/ bacteria slope, although the correlation is not as good as with biomass indicators ( $r \sim 0.3$ to 0.4 ). In the case of primary production, however, bacteria size spectral characteristics are poorly correlated with correlation coefficients of the regressions typically less than 0.1 .

For phytoplankton, the intercept proved to be the more sensitive parameter of environmental change compared to the slope and mean cell size (Table 3.2). Ambient nutrient concentrations are generally inversely correlated with the phytoplankton intercept (eg. $\mathrm{r} 0.75$ for $\mathrm{NO}_{3}$ ) ie. higher nutrients are associated with a relative decrease in small cells and an increase in larger phytoplankton, as also indicated by the positive relationships 
with mean phytoplankton size and slope (Fig. 3.12). While inversely correlated with ambient nutrients, the phytoplankton intercept is actually directly correlated with POC, PON, chlorophyll and integrated biomass ( $\mathrm{n} \sim 0.7$ to 0.9 ). This coupled with a decrease in mean phytoplankton size indicates the growing importance of small cells as organic mass increases in these oligotrophic waters. Similarly, beam attenuation shows a better correlation with the phytoplankton intercept $(\mathrm{r} \sim 0.5)$, although the correlation coefficient is not as good as for biomass indicators. In contrast, primary production rates show poor correlation with phytoplankton size spectral characteristics for these waters $(r<0.3)$.

\begin{tabular}{llllllllll}
\hline & \multicolumn{3}{l}{ Mean Phyto Size } & \multicolumn{3}{l}{ Phyto Slope } & \multicolumn{3}{c}{ Phyto Intercept } \\
& $\mathrm{Y}$ & $\mathrm{S}$ & $\mathrm{r}$ & $\mathrm{Y}$ & $\mathrm{S}$ & $\mathrm{r}$ & $\mathrm{Y}$ & $\mathrm{S}$ & $\mathrm{r}$ \\
\hline $\mathrm{NO}_{3}$ & -0.67 & 0.57 & 0.51 & -1.81 & 0.18 & 0.43 & 2.85 & -1.85 & 0.75 \\
$\mathrm{SiO}_{4}$ & 0.71 & 1.65 & 0.46 & -1.74 & 0.48 & 0.38 & 2.66 & -4.86 & 0.65 \\
$\mathrm{PO}_{4}$ & 2.29 & 1.37 & 0.52 & -1.41 & 0.29 & 0.37 & -0.57 & -2.60 & 0.54 \\
$\mathrm{POC}$ & 0.69 & -0.84 & 0.50 & -1.76 & -0.17 & 0.28 & 2.70 & 2.57 & 0.74 \\
$\mathrm{PON}$ & 0.02 & -0.85 & 0.47 & -1.81 & 0.18 & 0.41 & 4.87 & 2.82 & 0.75 \\
$\mathrm{CHL}$ & 0.11 & -0.35 & 0.55 & -1.94 & -0.12 & 0.48 & 4.51 & 1.19 & 0.88 \\
$\mathrm{BIO}$ & 2.47 & -0.46 & 0.52 & -1.38 & -0.09 & 0.31 & -3.49 & 1.56 & 0.87 \\
$\mathrm{PP}$ & 0.41 & 0.09 & 0.19 & -1.81 & 0.05 & 0.27 & 3.52 & -0.06 & 0.11 \\
$\mathrm{BEAM}$ & 0.62 & 0.10 & 0.01 & -1.54 & 0.73 & 0.18 & 6.90 & 20.7 & 0.47 \\
TEMP & 5.18 & -3.53 & 0.36 & -2.15 & 0.28 & 0.08 & -6.16 & 7.08 & 0.35 \\
\hline
\end{tabular}

Table 3.2. Linear regression coefficients for characteristics of phytoplankton size spectra (Y-intercept, S-slope, r-correlation coefficient) with standard measurements of the environment $\left(\mathrm{NO}_{3}\right.$-nitrate $\mu \mathrm{M}, \mathrm{SiO}_{4}$-silicate $\mu \mathrm{M}, \mathrm{PO}_{4}$-phosphate $\mu \mathrm{M}, \mathrm{POC}$-particulate organic carbon $\mu \mathrm{M}$, PON-particulate organic nitrogen $\mu \mathrm{M}, \mathrm{CHL}$-chlorophyll $\mu \mathrm{gl}^{-1}$, BIOintegrated flow-cytometric biomass $\mathrm{pgCml}^{-1}$, $\mathrm{PP}$-primary production $\mathrm{mgCm}^{-3} \mathrm{day}^{-1}$, BEAM-beam attenuation $\mathrm{m}^{-1}$, TEMP-temperature ${ }^{\circ} \mathrm{C}$ ). Data were pooled from all depths $(250 \mathrm{~m})$ and all seasons for the BATS station in the Sargasso Sea. 

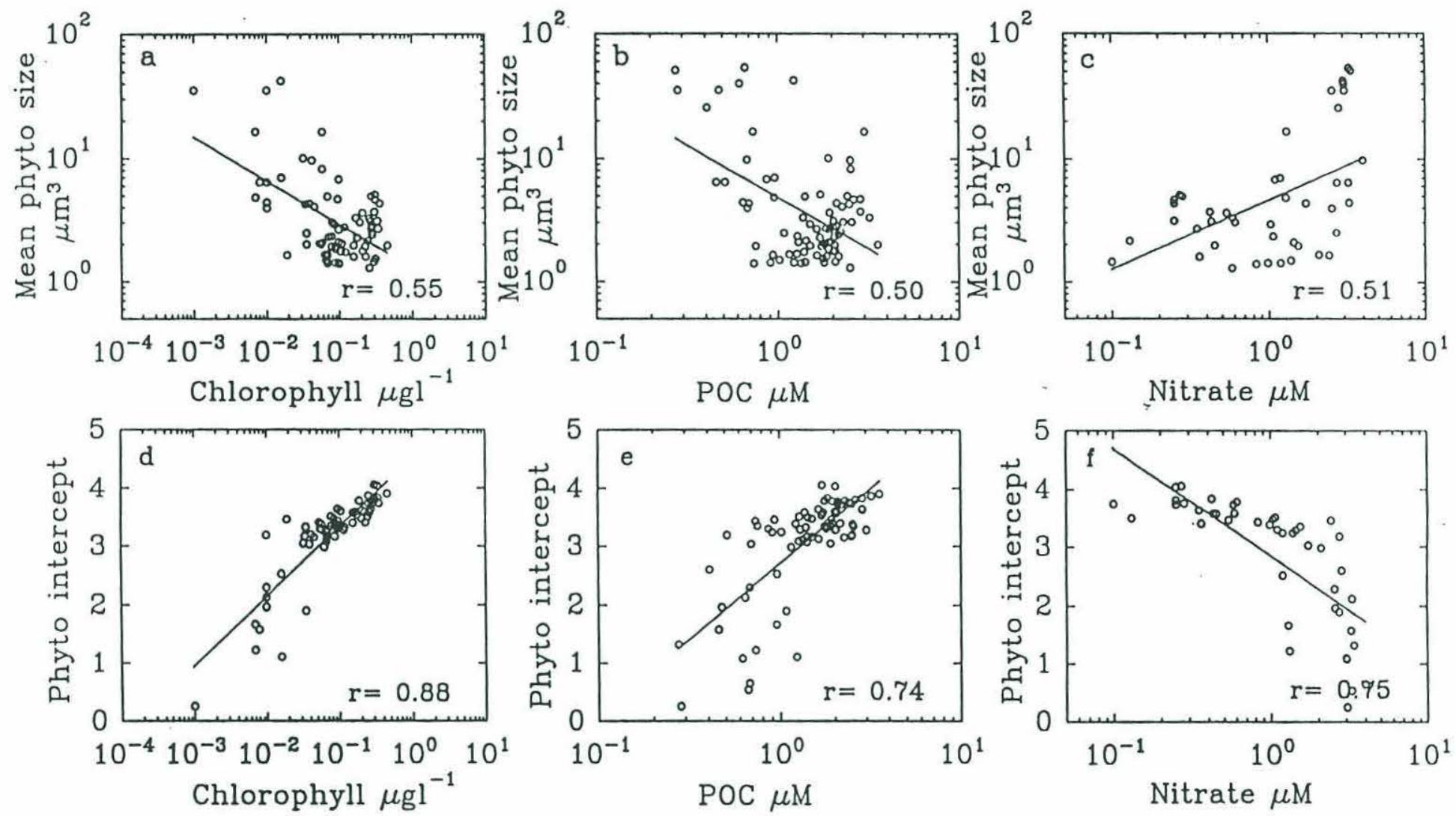

Fig. 3.12. Relationships between mean phytoplankton size (a, b, c) and phytoplankton intercept (d, e, f) with selected bulk environmental measurements of extracted chlorophyll, particulate organic carbon and nitrate concentration. Data were pooled from all depths in the Sargasso Sea BATS station. 


\section{DISCUSSION}

\section{Relationships Between Flow-Cytometric Measurements and Standard}

\section{Environmental Measurements}

Flow cytometric analysis is based on single cell measurements but an estimate of bulk community values can also be derived from an integration of individual cell properties (Yentsch and Campbell, 1991). Thus, the amount of living matter in the euphotic zone can be represented by integrated values of biomass or concentration from size spectra. The corresponding environmental measurements of bulk organic mass are extracted chlorophyll, POC and PON. In our study, we found chlorophyll to be well correlated to integrated biomass: $\log \mathrm{Chl}=-4.70+0.85 \log B, r=0.72$ (Fig. 3.13). The relationship between POC and integrated biomass was even more significant $(\log \mathrm{POC}=2.44+$ $0.427 \log B$ ), with a correlation coefficient, $r=0.86$.

Actual values of integrated biomass, however, were generally greater than measurements of POC in the upper layers of the euphotic zone above the chlorophyll maximum (Fig. 3.13). This can be attributed to the choice of biomass conversion factors taken from the literature. In particular, the range of size-biomass conversion factors for nano and microplankton varies considerably (80-220 $\left.\mathrm{fgC}_{\mathrm{gm}} \mathrm{m}^{-3}\right)$, leading to changes in total biomass which can be as high as a factor of 2.7 (Caron et. al., 1994). (For picoplankton, the range of conversion factors is less and gave integrated biomass values that were close to previous reported biomass figures for the Sargasso Sea eg. compared with Caron et. al., 1994) To get an idea of how these different biomass conversion factors could affect the biomass size spectra, we recomputed the integrated biomass using the above conversion factors for nanoplankton. When the lower conversion factor of $80 \mathrm{fgC}_{\mathrm{gm}}^{-3}$ was used, the majority of data points fell below the $y=x$ line, whereas the higher factor of $220 \mathrm{fgC} \mathrm{m}^{-3}$ resulted in most of the data falling above the line, especially at high POC levels. Our choice of Verity et. al.'s (1992) equation for nanoplankton $\left(C=0.433 \mathrm{~V}^{0.863}\right)$ gave biomass estimates that were closer to the higher factors $\left(220 \mathrm{fgC}_{\mathrm{gm}}{ }^{-3}\right)$ used by Caron et. al. 

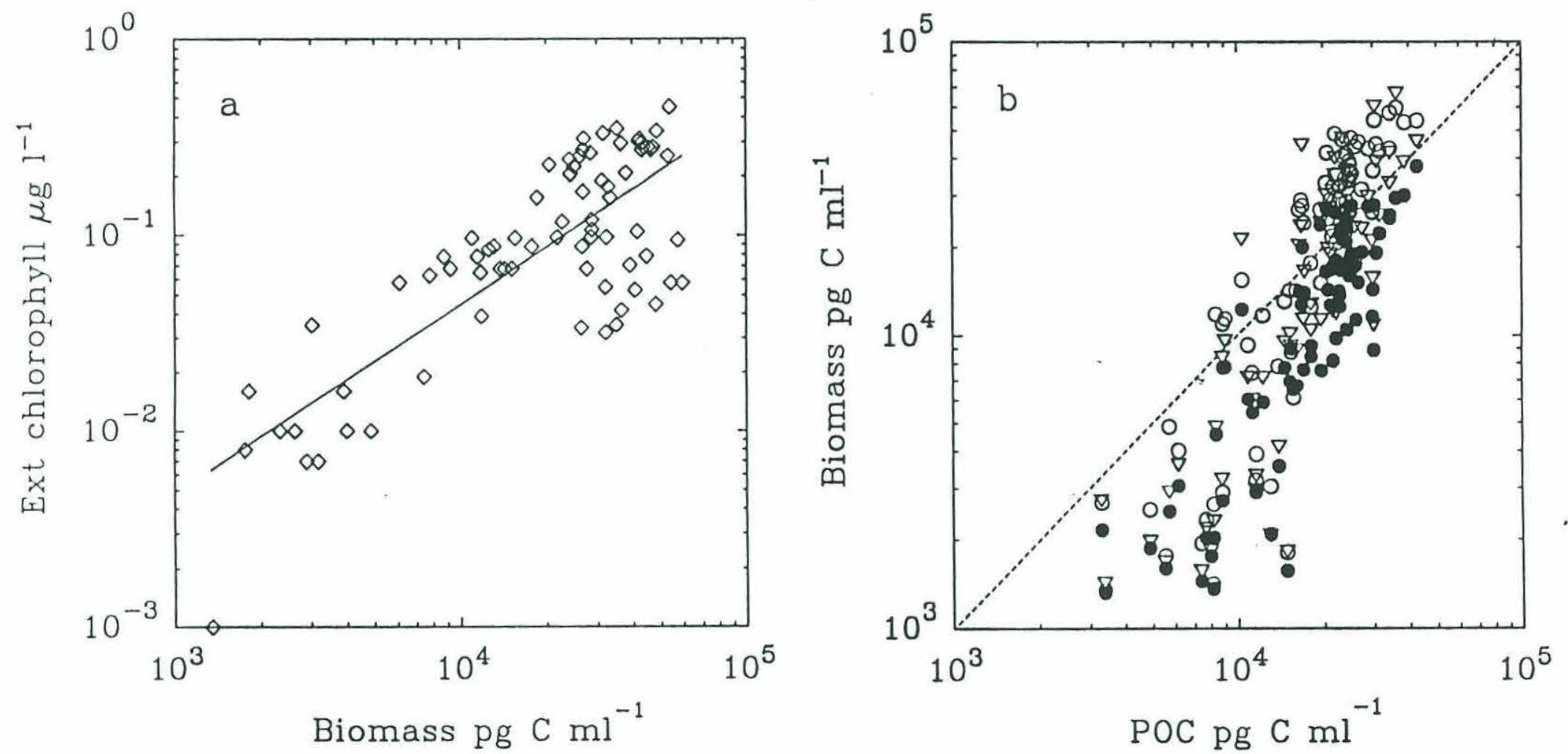

Fig. 3.13. Relationships between extracted chlorophyll and integrated (flow cytometric) biomass (a) and between integrated biomass and particulate organic carbon, POC (b). In (b), integrated biomass was calculated using the low biomass-size conversion factor of 80 $\mathrm{fgC} \mu \mathrm{m}^{-3}$ for nano/microplankton (closed circles), the high factor of $220 \mathrm{fgC} \mu \mathrm{m}^{-3}$ (open triangles) and that from Verity et. al. (1992) (open circles) which was the one actually used in this study. 
(1994). Such biomass estimates were often higher than actual POC measurements, especially in the upper layers of the euphotic zone where POC levels were higher. In terms of the effects on the normalized biomass size spectrum of phytoplankton, the differences between using the high and low conversion factors resulted in differences in the intercept and slope that were generally within $8 \%$ of the values obtained using Verity et. al.'s (1992) equation (Fig. 3.14). Although this percentage appears to be fairly small, the absolute biomass levels when integrated can be substantially different for the higher conversion factors to cause a problem with measured POC values. On the other hand, it could also be argued that POC measurements were underestimated because they excluded the majority of bacteria and to some extent, the small picophytoplankton, Prochlorococcus, since plankton was collected on GF/F filters with a nominal pore size of $0.7 \mu \mathrm{m}$. Such loss of carbon in POC measurements has been estimated at between 10 to $20 \%$ of POC values (Campbell et. al, 1994, Li et. al., 1992, Altabet, 1990), which would still be insufficient to account for the flow cytometric biomass exceeding POC measurements. At any rate, the good correlation between integrated biomass and $\mathrm{POC}$ as well as chlorophyll implies that trends in the size spectrum can still be roughly correlated to $\mathrm{POC}$ and chlorophyll through changes in integrated biomass obtained by flow cytometry.

Using the integrated biomass values, it was found that picoplankton $(<2 \mu \mathrm{m}$ diameter) generally constituted between about $30 \%$ (range between 12 to $66 \%$ ) of the total biomass in the upper $160 \mathrm{~m}$ of the water column, with higher proportions at lower depths (up to 95\%). For the upper euphotic zone, approximately half of this fraction was comprised of bacteria and the other half by photosynthetic organisms. Although the contributions of heterotrophic and phototrophic biomass to picoplankton biomass are comparable to other studies in the Sargasso Sea (Li et. al., 1992) and the Pacific oceans (Campbell et. al., 1994, Binder et. al., 1996), the relative proportion of bacteria to the entire microbial biomass from our study is less than previous measurements. Earlier studies using microscopy estimated more than $65 \%$ of the microbial carbon to be due to 


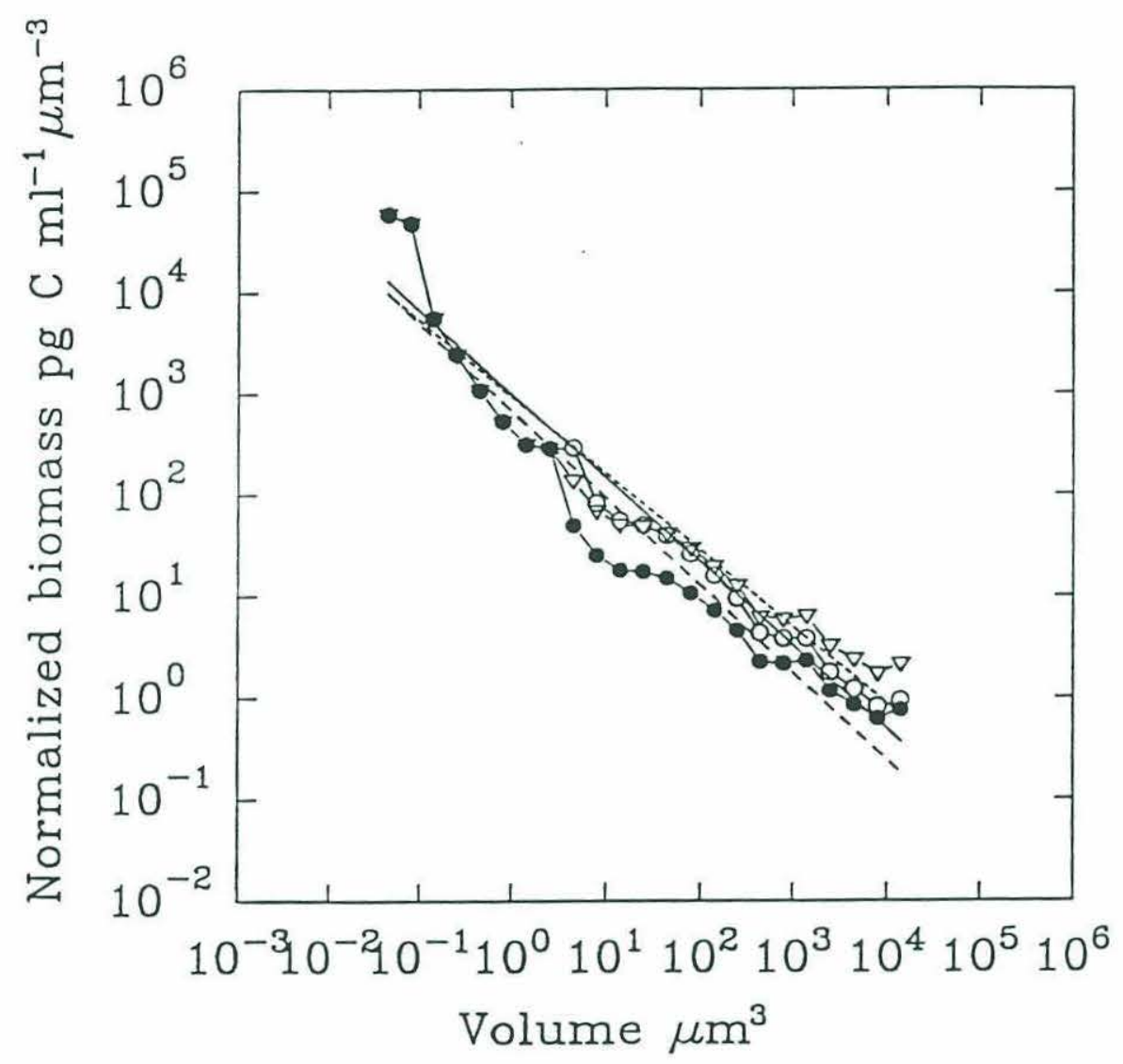

Fig. 3.14. Comparison of normalized biomass size spectra using different biomass-size conversion factors for the nano/microplankton range. Actual conversion factors used in this study resulted in a size spectrum (open circles, solid line) that was closer to that using the higher conversion factor of $220 \mathrm{fgC} \mu \mathrm{m}^{-3}$ (open diamonds, small dashed line) rather than the smaller factor of $80 \mathrm{fgC} \mathrm{mm}^{-3}$ (closed circles, long dashed line) from Caron et. al. (1994). Size spectra were taken from surface waters in September, 1992. 
bacteria alone in the oligotrophic Sargasso Sea (Fuhrman et. al., 1989) and Pacific oceans (Cho and Azam, 1990), with more recent estimates placing this fraction at about 30\% (Caron et. al., 1994). While our measurements of nanoplankton biomass may be high because of the chosen biomass conversion values, it is very possible that measurements of bacteria with epifluorescence microscopy probably included the photosynthetic prokaryotes, Prochlorococcus and therefore overestimated the bacterial contribution. This is because the red fluorescence of these small phytoplankton cells is quite low, making them difficult to discriminate from heterotrophic bacteria using microscopy (Cambell et. al., 1994). In fact, our flow cytometric estimates of picoplankton (ie. bacteria plus picophytoplankton) compare more favourably with the microscopy estimates of bacteria plus cyanobacteria by Caron et. al. (1994) (between 40 to $50 \%$ of the microbial biomass). Although Caron et. al. (1994) report the abundance of Prochlorophyte-like cells of between 1-3 $\mu \mathrm{m}$ in their measurements of phototrophic nanophytoplankton, it seems more likely that these cells were eukaryotic picophytoplankton, since earlier measurements of Prochlorococcus size have been estimated at around $0.7 \mu \mathrm{m}$ diameter (Chisholm et. al., 1988). If roughly $40 \%$ of their bacteria biomass measurements were comprised of photosynthetic Prochlorococcus (Binder et. al., 1996), this would give estimates of bacteria that are between $10-20 \%$, which is closer to our flow cytometric measurements. Based on these estimates as well as our measurements, the fraction of bacteria biomass in the oligotrophic Sargasso Sea is considerably less significant than thought previously, with the bulk of the microbial biomass coming from nanophytoplankton between 2 and $20 \mu \mathrm{m}$ (about $50 \% \pm 10 \%$ ).

In addition to POC and chlorophyll measurements, independent bacteria counts using a microscope were also made for samples collected in July and September (Knap et. al., 1994). While the basic profiles of bacteria abundance were similar for both our flow cytometric and microscope studies, the values obtained in the latter were generally higher by about $50 \%$. When the microscope counts were linearly regressed against our flow cytometric counts, the relation was significant ( $r=0.98$ ), with the data offset above the $y=x$ 
line (Fig. 3.15). The higher microscopy counts could be due to the inclusion of Prochlorococcus, since these organisms have low red fluorescence and are hard to detect with epifluorescence microscopy. At the same time, the different DNA stains used in the two techiques could have led to different estimates of bacteria abundance (Suzuki et. al., 1993, Binder et. al., 1996). This discrepancy between flow cytometric and microscopy bacteria cell counts could also account for some of the difference between the bacterial biomass estimates described above.

\section{Overall Characteristics of Size Spectra from the Sargasso Sea}

The contribution of various size fractions to the total microbial community can be expressed in greater resolution through the size spectrum compared to filter fractionation. For the nutrient poor waters of the Sargasso Sea where mean bacteria size was approximately $0.02 \mu \mathrm{m}^{3}(0.34 \mu \mathrm{m}$ diameter $)$ and mean phytoplankton size was typically

less than $5 \mu \mathrm{m}^{3}(2.1 \mu \mathrm{m})$, the size spectra were characterized by relatively steep slopes compared to coastal waters (Gin and Chisholm, 1996). The slope of the normalized concentration size spectrum for phytoplankton ranged from -1.6 to -2.2 , with an average of about -1.8 . For bacteria, the slope ranged from -1.7 to -2.7 , with an average of -2.24 . When combined together, the total slope for the microbial community ranged from -1.7 to -2.2 , averaging -1.9 . These values obtained from flow cytometry are comparable to previous measurements of size spectra. The earliest size spectra were from the Atlantic and Pacific oceans, measured with a Coulter counter and covering the size range from 1 to $100 \mu \mathrm{m}$ (Sheldon et. al., 1972). The study found that extensive regions in the world's oceans were characterized by flat biomass size spectra or normalized biomass size spectra with slopes of -1.0. Alternatively, the flat biomass spectrum can be re-expressed in terms of the normalized concentration size spectrum, with an equivalent slope of about -2 ie. slope of normalized concentration spectrum $\approx$ slope of normalized biomass spectrum minus one (Gin and Chisholm, 1996). In later studies using microscopy, size spectra from the North Pacific Ocean, ranging from nanoplankton to macrozooplankton, were found to 


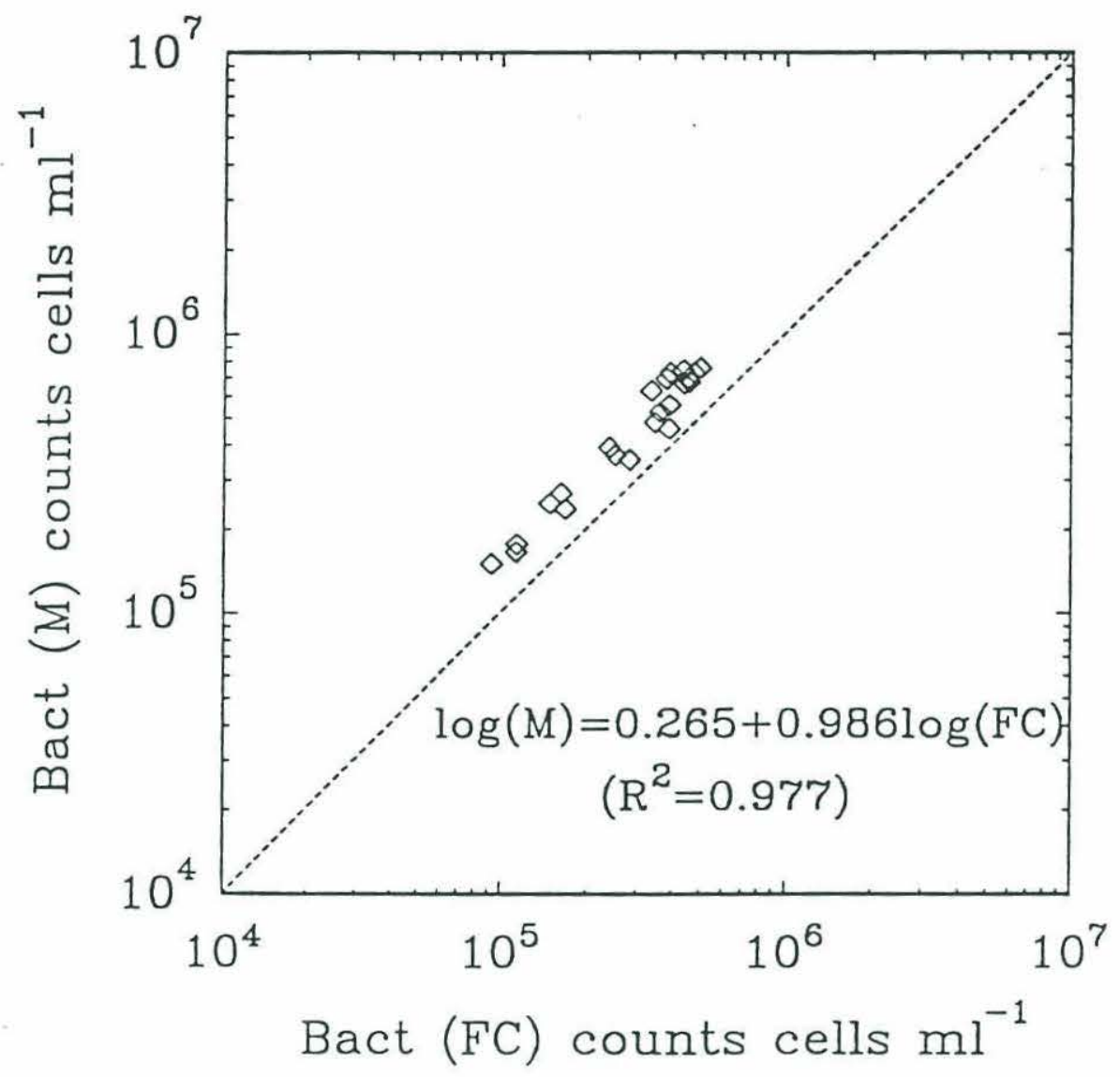

Fig. 3.15. Relationship between bacteria counts by epifluorescence microscopy (M) and flow cytometry (FC). The dashed line shows where counts from both techniques are equal. 
have equivalent slopes of the normalized concentration size spectrum ranging from -2 to 2.2 (Beers et. al., 1982, Rodriguez and Mullin, 1986). While these studies went beyond the largest size considered in our study, their spectra did not contain information on the picoplankton fraction, whose importance had formerly been underestimated.

Nevertheless, in spite of the different size ranges considered, their slope values were still comparable to the total slope values from our study. A more recent study of an oligotrophic high mountain lake measured the spectrum of organisms from picoplankton to mesoplankton (Rodriguez et. al., 1990). We recomputed the average slope for their pico and nanoplankton range so that it would be comparable to the size range considered in our study, and found the resultant slope to be similar (ie. -1.9). In addition, the authors measured the size distributions of component subgroups by size viz. pico, nano and micromesoplankton. Individually, these subgroups formed less steep slopes than the overall spectrum of organisms, with average slopes of -1.56 and -1.64 for the pico and nanoplankton respectively. (Note that these would translate into biomass size spectra that would have positive slopes.) These values for the individual subgroups were numerically higher than the values obtained for the bacteria and phytoplankton subgroups measured in our study, and could be partly due to the absence of heterotrophic nanoplankton in our measurements.

The slope value of -2 for the entire normalized concentration size spectrum has been explained by steady state theoretical models of size spectra for plankton. While earlier models were able to explain the slope value through a balance of anabolic and catabolic rates based on allometric rules (Platt and Denman, 1977, 1978), later models consisting of grazing mechanisms were equally successful (Silvert and Platt, 1980, Kiefer and Berwald, 1991, Armstrong, 1994). Our experimental value of -1.9 for the Sargasso Sea system is close to the -2 of the model results, considering our size range is somewhat restricted and did not include heterotrophic nano/microplankton. Recent studies have shown that the deviation of slope of subgroups (defined as groups of organisms with constant production efficiencies eg. phytoplankton, fish) from the overall spectrum slope is 
an indication of the extent of perturbation to the ecosystem (Gaedke, 1992, Rodriguez et. al., 1990). Since the slope from our restricted size range is close to the -2 value for the overall size spectrum ranging from phytoplankton to fish (Sheldon et. al., 1972), this suggests that the Sargasso Sea system is probably close to steady state and is not subject to significant environmental perturbations.

In the case of phytoplankton alone, our size spectra from the Sargasso Sea gave an average value that was comparable to the -1.8 found in nutrient limited waters of coastal Massachusetts and Cape Cod Bays in summer, compared to spring values at the coastal locations of about -1.4 (Gin and Chisholm, 1996). The phytoplankton slope value of about -1.8 was also obtained in a laboratory study measuring the maximum concentration achieved by phytoplankton cells at stationary phase in culture (Agusti and Kalff, 1989). The authors rejected the hypothesis that self shading was responsible for the existence of the size-dependent maximum concentration because of the similarity between the relationships obtained for light saturated and light limited cultures. Instead, the effect of cell size on metabolic processes were considered to be responsible. Although nutrients were not measured in their study, it is likely that phytoplankton were experiencing nutrient limitation under stationary phase conditions. We hypothesize that this value of the phytoplankton slope is attained under stressed, nutrient limited conditions and represents a lower bound for phytoplankton size spectra. Our phytoplankton size spectra measurements from the oligotrophic, nutrient poor waters of the Sargasso Sea are thus consistent with this hypothesis.

\section{The Response of Microbial Size Spectra to Environmental Perturbations}

Under nutrient stressed conditions, smaller cells have been argued to outcompete larger cells on the basis of their larger surface area to volume ratio (Smetachek, 1985), as well as their better nutrient uptake kinetics under diffusion limitation (Chisholm, 1992, Kiфrboe, 1993). In the Sargasso Sea, even fall and winter mixing do not appear to alleviate the nutrient poor situation very much since nitrate levels in the upper euphotic 
zone typically remain below $0.5 \mu \mathrm{M}$. Although fluctuations in the environment are small compared with temperate coastal environments, fairly good correlations were found between characteristics of size spectra and selected environmental measurements. Nutrients $\left(\mathrm{NO}_{3}\right.$, followed by $\mathrm{SiO}_{3}$ and then $\left.\mathrm{PO}_{4}\right)$ were particularly well correlated in a positive sense with mean bacteria size, bacteria slope and phytoplankton intercept of the normalized concentration size spectrum $(\mathrm{r} \sim 0.7)$. The same size spectral parameters were also well correlated, although in an inverse sense with POC, PON, integrated flow cytometric biomass and to a smaller extent, chlorophyll. Bacteria intercept, mean phytoplankton size and phytoplankton slope were also correlated with nutrient concentrations and biomass indicators, but to a lesser degree ( $\mathrm{r} \sim 0.5)$. These changes in size spectra indicated the growing importance of larger cells with enrichment, although such cells were generally in the larger picoplankton or small nanoplankton range because nutrient concentrations in the Sargasso Sea were so low. The inverse relationships between cell size and biomass indicators could be traced to depth changes rather than seasonal changes since most of the biomass production occured in the upper euphotic zone where nutrients were scarce and vice versa for lower depths. In the case of primary production rates neither bacteria nor phytoplankton size spectral characteristics showed a good correlation. Since primary productivity is the product of biomass and the specific growth rate, the lack of a correlation between primary productivity and size spectra must be due to the counteracting influence of changes in specific growth rates relative to biomass changes with size.

From this study, temperature did not seem to play a major role in determining the characteristics of either bacteria or phytoplankton size spectra ( $\mathrm{r} 0.3)$. Although temperature has been known to influence bacteria growth rates (Shiah and Ducklow, 1994) and phytoplankton growth rates directly through increases in uptake rates and halfsaturation constants (Goldman and Carpenter, 1974), the effects of temperature on cell size are less predictable: some studies showed that increases in temperature resulted in smaller bacteria size (Chrzanowski et. al., 1988), whilst others found no dependence at all 
(Cole et. al., 1993). The small range in temperature encountered in our study (18 to $26^{\circ} \mathrm{C}$ ) compared to that from temperate coastal waters (eg. 1 to $20^{\circ} \mathrm{C}$ ) was probably one reason why we did not observe much of a temperature dependence of size spectra. However, we did observe a rough inverse relationship on seasonal scales between temperature and mean phytoplankton size in surface waters and at the chlorophyll maximum. This is probably due to an indirect effect of temperature on cell size through influencing the structure of the water column and hence, the nutrient and light regime experienced by cells. For example, an increase in mean phytoplankton size was observed during cold spring temperatures when the mixed layer was deep and nutrient concentrations were slightly higher.

At the scale of depth changes, the influence of light must also be taken into account in addition to nutrients. In the Sargasso Sea, light is generally not limiting because of low particulate levels in the water column eg. POC is $\sim 3 \mu \mathrm{M}$ compared to $20 \mu \mathrm{M}$ for oceanic (Knap et. al., 1994) and coastal (Kelly et. al., 1994) waters respectively. In stratified waters, the smallest cells were generally present in the vicinity of the chlorophyll maximum (ie. low mean size and slope but high intercept values) even though nutrients were slightly higher than surface waters. At depths lower than the chlorophyll maximum, cell sizes of both bacteria and phytoplankton increased with depth in association with even higher nutrient levels but diminishing light conditions. These changes in size spectra were also observed in stratified waters of Massachusetts and Cape Cod Bays, and may be attributed to the coupled effects of diminishing light and increasing nutrients with depth on phytoplankton.

\section{CONCLUSIONS}

The relative greater proportion of small cells in the microbial community is a characteristic feature of oligotrophic environments. In this study, we have examined how size spectra of bacteria and phytoplankton vary with environmental changes according to depth and season. Correlations between characteristics of size spectra and environmental measurements showed that mean bacteria size, bacteria slope and phytoplankton intercept 
were the more sensitive indicators of environmental change in these waters. Nutrients, particularly nitrate, were well-correlated with these parameters in a positive sense $(r>0.7)$ whilst bulk indicators of biomass, such as POC, PON and chlorophyll were generally inversely correlated. These changes in size spectra with environmental measurements indicated the growing importance of larger cells with enrichment (eg. below the nutricline), although such cells were generally in the larger picoplankton or small nanoplankton range because nutrient concentrations in the Sargasso Sea were generally low. While nutrients play a significant role in governing microbial cell size for these waters, grazing processes are also of considerable importance :- Size-dependent grazing models, such as the random encounter model by Kiefer and Berwald (1991) adequately predict the slope of the size spectrum observed in open ocean waters. At the same time, nutrient regeneration through microbial processes would be beneficial in sustaining primary production in these oligotrophic waters (Fuhrman et. al., 1989, Kiфrboe, 1993). For example, while the small but stable size structure of bacteria could be a consequence of low nutrients (both organic and inrganic), it could also be the result of preferential grazing on larger bacteria to fuel the microbial loop. This is supported by laboratory studies which demonstrate the greater susceptibility of large bacteria to predation by heterotrophic nanoflagellates (Gin, 1996, Gonzalez et. al., 1990, Simek and Chzanowski, 1992). The lower C:N ratio of bacteria of about 4 (Wheeler and Kirchman, 1986, Caron, 1991) compared to 7 for picophytoplankton (Goldman et. al., 1979) of similar size range may also result in more efficient processing of scarce nutrients for these oligotrophic waters. Thus, both bottom-up and top-down processes are likely to be important factors in determining the characteristics of microbial size spectra in the oligotrophic Sargasso Sea.

\section{ACKNOWLEDGEMENTS}

We would like to thank Erik Zettler and Nicole Poulton for analyzing the nano/microplankton and picoplankton on the flow cytometers; Laurel Schaider for her 
help in data processing; Sheila Frankel, Brian Binder, Carol Duval and Kent Bares for development of analytical protocols for the flow cytometers; and Michelle DuRand and Lana Aref for helping to calibrate the instruments for size. The work was supported by National Science Foundation Ocean Division (USJGOFS) OCE-9022285, OCE-9302529, OCE-9012117, NOAA-Sea Grant (MIT) and fellowhip funding from the National University of Singapore Overseas Scholarship.

\section{REFERENCES (chapter 3)}

Agusti., S. and Kalff, J. 1989. The influence of growth conditions on the size dependence of maximal algal density and biomass. Limnol. Oceanogr. 34 (6): 1104-1108.

Altabet, M.A., 1990. Organic C, $\mathrm{N}$ and stable isotopic composition of particulate matter collected on glass-fibre and aluminium oxide filters. Limnol. Oceanogr. 35: 902-909.

Aref, L., 1996. Forward light scatter and how it relates to phytoplankton size in flow cytometry. MSc thesis, MIT.

Armstrong, R.A., 1994. Grazing limitation and nutrient limitation in marine ecosystems: Steady state solutions of an ecosystem model with multiple food chains. Limnol. Oceanogr. 39(3): 597-608.

Azam, F., Fenchel, T., Field, J.G., Gray, J.S., meyer-Reil, L.A. and Thingstad, F., 1983. The ecological role of microbes in the sea. Mar. Ecol. Prog. Ser. 10: 257-263.

Beers, J.R., Reid, F.M.H. and Stewart, G.L., 1982. Seasonal abundance of the microplankton population in the North Pacific central gyre. Deep Sea Res. 29: 217-245.

Binder, B., Chisholm, S.W., Olson, R.J., Frankel, S.L. and Worden, A.Z., 1996. Dynamics of pico-phytoplankton, ultra-phytoplankton and bacteria in the central equatorial Pacific. Deep Sea Res. (in press).

Campbell, L., Nolla, H.A. and Vaulot, D., 1994. The importance of Prochlorococcus to community structure in the central North Pacific Ocean. Limnol. Oceanogr. 39(4): 954961.

Caron, D., 1991. Evolving role of protozoa in aquatic nutrient cycles. In Reid P.C. et. al. (eds) Protozoa and their role in marine processes. (NATO-ASI Series, G25) SpringerVerlag, Heidelberg. 
Caron, D.A., Dam, H.G., Napp, J.M., Kremer, P., Lessard, E.J., Madin, L.P., Malone, T.C., Peele, E.R., Roman, M.R. and Youngbluth, M.J., 1995. The contribution of microorganisms to particulate carbon and nitrogen in surface waters of the Sargasso Sea near Bermuda. Deep Sea Res. Vol.42(6): 943-972.

Chisholm, S.W., Olson, R.J., Zettler, E.R, Goericke, R., Waterbury, J. and Welschmeyer, N., 1988. A novel free-living prochlorophyte abundant in the oceanic euphotic zone. Nature 334: 340-343.

Chisholm, S.W., 1992. Phytoplankton size. in P. Falkowski (ed.) Primary production and biogeochemical cycles in the sea, Brookhaven Syposium on Biology, 37.

Cho, B.C., Azam, F., 1988. Major role of bacteria in biogeochemical fluxes in the ocean's interior. Nature, Lond. 332: 441-443.

Cho, B.C., Azam, F., 1990. Biogeochemical significance of bacterial biomass in the ocean's euphotic zone. Mar. Ecol. Prog. Ser. 63: 253-259.

Chrzanowski, T.H., Crotty, R.D. and Hubbard, G.J., 1988. Seasonal variation in cell volume of epilimnetic bacteria. Microb. Ecol: 16: 155-163.

Chrzanowski, T.H., and Simek, K., 1992. Prey-size selection by freshwater flagellated protozoa. Limnol. Oceanogr. 35: 1429-1436.

Cole, J.J., Pace, M.L., Caraco, N.F. and Steinhart, G.S., 1993. Bacterial biomass and cell size distribution in lakes: More and larger cells in anoxic waters. Limnol. Oceanogr. 38(8): 1627-1632.

DuRand, M.D., 1995. Phytoplankton growth and diel variations in beam attenuation through individual cell analysis. Ph.D. Thesis. MIT/WHOI: 263pp.

Duval, C., 1993. Phototrophic and Heterotrophic Picoplankton in the Equatorial Pacific: Analysis by Flow Cytometry. MSc thesis. Massachusetts Institute of Technology.

Eppley, R.W. and Peterson, B.J., 1979. Particulate organic matter flux and particulate new production in the deep ocean. Nature, Lond. 282: 677-680.

Fuhrman, J.A., Sleeter, T.D., Carlson, C.A. and Proctor, L.A., 1989. Dominance of bacterial biomass in the Sargasso Sea and its ecological implications. Mar. Ecol. Prog. Ser. 57: 207-217. 
Gaedke, U., 1992. The size distribution of plankton biomass in a large lake and its seasonal variability. Limnol. Oceanogr. 37(6): 1202-1220.

Gin, K.Y.H., 1996. Microbial size spectra in diverse marine ecosystems. Sc.D. Thesis. MIT/WHOI (in press).

Gin, K.Y.H. and Chisholm, S.W., 1996. Temporal \& spatial variability of marine microbial size spectra: I. Massachusetts and Cape Cod Bays. (in prep)

Goldman, J.C. and Carpenter, E.J., 1974. A kinetic approach to the effect of temperature on algal growth. Limnol. Oceanogr. 19: 756-766.

Goldman, J.C., McCarthy, J.J. and Peavey, D.G., 1979. Growth rate influence on the chemical composition of phytoplankton in oceanic waters. Nature 279:210-215.

Gordon, H.R., Smith, R.C. and Zaneveld, J.R.V., 1984. Introduction to ocean optics. SPIE: Ocean Optics VII 489:2-41.

Hopcroft, R.R. and Roff, J.C., 1990. Phytoplankton size fractions in a tropical neritic ecosystem near Kingston, Jamaica. J. Plank. Res. 12: 1069-1088.

Hurtt, G.C. and Armstrong, R.A., 1995. A pelagic ecosystem model calibrated with BATS Data. Deep Sea Res. (in press).

Jerlov, N.G., 1976. Marine Optics. Elsevier Scientific Pub. Co., Amsterdam, 231 pp.

Jochem, F.J., Pollehne, F. and Zeitzschel, B., 1993. Productivity regime and phytoplankton size structure in the Arabian Sea. Deep Sea Res. II 40(3): 711-735.

Jurgens, K., Arnddt, H. and Rothhaupt, K.O., 1994. Zooplankton-mediated changes of bacterial community structure. Microb. Ecol. 27:27-42.

Kelly, J., Albro, C., Hennessy, J., Turner, J., Borkman, D. and Doering, P., 1994. Water quality monitoring in Massachusetts and Cape Cod Bays: December 1992, February and March 1993. MWRA Enviro. Quality Dept. Tech. Rpt. Series No. 94-2. Massachusetts Water Resources Authority, Boston, MA: 197.

Kiefer, D.A and Berwald, J., 1991. A random encounter model for the microbial planktonic community. Limnol. Oceanogr. (3): 457-467

Kiфrboe, T. 1993. Turbulence, phytoplankton cell size and the structure of pelagic food webs. Adv. in Mar. Bio. 29:1-72. 
Knapp, A.H., Michaels, A.F., Dow, R.L., Johnson, R.J., Gundersen, K., Sorensen, J.C., Close, A.R., Howse, F.A., Hammer, M., Bates, N., Doyle, A., Waterhouse, T., 1993. BATS Methods Manual, version 3. U.S.JGOFS Planning Office, Woodshole, MA. Knapp, A.H., Michaels, A.F., Dow, R.L., Johnson, R.J., Gundersen, K., Sorensen, J.C., Close, A.R., Hammer, M., Knauer, G.A., Lohrenz, S.E., Asper, V.A., Tuel, M., Ducklow, H., Quinby, H., Brewer, P. and Bidigare, R., 1994. Bermuda Atlantic Time-Series Studies: Data Report for BATS 37-48. U.S.JGOFS BATS Data Report B-4: 240pp.

Knapp, A.H., Michaels, A.F., Dow, R.L., Johnson, R.J., Gundersen, K., Sorensen, J.C., Close, A.R., Hammer, M., Knauer, G.A., Lohrenz, S.E., Asper, V.A., Tuel, M., Ducklow, H., Quinby, H., Brewer, P. and Bidigare, R., 1995. Bermuda Atlantic Time-Series Studies: Data Report for BATS 49-60. U.S.JGOFS BATS Data Report B-5: 240pp.

Lee, S. and Fuhrman, J.A., 1987. Relationship between biovolume and biomass of naturally derived marine bacteria plankton. Appl. Envir. Micro. 53: 1298-1303.

Li, W.K.W., Dickie, P.N., Irwin, B.D. and Wood, A.M., 1992. Biomass of bacteria, cyanobacteria, prochlorophytes and photosynthetic eukaryotes in the Sargasso Sea. Deep Sea Res. 39(3/4): 501-519.

Li, W.K.W., 1994. Phytoplankton biomass and chlorophyll concentration across the North Atlantic. Sci. Mar. 58(1-2): 67-79.

Olson, R.J., Zettler, E.A. and Anderesson, O.K., 1989. Discrimination of eukaryotic phytoplankton cell types from light scatter and autofluorescence properties measured by flow cytometry. Cytometry 10: 636-643.

Olson, R.J., Chisholm, S.W., Zettler, E.R. and Armbrust, E.V., 1990a. Pigments, size and distribution of Synechococcus in the North Atlantic and Pacific Oceans. Limnol.

Oceanogr. 35: 45-58.

Olson, R.J., Chisholm, S.W., Zettler, E.R., Altabet, M.A. and Dusenberry, J.A., 1990b. Spatial and temporal distributions of prochlorophyte picoplankton in the North Atlantic Ocean. Deep Sea Res. 37: 1033.

Platt, T. and Denman, K.L., 1977. Organization in the pelagic ecosystem. Helogol. Wiss. Meeresunters 30: 575-581.

Platt, T. and Denman, K.L., 1978. The structure of pelagic marine ecosystems. Rapp. P.V. Reun. Cons. Int. Explor. Mer 173: 60-65. 
Raimbult, P., Rodier, M. and Taupier-Letage, I., 1988. Size fraction of phytoplankton in the Ligurian Sea and the Algerian Basin (Mediterranean Sea): Size distribution versus total concentration. Mar. Microb. Food Webs 3:1.

Rodriguez, J. and Mullin, M. 1986. Relation between biomass and body weight of plankton in a steady state oceanic ecosystem. Limnol. Oceanogr. 31 (2): 361-370.

Rodriguez, J., Echevarria, F.and Jimenez-Gomez, F. 1990. Physiological and ecological calings of body size in an oligotrophic, high mountain lake (La Caldera, Sierra Nevada, Spain). J. Plankton Res. 12(3): 593-599.

Sheldon, R., Prakash, A. and Sutcliff, W., 1972. The size distribution of particles in the ocean. Limnol. Oceanogr. 17: 327-340.

Shiah, F.K. and Ducklow, H.W., 1994. Temperature and substrate regulation of bacterial abundance, production and specific growth rate in Chesapeake Bay, USA. Mar. Ecol.

Prog. Ser. 103:297-308.

Silvert, W. and Platt, T., 1980. Dynamic energy-flow model of the particle size distribution in pelagic ecosystems. In W. Charles Kerfoot (ed) Evolution and ecology of zooplankton communities. The University Press of New England.

Smetachek, V., 1985. Role of sinking in diatom life-history cycles: ecological, evolutionary and geological significance. Marine Biol. 84: 239-251.

Sprules, W.G. and Munawar, M. 1986. Plankton size spectra in relation to ecosystem productivity, size and perturbation. Can. J. Fish. Aquat. Sci. Vol. 43: 1789-1794.

Strathmann, R.R., 1967. Estimating the organic carbon content of phytoplankon from cell volume or plasma volume. Limnol. Oceanogr. 12: 411-418.

Suzuki, M.T., Sherr, E.B. and Sherr, B.F., 1993. DAPI direct counting underestimates bacterial abundances and average cell-size compared to AO direct counting. Limnol. Oceanogr. 38: 1566-1570.

Vaulot, D., Courties, C. and Partensky, F. 1989. A simple method to preserve oceanic phytoplankton for flow cytometry analysis. Cytometry 10: 629-635.

Verity, P.G., Robertson, C.Y., Tronzo, C.R., Andrews, M.G., Nelson, J.R. and Sieracki, M.E., 1992. Relationships between cell volume and the carbon and nitrogen content of marine photosynthetic nannoplankton. Limnol. Oceanogr. 37(7): 1434-1446. 
Waterbury, J.B., Watson, S.W., Valois, F.W. and Franks, D.G., 1986. Biological and ecological characterizations of the marine unicellular cyanobacterium Synechococcus. In Photosynthetic picoplankton, T. Platt and W.K. Li (eds). Can. Bull. Fish. Aq. Sci. 214: 71-120.

Wheeler, P.A. and Kirchman, D.L., 1986. Utilization of inorganic and organic nitrogen by bacteria in marine systems. Limnol. Oceanogr. 31(5): 998-1009. 
Chapter Four

TEMPORAL AND SPATIAL VARIABILITY IN MARINE MICROBIAL SIZE

SPECTRA: III. COMPARISON OF HIGH AND LOW PRODUCTIVITY

ECOSYSTEMS

\begin{abstract}
Microbial size spectra can serve as synoptic pictures of the food web for modelling aquatic ecosystems, but available data are limited and systematic comparisons of different ocean ecosystems have not been done. Here, we examine the variation of microbial size spectra with changes in ecosystem productivity and trophic state. Flow cytometrically generated size spectra of micro-organisms (ie. phytoplankton and bacteria) were analyzed with respect to the physical, chemical and biological characteristics of diverse marine ecosystems ranging from coastal waters in Massachusetts and Cape Cod Bays to open ocean waters in the Sargasso Sea and the equatorial Pacific. Pooled data from these areas showed that mean bacteria and phytoplankton sizes were positively correlated with typical indicators of trophic state, including primary productivity, chlorophyll-a, particulate organic carbon, biomass, beam attenuation, total nitrogen and silicate. The size spectrum was also analyzed in terms of the normalized concentration size spectrum (ie. normalized to size class) which was characterized by the intercept and slope of the linear regression to the log-transformed data. The bacteria intercept and phytoplankton slope were found to be particularly good correlates of indicators of ecosystem trophic state. More eutrophic waters were generally characterized by high values of bacteria intercept $\left(4.4\right.$ cells ml ${ }^{-1} \mu \mathrm{m}^{-}$ ${ }^{3}$ ) and less steep phytoplankton slopes (-1.3), reflecting the relative importance of large bacteria and large phytoplankton cells. In contrast, the lowest values of bacteria intercept ( 2 cells $\mathrm{ml}^{-1} \mu \mathrm{m}^{-3}$ ) and the steepest phytoplankton slopes (-1.8) were generally observed in oligotrophic oceanic waters as well as stratified, nutrient-stressed environments in coastal waters where small cells predominated. We hypothesize that the less steep phytoplankton slopes of productive waters represent an upper bound to the size spectrum when nutrient replete conditions exist and for which light may be the limiting factor. Conversely, the steep phytoplankton slopes of unproductive waters represent a lower bound constrained by nutrients and/or grazing. These size spectral characteristics of bacteria and phytoplankton can be extrapolated to the rest of the food chain to provide insight into the function and organization of the pelagic ecoystem.
\end{abstract}




\section{BACKGROUND}

Most methods of analyzing the trophic state of an aquatic ecosystem consist of bulk measurements of extracted chlorophyll-a, particulate and nutrient levels. While these methods are useful, they do not provide much insight into the detailed mechanisms or structure of the ecosystem. An alternative to studying bulk parameters is to look at the size spectrum of the biological community. The importance of size in ecological studies has long been recognised. Empirical size-based relationships of metabolic processes, such as respiration and growth rates, have been demonstrated from species to community level (Ahrens and Peters, 1991a). In the marine pelagial, size is also coupled to food web dynamics since larger organisms generally eat smaller organisms (Sheldon et. al., 1977). The use of size to describe trophodynamics becomes more relevant where microorganisms are concerned. In these situations, trophic levels become less distinguishable and specieslevel taxonomy becomes increasingly diffficùlt. A size-based approach thus provides a convenient approach to study the structure and function of ecosystems.

In the classical description of energy flow in a system, the majority of . phytoplankton production is consumed by mesozooplankton, which are in turn, eaten by fish. However, in recent years, a new concept of pelagic food webs has emerged where a substantial portion of system energy is believed to be efficiently recycled through bacteria, either directly or through predation by protozoa ie. the microbial loop (Azam et. al., 1983). In both systems, the flow of energy is intimately linked to the sizes of microorganisms, through allometric physiological processes (Platt \& Denman, 1977, 1978) and the transfer of biomass up and down the food chain (Boudreau \& Dickie, 1991, Silvert \& Platt, 1980). The way in which the pelagic community is structured depends on the trophic state or productivity of the ecosystem. Size-fractionation studies show a distinct pattern in the way chlorophyll is distributed from oligotrophic to eutrophic environments (Raimbult, 1988, Chisholm, 1992). Specifically, it appears that as total chlorophyll in the system increases, the amount of chlorophyll packaged in small cells reaches an upper limit, and the balance of chlorophyll is comprised of progressively larger and larger cells. Other 
studies which measured size spectra (from bacteria to zooplankton) of lake communities show that there is a systematic increase in the slope of the normalized biomass size spectrum (from -0.6 to -0.4) with increasing eutrophy (Rodriguez et. al., 1990, Echevarria \& Rodriguez, 1994, Rojo \& Rodriguez, 1994, Sprules \& Munawar, 1986). Again, this reflects the relative importance of larger phytoplankton, which subsequently translates into a propogation of biomass up the spectrum to larger organisms.

The current practice of assessing the trophic state of an ecosystem relies on bulk measurements which have limited use in interpreting how the ecosystem is structured. Furthermore, it has been shown that the typical indicators of standing stock of phytoplankton, such as chlorophyll and carbon do not necessarily convey the same information because the carbon:chlorophyll ratio is variable (Geider, 1987, Jimenez et. al., 1987). Recently, a study of coastal waters found that total bioviolume measurements were poorly correlated to chlorophyll in fluctuating systems (Ruiz et. al., 1992). However, if the biovolume of a particular size fraction (ie. nanoplankton) was considered alone, the correlation with chlorophyll gave a much better result. In another study using flow cytometric fluorescence and light scatter as proxies for chlorophyll and carbon, coastal waters had depth profiles of total fluorescence and total scattering that matched that of chlorophyll whereas for oceanic waters, only the fluorescence profile and not the scattering profile matched that of chlorophyll $(\mathrm{Li}, 1994)$. The implication of these findings is that standard bulk measurements such as chlorophyll and biomass may not only convey different information, but may also reveal very different size structures. Further work is needed to assess how community structure is linked to changes in the different bulk measurements of the ecosystem.

Currently, knowledge of microbial size spectra from the world's oceans is limited, particularly with regard to the very small end of the spectrum. In previous studies, we explored the temporal and spatial variability of microbial size spectra from high nutrient, high productivity waters in Massachusetts and Cape Cod Bays (Gin \& Chisholm, 1996) as well as low nutrient, low productivity waters in the Sargasso Sea (Gin et. al., 1996). In 
this paper, we compare the size spectra from these diverse ecosystems and also include size spectra from the equatorial Pacific, a high nutrient, low chlorophyll region (Minas et. al., 1986, Chavez, 1989) to complete the suite of ecosystem types. Specifically, we seek to quantify the effects of eutrophication on the microbial size spectrum through changes in mean cell size, intercept and slope of the normalized size spectrum (Platt \& Denman, 1977, Rodriguez \& Mullin, 1986). Past studies on size spectra usually focus on variability within a particular ecosystem but this makes comparison with other ecosystems difficult because of the methodological variability extending from different sampling and measurement techniques. In this study, the same method was used to analyze different ecosystems, thereby minimizing errors from cross-comparison. Flow cytometry was used to generate size spectra of concentration and biomass so that a comprehensive set of spectral characteristics could be used to examine the different ecosystem types. Each sampled location was characterized by standard environmental measurements of the bulk physical, chemical and biological properties and correlated to the associated size spectral characteristics. These empirical results were then used to discuss possible mechanisms that could influence the structure and organization of the pelagic ecosystem.

\section{METHODS}

\section{Field Sampling Scheme}

The study encompassed coastal waters in Boston Harbour, Massachusetts and Cape Cod Bays as well as oceanic waters in the Sargasso Sea and equatorial Pacific. These areas were chosen because they covered a broad range of ecosystem trophic states and showed diverse characteristics in the structure of the pelagic community. The trophic character of each water body was indicated by levels of chlorophyll, particulates, primary productivity and nutrients (Knap et. al., 1994, 1995, Kelly et. al., 1993, 1994a, b, c, d), with the Boston Harbour station being the most eutrophic of the sampled stations and the Sargasso Sea station representing the other extreme (Table 4.1). In between, the stations at Cape Cod and Massachusetts Bay showed environmental characteristics that were 
intermediate between the two extreme locations. The equatorial Pacific, on the other hand, was characterized by generally low primary production but high ambient nutrient levels ie. a high nutrient low chlorophyll region (Chavez, 1989).

\begin{tabular}{lllllll}
\hline $\begin{array}{l}\text { Sampled } \\
\text { Location }\end{array}$ & $\begin{array}{l}\text { CHL. } \\
\left(\mu \mathrm{g} \mathrm{I}^{-1}\right)\end{array}$ & $\begin{array}{l}\mathrm{PP}\left(\mathrm{mg} \mathrm{C}^{-3} \mathrm{day}^{-1}\right) \\
\mathrm{m}^{2}\end{array}$ & $\begin{array}{l}\mathrm{TN} \\
(\mu \mathrm{M})\end{array}$ & $\mathrm{DIN}^{*}(\mu \mathrm{M})$ & $\begin{array}{l}\mathrm{POC} \\
(\mu \mathrm{M})\end{array}$ & $\begin{array}{l}\mathrm{BEAM} \\
\left(\mathrm{m}^{-1}\right)\end{array}$ \\
\hline Boston & $3.7(2.9)$ & $1308(1267)$ & $23.9(7.3)$ & $8.8(8.1)$ & $24.1(9.3)$ & $2.6(0.5)$ \\
Harbor & & & & & & \\
Cape Cod Bay & $2.5(2.2)$ & $1886(823)$ & $12.7(4.6)$ & $1.4(1.8)$ & $13.8(8.0)$ & $1.0(0.3)$ \\
Mass. Bay & $2.0(3.4)$ & $\mathrm{ND}$ & $\mathrm{ND}$ & $2.8(3.7)$ & $\mathrm{ND}$ & $1.1(0.3)$ \\
Sargasso Sea & $0.13(.11)$ & $3.55(3.01)$ & $1.09(1.04)$ & $0.8(1.1)$ & $1.6(0.7)$ & $0.45(.04)$ \\
Equat. Pacific & $0.04(.05)$ & $10-15^{+}$ & $10.1(3.09)$ & $9.5(3.4)$ & $4.1(1.63)$ & $0.05(.02)$ \\
\hline
\end{tabular}

$* \mathrm{DIN}=\mathrm{NO}_{3}+\mathrm{NO}_{2}+\mathrm{NH}_{4}$

'Taken from Martin et. al., 1994

ND - no data

Table 4.1. Selected environmental characteristics used to indicate the trophic states of the 5 locations ie. the low nutrient, low chlorophyll Sargasso Sea; the high nutrient, low chlorophyll equatorial Pacific and high nutrient, high chlorophyll areas in Massachusetts and Cape Cod Bays. These include measurements of chlorophyll (CHL), primary productivity (PP), total dissolved inorganic nitrogen plus particulate nitrogen (TN), dissolved inorganic nitrogen (DIN), particulate organic carbon (POC) and beam attenuation (BEAM). Values given for the Sargasso Sea and coastal locations are seasonal-depth averages (standard deviation in parentheses) collected over the 1 year sampling period (see text), whereas the values for the equatorial Pacific are taken from a depth profile at $\left(0^{\circ}, 140^{\circ} \mathrm{W}\right)$ in October, 1992 . Measurements were compiled from Knap et. al. (1994, 1995) Kelly et. al. (1993, 1994a,b,c,d, 1995) for the coastal and Sargasso Sea data.

Sampling for size spectra was undertaken as part of larger ongoing projects. Sampling of the Boston Harbour, Massachusetts Bay and Cape Cod regions were undertaken in October 1992, February 1993, March, April, June and August 1993 in connection with the baseline water quality surveys conducted by MWRA (Kelly et. al., 1993, 1994a, b, c, d). Samples from the Sargasso Sea were collected from the Bermuda Atlantic Time Series (BATS) station which is located off Bermuda near the site of the Ocean Flux Program $\left(31^{\circ} 50^{\prime} \mathrm{N}, 6^{\circ}{ }^{\circ} 0^{\prime} \mathrm{W}\right)$. The study area is part of the Joint Global Ocean Flux Study (JGOFS), and international and interdisciplinary study (International 
Geosphere Biosphere Program - IGBP) with the goal of understanding the role of oceans in global carbon and nutrient cycles. Samples from the BATS station were collected in May 1992, July, September, November, February 1993, March and April, 1993 (Knap et. al., 1994, 1995). The additional samples from the equatorial Pacific were obtained on the US JGOFS EQPAC Process Study Cruise (September 24 - October 21, 1992) along $140^{\circ} \mathrm{W}$. These were collected from three locations (at $12^{\circ} \mathrm{S}, 4^{\circ} \mathrm{S}$ and $0^{\circ}$ ) along a transect from an oligotrophic, low nutrient area $\left(12^{\circ} \mathrm{S}\right)$ to a high nutrient-low chlorophyll area $\left(0^{\circ}\right)$.

Seawater was collected at discrete depths spanning the euphotic zone based on CTD (conductivity-temperature-depth) measurements. $200 \mathrm{ml}$ glutaraldehyde (Tousimis $25 \%$ stock solution) was pipetted into sterile $50 \mathrm{ml}$ centrifuge tubes and seawater from each depth was added up to the $50 \mathrm{ml}$ level to obtain a final concentration of $0.1 \%$ (Gin, 1996), except for the 1992 nano/microplankton samples which were fixed at $1 \%$ glutaraldehyde concentration. (Previous tests showed that there was not much difference in preservation between 0.1 to $1 \%$ glutaraldehyde for nano/micro phytoplankton - see Gin, 1996). Samples for each depth were divided into two for separate picoplankton and nano/microplankton analysis. (Note that the nano/microplankton samples from the equatorial Pacific were not preserved but were analyzed immediately using ship-board flow cytometry - see Zettler et. al., 1996) A surface sample at each station was also filtered $(0.2 \mu \mathrm{m}$ for nano/microplankton analysis; $0.02 \mu \mathrm{m}$ for picoplankton analysis) and treated in the same manner as the actual samples to act as reference controls for background fluorescence and scattering. Each sample was well mixed and then two aliquots (replicates) of $2 \mathrm{ml}$ were withdrawn each into $2 \mathrm{ml}$ cryovials for picoplankton analysis. The remainder of the samples in the centrifuge tubes (for nano/microplankton analysis) together with the picoplankton samples were then left in the dark for 10 to 15 minutes. After this time, the samples were immersed into liquid nitrogen for storage (Vaulot et. al., 1989). (Note that $1 \mathrm{~mm}$ holes were made in the caps of the centrifuge tubes because the tubes had a tendency to crack when frozen samples were thawed due to the pressure buildup behind the caps.) For the long term storage of coastal 
nano/microplankton, samples were subsequently transferred to a $-40^{\circ} \mathrm{C}$ freezer due to limited liquid nitrogen storage space (Gin, 1996). Picoplankton samples, being smaller, were stored for the long term in liquid nitrogen before flow cytometric analysis.

Additional standard measurements of the physical, chemical and biological characteristics of the water body were also made at the time of sample collection. For the coastal stations in Massachusetts and Cape Cod Bays, these included standard measurements of chlorophyll a, transmissometry, temperature, salinity, irradiance as well as measurements of dissolved ammonia, nitrate, nitrite, phosphate and silicate (Kelly et. al., 1993, 1994a, b, c, d). At the Boston Harbour and Cape Cod stations, additional samples were taken at the surface and mid-depth for laboratory measurements of biology/productivity. These included measurements of particulate organic carbon (POC) and nitrogen (PON); total suspended solids, extracted chlorophyll-a, phytoplankton and zooplankton identification and enumeration using microscopy and water column production using C-14 methods (Albro et. al., 1993). Auxillary measurements for the BATS station included temperature, salinity, dissolved oxygen, irradiance, nitrate, nitrite, phosphate, silicate, particulate organic carbon (POC) and nitrogen (PON), chlorophyll-a, primary production and bacterioplankton abundance (Knapp et. al., 1993). Environmental measurements for the equatorial Pacific samples included surface nitrate and depth profiles of temperature, beam attenuation and chlorophyll fluorescence (Kadar et. al., 1993).

\section{Flow Cytometry Analysis}

Samples were analyzed using two main instrument configurations on the flow cytometer (Gin, 1996). The first configuration (ie. 'pico' settings) was designed to analyze heterotrophic bacteria and picoplankton using dual-beam flow cytometry (Binder et. al., 1996, Duval, 1993, Monger \& Landry, 1993). Picoplankton samples were thawed and stained with Hoechst-33342 ( $0.5 \mu \mathrm{g} \mathrm{l}^{-1}$ final concentration) for 1 hour before analysis using blue and UV laser excitation. Excitation with blue light causes chlorophyllcontaining cells to fluoresce red whereas UV excitation causes DNA-containing cells 
stained with Hoescht to fluoresce blue. In this way, phytoplankton and bacteria could be discriminated from each other as well as from inorganic particles in the water (Gin, 1996). The second configuration (ie. 'nano/micro' settings) was designed to analyze larger phytoplankton cells using a single blue laser line (Olson et. al., 1989). A faster sample throughput (ie. $5-10 \mathrm{ml} \mathrm{min}{ }^{-1}$ compared to $5 \times 10^{-3} \mathrm{ml} \mathrm{min}^{-1}$ for 'pico' settings) was used to provide a reasonable statistical count of the larger cells since these were generally less numerous than picoplankton. For both configurations, standard calibration beads were used as references for fluorescence and light scatter.

Software (CytoPC) provided by D. Vaulot (Station Biologique, Roscoff, France) was used to analyse the populations on red fluorescence versus forward scatter (for phytoplankton) and blue fluorescence versus forward scatter (for bacteria). The data sets were aligned using the forward light scatter signals from standard beads which could be seen on both configurations. For this study, we chose to convert forward light scatter to volumetric size by applying empirical size-scatter calibrations measured on both the 'pico' and 'nano/micro' settings (DuRand, 1995, Aref, 1996, Gin, 1996). While these empirical calibrations do not account for odd cell shapes and changes in refractive index, we feel that as a first approximation, the use of size is valid because of the good correlation between forward scatter and cell size as well as the large size range (about 7 log decades) considered in this study, which would tend to mask details at the cellular level. At the same time, the use of physical size units enable the calculation of cell properties such as biomass. Biomass was estimated from cell size using literature values (Lee \& Fuhrman, 1987, Verity et. al., 1992, Strathman, 1967) as described in Gin et. al., 1996.

The size spectra were analyzed in two ways:- as histograms where the original data was reclassified into logarithmic size classes of equal width; and as normalized spectra where the original data was divided by the original size class width and made independent of size class (Platt \& Denman, 1977, 1978, Rodriguez \& Mullin, 1986, Sprules \& Munawar, 1986.) Normalization allows for comparison of size spectra from different sources, including theoretical models. These normalized spectra are typically 
characterized by the intercept and slope of the log-transformed data. For the analysis, regressions were calculated for the normalized concentration size spectra alone but these can be extrapolated to normalized biomass spectra:- the slope of the normalized concentration size spectrum is roughly equal to the slope of the concentration size spectrum minus one, and also the slope of the normalized biomass size spectrum minus one (Gin \& Chisholm, 1996). Patterns and trends in the histograms and normalized spectra were studied on both linear and logarithmic scales in order to extract as much information as possible.

The intercept of the normalized concentration size spectrum is, by definition, the abundance of small cells of $1 \mu \mathrm{m}^{3}$ ( $1.2 \mu \mathrm{m}$ diameter) but is also used in a more general way, to reflect the total abundance of organisms or the resource level of the system (Sprules \& Munawar, 1986). This is because the abundance of small cells generally exceeds that of larger cells by one or more orders of magnitude. (Note that the intercept of the normalized size spectrum of bacteria actually portrays the abundance of large bacteria whereas for phytoplankton, the intercept represents the abundance of small cells ie. picophytoplankton.) The slope is a useful measure of the overall distribution of cells and changes in the slope reflect the relative importance of the various size classes. One of the objectives of this study is to analyze the variation in slopes to perturbations in the environment. However, changes in slope are only meaningful when there is a good fit of data to the linear regression. For this reason, the main region of interest for normalized spectra is in the steadily decreasing function with size, to the right of the maximum, where the correlation coefficient, $r$, is generally greater than 0.97 (Gin \& Chisholm, 1996, Gin et. al., 1996). In this study, calculations of the intercept and slope were based only on the steadily decreasing function (ie. 'modified' normalized spectra). While this excluded the very small end of the spectrum, the information is not lost since it is still analyzed in other ways eg. through histograms. Mean cell sizes of both bacteria and phytoplankton were also calculated as additional descriptors of size spectral changes, not necessarily detected by changes in the intercept and slope. For example, a reduction in the abundance of the 
smallest cells alone would shift the mean of the normalized size spectrum to larger sizes, without necessarily changing the values of intercept and slope. On the other hand, using mean size alone could lose substantial information on the whole size spectrum. Hence, a combination of mean size, intercept and slope were used to document the size spectral changes in this study.

When considering the modified normalized spectra, variations in the intercepts and slopes for replicate spectra were typically less than $5 \%$ for bacteria, $1 \%$ for phytoplankton and $2 \%$ for total bacteria plus phytoplankton. Similar variations were also found between the spectral characteristics (ie. intercept and slope) of live and preserved size spectra, even though cell counts of specific populations could vary by up to $30 \%$ for live and preserved samples (Gin, 1996). The smaller differences for the normalized spectra arose because these were based on log scales which covered a broad range in abundance and size. On the whole, $5 \%$ provides a reasonable estimate of the analytical errors involved in this study.

\section{RESULTS}

\section{A Comparison of the Histogram Size Spectra for Ecosystems of Different Trophic}

\section{States}

Microbial size spectra from coastal waters of Massachusetts and Cape Cod Bays generally show greater abundances of large bacteria and large phytoplankton compared to oligotrophic waters in the Sargasso Sea (Fig. 4.1). For bacteria in early spring, there is a distinct shift in favour of larger size classes greater than $0.02 \mu \mathrm{m}^{3}(\sim 0.34 \mu \mathrm{m}$ diameter $)$ in response to increases in total biomass or resource level of the ecosystem (ie. in the order of the Sargasso Sea, Massachusetts Bay, Cape Cod Bay and Boston Harbour respectively). In contrast, the abundance of smaller bacteria size classes is surprisingly similar for all the stations. These differences are clearly seen in the flow cytometric signatures of bacteria from the oceanic Sargasso Sea and the Boston Harbour station, where the latter show a denser clustering of cells at higher forward light scatter (and 

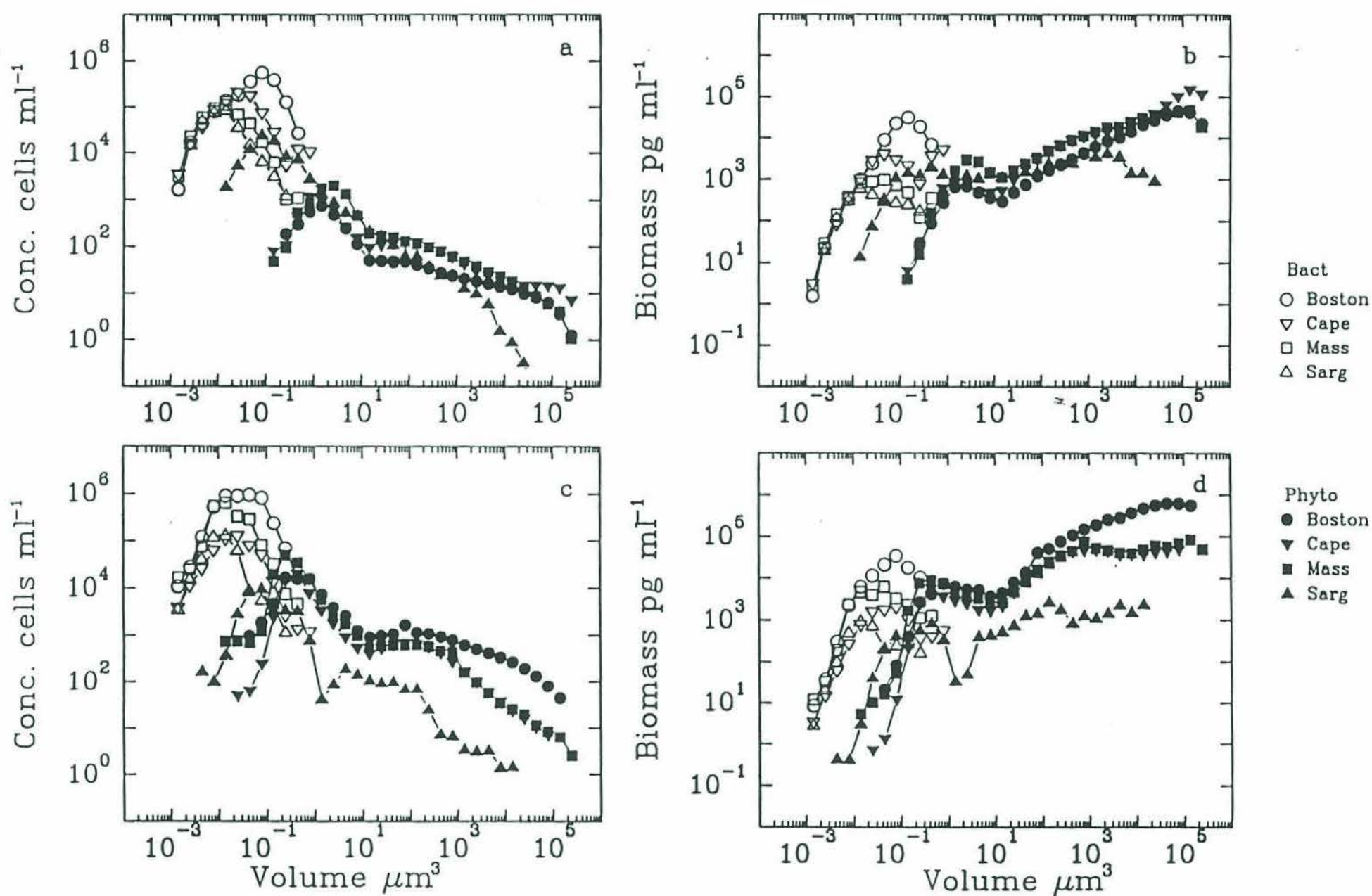

Fig. 4.1. Comparison of concentration and biomass size spectra (histograms) of surface bacteria (open symbols) and surface phytoplankton (closed symbols) from Boston Harbour (circle), Cape Cod Bay (inverted triangle), Massachusetts Bay (square) and the Sargasso Sea (upright triangle) in winter (a, b respectively) and summer (c, d). Winter samples were collected in February, 1993 (1992 for Sargasso Sea), whilst summer samples were collected in August, 1993 (coastal stations) and September, 1992 (Sargasso Sea). 
hence, size) than the former (Fig. 4.2). In the same way as bacteria, the phytoplankton size spectra from the oceanic Sargasso Sea station are skewed in favour of smaller size classes compared to the coastal stations. In particular, a predominance of very small picophytoplankton (corresponding to the species Prochlorococcus) is observed which is roughly of the same size as the modal bacteria size observed at the Boston Harbour station $\left(0.1 \mu \mathrm{m}^{3}\right.$ or $\left.0.6 \mu \mathrm{m}\right)$. However, the smallest phytoplankton for the coastal stations in the early spring period are eukaryotic ultraphytoplankton which are about 1 order of magnitude larger than the smallest phytoplankton observed in the oceanic case ie. $1 \mu \mathrm{m}^{3}$ $(1.25 \mu \mathrm{m})$. (Note that this order of magnitude difference apparent on volume scales is translated from a much smaller difference on diameter scales.) At the upper end of the scale, the coastal phytoplankton show greater abundances of microplankton $\left(2000 \mu \mathrm{m}^{3}\right.$ or $40 \mu \mathrm{m}$ ), leading to a less steep concentration size spectrum but a positive sloping effect on the biomass spectrum. In contrast, the oceanic biomass spectrum is almost flat (neglecting the very smallest cells), implying that equal-sized logarithmic classes in the size range 0.01 to $3 \times 10^{4} \mu \mathrm{m}^{3}(0.2$ to $40 \mu \mathrm{m})$ have roughly the same biomass, supporting the findings of Sheldon et. al., 1972. (Note that their study measured particles with a Coulter counter and covered the size range $1-100 \mu \mathrm{m}$.)

In the summer, the greater abundance and overall mean size of coastal bacteria and phytoplankton compared to their oceanic counterparts is again evident. However, the size spectra of summer populations are quite distinct from winter populations with a relative increase in smaller cells for the coastal stations due to an increase in Synecococcus of size $\sim 0.5 \mu \mathrm{m}^{3}(1 \mu \mathrm{m})$. This leads to a steepening of the phytoplankton size spectra especially for the Cape Cod and Massachusetts Bay stations. Although the modal peak for these coastal phytoplankton is offset to the right and displaced upwards of the oceanic peak (ie. Y-intercepts and mean sizes of coastal spectra are higher than oceanic ones), the overall distribution of cells is comparable to the oceanic case in that the slopes are of approximately equal value (about -1.75 ). In the case of Boston Harbour, the pico and nanoplankton ends of the spectrum are similar to the other two coastal stations, but the 

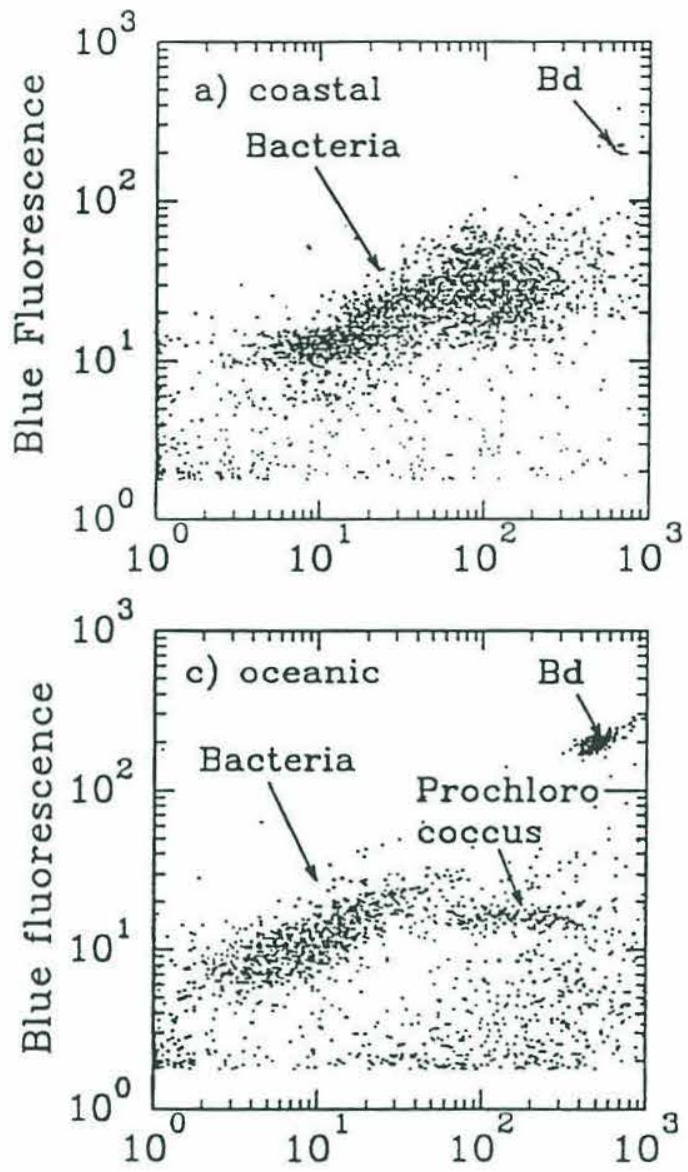

Rel. forward scatter

Fig. 4.2. Flow cytometric signatures of relative forward scatter vs. blue fluorescence from the DNA stain, Hoescht, of bacteria from surface waters of (a) Boston Harbour (June, 1993) and (b) the BATS station (February, 1993). Flow cytometric data were recorded in relative units on a scale of 256 channels representing 3 logarithmic decades and scaled relative to $0.46 \mu \mathrm{m}$ standard calibration bead's (Bd). 
microplankton show a more significant increase leading to a flatter concentration size spectrum (-1.35) but steeper biomass spectrum compared to the other stations.

In the equatorial Pacific, nitrate is high at the equator (eg. surface $\sim 6 \mu \mathrm{M}$ ) but falls off considerably both north and south of $0^{\circ}$ (eg. $0.5 \mu \mathrm{M}$ at $12^{\circ} \mathrm{S}$ ) (Barber \& Chavez, 1991). In spite of the wide variation in nutrient levels, the size spectra from these locations are very similar to each other and to size spectra from the oligotrophic Sargasso Sea, with most of the variation in the $2 \mu \mathrm{m}^{3}$ size range (Fig. 4.3). Mean sizes of bacteria range from 0.013 to $0.019 \mu \mathrm{m}^{3}(0.30$ to $0.34 \mu \mathrm{m})$ whilst that of phytoplankton range from about 1 to $5 \mu \mathrm{m}^{3}$ (1.2 to $2.1 \mu \mathrm{m}$ ). For comparison, the mean sizes of bacteria and phytoplankton in Boston Harbour when comparable nutrient levels were present in the water column were about $0.06 \mu \mathrm{m}^{3}$ and $200 \mu \mathrm{m}^{3}$ respectively (Gin \& Chisholm, 1996). Although not limited in inorganic nutrients, the equatorial Pacific is now known to be limited by the trace element, iron (Martin et. al., 1994), which explains why the microbial size spectra from this region is similar to that found in oligotrophic, nutrient limited waters of the Sargasso Sea. Recent incubation experiments have in fact, shown that the addition of iron to these waters results in a distinct shift from small to large phytoplankton cells, a characteristic feature of nutrient enrichment (Chisholm et. al., 1996, Cavender-Bares et. al., 1996).

\section{A Comparison of the Normalized Size Spectral Characteristics for Ecosystems of Different Trophic States}

The changes in the size spectrum with increased eutrophy can also be summarized in the characteristics of the averaged size spectra, regenerated from the average intercept and slope values of the normalized concentration size spectra collected over all depths and seasons for each of the sampling locations (Fig. 4.4, Table 4.2). For phytoplankton, the lower limit is bounded by a steep slope corresponding to the oligotrophic waters in the Sargasso Sea and equatorial Pacific. The upper limit is bounded by the Boston Harbour size spectra which is offset to the right and displaced upwards relative to the oceanic 

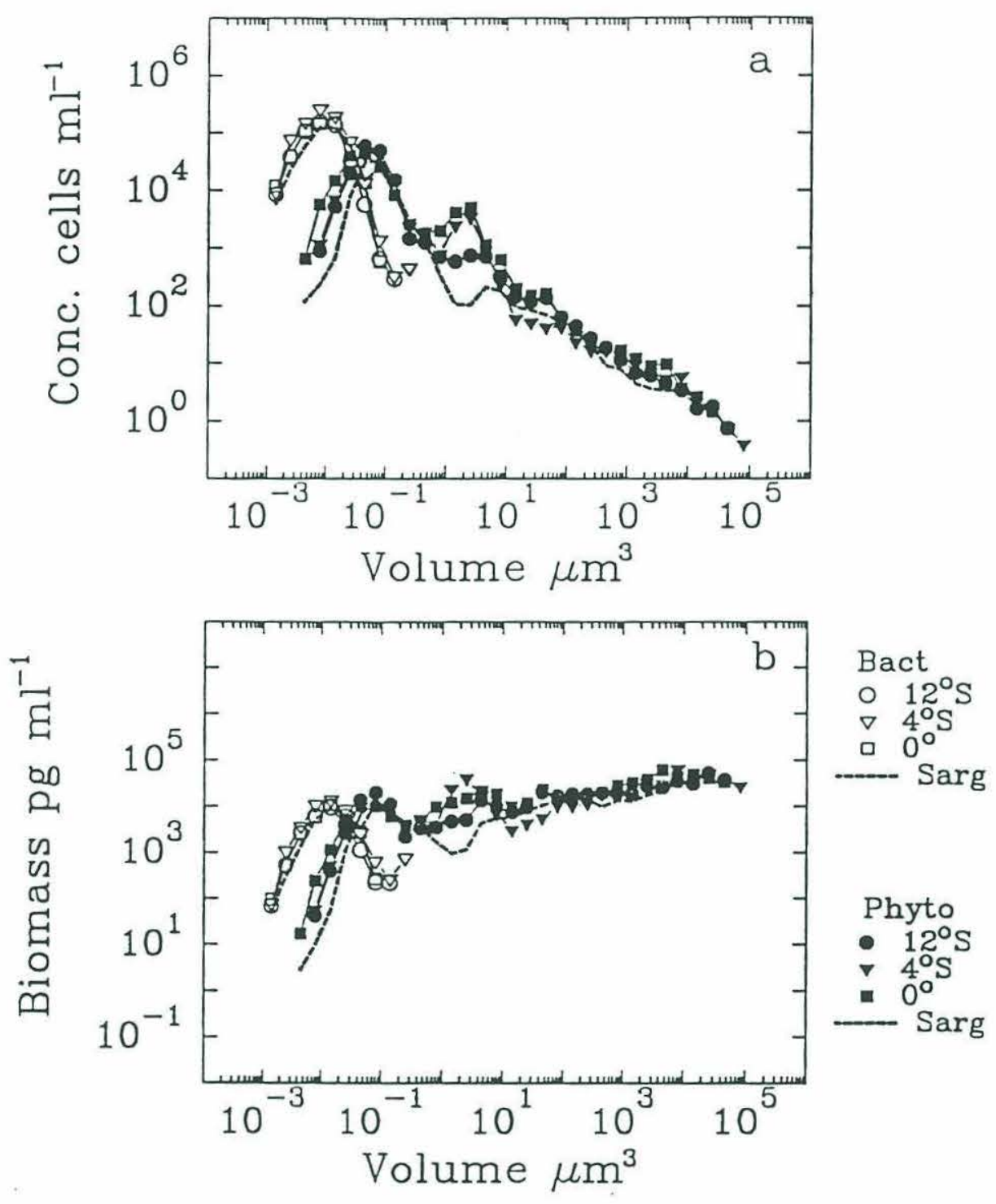

Fig. 4.3. Comparison of a) concentration and b) biomass size spectra (histograms) of surface bacteria (open symbols) and surface phytoplankton (closed symbols) from the equatorial Pacific (latitude $140^{\circ} \mathrm{W}$; longitude $12^{\circ} \mathrm{S}$-circle, $4^{\circ} \mathrm{S}$-inverted triangle, $0^{\circ}$ square) and the Sargasso Sea BATS station (dashed line). Samples for the equatorial Pacific were collected on September 25, 29 and October 3, 1992 (for $12^{\circ} \mathrm{S}, 4^{\circ} \mathrm{S}$ and $0^{\circ}$ respectively) and on September 15, 1992 for the BATS station. 

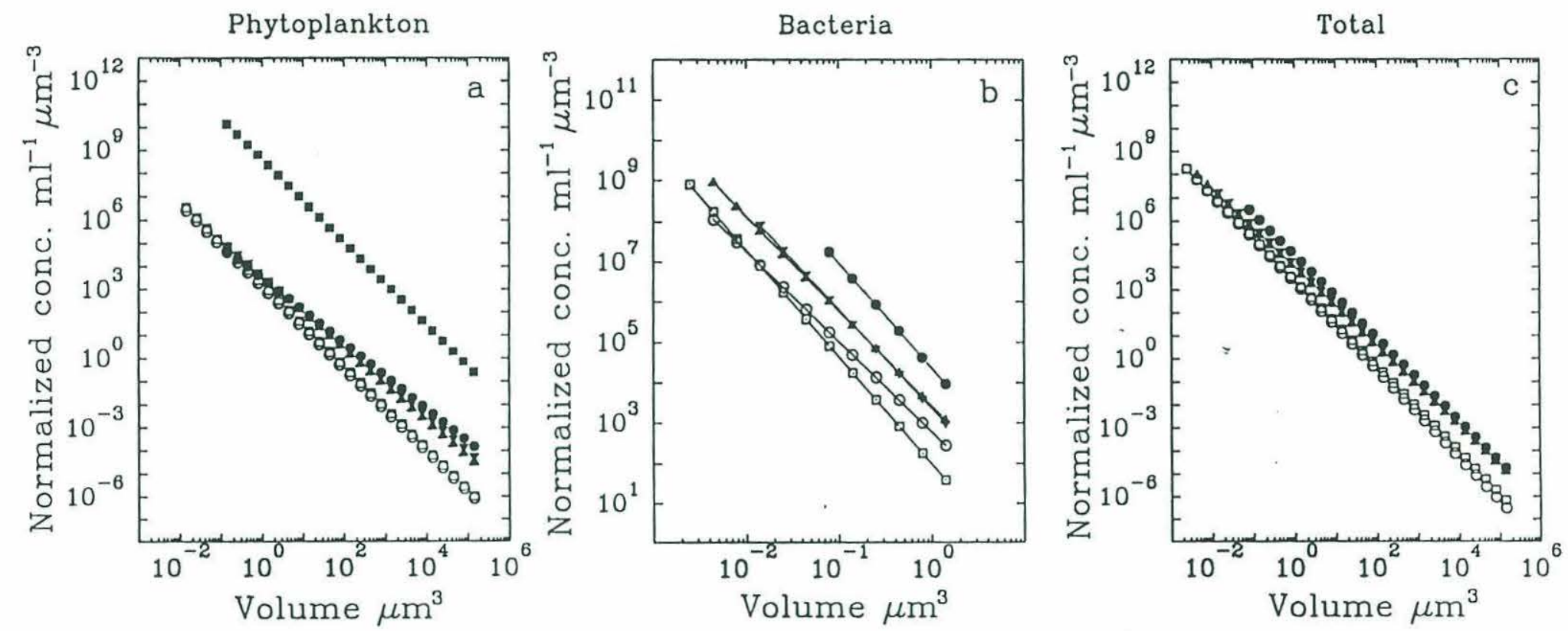

Fig. 4.4. Seasonal-depth averaged characteristics of the modified normalized concentration size spectra for a) phytoplankton, b) bacteria and c) total (bacteria plus phytoplankton) community. The spectra were regenerated from the seasonal-depth averaged Yintercept and slope of the normalized concentration size spectra for the equatorial Pacific (open square), the Sargasso Sea (open circle), Boston Harbour (closed circle), Cape Cod Bay (inverted closed triangle) and Massachusetts Bay (closed triangle). In a) the size spectrum of maximum phytoplankton concentration in culture is also illustrated for comparison (extrapolated from Agusti \& Kalff, 1989). This was obtained by measuring the maximum cell concentration achieved in culture for a number of phytoplankton species. 


\begin{tabular}{llllllllll}
\hline Sampled & \multicolumn{3}{c}{ Bacteria (B) } & \multicolumn{4}{c}{ Phytoplankton (P) } & \multicolumn{2}{c}{ Total (B+P) } \\
Location & Y & S & r & Y & S & r & Y & S & r \\
\hline Boston Harbor & 4.37 & -2.62 & 0.98 & 3.49 & -1.42 & 0.99 & 4.51 & -1.80 & 0.98 \\
Cape Cod Bay & 3.37 & -2.46 & 0.97 & 3.62 & -1.58 & 1.00 & 4.09 & -1.70 & 0.99 \\
Mass. Bay & 3.44 & -2.35 & 0.98 & 3.53 & -1.56 & 1.00 & 3.95 & -1.71 & 0.99 \\
Sargasso Sea & 2.78 & -2.24 & 0.98 & 3.10 & -1.79 & 0.99 & 3.32 & -1.91 & 0.99 \\
Equat. Pacific & 1.99 & -2.66 & 0.97 & 3.23 & -1.79 & 0.99 & 3.40 & -1.86 & 0.99 \\
\hline
\end{tabular}

Table 4.2. Spatially and temporally averaged spectral characteristics for the coastal and oceanic locations. The intercept (Y), slope (S) and correlation coefficient (r) were calculated from linear regressions of the normalized concentration size spectra of the bacteria, phytoplankton and total (bacteria plus phytoplankton) communities.

spectra. (Note that the averaged size spectra for the coastal stations are very similar to each other). Actual values of the averaged slope range from -1.8 to -1.4 for oligotrophic and eutrophic waters respectively. There also appears to be a convergence between the coastal and oceanic spectra at the small end of the scale eg. the intercept at $10^{\circ} \mu \mathrm{m}^{3}$ does not vary much. In addition, the modal peaks for coastal phytoplankton are offset to the right of the oceanic peaks, indicating that the smallest phytoplankton for coastal systems is larger than the smallest phytoplankton found in oceanic systems. In fact, the smallest coastal phytoplankton are typically Synecococcus of size $\sim 0.5 \mu \mathrm{m}^{3}(1 \mu \mathrm{m})$ whereas the smallest oceanic phytoplankton detected are Prochlorophytes which are much smaller at about $0.06 \mu \mathrm{m}^{3}(0.7 \mu \mathrm{m})$. For comparison, the equivalent size spectrum of the maximum concentration of phytoplankton cells is also shown (Agusti \& Kalff, 1989). This spectrum was obtained by culturing many different species of phytoplankton (from 2 to $5 \times 10^{6} \mu \mathrm{m}^{3}$ ) and measuring their maximum cell concentration at stationary phase. The slope of this spectrum is similar to the oceanic size spectra but is displaced upwards because of the greater biomass achieved in culture.

For bacteria, the smallest cells (ie. $<0.01 \mu \mathrm{m}^{3}$ or $0.3 \mu \mathrm{m}$ ) found in both coastal and oceanic waters are of similar size (eg. histograms in Fig. 4.1). The normalized concentration size spectra for bacteria generally depict an upward displacement with increased system trophy, quantified by an increase in the averaged intercept from 2.0 
(equatorial Pacific) to $4.4 \mathrm{cell} \mathrm{ml}^{-1} \mu \mathrm{m}^{-3}$ (Boston Harbour) ie. a greater abundance of large bacteria (Fig. 4.4). The bacteria slope, however, varies widely even within a particular environment, with no clear trend with ecosystem trophy (see later). On the whole, an increasing importance of large bacteria relative to smaller bacteria can be seen in the more eutrophic waters. For total (bacteria plus phytoplankton) spectra, the trend is similar to that of phytoplankton in that an upward displacement towards flatter slopes is observed from oligotrophic to eutrophic waters.

\section{Variation of Size Spectral Characteristics with Indicators of Trophic State}

\section{Relationships with Biological Measurements}

The chosen ecosystem locations cover a wide range of trophic states with different environmental changes impacting each system (Table 4.1). Highest primary production and particulates are generally found at the coastal stations whilst the lowest values are observed in the open ocean waters. Data pooled from all locations show that patterns can be found between the characteristics of size spectra and parameters indicative of the water's trophic state. Bulk measurements of particulate material (chlorophyll, POC and PON) are particularly well correlated with mean bacteria and phytoplankton size ( $r$ greater than 0.7 ), such that mean cell sizes generally increase with increasing abundance of living material in the system (Fig. 4.5, Tables 4.3,4.4). Similarly, well correlated positive relationships are also detected between mean bacteria/phytoplankton size and bacteria/phytoplankton biomass, the latter computed by integrating the flow cytometrically derived biomass size spectra (Fig. 4.6). (Note that the total integrated biomass is also directly proportional to the environmental measurements of $\mathrm{POC}$ and chlorophyll $(\mathrm{r}>0.8$, Table 4.5).) In the case of bacteria, the increase in mean size (from $\sim 0.01$ to $0.1 \mu \mathrm{m}^{3}$ ) with total bacteria biomass is attributed to an increase in the large bacteria fraction greater than about $0.3 \mu \mathrm{m}^{3}(0.8 \mu \mathrm{m})$ and a corresponding reduction in the small size fraction less than $0.3 \mu \mathrm{m}^{3}$ (Fig. 4.6). As with bacteria, mean sizes of phytoplankton cells also increase from oligotrophic oceanic waters $\left(\sim 1 \mu \mathrm{m}^{3}\right)$ to more eutrophic coastal waters $\left(>500 \mu \mathrm{m}^{3}\right)$. 

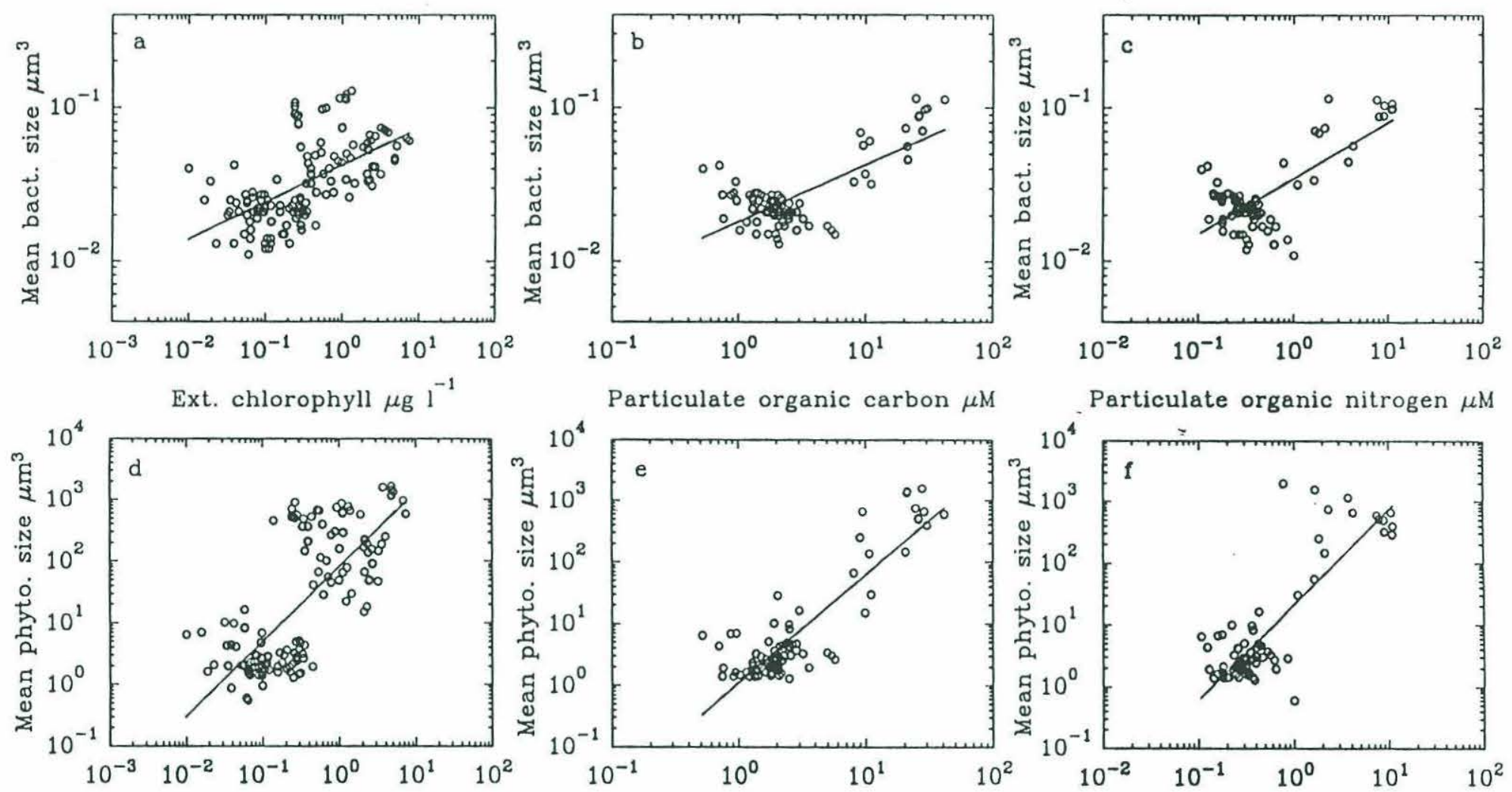

Ext. chlorophyll $\mu \mathrm{g} \mathrm{l}^{-1}$

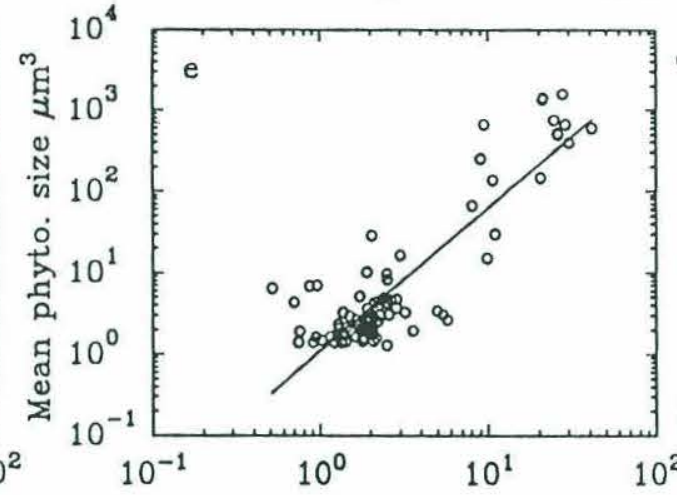

Particulate organic nitrogen $\mu \mathrm{M}$

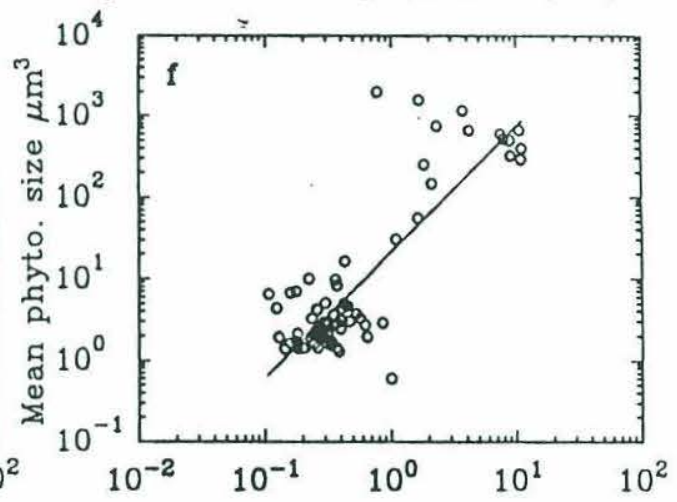

Particulate organic carbon $\mu \mathrm{M}$

Particulate organic nitrogen $\mu \mathrm{M}$

Fig. 4.5. Relationships between mean bacteria size (a, b, c) and mean phytoplankton size (d, e, f) with the bulk environmental measurements of extracted chlorophyll, particulate organic carbon and particulate organic nitrogen. Data were pooled from all depths in the Sargasso Sea BATS station (excluding oceanic samples greater than $160 \mathrm{~m}$ depth where total cell counts were generally less than $100 \mathrm{ml}^{-1}$ ) and the $12^{\circ} \mathrm{S}$ and $4^{\circ} \mathrm{S}$ equatorial Pacific stations. For the coastal stations, chlorophyll measurements were pooled from all depths at the three locations in Boston Harbour, Massachusetts and Cape Cod Bays, whilst POC and PON data were only available for surface and chlorophyll maximum samples at the Boston Harbour and Cape Cod Bay stations. 

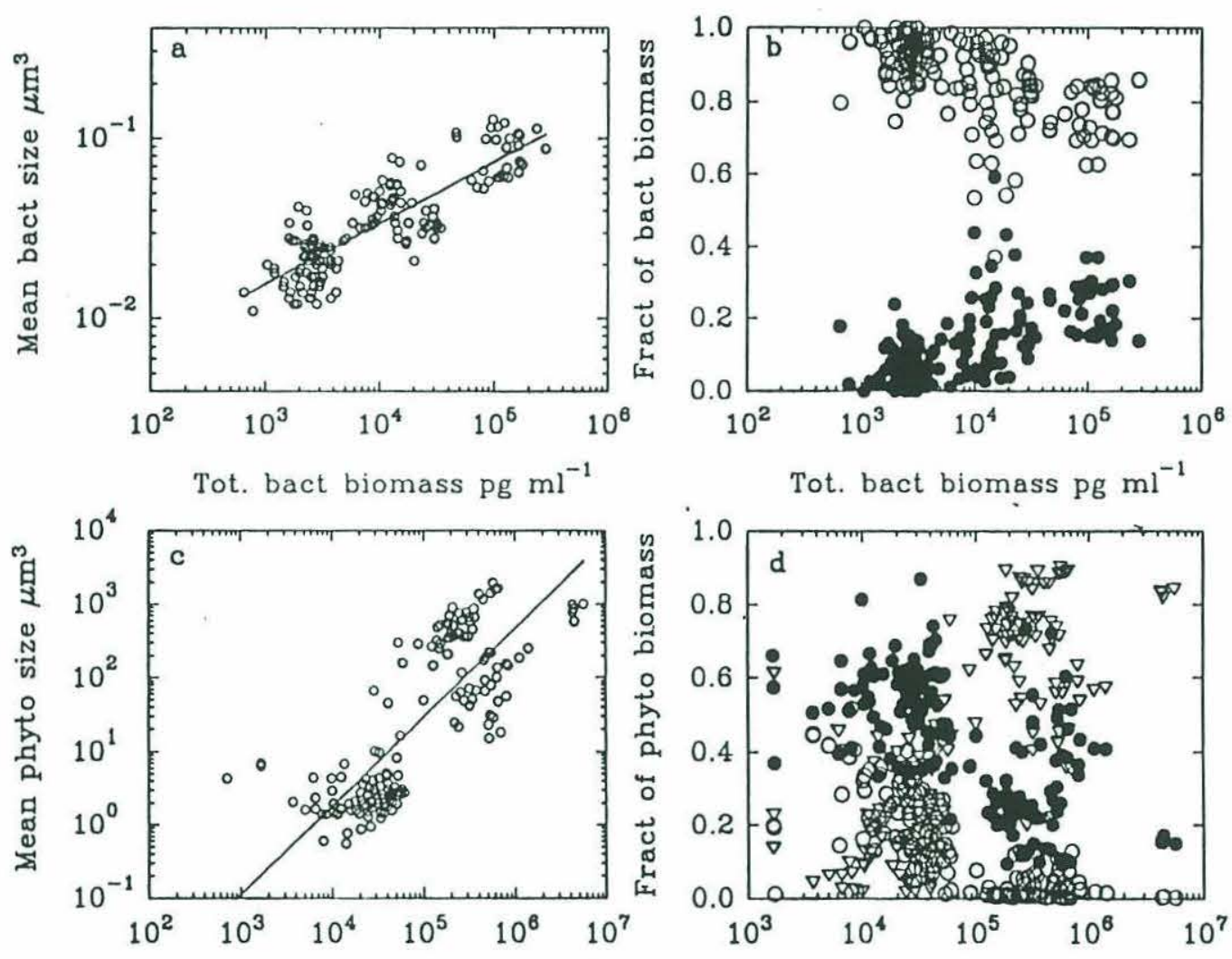

Tot. bact biomass $\mathrm{pg} \mathrm{\textrm {ml } ^ { - 1 }}$

Tot. phyto biomass $\mathrm{pg} \mathrm{\textrm {ml } ^ { - 1 }}$

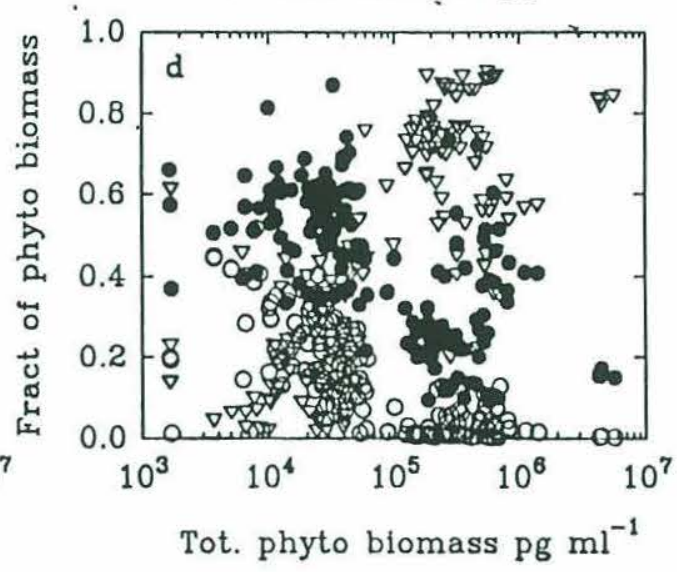

Fig. 4.6. Relationships between a) mean bacteria size and bacteria biomass and b) fraction of bacteria biomass in the size fraction 0.2 to $0.8 \mu \mathrm{m}$ (open circle), and size fraction greater than $0.8 \mu \mathrm{m}$ (closed circle). Similar relationships for phytoplankton are also shown in c) and d) respectively, where the size classes in d) consist of the pico $(0.2-2 \mu \mathrm{m}$ : open circle), nano (2-20 $\mu \mathrm{m}$ : closed circle) and micro ( $>20 \mu \mathrm{m}$ : open triangles) fractions. Data were pooled from all locations (ie. Boston harbour, Massachusetts Bay, Cape Cod Bay, Sargasso Sea and equatorial Pacific), except for the deepest oceanic samples greater than $160 \mathrm{~m}$. 
In particular, the increase in total phytoplankton biomass leads to a dramatic increase in the microplankton fraction and a subsequent decrease in the pico and nano fractions.

These changes in the size structure of bacteria and phytoplankton can also be deduced from shifts in the normalized concentration size spectra. Pooled data show positive relationships between the bacteria intercept and bacteria biomass as well as with the bulk environmental measurements of POC and chlorophyll ( $r>0.6-0.7$ ) (Fig. 4.7, Table 4.3). This increase in bacteria intercept is consistent with the general increase in picoplankton abundance with overall resource level of the system. In contrast, the bacteria slope shows a poorer correlation with bacteria biomass, chlorophyll and PON $(\mathrm{r}<0.26)$, but a better fit with POC $(r \sim 0.5)$. On the whole, considerable scatter in the data

\begin{tabular}{llllllllll}
\hline & \multicolumn{3}{c}{ Mean Bacteria Size } & \multicolumn{3}{c}{ Bacteria Slope } & \multicolumn{3}{c}{ Bacteria Intercept } \\
& $\mathrm{Y}$ & $\mathrm{S}$ & $\mathrm{r}$ & $\mathrm{Y}$ & $\mathrm{S}$ & $\mathrm{r}$ & $\mathrm{Y}$ & $\mathrm{S}$ & $\mathrm{r}$ \\
\hline $\mathrm{DIN}$ & -1.43 & 0.19 & 0.55 & -2.38 & -0.08 & 0.13 & 3.39 & 0.43 & 0.41 \\
$\mathrm{TN}$ & -1.52 & 0.26 & 0.69 & -2.41 & -0.14 & 0.24 & 3.07 & 0.62 & 0.57 \\
$\mathrm{SiO}_{4}$ & -1.59 & 0.39 & 0.79 & -2.36 & -0.14 & 0.18 & 2.93 & 1.05 & 0.70 \\
$\mathrm{PO}_{4}$ & -1.21 & 0.27 & 0.49 & -2.46 & -0.10 & 0.09 & 4.01 & 0.78 & 0.49 \\
$\mathrm{POC}$ & -1.73 & 0.39 & 0.77 & -2.22 & -0.43 & 0.51 & 2.54 & 0.97 & 0.66 \\
$\mathrm{PON}$ & -1.43 & 0.37 & 0.81 & -2.38 & -0.08 & 0.13 & 3.39 & 0.43 & 0.41 \\
$\mathrm{CHL}$ & -1.41 & 0.21 & 0.61 & -2.41 & -0.06 & 0.10 & 3.50 & 0.69 & 0.63 \\
$\mathrm{TBIO}$ & -1.43 & 0.37 & 0.81 & -1.84 & -0.11 & 0.21 & -0.40 & 0.73 & 0.70 \\
$\mathrm{BBIO}$ & -2.80 & 0.33 & 0.85 & -1.81 & -0.15 & 0.25 & -1.13 & 1.09 & 0.86 \\
$\mathrm{PP}$ & -1.70 & 0.15 & 0.79 & -2.44 & -0.05 & 0.18 & 2.56 & 0.37 & 0.70 \\
$\mathrm{BNOS}$ & -3.61 & 0.36 & 0.64 & -1.20 & -0.21 & 0.24 & -4.39 & 1.31 & 0.81 \\
BEAM & -1.38 & 0.65 & 0.84 & -2.46 & -0.54 & 0.38 & 3.43 & 1.84 & 0.80 \\
TEMP & -1.10 & -0.37 & 0.72 & -2.70 & 0.30 & 0.36 & 3.89 & -0.64 & 0.41 \\
\hline
\end{tabular}

Table 4.3. Correlations between environmental indicators of trophic state and characteristics of the normalized concentration size spectra of bacteria. The intercept $(\mathrm{Y})$, slope $(S)$ and the correlation coefficient $(r)$ were computed from the linear regression of selected environmental characteristics and the mean bacteria size, bacteria slope and bacteria intercept pooled from all the sampling locations (excluding samples greater than $160 \mathrm{~m}$ from the open oceans, and also excluding the equatorial Pacific samples for the nutrient regressions). These environmental measurements included dissolved inorganic nitrogen (DIN), total nitrogen ( $T N=D I N+P O N)$, silicate, phosphate, particulate organic carbon $(\mathrm{POC})$, particulate organic nitrogen (PON), chlorophyll $\left(\mathrm{CHL}-\mu \mathrm{gl}{ }^{-1}\right)$, total biomass (bacteria+phytoplankton biomass-pgCml ${ }^{-1}$ ), bacteria biomass (BBIO), primary 

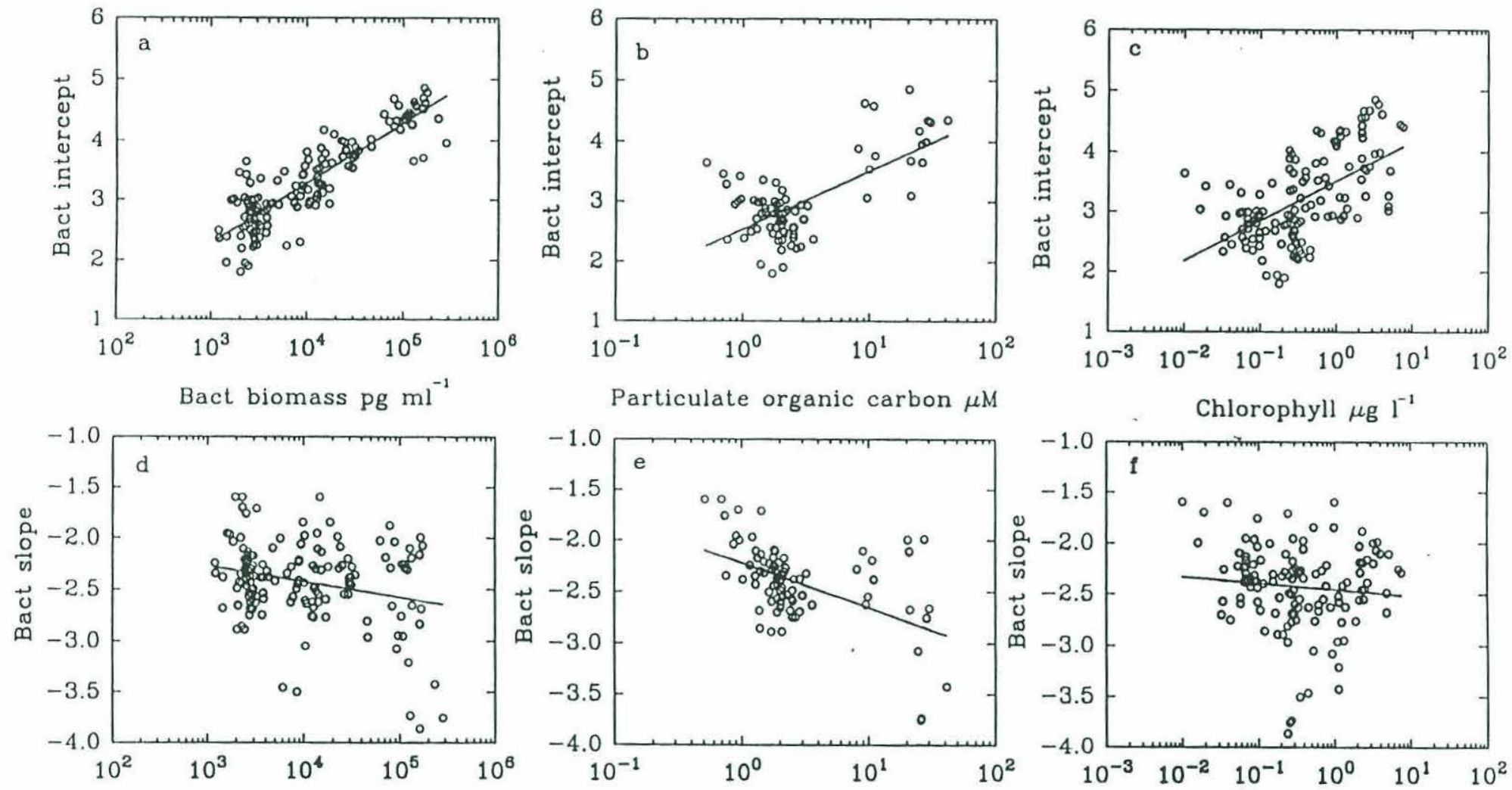

Particulate organic carbon $\mu \mathrm{M}$

Chlorophyll $\mu \mathrm{g} \mathrm{I}^{-1}$
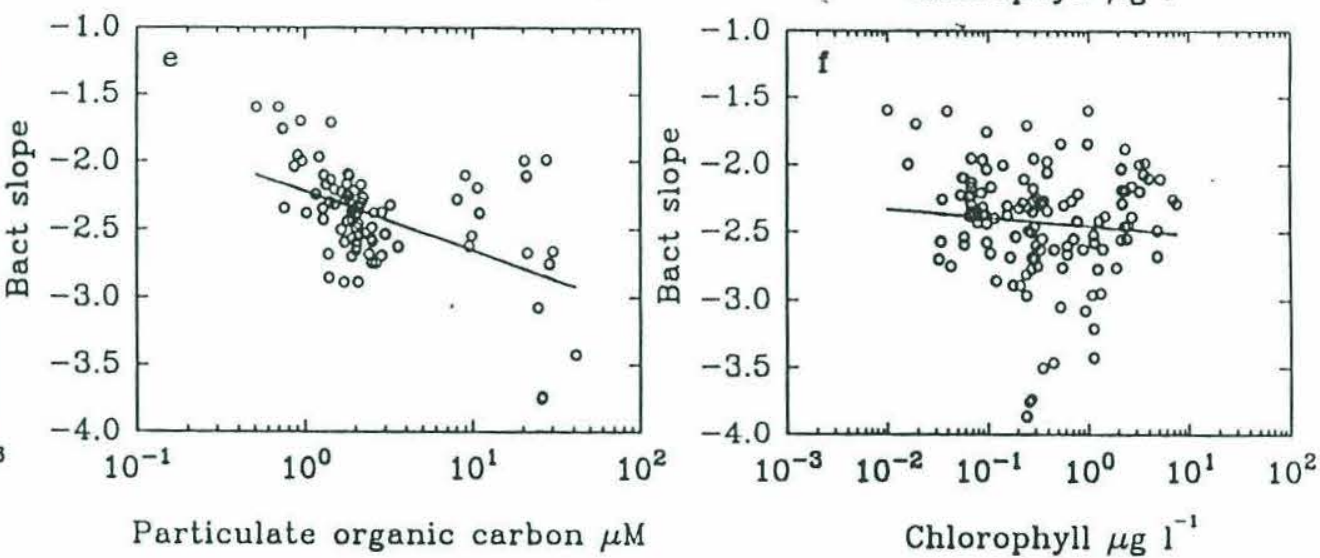

Fig. 4.7. Variation of the bacteria intercept $(a, b, c)$ and bacteria slope (d, e, f) with integrated bacteria biomass, particulate organic carbon and chlorophyll. The intercept and slope values were calculated from linear regressions of the modified normalized concentration size spectra of bacteria pooled from all locations (ie. Boston harbour, Massachusetts Bay, Cape Cod Bay, Sargasso Sea and equatorial Pacific), except for the deepest oceanic samples greater than $160 \mathrm{~m}$. Note that only POC data were available for surface and mid-depth samples at the Boston Harbour and Cape Cod Bay stations. Corresponding coefficients of regression are found in Table 4.3. 
productivity (PP), bacteria cell concentration (BNOS-cells $\mathrm{ml}^{-1}$ ), beam attenuation $\left(B E A M-m^{-1}\right)$ and temperature $\left(\right.$ TEMP- $\left.^{\circ} \mathrm{C}\right)$. Biomass measurements were obtained by integrating the flow cytometrically derived biomass size spectra. All nutrient measurements are in $\mu \mathrm{M}$ unless otherwise indicated.

\begin{tabular}{llllllllll}
\hline & \multicolumn{3}{c}{ Mean Phyto Size } & \multicolumn{3}{c}{ Phyto Slope } & \multicolumn{4}{c}{ Phyto Intercept } \\
& $\mathrm{Y}$ & $\mathrm{S}$ & $\mathrm{r}$ & $\mathrm{Y}$ & $\mathrm{S}$ & $\mathrm{r}$ & $\mathrm{Y}$ & $\mathrm{S}$ & $\mathrm{r}$ \\
\hline $\mathrm{DIN}$ & 1.72 & 0.57 & 0.38 & -1.64 & 0.10 & 0.32 & 3.62 & -0.31 & 0.44 \\
$\mathrm{TN}$ & 1.05 & 0.96 & 0.61 & -1.72 & 0.12 & 0.41 & 3.46 & -0.16 & 0.26 \\
$\mathrm{SiO}_{4}$ & 0.89 & 1.78 & 0.81 & -1.75 & 0.28 & 0.70 & 3.54 & -0.08 & 0.08 \\
$\mathrm{PO}_{4}$ & 2.70 & 1.31 & 0.61 & -1.47 & 0.19 & 0.46 & 3.53 & -0.01 & 0.01 \\
$\mathrm{POC}$ & 0.06 & 1.80 & 0.90 & -1.88 & 0.31 & 0.74 & 3.44 & 0.04 & 0.05 \\
$\mathrm{PON}$ & 1.39 & 1.58 & 0.86 & -1.64 & 0.10 & 0.32 & 3.41 & -0.04 & 0.06 \\
$\mathrm{CHL}$ & 1.69 & 1.13 & 0.76 & -1.63 & 0.16 & 0.56 & 3.71 & 0.33 & 0.54 \\
$\mathrm{TBIO}$ & -4.92 & 1.27 & 0.83 & -2.75 & 0.22 & 0.77 & 2.39 & 0.22 & 0.35 \\
PBIO & 1.18 & 0.56 & 0.79 & -2.70 & 0.21 & 0.76 & -2.34 & 0.23 & 0.39 \\
PP & 0.27 & 0.69 & 0.88 & -1.83 & 0.12 & 0.83 & 3.50 & $\sim 0$ & $\sim 0$ \\
PNOS & 6.51 & -1.15 & 0.61 & -0.90 & -0.17 & 0.49 & 1.11 & 0.55 & 0.71 \\
BEAM & 1.85 & 2.75 & 0.80 & -1.59 & 0.48 & 0.72 & 3.38 & 0.36 & 0.16 \\
TEMP & 3.33 & -1.92 & 0.83 & -1.36 & -0.30 & 0.71 & 3.14 & 0.39 & 0.41 \\
\hline
\end{tabular}

Table 4.4. Correlations between environmental indicators of trophic state and characteristics of the normalized concentration size spectra of phytoplankton. The intercept $(\mathrm{Y})$, slope $(\mathrm{S})$ and the correlation coefficient $(\mathrm{r})$ were computed from the linear regression of selected environmental characteristics (as in Table 4.3) and the mean bacteria size, bacteria slope and bacteria intercept pooled from all the sampling locations (excluding samples greater than $160 \mathrm{~m}$ from the open oceans).

\begin{tabular}{llll}
\hline & $\mathrm{Y}$ & $\mathrm{S}$ & $\mathrm{r}$ \\
\hline POC v TBIO & -1.90 & 0.51 & 0.86 \\
CHL v TBIO & -3.72 & 0.67 & 0.84 \\
BBIO v PBIO & 1.18 & 0.56 & 0.79 \\
BSIZE v PSIZE & -1.76 & 0.20 & 0.85 \\
\hline
\end{tabular}

Table 4.5. Linear regression coefficients (Y-intercept, S-slope, $r$-correlation coefficient) of the bulk environmental measurements of particulate organic carbon $(\mathrm{POC}-\mu \mathrm{M})$ and chlorophyll (CHL- $\mu \mathrm{gl}^{-1}$ ) with total (bacteria+phytoplankton) biomass (TBIO- $\mathrm{pgCml}^{-1}$ ). The results for the linear regression between bacteria biomass $\left(\mathrm{BBIO}-\mathrm{pgCml}^{-1}\right.$ ) and phytoplankton biomass (PBIO) together with the relation between mean bacteria size $\left(\mathrm{BSIZE}-\mu \mathrm{m}^{3}\right)$ and mean phytoplankton size (PSIZE) are also given. 
exists with values of slope ranging widely from -1.3 to -3.8 . The lack of a good correlation between bacteria slope and the bulk indicators of biomass implies that bacteria slope alone is insufficient for characterizing the bacteria community according to trophic state.

While the bacteria intercept appears to be a better correlate of ecosystem biomass levels than bacteria slope, the reverse is true for the phytoplankton intercept and slope. For example, the correlation between the phytoplankton intercept and POC or biomass is poor ( $r \sim 0.05,0.35$ respectively) compared to that between phytoplankton slope and POC or biomass ( $r \sim 0.75,0.77)$ (Fig. 4.8, Table 4.4). In the case of chlorophyll, however, the $\mathrm{R}^{2}$ values are similar for both the phytoplankton intercept and slope. The difference in trend between chlorophyll and the bulk indicators of biomass could be due to depth variability in the carbon: chlorophyll ratio which has been observed in open ocean environments $(\mathrm{Li}, 1994)$. The lack of a good correlation between the phytoplankton intercept and total biomass supports the notion that picophytoplankton abundance may reach an upper limit with systems of increasing biomass or eutrophy. On the other hand, the well correlated positive relationship between phytoplankton slope and phytoplankton biomass implies that phytoplankton slope changes (in addition to mean phytoplankton size changes) are suitable indicators of eutrophication ie. as biomass in the system increases, the size spectrum becomes less steep in favour of larger cells. Not surprisingly, primary production rates are also better correlated with mean phytoplankton size ( $\mathrm{r} \sim 0.88)$, phytoplankton slope $(\mathrm{r} \sim 0.83)$, mean bacteria size $(\mathrm{r} \sim 0.8)$ and bacteria intercept $(\mathrm{r} \sim 0.7)$, rather than the phytoplankton intercept and bacteria slope (Fig. 4.9, Tables 4.3, 4.4).

In addition to biomass as an indicator of trophic state, measurements of cell concentration are also used in a general way to quantify the amount of living material present in the water column. In this study, positive correlations are also found between total bacteria cell concentration and the bacteria intercept $(\mathrm{r} \sim 0.81)$ and mean bacteria size (r 0.64) (Table 4.3). In the case of total phytoplankton cell concentration and characteristics of the phytoplankton size spectra, the phytoplankton intercept and the 

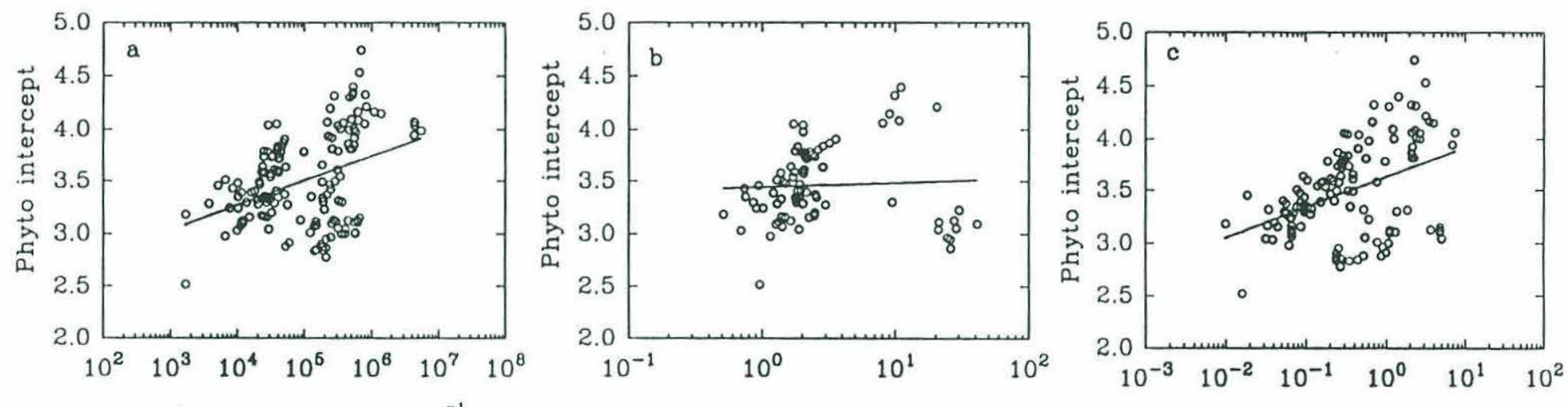

Phyto biomass $\mathrm{pg} \mathrm{ml^{-1 }}$

Particulate organic carbon $\mu \mathrm{M}$
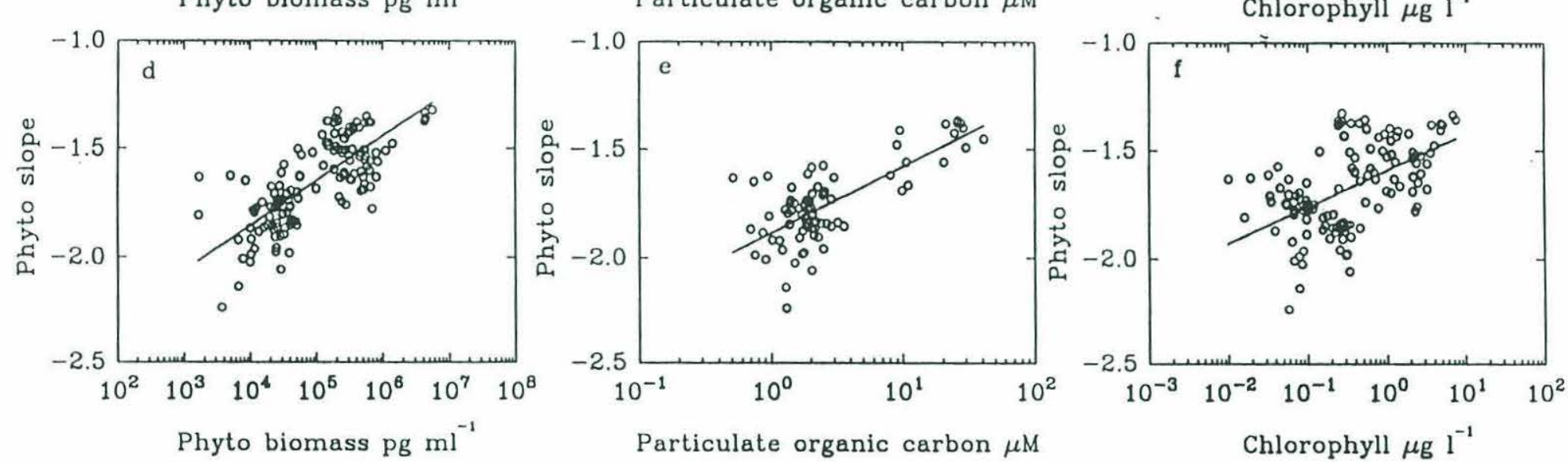

Fig. 4.8. Correlations of the phytoplankton intercept (a, b, c) and phytoplankton slope (d, e, f) with integrated phytoplankton biomass, particulate organic carbon and chlorophyll. The intercept and slope values were calculated from linear regressions of the modified normalized concentration size spectra of bacteria pooled from all locations (ie. Boston harbour, Massachusetts Bay, Cape Cod Bay, Sargasso Sea and equatorial Pacific), except for the deepest oceanic samples greater than $160 \mathrm{~m}$. Note that for the coastal stations, POC data were only available for surface and mid-depth samples at the Boston Harbour and Cape Cod Bay stations. Corresponding coefficients of regression are found in Table 4.4. 

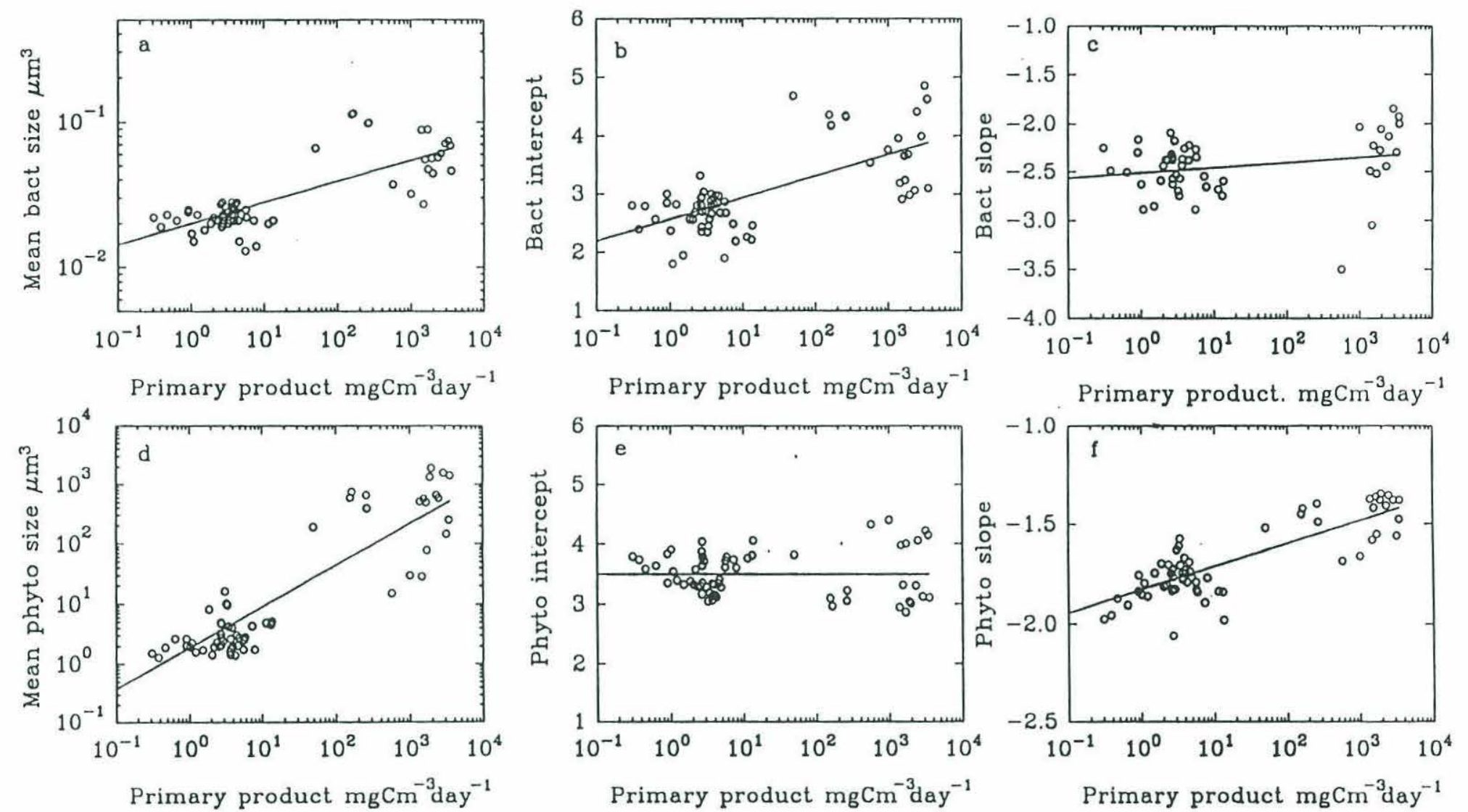

Fig. 4.9. Relationships between primary productivity and the characteristics of size spectra. In general, good correlations were found between primary productivity and mean bacteria size (a), bacteria intercept (b) but not the bacteria slope (c). In contrast, good correlations exist for mean phytoplankton size (d) and phytoplankton slope (f) but not phytoplankton intercept (e). Data were pooled from the Sargasso Sea (excluding oceanic samples greater than $100 \mathrm{~m}$ ) and the surface and mid-depths of Boston Harbour and Cape Cod Bay. Corresponding coefficients of regression are found in Tables 4.3 and 4.4 . 
mean phytoplankton size showed the highest correlation ( $\mathrm{r} 0.71$ and 0.61 respectively). However, the mean size actually showed a negative relationship, implying that as phytoplankton cell concentration increased, the mean size decreased. This can be explained by the fact that picoplankton numbers exceed those of larger phytoplankton by at least one order of magnitude so that changes in cell concentration at the pico end will effect greater changes in total cell concentration. This is bourne out by measurements of the maximum concentration of phytoplankton cells measured at each of the stations, which are roughly of the same order of magnitude $\left(\sim 10^{5} \mathrm{ml}^{-1}\right)$ despite the wide range in trophic states between locations. Thus, analyzing the phytoplankton community using cell numbers alone is limited and could be subject to erroneous interpretation in the absence of size structure information.

\section{Relationships with Chemical and Physical Measurements}

Linear regressions between size spectral characteristics and other chemical and physical measurements again show that mean bacteria size, bacteria intercept, mean phytoplankton size and phytoplankton slope are the more sensitive spectral parameters of environmental change. For example, beam attenuation shows strong correlation with these spectral characteristics ( $r \sim 0.8)$ such that a greater predominance of larger bacteria and phytoplankton is associated with higher levels of beam attenuation (Fig. 4.10). Temperature also shows well correlated inverse relationships with mean bacteria size ( $r \sim 0.71)$, mean phytoplankton size ( $r \sim 0.83$ ) and phytoplankton slope ( $\mathrm{r} \sim 0.71)$, implying that smaller cells are generally associated with warmer temperatures and vice versa. While temperature may affect cells directly, temperature also reflects other phenomena, such as the stability of the water column and hence the nutrient environment experienced by cells. Good correlations also exist between size spectra and selected nutrients, particularly silicate ( $\mathrm{r} \sim 0.7-0.8)$ and to a smaller extent, phosphorus ( $\mathrm{r} \sim 0.5)$. Poorer correlations are generally found with inorganic nitrogen measurements such as nitrate and ammonium $(r<0.3)$, although the mean bacteria size and phytoplankton intercept show slightly better 

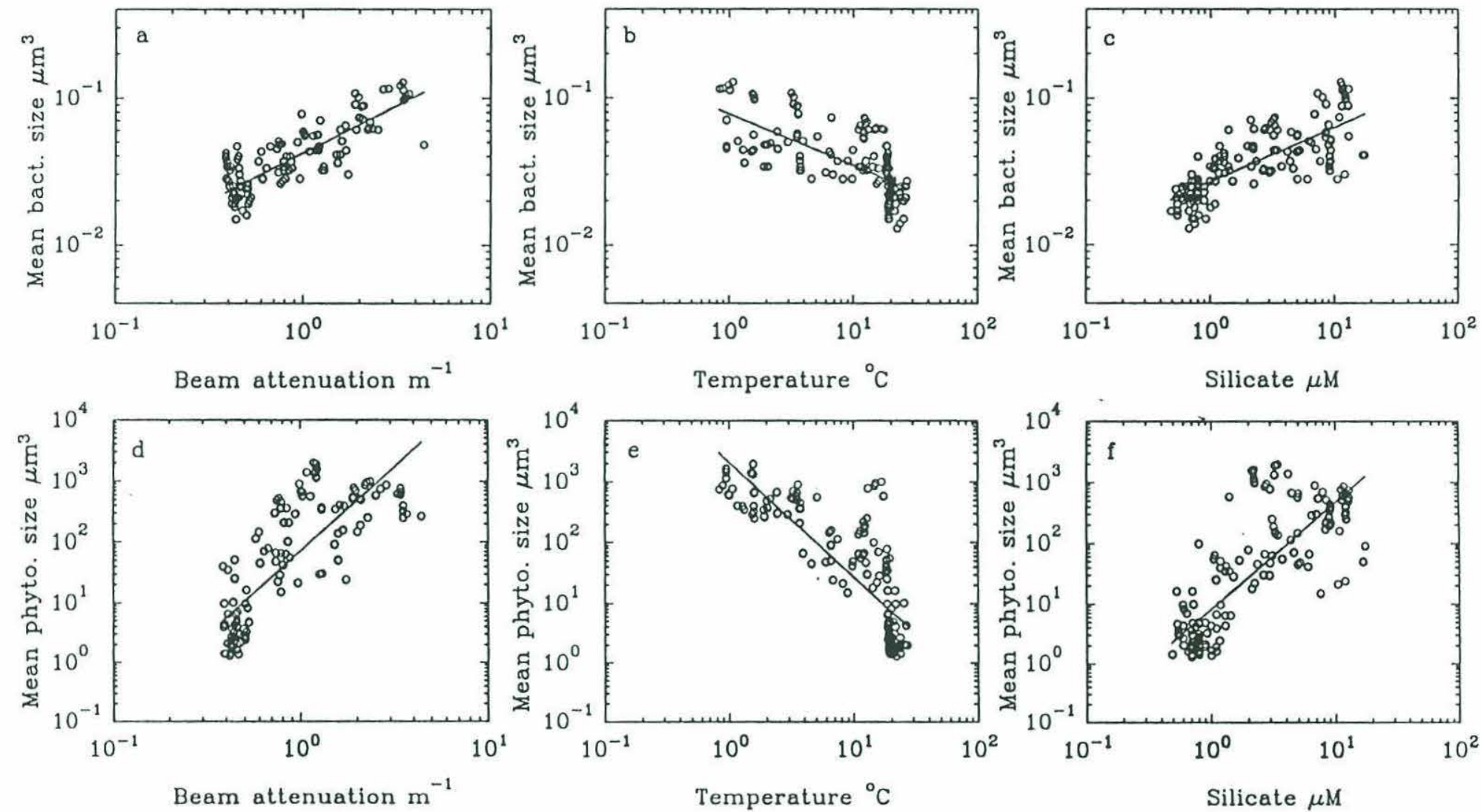

Fig. 4.10. Relationships between mean bacteria size (a, b, c) and mean phytoplankton size (d, e, f) with beam attenuation, temperature and silicate. Data were pooled from all samples excluding the deepest oceanic samples greater than $160 \mathrm{~m}$. Corresponding coefficients of regression are found in Tables 4.3 and 4.4. 
correlations ( $\mathrm{r} \sim 0.4)$. If, however, the spectral parameters are regressed against total nitrogen (dissolved inorganic nitrogen plus PON), the relationships with mean bacteria size, bacteria slope and mean phytoplankton size become more significant $(r>0.6)$.

\section{DISCUSSION}

\section{The Range and Variability of Microbial Size Spectra}

In this study, the characteristics of microbial size spectra from diverse marine ecosystems have been presented. Oligotrophic waters of the Sargasso Sea characterized by low nutrients and low productivity gave normalized concentration size spectra that were relatively steep (eg. phytoplankton slope $~-1.8$ ). In addition, high nutrient low chlorophyll waters of the equatorial Pacific also gave similar steep slopes typical of the oligotrophic Sargasso Sea. In contrast, more eutrophic coastal waters of the Massachusetts and Cape Cod Bay areas with high nutrients and high productivity were typified by less steep phytoplankton slopes, with values greater than -1.8 to a maximum of about -1.35 for Boston Harbour.

Studies on freshwater phytoplankton encompassing lakes of different productivity gave equivalent slopes of -1.64 and -1.41 for oligotrophic and eutrophic systems respectively, (Rodriguez et. al., 1990, Rojo \& Rodriguez, 1994). (Note that these slopes were originally presented in terms of the normalized biomass size spectrum but can be reexpressed in terms of the normalized concentration size spectrum as discussed in the Methods section.) Their results fall within the range of our field data although the minimum values $(-1.8)$ we encountered were much lower. In fact, this minimum slope value is the same as that of the size spectrum of maximum phytoplankton cell concentration achieved at stationary phase in culture (Agusti \& Kalff, 1989), as well as particular size spectra near the chlorophyll maxima of the Massachusetts and Cape Cod Bay stations in late summer (Gin, 1996). The common environmental factor in these three examples were the relatively nutrient stressed conditions phytoplankton were experiencing. We hypothesize that the steep phytoplankton slope corresponding to a 
value of around - 1.8 represents a lower bound to the size structure of phytoplankton cells and occurs under nutrient limiting conditions. (Note that while the equatorial Pacific has relatively high concentrations of inorganic nutrients, the waters are limited in the trace metal, iron, thereby also limiting primary production.) At the other extreme, the maximum slope value of around -1.3 could represent an upper bound corresponding to high productivity or high nutrient environments. Our field data showed that such size spectra were typical of the shallow coastal locations in Boston Harbour and Cape Cod Bay in the winter/early spring where mixing and high nutrient concentrations prevailed.

The inclusion of bacteria to the size spectrum of phytoplankton generally resulted in steeper slopes than from phytoplankton alone. However, the same trend of increasing slope value was obtained from oligotrophic to eutrophic waters ie. from -2.0 to -1.75 . These results fall within the same range as that measured in another study of some 15 freshwater lake sites, where organisms ranged from 0.2-1600 $\mu \mathrm{m}$ (Ahrens \& Peters, 1991b).

\section{Environmental Regulation of Size Spectra}

Our results showed that mean bacteria size, bacteria intercept, mean phytoplankton size and phytoplankton slope were the characteristics of microbial size spectra most sensitive to environmental changes. In particular, good correlations were found between these spectral characteristics and primary production, $\mathrm{POC}, \mathrm{PON}$, integrated biomass,

chlorophyll, beam attenuation, total nitrogen, silicate, phosphate and temperature $(r>0.6)$. These results are consistent with a shift in the size spectrum to a relative dominance of large bacteria and large phytoplankton with eutrophication. At the same time, the relatively poor correlation between eutrophication indicators and the phytoplankton intercept supports the hypothesis that an upper limit may exist for picoplankton abundance in the field. As with size fractionation chlorophyll studies (Raimbult et. al., 1988, Hopcroft \& Roff, 1990, Robles-Jarero \& Lara-Lara, 1993), our results showed that the 
variability in size structure associated with eutrophy is due progressively to larger and larger cells.

In a previous study, the seasonal variations in phytoplankton size spectra of the same locations in Massachusetts and Cape Cod Bays were examined and found to show a predominance of small cells in the latter part of summer, where biomass levels were generally higher than the earlier spring bloom period (Gin \& Chisholm, 1996). This trend in spectral characteristics at the level of seasonal perturbations is different from the overall trend observed for biomass levels across ecosystems of different trophic states, where the latter show a relatively greater importance of larger cells for systems of higher biomass. The question of whether a system is undergoing a transient change in the size spectrum or is at steady state needs to be considered when examining spectral trends and patterns (Gaedke, 1992). For example, at the beginning of the spring bloom at the temperate coastal stations, most of the nitrogen is present in the water column, whereas at the height of the growing season, most of the nitrogen is incorporated into biomass and very little is actually measured in the water column. Nitrogen is also known to be the limiting nutrient for primary production in Massachusetts and Cape Cod Bays at certain times of the year (Townsend et. a., 1990). As such, instantaneous ambient dissolved inorganic nitrogen levels were poorly correlated with size spectral characteristics. Total PON plus dissolved inorganic nitrogen, on the other hand, was better correlated to size spectra because unsteady effects were lessened. In dynamic situations, trends in the spectra appear to be be more sensitive to the direction of change in nitrate concentrations, rather than absolute biomass or nitrate levels ie. as nitrate levels diminished, the spectra shifted towards smaller cells. From an ecosystem level of analysis, the same can be said for the shift from eutrophic to oligotrophic systems, where decreasing overall nitrate concentrations resulted in the relative predominance of small cells.

In contrast to nitrate, however, ambient values of silicate and phosphorus were better correlated with the characteristics of size spectra across ecosystems, partly because these nutrients were not limiting production. Silicate, in particular, showed very good 
positive correlations with mean cell size, the bacteria intercept and phytoplankton slope $\left(\mathrm{R}^{2} \sim 0.7\right.$ to 0.8$)$ ie. higher silicate concentrations were associated with a greater relative proportion of large cells, both for phytoplankton and bacteria. Silicon is required by diatoms in the formation of their cell walls and our results suggest that the increase in fraction of large cells with eutrophication is due mainly to an increase in diatoms. In addition, increases in silicate are also associated with a predominance of large bacteria even though bacteria do not use silicate directly for growth. Bacteria do, however, depend on phytoplankton release of dissolved organics/ exudates for heterotrophic consumption (Goldman et. al., 1979, Azam et. al., 1983, Cole et. al., 1988) and diatom growth may be intimately linked with the growth of large bacteria cells.

While the effects of temperature on cell metabolic rates are well known (Gordon et. al., 1980, Shiah \& Ducklow, 1994), the effects on cell size are less obvious. The influence of temperature on bacteria cell size, for example, is contradictory:- some studies report that temperature has no effect (Cole et. al., 1993) while other studies have found an inverse relationship with size (Chrzanowski et. al., 1988). We also found a strong inverse correlation between temperature and the size spectra of both bacteria and phytoplankton. This is due to the effect of temperature on the stability of the water column and hence, the supply of nutrients to microorganisms, as suggested by Kiфrboe, 1993. Decreasing nutrient concentrations were usually accompanied by stratification in warm temperatures, where the stability of the water column prevented nutrient replenishment through physical processes. These high temperatures were generally correlated with microbial size spectra that were skewed to smaller size classes with steeper normalized phytoplankton slopes of about -1.8 (eg. the open ocean waters and the temperate coastal locations in late summer) and a relative importance of small bacteria. On the other hand, the dominance of large bacteria and large phytoplankton or less steep normalized size spectra (-1.3) were linked to weakly stratified or mixed waters. Such environments were typical of colder temperatures in winter, early spring or late fall where cooling of surface waters enhanced convective exchange. Mixed conditions were also evident at the mouth of Boston 
Harbour throughout the year because of strong tidal currents. In such waters, turbulence plays the critical role in delivering nutrients to autotrophic cells as well as preventing these large cells from settling out of the water column. The associated size structure of phytoplankton in these bloom conditions could be controlled by light limitation as self shading effects have been known to increase with larger cells (Geider et. al., 1987). Environmental measurements of beam attenuation and particulate matter during this time also showed higher turbidity levels in the water column (especially in Boston Harbour) which strongly suggest light limitation of phytoplankton.

\section{A Comparison of Field Measurements with Steady State Models of the Size}

\section{Spectrum}

The size spectrum typical of open ocean environments has been explained by a number of different theoretical models. One of the earliest models to describe size spectra . for unicells was proposed by Platt and Denman $(1977,1978)$. By considering the steady state flux of biomass from small to large organisms through a balance of anabolism and catabolism and using published values of physiological rules, the authors predicted that the equivalent slope of the normalized concentration size spectrum would be -1.82 . This is essentially the same as the lower bound values obtained in our measurements of phytoplankton size spectra as well as that of maximum cell concentration in culture (Agusti \& Kalff, 1989). While size-based physiological constraints have been suggested to be the underlying reason for the characteristics of size spectra, other studies argue that geometric constraints could be responsible (Duarte et. al., 1987). In these latter studies, the maximum cell concentration when re-expressed in terms of the average distance between organisms, was found to be proportional to the length of the organism. The fact that the diffusive range of a particle has also been shown to scale with the linear dimensions of a cell (Silvert \& Platt, 1980) suggests that space restrictions could indeed play an important role in determining the upper abundance of cells. 
Other models used to explain the steady state size spectrum of micro-organisms focused on grazing as the main mechanism of biomass transfer up the food chain (Silvert \& Platt, 1980, Boudreau et. al., 1991, Kiefer \& Berwald, 1991). Grazing models differ from earlier physiological models in that steady state growth rates were assumed to increase with increases in both predator and prey concentrations instead of being uniquely determined by cell size as with allometric rules. This is also supported by increasing evidence which show that growth rates for micro-organisms are less likely to be tightly related to size (Banse, 1982). Respiration losses are also treated implicitly in grazing hypotheses through an assimilation efficiency and are considered less important than losses by predation. One such grazing model describes a random encounter event in which phagotrophic cells swim randomly through the water encountering prey of smaller size within a certain size range (Keifer \& Berwald, 1991). The model assumes that the clearance rate by a predator is proportional to the square of its diameter and that prey sizes vary with predator sizes. The conceptual framework for the random encounter model appears particularly relevant to unicellular organisms in the size range 0.3 to 100 $\mu \mathrm{m}$ where the absence of physical refuges exposes cells to predation. The model predicts an equivalent slope of -2.0 for the normalized concentration size spectrum which is slightly lower than our averaged slope measured from open ocean waters, but still within the range of values encountered.

Recent theoretical developments suggest that the size structure of an ecosystem can be analyzed at two levels:- one that spans the entire size range of organisms and the other, at the level of a trophic group of organisms where the production efficiency is constant (Dickie et. al, 1987, Boudreau et. al., 1991). The first level corresponds to an overall physiological scaling, reflecting the metabolic constraints of organisms with size, whilst the second is an ecological scaling which allows for population density adjustments to changes in food supply (eg. Gaedke, 1992, Sprules \& Goyke, 1994). Using a generalized model of energy flow from prey to predator (grazing) coupled with the allometric function of specific production, it was shown that the biomass size spectrum 
(log scales) of a subgroup at the ecological scaling conforms to a parabola, plus a periodic function (Thiebaux \& Dickie, 1992, 1993). The parabolic function follows from predatorprey interactions and their allometric features, whilst the periodic component is based on the premise that predators in aquatic ecosystems generally feed on prey that are smaller by a fixed ratio. The model formulation, however, does not apply to the bacteria end of the spectrum where other mechanisms operate. Our results showed that the bacteria biomass size spectra did comprise of parabolic domes, but were compressed because of the more restricted size range of these organisms. In the case of phytoplankton, approximate parabolic domes could also be identified, although in the coastal samples, the tail end of the spectrum appeared to be truncated because of the greater predominance of microplankton (NB. size range was approximately 0.2 to $70 \mu \mathrm{m}$ ).

\section{Explanation of Dynamic Changes in the Size Spectrum Based on Nutrient Uptake Kinetics}

While the above models are able to describe the size spectra of steady state systems of open ocean environments, further work is necessary to model the dynamics of size spectra, particularly at the smaller end of the scale where mechanisms such as nutrient uptake kinetics and the reverse flow of carbon (eg. through exudation and remineralization) need to be accounted for. These concepts have recently been incorporated into sized-based ecosystem models of carbon and nutrient flows in the Southern Benguela region (Maloney \& Field, 1991a,b) as well as the Sargasso Sea (Hurtt \& Armstrong, 1995). In oligotrophic environments, the predominance of small cells can be explained by nutrient uptake kinetics. Nutrient uptake depends on cell surface area and therefore small cells will generally outcompete larger cells because of their higher surface area to volume ratio ie. specific uptake rate is inversely proportional to cell radius (eg. Smetacek, 1985). Nutrient levels have been found to influence cell uptake rates through a hyperbolic law that is defined by two constants:- the maximum specific uptake rate $\mu_{\mathrm{m}}$ and the half-saturation constant, $\mathrm{K}_{s}$ (Monod, 1942). Empirically, both these values have been 
found to be size dependent although in different ways:- $\mu_{\mathrm{m}}$ is negatively correlated with size (Laws, 1975, Banse, 1982) whereas $\mathrm{K}_{\mathrm{s}}$ is positively correlated (Malone, 1980). At low nutrient concentrations, small cells will tend to have higher uptake rates than large cells and thus, can easily dominate the situation. In particular, when nutrient concentrations are exceptionally low, the diffusion rate of molecules towards the cell surface may limit the nutrient supply to the cell (Hudson \& Morel, 1991). If the potential uptake rate exceeds the diffusion rate, a nutrient-depleted region around the cell will be established and the uptake rate becomes diffusion limited. By considering diffusive flux of nutrient to the cell, the diffusion-limited nutrient uptake rate is calculated to be proportional to the inverse of the squared cell radius (Chisholm, 1992, Kiфrboe, 1993). Thus, small size is a major competitive advantage both from the point of view of higher specific uptake rates and when diffusion processes are controlling uptake at low nutrient concentrations. This is consistent with the results from this study which showed that oligotrophic waters were characterized by the predominance of small cells, not only as a fraction of the whole community but also within the individual subgroups of bacteria and phytoplankton. Similarly, under stratified, nutrient stressed conditions in summer, size spectra from coastal temperate waters shifted towards smaller cells which presumably were able to incorporate nutrients more efficiently.

Although the above considerations could explain why small cells dominate oligotrophic or nutrient poor waters, they do not explain why large cells should exist at all in these environments. Several possible mechanisms exist which can enhance the advective transport of nutrients to the cell surface under stratified, nutrient-poor conditions (Chisholm, 1992). These include adaptations such as swimming and/or sinking (Kiфrboe, 1993). However, these effects only partially compensate for the disadvantages of being large - very large cells would still be ineffective as they would tend to sink rapidly out of the photic zone because settling velocity is proportional to the square of the radius (Smayda, 1970). Other mechanisms include adjusting cell buoyancy to facilitate daily excursions between the nutricline and surface waters (Villareal \& Carpenter, 1989), 
symbiosis with nitrogen-fixing cyanobacteria (Heinbokel, 1986, Martinez et. al., 1983) and adapting cell shapes to increase surface area (Grover, 1989). On the other hand, large cells are able to dominate eutrophic environments where generally higher levels of resources exist. Recent evidence suggests that the negative dependency of specific growth rates on size for phytoplankton is quite weak. For example, the growth rates of many larger phytoplankton species have been found to be comparable or even faster than that of smaller species (Banse, 1982). This result, coupled with a greater capacity for luxuriant nutrient uptake (Droop, 1968, Goldman \& McCarthy, 1978) helps to push the competitive advantage to large cells in high nutrient environments, as observed in the more eutrophic coastal waters. Diatoms, in particular, appear to be well-adapted to these situations often resulting in blooms. Eventually, however, excessive phytoplankton growth could impose light limitation, thus setting an upper bound to the size spectrum, as observed in the spring and fall bloom in Boston Harbour.

Our results further show that large bacteria are generally associated with large phytoplankton and vice versa (Fig. 4.11, Table 4.5). The correlation between mean bacteria size and mean phytoplankton size is consistent with the nutrient uptake argument where high phytoplankton biomass levels would result in a greater release of dissolved organic carbon for heterotrophic bacteria consumption, and thus favour larger bacteria. Earlier studies showed that in the euphotic zone of the oligotrophic open ocean, the biomass of bacteria may be more than 2-3 times that of phytoplankton (Fuhrman et. al., 1989, Cho \& Azam, 1990) although more recent measurements suggest that these estimates may be too high (Caron et. al., 1994, Gin et. al., 1996). This is due in part to the problem of choosing empirical factors to convert cell size to biomass (Caron et. al., 1994). Nevertheless, the results from our comparison across diverse ecosystems did show that oceanic waters generally had a greater proportion of bacteria by biomass than coastal waters (Fig. 4.12). The exception, however, is for Boston Harbour, whose close proximity to a sewer outfall may have created exceptionally favourable conditions for bacteria growth, especially large bacteria. In addition, the region is also subject to 

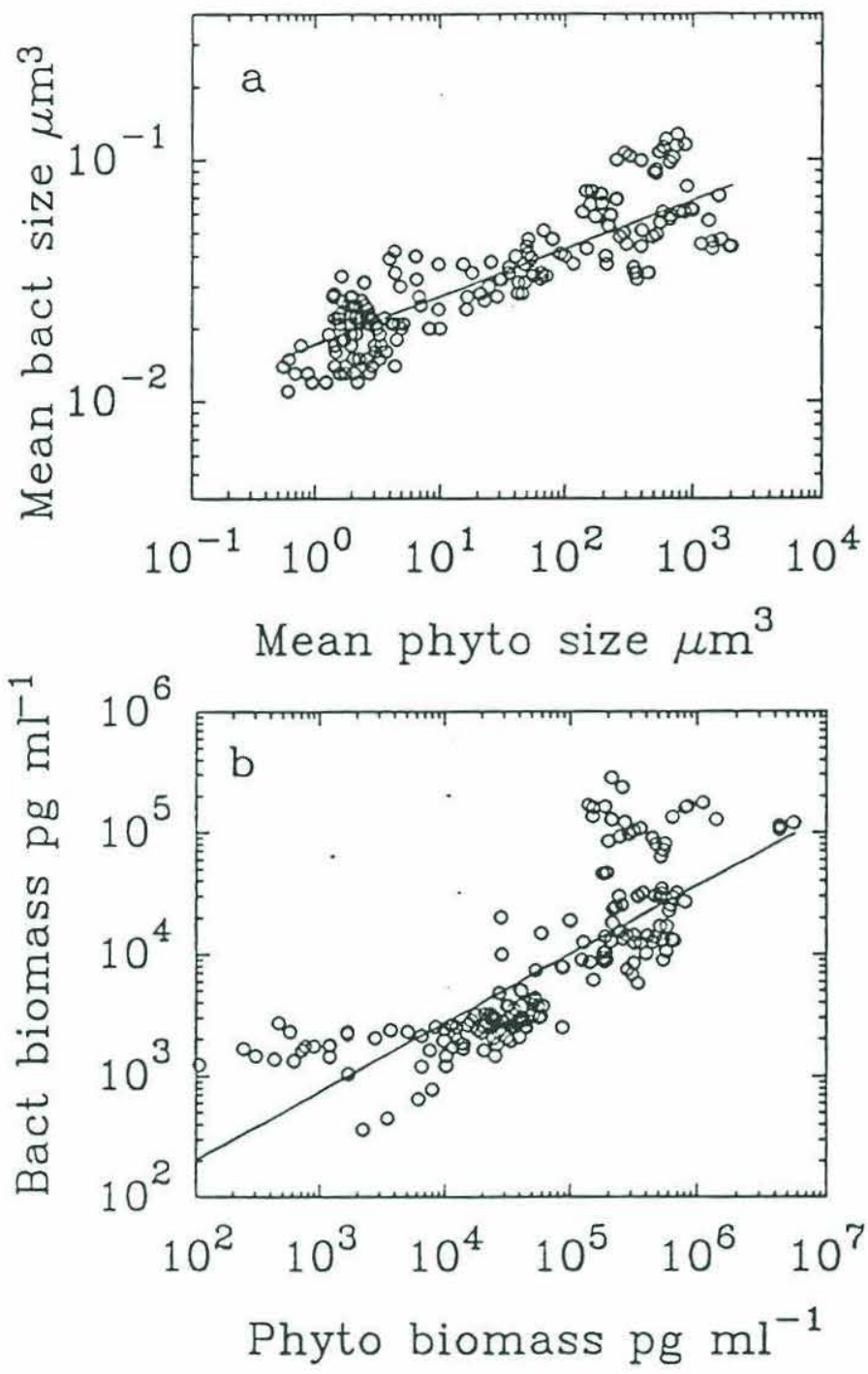

Fig. 4.11. Positive correlation relationships between a) mean bacteria population size and mean phytoplankton population size and b) total bacteria biomass and total phytoplankton biomass. Data were pooled from all locations excluding the deepest oceanic samples greater than $160 \mathrm{~m}$. Corresponding coefficients of regression are found in Table 4.5. 

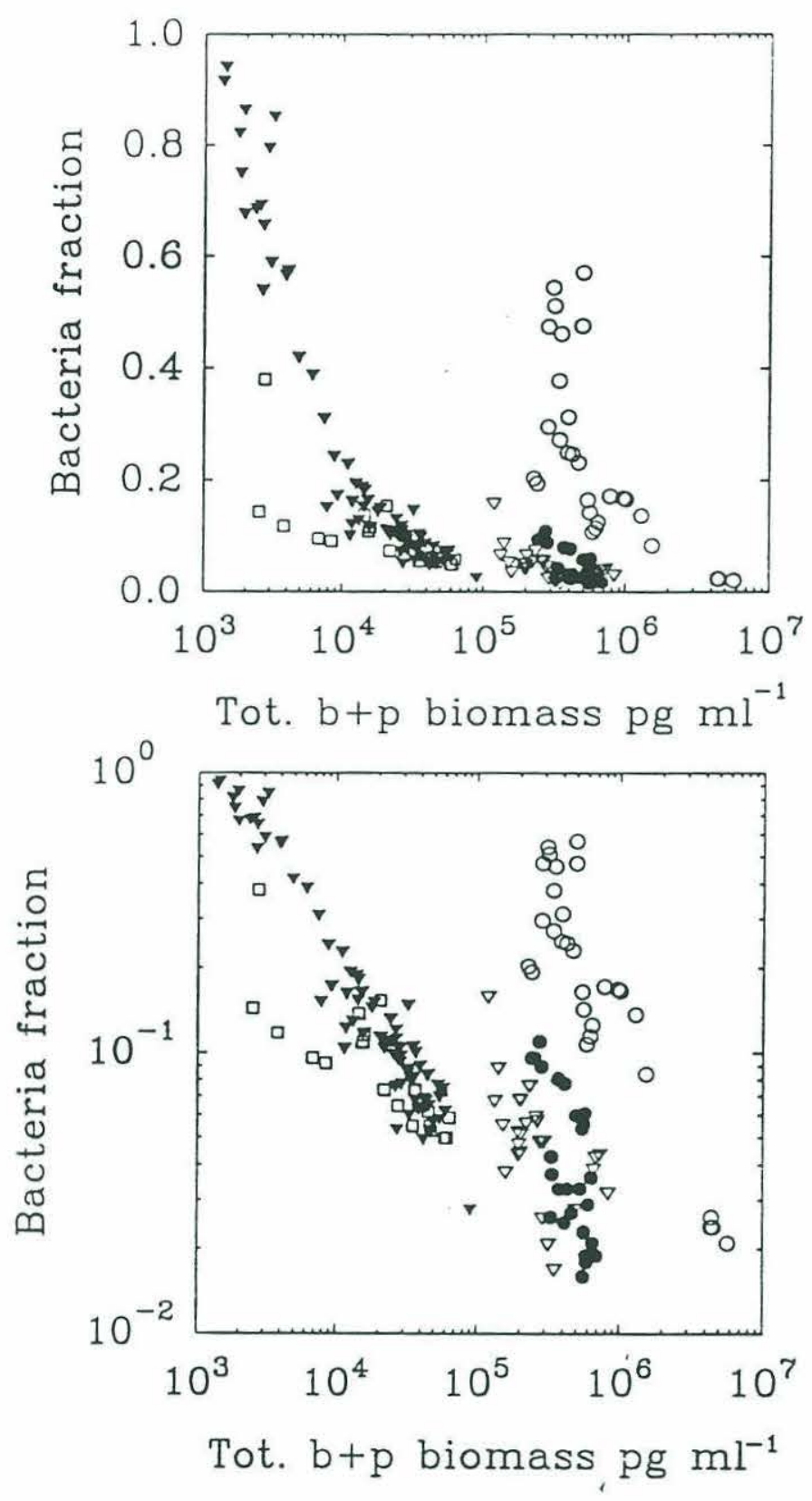

Fig. 4.12. Fraction of bacteria by biomass in total community plotted on linear and log scales for Boston Harbour (open circle), Cape Cod Bay (closed circle), Massachusetts Bay (open triangle), the Sargasso Sea (closed triangle) and the equatorial Pacific (square), excluding the deepest oceanic samples greater than $160 \mathrm{~m}$. 
periodic discharges of untreated combined sewer overflows from Boston city (Rex, 1991). Overall, however, a relative increase in bacteria biomass is believed to result in a more rapid and efficient recycling mechanism through the microbial loop (Azam et. al., 1983). Coupled with the fact that small cells have high surface area to volume ratios, rapid growth rates and slower sinking rates, the greater fraction of bacteria could enhance the retention of nutrients contained in organisms remaining within the photic zone and thus enhance ecosystem efficiency (Wehr and Campbell, 1994).

The results also show that the size niche occupied by the very small phytoplankton, Prochlorococcus, in oligotrophic oceanic waters (ie. $\sim 10^{-1} \mu \mathrm{m}^{3}$ or $0.6 \mu \mathrm{m}$ diameter) is occupied by large bacteria in eutrophic coastal waters (eg. Fig. 4.1). (Note that small bacteria less than $10^{-2} \mu \mathrm{m}^{3}$ are present in both types of environment.) That very small autotrophic picoplankton should be present in such high concentrations in oceanic waters is in accord with the low nutrient regime of these waters:- low levels of inorganic nutrients would favour small phytoplankton and low primary production would result in low levels of organic exudates that would favour small bacteria. While small cells would generally result in a greater retention of nutrients in the water column compared to large cells because of reduced sinking losses, recent studies on lake picoplankton reveal that greater sedimentation losses (or downward nutrient fluxes) were associated with bacteria compared to picophytoplankton (Wehr and Campbell, 1994). In nutrient stressed lake waters, picophytoplankton were found to better retain nutrients in the water column, perhaps because of the higher $\mathrm{C}: \mathrm{N}$ and $\mathrm{C}: \mathrm{P}$ ratios of phytoplankton compared to bacteria (Caron, 1991) ie. bacteria are more likely to be limited by inorganic nutrients than phytoplankton of similar size in nutrient stressed environments (Thingstad, 1987). Thus, phytoplankton play both complementary and competitive roles with bacteria:- production of phytoplankton exudates favours or complements bacterial growth whereas under nutrient stressed environments, picophytoplankton can potentially outcompete large bacteria for scarce inorganic nutrients $(\mathrm{N}, \mathrm{P})$ and at the same time, enhance ecosystem efficiency in the microbial loop. 


\section{Explanation of Dynamic Changes in the Size Spectrum Based on Grazing}

\section{Mechanisms}

It has also been argued that the dominance of large cells in eutrophic environments is a consequence of reduced predation on large cells. This hypothesis is based on the observation that in planktonic food chains, small prey are generally eaten by small predators and large prey are eaten by large predators (Sheldon et. al., 1977, Azam et. al., 1983, Monger \& Landry, 1991). For large phytoplankton size to provide a refuge from predation, the relative concentration of predators must either decrease with increasing cell size and/or generation times of predators must increase more rapidly than generation times of their prey populations, yielding a lagged numerical response (Kiфrboe, 1993). Both appear to be the case for the marine pelagial. Studies on the specific growth rates of heterotrophic organisms reveal a body mass dependency with a mass exponent of about 0.25 to -0.35 (Laws, 1975, Peters, 1983). However, the relationship between phytoplankton specific growth rates and body size appears to be weaker with the weight exponent varying between -0.11 to -0.17 (Banse, 1982, Joint, 1991). Since the generation times of both unicellular and multicellular organisms are inversely proportional to the specific growth rate, it follows that the generation time increases faster with size in zooplankton predators than in their phytoplankton prey populations. Thus, the lag in zooplankton response to phytoplankton blooms will be increased with increasing phytoplankton cell size and mesozooplankton will generally be unable to control population sizes of large phytoplankton.

This argument could also explain the size spectral characteristics from the coastal eutrophic stations in spring. While nutrients must be high in order to stimulate growth of large phytoplankton, the continued existence of large cells is more likely a consequence of the slow numerical response of larger grazer populations, especially when temperatures are low resulting in lower growth and metabolic rates of zooplankton (Vidal, 1980). In stratified oligotrophic waters, the mere presence of large though rare cells, despite the inherent disadvantages of being large, can also be explained because their risk of being 
eaten is lower. In the case of picoplankton, the generation times of small phytoplankton and bacteria are of the same order of magnitude as their protozoan predators (Kiфrboe, 1993). Hence, even though small prey cells are more efficient in nutrient uptake and growth, their populations are more susceptible to control by grazer populations. This could explain the strikingly constant and relatively low concentration of picoplankton in oligotrophic oceans as well as the upper limit to picoplankton abundance that is observed in our size spectral results and size-fractionated chlorophyll studies (Raimbult, 1988, Chisholm, 1992). At the same time, the closely coupled relationship between picoplankton and their grazers would be beneficial in recycling scarce nutrients back into the water column through the microbial loop (Azam \& Smith, 1991). In particular, the predominance of small bacteria in oligotrophic waters supports laboratory experiments which show preferential grazing of large bacteria (Simek \& Chrzanowski, 1992, Gin, 1996). Since the C:N ratio of bacteria is generally less than that of phytoplankton, preferential grazing of large bacteria as opposed to phytoplankton of similar size would imply better regeneration of nutrients through the microbial loop.

The size spectrum of the microbial community has important implications in understanding the structure and function of the pelagic ecosystem. We have shown that productive coastal waters are characterized by pronounced dome shaped biomass size spectra and dominated by large bacteria and large phytoplankton. This community structure typically supports the classical herbivorous food chain, which comprises few trophic levels and is based on new nitrogen entering the ecosystem (Cushing, 1989, $\mathrm{Ki} \phi$ rboe, 1993). Such ecosystems usually give rise to a net accumulation of catchable biomass which is important for fisheries. In contrast, the flatter biomass spectra observed for steady state oceanic systems could reflect the significant variations in predator-prey interactions that arise from competitive systems over prolonged periods (Thiebaux \& Dickie, 1993). In these oligotrophic environments where nutrients are scarce, the dominance of small bacteria and small phytoplankton support the hypothesis of a microbial based food web where processing of material is more efficiently channelled through small 
sizes (Azam et. al., 1983, Cho \& Azam, 1990). These microbial food webs are typically long and primarily based on regenerated production which is retained within the ecosystem.

\section{CONCLUSIONS}

The results of this study confirm previous studies in that mean cell sizes generally increase with increasing eutrophy of marine ecosystems. However, by using size spectra to measure the biological characteristics of the system, a better resolution of the microbial community can be made which offers a framework to explore the mechanistic functions at work in the food web. In particular, it was found that the phytoplankton slope and the bacteria intercept were well correlated with indicators of trophic state, such as POC, chlorophyll, primary productivity, total nitrogen and silicate. The slope of the phytoplankton size spectrum across ecosystems of different productivity and trophic state ranged from a minimum averaged value of about -1.8 for oligotrophic, low productivity waters in the Sargasso Sea and equatorial Pacific to a maximum of about -1.3 for coastal productive waters in Massachusetts and Cape Cod Bays. With bacteria included in the size spectrum, the slope ranged from about -2 to -1.7 for oceanic and coastal waters respectively. Our results showed that large cells (corresponding to higher slope values) were typically associated with turbulent mixed waters where nutrient concentrations were high. In particular, the good correlation between silicate and the prevalence of large cells confirm that diatoms play a major role as ecosystem productivity increases. The dominance of large cells could also be explained by the dynamic interactions between larger phytoplankton and their predators ie. the considerable timelag between large cells and their metazooplankton predators implies that blooms will initially be left unchecked. In these conditions, light may be the limiting factor leading to an upper bound of the size spectrum of the microbial community. Conversely, under warm stratified conditions, a shift towards both small bacteria and phytoplankton sizes was observed since small cells are superior competitors when it comes to nutrient stressed environments. Large cells 
were rare presumably because of their lower growth rates at reduced nutrient concentrations, lower nutrient uptake kinetics and greater tendency to sink out of the photic zone under stratified conditions. For pico and small nanoplankton, it appears that populations could be more tightly controlled by predator-prey interactions since the generation times of predator and prey are comparable. Thus, populations of pico and small nanoplankton were generally more stable in time and space (ie. phytoplankton intercept was less variable) compared to the large fluctuations observed with larger nano and microplankton (reflected in slope changes) for ecosystems of increasing productivity.

\section{ACKNOWLEDGEMENTS}

We would like to thank Keith Lichten, Laurel Schaider, Dave Borkman and Toni Chute for helping to collect our coastal samples; Erik Zettler and Nicole Poulton for analyzing the oceanic nano/microplankton and picoplankton on the flow cytometers; Sheila Frankel, Brian Binder, Carol Duval and Kent Bares for development of analytical protocols for the flow cytometers; Michelle DuRand and Lana Aref for their help in calibrating the instruments for size; Jim Murray, Wilford Gardner, Robert Bidigare and Patricia Wheeler for their equatorial Pacific environmental measurements. The work was supported by the Massachusetts Water Resources Authority contract \#S179, National Science Foundation Ocean Division (USJGOFS) OCE-9022285, OCE-9302529, OCE9012117, NOAA-Sea Grant (MIT) and fellowhip support from the National University of Singapore Overseas Scholarship.

\section{REFERENCES (chapter 4)}

Agusti., S. and Kalff, J. 1989. The influence of growth conditions on the size dependence of maximal algal density and biomass. Limnol. Oceanogr. 34 (6): 1104-1108.

Ahrens, M.A. and Peters, R.H., 1991a. Plankton community respiration: relationships with size distribution and lake trophy. Hydrobiologia 224: 77-87. 
Ahrens, M. and Peters, R. 1991b. Patterns and limitations in limnoplankton size spectra. Can J. Fish. Aquat. Sci. Vol 48: 1967-1978.

Albro, C.S., Kelly, J.R., Hennessy, J., Doering, P. and Turner, J., 1993. Combined work/quality assurance project plan for baseline water quality monitoring: 1993-1994. Massachusetts Water Resources Authority, Boston, MA. Miscellaneous Report 14. 73pp.

Aref, L., 1996. Forward light scatter and how it relates to phytoplankton size in flow cytometry. MSc thesis, MIT.

Azam, F., Fenchel, T., Field, J.G., Gray, J.S., meyer-Reil, L.A. and Thingstad, F., 1983. The ecological role of microbes in the sea. Mar. Ecol. Prog. Ser. 10: 257-263.

Azam, F. and Smith, D.C., 1991. Bacterial influence on the variability in the oceans's biogeochemical state: a mechanistic view. in S. Demers (ed.) Particle analysis in oceanography.Springer-Verlag, Vol G27.

Banse, K., 1982. Cell volumes, maximal growth rates of unicellular algae and ciliates and the role of ciliates in the marine pelagial. Limnol. Oceanogr. 27: 1059-1071.

Barber, R.T. and Chavez, F.P., 1991. Regulation of primary productivity rate in the Equatorial Pacific. Limnol. Oceanogr. 36(8): 1803-1815.

Boudreau, P.R., Dickie, L.M. and Kerr, S.R., 1991. Body-size spectra of production and biomass as system-level indicators of ecological dynamics. J. Theor. Biol. 152: 329-339.

Bratbak, G. and Thingstad, T.F., 1985. Phytoplankton-bacteria interactions: an apparent paradox? Analysis of a model system with both competition and commensalism. Mar. Ecol. Prog. Ser. 25: 23-30.

Caron, D., 1991. Evolving role of protozoa in aquatic nutrient cycles. In Reid P.C. et. al. (eds) Protozoa and their role in marine processes. (NATO-ASI Series, G25) SpringerVerlag, Heidelberg.

Caron, D.A., Dam, H.G., Napp, J.M., Kremer, P., Lessard, E.J., Madin, L.P., Malone, T.C., Peele, E.R., Roman, M.R. and Youngbluth, M.J., 1995. The contribution of microorganisms to particulate carbon and nitrogen in surface waters of the Sargasso Sea near Bermuda. Deep Sea Res. Vol.42(6): 943-972.

Chavez, F.P., 1989. Size distribution of phytoplankton in the central and eastern tropical Pacific. Global Biogeochem. Cycles 3: 27-35 
Chisholm, S.W., Olson, R.J., Zettler, E.R, Goericke, R., Waterbury, J. and Welschmeyer, N., 1988. A novel free-living prochlorophyte abundant in the oceanic euphotic zone. Nature 334: 340-343.

Chisholm, S.W., 1992. Phytoplankton size. in P. Falkowski (ed.) Primary production and biogeochemical cycles in the sea, Brookhaven Syposium on Biology, 37.

Cho, B. C., Azam, F., 1990. Biogeochemical significance of bacterial biomass in the ocean's euphotic zone. Mar. Ecol. Prog. Ser. 63: 253-259.

Cole, J.J., Findlay, S. and Pace, M.L., 1988. Bacterial production in fresh and saltwater ecosystems: a cross-system overview. Mar. Ecol. Prog. Ser. 43: 1-10.

Cole, J.J., Pace, M.L., Caraco, N.F. and Steinhart, G.S., 1993. Bacterial biomass and cell size distribution in lakes: More and larger cells in anoxic waters. Limnol. Oceanogr. 38(8): 1627-1632.

Chrzanowsky, T.H., Crotty, R.D. and Hubbard, G. J., 1988. Seasonal variation in cell volume of epilimnetic bacteria. Microb. Ecol. 16: 155-163.

Cushing, D.H., 1989. A difference in structure between ecosystems in strongly stratified waters and those that are only weakly stratified. J. Plankton Res. 11: 1-13.

Dickie, L.M., Kerr, S.R. and Boudreau, P. R., 1987. Size-dependent processes underlying regularities in ecosystem structure. Ecol. Mono. 57(3): 233-250.

Droop, M.R, 1968. Vitamin $B_{12}$ and marine ecology. 4. The kinetics of uptake, growth, and inhibition in Monochrysis lutherii. J. Mar. Biol. Assoc. U.K. 48: 689-733.

Duarte, C.M., Agusti, S. and Peters, H. 1987. An upper limit to the abundance of aquatic organisms. Oecologia (Berlin) 74: 272-276.

DuRand, M.D., 1995. Phytoplankton growth and diel variations in beam attenuation through individual cell analysis. Ph.D. Thesis. MIT/WHOI: 263pp.

Duval, C., 1993. Phototrophic and Heterotrophic Picoplankton in the Equatorial Pacific: Analysis by Flow Cytometry. MSc thesis. Massachusetts Institute of Technology.

Echevarria, F. and Rodriguez, J., 1994. The size structure of plankton during a deep bloom in a stratified reservoir. Hydrobiologia 284: 113-124. 
Fuhrman, J.A., Sleeter, T.D., Carlson, C.A. and Proctor, L.A., 1989. Dominance of bacterial biomass in the Sargasso Sea and its ecological implications. Mar. Ecol. Prog. Ser. 57: 207-217.

Gaedke, U., 1992. The size distribution of plankton biomass in a large lake and its seasonal variability. Limnol. Oceanogr. 37(6): 1202-1220.

Geider, R.J., 1987. Light and temperature dependence of the carbon to chlorophyll a ratio in microalgae and cyanobacteria: implications for physiology and growth of phytoplankton. New. Phytol. 106: 1-34.

Gin, K.Y.H., 1996. Microbial Size Spectra in Diverse Marine Ecosystems. ScD Thesis, Massachusetts Institute of Technology, Dept of Civil Engineering (in prep).

Gin, K.Y.H. and Chisholm, S.W., 1996. Temporal \& spatial variability of marine microbial size spectra: I. Massachusetts and Cape Cod Bays. (in prep)

Gin, K.Y.H., Chisholm, S.W. and Olson, R. J., 1996. Temporal \& spatial variability of marine microbial size spectra: II. The Bermuda Atlantic time series. (in prep)

Goldman, J.C. and McCarthy, J.J., 1978. Steady-state growth and ammonium uptake of a fast growing marine diatom. Limnol. Oceanogr. 19: 756-766.

Goldman, J.C., McCarthy, J.J. and Peavey, D.G., 1979. Growth rate influence on the chemical composition of phytoplankton in oceanic waters. Nature, 279: 210-214.

Gordon, D.M., Birch, P.B. and McComb, A.J., 1980. The effect of light, temperature, and salinity on photosynthetic rates of an estuarine Cladophora. Bot. Mar. 23: 749-755.

Grover, J.P., 1989. Influence of cell shape and size on algal competitive ability. J. Phycol. 25: 402 .

Heinbokel, J.F., 1986. Occurrence of Richelia intracellularis (Cyanophyta) within the diatoms Hemiaulus haukii and H. membranaceus off Hawaii. J. Phycol. 22: 399.

Hopcroft, R.R. and Roff, J.C., 1990. Phytoplankton size fractions in a tropical neritic ecosystem near Kingston, Jamaica. J. Plankton Res. 12(5): 1069-1088.

Hudson, R.J. and Morel, F.M.M., 1991. Trace metal transport by marine microorganisms: Implications of metal coordination kinetics. Deep Sea Res. 40: 129-150.

Hulburt, E.M., 1962. Phytoplankton in the Southwestern Sargasso Sea and North Equatorial Current, February, 1961. Limnol. Oceanogr. 7: 307-315. 
Hurtt, G.C. and Armstrong, R.A., 1995. A pelagic ecosystem model calibrated with BATS Data. Deep Sea Res. (in press).

Jimenez, F., Rodriguez, J., Bautista, B. and Rodriguez,V., 1987. Relations between chlorophyll, phytoplankton cellabundance and biovolume during a winter bloom in Mediterranean coastal waters. J. Exp. Mar. Biol. Ecol.105: 161-173.

Joint, I. 1991. The allometric determination of pelagic production rates. J. Plankton Res. 13: 69-81.

Jurgens, K., Arnddt, H. and Rothhaupt, K.O., 1994. Zooplankton-mediated changes of bacterial community structure. Microb. Ecol. 27:27-42.

Kadar, S., Leinen, M. and J.W. Murray, 1993. U.S.JGOFS Equatorial Pacific Process Study sampling \& analytical protocols.

Kelly, J., Albro, C., Foster, K., Hennessy, J., Doering, P., Reed, L., Requintina, E., Turner, J. and Borkman, D. 1993. Water quality monitoring in Massachusetts and Cape Cod Bays: annual report for 1992. MWRA Enviro. Quality Dept. Tech. Rpt. Series No. 93-16. Massachusetts Water Resources Authority, Boston, MA: 129.

Kelly, J., Albro, C., Hennessy, J., Turner, J., Borkman, D. and Doering, P., 1994a. Water quality monitoring in Massachusetts and Cape Cod Bays: December 1992, February and March 1993. MWRA Enviro. Quality Dept. Tech. Rpt. Series No. 94-2. Massachusetts Water Resources Authority, Boston, MA: 197.

Kelly, J., Albro, C., Hennessy, J., Turner, J., Borkman, D. and Doering, P., 1994b. Water quality monitoring in Massachusetts and Cape Cod Bays: April and May 1993. MWRA Enviro. Quality Dept. Tech. Rpt. Series No. 94-3. Massachusetts Water Resources Authority, Boston, MA: 143.

Kelly, J., Albro, C., Hennessy, J., Turner, J., Borkman, D. and Doering, P., 1994c. Water quality monitoring in Massachusetts and Cape Cod Bays: June and July 1993. MWRA Enviro. Quality Dept. Tech. Rpt. Series No. 94-11. Massachusetts Water Resources Authority, Boston, MA: 152.

Kelly, J., Albro, C., Hennessy, J., Turner, J., Borkman, D. and Doering, P., 1994d. Water quality monitoring in Massachusetts and Cape Cod Bays: August and September 1993. MWRA Enviro. Quality Dept. Tech. Rpt. Series No. 94-12. Massachusetts Water Resources Authority, Boston, MA: 152.

Kelly, J. R. and Turner, J., 1995. Water column monitoring in Massachusetts and Cape Cod Bays: annual report for 1993. MWRA Environ. Quality Dept. Tech. Rpt. Series No. 95-16. Massachusetts Water Resources Authority, Boston, MA: 162. 
Kiefer, D.A and Berwald, J., 1991. A random encounter model for the microbial planktonic community. Limnol. Oceanogr. (3): 457-467

Kiфrboe, T. 1993. Turbulence, phytoplankton cell size and the structure of pelagic food webs. Adv. in Mar. Bio. 29:1-72.

Knapp, A.H., Michaels, A.F., Dow, R.L., Johnson, R.J., Gundersen, K., Sorensen, J.C., Close, A.R., Howse, F.A., Hammer, M., Bates, N., Doyle, A., Waterhouse, T., 1993.

BATS Methods Manual, version 3. U.S.JGOFS Planning Office, Woodshole, MA.

Knapp, A.H., Michaels, A.F., Dow, R.L., Johnson, R.J., Gundersen, K., Sorensen, J.C., Close, A.R., Hammer, M., Knauer, G.A., Lohrenz, S.E., Asper, V.A., Tuel, M., Ducklow, H., Quinby, H., Brewer, P. and Bidigare, R., 1994. Bermuda Atlantic Time-Series Studies : Data Report for BATS 37- 48. U.S.JGOFS BATS Data Report B-4: 240pp.

Knapp, A.H., Michaels, A.F., Dow, R.L., Johnson, R.J., Gundersen, K., Sorensen, J.C., Close, A.R., Hammer, M., Knauer, G.A., Lohrenz, S.E., Asper, V.A., Tuel, M., Ducklow, H., Quinby, H., Brewer, P. and Bidigare, R., 1995. Bermuda Atlantic Time-Series Studies : Data Report for BATS 49-60. U.S.JGOFS BATS Data Report B-5: 240pp.

Laws, E. A., 1975. The importance of respiration losses in controlling the size distribution of marine phytoplankton. Ecology 56: 419-426.

Laws, E.A. and Bannister, T.T., 1980. Nutrient- and light-limited growth of Thalassiosira fluviatilis in continuous culture, with implications for phytoplankton growth in the ocean. Limnol. Oceanogr. 25: 457-473.

Lee, S. and Fuhrman, J.A., 1987. Relationship between biovolume and biomass of naturally derived marine bacteria plankton. Appl. Envir. Micro. 53: 1298-1303.

Li, W.K., 1994. Phytoplankton biomass and chlorophyll concentration across the North Atlantic. Sci. Mar. 58(1-2): 67-79.

Malone, T.C., 1980. Algal Size. in I. Morris (ed.), The Physiological Ecology of Phytoplankton, Univ. Calif.: 443-463.

Maloney,C.L. and Field, J.G., 1991. The size-based dynamics of plankton food webs. I. A simulation model of carbon and nitrogen flows. J. Plankton Res. 13(5): 1003-1038.

Martin, J.H., Coale, K.H., Johnson, K.S., Fitzwater, S.E., Gordon, R.M., Tanner, S.J., Hunter, C.N., Elrod, V.A., Nowicki, J.L., Coley, T.L., Barber, R.T., Lindley, S., Watson, A.J., Van Scoy, K., Law, C.S., Liddicoat, M.I., Ling, R., Stanton, T., Stockel, J., Collins, C., Anderson, A., Bidigare, R., Ondrusek, M., Latasa, M., Millero, F.J., Lee, K., Yao, W., 
Zhang, J.Z., Friederich, G., Sakamoto, C., Chavez, F., Buck, K., Kolber,Z., Greene, R., Falkowski, P., Chisolm, S.W., Hoge, F., Swift, R., Yungel, J., Turner, S., Nightingale, P., Hatton, A., Liss, P. and Tindale, N.W., 1994. Testing the iron hypothesis in ecosystems of the equatorial Pacific Ocean. Nature 371: 123-129.

Martinez, L., Silver, M.W., King, J.M. and Alldredge, A.L., 1983. Nitrogen fixation by floating diatom mats: A source of new nitrogen to oligotrophic ocean waters. Science 221: 152 .

Menzel, D. W. and Ryther, J.H., 1960. The annual cycle of primary production in the Sargasso Sea off Bermuda. Deep Sea Res. 6: 351-367.

Minas, H. J., Minas, M. and Train Packard, T., 1986. Productivity in upwelling areas deduced from hydrographic and chemical fields. Limnol. Oceanogr. 31: 1182-1206.

Monger, B.C. and Landry, M.R., 1991. Prey size dependency of grazing by free-living marine flagellates. Mar. Ecol. Prog. Ser. 74:239-248.

Monger, B. C. and Landry, M.R., 1993. Flow Cytometric Analysis of Marine Bacteria Using Hoechst 33342. Appl. Env. Microbiology 59: 905-911.

Monod, J., 1942. Recherches sur la croissance des cultures bacteriennes. Hermann et Cie, Paris.

Myklestad, S., Holm-Hansen, O., Varum, K.M. and Volcani, B.E., 1989. Rate of release of extracellular amino acids and carbohydrates from the marine diatom Chaetoceros affinis. J. Plankton Res. 11: 763-773.

Olson, R.J., Zettler, E.A. and Anderesson, O.K., 1989. Discrimination of eukaryotic phytoplankton cell types from light scatter and autofluorescence properties measured by flow cytometry. Cytometry 10: 636-643.

Peters, R. H., 1983. The Ecological Implications of Body Size. Cambridge: Cambridge University Press.

Platt, T. and Denman, K.L., 1977. Organization in the pelagic ecosystem. Helogol. Wiss. Meeresunters 30: 575-581.

Platt, T. and Denman, K.L., 1978. The structure of pelagic marine ecosystems. Rapp. P.V. Reun. Cons. Int. Explor. Mer 173: 60-65. 
Raimbult, P., Rodier, M. and Taupier-Letage, I., 1988. Size fractionation of phytoplankton in the Ligurian Sea and the Algerian Basin (Mediterranean Sea): Size distribution versus total concentration. Mar. Microb. Food Webs 3: 1.

Rex, A.C., 1991. Combined sewer overflow receiving water monitoring: June 1989October 1990. MWRA Technical Report. Massachusetts Water Resources Authority, Boston, MA: 337.

Robles-Jarero, E.G. and Lara-Lara, J. R., 1993. Phytoplankton biomass and primary productivity by size classes in the Gulf of Tehuantepec, Mexico. J. Plankton Res. 15(12): 1341-1358.

Rodriguez, J. and Mullin, M. 1986. Relation between biomass and body weight of plankton in a steady state oceanic ecosystem. Limnol. Oceanogr. 31 (2): 361-370.

Rodriguez, J., Echevarria, F.and Jimenez-Gomez, F. 1990. Physiological and ecological scalings of body size in an oligotrophic, high mountain lake (La Caldera, Sierra Nevada, Spain). J. Plankton Res. 12(3): 593-599.

Rojo, C. and Rodriguez, J., 1994. Seasonal variability of phytoplankton size structure in a hypertrophic lake. J. Plankton Res.16(4):317-335.

Ruiz, J., Guerrero, V., Rodriguez, V. and Rodriguez, J., 1992. Chlorophyll and size biomass spectrum of phytoplankton. Analysis of fluctuations in eutrophic, coastal waters. In G. Columbo, I. Ferrari, V.U. Ceccherelli \& R. Rossi (eds), Marine eutrophication and population dynamics. Olsen and Olsen, Denmark: 59-62.

Sheldon, R., Prakash, A. and Sutcliff, W., 1972. The size distribution of particles in the ocean. Limnol. Oceanogr. 17: 327-340.

Sheldon, R., Sutcliff, W.H.Jr and Parajafe, M.A., 1977. Structure of pelagic food chain and relation between plankton and fish production. J. Can. Fish. Res. Board 34: 23442352 .

Shiah, F.K. and Ducklow, H. W., 1994. Temperature and substrate regulation of bacterial abundance, production and specific growth rate in Chesapeake Bay, USA. Mar. Ecol. Prog. Ser. 103: 297-308.

Silvert, W. and Platt, T., 1980. Dynamic energy-flow model of the particle size distribution in pelagic ecosystems. In W. Charles Kerfoot (ed) Evolution and ecology of zooplankton communities. The University Press of New England. 
Simek, K. and Chrzanowski, T.H., 1992. Direct and indirect evidence of size-selective grazing on pelagic bacteria by freshwater nannoflagellates. Appl. Environ. Micro. 58(11): 3715-3720.

Smayda, T.J., 1980. Phytoplankton species succession. in I. Morris (ed.), The Physiological Ecology of Phytoplankton, Univ. Calif.: 483-570.

Smetachek, V., 1985. Role of sinking in diatom life-history cycles: ecological, evolutionary and geological significance. Marine Biol. 84: 239-251.

Sprules, W.G. and Munawar, M. 1986. Plankton size spectra in relation to ecosystem productivity, size and perturbation. Can. J. Fish. Aquat. Sci. Vol. 43: 1789-1794.

Sprules, W.G. and Goyke, A.P., 1994. Size-based structure and production in the pelagia of Lakes Ontario and Michigan. Can. J. Fish. Aquat. Sci. 51: 2603-2611.

Strathmann, R.R., 1967. Estimating the organic carbon content of phytoplankon from cell volume or plasma volume. Limnol. Oceanogr. 12: 411-418.

Theibaux, M.L. and Dickie, L.M., 1992. Models of aquatic biomass size spectra and the common structure of their solutions. J. theor. Biol. 159: 147-161.

Theibaux, M.L. and Dickie, L.M., 1993. Structure of the body-size spectrum of the biomass in aquatic ecosystems: A consequence of allometry in predator-prey interactions. Can. J. Fish. Aquat. Sci. 50: 1308-1317.

Thingstad, T.F., 1987. Utilization of N, P, and organic C by heterotrophic bacteria. 1 . Outline of a chemostat theory with a consistent concept of 'maintenance' metabolism. Mar. Ecol. Prog. Ser. 35: 99-109.

Townsend, D.W., Cammen, L.M., Christensen, J.P., Ackleson, S.G., Keller, M.D., Haugen, E.M., Corwin, S., Bellows, W.J. and Brown, J.F., 1990. Seasonality of oceanographic conditions in Massachusetts Bay. Final Report for Massachusetts Water Resources Authority. Bigelow Laboratory for Ocean Sciences. December, 98pp.

Vaulot, D., Courties, C. and Partensky, F., 1989. A simple method to preserve oceanic phytoplankton for flow cytometric analysis. Cytometry 10: 629-635.

Verity, P.G., Robertson, C.Y., Tronzo, C.R., Andrews, M.G., Nelson, J.R. and Sieracki, M.E., 1992. Relationships between cell volume and the carbon and nitrogen content of marine photosynthetic nannoplankton. Limnol.Oceanogr. 37(7): 1434-1446. 
Vidal, J., 1980. Physioecology of zooplankton. I. Effects of phytoplankton concentration, temperature and body size on the growth rate of Calanus pacificus and Pseudocalanus sp. Mar. Biol. 56: 111-134.

Villareal, T.A. and Carpenter, E.J., 1989. Nitrogen fixation, suspension characteristics and chemical composition of Rhizolenia mats in the central N. Pacific Gyre. Biol. Oceanogr. 6: 327.

Walsh, J., 1976. Herbivory as a factor in patterns of nutrient utilization in the sea. Limnol. Oceanogr. 21: 1-13.

Wehr, J.D., Le, J. and Campbell, L., 1994. Does microbial biomass affect pelagic ecosystem efficiency? An experimental study. Microb. Ecol. 27: 1-17.

Yentsch, C.M. and Campbell, J.W., 1991. Phytoplankton growth: perspectives gained by flow cytometry. J. Plankton Res. 13 Supplement: 83-108.

Zettler, E.R., Olson, R.J., Binder, B.J., Chisholm, S.W., Fitzwate, S.E. and Gordon, R.M., 1996. Iron-enrichment bottle experiments in the Equatorial Pacific: Responses of individual phytoplankton cells. Deep Sea Res. (in press). 


\title{
Chapter 5
}

\section{A STUDY OF THE SIZE SPECTRAL RESPONSE OF PICOPLANKTON TO NUTRIENT ENRICHMENT AND GRAZING}

\begin{abstract}
The response of picoplankton size spectra to nutrient enrichment and changes in grazing pressure through dilution were studied using bottle incubation experiments. Enriched and unenriched seawater from coastal Massachusetts Bay and the oceanic Sargasso Sea were serially diluted with filtered seawater and compared to control samples during a four day incubation period. Enrichment of seawater with inorganic nutrients generally resulted in the stimulation of larger cells, both for bacteria and picophytoplankton. When coupled with dilution, the enriched bottles showed a distinct increase in large bacteria (ie. greater than $0.07 \mu \mathrm{m}^{3}$ or $0.5 \mu \mathrm{m}$ diameter) compared to the controls, implying that these bacteria were particularly susceptible to grazing in the field. Under reduced grazing pressure, coastal bacteria appeared to respond more favourably to unenriched rather than enriched conditions whereas oceanic bacteria showed the reverse response. In the case of picophytoplankton, the results indicated that grazing did not significantly alter the size structure of the community although cell abundance was affected. Instead, the picophytoplankton size spectra appeared to be more sensitive to changes in nutrient level and competition from sized-based nutrient kinetics. Overall, these results imply that different size fractions of the picoplankton community play different roles in energy and organic matter transfer within the aquatic ecosystem. The fact that bulk or whole community properties are commonly measured implies that these relationships between the different subcomponents of the microbial community are often overlooked.
\end{abstract}

\section{BACKGROUND}

Free-living bacteria have been shown to form a substantial part of the suspended particulate organic matter in marine habitats, especially in oligotrophic ecosystems where bacteria biomass can comprise more than $70 \%$ of the microbial carbon in the euphotic zone (Fuhrman et. al., 1989). Together with phototrophic picoplankton, they form the base of a complex microbial food web, which can account for a large proportion of 
planktonic respiration, productivity and nutrient recycling (Azam \& Smith, 1991). The microbial loop is believed to enhance ecosystem efficiency through rapid recycling and reduced sinking rates, thus reducing the loss of nutrients contained in organisms within the water column. Some authors propose that different microbial compartments may have contrasting effects on the presumed enhanced efficiency provided by the microbial loop. For example, recent studies show that nutrients in the water column are retained to a greater extent and total sedimentation rates are lower when picophytoplankton are relatively more important than bacteria in the system (Wehr and Campbell, 1993). This may be due to the way in which picophytoplankton and bacteria (of similar sizes but different physiology) compete for inorganic nutrients. At the same time, it is not clear how predators will have an effect on these two components of the microbial loop, through nutrient regeneration and consumption. In order to further our understanding of aquatic food webs, it is important to study micro-organisms in their natural consortia as far as possible. Field studies are generally useful in providing real-time information on the responses of size spectra to the natural physical, chemical and biological processes in the ecosystem. However, it is difficult to isolate the key mechanisms affecting size spectra using these methods, given the many influential factors at work and the complex interplay between them in the natural marine environment. To study such mechanisms, experiments are necessary in which controlling factors are systematically varied to determine the size spectral response.

Experimental studies of this nature show that control of the bacterial community size structure is linked to size-selective grazing by heterotrophic nanoflagellates. A number of investigators found that larger bacteria cells were preferentially ingested by flagellates, (Gonzalez et. al., 1990, Simek and Chzanowski, 1992, Jurgens et. al., 1994). However, the incubation methods used were not necessarily representative of the natural consortium of micro-organisms typically found in the field. For example, either artificial distributions of dead fluorescence-labelled bacteria were fed to natural mixtures of predators or natural populations of bacteria were fed to selected predators that had been 
cultured in the laboratory. On the other hand, nutrients have also been argued to be the main regulator of the bacteria community (Billen et. al., 1990). Strong positive correlations have been found for bacteria size and phytoplankton numbers suggesting that the availability of dissolved organic carbon through phytoplankton exudation is an important determinant of the bacteria size spectra (Psenner and Sommaruga, 1992). Recent studies have further suggested that small phytoplankton cells lose a larger fraction of their stored dissolved compounds than large cells (ie. those less than $10 \mu \mathrm{m}$ ) on the basis of passive diffusion (Kiфrboe, 1993). Thus, dissolved organic matter release is expected to be relatively more important in oligotrophic, stagnant waters characterized by pico and nanoplankton. The issue of whether bottom-up (nutrient) or top-down (grazing) control is more important in structuring the picoplankton community is one that is still unresolved due to the conflicting evidence. Part of the difficulty lies in the fact that shifts between bottom-up and top-down control modes often occur rapidly, making them difficult to detect in natural ecosystems (Psenner and Sommaruga, 1992).

This study is designed to test the size spectral responses of natural assemblages of picoplankton to nutrient enrichment and grazing and to understand how these two mechanisms affect the size spectra from oligotrophic and eutrophic environments. Specifically, the following questions are addressed:-

How does enrichment with inorganic nutrients influence the size spectra of bacteria and picophytoplankton?

How does altering the predator-prey encounter rates of heterotrophic nanoplankton through dilution affect the bacteria and picophytoplankton size spectra?

How do these interactions vary for a community dominated by small cells as opposed to one that is predominantly large-celled ie. for ecosystems of different trophic status? 


\section{METHODS}

\section{Experimental Design}

The experiment was designed to study both the combined and separate effects of nutrient enrichment and grazing on the picoplankton size spectrum. Samples were taken from both coastal and oceanic waters in order to compare the size spectral responses from two different initial size structures of the microbial community ie. coastal size spectra with a greater relative proportion of larger cells compared to oceanic spectra (chapter 4). Experiments were conducted in mid-summer where it was anticipated that phytoplankton assemblages were well-developed and probably experiencing nutrient limitation at the time of sampling. In this way, chances of detecting size spectral responses to nutrient stimulation were more likely. To study predation effects on the picoplankton size spectrum, the samples were diluted with filtered seawater, following the methods of Landry \& Hassett, 1982. In this type of experiment, a dilution series is established by mixing seawater containing the intact plankton assemblage with the same seawater which has had most of the organisms removed by filtration $(0.2 \mu \mathrm{m}$ sized filter). The principle of the dilution technique is that it causes a decrease in encounter rates between predator and prey, thus decreasing the grazing pressure on prey cells, without direct handling of the live plankton. The change in prey concentration, $\mathrm{P}$, over some time, $\mathrm{t}$, can be represented by the exponential equation:

$P_{t}=P_{o} e^{(k-g) t}$

where $\mathrm{k}$ and $\mathrm{g}$ are the intrinsic growth rate and grazing mortality respectively. These rates can be inferred from the observed changes in population density following incubations of different dilutions. For this study, a dilution series consisting of filtered seawater to whole seawater in the ratios $0: 1,1: 3,1: 1$ and $3: 1$ were used. The corresponding equations describing the changes in phytoplankton over time, $t$, are: 


$$
\begin{array}{ll}
P_{t}=P_{o} e^{(k-g) t} & \text { or apparent growth rate }=1 / t \ln \left(P_{t} / P_{o}\right)=k-g \\
P_{t}=P_{o} e^{(k-0.75 g) t} & \text { or apparent growth rate }=1 / t \ln \left(P_{t} / P_{o}\right)=k-0.75 g \\
P_{t}=P_{o} e^{(k-0.50 g) t} & \text { or apparent growth rate }=1 / t \ln \left(P_{t} / P_{o}\right)=k-0.50 g \\
P_{t}=P_{o} e^{(k-0.25 g) t} & \text { or apparent growth rate }=1 / t \ln \left(P_{t} / P_{o}\right)=k-0.25 g
\end{array}
$$

The apparent growth rate of prey cells is linearly related to the dilution factor, such that the negative slope of this relationship is the grazing mortality rate, g, and the Yintercept is the intrinsic growth rate, $\mathrm{k}$. As dilution increases, the prey are thought to be able to grow at a rate more closely approaching their intrinsic rate because grazing pressure is relieved. The method is based on the assumption that the intrinsic growth rates of prey cells remain constant, which is the case for nutrient-replete systems. For this reason, inorganic nutrients were added to saturate growth rates of phytoplankton for the experiments. In the case of bacteria, however, dissolved organic matter is also required for heterotrophic consumption, but this was not added explicitly in the experiment. Instead, it was assumed that the stimulation of phytoplankton growth from inorganic nutrients would also lead to an increase in dissolved organic exudates which would subsequently stimulate bacteria growth (Azam \& Smith, 1991).

The experimental design is summarized in Fig. 5.1 and Table 5.1. The unenriched samples acts as a control for the entire experiment (G). Comparing this control with the enriched samples (B) reveals the nutrient enrichment effect on the size spectrum. When the dilution treatments $(\mathrm{H}, \mathrm{I}, \mathrm{J})$ are compared with the unenriched control $(\mathrm{G})$, the effects of grazing and nutrient stimulation by recycling/dilution can be shown. To observe the grazing effects alone, the enriched dilutions $(C, D, E)$ have to be compared with the enriched controls (B), assuming that phytoplankton and bacteria are not nutrient limited and are growing at maximal rates. Finally, a comparison between the unenriched and enriched dilutions (eg. C \& H) will show the combined effects of grazing, nutrient enrichment and stimulation by recycling/dilution. In total, eight different treatments ( $x 2$ replicates) were performed for each ecosystem, as summarized in Table 5.1. 


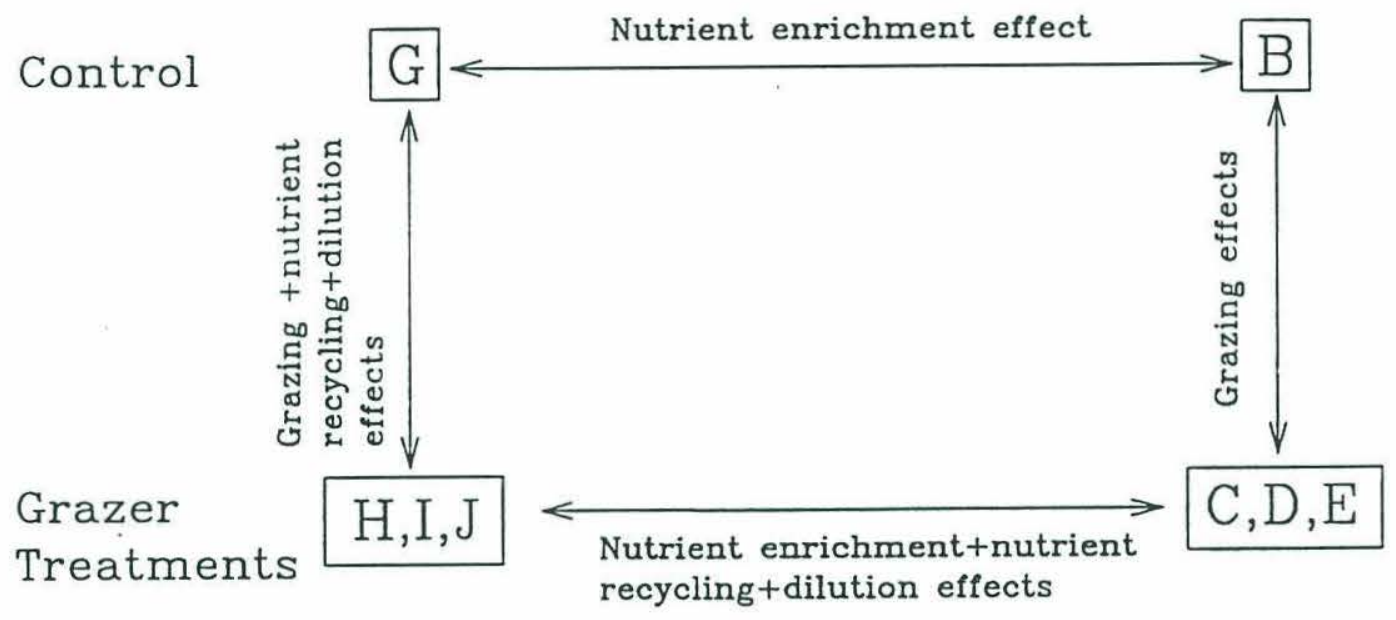

Fig. 5.1. Summary of the experimental design used to study the effects of nutrient enrichment and grazing on the picoplankton size spectrum. B and G represent the controls for the enriched and unenriched treatments respectively, whilst $C(1: 3), D$ (1:1), E (3:1) are the enriched dilution treatments and $H(1: 3), I(1: 1), J(3: 1)$ are the unenriched dilution treatments. The ratio given is the ratio of filtered seawater (through $0.22 \mu \mathrm{m}$ ) to pre-screened seawater (through $64 \mu \mathrm{m}$ mesh). 


\begin{tabular}{lll}
\hline TREATMENT & ENRICHED & UNENRICHED \\
\hline Control & $\mathrm{B} 1, \mathrm{~B} 2$ & $\mathrm{G} 1, \mathrm{G} 2$ \\
Dilution $1: 3^{*}$ & $\mathrm{C} 1, \mathrm{C} 2$ & $\mathrm{H} 1, \mathrm{H} 2$ \\
Dilution $1: 1$ & $\mathrm{D} 1, \mathrm{D} 2$ & $\mathrm{I} 1, \mathrm{I} 2$ \\
Dilution $3: 1$ & $\mathrm{E} 1, \mathrm{E} 2$ & $\mathrm{~J} 1, \mathrm{~J} 2$ \\
\hline
\end{tabular}

Table 5.1. Summary of treatments for incubation bottle experiments to test the effects of grazing pressure and nutrient enrichment. Changes in grazing pressure were carried out by dilution with filtered seawater, where the ratio given is the ratio of filtered seawater $(0.22 \mu \mathrm{m})$ to pre-screened sample seawater $(64 \mu \mathrm{m})$. Each treatment is given a letter designation followed by a number that indicates the replicate. In total, $8 \times 2$ treatments were performed for each of the coastal and oceanic incubation experiments.

\section{Sampling Scheme}

Field samples for the bottle incubation experiments were obtained from the oceanic Sargasso Sea $\left(35^{\circ} \mathrm{N}, 69^{\circ} \mathrm{W}\right)$ on July 8th, 1993 and the coastal waters of Massachusetts Bay $\left(42^{\circ} 21.4^{\prime} \mathrm{N}, 70^{\circ} 42.3^{\prime} \mathrm{W}\right)$ on July 28 th, 1993 respectively. Nutrient media for the experiment were based on F/2 media, and consisted of inorganic nutrients as well as trace metals and vitamins (Guillard, 1975). Stock concentrations of the major nutrients for F/2 enrichment were as follows: $\mathrm{NO}_{3}-883 \mu \mathrm{M}, \mathrm{PO}_{4}-36.3 \mu \mathrm{M}, \mathrm{SiO}_{4}-100 \mu \mathrm{M} .20 \mathrm{ml}$ of each stock solution was added to $2 \mathrm{~L}$ of sample seawater for the coastal experiment $(\mathrm{F} / 2)$, whereas $2 \mathrm{ml}$ of each stock was added to $2 \mathrm{~L}$ for the oceanic samples $(\mathrm{F} / 20)$. These different levels of nutrient enrichment were used because coastal plankton generally require higher nutrient levels to saturate growth rates, whereas those from oceanic regions require lower nutrient concentrations (Malone, 1980).

The inorganic nutrient stocks were added to the relevant incubation bottles using sterile seriological pipettes just prior to sample collection. Seawater collected in acidcleaned go-flo bottles were taken from depths of $25 \mathrm{~m}$ (corresponding to $40 \%$ of surface light level, using a Secchi depth ${ }^{1}$ of $41 \mathrm{~m}$ ) and $19 \mathrm{~m}$ (corresponding to $8 \%$ light levels at the chlorophyll maximum), for oceanic and coastal waters respectively. Samples were gravity

\footnotetext{
${ }^{1}$ The light extinction coefficient, $\mathrm{k}$, was estimated from the Secchi depth, Ds, according to the empirical relation proposed by Poole \& Atkins (1929): $\mathrm{k}=1.7 / \mathrm{Ds}$.
} 
filtered through a $64 \mu \mathrm{m}$ Nitex mesh and transfered into 21 incubation bottles through darkened tubing. The mesh was to screen out larger zooplankton from entering the bottles whilst the darkened tubing was to minimize harmful exposure of phytoplankton to high surface light levels. Filtered seawater (pumped through a $0.22 \mu \mathrm{m}$ Millipore filter) was then added to fulfill the required dilutions for the relevant bottles. Subsamples of 50 $\mathrm{ml}$ (representing initials for the experiment) were then withdrawn from each bottle and preserved for picoplankton analysis, as described in chapter 2 . The remainder of the samples were then incubated in simulated field conditions:- For the oceanic samples, bottles were placed in ziplock bags and placed in an on-deck $27 \times 36 \times 11$ " perspex incubator, screened with neutral density filters (40\% reduction) and filled with running seawater to maintain a temperature of $28^{\circ} \mathrm{C}$. In the case of coastal samples, the bottles were transferred to a Percival incubator set at $17^{\circ} \mathrm{C}$ and at approximately 6 to $8 \%$ of surface light levels. In both cases, the priority was to set light levels in the incubators as close as possible to ambient levels. Temperature settings were less amenable to change and for the coastal experiment, was much higher than the actual temperature from where the samples were taken ie. $7^{\circ} \mathrm{C}$. All sample collection devices were acid-cleaned prior to use.

Subsampling of the incubation bottles were carried out after 1, 2, 3 and 4 days, using preservation protocols as described in the previous chapter. The picoplankton samples were then stored in liquid nitrogen for about 6 months to a year before flow cytometric analysis.

\section{Flow Cytometric Analysis}

Dual-beam flow cytometry was used to analyze bacteria from picophytoplankton using the 'pico' settings on an Epics 753 flow cytometer (Appendix C). Typical signatures of coastal bacteria and picophytoplankton are illustrated in Fig. 5.2a and b. These sub-populations were easily discriminated based on the organisms' fluorescence properties as outlined in Appendix C. However, in the case of the oceanic samples, a 

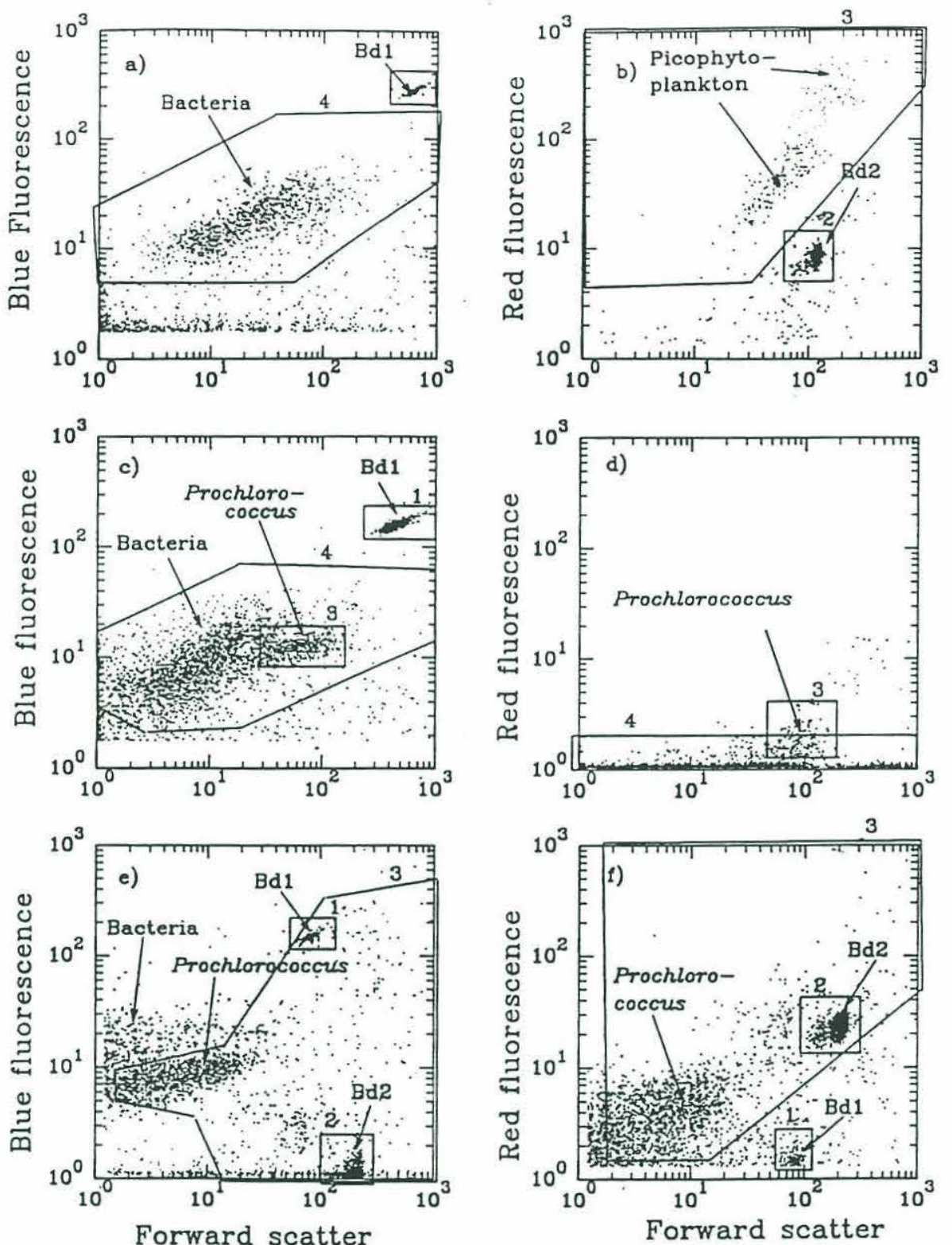

Fig. 5.2. Flow cytometric signatures of bacteria and picophytoplankton analyzed on the 'pico' settings of an Epics 753 flow cytometer. In the coastal incubation experiment, bacteria (a) and picophytoplankton (b) could be easily discriminated from each other because the red fluorescence of the picophytoplankton was well above the baseline. In the oceanic incubation experiments, however, the red fluorescence of Prochlorococcus (window 3 ) was close to the baseline (d) and had to be separated from bacteria on blue fluorescence versus forward scatter (c), where the population was gated out from the bitmap defining bacteria (bitmap 4). In this way, bacteria was discriminated for analysis. When analyzing for picophytoplankton, the bitmaps (bitmap 3) were drawn on blue (e) and red (f) fluorescence versus forward scatter, as shown. Reference beads of $0.46 \mu \mathrm{m}(\mathrm{Bd} 1)$ and $0.57 \mu \mathrm{m}(\mathrm{Bd} 2)$ were also run to provide a reference frame for analysis. 
problem was encountered in resolving the smallest picophytoplankton (Prochlorococcus) from the tail end of the bacteria spectrum. Normally, these phytoplankton cells are easily discriminated from bacteria on the scattergram of red fluorescence vs forward scatter where they are generally situated well above the bacteria community (Figs. C3, C4 in Appendix C). In this experiment, however, oceanic samples were withdrawn from $25 \mathrm{~m}$ depth which constitutes a relatively high light environment. Accordingly, the red fluorescence of picophytoplankton was very low and in the case of Prochlorococcus, resulted in part of the population being embedded near the baseline of red fluorescence near bacteria (Fig. 5.2d). When analyzing for bacteria, further discrimination was possible using the blue fluorescence vs forward scatter scattergram where the Prochlorophytes generally protruded out from the bacteria population as a tight horizontal cluster (Fig. 5.2c). Using different combinations of cell parameters (viz. red, blue fluorescence, forward and right angle light scatter), it was possible to separate most of the Prochlorococcus from the tail end of the bacteria spectrum, although not perfectly. When analyzing for picophytoplankton, the populations were generally identified in the red fluorescence versus forward scatter scattergram as a continuous cluster of cells at some angle to the horizontal, with Prochlorococcus partially embedded in the bacteria cluster in the lower left hand corner of the scattergram and Synechococus in the upper right hand corner (Fig. 5.2f). Further discrimination was possible using the blue fluorescence vs forward scatter scattergram (Fig. 5.2e) as well as other combinations of cell parameters. The fact that Synechococcus showed a progressive increase in red fluorescence during the four day incubation period also suggested that phytoplankton in the bottles were experiencing light adaptation, making it easier to detect the cells. One would thus also expect an increase in the mean red fluorescence of Prochlorococcus (if present) with each day of the experiment:- this would assist in shifting the tail end of the population out of the bacteria cluster in the red fluorescence versus forward scatter scattergram.

As with previous chapters, the size spectra of cell concentration was obtained by converting forward light scatter to size using empirical calibration equations (Appendix 
D). To facilitate easier comparison of size spectral differences between treatments, the difference between the treated sample at time $t, \mathrm{Y}_{\mathrm{t}}$, and the corresponding initial spectrum, $\mathrm{Y}_{\mathrm{i}}$, normalized to the total initial cell concentration, $\mathrm{C}_{\mathrm{i}}$, was also computed to give the normalized difference spectrum, $D_{N}$ for each treatment:-

$D_{N}=\left(Y_{t}-Y_{i}\right) / C_{i}$

Positive normalized difference spectra reflect an increase in abundance for those size categories whereas negative regions show a depletion. However, because the difference spectra are plotted on linear scales, changes in the large end of the bacteria spectrum (which may be 1-2 orders of magnitude less in concentration) could be masked. For this reason, the actual size spectra plotted on logarithmic scales are also presented. Results for replicates were viewed separately to assess the consistency of trends, rather than taking averages of spectra which could overlook refined details.

\section{RESULTS}

\section{Coastal waters of Massachusetts Bay}

Bacteria abundances from this region are typically $1 \times 10^{6} \mathrm{ml}^{-1}$, with a mean population size of $0.04 \mu \mathrm{m}^{3}$ ( $0.43 \mu \mathrm{m}$ diameter). The initial size spectrum of bacteria is characterized by a somewhat 'flattened' unimodal distribution with maximum cell concentrations in the range 0.01 to $0.05 \mu \mathrm{m}^{3}$ (0.27 to $0.46 \mu \mathrm{m}$ ) (Fig. 5.3). For picophytoplankton, the initial size spectrum is also unimodal, comprising of smaller Synechococcus $\left(0.4 \mu \mathrm{m}^{3}\right.$ or $\left.0.92 \mu \mathrm{m}\right)$ and slightly larger eukaryotic picophytoplankton (2 $\mu \mathrm{m}^{3}$ or $\left.1.6 \mu \mathrm{m}\right)$. Total picophytoplankton counts are approximately $5 \times 10^{4} \mathrm{ml}^{-1}$ with a mean size of $0.6 \mu \mathrm{m}^{3}(1.1 \mu \mathrm{m})$. In general, the more diluted bottles had progressively lower cell counts (as expected), and replicates for each treatment compared favourably with each other (Table 5.2). However, one of the enriched dilution treatments (ie. D at 1:1 dilution) had unsually high cell counts for both replicates which was not consistent 
with the dilution. One possible reason is that extra material may have squeezed through the filters during the prescreening process.

\begin{tabular}{lrllcl}
\hline $\begin{array}{l}\text { Treat- } \\
\text { ment }\end{array}$ & Bacteria & $\begin{array}{l}\text { Pico-phyto } \\
\text { plankton }\end{array}$ & $\begin{array}{l}\text { Treat- } \\
\text { ment }\end{array}$ & Bacteria & $\begin{array}{l}\text { Pico-phyto } \\
\text { plankton }\end{array}$ \\
\hline B1 & $1,149,606$ & 40,443 & B2 & $1,118,575$ & 46,374 \\
C1 & 712,691 & 18,811 & C2 & 550,620 & 24,097 \\
D1 & 980,443 & 50,863 & D2 & 610,459 & 25,879 \\
E1 & 336,846 & 12,160 & E2 & 406,618 & 16,283 \\
G1 & $1,200,081$ & 44,050 & G2 & $1,222,228$ & 45,690 \\
H1 & 609,117 & 21,318 & H2 & 709,172 & 20,564 \\
I1 & 378,357 & 11,786 & I2 & 453,466 & 12,954 \\
J1 & 209,358 & 5,989 & J2 & 294,786 & 5,908 \\
\hline
\end{tabular}

Table 5.2. Initial concentrations of bacteria and picophytoplankton for the coastal incubation bottles. Samples were taken from Massachusetts Bay on July 28th and analyzed flow cytometrically. Note that initial concentrations for $\mathrm{A}$ and $\mathrm{F}$ treatments were not measured, but were assumed to be close to the B and $\mathrm{G}$ treatments (ie. only difference is that copepods were added to the A and F bottles). Concentrations are given as no. of cells $\mathrm{ml}^{-1}$.

\section{Bacteria}

Overall, there is little variation in the bacteria size spectrum during the 4 day incubation period for the unenriched control ( $G$ in Figs. 5.3 to 5.7). In contrast, the effects of dilution are more significant on the size structure of bacteria. The response in the unenriched diluted bottles (H,I,J) after one day consists of a shift in the community to larger sizes (see peak at $\sim 0.1 \mu \mathrm{m}^{3}$ ), which is not as noticeable in the unenriched control (Fig. 5.4). The increase in abundance of large bacteria becomes more prominant on days 2 and 3 where distinct peaks are visible in this size range (Figs. 5.5, 5.6). The more diluted the sample, the higher the peak observed relative to the initial, together with an increase in abundance of the medium sized bacteria (ie. those between 0.01 and $0.1 \mu \mathrm{m}^{3}$ or 0.27 to $0.58 \mu \mathrm{m})$. This is consistent with the assumption that increased dilution will reduce grazing pressure and therefore increase bacteria production. By day 4 , however, the less diluted samples $(\mathrm{H}, \mathrm{I})$ appear to have reverted back to lower concentration levels, with a 

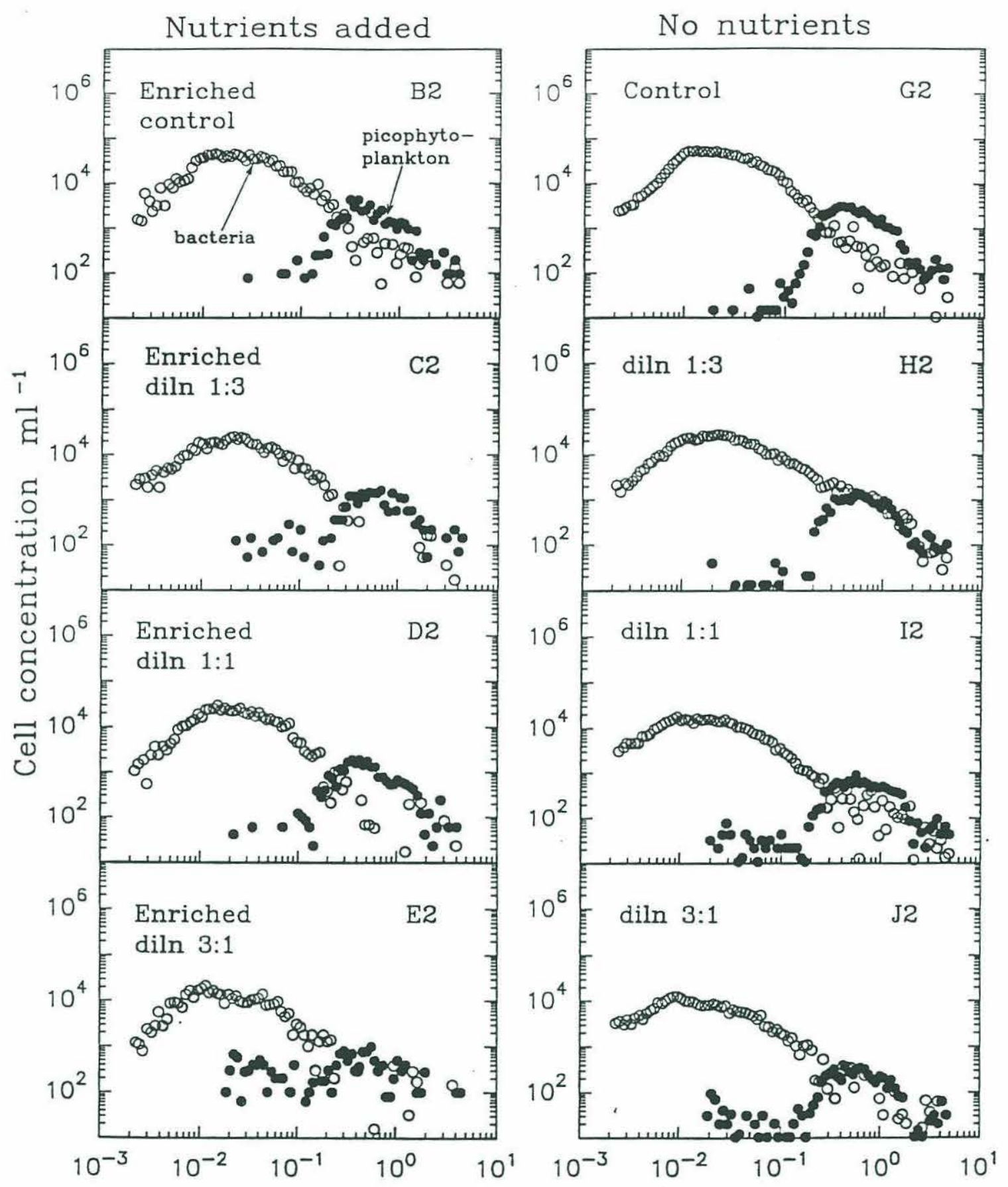

\section{Cell volume $\mu \mathrm{m}^{3}$}

Fig. 5.3. Histogram concentration size spectra of bacteria (open circle) and picophytoplankton (closed circle) for the coastal incubations (Massachusetts Bay) at the beginning of the experiment. The letter designation corresponds to the treatments listed in Table 4.1 and the number indicates the replicate bottle. The left hand panel of graphs represent the treatments enriched with inorganic nutrients whilst the unenriched treatments are shown in the right hand panel. 


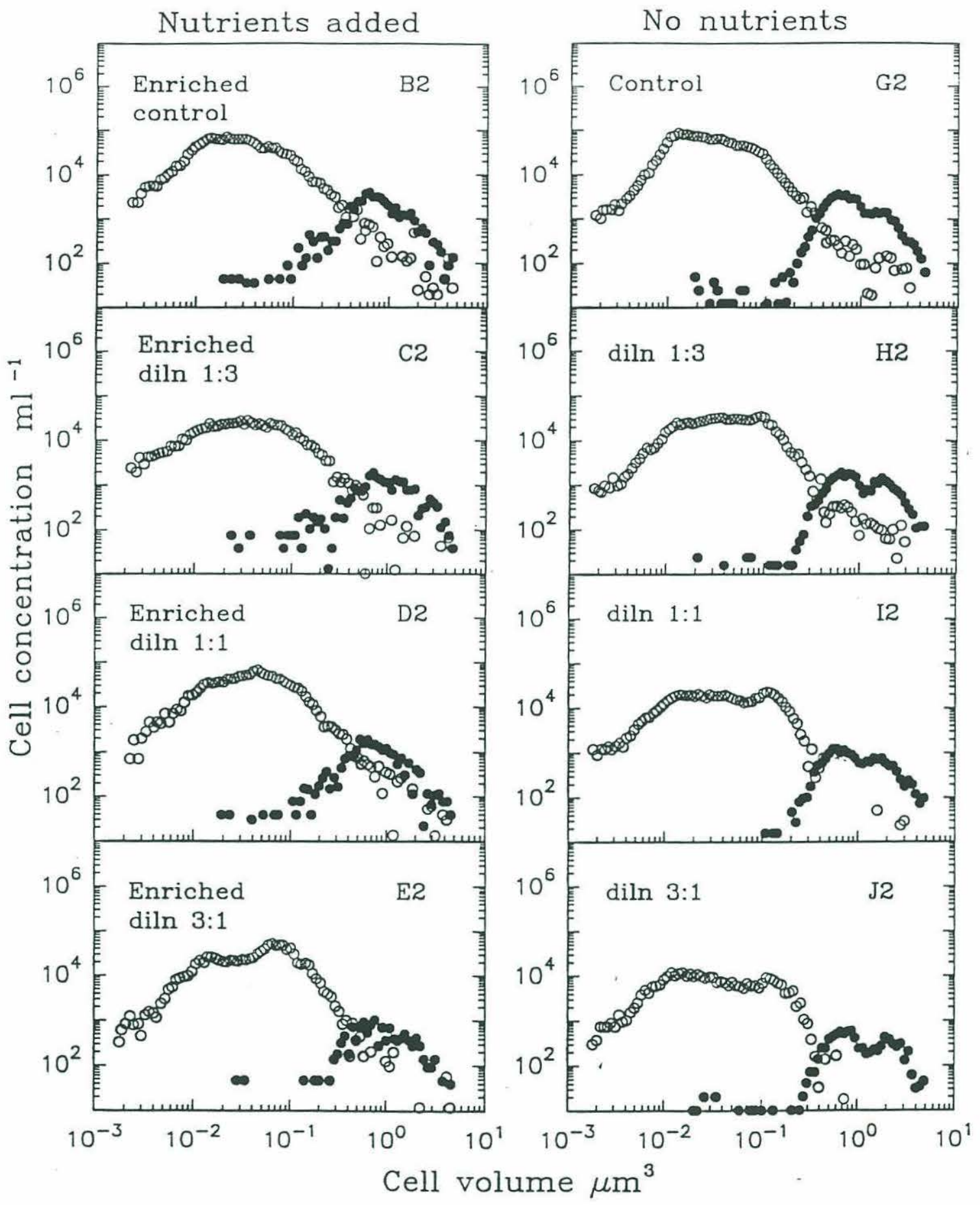

Fig. 5.4. Histogram concentration size spectra of bacteria (open circle) and picophytoplankton (closed circle) for the coastal experiment after incubating samples for 1 day in simulated field conditions. 


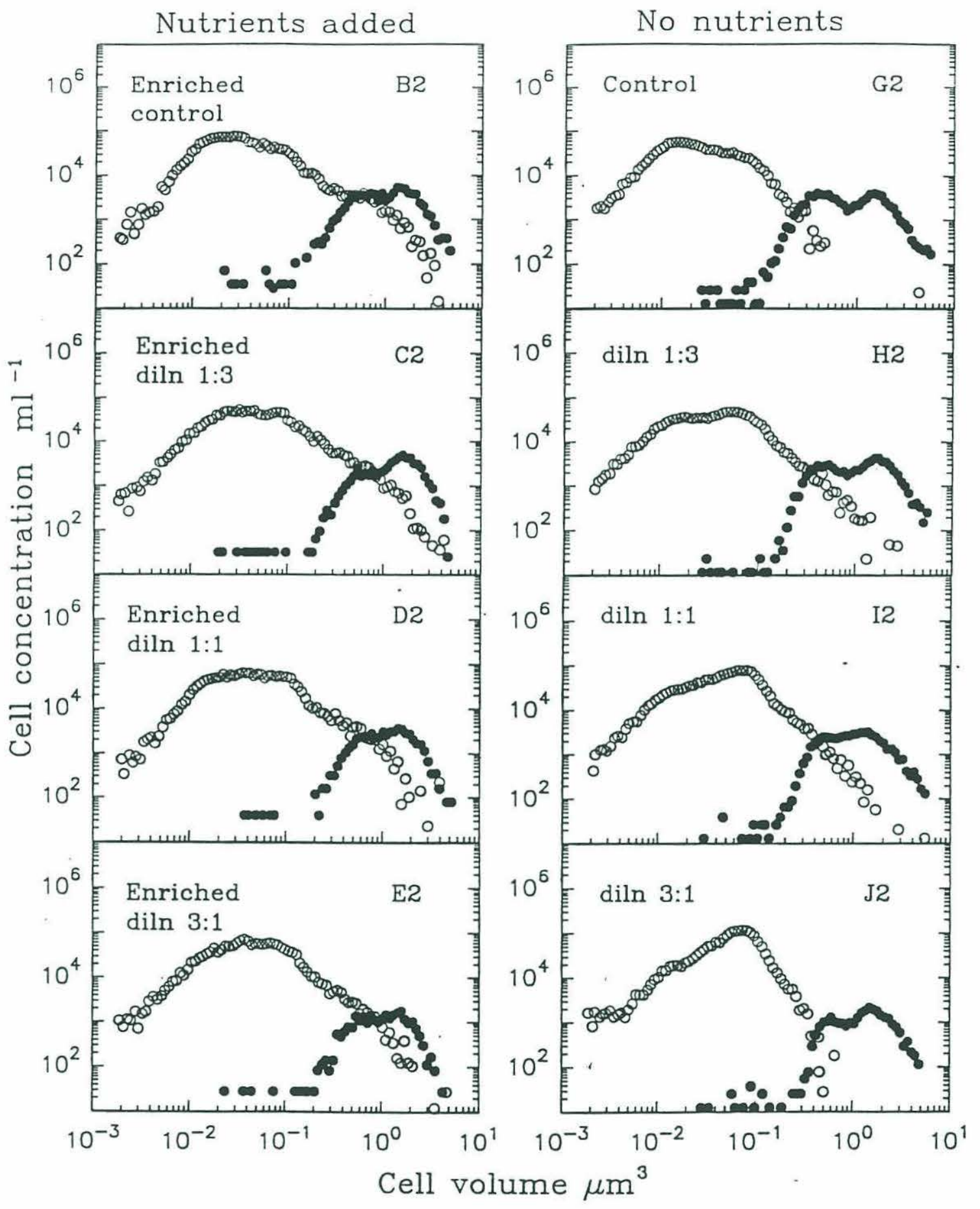

Fig. 5.5. Histogram concentration size spectra of bacteria (open circle) and picophytoplankton (closed circle) for the coastal experiment after incubating samples for 2 days in simulated field conditions. 


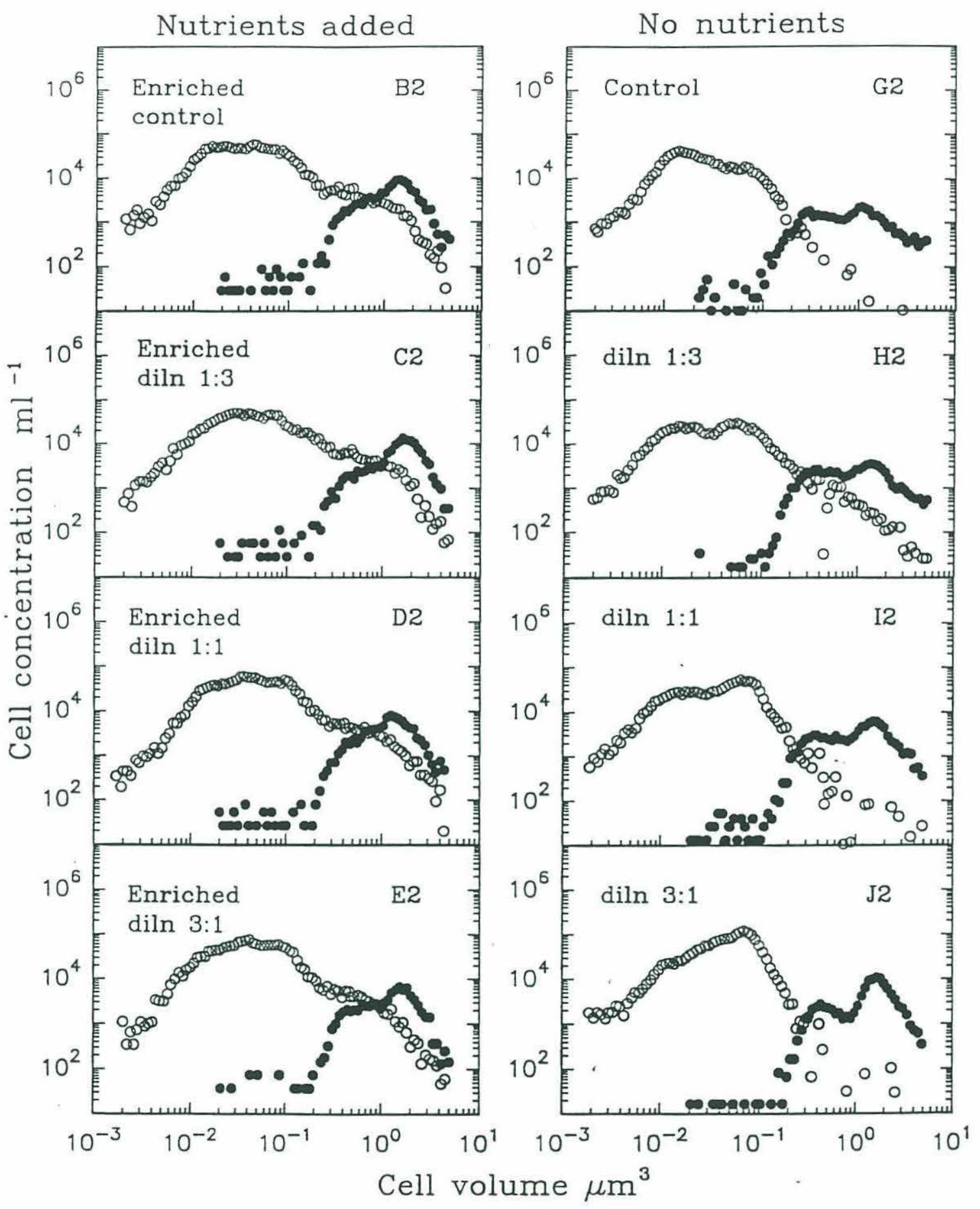

Fig. 5.6. Histogram concentration size spectra of bacteria (open circle) and picophytoplankton (closed circle) for the coastal experiment after incubating samples for 3 days in simulated field conditions. 


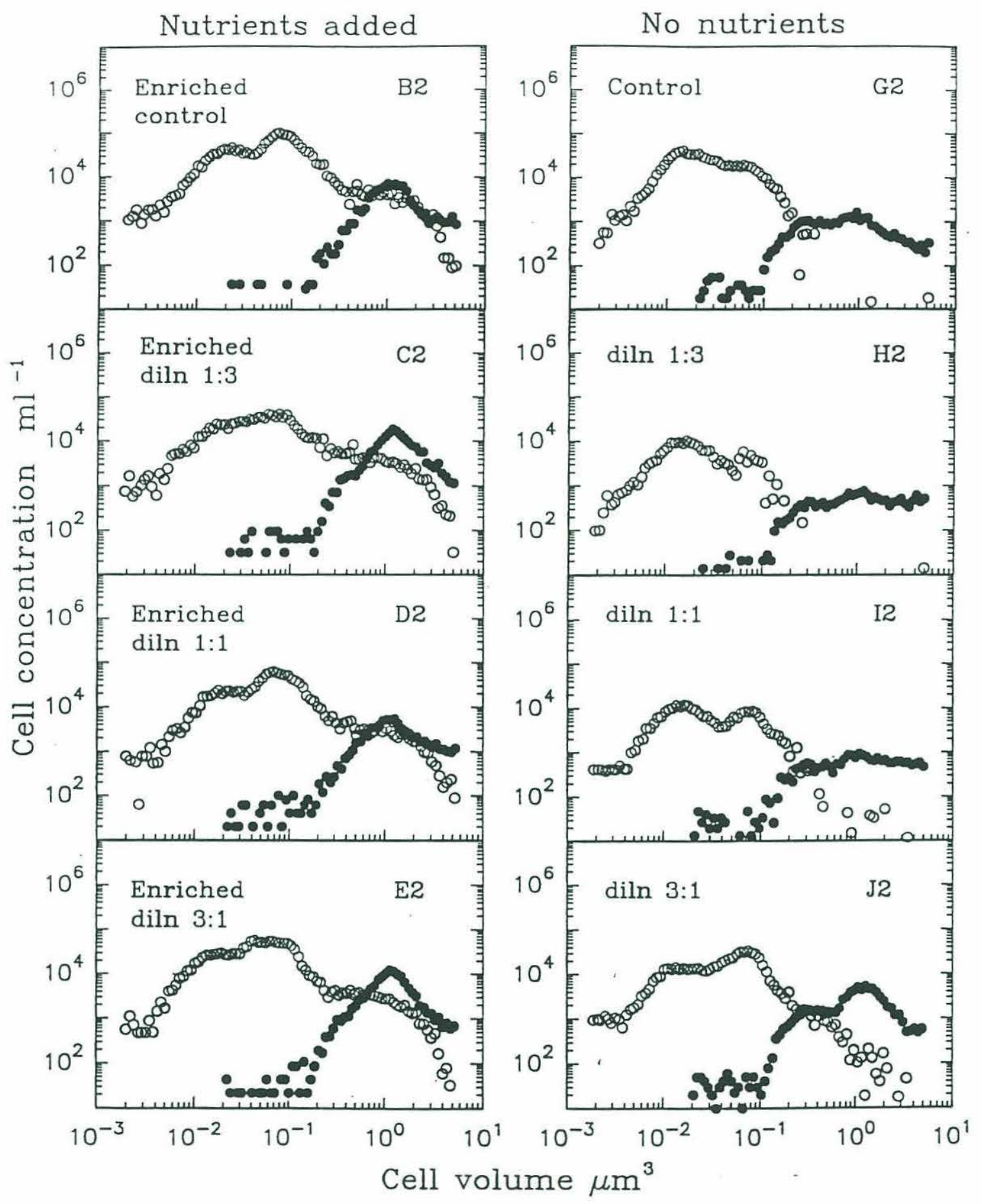

Fig. 5.7. Histogram concentration size spectra of bacteria (open circle) and picophytoplankton (closed circle) for the coastal experiment after incubating samples for 4 days in simulated field conditions. 
decrease in overall abundance of bacteria, particularly of the larger sizes (Fig. 5.7). As a result, there is a shift in the peak back to smaller sizes, similar to the unenriched control (G) of the same time. However, an exception lies for the most diluted sample (J) for which larger sizes persist in dominating the bacteria community even though the response is not as dramatic as on days 2 and 3 . These changes in the unenriched bottles are more clearly illustrated in the evolution of normalized difference spectra for both replicates (Fig. $5.8)$.

The enriched controls (B) show a small increase in both size and abundance of bacteria after the first day, with little subsequent change until the 4th day when a more significant change in structure is observed: a shift occurs towards larger bacteria with sizes greater than $0.12 \mu \mathrm{m}^{3}$ and a corresponding decrease in small bacteria (ie. those less than $0.01 \mu \mathrm{m}^{3}$ ) (eg. compare Figs. 5.3 and 5.7). A substantial increase in the largest heterotrophs greater than $0.3 \mu \mathrm{m}^{3}$ is also observed, although this is not detected in the normalized difference spectra plotted on linear scales (Fig. 5.9). This change in structure is accompanied by a visible diatom bloom in the phytoplankton community (ie. bottles went brown), confirmed by microscope analysis. If the enriched control (B) is compared to the unenriched control $(\mathrm{G})$, the difference in spectra is only visible after about two days, and is really only significant on the 4th day when the bloom is fully underway (Figs. 5.8, 5.9).

Ideally, a comparison of the enriched dilution bottles (C,D,E) would show the response of size spectra to a reduction in grazing pressure alone. In general, the trends in the enriched dilution bottles are also similar to those in the unenriched dilution bottles $(\mathrm{H}, \mathrm{I}, \mathrm{J})$ although the responses are not as dramatic. Relative to the enriched control (B) on the same day, the enriched dilution bottles all show an increase in medium sized bacteria $\left(0.01\right.$ to $0.1 \mu \mathrm{m}^{3}$ ), with the largest increases in the most diluted enriched bottles (eg. Figs. 5.5, 5.9). The shift to larger sizes with dilution in the first three days is most likely from a reduction in grazing pressure on this size category since the enriched controls show little change in comparison. By day 4, the bacteria size spectra of the enriched dilutions shift 


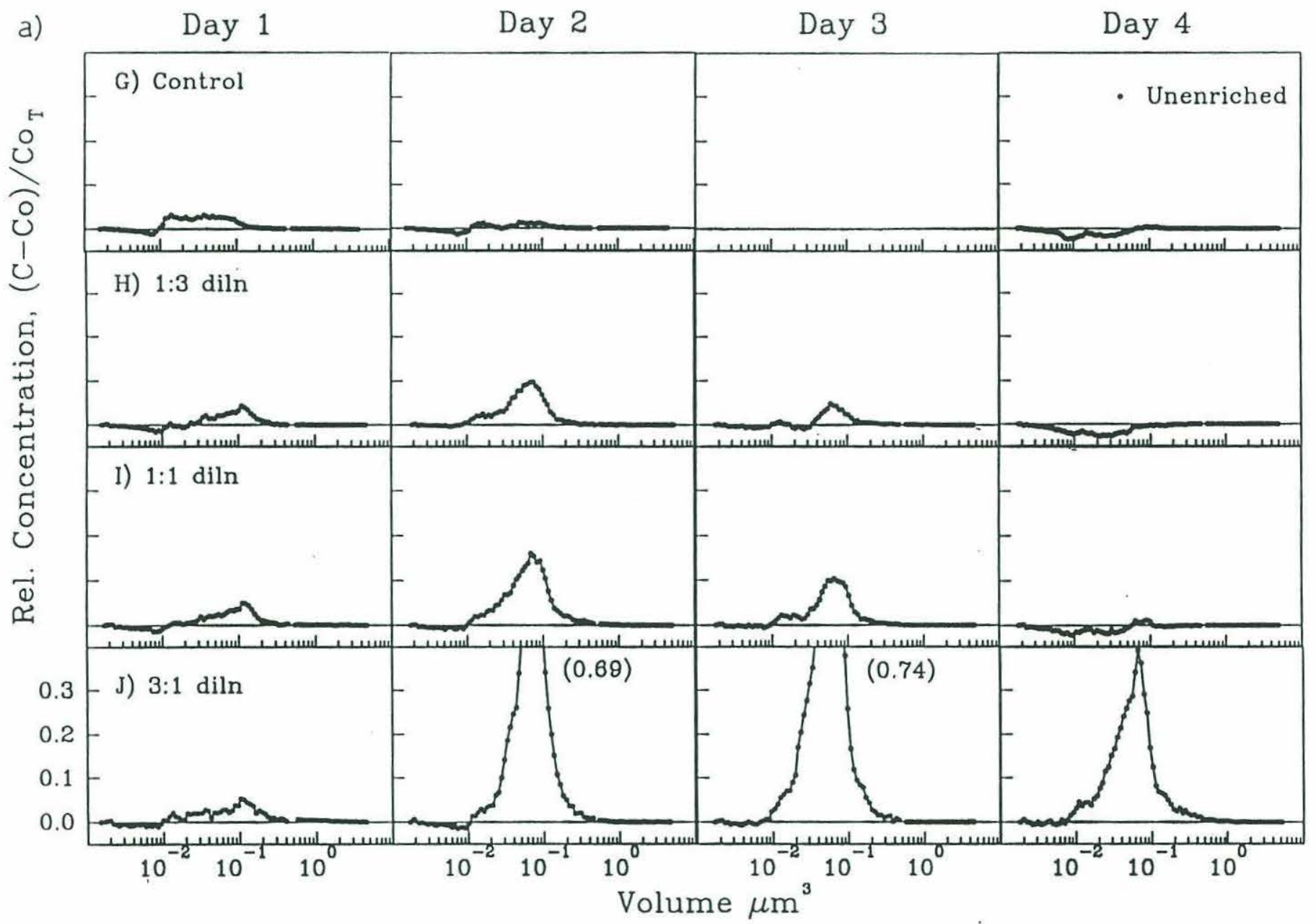

Fig. 5.8. Evolution of the normalized difference spectra for unenriched bacteria in the coastal incubation experiment. Normalized difference spectra were computed by taking the difference between the spectra of a treated sample at some specified time and its corresponding initial $(\mathrm{C}-\mathrm{Co})$, and dividing the difference by the total initial bacteria concentration $\left(\mathrm{Co}_{\mathrm{T}}\right)$. $\mathrm{G}$ represents the unenriched control treatment while $\mathrm{H}(1: 3), \mathrm{I}(1: 1)$ and $\mathrm{J}(3: 1)$ are the unenriched dilution treatments. Replicate time courses are shown in (a) and (b). 


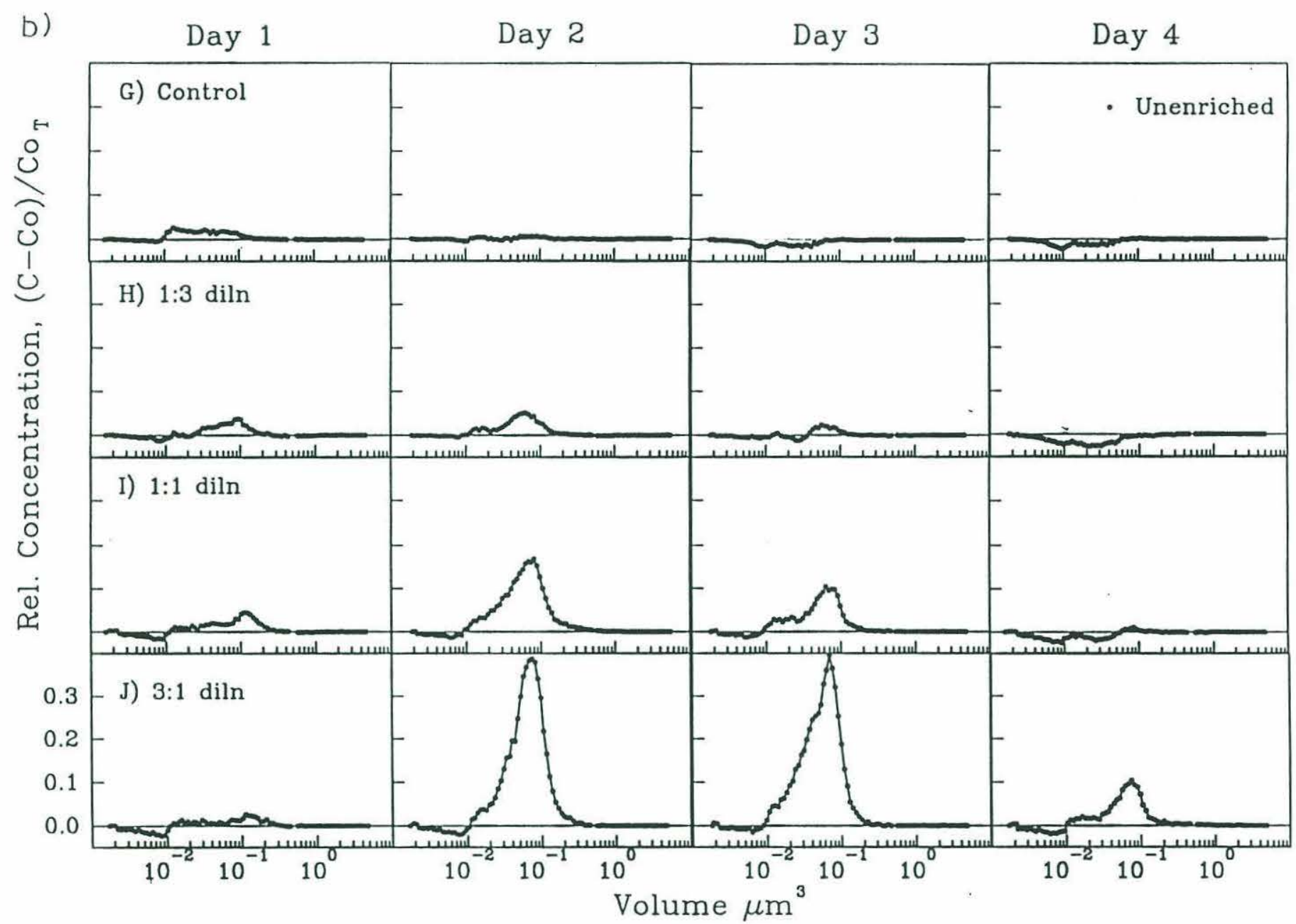

Fig. 5.8....continued 


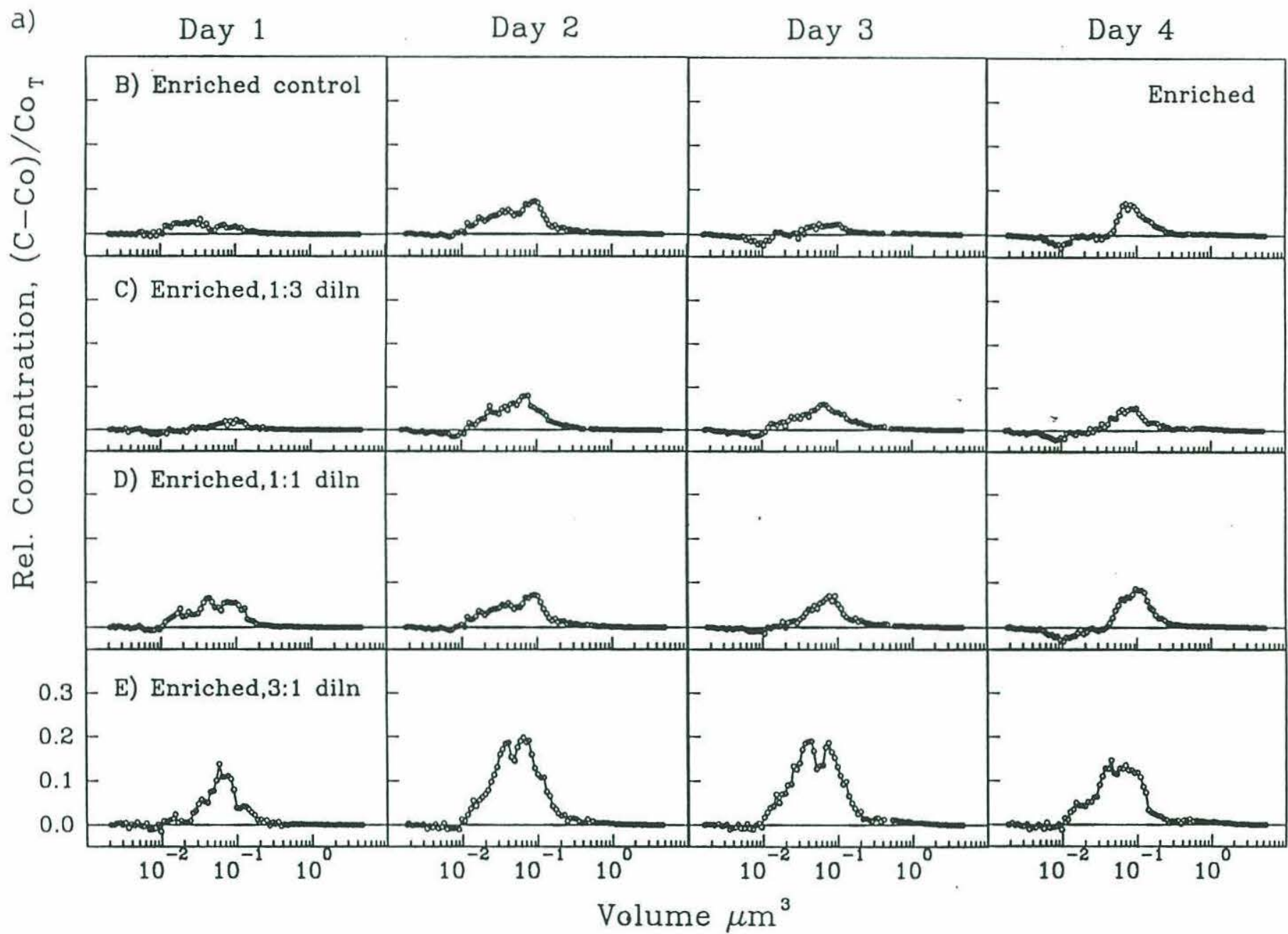

Fig. 5.9. Evolution of the normalized difference spectra for bacteria enriched with inorganic nutrients in the coastal incubation experiment. B represents the enriched control treatment while C (1:3), D (1:1) and E (3:1) are the enriched dilution treatments. Replicate time courses are shown in (a) and (b). 


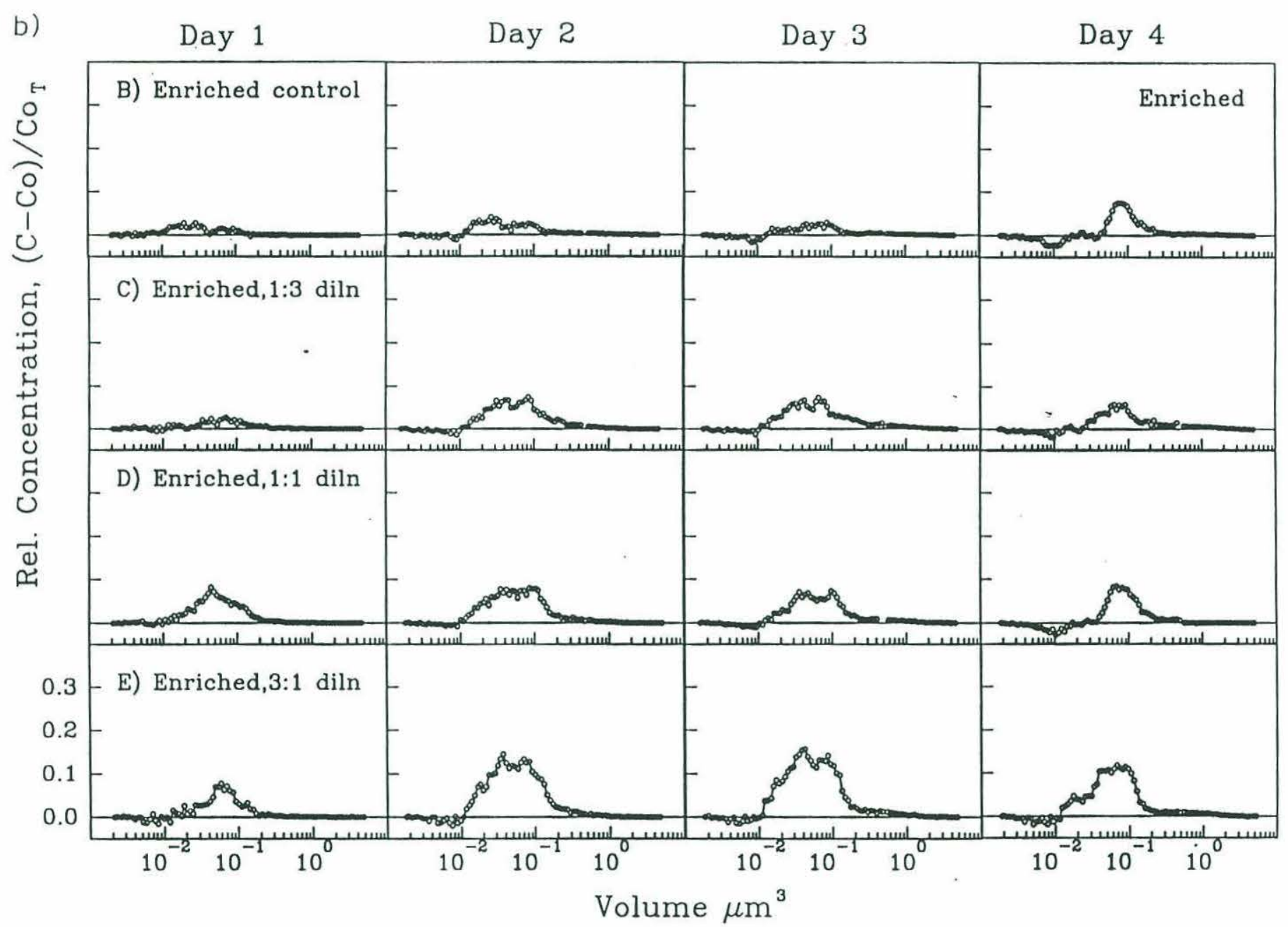

Fig. 5.9....continued 
even more to larger sizes and is comparable to the enriched controls (B) of the same time (Figs. 5.7, 5.9). This could be due to the response of large bacteria to the 'bloom' of phytoplankton that occurred at around this time.

Even though both the enriched and unenriched bottles show a response in the same size category to dilutions, the response of the unenriched diluted bottles is more dramatic than the corresponding enriched bottles for days 2 and 3 (compare Figs. 5.8, 5.9). From these results, it appears that, under reduced grazing pressure, nutrient stressed environments (ie. in terms of inorganic nutrients) are able to stimulate large bacteria (of approximately $0.08 \mu \mathrm{m}^{3}$ ) to a greater extent than nutrient rich environments for coastal waters.

\section{Picophytoplankton}

The size spectra of picophytoplankton are characterized by two main populations comprising smaller Synechococcus $\left(0.4 \mu \mathrm{m}^{3}\right.$ or $\left.0.9 \mu \mathrm{m}\right)$ and slightly larger eukaryotic picoplankton $\left(2 \mu \mathrm{m}^{3}\right.$ or $\left.1.6 \mu \mathrm{m}\right)$. In the unenriched control $(\mathrm{G})$, a shift in both the Synechococcus and eukaryotic picoplankton to larger sizes is observed after 1 day (Fig. 5.4). By day 2, both populations shrink back to their original size, but the concentration of eukaryotic picoplankton increases substantially to form a distinct bimodal distribution (Fig. 5.5). Subsequent days, however, show a progressive decrease in abundance and size of both populations relative to the initial (Figs. 5.6, 5.7). These changes can also be seen in the evolution of normalized difference spectra (Fig. 5.10). In the unenriched dilution bottles $(\mathrm{H}, \mathrm{I}, \mathrm{J})$, a bimodal distribution is seen even after the first day, with slight increases in both population concentrations relative to initials (Fig. 5.4). As with the unenriched control, a shift in size spectrum to the right is also observed in the unenriched dilution treatments. The same changes in size structure are observed as in the unenriched controls, except that the changes relative to initials are more pronounced with increasing dilution (Fig. 5.10). In particular, the eukaryotic picophytoplankton show a more significant increase in concentration than Synechococcus, implying that in the field, the slightly larger 
eukaryotic picoplankton may be preferentially grazed. By day 4 , however, significant reductions in concentrations are observed in the less diluted bottles (H,I) whereas the most diluted bottle (J) still contains high numbers of picophytoplankton, similar to the previous day (Figs. 5.7, 5.10). This could be partly due to an enrichment effect from the higher dilution which helps to sustain the picophytoplankton populations ie. nutrients are less likely to run out in the most diluted bottles.

In the case of the enriched control (B), the picophytoplankton show a similar shift to larger sizes as the unenriched control after 1 day (Figs. 5.3, 5.4). However, unlike the unenriched control, the structure of the community remains skewed to larger sizes throughout the entire incubation period (Fig. 5.11). On day 2, the abundance of eukaryotic picoplankton increases substantially resulting in a skewed bimodal distribution (Fig. 5.5). As time progresses, the continued rise in eukaryotic picoplankton abundance eventually leads to a unimodal distribution where the mean size is $1.4 \mu \mathrm{m}^{3}$ (Figs. 5.7, 5.11). Compared to the unenriched controls, a definite switch from smaller Synechococcus to larger eukaryotic picoplankton is observed in the time course of the experiment. This is consistent with the hypothesis that larger cells can outcompete smaller cells in nutrient rich environments, even though the difference in size between these two populations is small. For the enriched dilution bottles $(\mathrm{C}, \mathrm{D}, \mathrm{E})$, similar changes in the size structure are observed as with the enriched control ie. a shift to dominance of eukaryotic picoplankton (Fig. 5.11). However, increasing dilution did not produce much difference relative to the enriched control until day 2 onwards. Between the 1:3 (C) and 3:1 (E) dilutions, little change is observed. The 1:1 dilution (D), however, had a lower response than expected partly because the initial cell concentrations were higher than expected. Overall, it appears that the response of coastal picophytoplankton to a reduction in grazing pressure through dilution affects cell abundance more than cell size. There are also significant differences in the way the picophytoplankton in the enriched dilutions respond compared with the unenriched dilutions: the spectra for the unenriched dilutions show additional responses 


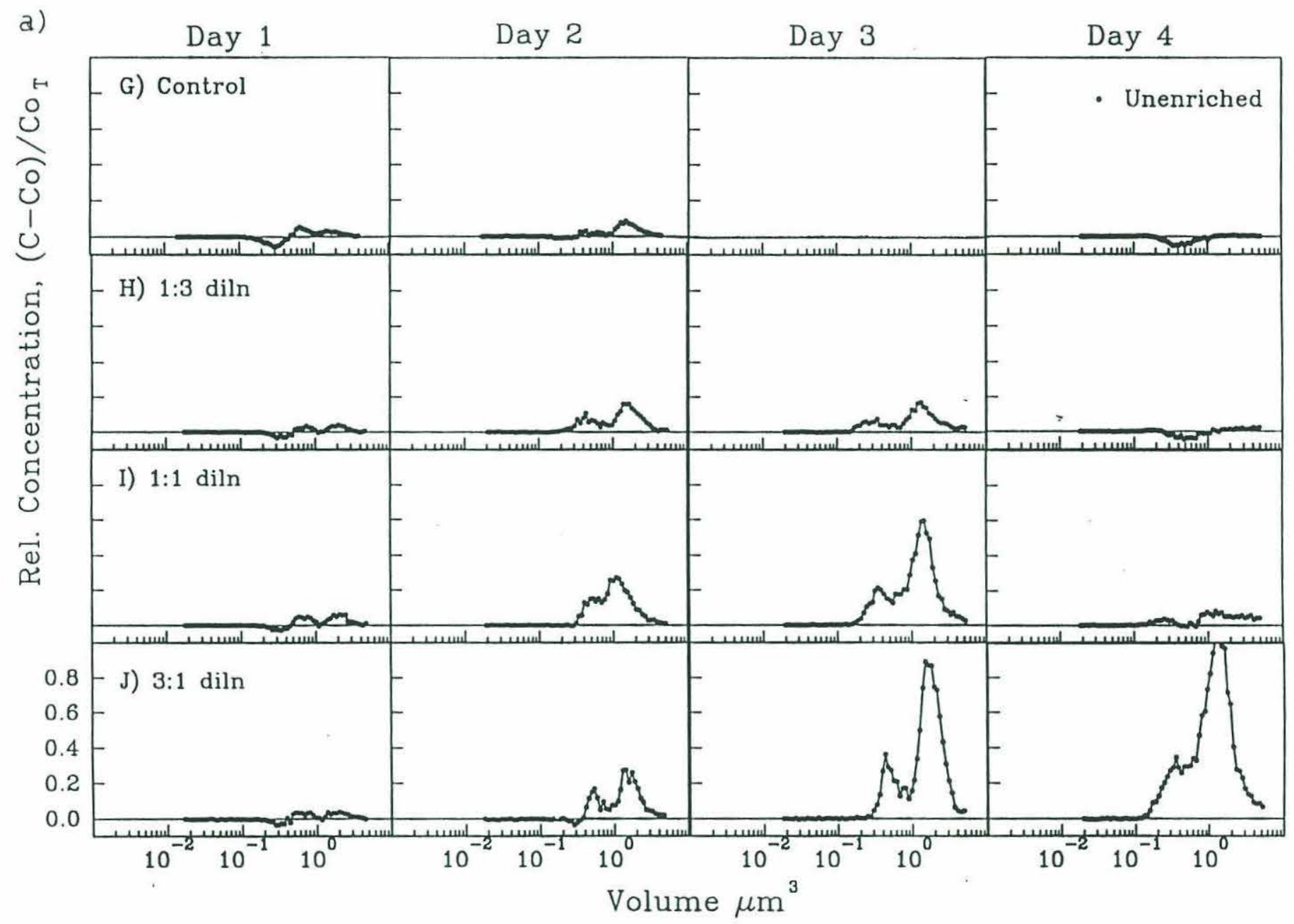

Fig. 5.10. Evolution of the normalized difference spectra for unenriched picophytoplankton in the coastal incubation experiment. G represents the unenriched control treatment while $\mathrm{H}(1: 3), \mathrm{I}(1: 1)$ and $\mathrm{J}(3: 1)$ are the unenriched dilution treatments. Replicate time courses are shown in (a) and (b). 


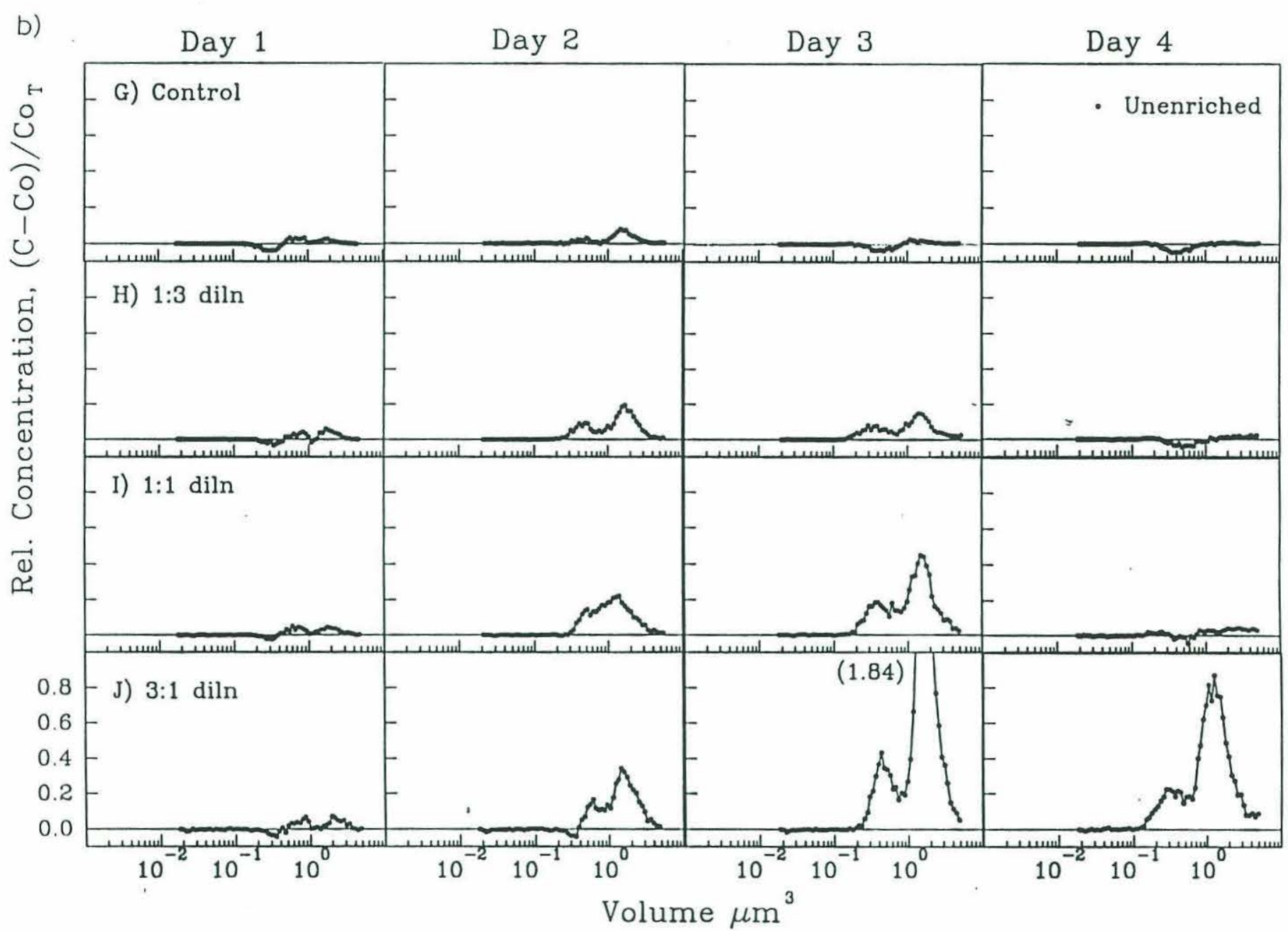

Fig. 5.10....continued 
a)
Day 1
Day 2

Day 3

Day 4

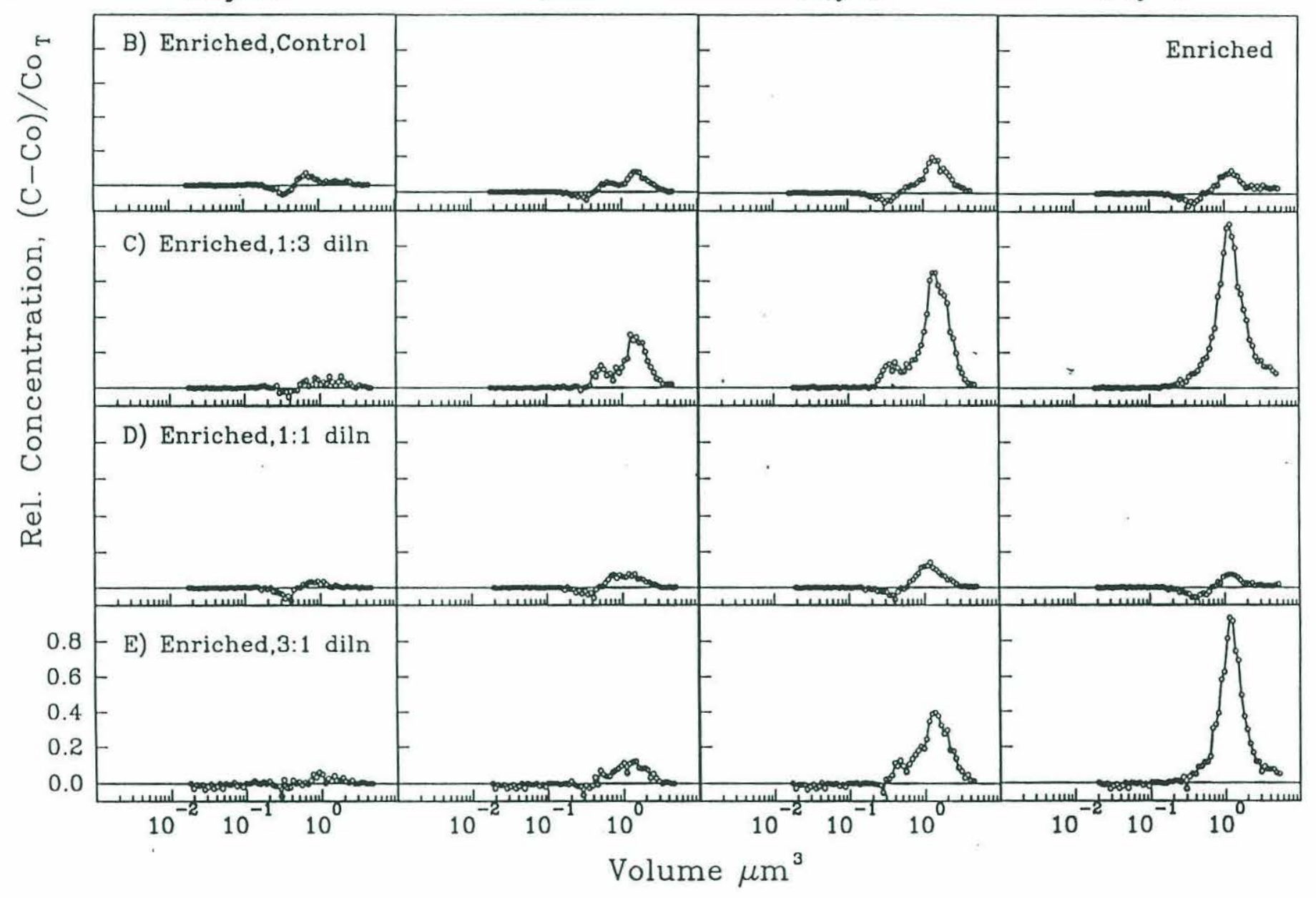

Fig. 5.11. Evolution of the normalized difference spectra for picophytoplankton enriched with inorganic nutrients in the coastal incubation experiment. B represents the enriched control treatment while C (1:3), D (1:1) and E (3:1) are the enriched dilution treatments. Replicate time courses are shown in (a) and (b). 


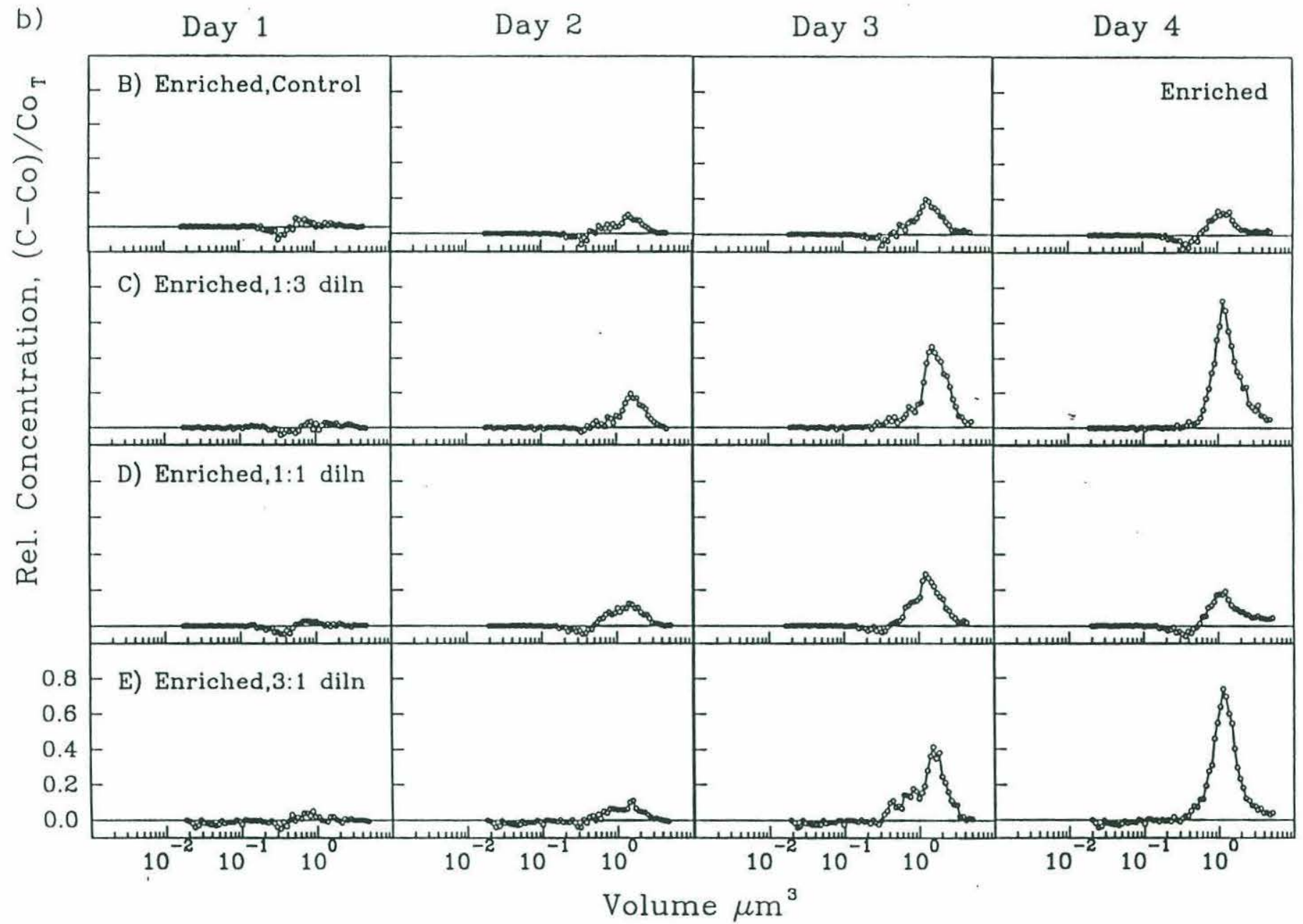

Fig. $5.11 \ldots$ continued 
from smaller Synechococcus cells, with relatively greater increases in the more diluted bottles (I, J), especially on day 3 (compare Figs. 5.10, 5.11).

\section{The Sargasso Sea}

In general, bacteria and picophytoplankton size spectra from the oligotrophic Sargasso Sea are skewed to smaller cells compared with coastal samples. The mean sizes of the oceanic bacteria and picophytoplankton are approximately $0.02 \mu \mathrm{m}^{3}(0.34 \mu \mathrm{m})$ and $0.3 \mu \mathrm{m}^{3}(0.8 \mu \mathrm{m})$ respectively, compared to $0.04 \mu \mathrm{m}^{3}(0.43 \mu \mathrm{m})$ and $0.6 \mu \mathrm{m}^{3}(1.1 \mu \mathrm{m})$ for the coastal bacteria and picophytoplankton respectively. As discussed in the Methods section, the sub-population of Prochlorococcus could not be resolved perfectly from the bacteria population, due to the very low red fluorescence of these picophytoplankton. This seemed to affect mainly the smallest Prochlorococcus, leading to an asymmetric peak in the first hump of the picophytoplankton size spectrum (Fig. 5.12). Most of the samples revealed a substantial drop in Prochlorococcus abundance after only one day, whereas Synechococcus were present in most of the bottles throughout the experiment. Part of the reason for the disappearance of Prochlorococcus is that they are very sensitive organisms and could have encountered trace metal toxicity introduced while filtering seawater. Initial cell concentrations for bacteria and picophytoplankton are given in Table 5.3.

\section{Bacteria}

The bacteria spectrum is initially characterized by small sizes but over the four day incubation period, the spectrum gradually changes to one where the larger bacteria dominate (Figs. 5.12 to 5.16 ). The unenriched controls $(G)$ show a progressive increase in bacteria greater than $0.03 \mu \mathrm{m}^{3}$ whereas bacteria smaller than this size tend to maintain roughly similar concentrations with time (Fig. 5.17). Increased organics from nutrient stressed phytoplankton may have contributed to this change in size structure for the unenriched controls. In the case of the unenriched dilutions (H,I,J), the responses of bacteria relative to the control show a definite shift to larger sizes $\left(0.1 \mu \mathrm{m}^{3}\right)$, similar to the 


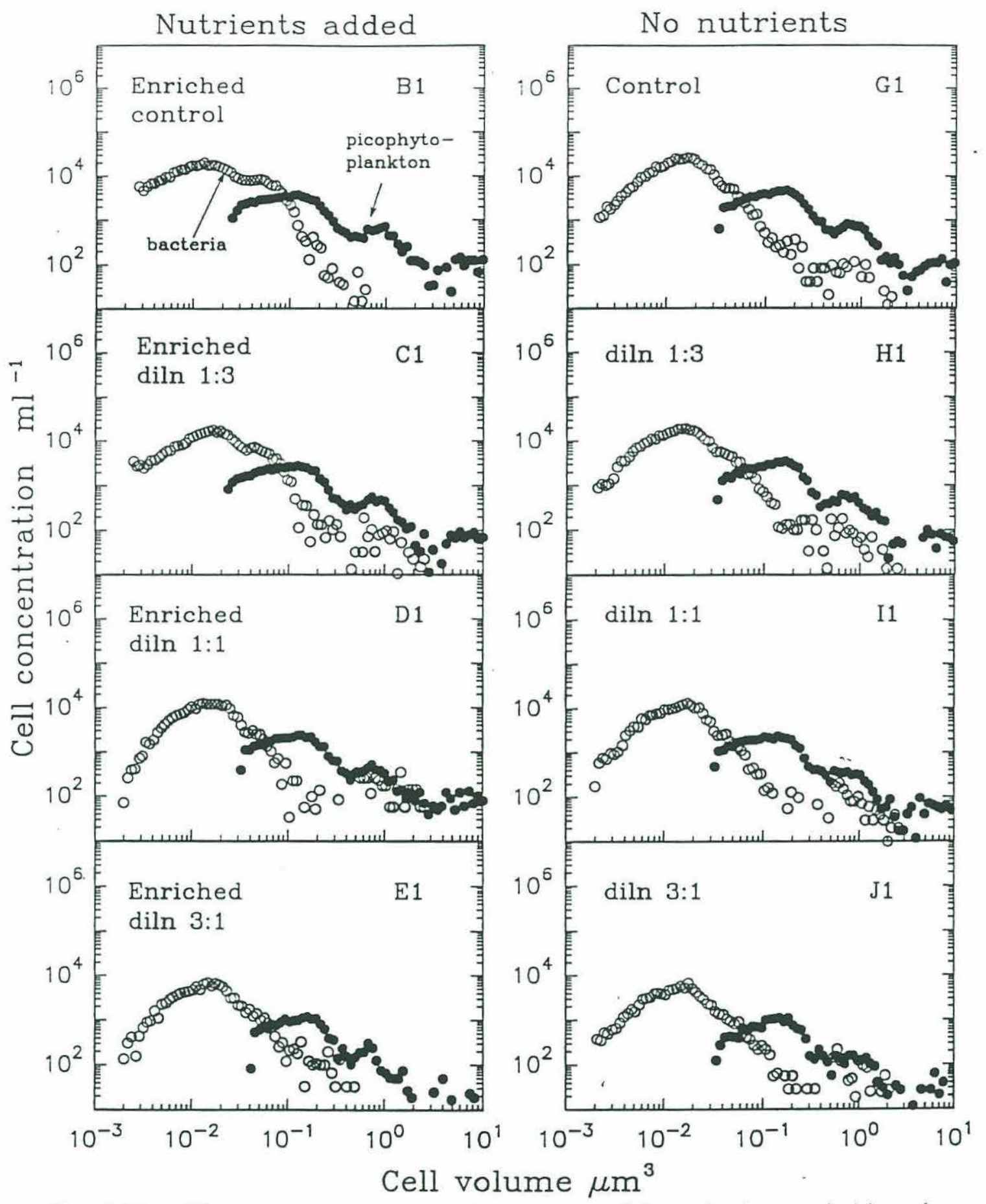

Fig. 5.12. Histogram concentration size spectra of bacteria (open circle) and picophytoplankton (closed circle) for the oceanic incubations (Sargasso Sea) at the beginning of the experiment. The letter designation corresponds to the treatments listed in Table 4.1 and the number indicates the replicate bottle. The left hand panel of graphs represent the treatments enriched with inorganic nutrients whilst the unenriched treatments are shown in the right hand panel. 


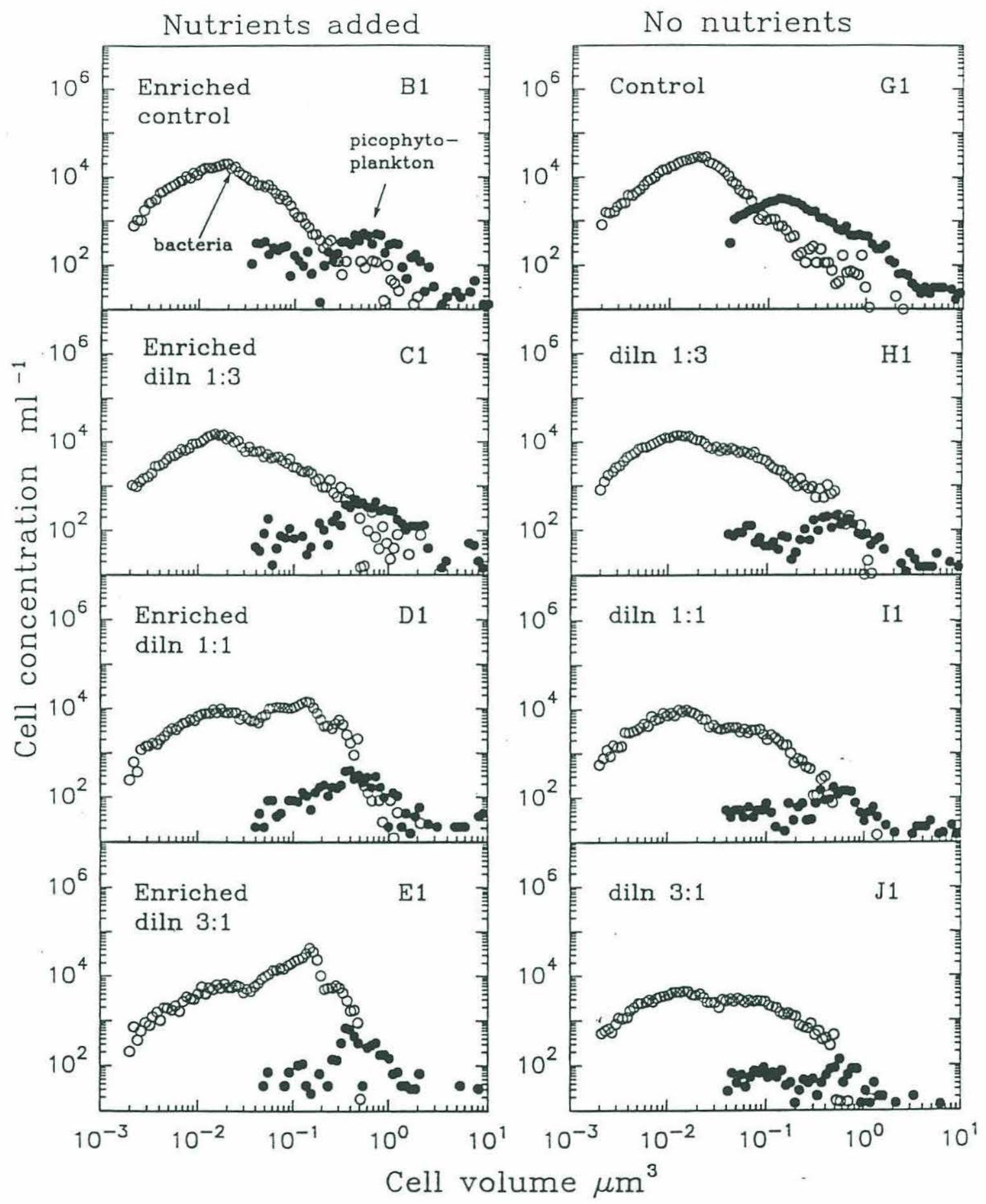

Fig. 5.13. Histogram concentration size spectra of bacteria (open circle) and picophytoplankton (closed circle) for the oceanic experiment after incubating samples for 1 days in simulated field conditions. 


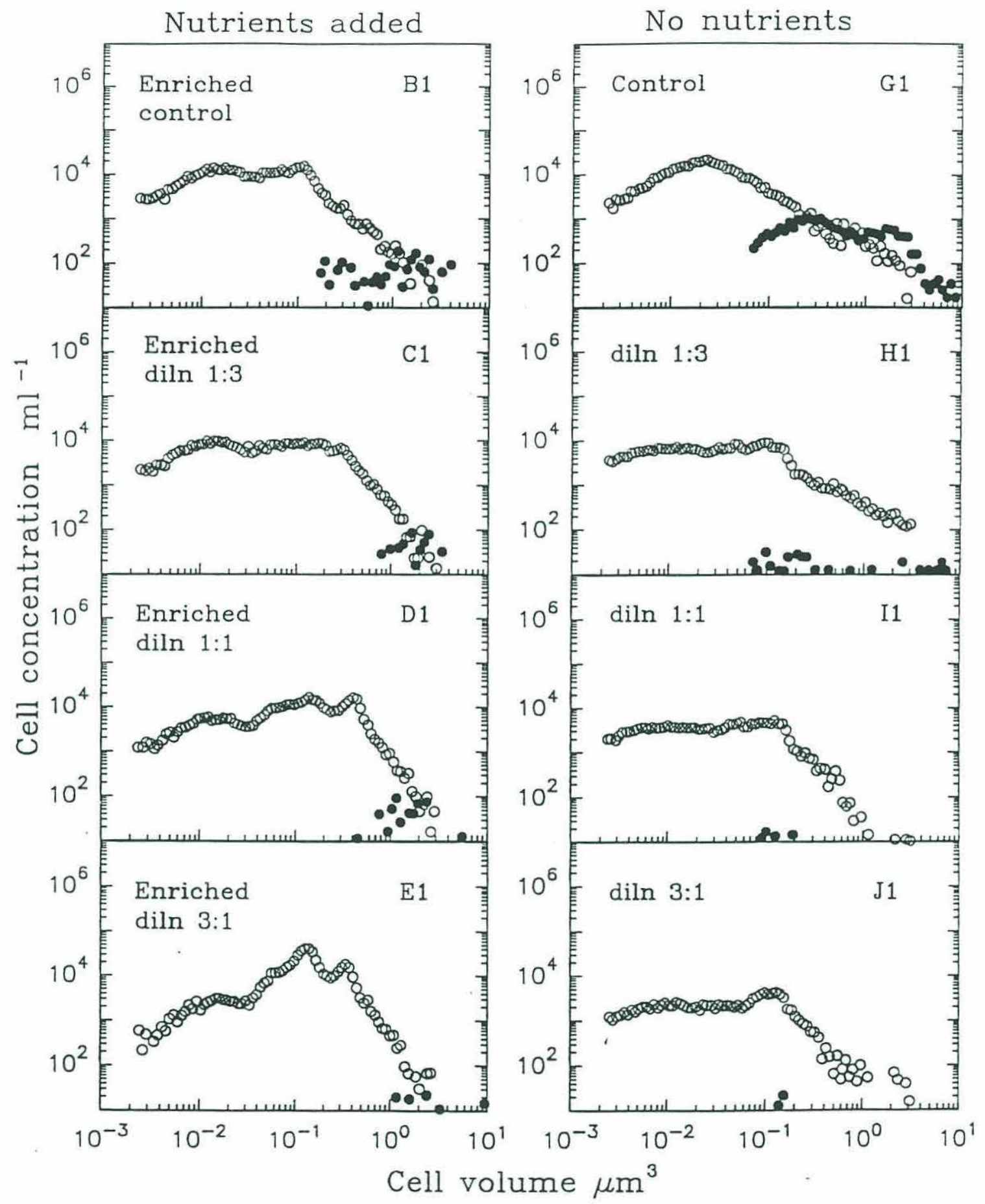

Fig. 5.14. Histogram concentration size spectra of bacteria (open circle) and picophytoplankton (closed circle) for the oceanic experiment after incubating samples for 2 days in simulated field conditions. 


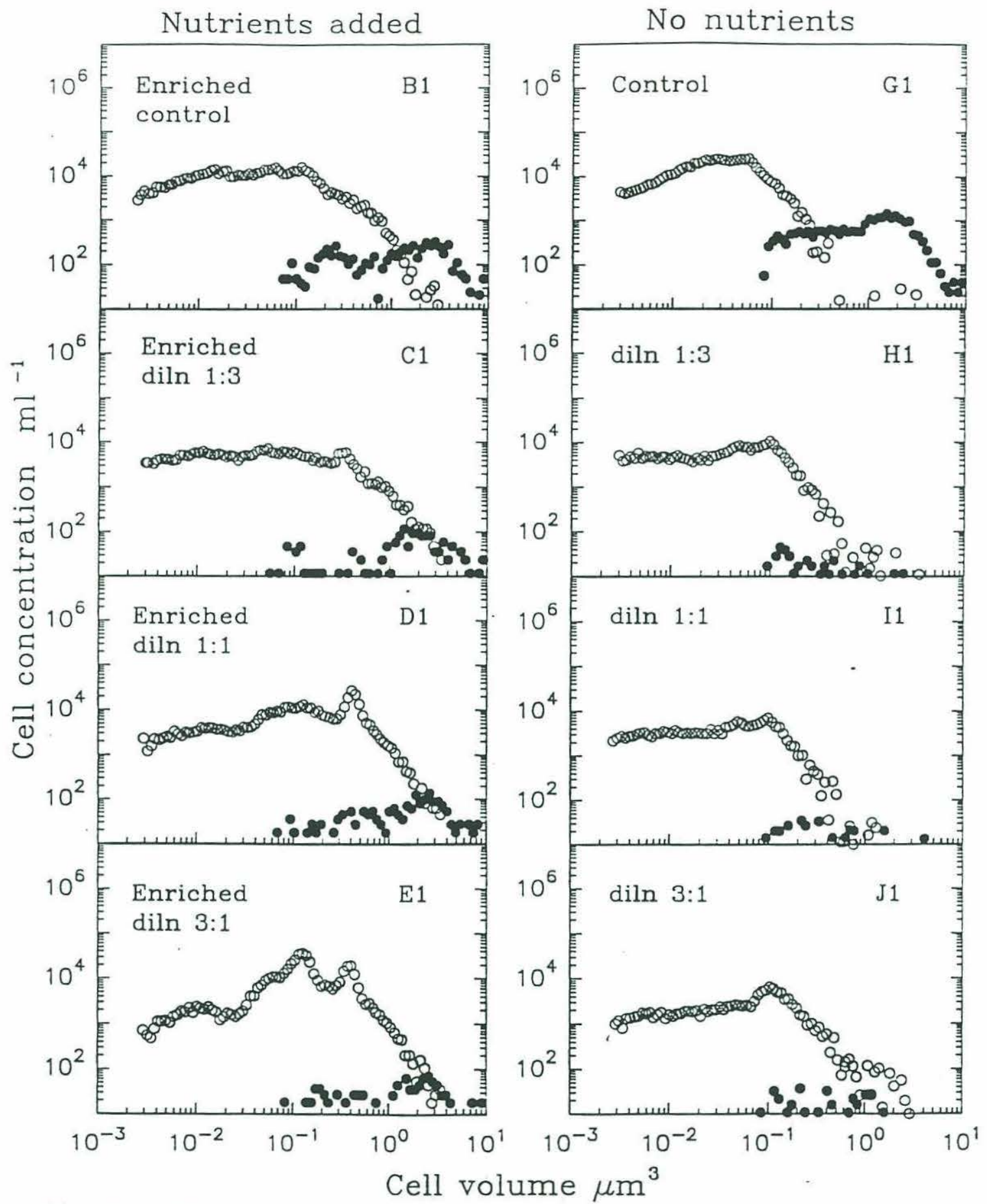

Fig. 5.15. Histogram concentration size spectra of bacteria (open circle) and picophytoplankton (closed circle) for the oceanic experiment after incubating samples for 3 days in simulated field conditions. 


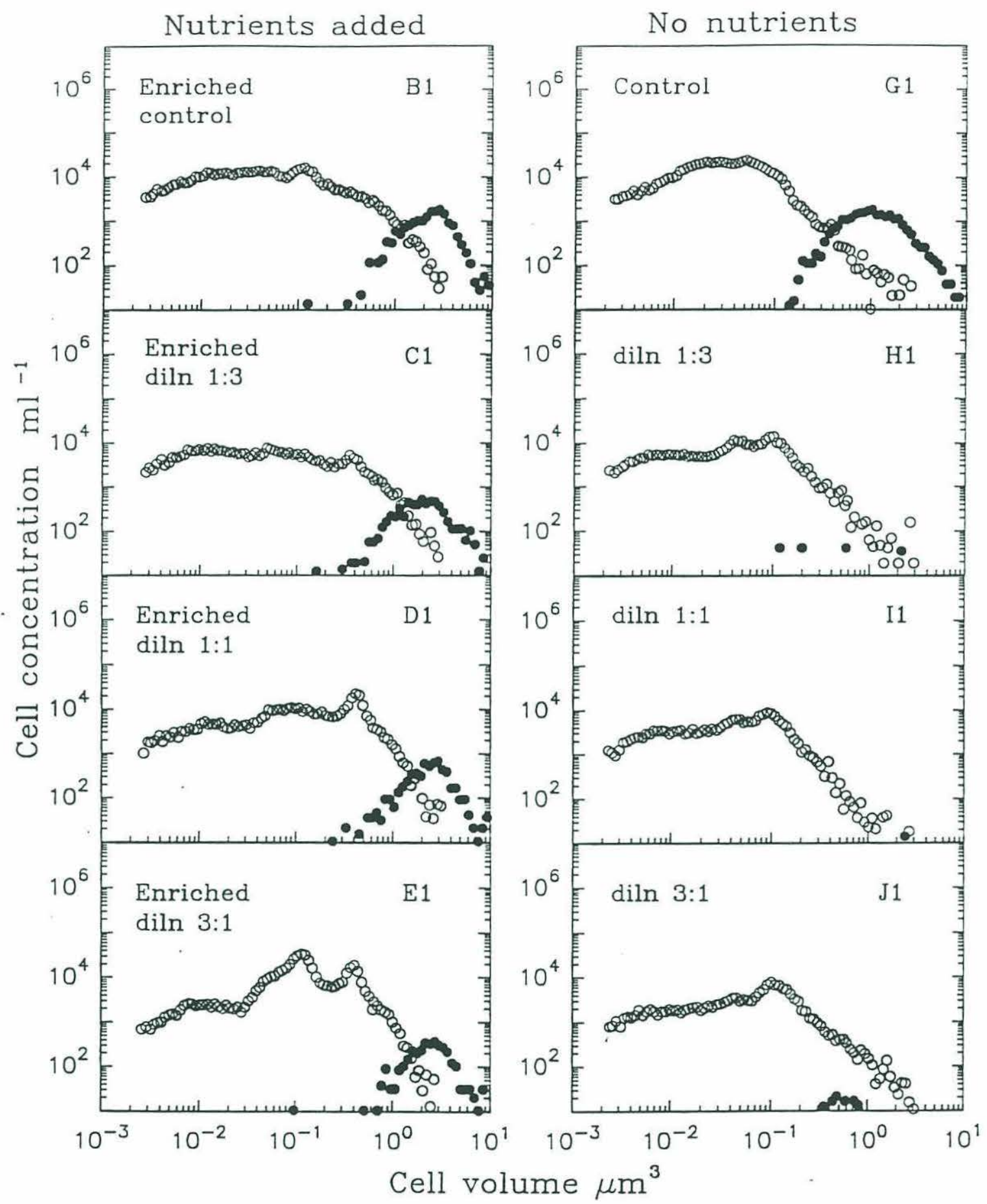

Fig. 5.16. Histogram concentration size spectra of bacteria (open circle) and picophytoplankton (closed circle) for the oceanic experiment after incubating samples for 4 days in simulated field conditions. 


\begin{tabular}{llllll}
\hline $\begin{array}{l}\text { Treat- } \\
\text { ment }\end{array}$ & Bacteria & $\begin{array}{l}\text { Pico-phyto } \\
\text { plankton }\end{array}$ & $\begin{array}{l}\text { Treat- } \\
\text { ment }\end{array}$ & Bacteria & $\begin{array}{l}\text { Pico-phyto } \\
\text { plankton }\end{array}$ \\
\hline B1 & 430,070 & 73,691 & B2 & 456,711 & 74,956 \\
C1 & 344,861 & 56,243 & C2 & 339,758 & 56,302 \\
D1 & 224,655 & 42,634 & D2 & 216,083 & 47,350 \\
E1 & 115,285 & 18,228 & E2 & 130,771 & 20,057 \\
G1 & 445,930 & 77,930 & G2 & 478,698 & 88,587 \\
H1 & 345,291 & 56,177 & H2 & 315,066 & 64,819 \\
I1 & 209,030 & 41,628 & I2 & 216,646 & 44,022 \\
J1 & 103,036 & 16,671 & J2 & 104,194 & 17,652 \\
\hline
\end{tabular}

Table 5.3. Initial concentrations of bacteria and picophytoplankton for the oceanic incubation bottles. Samples were taken from the Sargasso Sea on July 8th and analyzed flow cytometrically. Concentrations are given as no. of cells $\mathrm{ml}^{-1}$.

coastal bacteria (eg. Figs. 5.12, 5.14). In addition, a decrease in abundance of small bacteria is also seen, resulting in a roughly uniform distribution for cells less than 0.02 $\mu \mathrm{m}^{3}$. The corresponding normalized difference spectra show that the responses in the unenriched dilutions are generally low relative to initials (Fig. 5.17). These changes in the size spectrum could be attributed to a combination of reduction in grazing pressure and increased dissolved organic production from nutrient 'stressed' phytoplankton.

In the enriched treatments, the bacteria size spectrum of the controls (B) progressively changes from a narrow distribution with a modal size of $0.02 \mu \mathrm{m}^{3}$ (Fig. 5.12) to one that is more uniform (Fig. 5.16). In particular, enrichment from inorganic nutrients seems to favour the bacteria size classes greater than $0.05 \mu \mathrm{m}^{3}$, especially after day 2 (Figs. 5.14, 5.18). This shift to larger sizes is more significant than for the unenriched control, implying that enriching with inorganic nutrients favours the growth of larger bacteria either directly or indirectly through increases in phytoplankton biomass. (The mean bacteria size of the enriched samples after 4 days is $0.12 \mu \mathrm{m}^{3}$ whereas that of the unenriched is about $0.06 \mu \mathrm{m}^{3}$.) Similar trends in the bacteria spectrum were also observed in the coastal experiment. In the case of the enriched dilution treatments (C,D,E), a distinct shift to larger size (from 0.01 to $0.2 \mu \mathrm{m}^{3}$ ) is observed with increasing dilution even after one day, particularly for replicate 1 (Figs. $5.13,5.18$ ). As time progresses, twin 


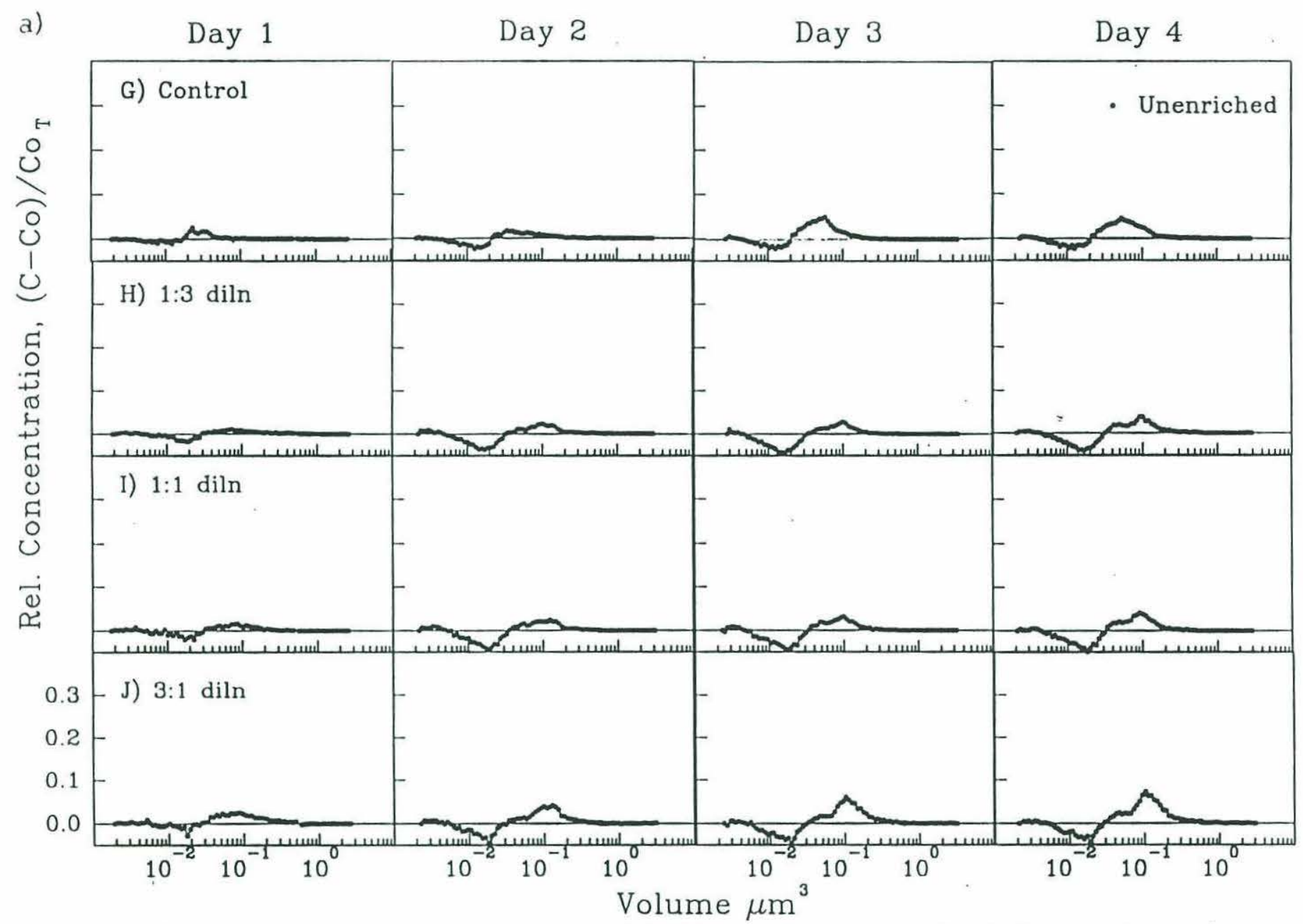

Fig. 5.17. Evolution of the normalized difference spectra for unenriched bacteria in the oceanic incubation experiment. G represents the unenriched control treatment while $\mathrm{H}(1: 3), \mathrm{I}(1: 1)$ and J (3:1) are the unenriched dilution treatments. Replicate time courses are shown in (a) and (b). 


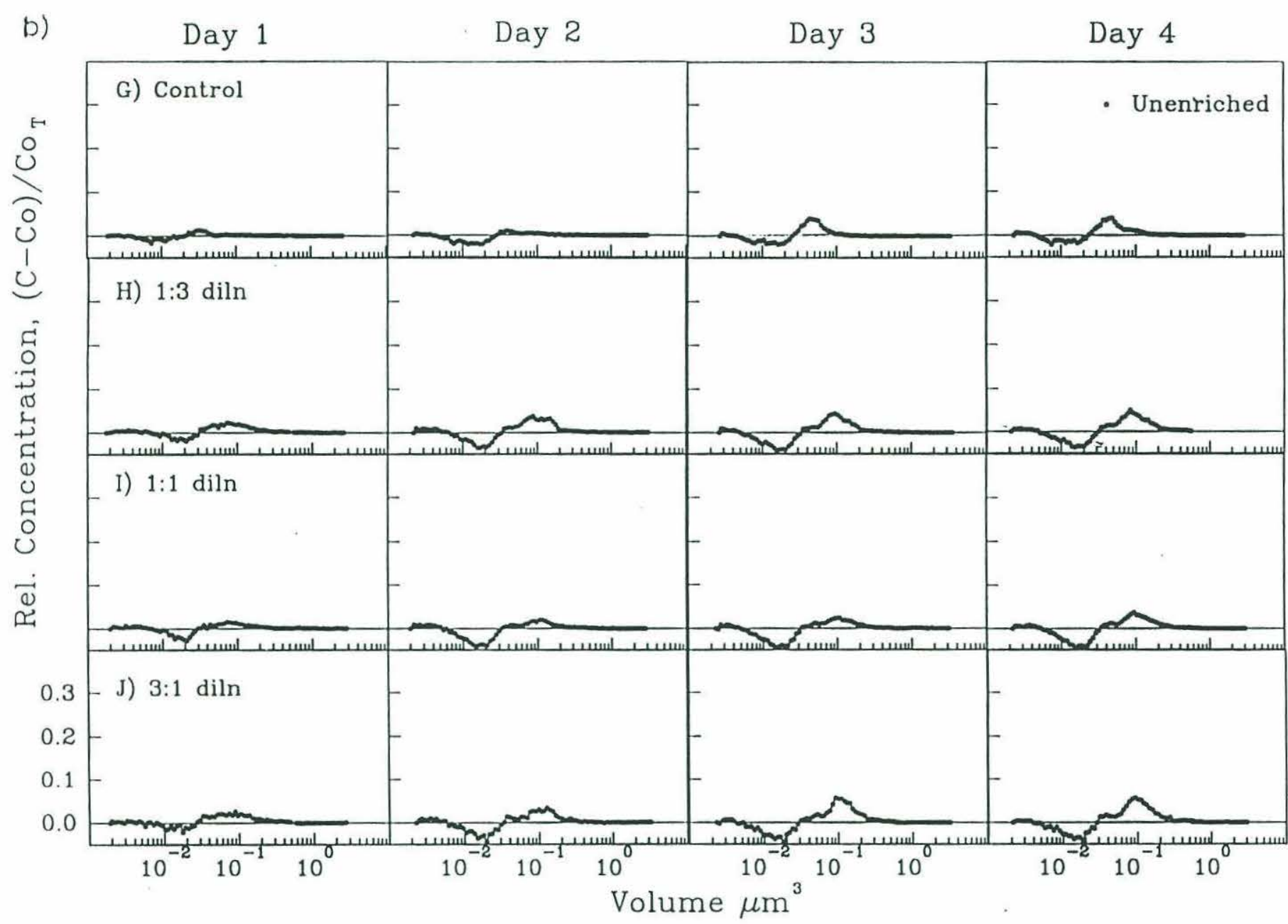

Fig. 5.17.... continued 


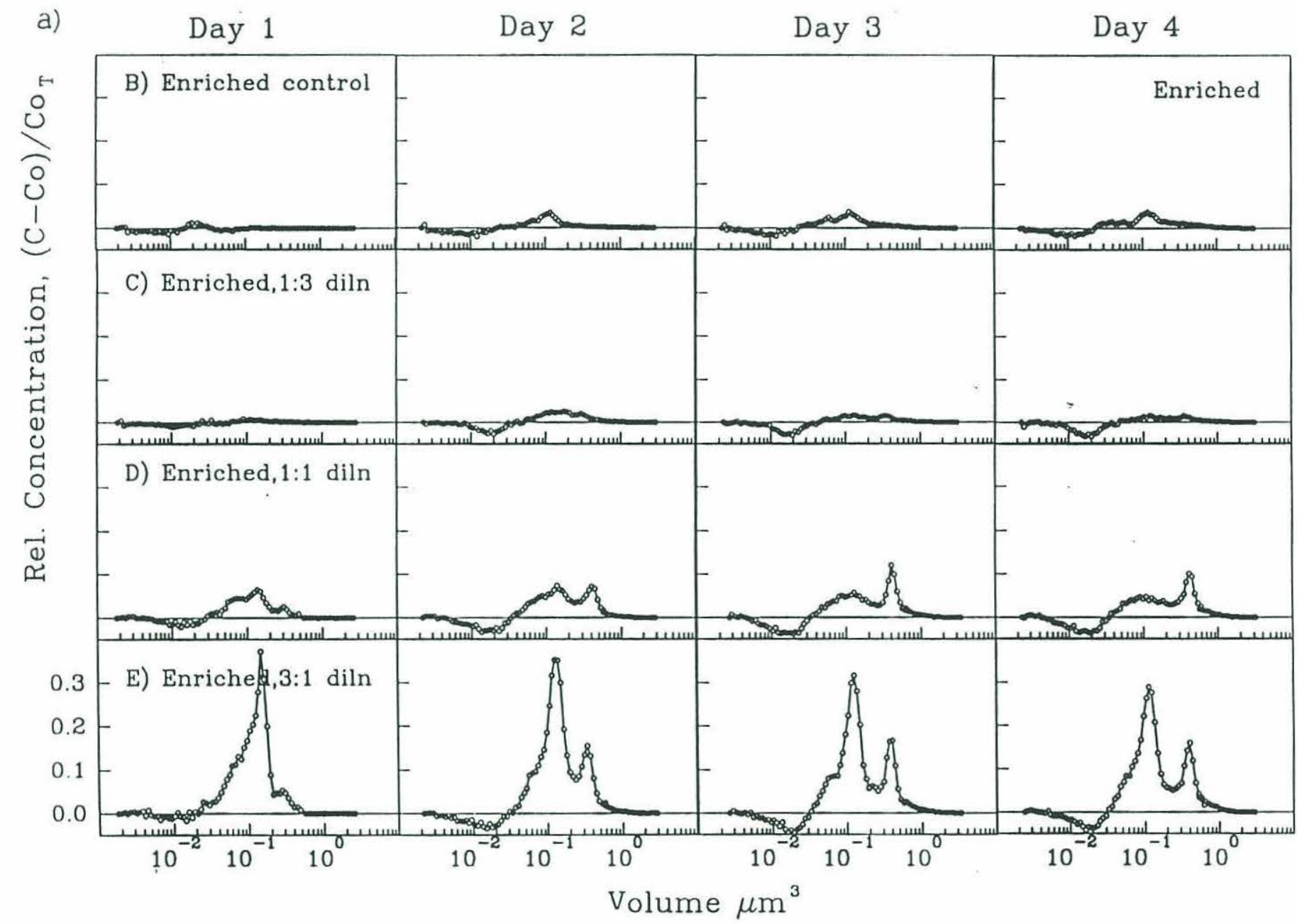

Fig. 5.18. Evolution of the normalized difference spectra for bacteria enriched with inorganic nutrients in the oceanic incubation experiment. B represents the enriched control treatment while C (1:3), D (1:1) and E (3:1) are the enriched dilution treatments. Replicate time courses are shown in (a) and (b). 


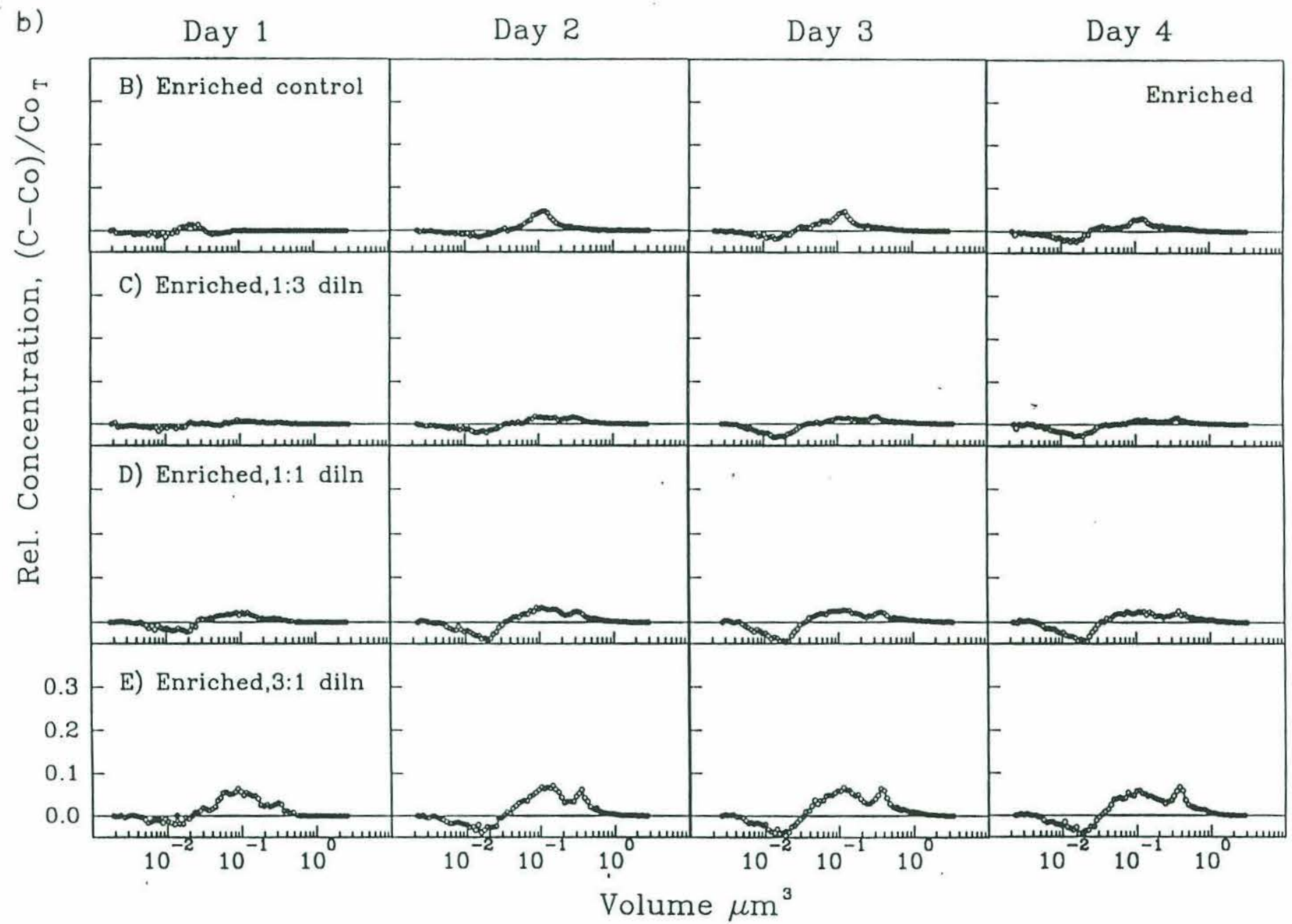

Fig. 5.18.... continued 
peaks are formed in the size spectra of the most diluted bottles (E), corresponding to large bacteria sizes of 0.1 and $0.4 \mu \mathrm{m}^{3}$ (Figs. 5.14 to 5.16). The first peak at $0.1 \mu \mathrm{m}^{3}$ also corresponds to the peak observed in the enriched control (B) and may have arisen from similar processes in the inorganic enrichment (Fig. 5.18). The peak at $0.4 \mu \mathrm{m}^{3}$, on the other hand, is a distinct feature only of the enriched dilution bottles, especially in the most diluted bottles (D,E). Note that the heterotrophic peak at $0.4 \mu \mathrm{m}^{3}$ is absent and cells are more uniformly distributed in the corresponding unenriched dilutions (H,I,J) (compare Figs. 5.17, 5.18). Since increasing dilution favours the growth of large bacteria, these micro-organisms must be preferentially grazed in the field. The rapid response of these micro-organisms to a reduction in grazing pressure also suggests that growth and predation of large bacteria are closely coupled and that these populations are probably effectively controlled in oceanic environments.

\section{Picophytoplankton}

The picophytoplankton population comprises mainly of Prochlorococcus and Synechococcus, with mean population sizes of $0.2 \mu \mathrm{m}^{3}(0.7 \mu \mathrm{m})$ and $0.8 \mu \mathrm{m}^{3}(1.2 \mu \mathrm{m})$ respectively. Initially, the unenriched controls $(G)$ show a trimodal spectrum such that cell concentration decreases with increasing size (Fig. 5.12). As time progresses, however, the spectrum gradually shifts in favour of large picophytoplankton (Synechococcus), so that

eventually a unimodal distribution is observed, centred at approximately $1 \mu \mathrm{m}^{3}$ (Fig. 5.16). In contrast to the unenriched controls, the abundance of picophytoplankton in the unenriched dilutions (H,I,J) gradually diminish to negligible levels, especially after day 2 of the experiment (Fig. 5.14 to 5.16). The corresponding normalized difference spectra show significant areas with negative values, indicating the dramatic decrease in concentration of these organisms (Fig. 5.19). Note that only the controls (G) have positive areas, reflecting growth in the larger picoplankton size categories. One possibility is that the dilutions might have reduced grazing pressure sufficiently on larger 


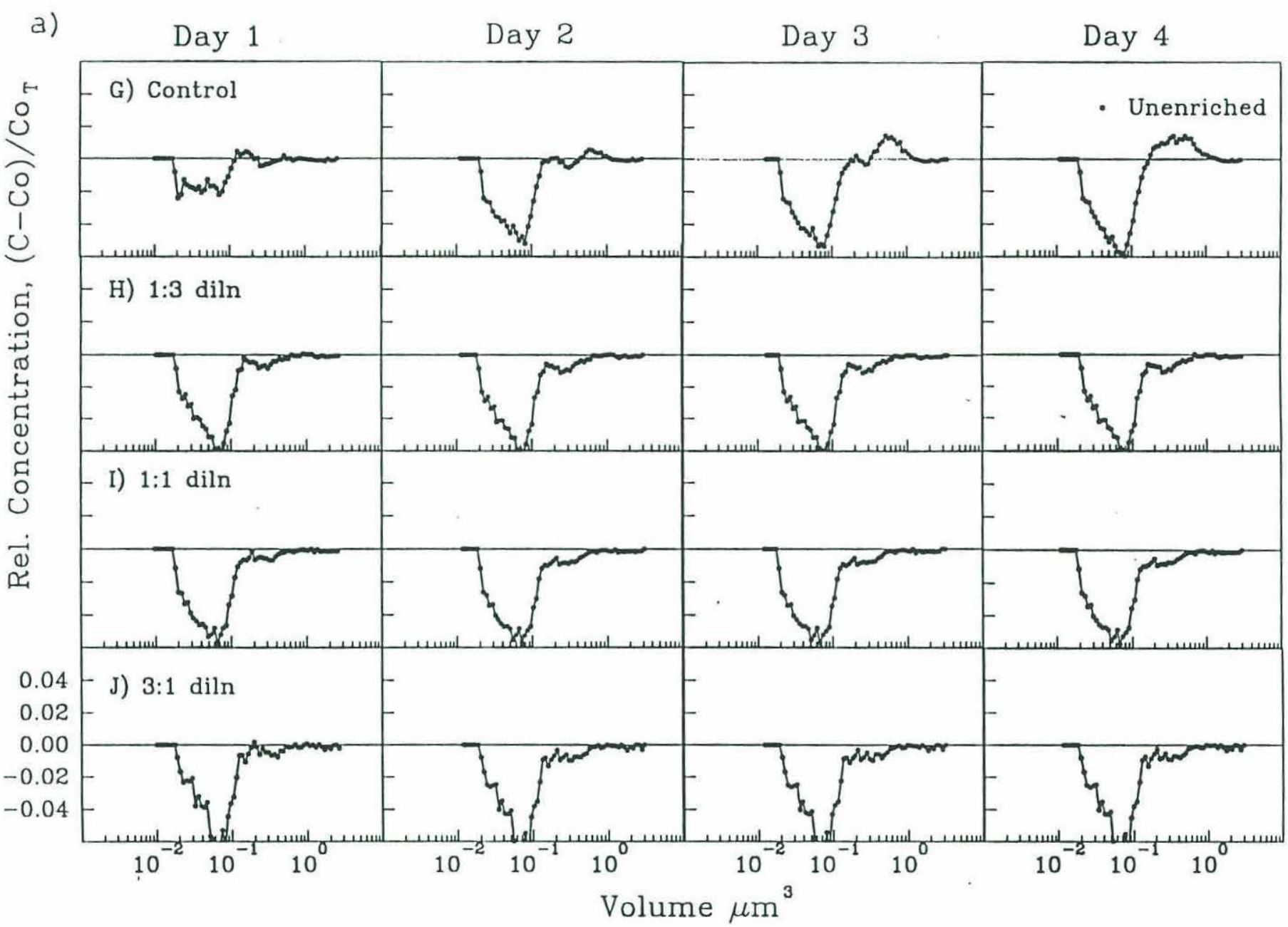

Fig. 5.19. Evolution of the normalized difference spectra for unenriched picophytoplankton in the oceanic incubation experiment. G represents the unenriched control treatment while $\mathrm{H}(1: 3), \mathrm{I}(1: 1)$ and $\mathrm{J}(3: 1)$ are the unenriched dilution treatments. Replicate time courses are shown in (a) and (b). 


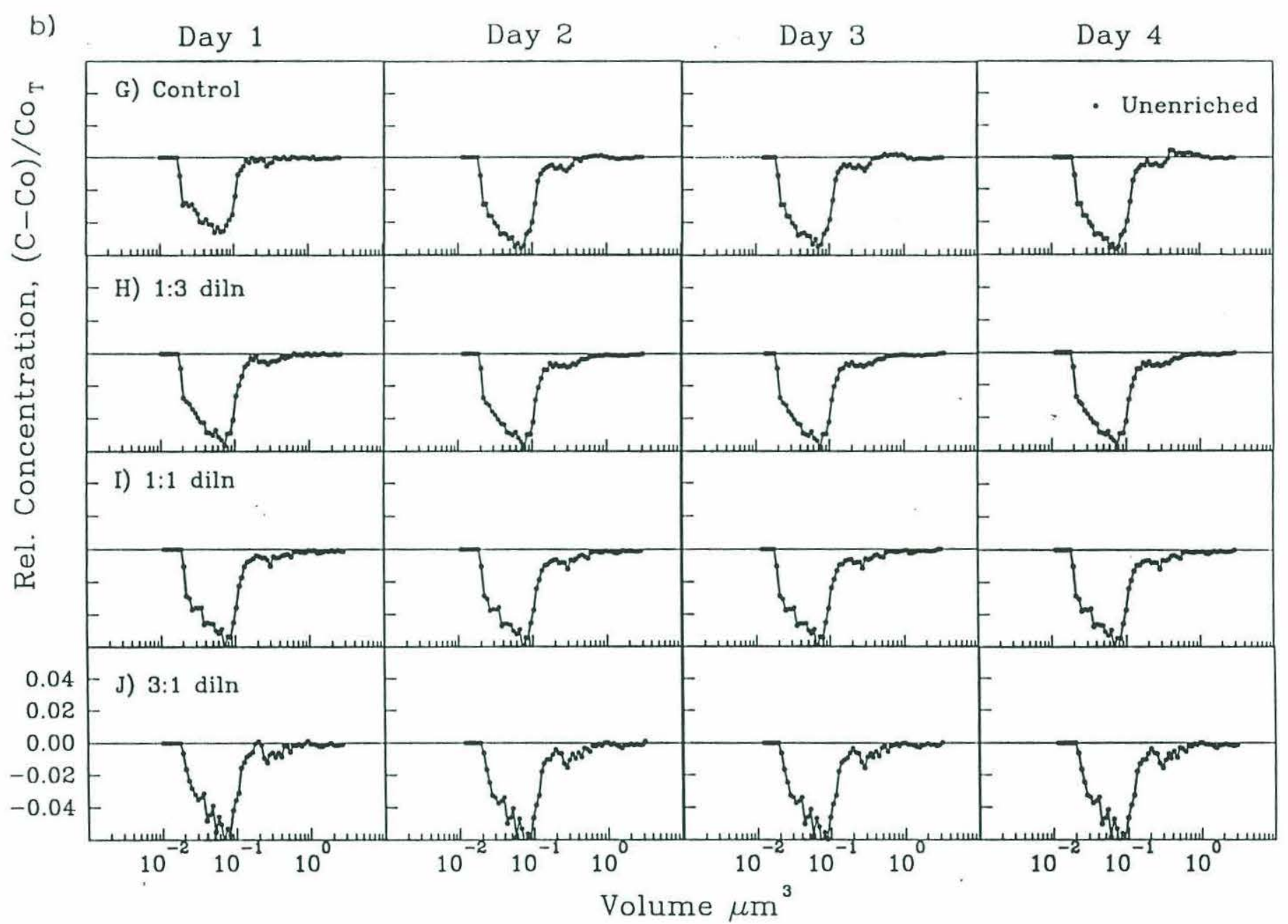

Fig. 5.19.... continued 


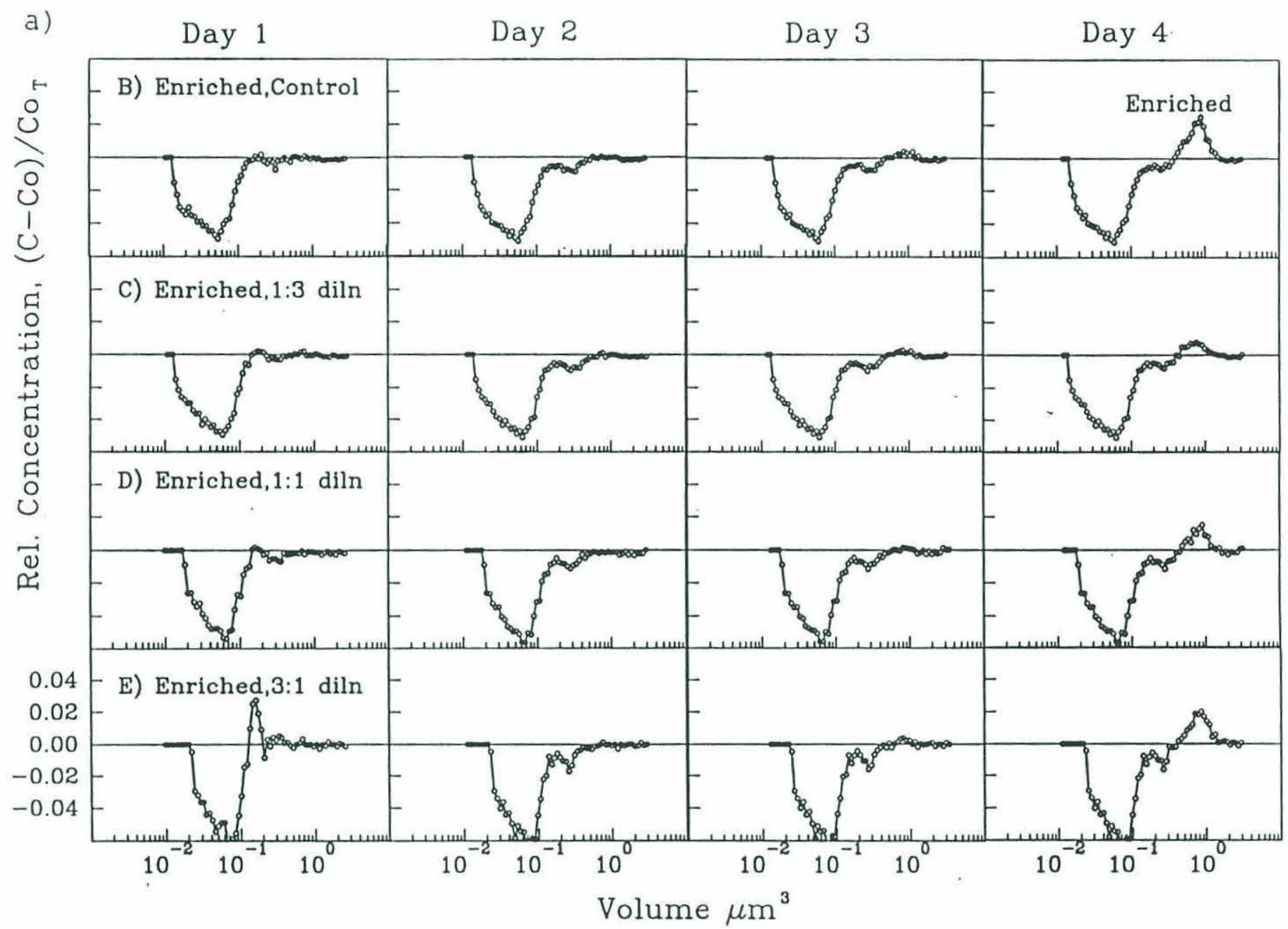

Fig. 5.20. Evolution of the normalized difference spectra for picophytoplankton enriched with inorganic nutrients in the oceanic incubation experiment. B represents the enriched control treatment while C (1:3), D (1:1) and E (3:1) are the enriched dilution treatments. Replicate time courses are shown in (a) and (b). 


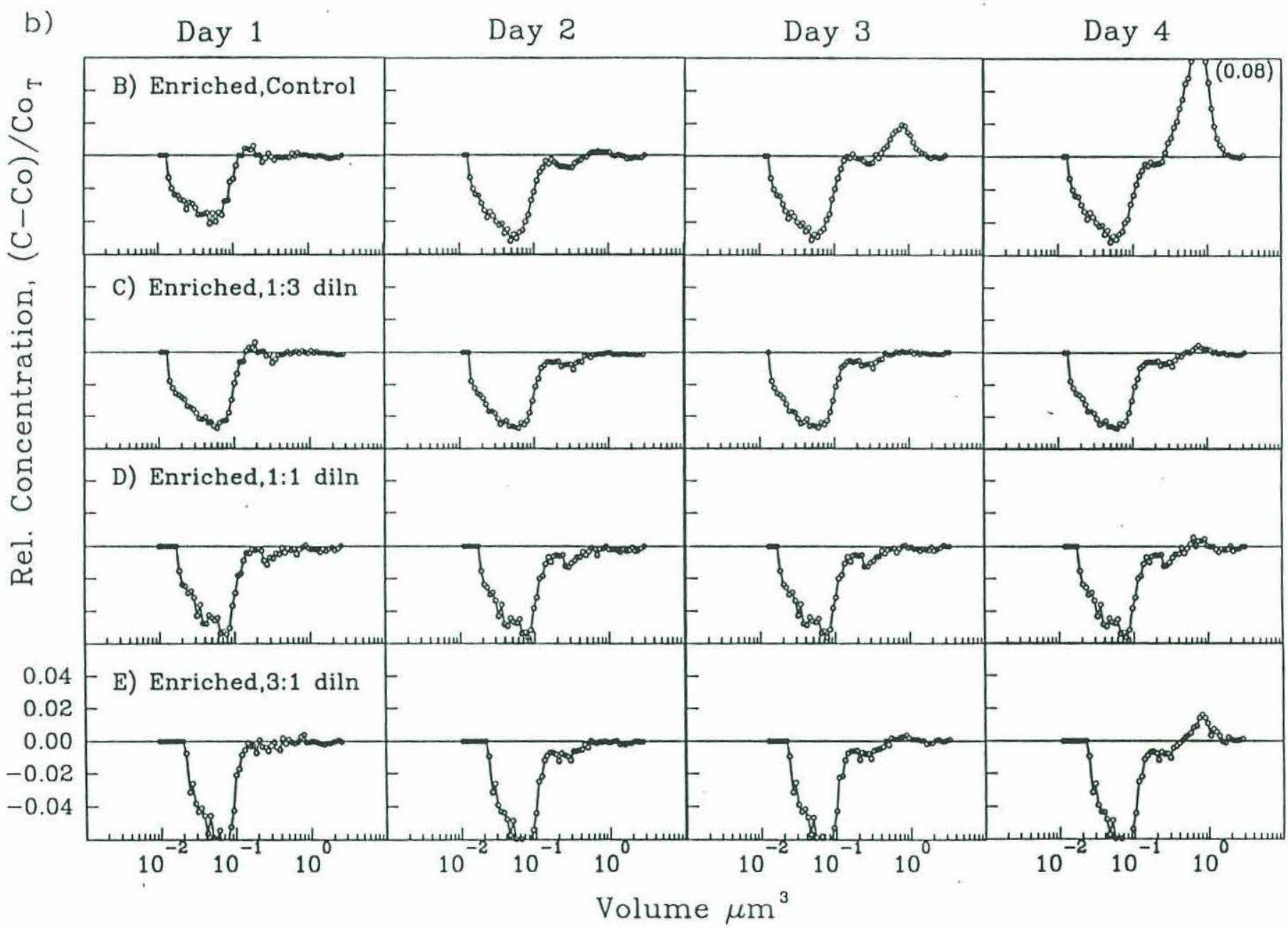

Fig. 5.20.... continued 
phytoplankton so that picophytoplankton were outcompeted. Enrichment by the dilution effect may also have stimulated the growth of larger phytoplankton.

The phytoplankton in the enriched controls (B) show a similar shift as the unenriched controls $(\mathrm{G})$ to larger sizes over the 4 day incubation period (compare Figs. $5.19,5.20)$. The difference, however, is that the decrease in picophytoplankton is more substantial in the enriched control so that by day 2, very few cells are detected (Fig. 5.14). The reduction in picophytoplankton abundance in the enriched controls could also be explained by the larger phytoplankton outcompeting the picophytoplankton in the presence of elevated nutrient levels. (Note that a similar absence of picophytoplankton is observed in the unenriched dilutions on the same day.) By day 3, however, there are some signs of rejuvenation in the populations and by day 4 , the entire picophytoplankton community is dominated by large Synechococcus of about $3 \mu \mathrm{m}^{3}$ (Fig. 5.16). One possible reason is that by day 4 , the nutrients may have been drawn down sufficiently to switch the competitive edge from larger nano/microplankton back to picophytoplankton. Overall, the enriched bottles show a greater overall increase in size as well as fewer small picophytoplankton (ie. Prochlorococcus) compared with the unenriched control. There is also little difference between enriched dilutions $(C, D, E)$ for the picophytoplankton compared to the response of bacteria size spectra to the same treatments (Figs. 5.18, 5.20). As with the enriched controls, the picophytoplankton in the enriched dilutions progressively decrease in abundance, almost disappearing by day 2 and then subsequently reappearing on day 4, but at larger sizes (Figs. 5.16, 5.20). From the similarity in size structure between the enriched dilutions and the enriched controls, one can infer that the grazing impact on the picophytoplankton is small compared to the effects of nutrient enrichment.

\section{Grazing Rates}

Following the mathematical formulation described in the Methods section, we also calculated the intrinsic growth rates, $\mathrm{k}$, and grazing mortality rates, $\mathrm{g}$, of the bacteria and 
picophytoplankton populations after an incubation period of one day (Fig. 5.21, Table 5.4). In the case of the oceanic bacteria, a grazing coefficient of about 1.5 day $^{-1}$ was determined from the linear regression to the enriched data, implying that a substantial amount of some $80 \%$ of the bacteria standing crop was being lost per day to grazing. In comparison, the coastal bacteria had a grazing mortality of 0.7 day $^{-1}$, which corresponds to a loss of about $50 \%$ per day. The corresponding intrinsic growth rates obtained for the oceanic and coastal bacteria were $1.3 \mathrm{day}^{-1}$ and $1 \mathrm{day}^{-1}$ respectively. These were not expected to reflect the actual growth rates of bacteria in the field but instead, provided an upper limit to bacterial growth rates from these two diverse ecosystems. In the absence of added inorganic nutrients, the dilutions gave lower values of growth rates as well as a poorer fit to the linear regression. This was most likely a result of cells experiencing nutrient limitation.

\begin{tabular}{llllllll}
\hline Population & Ecosystem & \multicolumn{2}{l}{ Enriched } & \multicolumn{4}{c}{ Unenriched } \\
& & Y & \multicolumn{1}{l}{ S } & \multicolumn{1}{l}{ r } & \multicolumn{1}{c}{ Y } & \multicolumn{1}{c}{ S } & \multicolumn{1}{r}{} \\
\hline Bacteria & Oceanic & 1.27 & -1.57 & 0.83 & 0.28 & -0.26 & 0.67 \\
& Coastal & 1.00 & -0.68 & 0.74 & 0.36 & -0.02 & 0.05 \\
Picophyto & Oceanic & -2.08 & 0.30 & 0.19 & -3.18 & 1.63 & 0.57 \\
plankton & Coastal & -0.23 & 0.42 & 0.61 & 0.51 & -0.35 & 0.76 \\
\hline
\end{tabular}

Table 5.4. Linear regression coefficients for the apparent growth rates of bacteria and picophytoplankton as a function of the dilution factor, corresponding to Fig. 5.21. Yintercept $(\mathrm{Y})$, slope $(\mathrm{S})$ and correlation coefficient $(r)$ were calculated for both enriched and unenriched samples.

In the case of picophytoplankton, the results did not behave as expected. For oceanic picophytoplankton, the linear regressions to the data were poor and cell growth rates were depressed to negative values, even for the enriched dilutions. For coastal picophytoplankton, the regressions to the data were better fitted, but the results for the enriched dilutions still showed negative growth rates. It is possible that competition effects from larger phytoplankton in the presence of elevated nutrient levels resulted in the significant decrease in picophytoplankton numbers. 

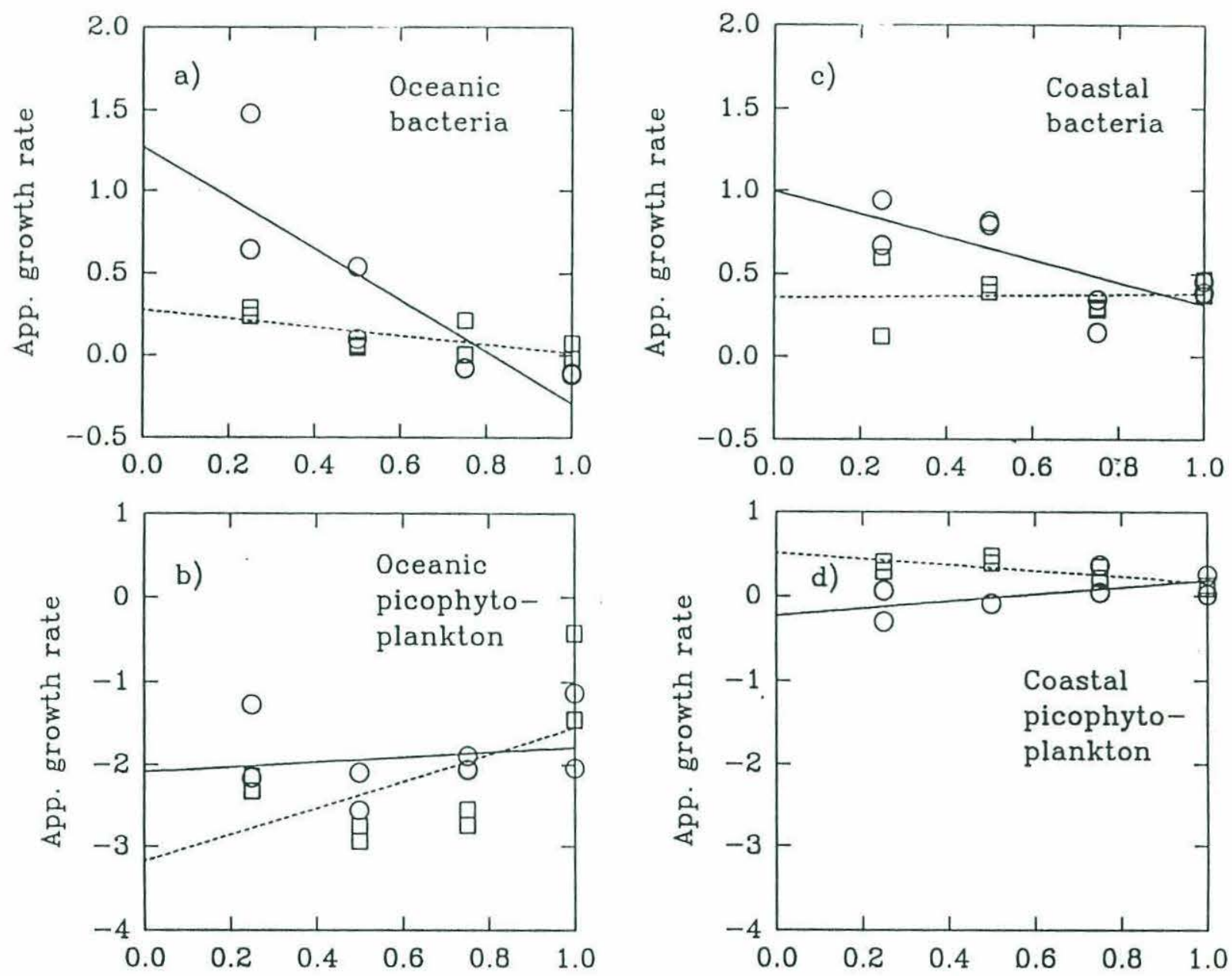

Fraction of unfiltered seavater

Fraction of unfiltered seawater

Fig. 5.21. Apparent growth rates as a function of the dilution factor for the oceanic (a, b) and coastal (c, d) incubation experiments. Intrinsic growth rates and grazing mortality rates for bacteria and picophytoplankton were estimated from the coefficients of the linear regressions to the data for the enriched dilutions (circles, solid line). For comparison, regressed data from the unenriched dilutions are also shown (squares, dashed line). 


\section{DISCUSSION}

In order to manage aquatic ecosystems, it is important to know which mechanisms of control predominate in the microbial food webs. Billen et. al., 1990 compared freshwater and marine systems of different trophic status and concluded that bacteria biomass was generally controlled by nutrients ie. bottom-up control. However, 'bulk' values such as biomass can mask certain ecological and physiological processes that are important in understanding the functioning of microbial food webs (Letarte et. al., 1991). For this reason, increasing emphasis has been placed on the importance of size in microbial studies. Psenner and Sommaruga, 1992 found from lake measurements that nutrient supply was a more effective determinant of bacteria size, whereas predation largely controlled bacteria abundance. However, their study also showed that both control modes could change rapidly, making them difficult to detect in natural ecosystems.

\section{Nutrient Effects}

Our study showed that both nutrients and predation were important factors in controlling bacteria size, whereas only nutrients seemed to play a significant role in controlling picophytoplankton size. The case for nutrient control of the picoplankton size spectrum is based on the larger surface area to volume ratio of small cells compared to large cells, and has been shown experimentally for bacteria in chemostat experiments (Kuenen et. al., 1977) as well as for phytoplankton (Smith \& Kalff, 1982). This places small cells at a competitive advantage, particularly in nutrient poor environments such as the oligotrophic Sargasso Sea (chapters 3,4). In the incubation experiments, field nitrate measurements at the time of sample collection were low at both locations eg. $0.5 \mu \mathrm{M}$ at the coastal location (Kelly et. al., 1994) and typically undetectable levels for the oceanic station (Knapp et. al., 1994). Although nutrients were not actually measured in the incubation bottles, nutrient limiting conditions probably developed in the unenriched bottles, particularly as the incubation period increased. As expected, the resulting picoplankton size spectrum in these bottles generally showed a shift to smaller sizes 
compared with the corresponding enriched treatments. The addition of large doses of inorganic nutrients into the system would be beneficial to larger nano and microplankton which have higher half-saturation constants (Malone, 1980) and a greater capacity to store nutrients (Droop, 1968). Although phytoplankton greater than $2 \mu \mathrm{m}$ were not actually enumerated in this incubation study, a shift to larger picoplankton was still observed after the 4 day incubation period for both the coastal and oceanic enriched samples. (Note that for the coastal samples, microscope examination showed that diatoms proliferated in the enriched bottles.) In the case of coastal picophytoplankton, the response consisted of a smooth transition to larger sizes with enrichment whereas for oceanic picophytoplankton, the shift was preceded by a substantial drop in picophytoplankton abundance. The difference in behaviour between the two systems could lie in the relative sensitivity of the indigenous phytoplankton populations to enrichment:- For the oceanic experiment, one possibility is that 'opportunistic' larger phytoplankton (ie. nano/microplankton) were able to outcompete smaller cells in the presence of elevated nutrient levels. However, as nutrients were used up, the competitive edge switched back again to picophytoplankton.

While both bacteria and phytoplankton require inorganic nutrients, bacteria further require dissolved organic matter (DOM) for heterotrophic growth (Goldman et. al., 1979, Azam et. al., 1983, Cole et. al., 1988). This was not added explicitly in the experiment but is generally produced through lysis of all types of organisms, sloppy feeding by zooplankton (Marshall \& Orr, 1962) as well as by excretion from phytoplankton during normal, healthy growth (Mague et. al., 1980). In the experiments, zooplankton greater than $64 \mu \mathrm{m}$ were screened out of the samples, so that the main source of DOM was most likely from phytoplankton exudation. The incubation experiments revealed that larger bacteria sizes were associated with higher levels of inorganic nutrients in the system ie. the enriched bottles. This is probably due to the close coupling between phytoplankton and bacteria growth, such that increased inorganic nutrients stimulated phytoplankton growth, which subsequently increased dissolved organics in the system. Positive correlations between bacteria and phytoplankton abundance have been seen elsewhere (Cole et. al., 
1988), but the results from the bottle incubations further show that large bacteria are preferred either directly or indirectly when the system is enriched with inorganic nutrients. This supports the field results in chapter 4 where bacteria size and phytoplankton size (spanning eutrophic and oligotrophic environments) were found to be positively correlated.

\section{Effects of Predation}

In this study, dilutions with filtered seawater were used to study the size spectral responses of picoplankton to changes in grazing pressure. This method has the advantage of studying a mixed natural assemblage with minimal disturbance to the system, compared to other studies which rely on physical separation (eg. size fractionation) or chemical inhibition. The primary assumption in these methods is that the probability of a cell being consumed is a direct function of the rate of encounter of predators with prey cells, so that as dilution increases the grazing pressure on prey cells diminishes (Landry \& Hasset, 1982). For both coastal and oceanic experiments, a reduction in grazing pressure of heterotrophic nanoplankton through dilution (ie. a reduction in predator-prey encounter rates) resulted in a dramatic increase in medium and large bacteria (greater than $0.04 \mu \mathrm{m}^{3}$ ) but appeared to have little effect on the size structure of the picophytoplankton community. (Note, however, that there was still an effect on picophytoplankton abundance.) The shift in the bacteria size spectrum suggests that large bacteria are preferentially grazed in the field and that smaller bacteria are less susceptible to grazing impacts. Larger bacteria cells were also found to be preferentially ingested by heterotrophic nanoflagellates in a freshwater study by Simek \& Chzanowski, 1992. In particular, their results showed that bacteria less than $0.1 \mu \mathrm{m}^{3}$ were hardly eaten whereas those between $0.2-0.4 \mu \mathrm{m}^{3}$ were ingested at the highest rates. Gonzalez et. al., 1990 also found that flagellates showed a pronounced response to bacterial size, with a threefold higher grazing rate on large bacteria $\left(0.08\right.$ to $\left.1.0 \mu \mathrm{m}^{3}\right)$ than on small bacteria $\left(0.03 \mu \mathrm{m}^{3}\right)$. The findings from this latter study are comparable to the results of our study where in 
general, cells greater than $0.07 \mu \mathrm{m}^{3}$ profited the most from a reduction in grazing pressure. Thus grazing could be responsible for maintaining the relatively stable bacteria size structure characterized by small cells in oligotrophic or nutrient-poor conditions (Ammerman et. al., 1984). Small size is advantageous not only as a refuge from predation (Chrzanowski \& Simek, 1990) but also serves to increase the surface to volume ratio needed for higher substrate incorporation for starved cells as discussed previously (Kuenen et. al., 1977).

If large bacteria are more likely to be grazed by predators, they can be a more important link in the microbial loop for biomass transfer and nutrient recycling (Azam et. al., 1983). In particular, the high grazing rate on the Sargasso Sea bacteria confirms the importance of bactivory in providing regenerated nutrients to this oligotrophic region. Size-dependent bactivory might not only crop bacterial production but also might control species diversity through selection of strains that can balance grazing losses with growth rates (Simek \& Chzanowski, 1992). In a study of freshwater lakes, it was found that bacteria production was significantly correlated with bacteria abundance for the small size fraction $\left(<1 \mu \mathrm{m}^{3}\right)$, but not with the larger fraction (Letarte and Pinel-Alloul, 1991). In contrast, production rates in larger cells was more variable and appeared to be better correlated with primary production, and hence the eutrophic character of the system. Our study also suggests that larger bacteria are more sensitive than small bacteria to increases in primary production when enrichment takes place. At the same time, larger bacteria are also more susceptible to predation. Consequently, the role of these larger bacteria could be important, not only in trophic exchanges but also in metabolic activity and nutrient recycling since they produce more biomass per cell (Lee \& Fuhrman, 1987).

\section{Combined Effects of Predation and Nutrient Enrichment}

In the coastal experiment, the bacteria spectrum responded more significantly in the unenriched dilutions whereas for the oceanic case, the greater response came from the enriched samples. This indicates that bacteria from the two contrasting ecosystems adapt 
differently to ambient nutrient conditions when the grazing pressure is reduced. Previous studies have shown that stressed phytoplankton tend to increase excretion of dissolved organic carbon (Myklestad et. al., 1989, Azam \& Smith, 1991). At the same time, it has also been shown that small phytoplankton (less than $10 \mu \mathrm{m}$ ) could lose a greater fraction of their stored dissolved compounds than larger cells, simply based on passive diffusion (Kiфrboe, 1993). In the unenriched dilutions where small cells were favoured in nutrientlimited conditions, this potential increase in phytoplankton exudation when combined with a reduction in grazing pressure, led to a significant response in the bacteria size spectrum. That bacteria of larger size should be preferentially stimulated is compatible with the hypothesis that larger cells can outcompete smaller cells at higher levels of nutrients ie. dissolved organic compounds. However, a reduction in grazing pressure under enriched conditions when sufficient inorganic nutrients were present, could lead to the larger phytoplankton outcompeting large bacteria and thus the response of coastal bacteria in the enriched dilutions was less. In addition, phytoplankton may produce different labile exudates during exponential growth as compared with senescence or 'stressed' growth, thus stimulating different sized bacteria (Letarte et. al., 1992). In contrast to the coastal experiments, large oceanic bacteria seem to be more responsive to inorganic nutrient enrichment under reduced grazing pressure, either directly or indirectly from dissolved organics released from the growth of phytoplankton. One explanation could be that inorganic nutrients are limiting not only for oceanic phytoplankton but also for oceanic bacteria, so that the larger bacteria could only respond to the decrease in grazing pressure when sufficient inorganic nutrients were also present, as in the enriched bottles.

\section{A Comparison of Size Spectra from Coastal and Oceanic Waters and the Results of the Incubation Experiments}

The incubation study of the size spectral response to enrichment and changes in grazing pressure provides a framework against which field size spectra can be compared. In a parallel study of the seasonal variation of size spectra from the coastal Massachusetts 
Bay area, size spectra from winter/early spring were characterized by asymmetric distributions with modal bacteria sizes of $\sim 0.1 \mu \mathrm{m}^{3}$ (eg. February spectra of Boston Harbour in Fig. 2.12, chapter 2). At this time of year, nutrient levels were generally high (Albro et. al., 1994) and represented enriched conditions for the microbial community. Results from the coastal incubation experiment also showed a similar shift of the modal bacteria size to $0.1 \mu \mathrm{m}^{3}$ with enrichment (B in Fig. 5.7), suggesting that bottom-up mechanisms were probably important in structuring the bacteria community during this time. Similarly, picophytoplankton also showed larger sizes $\left(\sim 2 \mu \mathrm{m}^{3}\right)$ in the winter field samples, which complemented the results of the enriched incubation experiments. As the growing season progressed into summer and nutrient levels were drawn down, field samples showed a growing relative importance of small cells, both for bacteria and picophytoplankton (eg. Fig. 2.12, chapter 2). The results of the incubation experiments also showed that as nutrients became more limiting, the picoplankton size spectra were also characterized by smaller cells. Furthermore, in the presence of heterotrophic nanoplankton grazers, the spectrum remained skewed to smaller size classes ( $\mathrm{G}$ in Fig. 5.7). In the field situation, summer grazing of bacteria could thus be important in structuring the picoplankton community, especially in cropping the larger cells. In addition, cascading trophic interactions through metazooplankton predation on heterotrophic nanoplankton may also play an indirect role in regulating the structure of the bacteria community (Jurgens et. al., 1994).

A comparison of ecosystems of different trophic status shows that the relative importance of bacteria biomass compared to phytoplankton increases with increasing oligotrophy (Cho \& Azam, 1990, Fuhrman et. al., 1989, Simon et. al., 1992). However, there have been conflicting reports on whether bacteria size is related to the trophic state of the system. Bird \& Kalff, 1984, for example, found from literature data that bacteria size was inversely related to bacteria counts and to the eutrophication gradient. However, other studies showed that on a transect from nearshore waters to the open ocean, there was a shift in the microbial community from large bacteria (greater than $1 \mu \mathrm{m}$ ) to a greater 
predominance of small bacteria (Griffith et. al., 1990, Wiebe, 1984). Our measurements of bacteria size spectra from coastal and oceanic waters support the latter studies (chapter 4). In the oligotrophic Sargasso Sea where nutrient levels are often undetectable, the plankton are characterized by a predominance of small cells, both for bacteria and phytoplankton (chapter 3). While nutrients may be the controlling factor of microbial biomass, the size structure of picoplankton could also be tightly regulated by grazers (Fenchel, 1988). Our dilution experiments showed that the oceanic bacteria size structure was effectively regulated by heterotrophic nanoplankton grazing. In particular, the preferential grazing of large bacteria via the microbial loop would have implication in the recycling of nutrients to the system and hence, system efficiency. In contrast, the presence of large bacteria and large phytoplankton in eutrophic systems would tend to lower ecosystem efficiency through an apparent lack of grazing pressure on large bacteria via the microbial loop. Such systems would have to depend on external sources of inorganic nutrients into the system to sustain the prescence of large cells.

\section{REFERENCES (chapter 5)}

Ammerman, J. W., Fuhrman, J.A., Hagstrom, A. and Azam, F., 1984. Bacterioplankton growth in seawater: I. Growth kinetics and cellular characteristics in seawater cultures. Mar. Ecol. Prog. Ser. 18: 31-39.

Azam, F., Fenchel, T., Field, J.G., Gray, J.S., meyer-Reil, L.A. and Thingstad, F., 1983. The ecological role of microbes in the sea. Mar. Ecol. Prog. Ser. 10: 257-263.

Azam, F. and Smith, D.C., 1991. Bacterial influence on the variability in the oceans's biogeochemical state: a mechanistic view. in S. Demers (ed.) Particle analysis in oceanography.Springer-Verlag, Vol G27.

Billen, G., Servais, P. and Becquevort, S., 1990. Dynamics of bacterioplankton in oligotrophic and eutrophic environments: bottom-up or top-down control ? Hydrobiologia 207: $37-42$.

Cho, B. C., Azam, F., 1990. Biogeochemical significance of bacterial biomass in the ocean's euphotic zone. Mar. Ecol. Prog. Ser. 63: 253-259. 
Chrzanowski, T. H. and Simek, K., 1990. Prey-size selection by freshwater flagellated protozoa. Limnol. Oceanogr. 35: 1429-1436.

Cole, J.J., Findlay, S. and Pace, M.L., 1988. Bacterial production in fresh and saltwater ecosystems: a cross-system overview.

Droop, M.R, 1968. Vitamin $B_{12}$ and marine ecology. 4. The kinetics of uptake, growth, and inhibition in Monochrysis lutherii. J. Mar. Biol. Assoc. U.K. 48: 689-733.

Fenchel, T., 1988. Marine plankton food chains. Ann. Rev. Ecol. Syst. 19: 1938.

Fuhrman, J.A., Sleeter, T.D., Carlson, C.A. and Proctor, L.M., 1989. Dominance of bacterial biomass in the Sargasso Sea and its ecological implications. Mar. Ecol. Prog. Ser. 57: 207-217.

Gonzalez, J.M., Sherr, E.B. and Sherr, B.F., 1990. Size-selective grazing on bacteria by natural assemblages of estuarine flagellates and ciliates. Appl. Environ. Microbiol. 56: 583-589.

Goldman, J.C., McCarthy, J.J. \& Peavey, D.G., 1979. Growth rate influence on the chemical composition of phytoplankton in oceanic waters. Nature, 279: 210-214.

Griffith, P.C., Douglas, D.J. and Wainright, S.C., 1990. Metabolic activity of sizefractionated microbial plankton in estuarine, nearshore, and continental shelf waters of Georgia. Mar. Ecol. Prog. Ser. 59: 263-270.

Guillard, R. R. L., 1975. Culture of Phytoplankton for Feeding Marine Invertebrates. In Smith, W.L. \& Chanley, M.H. (eds) Culture of Marine Invertebrate Animals. Plenum, New York: 338.

Jurgens, K., Arndt, H. and Rothhaupt, K. O., 1994. Zooplankton-mediated changes of bacterial community structure. Microb. Ecol. 27: 27-42.

Kelly, J., Albro, C., Hennessy, J., Turner, J., Borkman, D. and Doering, P., 1994c. Water quality monitoring in Massachusetts and Cape Cod Bays: June and July 1993. MWRA Enviro. Quality Dept. Tech. Rpt. Series No. 94-11. Massachusetts Water Resources Authority, Boston, MA: 152.

Kiфrboe, T. 1993. Turbulence, phytoplankton cell size and the structure of pelagic food webs. Adv. in Mar. Bio.29:1-72.

Knapp, A.H., Michaels, A.F., Dow, R.L., Johnson, R.J., Gundersen, K., Sorensen, J.C., Close, A.R., Hammer, M., Knauer, G.A., Lohrenz, S.E., Asper, V.A., Tuel, M., Ducklow, 
H., Quinby, H., Brewer, P. and Bidigare, R., 1994. Bermuda Atlantic Time-Series Studies : Data Report for BATS 37-48. U.S.JGOFS BATS Data Report B-4: 240pp.

Kuenen, J.G., Boonstra, J., Scroder, H.G. and Veldkamp, H., 1977. Competition for inorganic substrates among chemoorganotrophic and chemolithotrophic bacteria. Microb. Ecol. 3: 119-130.

Landry, W. R. and Hassett, R.P, 1982. Estimating the grazing impact of marine microzooplankton. Mar. Biol. 67: 283-288.

Lee, S. and Fuhrman, J.A., 1987. Relationship between biovolume and biomass of naturally derived marine bacteria plankton. Appl. Envir. Micro. 53: 1298-1303.

Letarte, Y. and Pinel-Alloul, B., 1991. Relationships between bacterioplankton production and limnological variables: Necessity of bacterial size considerations. Limnol. Oceanogr. 36(6): 1208-1216.

Letarte, Y., Hansen, H.J., Sondergaard, M. and Pinel-Alloul, P., 1992. Production and abundance of different bacterial size classes: relationship with primary production and chlorophyll concentration. Arch. Hydrobiol. 126(1): 15-26.

Mague, T.H., Friberg, E., Hughes, D.J. and Morris, I., 1980. Extracellular release of carbon by marine phytoplankton: a physiological approach. Limnol. Oceanogr. 25: 262279.

Malone, T.C., 1980. Algal Size. in I. Morris (ed.), The Physiological Ecology of Phytoplankton, Univ. Calif.: 443-463.

Marshall, S.M. and Orr, A.P., 1962. Food and feeding in copepods. Rapports et. Proces Verbaux des Reunions du Conseil Permanent International pour l'Exploration de la Mer 153: 92-98.

Myklestad, S., Holm-Hansen, O., Varum, K.M. and Volcani, B.E., 1989. Rate of release of extracellular ammino acids and carbohydrates from the marine diatom Chaetoceros affinis. J. Plankton Res. 11: 763-773.

Psenner, R. and Sommaruga, R., 1992. Are rapid changes in bacterial biomass caused by shifts from top-down to bottom-up control ? Limnol. Oceanogr. 27(5): 1092-1100.

Simek, K. and Chrzanowski, T.H., 1992. Direct and indirect evidence of size-selective grazing on pelagic bacteria by freshwater nanoflagellates. Appl. Environ. Micro. 58(11): 3715-3720. 
Simon, M., Cho, B.C. and Azam, F., 1992. Significance of bacterial biomass in lakes and the oceans: comparison to phytoplankton biomass and biogeochemical implications. Mar. Ecol. Prog. Ser. 86: 103-110.

Smith, R.E.H. and Kalff, J., 1982. Size-dependent phosphorus uptake kinetics and cell quota in phytoplankton. J. Phycol. 18: 275-284.

Wehr, J.D., Le, J. and Campbell, L., 1994. Does microbial biomass affect pelagic ecosystem efficiency? An experimental study. Microb. Ecol. 27: 1-17.

Wiebe, W.J., 1984. Physiological and biochemical aspects of marine bacteria. in J.E. Hobbie and P.J. leB William (eds), Heterotrophic activity in the sea. Plenum. 


\section{Chapter 6}

\section{CONCLUSIONS}

The objectives of this study were to examine how the characteristics of microbial size spectra varied with eutrophication or increases in ecosystem productivity, as well as how size spectra responded to environmental perturbations. Flow cytometry was used to enumerate bacteria and phytoplankton cells and to generate size spectra of these microorganisms by empirically converting their light scattering characteristics to volumetric size. We began by describing the temporal and spatial variation of bacteria and phytoplankton size spectra from high nutrient, productive coastal waters in Massachusetts and Cape Cod Bays. We next explored the range and variability of microbial size spectra from an oligotrophic, low productivity area in the Sargasso Sea. This data coupled with size spectra measurements from a high nutrient, low chlorophyll region in the equatorial Pacific provided the broad framework from which to draw out correlations of microbial size spectra with typical environmental characteristics. In order to study specific effects on the size spectrum, we conducted incubation experiments whereby seawater was systematically manipulated by nutrient enrichment and dilution, the latter causing a reduction in grazing pressure. The main results from these field and incubation experiments are summarized as follows:-

At the level of seasonal impacts, the results from temperate coastal waters showed greater fluctuations in the microbial size spectrum compared to open ocean waters in the subtropics. In general, a spectrum reflecting the predominance of larger cells was observed in winter and early spring, where low temperatures resulted in well-mixed environments and higher concentrations of nutrients. As the spring bloom progressed into summer, a distinct shift in the size spectrum to smaller cells was observed, coinciding with diminishing nutrient concentrations, rising temperatures and consequent stratification of the water column. In these stratified waters, the depth variation of size spectra was such 
that larger mean bacteria and phytoplankton sizes were observed in surface and very deep waters, whereas the smallest sizes were typically seen around the thermocline, near or at the chlorophyll maximum. Bacteria growth was generally well correlated with phytoplankton growth, with mean bacteria sizes varying positively with mean phytoplankton sizes. The counteracting effects of nutrients and light may be responsible for the depth variation in phytoplankton and bacteria size spectra observed. In the fall, decreasing temperatures destabilized the water column, replenishing nutrients which in certain cases triggered a fall bloom and a subsequent shift in the spectrum to larger sizes.

Although earlier studies have indicated the dominance of larger phytoplankton in eutrophic environments compared to oligotrophic ones, few studies have analyzed these changes in terms of the size spectrum. The advantage of using the size spectrum is that it gives information on cell numbers and biomass as well as size, while also being easily quantified by the slope and intercept of the log-transformed data. Our results showed that the size spectral characteristics sensitive to environmental change were the mean bacteria size, bacteria intercept, mean phytoplankton size and phytoplankton slope. Increases in ecosystem productivity, chlorophyll, particulate and nutrient levels were generally accompanied by shifts in the size spectra to larger bacteria and phytoplankton cells.

In terms of the slope of the normalized concentration size spectrum for phytoplankton, values ranged from about -1.8 (oligotrophic unproductive waters in the Sargasso Sea and equatorial Pacific) to about -1.3 (meso-eutrophic productive waters in Boston Harbour and Cape Cod Bay). The lower value could represent a lower bound limit for the phytoplankton size spectrum under increasing nutrient-stressed conditions and considerable grazing impacts. In contrast, the upper value could represent light limiting conditions in nutrient replete waters where grazing effects are minimal. Conceivably, the upper bound value we measured could also be exceeded in more eutrophic or hypereutrophic conditions, where the spectrum may shift to a dominance of only one or a few species. Such communities may be subject to autogenic factors resulting in an internal reorganization of size structure. While changes in phytoplankton slope were sensitive to 
eutrophication effects, the phytoplankton intercept was found to be less variable ( 3.4 cells $\mathrm{ml}^{-1} \mu \mathrm{m}^{-3}$ ) and appeared to reach an upper bound for the more eutrophic coastal systems. Since the intercept represents the abundance of picoplankton, these results confirm size-fractionated chlorophyll studies which show that as total chlorophyll in the system increased, additional chlorophyll is due to progressively larger and larger cells. In terms of size spectra, these changes with increasing ecosystem productivity were reflected in an anti-clockwise rotation of the spectrum, centred more or less in the picoplankton region.

For bacteria size spectra, both the mean size and intercept showed positive correlations with indicators of eutrophication. These changes illustrate the growing importance of large bacteria in productive waters, a probable consequence of a reduction in nannoflagellate grazing of picoplankton and increased dissolved organics available from increased primary production. These hypotheses were confirmed by the incubation experiments designed to study nutrient enrichment and grazing effects on the picoplankton community. Specifically, the results showed that inorganic nutrient enrichment led to a definite shift to larger cells, for both bacteria and picophytoplankton. It was also found that a reduction in grazing pressure through dilution methods led to an increase in larger bacteria, especially for enriched (with inorganic nutrients) samples from oceanic waters but unenriched samples from coastal waters. In contrast, the effects on picophytoplankton size were negligible, although increases in cell numbers of existing size classes were observed with dilution. While the influences on the larger nanno and microphytoplankton community were not measured, it seems plausible to extend the picoplankton results to the larger community based on the field measurements of size spectra. Thus, the coupled effects of increasing nutrients and a reduction in grazing will have a positive effect on larger cell sizes and hence, increases in mean bacteria and phytoplankton sizes, the bacteria intercept and phytoplankton slope. Steep microbial size spectra indicating the predominance of small cells (typical of oceanic, unproductive waters) can thus be explained by significant grazing impacts on the larger bacteria and phytoplankton 
community in low nutrient waters. On the other hand, less steep size spectra reflecting the predominance of larger cells (typical of coastal, productive waters) can be attributed to a reduction in grazing pressure in high nutrient environments.

The results of this thesis show that microbial size spectra is an effective means to capture the dynamics of the microbial community in response to external perturbations to the system. In particular, our results could be used to test system model approaches to size spectra, although this is beyond the scope of the present thesis. At a time when mankind is causing greater disturbance to the marine environment through coastal developments, it becomes increasingly important to be able to assess the environment impacts and possible deterioration of the ecosystem from anthropogenic sources. One way to monitor these changes is to use microbial size spectra as a signature or indicator of ecosystem health and trophic state. Knowledge of where a particular size spectrum is in relation to the upper and lower bounds can give some idea of where the ecosystem is heading, and also serve to give early warning of possible detrimental effects, such as excessive eutrophication. Changes in the size structure of the microbial community could also alter food-web interactions through grazing processes which from a practical point of view, would affect fisheries or aquaculture systems. In the past, size spectra have been used successfully to predict fish stocks and hence is important for fisheries management. Shifts in the microbial size spectrum also have important implications in the biogeochemical cycling of carbon and nutrients within the ecosystem. While bulk environmental measurements are useful as indicators of overall ecosystem capacity, the microbial size spectrum gives additional information on how biomass is actually partitioned between small and large cells, with consequences for nutrient cycling and biomass transfer to higher organisms. From a global perspective, this is important in understanding the role of oceans in both the natural and disturbed carbon cycle. 


\section{Appendix A}

\section{DISCRETE AND CONTINUOUS FUNCTIONS OF SIZE SPECTRA}

Empirical studies usually describe particle size distributions as normalized biomass size spectra which conform to a power law ie.

$$
\mathrm{Bv} / \Delta \mathrm{V}=\mathrm{AVb}
$$

where $\mathrm{Bv}$ is the total biomass in volume size class, $\mathrm{v} ; \mathrm{A}$ and $\mathrm{b}$ are constants and $\Delta \mathrm{V}$ is the size class interval. By plotting the size spectra on log scales, the data should fall on a straight line whose $\mathrm{y}$-intercept is $\log \mathrm{A}$ and slope is $\mathrm{b}$.

$$
\log \mathrm{Bv} / \Delta \mathrm{V}=\log \mathrm{A}+\mathrm{b} \log \mathrm{V}(\mathrm{A} 2)
$$

Field studies of size spectra spanning bacteria to fish have shown this value of $b$ to be approximately equal to -1 (Rodriguez \& Mullin, 1986, Gaedke, 1992). The same result will also be obtained if the cumulative biomass distribution, B, is differentiated with respect to size, $\mathrm{V}$ :

$$
\mathrm{dB} / \mathrm{dV}=\mathrm{Bv} /\left.\Delta \mathrm{V}\right|_{\Delta \mathrm{v} \rightarrow 0}=\mathrm{AVb}
$$

Note that for large $\Delta \mathrm{V}$, the approximations may no longer be appropriate. Part of the reason for this is that for larger size classes (equal-sized log classes), the very first and last classes could exceed the range of data and hence any regression on the data would subsequently be affected. For very small $\Delta \mathrm{V}$, however, the results should converge to a stable value of the slope. In the limit as $\Delta V \rightarrow 0, B v / \Delta V$ is equal to $d B / d V$ ie. the derivative of the cumulative biomass distribution. It is preferable to present the data in the 
form of normalized size spectra (ie. $\mathrm{dB} / \mathrm{dV}$ ) since these are independent of the width of the size class.

If the normalized biomass spectra is integrated with respect to size, then the actual biomass size distribution is obtained :

$$
\begin{aligned}
& \int_{0}^{B} \mathrm{~dB}=\int_{0}^{\mathrm{V}}(\mathrm{Bv} / \Delta \mathrm{V}) \mathrm{dV} \\
& \mathrm{B}=\mathrm{CV}+1
\end{aligned}
$$

where $\mathrm{B}$ and $\mathrm{V}$ are arbitrary biomass and size class values and $\mathrm{C}$ is a constant. The slope of the logarithmically transformed biomass size spectra is given by $(b+1)$ and if $b=-1$, then a flat spectrum will result. This was shown with field data from a variety of oceanic locations ranging from the Pacific to the Atlantic (Sheldon 1972).

Alternatively, particle size spectra may be given in terms of an average particle concentration, $\mathrm{Nv}$, ie.

$$
\mathrm{Nv}=\mathrm{Bv} / \mathrm{Cv}
$$

where $\mathrm{Cv}$ is the cellular biomass. If cell biomass is assumed to be a linear function of cell volume, then:

$$
\mathrm{Nv}=\mathrm{Bv} / \mathrm{V}=\mathrm{A}(\Delta \mathrm{V} / \mathrm{V}) \mathrm{V}^{\mathrm{b}}
$$

for small $\Delta \mathrm{V}$. If the data has been transformed to equal-sized logarithmic classes, then the ratio $(\Delta \mathrm{V} / \mathrm{V})$ is a constant and

$$
\mathrm{Nv}=\mathrm{A}^{\prime} \mathrm{V}^{\mathrm{b}}
$$


where $\mathrm{A}^{\prime}$ is constant. The slope of the logarithmically transformed concentration distribution should then be the same as the slope of the normalized biomass distribution. If $\mathrm{N}$ is the cumulative concentration distribution, then the derivative of $\mathrm{N}$ with respect to size, $\mathrm{V}$, is

$$
\mathrm{dN} / \mathrm{dV}=\mathrm{Nv} /\left.\Delta \mathrm{V}\right|_{\Delta \mathrm{V} \rightarrow 0}=\mathrm{A}(\Delta \mathrm{V} / \mathrm{V}) \mathrm{V}^{\mathrm{b}} / \Delta \mathrm{V}=\mathrm{A}^{\prime} \mathrm{Vb}^{-1}
$$

ie. the derivative of the concentration size distribution (normalized concentration size spectra) should have a slope of (b-1) and is irrespective of the size class range, $\Delta \mathrm{V}$. (Note that $\mathrm{dN} / \mathrm{dV}$ can also be written in terms of diameter, $\mathrm{D}$ ).

$$
\mathrm{dN} / \mathrm{dD}=\mathrm{A}^{\mathrm{N}}\left(\mathrm{D}^{3}\right)^{\mathrm{b}-1} \mathrm{D}^{2}=\mathrm{A}^{\prime \prime} \mathrm{D}^{3 \mathrm{~b}-1}
$$

where $\mathrm{A}$ " and $\mathrm{A}$ "' are constants. Empirical evidence suggest a slope for $\mathrm{dN} / \mathrm{dD}$ of -4 (Mc Cave, 1975) and hence $b=-1$. This is consistent with the slope of the normalized biomass spectrum as described above. 


\section{APPENDIX B}

\section{SAMPLE PRESERVATION}

One of the questions faced with analyzing samples is whether to run samples live at sea or preserve them and analyze them later on land. The first alternative may appear to be the better solution but it is not always practical to take a flow cytometer on board a ship. When dealing with large numbers of samples, the most practical way is to preserve the samples at the time of collection and analyze them on the flow cytometer later.

Unfortunately, preservation usually causes some change in the fluorescence, numerical abundance and light scattering properties of cells.

\section{Comparison of Different Preservation Fixatives}

A preliminary test was conducted to assess the best and most practical preservation treatment for our samples. Fixatives such as glutaraldehyde (Vaulot et. al., 1989, Sieracki \& Cucci, 1993) and paraformaldehyde (Hall, 1991, Landry \& Kirschtein, 1993), the cryoprotectant, dimethylsulfoxide (DMSO) and various mixtures of the three were tested (Table B1). Duplicate samples were taken from the chlorophyll maximum $(116 \mathrm{~m})$ at a station in the Sargasso Sea $\left(27^{\circ} \mathrm{N}, 67^{\circ} 60 \mathrm{~W}\right)$. The seawater was added to

\begin{tabular}{lllll}
\hline Treatment & \multicolumn{4}{l}{ Final Concentration (\%) } \\
\hline Glutaraldehyde & 0.1 & 0.5 & 1.0 & 2.5 \\
Paraformaldehyde & 0.2 & 0.4 & 0.6 & \\
Glut.: Para. & $1: 0.2$ & $1: 0.4$ & $1: 0.6$ & \\
& $0.2: 0.2$ & $0.5: 0.2$ & $0.8: 0.2$ & \\
DMSO & 10 & & & \\
DMSO, Glut. & 10,1 & & \\
DMSO, Para. & $10,0.2$ & & \\
DMSO, Glut., Para. & $10,1,0.2$ & & \\
No fixative & & & \\
\hline
\end{tabular}

Table B1. Preservation treatments on Sargasso Sea water using a variety of fixatives (glutaraldehyde, paraformaldehyde, DMSO) with final concentrations in solutions as shown. 
prelabelled tubes to which the specified amount of preservative according to the final concentrations given in Table B1, had just been added. The preserved samples were then mixed thoroughly and then left in the dark for about $15 \mathrm{mins}$, before immersion into liquid nitrogen for storage. Samples that contained paraformaldehyde were left for a longer period (ie. $1 \mathrm{hr}$ ) before immersion into liquid nitrogen. At the same time, initials for the preservation experiment were run on an Epics $\mathrm{V}$ flow cytometer (nano/microplankton on 'nano/micro' settings, as described in Appendix C) and a Facscan flow cytometer (picophytoplankton). The preserved samples were run on the same instruments as the initials one month later, after thawing the samples in a water bath at room temperature.

The results showed that for nano/microphytoplankton, glutaraldehyde at a concentration ranging from 0.1 to $1 \%$ was the best fixative in terms of preserving cell numbers, forward scatter and chlorophyll fluorescence (Fig. B1). In general, these treatments resulted in about a 10\% decrease in total cell counts, C, a 30\% decrease in relative forward scatter (reflecting size changes - Appendix D), S, and a $10 \%$ increase in red fluorescence, $F$. To summarise these changes, a decay index $(\mathrm{Z})$ was calculated as the sum of the differences in these parameters relative to their respective initials.

$Z=\left|C-C_{0}\right|+\left|S-S_{0}\right|+\left|F-F_{0}\right|(B 1)$

In the case of picophytoplankton, however, the different treatments affected the samples to similar extents and it was difficult to isolate a particular treatment that was far superior to the others (eg. preservation effects on Synechococcus in Fig. B2). However, in order to keep the preservation protocol as simple as possible, it was decided to use a glutaraldehyde concentration at $0.1 \%$ glutaraldehyde for both picoplankton and nano/microplankton. The samples were divided into two lots (ie. $2 \mathrm{ml}$ cryovials for picoplankton and $50 \mathrm{ml}$ centrifuge tubes for nano/microplankton samples) and then fixed for 10 minutes in the dark, followed by immersion into liquid nitrogen for longer term storage. 

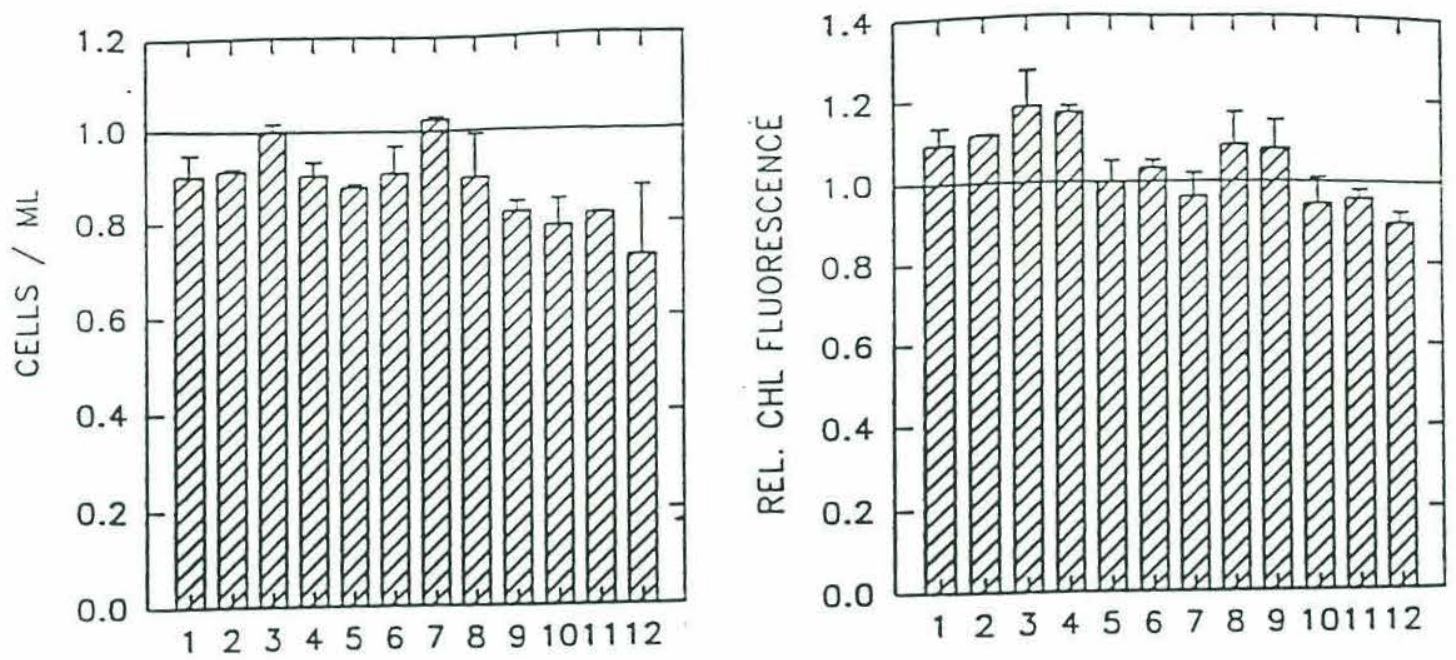

TREATMENT
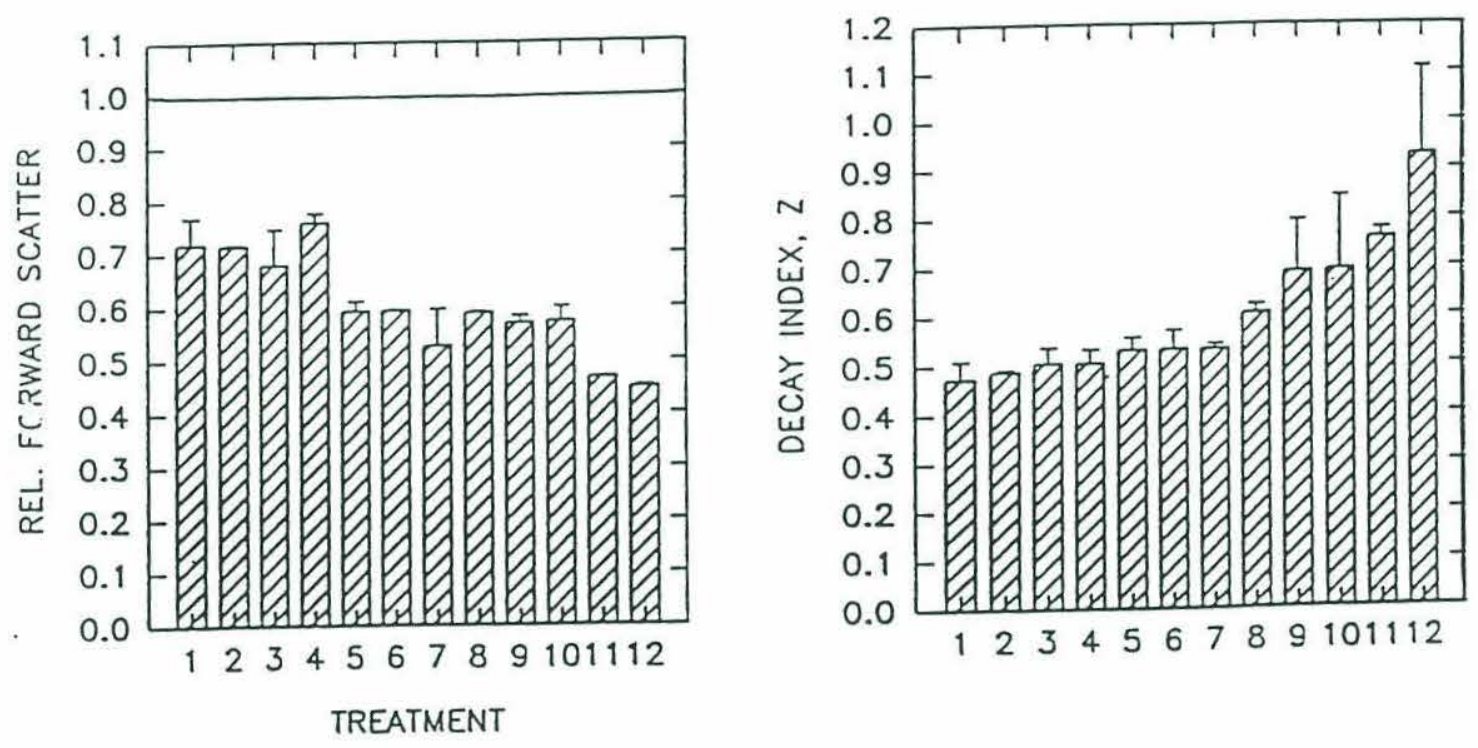

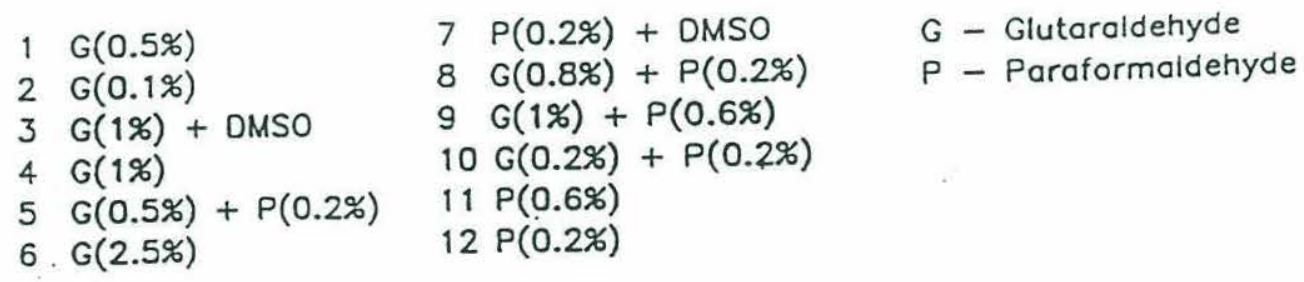

Fig. B1. Preservation results for nano/micro phytoplankton using various combinations of glutaraldehyde $(\mathrm{G})$, paraformaldehyde $(\mathrm{P})$ and dimethylsulfoxide (DMSO). Changes in total cell concentration, forward scatter and red fluorescence relative to initial values for 12 treatments are given. In addition, a decay index, $Z$, was also computed which gave an indication of the combined preservation effects on these cell properties. 

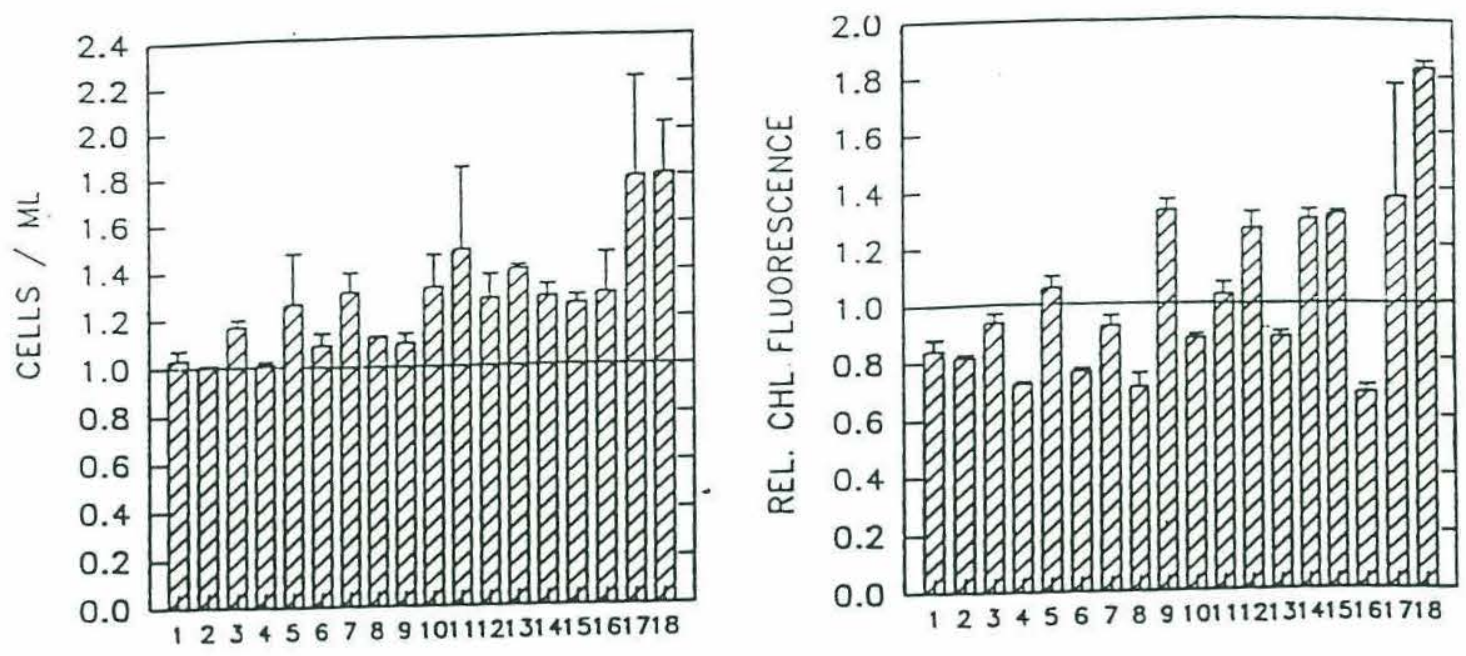

TREATMENT
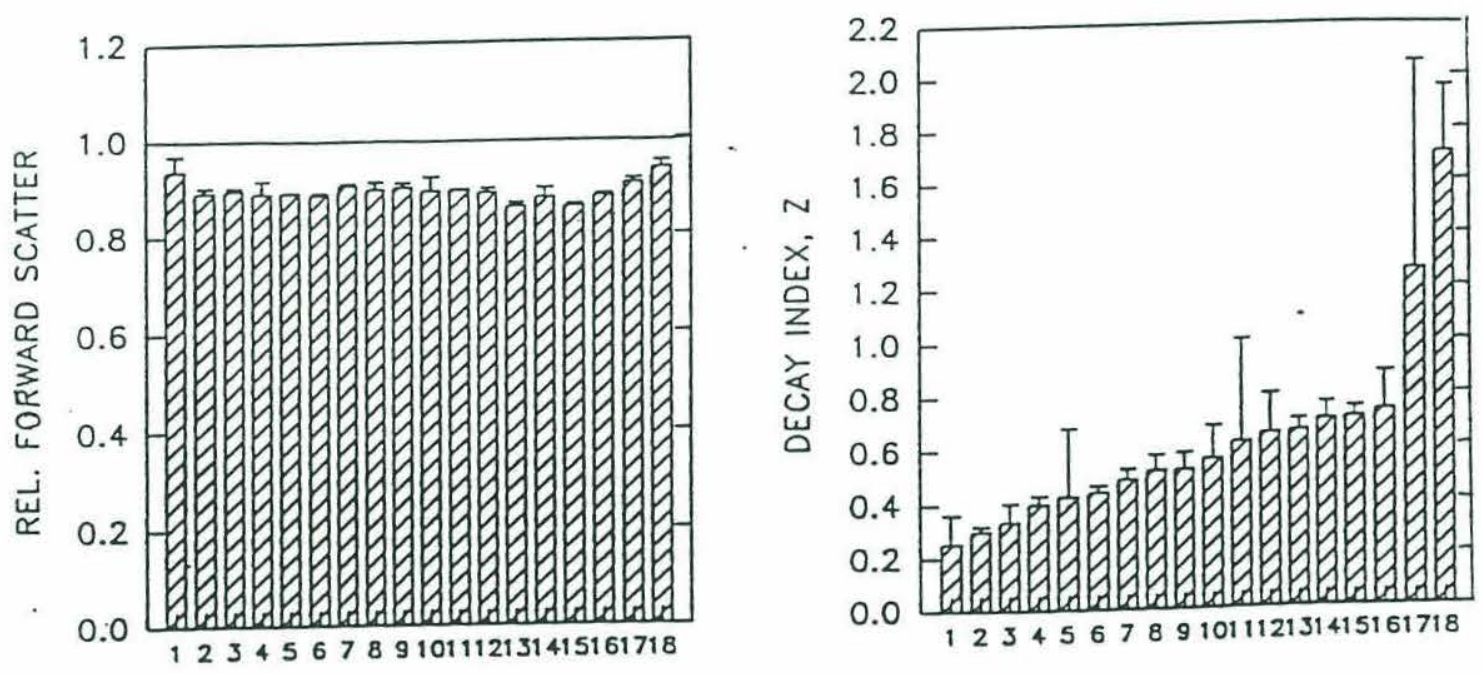

TREATMENT

G - Glutaraldehyde P - Paraformaldehyde

$\begin{array}{llrlrl}1 & \mathrm{OMSO}+\mathrm{G}(1 \%)+P(0.2 \%) & 7 & G(0.5 \%) & 13 & G(1 \%)+D M S O \\ 2 & G(2.5 \%) & 8 & G(1 \% \%)+P(0.4 \%) & 14 & P(0.6 \%) \\ 3 & G(0.5 \%)+P(0.2 \%) & 9 & P 0.4 \%) & 15 & P(0.2 \%)+D M S O \\ 4 & G(1 \%)+P(0.6 \%) & 10 & G(1 \%) & 16 & G(1 \%)+P(0.2 \%) \\ 5 & G(0.1 \%) & 11 & G(0.2 \%)+P(0.2 \%) & 17 & \text { NO PRESERVATIVE } \\ 6 & G(0.8 \%)+P(0.2 \%) & 12 & P(0.2 \%) & 18 & \text { DMSO }\end{array}$

Fig. B2. Preservation results for the picophytoplankton, Synechococcus, using various combinations of glutaraldehyde $(G)$, paraformaldehyde $(P)$ and dimethylsulfoxide (DMSO). 


\section{Preservation Effects on Sub-populations}

We used this preservation protocol to test its effect on the size structure of bacteria, picophytoplankton and nano/microphytoplankton. Sargasso seawater taken from $120 \mathrm{~m}$ depth in July, 1993, was preserved in duplicate or triplicate using this protocol and reanalyzed 2.5 months (for picoplankton) and 7 months (for nano/microplankton) later, using the relevant instrument configuration as described in Appendix C. Size spectra of both initial and preserved samples were calculated according to empirical size calibrations in Appendix D. For individual sub-populations, the change in total cell concentration and mean cell size range from about 4 to $30 \%$ (Table B2). (Note that replicate samples

\begin{tabular}{llllll}
\hline Plankton & Type & Parameter & Initial & Preserved & $\begin{array}{l}\% \\
\text { change }\end{array}$ \\
\hline Bacteria & Oceanic & $\mathrm{C}(\mathrm{cellls} / \mathrm{ml})$ & $428,356(0.10)$ & $410949(0.01)$ & 4 \\
& & $\mathrm{~V}\left(\mu \mathrm{m}^{3}\right)$ & $0.0122(0.02)$ & $0.0167(0.04)$ & 27 \\
Picophyto & Oceanic & $\mathrm{C}(\mathrm{cells} / \mathrm{ml})$ & $81,916(0.10)$ & $57,557(0.02)$ & 30 \\
& & $\mathrm{~V}\left(\mu \mathrm{m}^{3}\right)$ & $0.057(0.02)$ & $0.060(0.03)$ & 5 \\
Picophyto & Coastal & $\mathrm{C}\left(\mathrm{cellls}^{3} / \mathrm{ml}\right)$ & $48,701(0.05)$ & $46,581(0.01)$ & 4 \\
& & $\mathrm{~V}\left(\mu \mathrm{m}^{3}\right)$ & $0.251(0.01)$ & $0.349(0.02)$ & 28 \\
Nano/ & & $\mathrm{C}\left(\mathrm{cellls}_{\mathrm{s}} / \mathrm{ml}\right)$ & $1,903(0.01)$ & $1,625(0.02)$ & 15 \\
micro & & $\mathrm{V}\left(\mu \mathrm{m}^{3}\right)$ & $22.9(0.08)$ & $34.4(0.07)$ & 33 \\
\hline
\end{tabular}

Table B2. Preservation results showing the changes in total cell concentration, C, and mean cell size, $\mathrm{V}$, for bacteria, picophytoplankton and nano/microplankton populations. Oceanic samples were taken at 120m depth from the Sargasso Sea in July, 1993, whilst coastal samples were taken from the surface waters of Vineyard Sound in August, 1992. The values given are the averages of duplicates or triplicates, and numbers in parentheses are the coefficients of variation.

generally had coefficients of variation that were less than $10 \%$ for total cell concentration and less than $8 \%$ for mean cell size of each sub-population.) Although these changes are quite substantial when viewed on linear scales, the differences become less obvious when the spectra are analyzed on log scales:- the overall size structures of the populations are still fairly well maintained with preservation (Figs. B3-B5). When the entire microbial spectrum ranging from bacteria to microplankton (ie. $10^{-3}$ to $10^{4} \mu \mathrm{m}^{3}$ ) is considered, the 

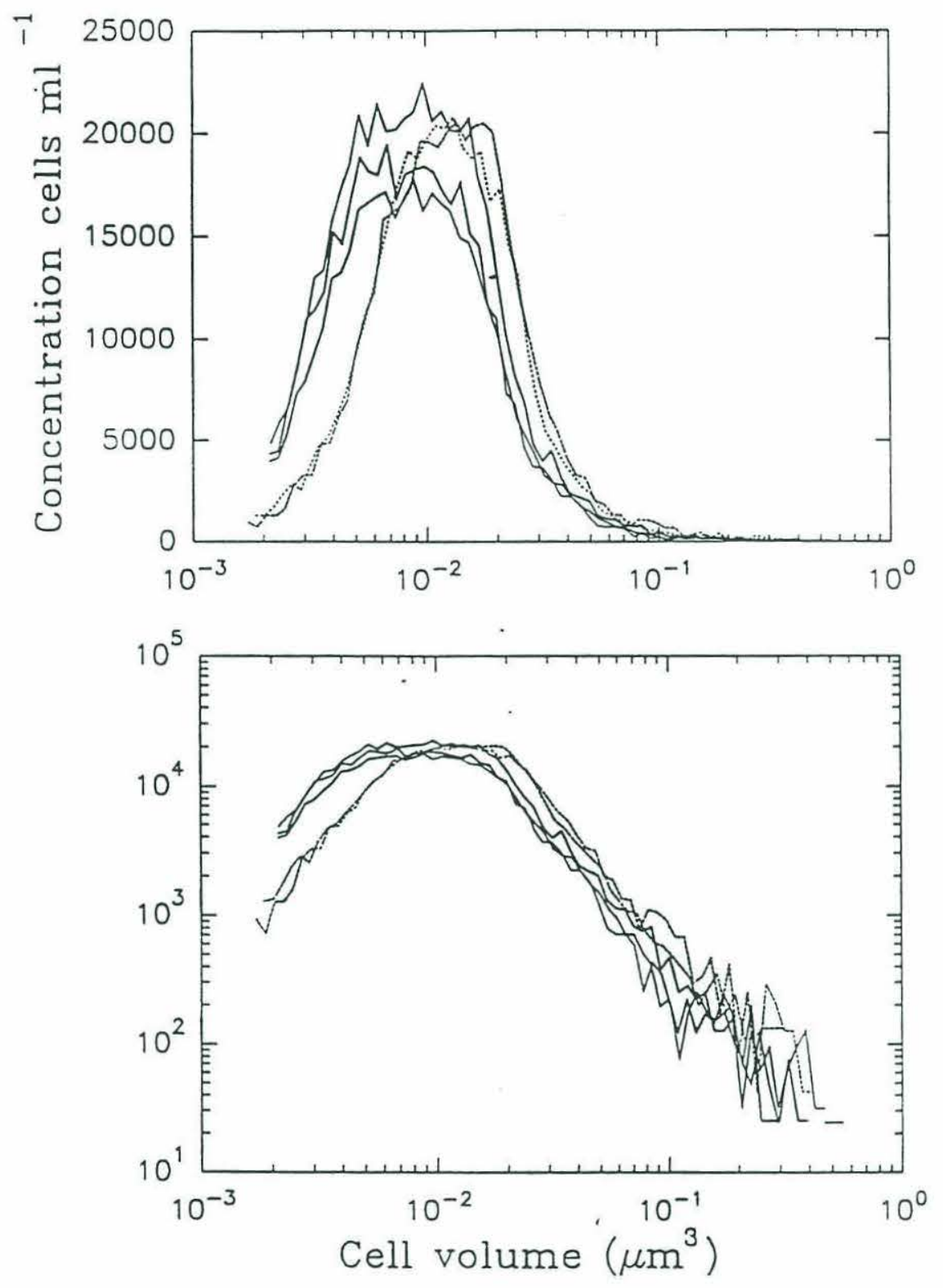

Fig. B3. Preservation results for bacteria size spectra taken from $120 \mathrm{~m}$ depth in the Sargasso Sea in July, 1993. Initials (solid lines) were run in triplicate on 'pico' settings using dual-beam flow cytometry. Duplicate preserved samples (dashed lines) were fixed with glutaraldehyde $(0.1 \%)$ and stored in liquid nitrogen for 10 weeks before flow cytometric analysis. Cell volume was estimated from forward light scatter using the empirical picoplankton calibration equation, described in Appendix D. 

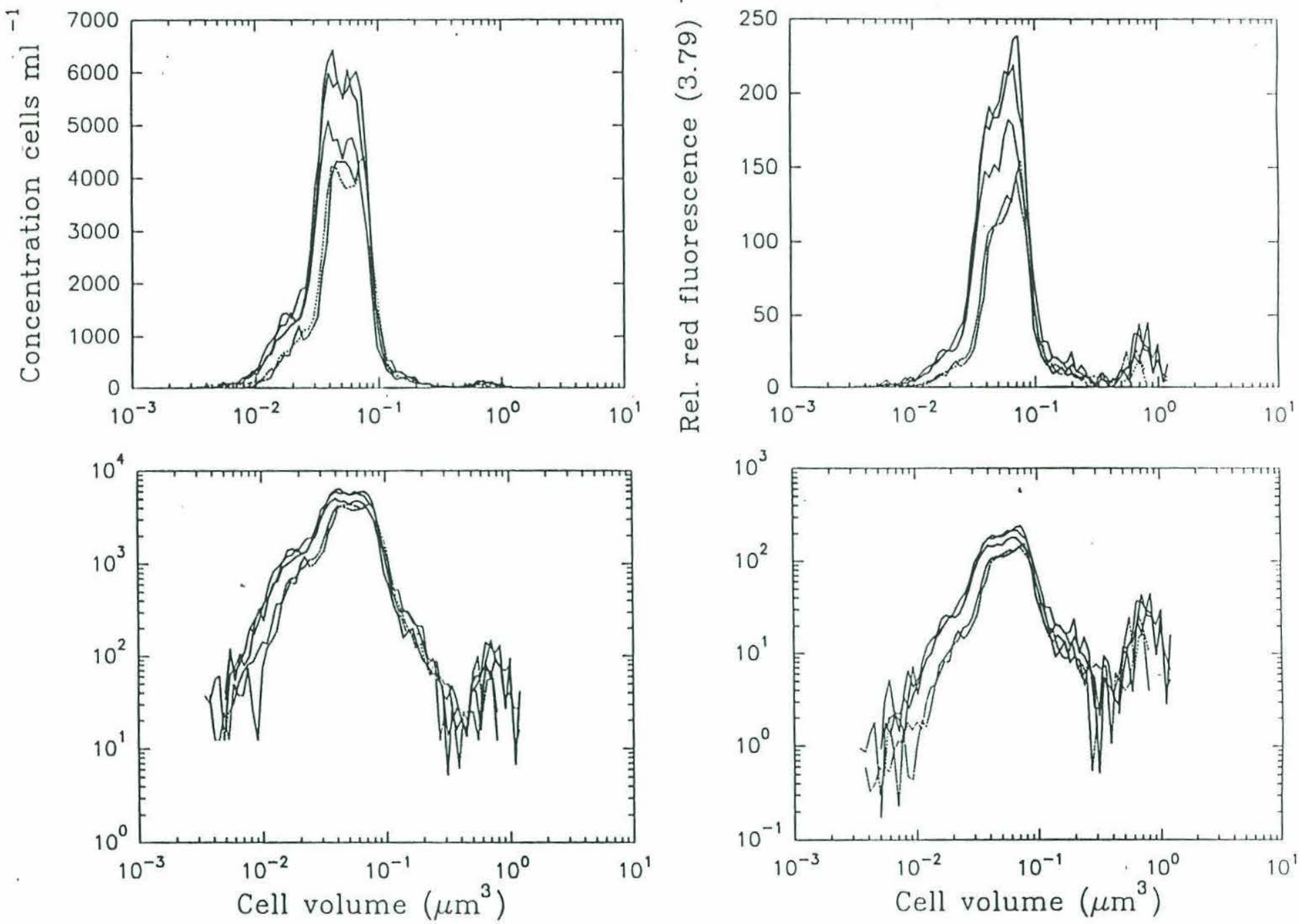

Fig. B4. Preservation results for picophytoplankton size spectra taken from the same location as Fig. B3. Preserved samples were fixed with glutaraldehyde $(0.1 \%)$ and stored in liquid nitrogen for 10 weeks before flow cytometric analysis. Changes in size spectra of red fluorescence (relative to $0.57 \mu \mathrm{m}$ beads) are also shown and were obtained by integrating the red fluorescence over each forward scatter channel. 

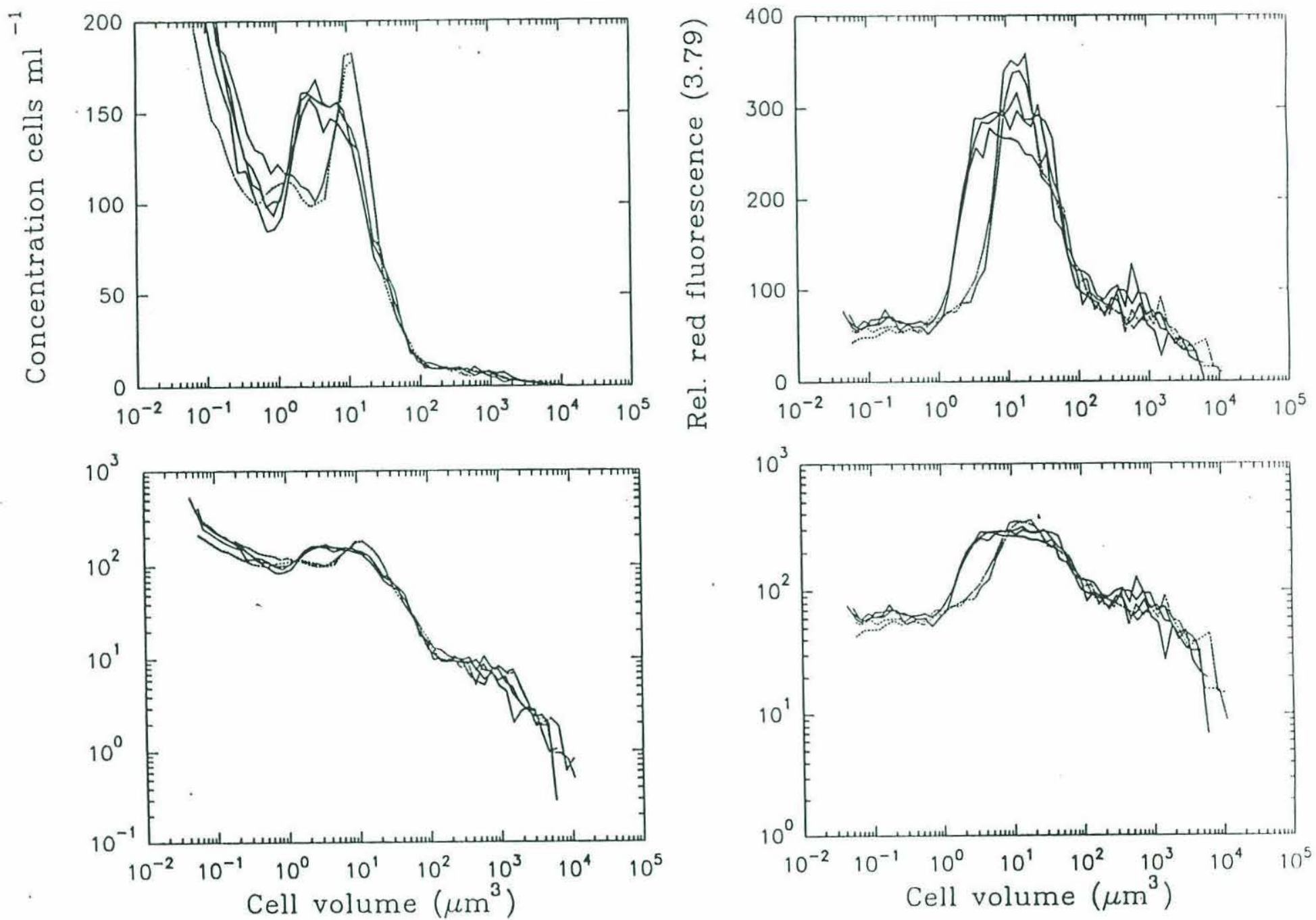

Fig. B5. Preservation results for nano/micro phytoplankton size spectra taken from the same location as Fig. B3. Preserved samples were fixed with glutaraldehyde $(0.1 \%)$ and stored in liquid nitrogen for 7 months before flow cytometric analysis. Cell volume was estimated from forward light scatter using the empirical nano/microplankton calibration equation, described in Appendix D. 
differences become even smaller (Fig. B6). Quantitatively, these can be measured by changes in the slope and intercept of the normalized concentration size spectrum (see Data Processing under Methods in chapter 2), which are typically less than 5\% for both bacteria and phytoplankton. At the same time, the variation in these parameters for replicate spectra (in triplicate) is also less than $5 \%$.

One problem that arises with the storage of field samples is that the nano/microplankton samples, which are frozen in $50 \mathrm{ml}$ centrifuge tubes, take up large amounts of liquid nitrogen dewar space. The initial preservation studies showed that immersion of samples into liquid nitrogen was important for preservation but if frozen samples could subsequently be stored in freezers, this would solve the long-term problem of inadequate dewar storage space. A test was conducted to assess the feasibility of storing preserved nano/microphytoplankton in a $-40^{\circ} \mathrm{C}$ freezer. Using coastal seawater from Vineyard Sound mixed together with cultures of coccolithophores and pennate diatoms, replicate samples were analyzed fresh on the 'nano/micro' settings of an Epics V flow cytometer as well as preserved with glutaraldehyde at $0.1 \%$ concentration, frozen in liquid nitrogen for 24 hours and subsequently transferred to a 'walk-in' $-40^{\circ} \mathrm{C}$ freezer. Replicate samples were also preserved and stored in liquid nitrogen for comparison. Preserved samples were analyzed on the same instrument settings two weeks later. The results show that the preserved size spectra stored in the $-40^{\circ} \mathrm{C}$ freezer (Fig. B7) was a feasible alternative to storage in liquid nitrogen and in fact, gave slightly better results than samples stored in liquid nitrogen (Fig. B8) for this particular seawater.

Although preservation results in some changes to cell concentration and forward light scatter of cells, it is still the most practical way to deal with large quantities of samples. Most of the samples collected for this study were subject to the same preservation treatment, but it is also noted that different indigenous populations at the time of sampling may show different sensitivity to our preservation protocol. Nevertheless, considering the large range of cell sizes covered in this study (ie. log scales), 

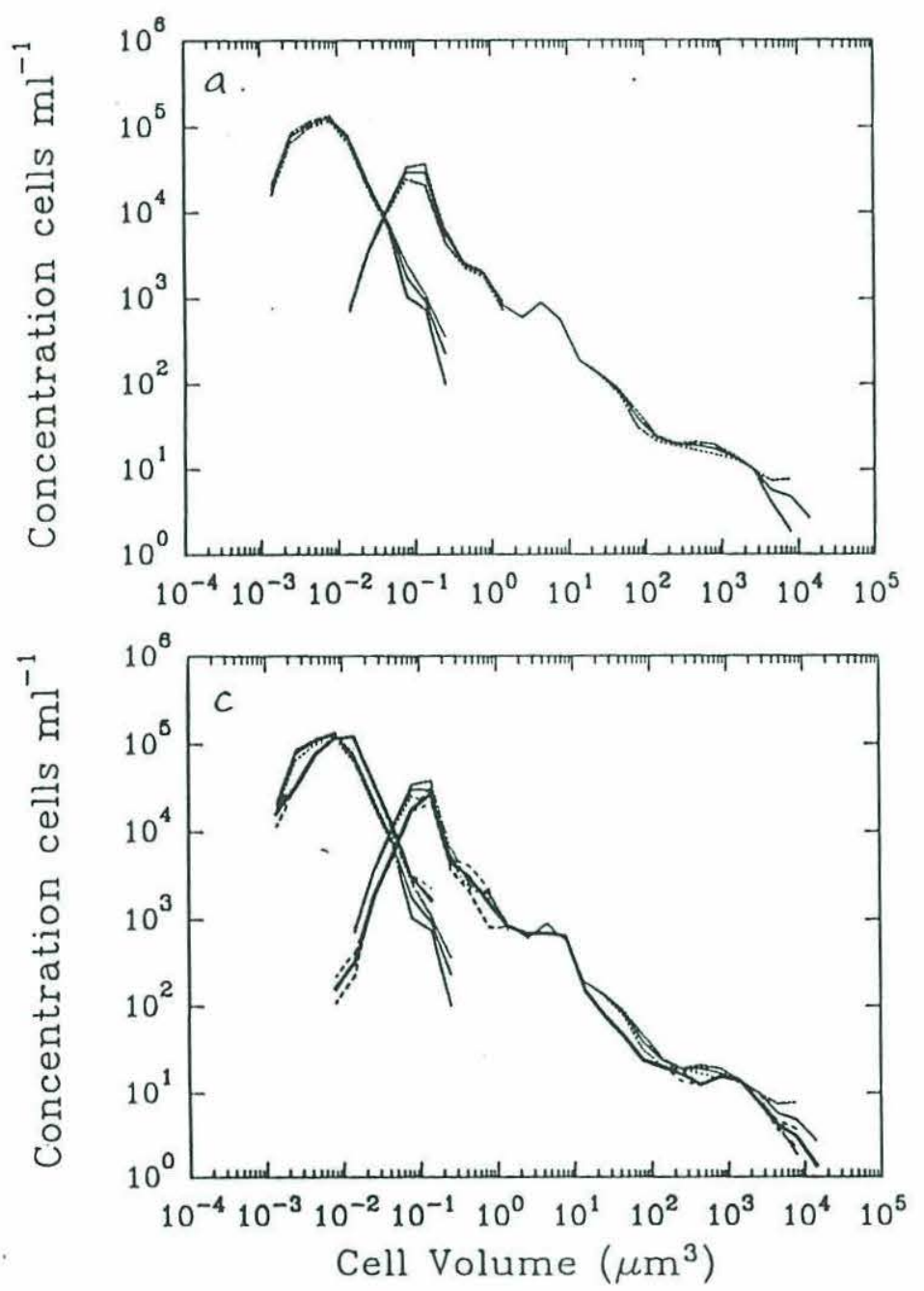

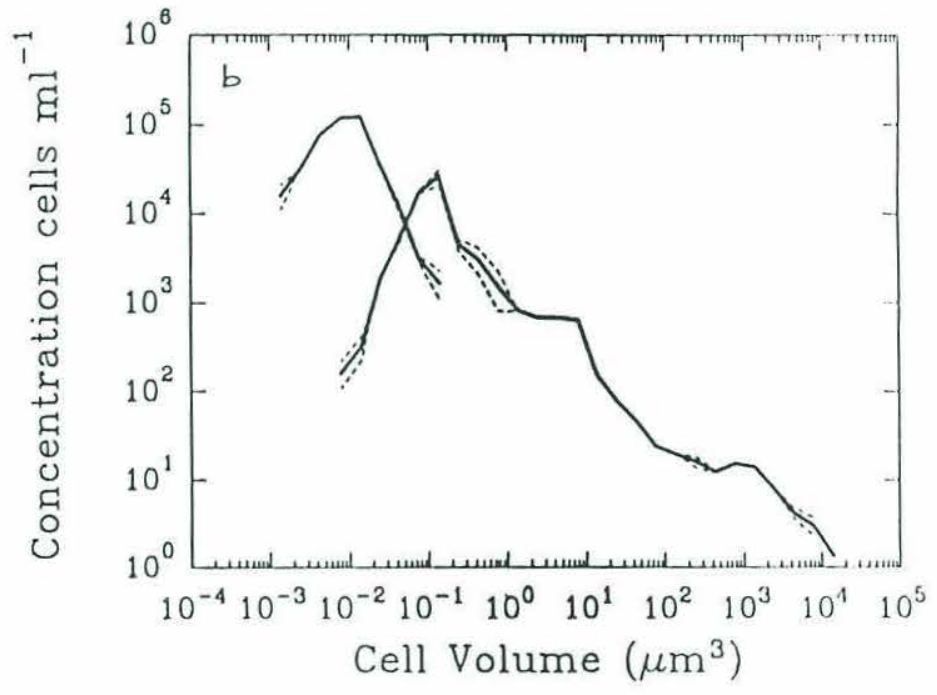

Cell Volume $\left(\mu \mathrm{m}^{3}\right)$

Fig. B6. A comparison of a) the average initial size spectrum of bacteria and phytoplankton (thin solid line), b) the average preserved spectrum (thick solid line) and c) the combined initial and preserved size spectrum, plotted on log scales. The envelope of dotted lines show the difference of 1 standard deviation from the average. Samples were taken from 120m depth in the Sargasso Sea in July, 1993. 

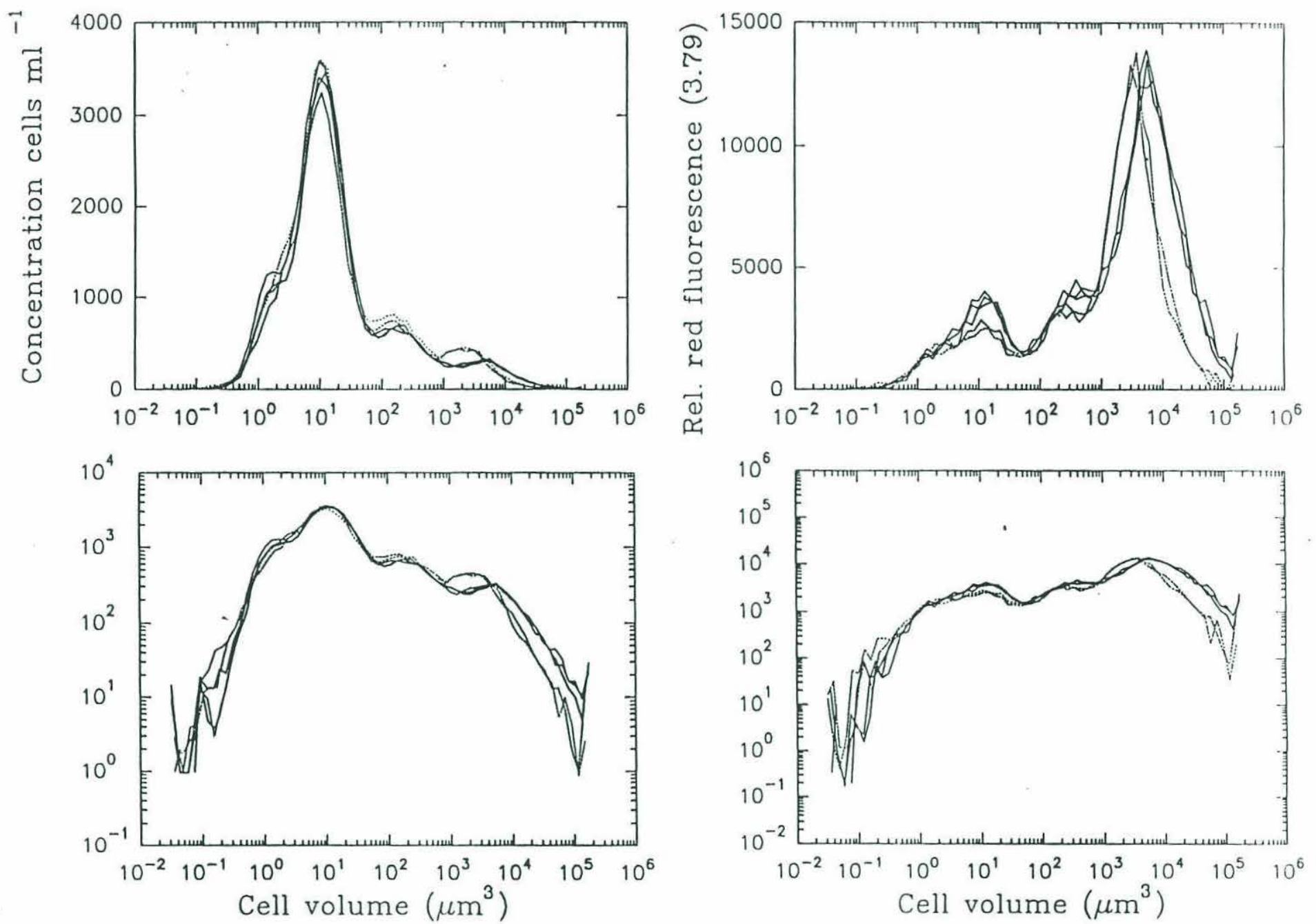

Fig. B7. Preservation results for nano/micro phytoplankton fixed in glutaraldehyde $(0.1 \%)$, immersed in liquid nitrogen and subsequently stored in a $-40^{\circ} \mathrm{C}$ freezer for 2 weeks before reanalysis. Replicate initial (solid lines) and preserved (dotted lines) size spectra are shown. Samples were taken from coastal Vineyard Sound waters, and supplemented with cultures of pennate diatoms and coccolithophores. 

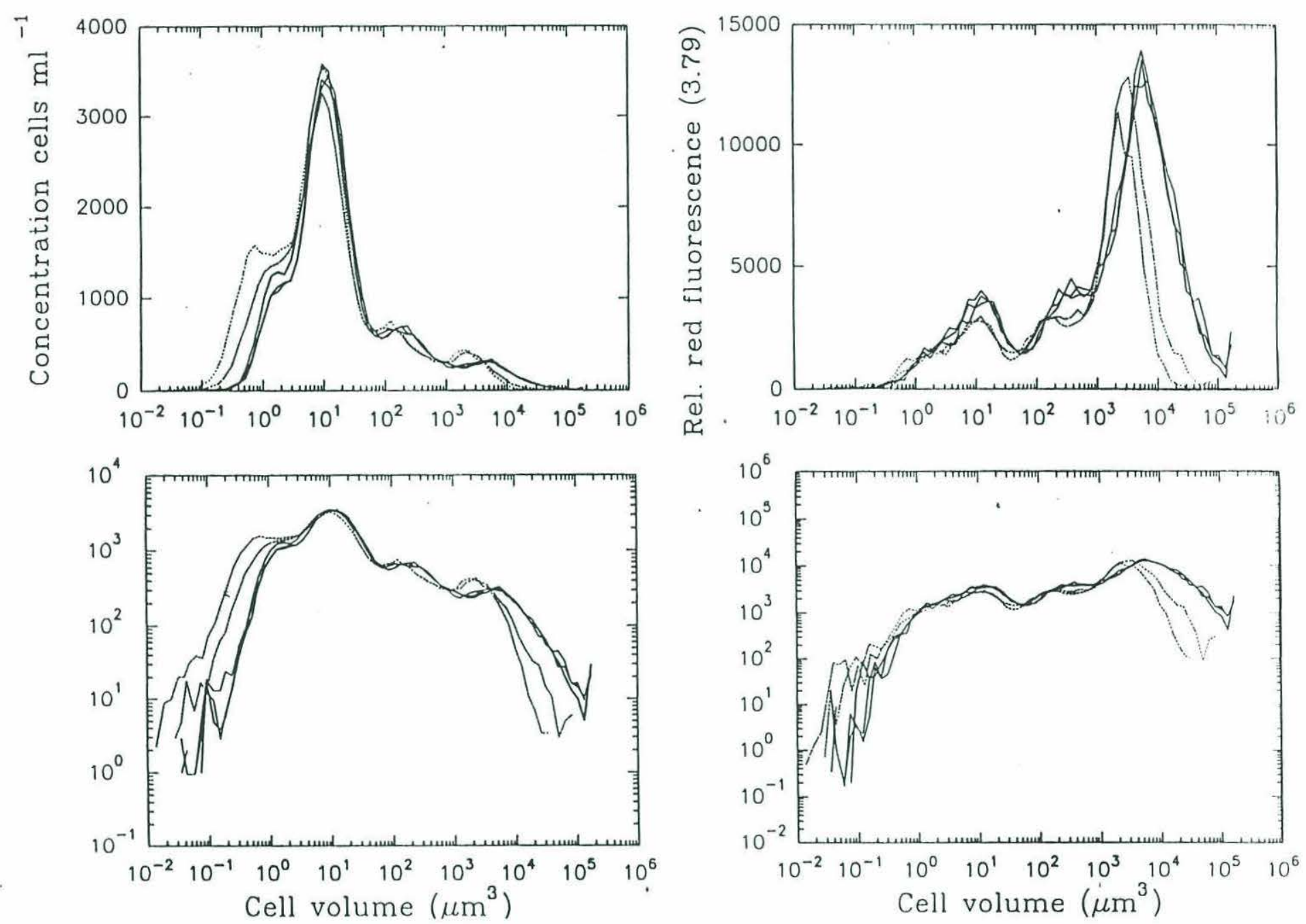

Fig. B8. Preservation results for nano/micro phytoplankton fixed in glutaraldehyde $(0.1 \%)$, and stored in liquid nitrogen for 2 weeks before reanalysis. Samples were taken from coastal Vineyard Sound waters, and supplemented with cultures of pennate diatoms and coccolithophores. 
these changes are expected to be less significant than the temporal and spatial variation of size spectra from the field. 


\section{APPENDIX C}

\section{FLOW CYTOMETRY ANALYSIS}

Flow cytometry is becoming increasingly popular in environmental science as a tool to study populations of microorganisms (Chisholm, 1988, Olson et. al., 1990, Li, 1994). The method consists of analyzing a stream of particles in single file through the focus of one or more laser beams. Light scattering and fluorescent properties of individual particles are captured at a rapid rate which can then be used to distinguish populations of particles with similar properties. Forward angle light scattering is measured in the direction of the laser beam (roughly $3^{\circ}-19^{\circ}$ at $488 \mathrm{~nm}$ - Michelle DuRand) whereas right angle light scattering $\left(73^{\circ}-107^{\circ}\right.$ - Michelle DuRand) and fluorescence are measured perpendicular to the laser beam's direction.

\section{Discrimination of Bacteria and Phytoplankton from other Particles}

Autofluorescence from phytoplankton pigments, such as chlorophyll and phycoerythrin (red $(660-700 \mathrm{~nm})$ and orange $(530-630 \mathrm{~nm})$ fluorescence respectively), are used routinely to discriminate phytoplankton cells from other particles. Since all particles will give some degree of scatter, non-fluorescent particles can be separated from autotrophic particles because they will scatter light but not fluoresce in the orange or red end of the spectrum. Recently, staining protocols have been developed to differentiate bacteria from autotrophic populations (Monger and Landry, 1993). This involves staining samples with the DNA stain, Hoechst 33342 and using both blue $(488 \mathrm{~nm})$ and UV $(345 \mathrm{~nm})$ laser excitation (dual beam flow cytometry) to analyze the samples. Excitation with blue light causes chlorophyll-containing cells to fluorescence red whereas UV excitation causes DNA-containing cells stained with Hoechst to fluoresce blue. In this way, phytoplankton (with both DNA and chlorophyll) and bacteria (only DNA) can be 
easily discriminated. Other non-biological particles can be detected because they scatter light but do not fluoresce.

\section{Different Instrument Configurations}

Samples were analyzed using two main instrument configurations. The first configuration ('pico' setting) was designed to analyze heterotrophic bacteria and picophytoplankton in the size range of 0.2 to $2.0 \mu \mathrm{m}$ using dual-beam flow cytometery on an EPICS 753 instrument (Fig. C1). Following Duval, 1993 and Binder et. al., 1996, a spherical lens was used to focus blue ( $488 \mathrm{~nm})$ and UV ( $345 \mathrm{~nm})$ laser beams to a tight spot, measuring approximately $20 \mu \mathrm{m}$ in diameter. Since bacteria generally exceed the range of conventional flow cytometers, the instrument was modified to detect forward light scatter with greater sensitivity by replacing the photodiodes with photomultiplier tubes. Instrument flow rates for analyzing picoplankton were adjusted to approximately $0.01 \mathrm{ml} \mathrm{min}^{-1}$. Nano/microplankton from about 2 to $70 \mu \mathrm{m}$ were analyzed on two EPICS $\mathrm{V}$ flow cytometers using a different configuration from the picoplankton analysis ie. 'nano/micro' setting. In this set-up, a single blue laser line focused through a $40 \mathrm{~mm}$ and 150mm lens was used for cell excitation (Fig. C2), following Olson et. al., 1989. Since the abundance of larger phytoplankton was of several orders of magnitude less than that of picoplankton, larger volumes of sample had to be analyzed before reasonable statistical cell counts could be made. To achieve this, larger sized sample tubing and needles was used to process larger volume throughput (eg. $2-10 \mathrm{ml} \mathrm{min}^{-1}$ ).

The flow cytometric data collected was stored as listmodes and as two-parameter histograms in 'easy' format. Listmodes enable the correlation of the five data parameters (ie. forward and right angle light scatter, red, blue and orange fluorescence) so that data defined on any two parameters can be reanalyzed on any combination of the other data parameters. Histograms, on the other hand, are not correlated to the other data parameters and hence, there is less flexibility when manipulating the data. The advantage of histograms, however, is that they take up much less computer storage space compared 


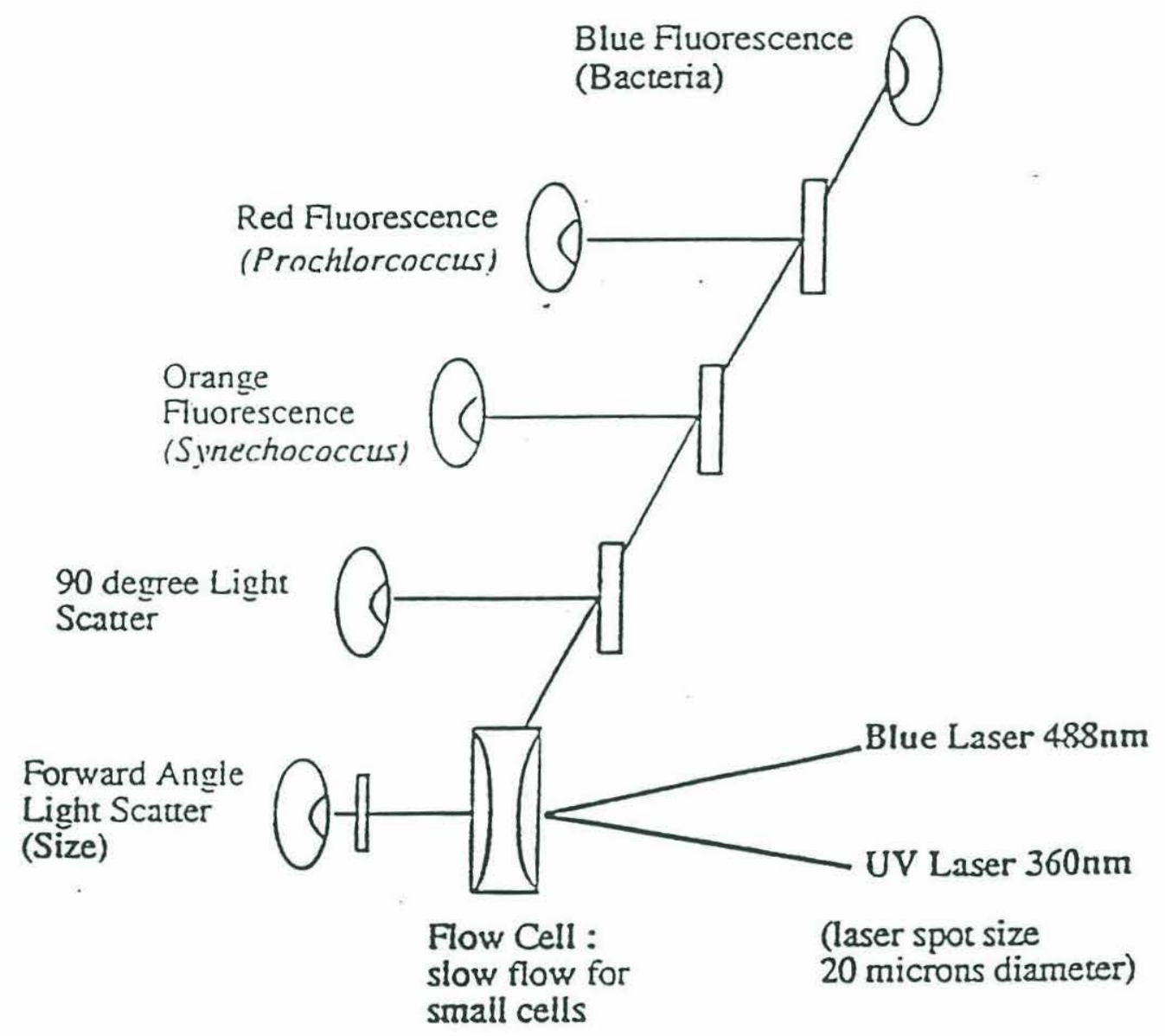

Fig. C1. Schematic of the 'pico' setting instrument configuration for analysing bacteria and picophytoplankton using dual beam flow cytometry, as described in the text. A spherical lens was used to focus the laser beam to a spot size of approximately $20 \mu \mathrm{m}$ in diameter. Forward angle light scatter, which is an indicator of size, was collected in the direction of the laser beam and passed through a beam blocker to reduce background noise levels. Right angle scatter together with red, orange and blue fluorescence were collected at right angles to the laser beams, after having passed through the apropriate filters. All signals were collected with sensitive photomultiplier tubes. 


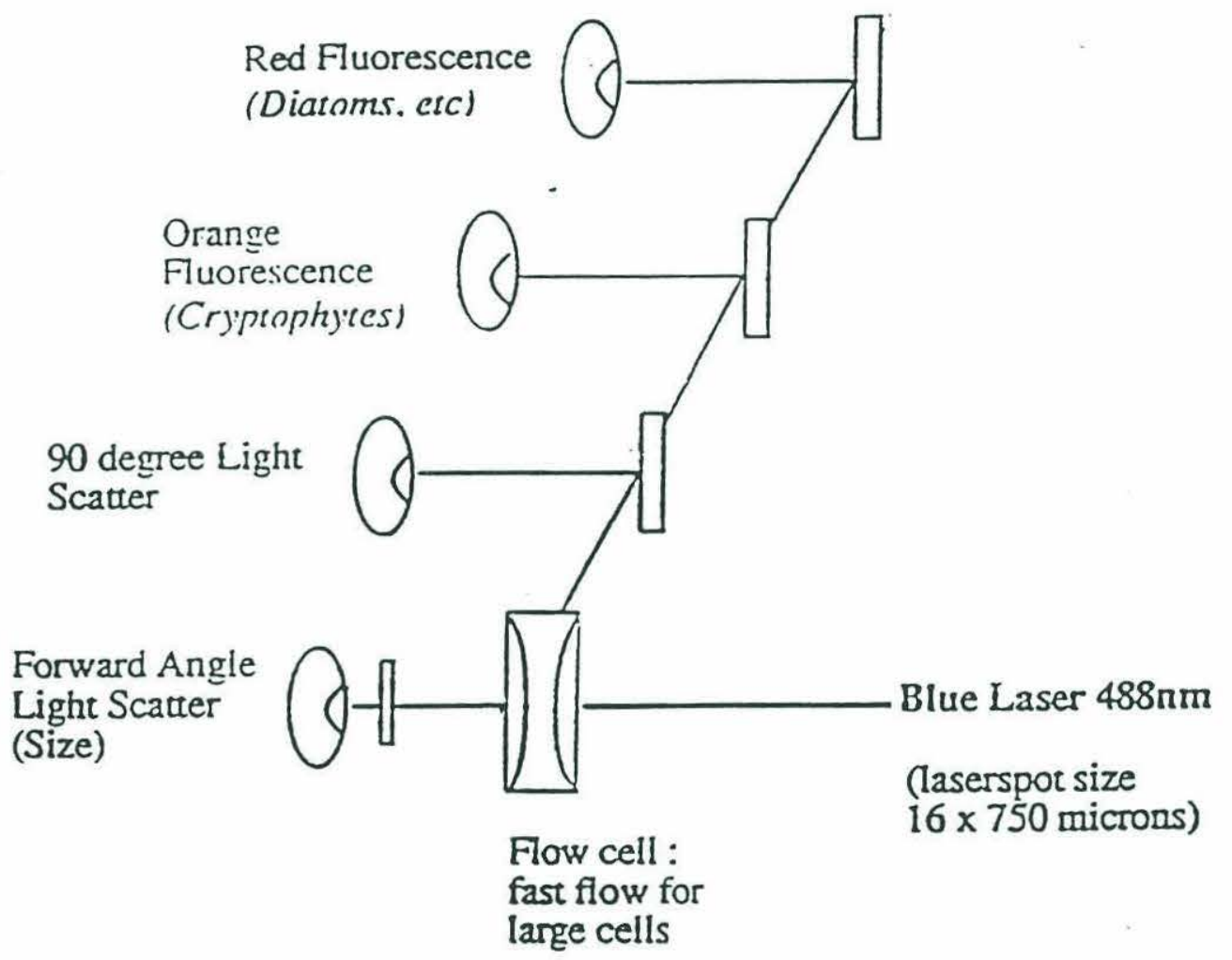

Fig. C2. Schematic of the 'nano/micro' setting instrument configuration for analysing nano/micro phytoplankton using single beam flow cytometry, as described in the text. A $150 \mathrm{~mm}$ lens was used to focus the laser beam to a spot size of approximately $16 \times 750 \mu \mathrm{m}$. Only four parameters were collected on these settings viz. forward angle light scatter, right angle scatter, red and orange fluorescence. 
with listmode data. Each data parameter was recorded in relative units on a scale of 64 or 256 channels representing three logarithmic decades. These logarithmic channels could be converted to a linear scale via :

$$
\mathrm{X}=\mathrm{A} .10(\mathrm{FACT} * \mathrm{~N} / \mathrm{C})
$$

where $\mathrm{X}$ is the linearized channel number, $\mathrm{A}$ is a constant (taken as 1 ), FACT is the empirical log-lin calibration factor for the amplifier, $\mathrm{N}$ is the logarithmic channel number and $\mathrm{C}$ is the total number of channels.

\section{Protocol for Analyzing Picoplankton on the Flow Cytometer ('pico' settings)}

Lasers for dual-beam flow cytometry were warmed up for 1 hour and peaked to optimize output (blue laser - 800 mW, 31.5 A; UV laser - 300 mW, 39 A). During this time, the sample lines were equilibrated with Hoechst-33342 solution ie. $5 \mathrm{ml}$ of $0.02 \mu \mathrm{m}$ filtered seawater $+100 \mu \mathrm{l}$ Hoechst stock solution $\left(27 \mathrm{~g} \mathrm{~g}^{-1}\right)$. Working stock ${ }^{1}$ solutions of $0.46 \mu \mathrm{m}$ ("Fluoresbrite BB", Polysciences) and $0.57 \mu \mathrm{m}$ standard calibration beads ("Fluorescite YG") were sonicated for 3 minutes to break up the clusters of beads. 0.2 $\mu \mathrm{m}$-filtered Q-water was used as sample sheath for the instrument.

After aligning the lasers, bead calibrations were made (at least in duplicate) because flow rates in the instrument can vary on a daily basis. By calibrating the flow rate each day using standard beads, the actual volume analyzed per sample can be calculated from the number of beads counted within each sample. Solutions for bead calibrations were made by adding glutaraldehyde ( $0.1 \%$ final concentration) and $20 \mu \mathrm{l}$ of $0.46 \mu \mathrm{m}$ beads and $10 \mu \mathrm{l}$ of $0.57 \mu \mathrm{m}$ beads to $0.5 \mathrm{ml}$ Hoechst stained-filtered seawater. The weight of sample run in a known time period together with the number of beads (counted

\footnotetext{
${ }^{1}$ Working stock solutions of beads were made by adding one drop of the primary stock solution to $10 \mathrm{ml}$ of fresh Q-water.
} 
on orange fluorescence) run in the same time were used to calculate the number of beads per $\mathrm{ml}$ (Olson et. al., 1993). The number of cells per ml, C,was calculated as

$$
\mathrm{C}=\mathrm{N} \times \mathrm{B}_{\mathrm{d}} / \mathrm{B}
$$

where $B_{c}$ is the bead calibration, $B$ is the number of beads in the sample and $N$ is the number of cells. The percentage differences between bead calibrations were generally within $5 \%$.

Frozen samples were thawed in a water bath at room temperature, after which $10 \mu \mathrm{l}$ Hoechst was added to $0.5 \mathrm{ml}$ of sample. The stained sample was left in the dark for 1 hour before flow cytometric analysis. The instrument was set to trigger off right angle scatter and MDADS II (Epics) software was used to capture listmodes, gated on red fluorescence (for picophytoplankton analysis) and on blue fluorescence (for bacteria analysis). Prior to running, the needle was rinsed with Q-water and sample lines were flushed with sheath. Background noise levels were checked by viewing the ungated forward scatter signal on an oscilloscope and ensuring that counts were less than $10 \mathrm{cps}$. $20 \mu \mathrm{l}$ of $0.46 \mu \mathrm{m}$ beads and $10 \mu \mathrm{l}$ of $0.57 \mu \mathrm{m}$ beads were added into the stained sample and vortexed thoroughly just before running. Samples for bacteria analysis were run for about 5 minutes at high forward scatter sensitivity, during which time some 40,000 data points were collected. Picophytoplankton samples were analysed for approximately 15 minutes at slightly lower sensitivity. Filtered seawater blanks were analyzed in a similar manner. Bead mixes ('bact' setting; 0.22, 0.30, 0.46, $0.57 \mu$ m beads; 'pico' setting: 0.46 , $0.57,0.66$ or $0.75,1.0,2.02 \mu \mathrm{m}$ beads) were also run to assist in merging the data sets on forward light scatter ie. $0.46 \mu \mathrm{m}$ beads to merge bacteria and phytoplankton, $0.66 \mu \mathrm{m}$ (or $0.75 \mu \mathrm{m}$ ) beads to merge picophytoplankton and nano/ microphytoplankton. ( $2.02 \mu \mathrm{m}$ beads were used to merge red fluorescence for the pico and nano/microplankton - see Appendix E). The flow cell was periodically cleaned during the day by wiping the outside 
surface with a cotton bud soaked in methanol. Data from MDADS II was epinetted to a $\mathrm{PC}$ for data processing.

\section{Protocol for Analyzing Nano/Microplankton on the Flow Cytometer ('Nano/Micro'} Settings)

Nano/microplankton samples were analysed using the 'nano/micro' instrument setting. The blue laser was warmed up at $600 \mathrm{~W}$ for 1 hour before samples were run. Saline solution $(35 \% \mathrm{NaCl})$ was made to simulate seawater for sheath since this helped to reduce background noise. Data was collected using a Cicero Box (triggered on forward light scatter) and Cyclops software for analysis. Bead calibrations were performed at least in duplicate using $3.79 \mu \mathrm{m}$ or $5.95 \mu \mathrm{m}$ (oceanic and coastal samples respectively) beads added to $0.2 \mu \mathrm{m}$-filtered seawater. Bead mixes, comprising of 0.66 or $0.75,1.00,2.02$, $2.99,5.95$ and $9.5 \mu \mathrm{m}$ beads, were also run to assist in overlapping data with the 'pico' setting. Samples were thawed in a water bath at $25^{\circ} \mathrm{C}$ and $45 \mathrm{ml}$ aliquots were withdrawn. $50 \mu \mathrm{l}$ of 2.02 and $3.79 \mu \mathrm{m}$ (or $5.95 \mu \mathrm{m}$ ) beads were added to each sample just prior to analysis. Approximately 200,000 data points were collected on listmodes gated on red fluorescence.

\section{Identification of Cell Populations}

Software (CytoPC) provided by D. Vaulot (Station Biologique, Roscoff, France) was used to analyze the data and discriminate bacteria and phytoplankton from other particles. (Note that a modified version of Cytopc (Michelle DuRand, pers. comm.) was used to analyze nano/microplankton captured with Cyclops software). Bacteria were generally identified as a cluster of cells (bitmap 3 ) that contained significant blue fluorescence relative to standard $0.46 \mu \mathrm{m}$ beads (window 1 ) on the blue fluorescence vs forward scatter scattergram (Fig. C3). Red fluorescing phytoplankton were excluded from the analysis by only defining cells with negligible red fluorescence within bitmap 3 on the red fluorescence vs forward scatter scattergram. Further discrimination of bacteria 

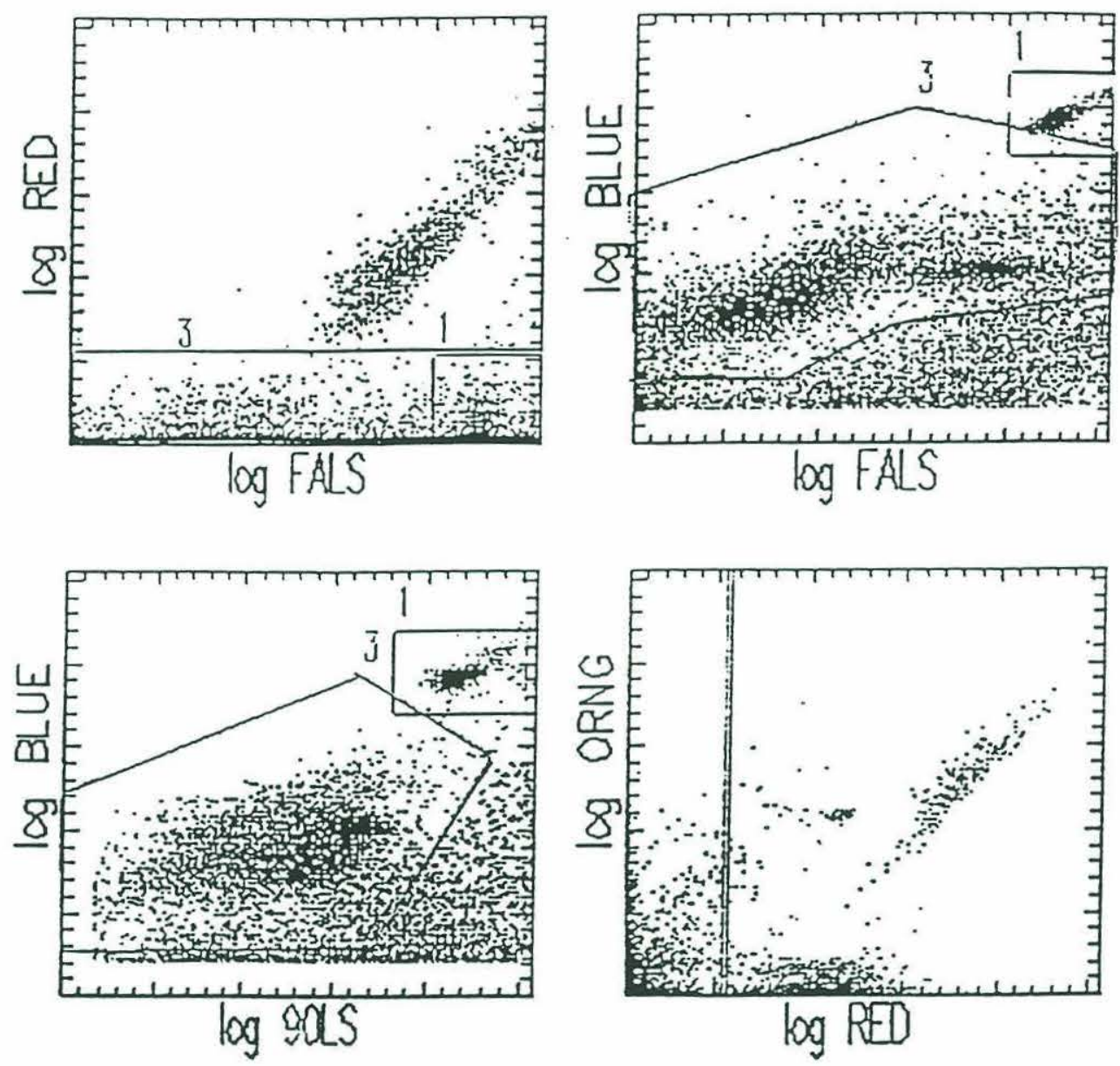

Fig. C3. Discrimination of bacteria (bitmap 3) from phytoplankton using Cytopc software. Phytoplankton were excluded from bitmap 3 in the red fluorescence (RED) versus forward scatter (FALS) scattergram because they fluoresced red to a greater degree than bacteria. DNA-containing cells stained with Hoechst 33342 fluoresced blue and hence bacteria could be defined on the blue fluorescence (BLUE) versus forward scatter scattergram using bitmap 3 gated on the previous scattergram ie. RED vs FALS. Further discrimination was possible using the right angle scatter signal (90LS). $0.46 \mu \mathrm{m}$ beads are also shown as a reference (window 1). This example was taken at $2 \mathrm{~m}$ depth from the Sargasso Sea Station (BATS) on February 9, 1993. 
was possible using right angle scatter and orange fluorescence. Picophytoplankton could be distinguished from bacteria and other particles because of their high red fluorescence (window 3) relative to standard $0.57 \mu \mathrm{m}$ beads (window 1) (Fig. C4). Generally, picophytoplankton signatures emerged as a continuous cluster of cells which had increasing red fluorescence with increasing forward light scatter. Orange fluorescence could also be used to differentiate phycoerythrin-containing species, such as Synechococcus, but individual speciation was unnecessary for this study. A similar sweep of cells on the red fluorescence versus forward scatter scattergram was also observed for the larger nano/ microphytoplankton obtained from the 'nano/micro' instrument configuration (window 3 in Fig. C5). Note that the thick cluster of cells in the lower left hand corner of the red fluorescence versus forward scatter are Synechococcus, which form part of the overlapping population with the 'pico' settings. 

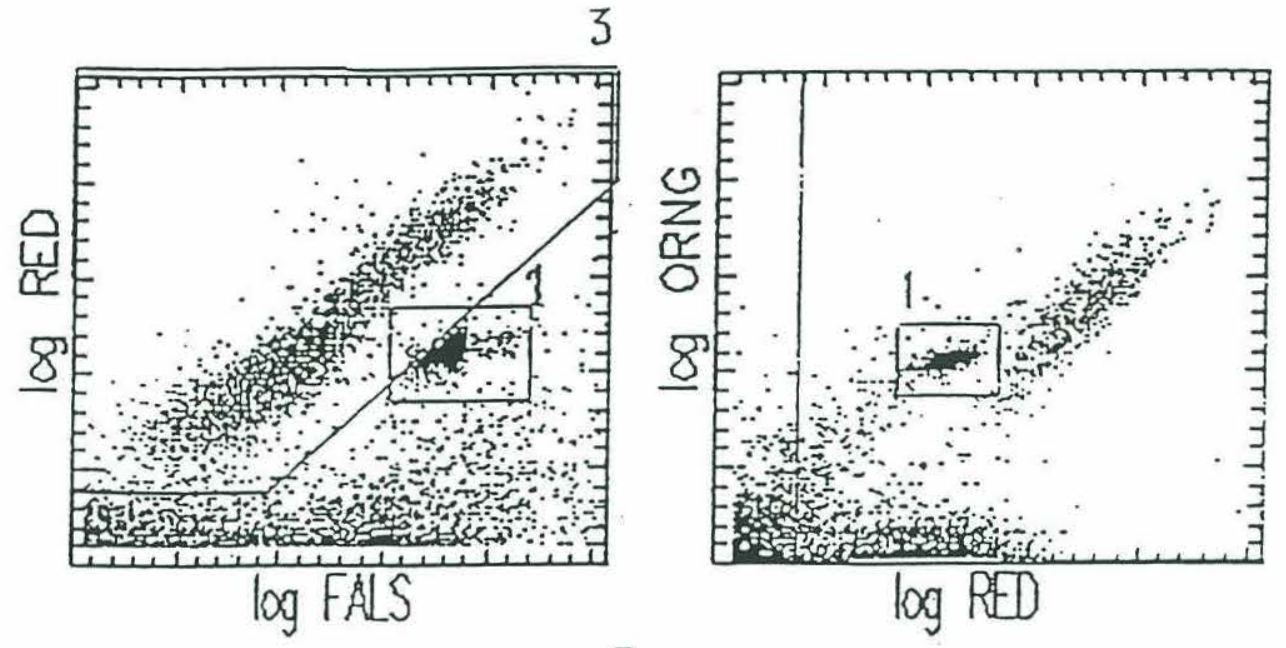

3
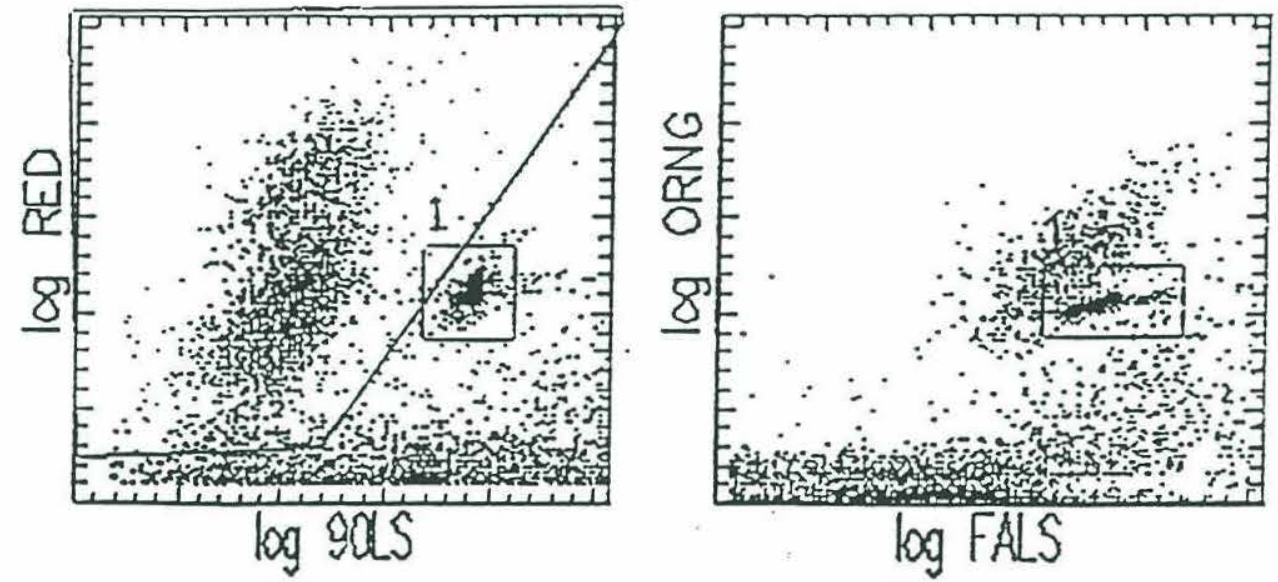

Fig. C4. Discrimination of picophytoplankton from other particles, corresponding to the same sample discussed in Fig. C3. Picophytoplankton formed a continuous cluster of cells that showed increasing red fluorescence with increasing forward scatter (bitmap3). $0.57 \mu$ $\mathrm{m}$ beads are also shown for reference (window 1). Note that Synechococcus could be differentiated from other phytoplankton because they also fluoresce orange (ORNG) in addition to red. 

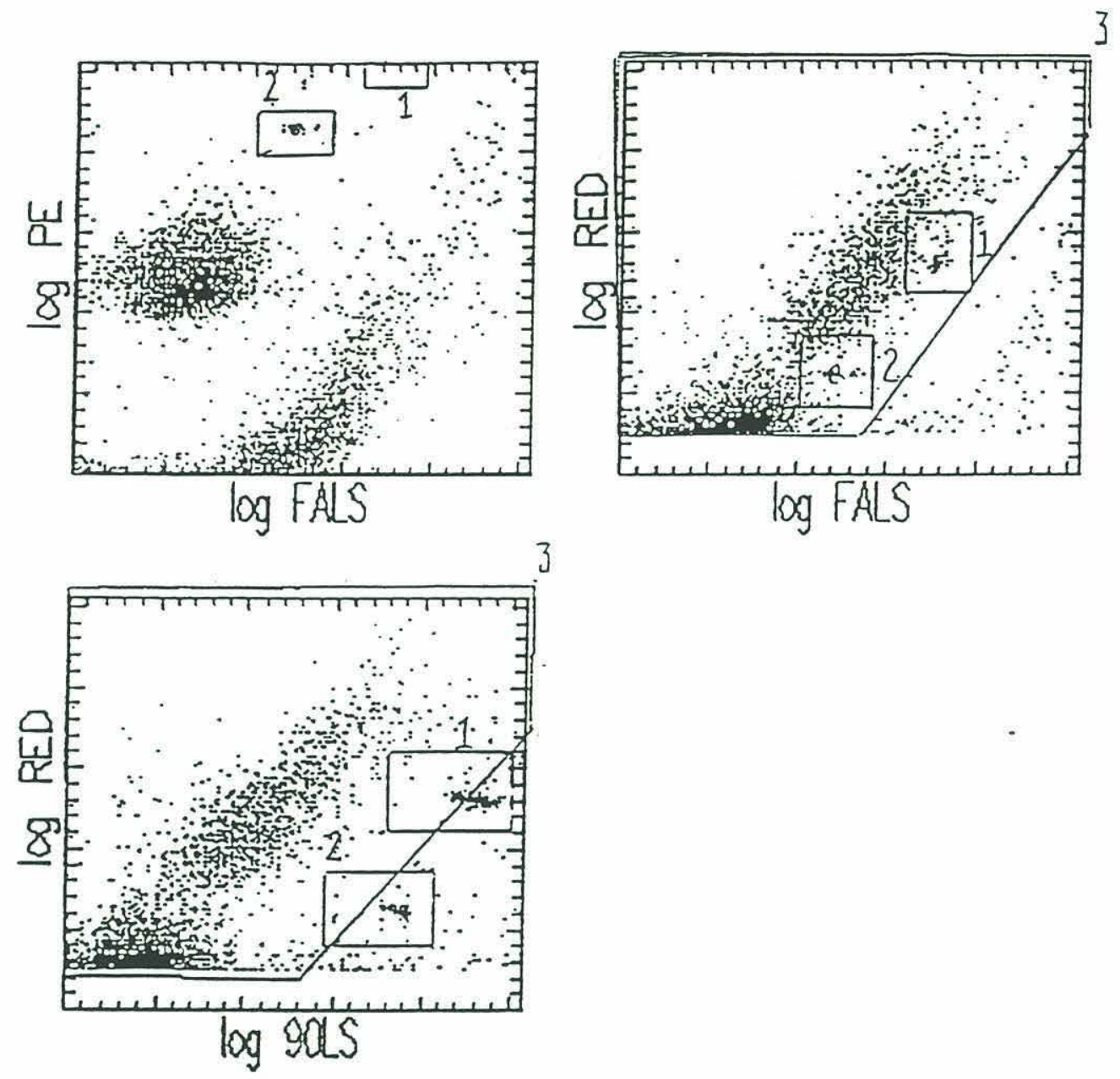

Fig. C5. Discrimination of nano/micro phytoplankton from other particles, corresponding to the same samples discussed in Figs. C3 and C4. As with picophytoplankton, the larger nano/micro phytoplankton also formed a continuous cluster, which could easily be identified on red fluorescence versus forward scatter (bitmap 3). $3.79 \mu \mathrm{m}$ (window 1) and $2.02 \mu \mathrm{m}$ (window 2) are also shown for reference. Note that the dense population of cells in the left hand corner of the RED vs FALS scattergram corresponds to Synechococcus, which also fluoresces orange (PE). 


\section{APPENDIX D \\ SIZING THE MICRO-ORGANISMS FROM EMPIRICAL CALIBRATION EQUATIONS}

The generation of flow cytometric spectra hinges on empirical relationships between forward light scatter and size, which are dependent on instrument configuration as well as instrument type. By calibrating each instrument for size, variations in laser power, collection angle of scattering, etc, could be neglected since only the final result, ie. size, was of interest to the study. In total, three flow cytometers were used in the experiments: one instrument for the 'pico' settings (Epics 753) and two for the 'nano/micro' settings (Epics V-I for oceanic samples and Epics V-II for coastal samples).

\section{The Picoplankton Calibration Equation}

Filtration was used to estimate picoplankton size because it provides an operational definition of size which is widely used in ecological studies. Samples (in duplicate) taken from coastal Vineyard Sound, the Gulf Stream and the oceanic Sargasso Sea were first preserved with $0.1 \%$ glutaraldehyde and then filtered through Poretics polycarbonate filters of sizes $0.4,0.6,0.8$ and $1.0 \mu \mathrm{m}$ using gentle pressure on a $10 \mathrm{ml}$

syringe (Brian Binder, pers. comm.) or by gravity (Aref, 1996). The filtrates were then analyzed for bacteria on an Epics 753 using the 'pico' configuration, as described in Appendix C. The concentration distributions (as a function of forward scatter relative to $0.46 \mu \mathrm{m}$ beads) were then expressed as a fraction of the unfiltered concentration distribution, and the $50 \%$ retention value of forward scatter was obtained for each filtrate. This gave an average value for the forward scatter corresponding to the filter size used. Plotted on logarithmic scales, the data fell on straight lines whose regressions gave the following equations: 
Vineyard Sound (Binder)

Gulf Stream (Aref)

Sargasso Sea (Aref)

Average of the above

$$
\text { FLS }=1.233 \times \text { VOL }^{1.11}
$$

$\left(R^{2}=0.99, N=3\right)$

$\mathrm{FLS}=2.979 \times \mathrm{VOL}^{1.22}$

$\left(\mathrm{R}^{2}=0.99, \mathrm{~N}=3\right)$

$\mathrm{FLS}=2.148 \times \mathrm{VOL}^{1.01}$

$\left(\mathrm{R}^{2}=0.99, \mathrm{~N}=3\right)$

where FLS is the forward scatter relative to $0.46 \mu \mathrm{m}$ beads, and VOL is the average volume based on an equivalent spherical diameter corresponding to the filter pore size. The corresponding coefficients of variation for the Y-intercept and slopes for these regressions are $34 \%$ and $8 \%$ respectively. At the time field samples for size spectra were being analyzed, not all the picoplankton calibrations were available. The actual picoplankton calibration equation used for spectra generation was based on a restricted data set taken from the Gulf Stream (Lana Aref, pers. comm.) as follows (Fig. D1):

Picoplankton calibration used: $\quad$ FLS $=3.327 \times$ VOL $^{1.16} \quad\left(\mathrm{R}^{2}=0.99, \mathrm{~N}=3\right)$

This equation fell within the envelope of the combined data set although the picoplankton calibration equations may vary for different types of water bodies (Lana Aref, pers. comm.). More studies are required to verify this. While the picoplankton calibration is somewhat crude, it nevertheless estimated cell sizes that were comparable to previous reported measurements of Prochlorococcus $(\sim 0.7 \mu \mathrm{m})$ and Synechococcus $(\sim 1$ $\mu \mathrm{m})$ (Chisholm, 1988, Campbell et. al., 1994).

The exponent value of about 1.1 is lower than that predicted from Mie theory as described by Van De Hulst (1957). According to Mie theory, the picoplankton end of the spectrum should conform to a forward scatter dependency on $\operatorname{VOL}^{2}$ (ie $\mathrm{r}^{6}$ ). The difference in the results can be partly explained by the different collection angles of 


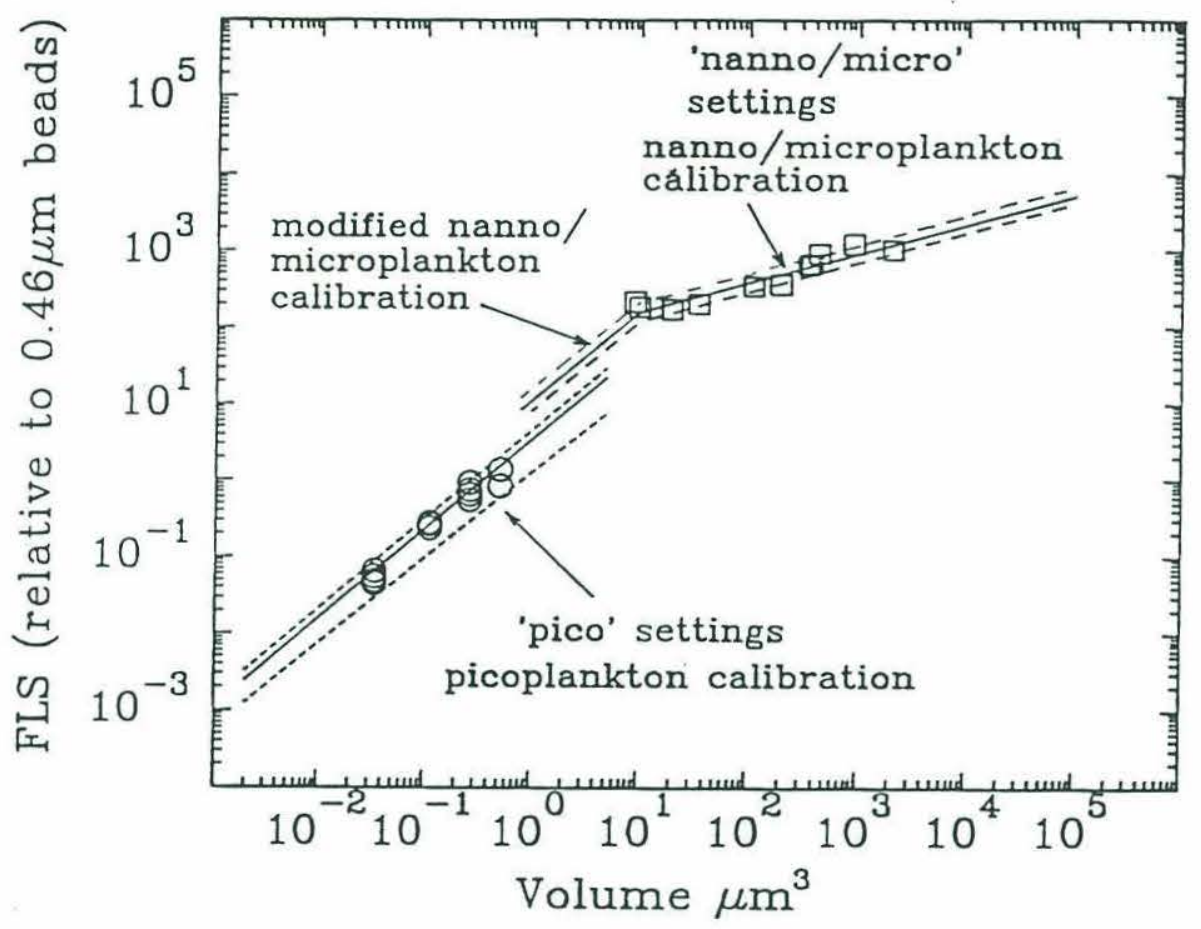

Fig. D1. Empirical size calibration equations used in the flow cytometric generation of size spectra. Data for the picoplankton calibration equation (circles) was obtained by taking the $50 \%$ retentate value of flow cytometrically analyzed filtrates and regressing them against the equivalent volume corresponding to the average pore size on each filter $(0.4,0.6,0.8$ and $1.0 \mu \mathrm{m}$ filters). Samples were collected from both coastal (Vineyard Sound) and oceanic (Sargasso Sea and the Gulf Stream) sources and analyzed on the 'pico' settings of an Epics 753 (Aref, 1996, Binder, pers. comm.). The nanno/microplankton calibration was obtained by sizing phytoplankton cultures with a Coulter counter and subsequently analyzing them on the 'nanno/micro' settings of an Epics $\mathrm{V}$ flow cytometer (squares). To enable a smooth transition from pico to nanno/micro scales, a modified nanno/microplankton calibration (based on the same slope as the picoplankton calibration) was applied to data from the 'nanno/micro' settings which were less than $10 \mu \mathrm{m}^{3}$. Note that in order to merge the data, standard beads were used to scale the forward light scatter from one setting to another. 
forward scattering since in flow cytometry, the collection angle is generally larger $\left(\sim 3-19^{\circ}\right)$ than that considered for the thoeretical curve $\left(<2^{\circ}\right)$. The empirical picoplankton calibration can be further refined using custom-made filters of smaller size to see if, in fact, the smaller end of the spectrum steepens to follow the $r^{6}$ dependency, as predicted from theory. However, as a first approximation, the filter-fractionation calibration provides a rough estimate of picoplankton size for cells between 0.03 to $1 \mu \mathrm{m}^{3}$.

\section{The Nano/Microplankton Calibration Equations}

For the calibration of larger phytoplankton, thirteen different sized cell cultures ranging from 10 to $2000 \mu \mathrm{m}^{3}$ were used. Average volumes of phytoplankton populations in exponential phase were measured using a Coulter counter (Durand, 1995). The cultures were then run immediately on the 'nano/micro' configuration for the Epics V-I instrument (oceanic samples), whereas the cultures were preserved in $0.1 \%$ glutaraldehyde and stored in liquid nitrogen before flow cytometric analysis for the Epics V-II (coastal samples). The average forward scattering of each cell culture, relative to standard beads (eg. $3.79 \mu \mathrm{m}$ ), were then linearly regressed against mean cell volumes to give the following calibration equations (Fig. D1):
Oceanic (Epics V-I)
FLS $=\mathrm{K} 3 \times 0.214 \times \mathrm{VOL}^{0.390}$
$\left(\mathrm{R}^{2}=0.96, \mathrm{~N}=11\right)$
Coastal (Epics V-II)
$\mathrm{FLS}=\mathrm{K} 3 \times 0.301 \times \mathrm{VOL}^{0.382}$
$\left(\mathrm{R}^{2}=0.95, \mathrm{~N}=11\right)$

where $\mathrm{K} 3$ is the linear factor to convert from a distribution normalized to $3.79 \mu \mathrm{m}$ (K3 95) or $5.9 \mu \mathrm{m}$ (K3 217) beads (ie. 'nano/micro' settings) to one that is normalized to $0.46 \mu \mathrm{m}$ beads ('pico' settings).

\section{Merging the picoplankton and nano/microplankton to form a continuous spectrum}

The final size spectrum is obtained by merging the data from the 'pico' and 'nano/micro' instrument settings. This is achieved by overlapping the forward light scatter 
signals of standard beads which can be seen on both configurations (eg. 0.66 or $0.75 \mu \mathrm{m}$ beads). Once the spectra have been aligned, forward scatter is converted to volume using the empirical size calibration equations. The relationship between forward light scatter and particle size for the entire size spectrum is a non-linear function as shown in Fig. D1. However, as discussed above, the calibration equation for the nano/microplankton end of the spectrum conforms quite well to the larger end of the theoretical curve but the empirical picoplankton calibration is shallower than that predicted by theory. At the time the data for this thesis was processed, the only available picoplankton calibration was based on four filter sizes, ranging from 0.4 to $1.0 \mu \mathrm{m}$. In the absence of data points beyond this range, it was assumed that the picoplankton calibration equation also extended beyond this range, at least for data obtained on the 'pico' settings (ie. up to a relative forward scatter of about 30 bd units).

In the case of the nano/micro calibration equation, data below $10 \mu \mathrm{m}^{3}$ was unavailable. If forward scatter is converted to size using this equation for the entire range of data obtained on the nano/micro settings, this results in an unrealistic spreading of the data at the small end of the spectrum. The question is how to resolve the overlapping region, knowing that the upper end of the picoplankton calibration and lower end of the nano/microplankton calibration are not necessarily an accurate portrayal of the true situation. One way is to merge the same populations that are observed on both settings eg. Synechococcus and eukaryotic picophytoplankton. As a first approximation, the picoplankton calibration was left unchanged and the lower end (ie. less than $10 \mu \mathrm{m}^{3}$ ) of the nano/microplankton equation was modified so that it had the same slope as the picoplankton calibration:

\section{Equations A}

Picoplankton

FLS $=3.33 \times$ VOL $^{1.163}$

Nano/microplankton

$\mathrm{FLS}=11.0 \times \mathrm{VOL}^{1.163}$

$\left(\mathrm{VOL}<10 \mu \mathrm{m}^{3}\right)$ 
(Epics V-I, coastal)

$$
\text { FLS }=66.5 \times \text { VOL }^{0.382}
$$

$\left(\mathrm{VOL}>10 \mu \mathrm{m}^{3}\right)$

Nano/microplankton

$$
\text { FLS }=8.0 \times \text { VOL }^{1.163}
$$

$\left(\right.$ VOL $\left.<10 \mu \mathrm{m}^{3}\right)$

(Epics V-II, oceanic)

FLS $=47.3 \times$ VOL $^{0.39}$

$\left(\right.$ VOL $\left.>10 \mu \mathrm{m}^{3}\right)$

This modification of the nano/microplankton calibration equation actually resulted in a good fit to the overlapping picophytoplankton data (Fig. D3). For this reason, all the data were merged using the picoplankton and modified nano/microplankton calibration equations.

If standard beads are used instead of cells, the data fall on a calibration curve that is more akin to the theoretical curve (Fig. D2 ). This is due to the different refractive index of cells compared to beads and also partly because of the greater number of bead sizes available, whereas only few options exist for filter sizes in the picoplankton range. On further examination of the picoplankton filtration data, it appears that the data may, in fact, fall on the transition part of the non-linear curve of the beads (at least for sizes greater than $0.03 \mu^{3}$ ), except that it is shifted downwards (Lana Aref, pers. comm.).

To give an idea of how a steeper picoplankton calibration might affect the results, the lower end of the spectrum was computed using an equation equivalent to the regression of the beads data (ie. slope equal to 1.78), whilst the upper end was based on an average slope intermediate between the 'pico' and 'nano/micro' slopes (ie. 1.08). For the lower end of the nano/microplankton end of the calibration, the intermediate slope was also used to facilitate the transition to the steeper picoplankton curve.

\section{Equations B}

Picoplankton

$$
\begin{array}{ll}
\text { FLS }=7.72 \times \text { VOL }^{1.78} & \left(\text { VOL }<0.3 \mu \mathrm{m}^{3}\right) \\
\text { FLS }=3.07 \times \text { VOL }^{1.08} & \left(\text { VOL }>0.3 \mu \mathrm{m}^{3}\right)
\end{array}
$$

Nano/microplankton

$$
\text { FLS }=13.3 \times \text { VOL }^{1.08}
$$

$\left(\mathrm{VOL}<10 \mu \mathrm{m}^{3}\right)$ 


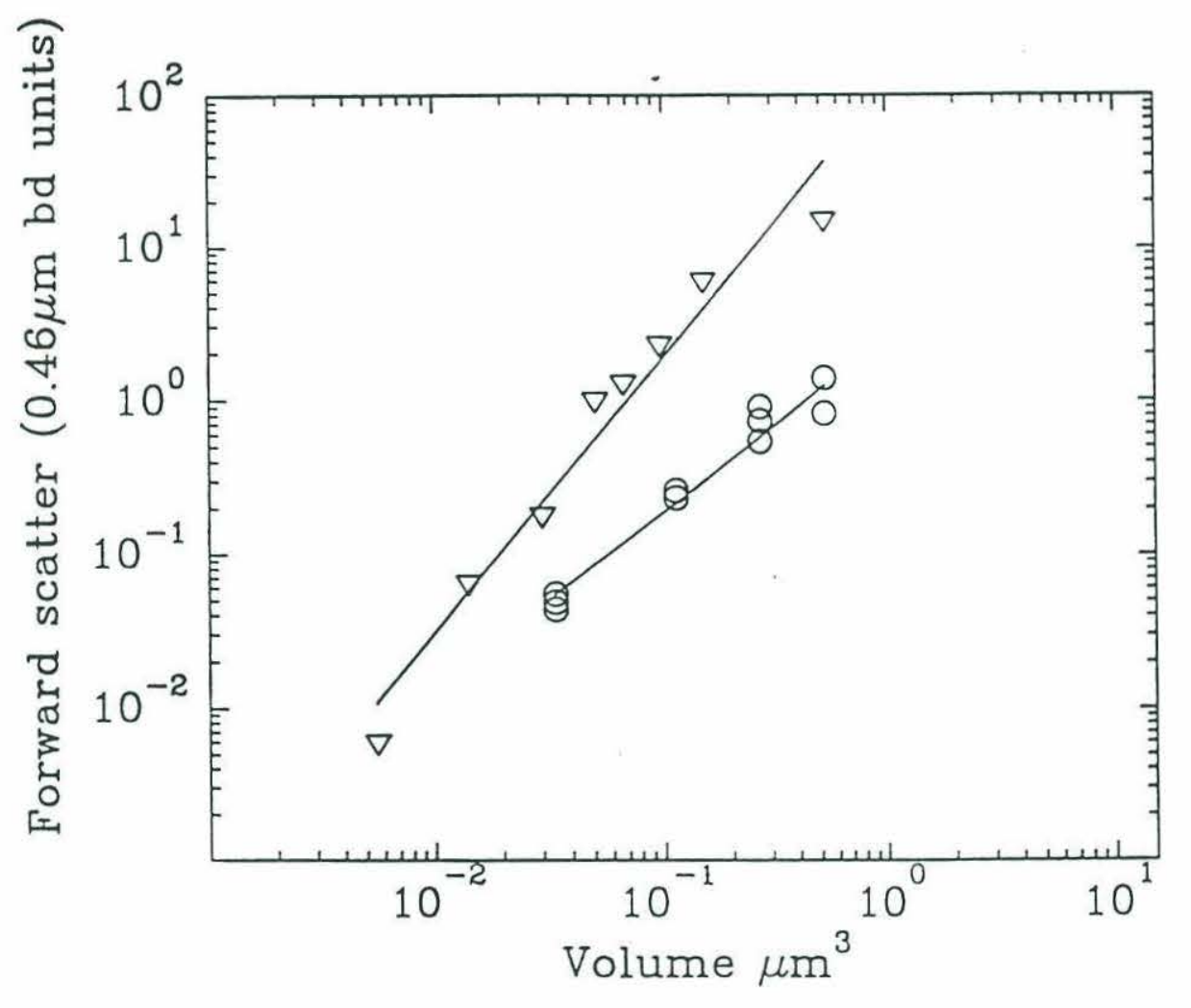

Fig. D2. Empirical size calibration equation using beads of various sizes (triangles), together with the filtration data described in Fig. 1. The beads data consisted of a mixture of UV-excitable and blue-excitable Fluoresbrite standard calibration beads (Polysciences) taken from Binder (unpubl. data). Samples were analyzed on the 'pico' settings of an Epics 753 instrument, using dual-beam flow cytometry. 


$$
\text { FLS }=66.5 \times \text { VOL }^{0.382} \quad\left(\mathrm{VOL}>10 \mu \mathrm{m}^{3}\right)
$$

In doing so, the resultant spectrum also gave a good fit of the overlapping picophytoplankton data, although the overall picoplankton component was compressed into a narrower size range (Fig. D3). This caused the normalized spectrum to steepen relative to the original spectrum generated from equations $\mathrm{A}$, but overall effects on the phytoplankton and total spectrum were small (eg. about 5\% variation in spectral characteristics). However, the effects on the bacteria end of the spectrum were more significant since the entire bacteria distribution was compressed (eg. 17\% variation in slope or $30 \%$ variation in mean population size). These comparisons give an indication of how the size spectrum could change with different values of the picoplankton calibration. For the actual spectra generated in this thesis, differences in the picoplankton calibration would not affect the relative comparison of data since the same calibration equation was used throughout the data set. 

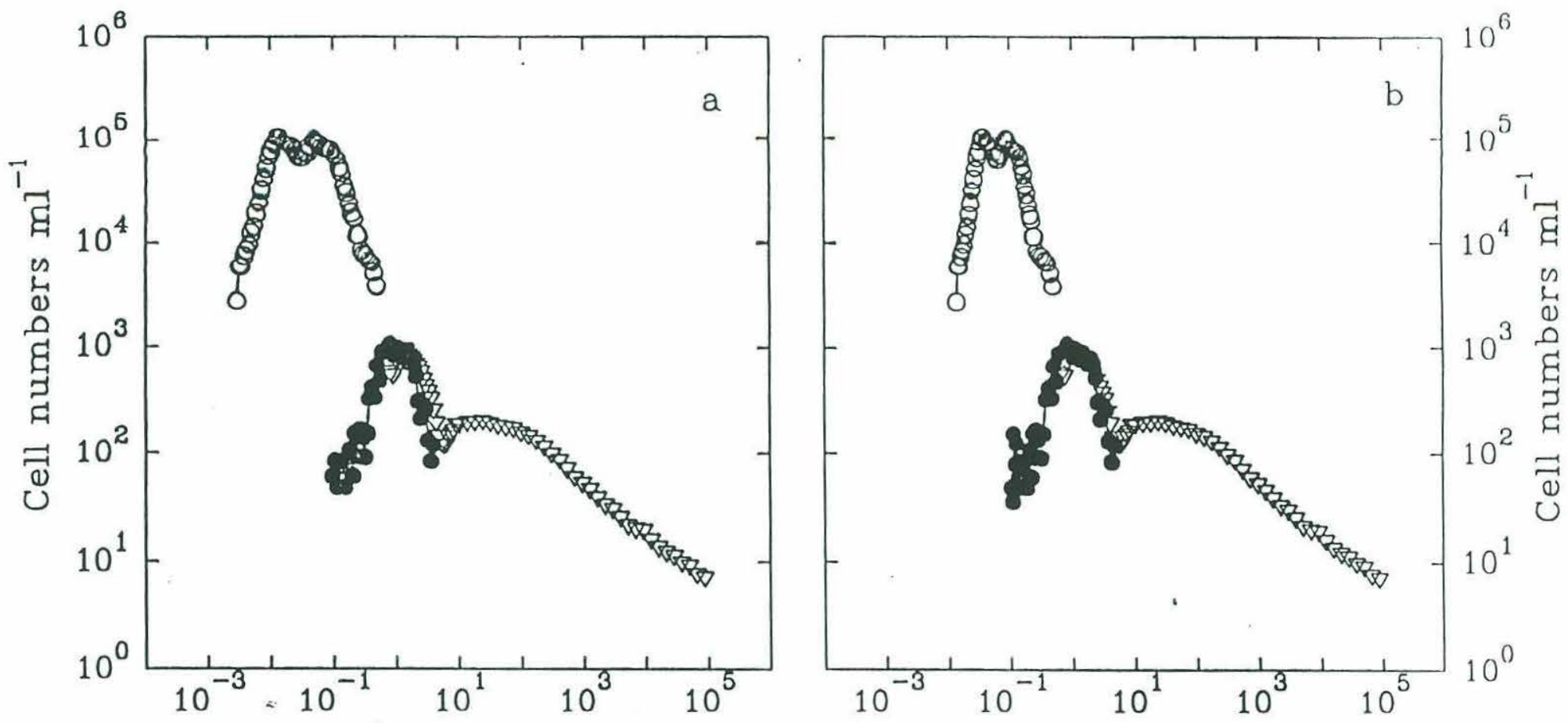

Volume $\mu \mathrm{m}^{3}$

Fig. D3. Merging the pico and nanno/microplankton ends of the spectrum using a) the empirical picoplankton calibration for the 'pico' data, the empirical and modified nanno/microplankton calibration for the 'nanno/micro' data; and b) a steeper picoplankton calibration curve (corresponding to the empirical calibration using beads), the same empirical nanno/microplankton calibration and modified equations with intermediate slopes for the transition regions. For this particular example, the size spectra was obtained from the surface of the Boston Harbour station in October, 1992. Dual-beam flow cytometry was used to distinguish bacteria (open circles) from picophytoplankton (closed circles) on the 'pico' settings, whilst the larger end of the picophytoplankton together with nanno/microphytoplankton (upside down triangles) were analyzed on the 'nanno/micro' settings. Both sets of equations show a good fit for the overlapping picophytoplankton populations obtained on the two instrument settings. Note that a steeper picoplankton calibration equation results in a compression of the picoplankton end of the spectrum and hence a steepening of the entire spectrum. 


\section{APPENDIX E}

\section{SIZE SPECTRA OF FLUORESCENCE}

In addition to concentration and biomass size spectra, flow cytometers also have the capacity to generate size spectra of fluorescence. One of the questions we addressed was whether red fluorescence measurements were comparable to extracted chlorophyll measurements. Chlorophyll is frequently used to indicate phytoplankton biomass levels and hence, fluorescence size spectra could, in theory, provide an alternative means to directly infer the partitioning of living matter according to ecosystems of different trophic states.

To compute fluorescence size spectra, the fluorescence (relative to $0.57 \mu \mathrm{m}$ beads) per size class was integrated as follows:

$S_{i}=\sum F_{i, j} \times N_{i, j}$

where $S_{i}$ is the integrated fluorescence for size class, $i ; F_{i j}$ is the fluorescence channel $j$ and $\mathrm{N}_{\mathrm{i}, \mathrm{j}}$ is the cell concentration in class $\mathrm{i}, \mathrm{j}$. As with merging data from the 'pico' and 'nano/micro' settings on forward scatter, the phytoplankton data from both settings were also merged on red fluorescence. By observing the same mixture of various sized beads captured on both 'pico' and 'nano/micro' settings, the positions of overlapping beads on red fluorescence (eg. 0.66 and $2.02 \mu \mathrm{m}$ beads) were used to merge the fluorescence spectra of both ends of the spectrum. In the overlapping region between the 'pico' and 'nano/micro' settings (ie. between $\sim 1$ to $7 \mu \mathrm{m}^{3}$ ), the fluorescence data were given a weighted average so that a smooth transition from pico to nanoplankton was obtained for the size spectra. 


\section{Differences in Fluorescence Yield due to Different Instrument Configurations}

In general, bead ratios measured on different instrument configurations did not vary much (eg. $~ 4 \%$ ), but significant differences were obtained when observing fluorescence of cells relative to standard beads (by about 3 to 4 times). To understand how this discrepancy arose, it was necessary to study the differences between the two instrument settings. In general, relative fluorescence measured varies with excitation irradiance and mean residence time of cells in the illuminated volume of the flow cytometer (Neale et. al., 1989). For the 'pico' configuration, the laser beam is focused to an intense spot size of $20 \mu \mathrm{m}$ diameter (using a spherical lens) and the sample flow is slow $\left(0.01 \mathrm{ml} \mathrm{min}^{-1}\right)$, whereas the 'nano/micro' configuration has a wider beam spot size of 16 $\mathrm{x} 750 \mu \mathrm{m}$ (using a $40 \mathrm{~mm}$ and $150 \mathrm{~mm}$ lens) and the flow is rapid $\left(5 \mathrm{ml} \mathrm{min}^{-1}\right)$. The beam for the 'pico' setup is thus more intense and the interrogation time of cells longer than that for the 'nano/micro' configuration. Under normal laser excitation, fluorescence is emitted when energy from the excited state is released in the prescence of closed reaction centres ie. unavailable for photochemistry. However, at very high light intensities, there is a probability that two or more excited states may exist in the antenna of a reaction centre at the same time. Under these conditions, an annihilation process may occur between two excited states where the energy of one or both excitations is lost as heat (Campillo and Shapiro, 1978). This could cause the decrease in fluorescence yield for cells observed on the 'pico' setting compared to the 'nano/plankton' setting (Epics V-II), as seen in Fig. E1. Similar results were also obtained in a study of Nanochlorous ( $2 \mu \mathrm{m}$ diameter) using both the more intense laser beam from the pico configuration and the less intense beam from the nano/micro configuration of the Epics V-I instrument (Michelle Durand, pers. comm.). In both cases, the difference in fluorescence yield between the two configurations for the same population is roughly 4 times. The implication of these findings is that the fluorescence contribution from picophytoplankton is probably underestimated. This discrepancy is likely to be more significant in areas where the picophytoplankton play a major role in the community, such as at the chlorophyll 


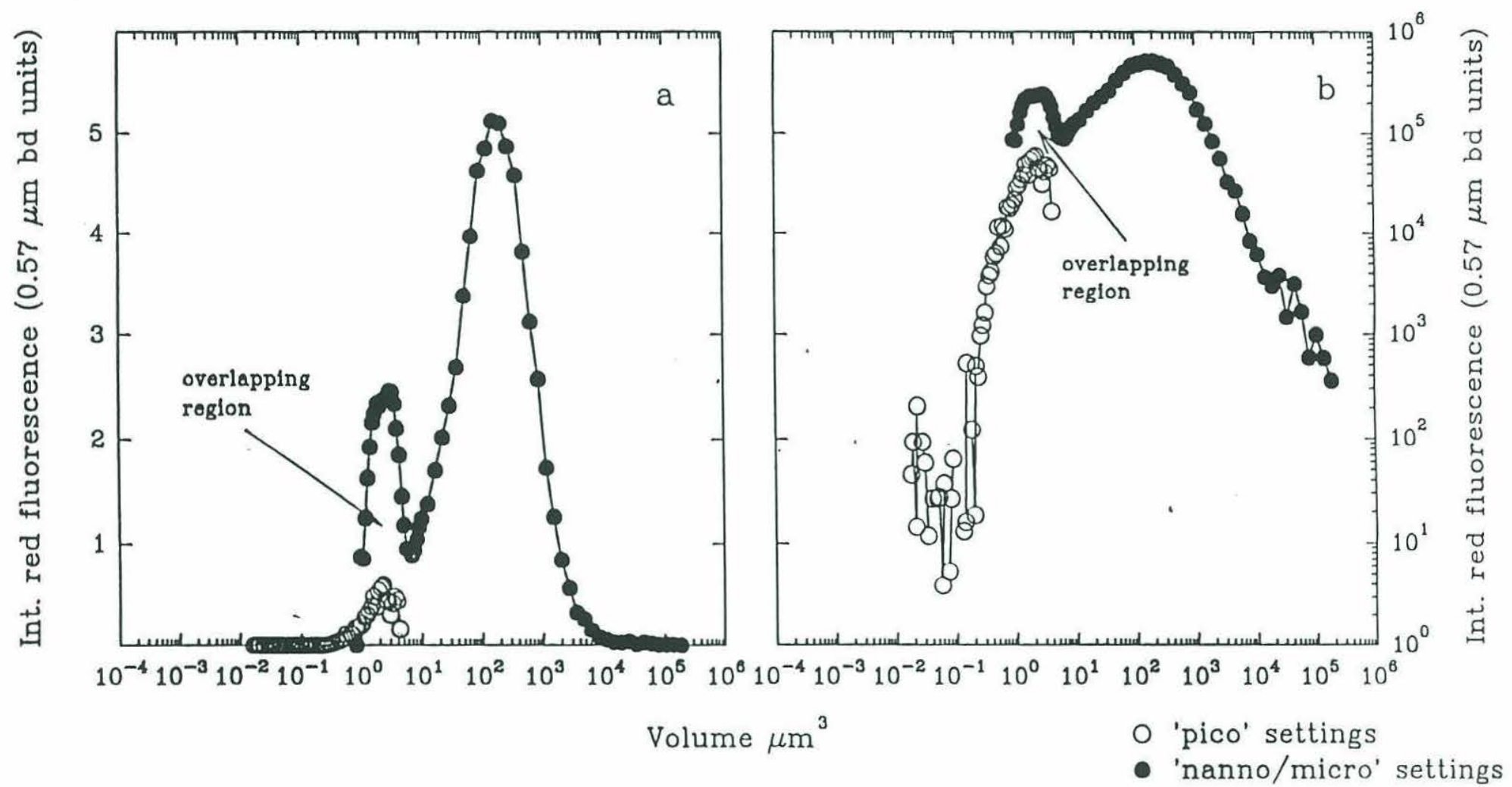

Fig. E1. Fluorescence size spectra plotted on a) linear and b) log scales to highlight the difference in fluorescence yield for the 'pico' (open circles) and 'nano/micro' (closed circles) settings for the overlapping area. This example was taken from the surface of the Massachusetts Bay station in June, 1993. 
maximum of nutrient stressed waters. For example, depth profiles of extracted chlorophyll and total integrated fluorescence (normalized to surface values) for the Sargasso Sea show that the greatest difference occurs at and just below the chlorophyll maximum in the summer and fall periods (Fig. E2). On the whole, however, the overall trends and salient features of the chlorophyll profile are still reproduced in the fluorescence profile.

\section{Trends in Fluorescence Size Spectra with Chlorophyll}

If the data is pooled from all the coastal and oceanic samples, the relationship between total integrated fluorescence and extracted chlorophyll-a measurements show a strong positive correlation with an $\mathrm{R}^{2}$ of 0.92 (Fig. E3). Size-fractionated chlorophyll studies have shown that as total chlorophyll in the system increases, the proportion of chlorophyll from the nano and microplankton generally increases at the expense of the -picoplankton (Raimbult, 1988, Hopcroft and Roff, 1990). In the case of the flow cytometric results, a general decreasing trend in the picoplankton fraction, together with a corresponding increase in the nanoplankton fraction, is also observed but only for the larger values of total fluorescence $\left(>10^{6}\right.$ rel. bd units) or chlorophyll $\left(>0.3 \mu \mathrm{g} \mathrm{l}^{-1}\right)$ in the system. However, it appears that, irrespective of the trophic state of the system, the dominant contributors to fluorescence are nanoplankton $(\sim 70 \%)$ and to a lesser extent, picoplankton ( 30\%), with generally less than $10 \%$ from the microplankton ${ }^{1}$. Since nanoplankton contribute to the bulk of the fluorescence size spectrum (ie. between 4 and $4000 \mu \mathrm{m}^{3}$ ), the good correlation between total fluorescence and chlorophyll follows because as total chlorophyll in the system increases, the nanoplankton concentration and fluorescence also increases and hence, the total fluorescence increases. In addition, the picoplankton contribution is expected to be even smaller with increasing eutrophy (chapter 4) and so the underestimation effect of the 'pico' settings is likely to be less significant.

\footnotetext{
${ }^{1}$ Note that the entire range of microplankton was not measured due to instrument limitations. The maximum cell size measured with the flow cytometer was approximately $70 \mu \mathrm{m}^{3}$ for coastal samples and $55 \mu \mathrm{m}^{3}$ for oceanic samples.
} 


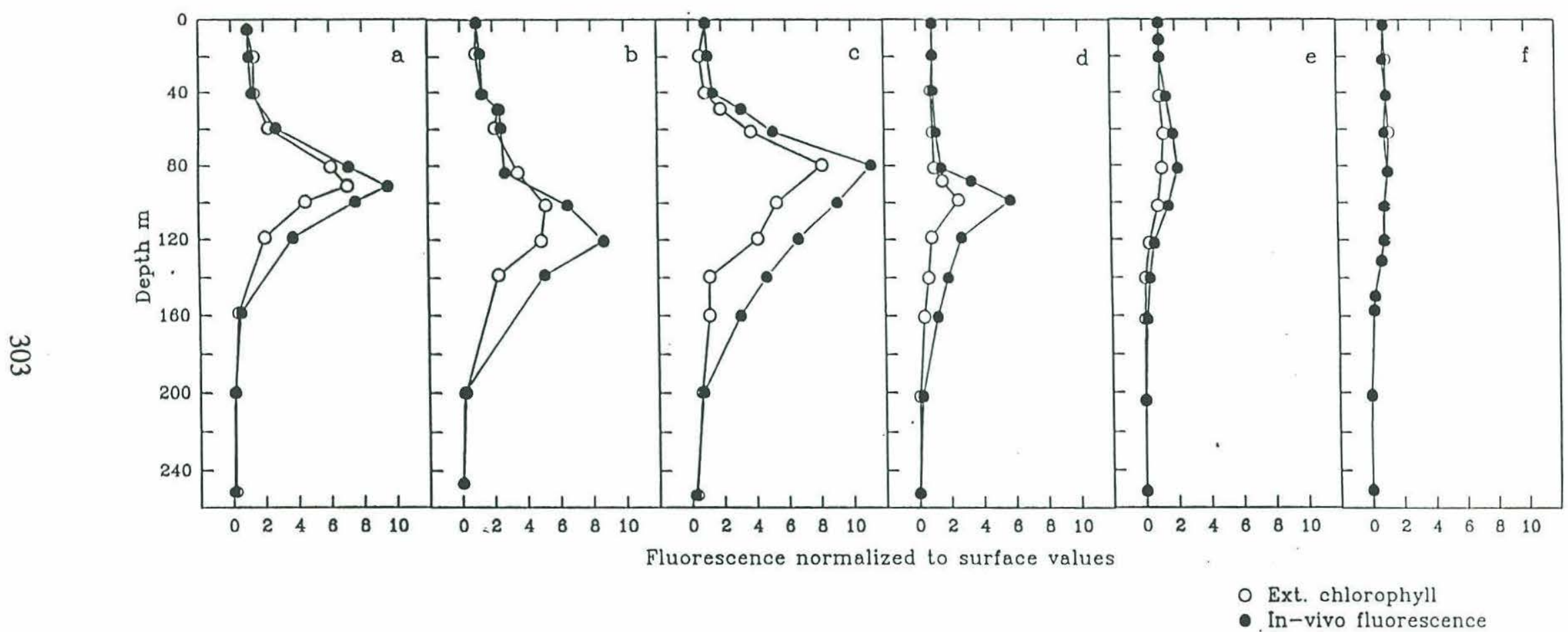

Fig. E2. Comparison of depth profiles of extracted chlorophyll-a (open circle) and flow cytometrically-derived total red fluorescence (closed circle), normalized to surface values. Samples were obtained from the Sargasso Sea in a) May 1992, b) July, c) September, d) November, e) February and f) March. 


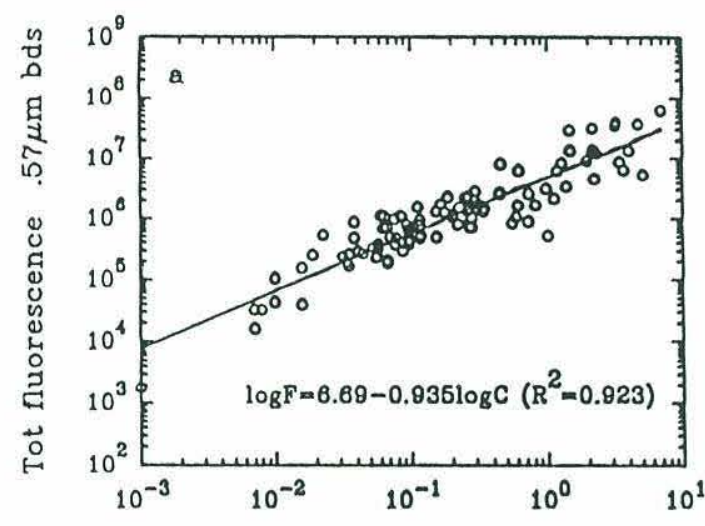

Ext. chlorophyll $\mu \mathrm{g} \mathrm{^{-1 }}$

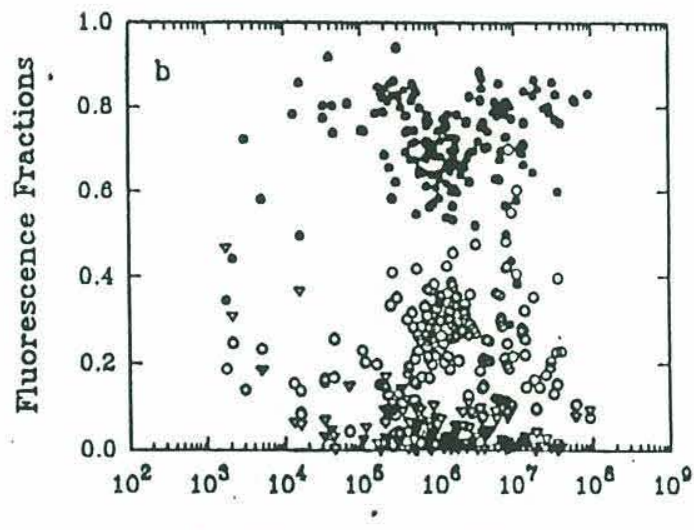

Tot fluorescence $.57 \mu \mathrm{m}$ bds

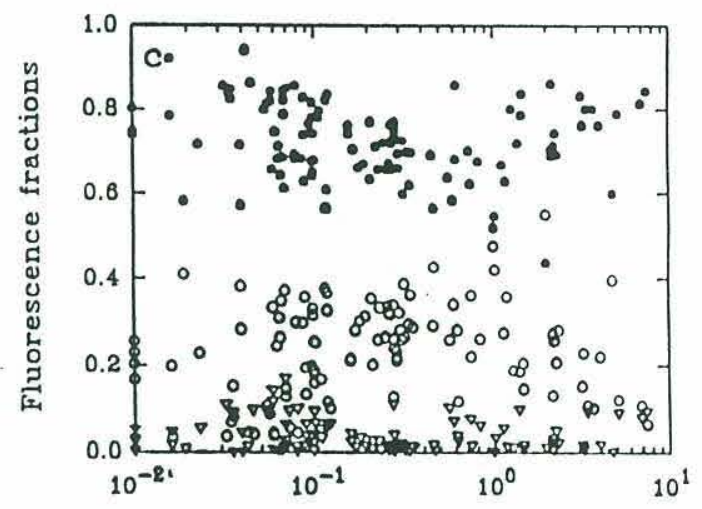

Ext. chlorophyll $\mathrm{mg} \mathrm{^{-1 }}$

Fig. E3. Relationships between flow cytometrically-derived red fluorescence and extracted chlorophyll-a measurements. A postive correlation is observed between a) total integrated fluorescence (rel. to $0.57 \mu \mathrm{m}$ beads) and chlorophyll-a measurements. The size fractions of fluorescence (pico-open circle, nano-closed circle, micro-inverted triangle) are also shown as functions of b) total fluorescence and c) extracted chlorophyll. Overall, nanoplankton contribute to the bulk of the fluorescence with less than $10 \%$ coming from the microplankton. Data for a) and c) were pooled from all samples from the Sargasso Sea, the $12^{\circ} \mathrm{S}$ and $4^{\circ} \mathrm{S}$ equatorial Pacific stations, the surface and mid-depth samples from Boston Harbour and Cape Cod Bay, and all depth samples at F22 in October 1992, August 1993. Data for b) were pooled from all samples. 
Furthermore, a factor of 4 on linear scales is minor when considered on log scales. Other studies of eutrophic coastal systems have also shown that the biovolume of the nanoplankton but not the microplankton, correlates well with extracted chlorophyll measurements (Ruiz et. al., 1992). The question that remains is why the fluorescence of the microplankton fractions (ie. $>4000 \mu \mathrm{m}^{3}$ ) are so low in comparison?

One possible reason is that larger cells have a lower efficiency in light harvesting because self-shading effects generally increase with increasing cell size (Geider et. al., 1986). The reduction in light harvesting efficiency is more clearly shown in the results of the size spectra of mean fluorescence per cell (Fig. E-4):

$\mathrm{MF}_{\mathrm{i}}=\mathrm{S}_{\mathrm{i}} / \mathrm{N}_{\mathrm{i}}$

where $\mathrm{MF}_{\mathrm{i}}$ is the mean cellular fluorescence for size class, $\mathrm{i} ; \mathrm{S}_{\mathrm{i}}$ is the integrated fluorescence for $\mathrm{i}$, and $\mathrm{N}_{\mathrm{i}}$ is the total cell concentration in $\mathrm{i}$. The fact that the fluorescence per cell for coastal samples is essentially constant with size implies that the "package effect' for larger phytoplankton (ie. microplankton) is quite significant for productive environments where light is more likely to be limiting. Smaller phytoplankton (eg. nanoplankton), on the other hand, are more inclined to be better at light harvesting and utilization (Kiфrboe, 1993) and hence, the dominance of these fractions in the fluorescence size spectra. In contrast, the mean fluorescence per cell from oceanic environments shows a continuous increase in mean fluorescence per cell with size. Instrument differences are partly responsible for the discrepancy (bead ratios differ by a linear factor of two for the same 'nano/micro' configuration on different instruments) but these differences are small when considered on log scales. For the same size range of cells (ie. between 1 and 1000 $\mu \mathrm{m}^{3}$ ) it appears that the coastal nanoplankton have more fluorescence per cell than their oceanic counterparts. One possible reason is that coastal nanoplankton are better adapted to the more turbid waters of productive coastal areas by producing more chlorophyll per cell (Geider et. al., 1986) whereas phytoplankton from oceanic regions show less 


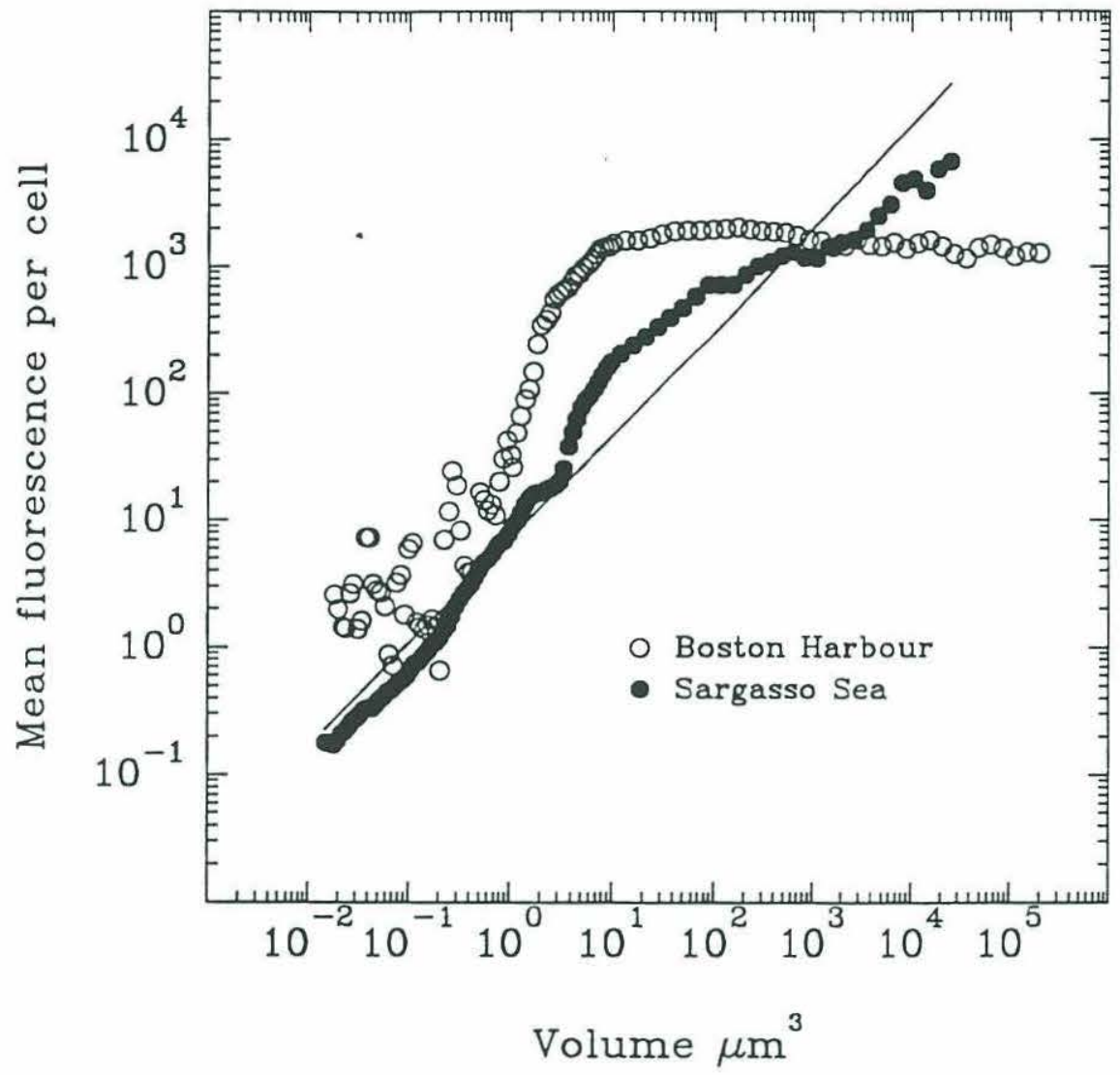

Fig. E4. Size spectra of mean cell fluorescence for the surface waters of the coastal Boston Harbour station (open circles) and the oceanic Sargasso Sea station (closed circles). Mean cell fluorescence was calculated by dividing the integrated fluorescence in each size class by the cell concentration for the same class. 
chlorophyll per cell because the waters are much clearer. Since light is not limiting in oceanic regions, the mean fluorescence per cell correlates well with cell size. For these oceanic spectra, the linear regressions to the data result in slope values, c, ranging from 0.7 to 1.0 ie.

$\log \mathrm{MF}=\log \mathrm{A}+\mathrm{c} \log \mathrm{V}$

where $\mathrm{MF}$ is the mean cell fluorescence, $\mathrm{V}$ is the cell volume and $\mathrm{A}, \mathrm{c}$ are the regression constants. This implies that the mean cell fluorescence scales with cell area (ie. $\mathrm{V}^{0.7}$ or $\left.\sim r^{2}\right)$ at one extreme, and scales with cell volume at the other. In general, mean fluorescence scales with cell volume near the surface and gradually changes so that it scales with cell area near the chlorophyll maximum. This could be an adaptation to optimize light harvesting:- in the upper layers of the water column, scattering of light in three dimensions would be more effectively captured if chlorophyll scales with volume; deeper in the water column near the thermocline, light irradiation is principally from above so that cell surface area would be more effective than volume in capturing light.

In summary, the results show that there are some limitations to using fluorescence size spectra generated from flow cytometry as proxies for chlorophyll measurements.

Firstly, the difference in fluorescence yield between the picoplankton and nano/microplankton differs by a factor of about 4 and could be significant for regions with high concentrations of picoplankton. In addition, while the correlation between chlorophyll and carbon is consistent in coastal waters, the relationship appears to be more variable in oceanic environments, where picoplankton again predominate ( $\mathrm{Li}$ et. al., 1994). Hence, more care is required to interpret fluorescence size spectra as indicators of biomass from oceanic regions compared to coastal regions. 
APPENDIX F

ADDITIONAL FIGURES OF MICROBIAL SIZE SPECTRA FROM BOSTON HARBOUR, MASSACHUSETTS AND CAPE COD BAYS 


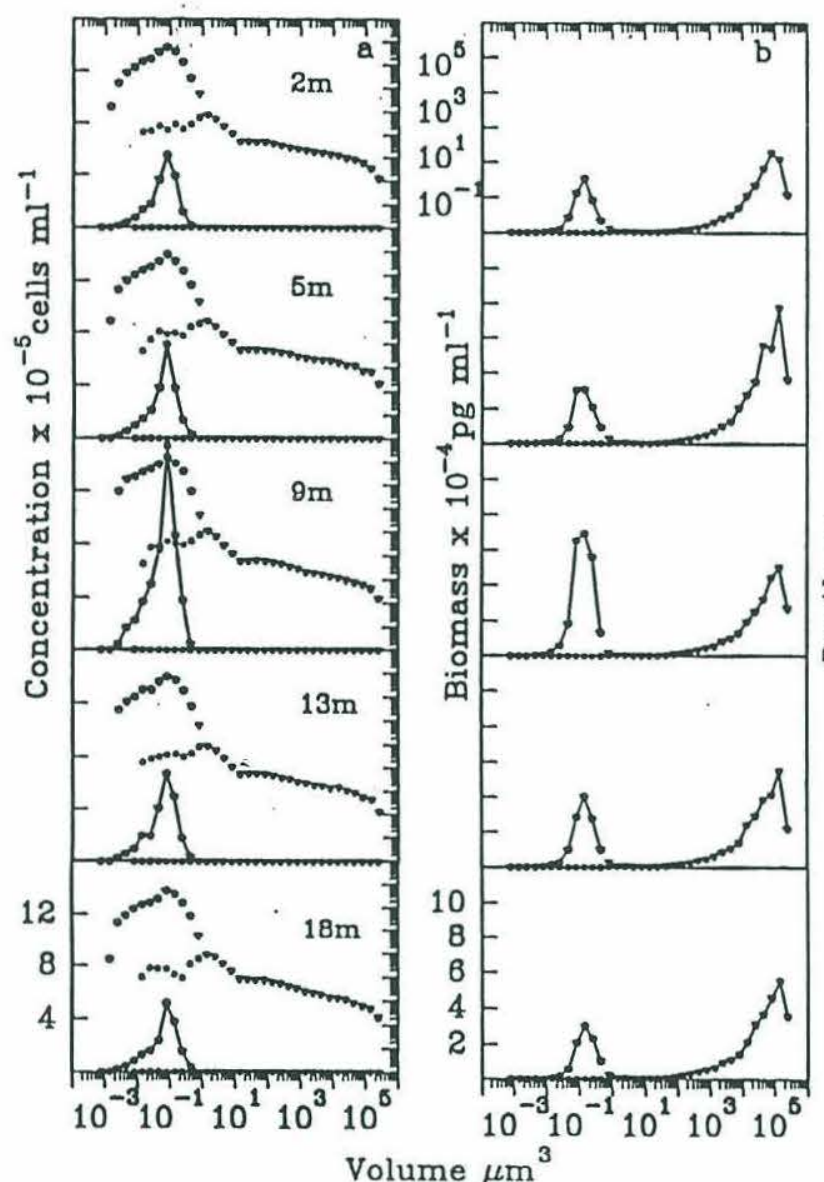

Beam atten. $\mathrm{m}^{-1}$ Nitrate $\mu \mathrm{M} \bullet$
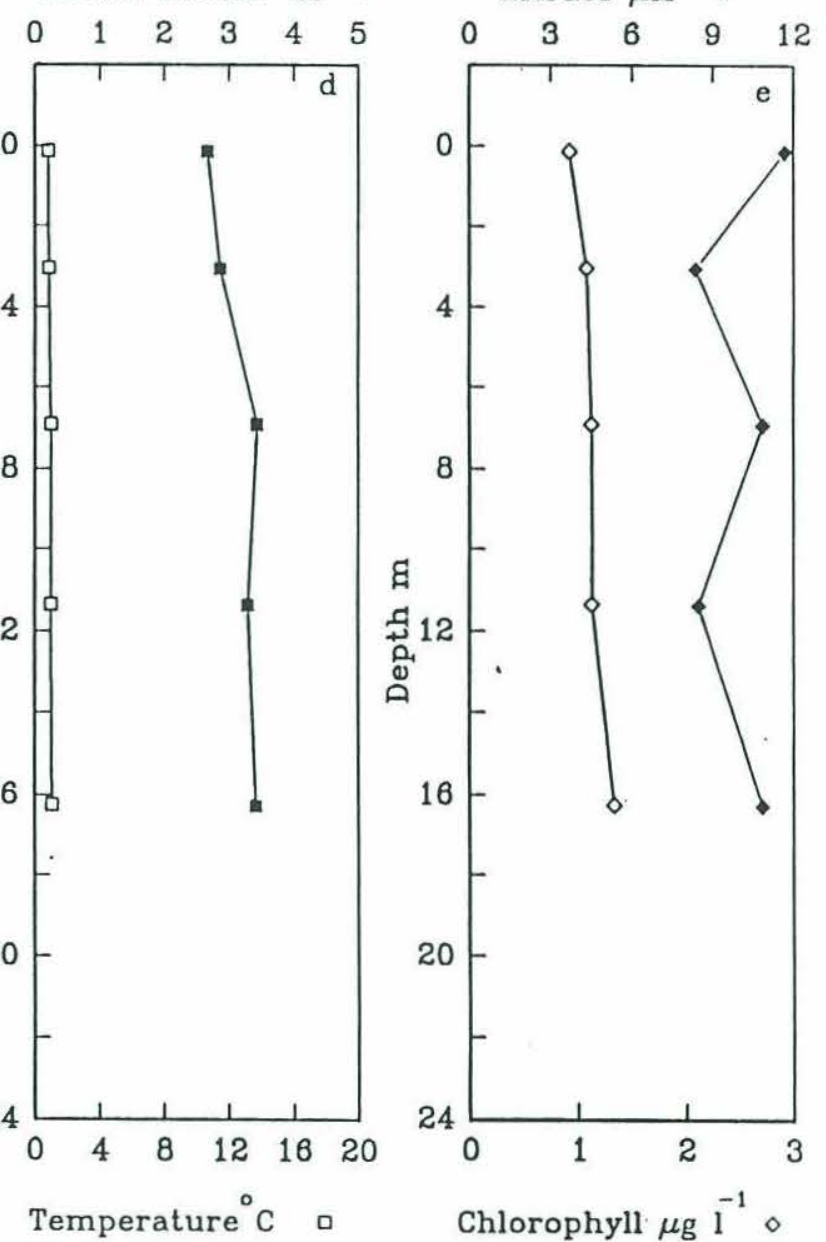

Fig. F1. Depth profiles of flow cytometrically generated size spectra for the station in Boston Harbour $\left(42^{\circ} 20.4^{\prime} \mathrm{N}, 70^{\circ} 56.5^{\prime} \mathrm{W}\right)$ on February 23, 1993 at 0715 hrs. Histogram size spectra of concentration and biomass for bacteria (open circles), phytoplankton (closed circles) and combined bacteria plus phytoplankton (open triangles) are shown in panels a and b respectively. Corresponding depth profiles of temperature (open squares), beam attenuation (closed squares), extracted chlorophyll (open diamonds) and nitrate concentration (closed diamonds) are also shown in panels c and d. Environmental measurements were taken from Kelly et. al., 1994a. 

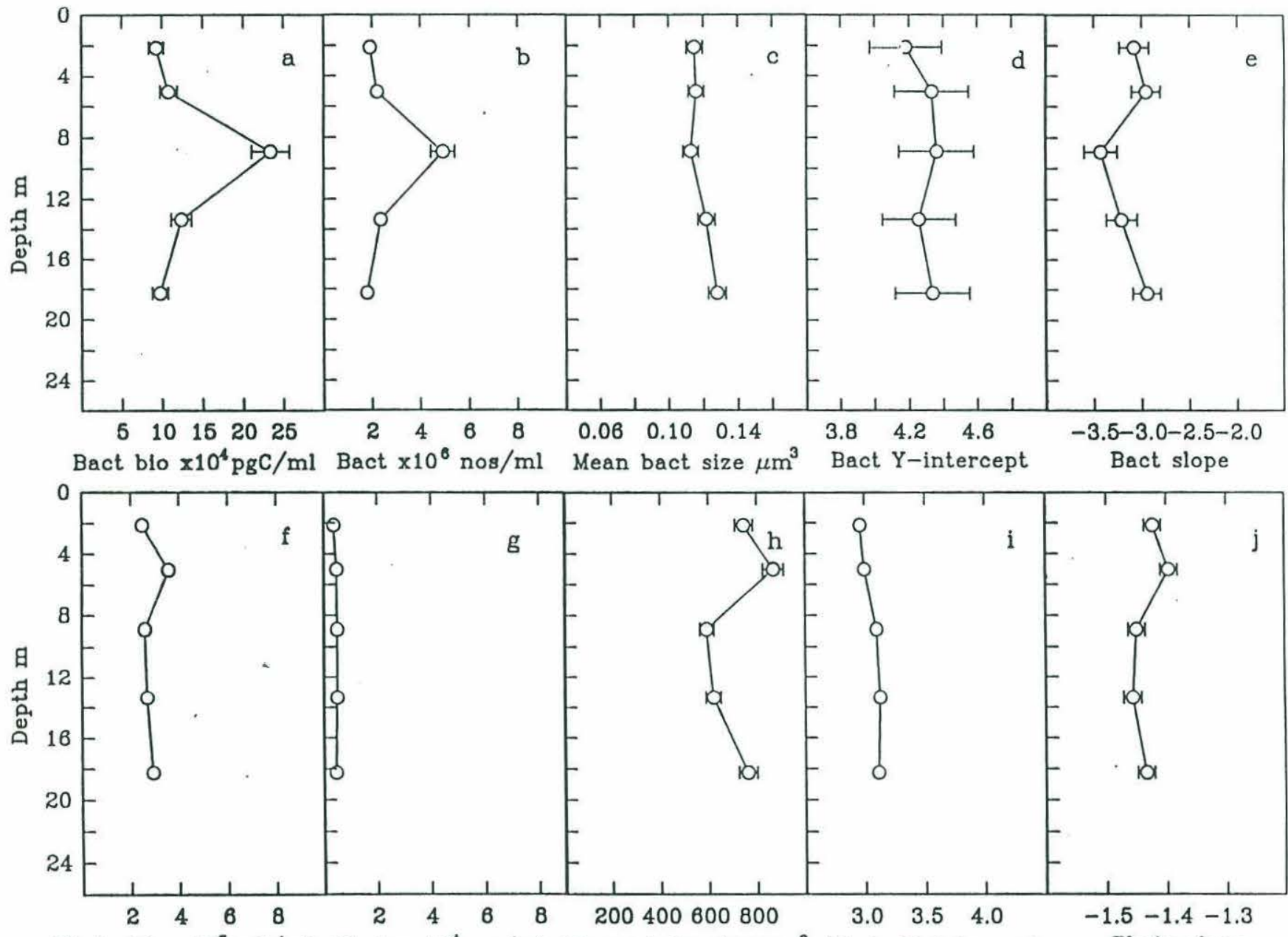

Phyto blo $\times 10^{5} \mathrm{pgC} / \mathrm{ml}$ Phyto $\times 10^{4} \mathrm{nos} / \mathrm{ml}$ Mean phyto size $\mu \mathrm{m}^{3}$ Phyto Y-intercept Phyto slope

Fig. F2. Depth profiles of size spectral characteristics for Boston Harbour $\left(42^{\circ} 20.4^{\prime} \mathrm{N}, 70^{\circ} 56.5^{\prime} \mathrm{W}\right)$ on February $23,1993 \mathrm{at} 0715 \mathrm{hrs}$, corresponding to the size spectra and environmental conditions shown in Fig. F1: a) Mean bacteria size, b) bacteria intercept, c) bacteria slope, d) bacteria cell concentration, e) bacteria biomass, f) mean phytoplankton size, g) phytoplankton intercept, h) phytoplankton slope, i) phytoplankton cell concentration and j) phytoplankton biomass. (Error bars correspond to one standard deviation:- those without error bars have small standard deviations which fall within the symbols.) 


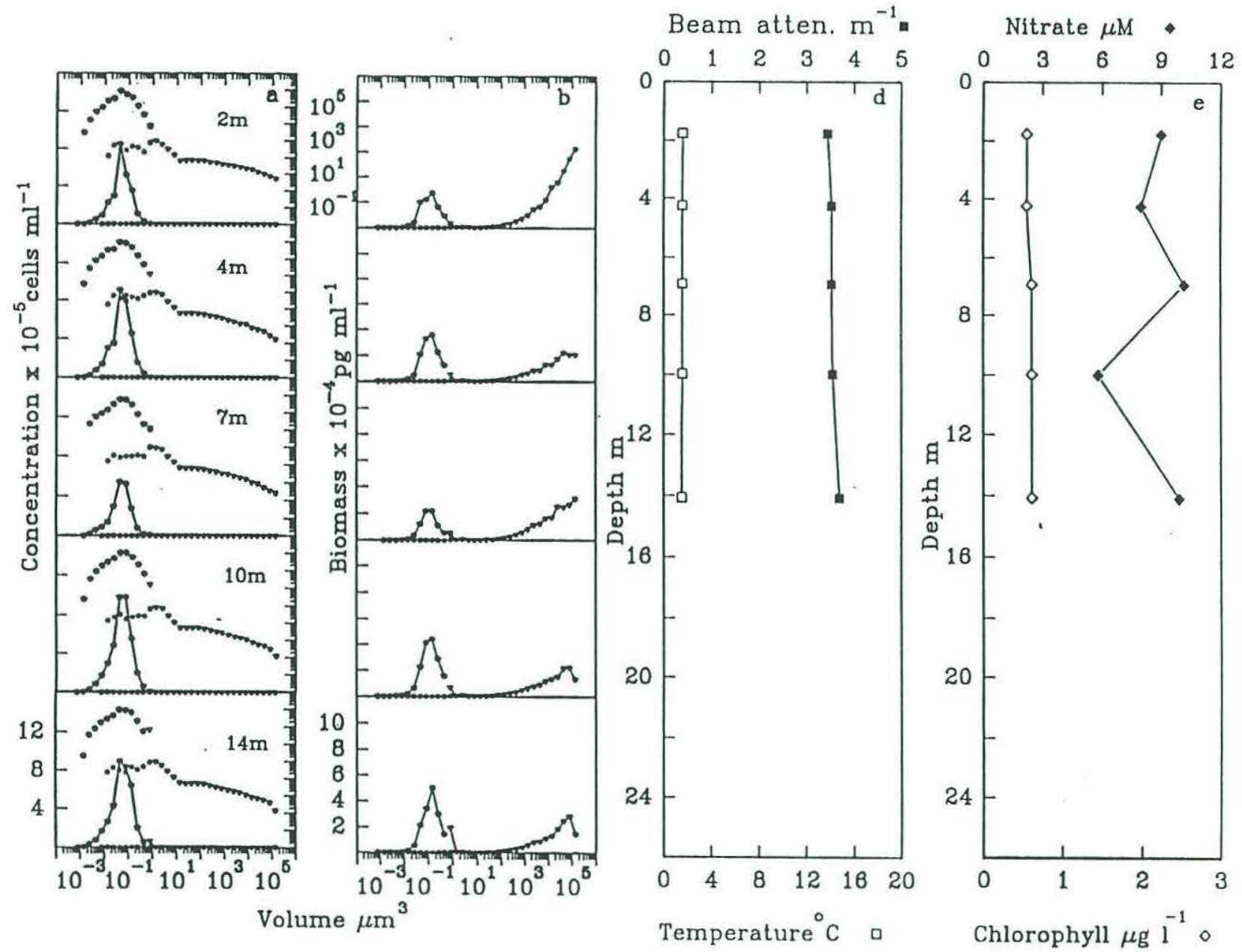

Fig. F3. Depth profiles of flow cytometrically generated size spectra and environmental measurements for the station in Boston Harbour ( $\left.42^{\circ} 20.4^{\prime} \mathrm{N}, 70^{\circ} 56.5^{\prime} \mathrm{W}\right)$ on March 9, 1993 at 0655 hrs. Environmental measurements were taken from Kelly et. al., 1994a. 

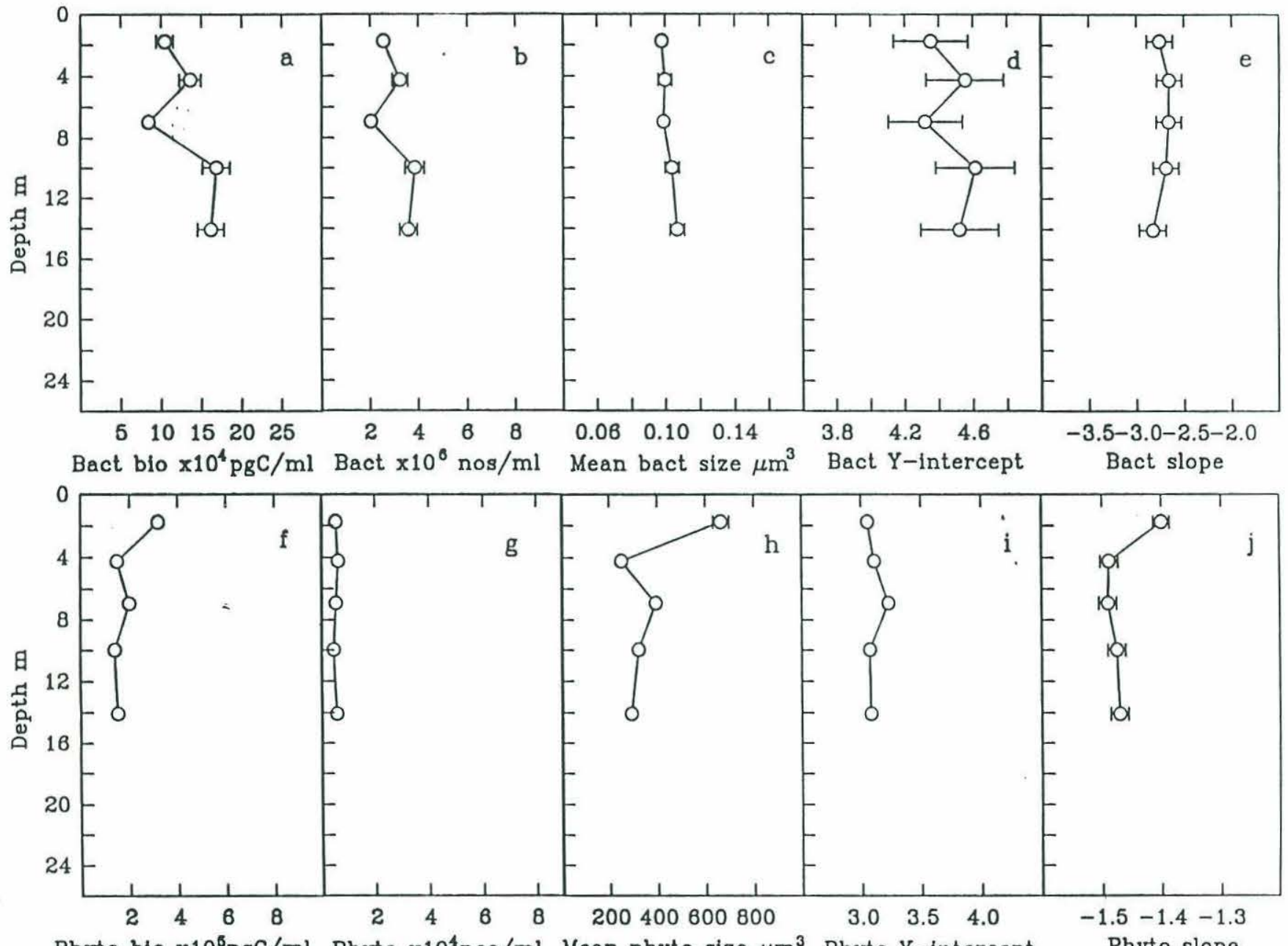

Phyto blo $\times 10^{6} \mathrm{pgC} / \mathrm{ml}$ Phyto $\times 10^{4} \mathrm{nos} / \mathrm{ml}$ Mean phyto size $\mu \mathrm{m}^{3}$ Phyto Y-intercept

Fig. F4. Depth profiles of size spectral characteristics for Boston Harbour $\left(42^{\circ} 20.4^{\prime} \mathrm{N}, 70^{\circ} 56.5^{\prime} \mathrm{W}\right)$ on March 9,1993 at $0655 \mathrm{hrs}$, corresponding to the size spectra and environmental conditions shown in Fig. F3. 

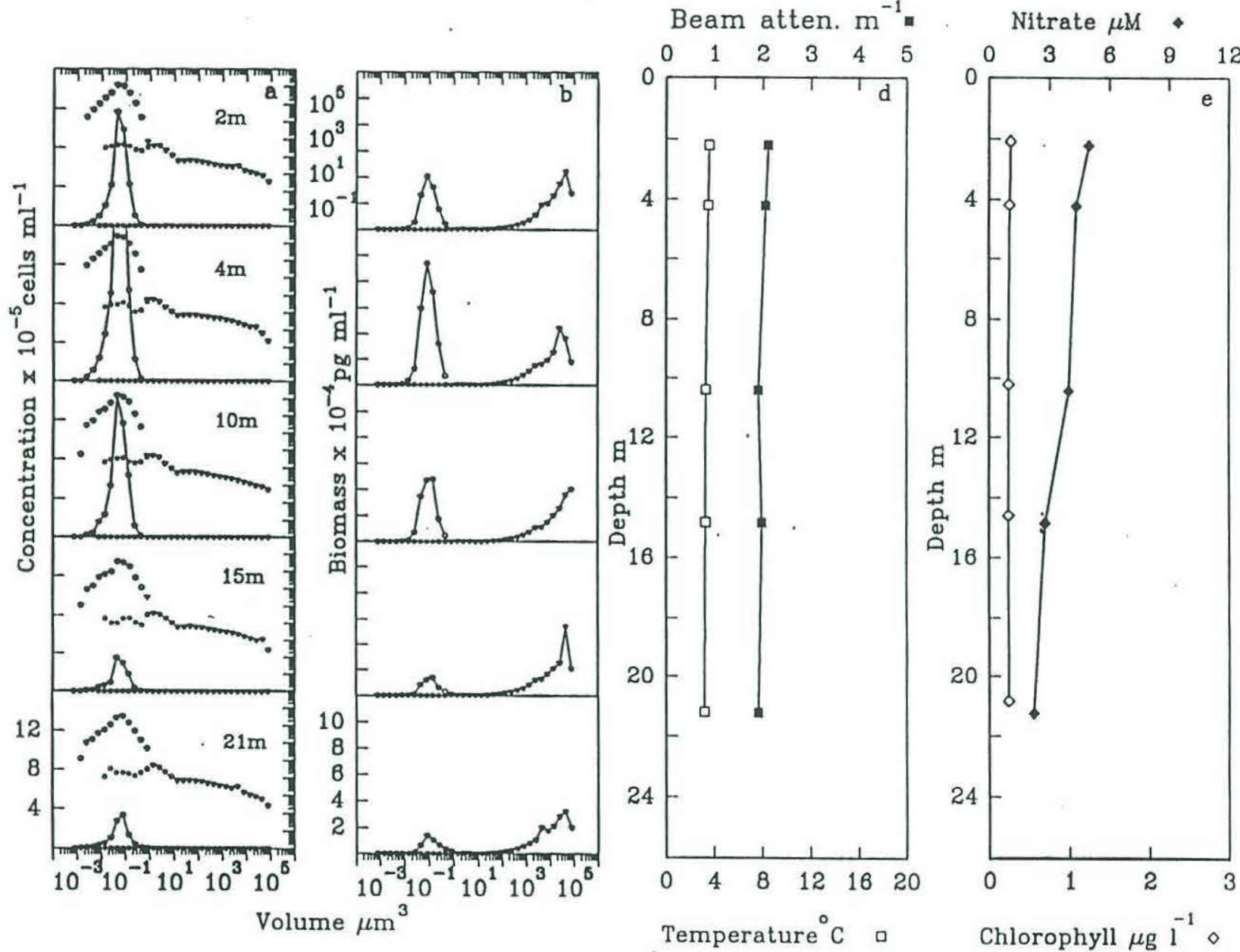

Fig. F5. Depth profiles of flow cytometrically generated size spectra and environmental measurements for the station in Boston Harbour ( $\left.42^{\circ} 20.4^{\prime} \mathrm{N}, 70^{\circ} 56.5^{\prime} \mathrm{W}\right)$ on April 6, 1993 at 0655 hrs. Environmental measurements were taken from Kelly et. al., 1994b. 

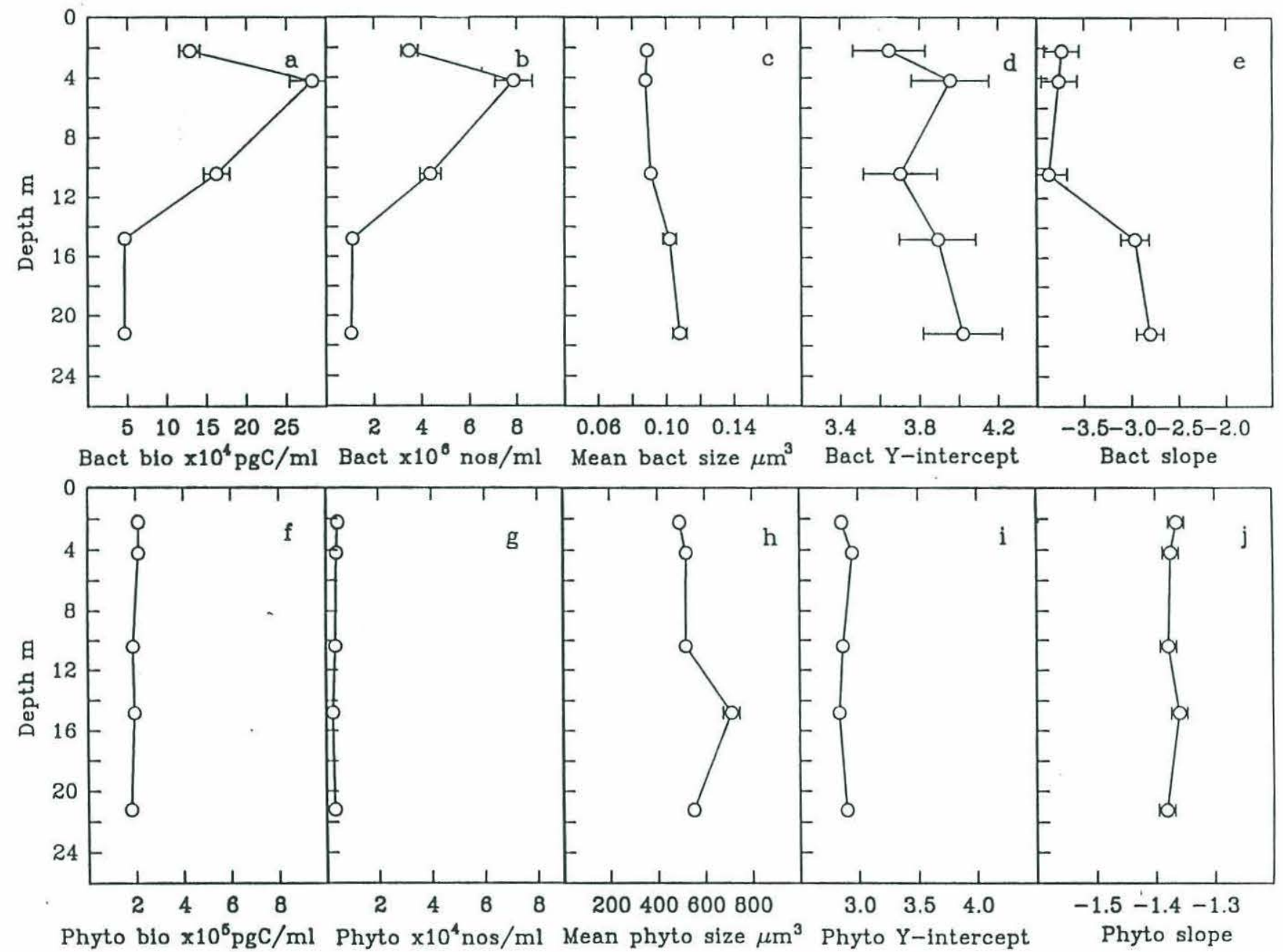

Fig. F6. Depth profiles of size spectral characteristics for Boston Harbour $\left(42^{\circ} 20.4^{\prime} \mathrm{N}, 70^{\circ} 56.5^{\prime} \mathrm{W}\right)$ on April 6, 1993 at $0655 \mathrm{hrs}$, corresponding to the size spectra and environmental conditions shown in Fig. F5. 

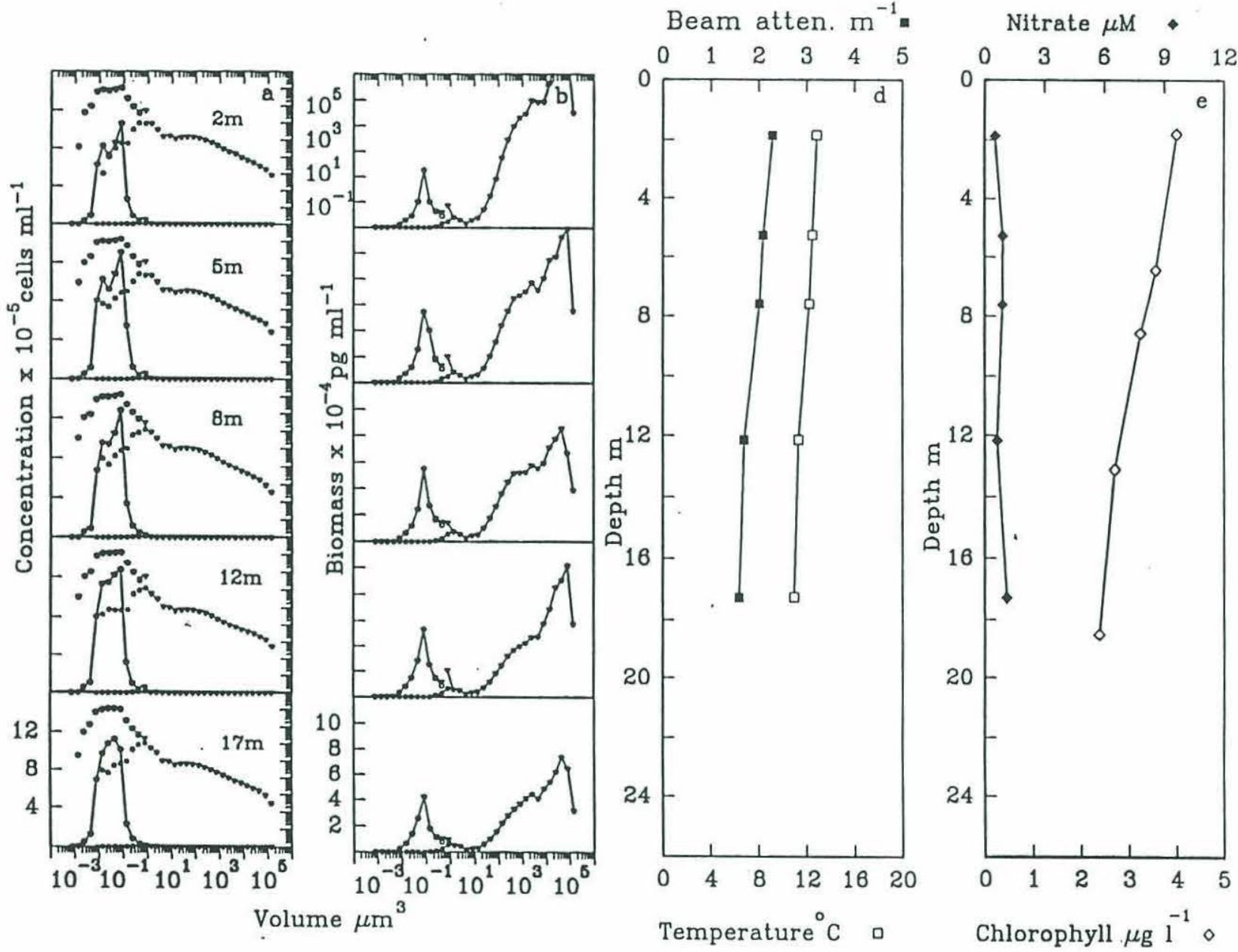

Fig. F7. Depth profiles of flow cytometrically generated size spectra and environmental measurements for the station in Boston Harbour $\left(42^{\circ} 20.4^{\prime} \mathrm{N}, 70^{\circ} 56.5^{\prime} \mathrm{W}\right)$ on June 25,1993 at $0700 \mathrm{hrs}$. Environmental measurements were taken from Kelly et. al., 1994c. 

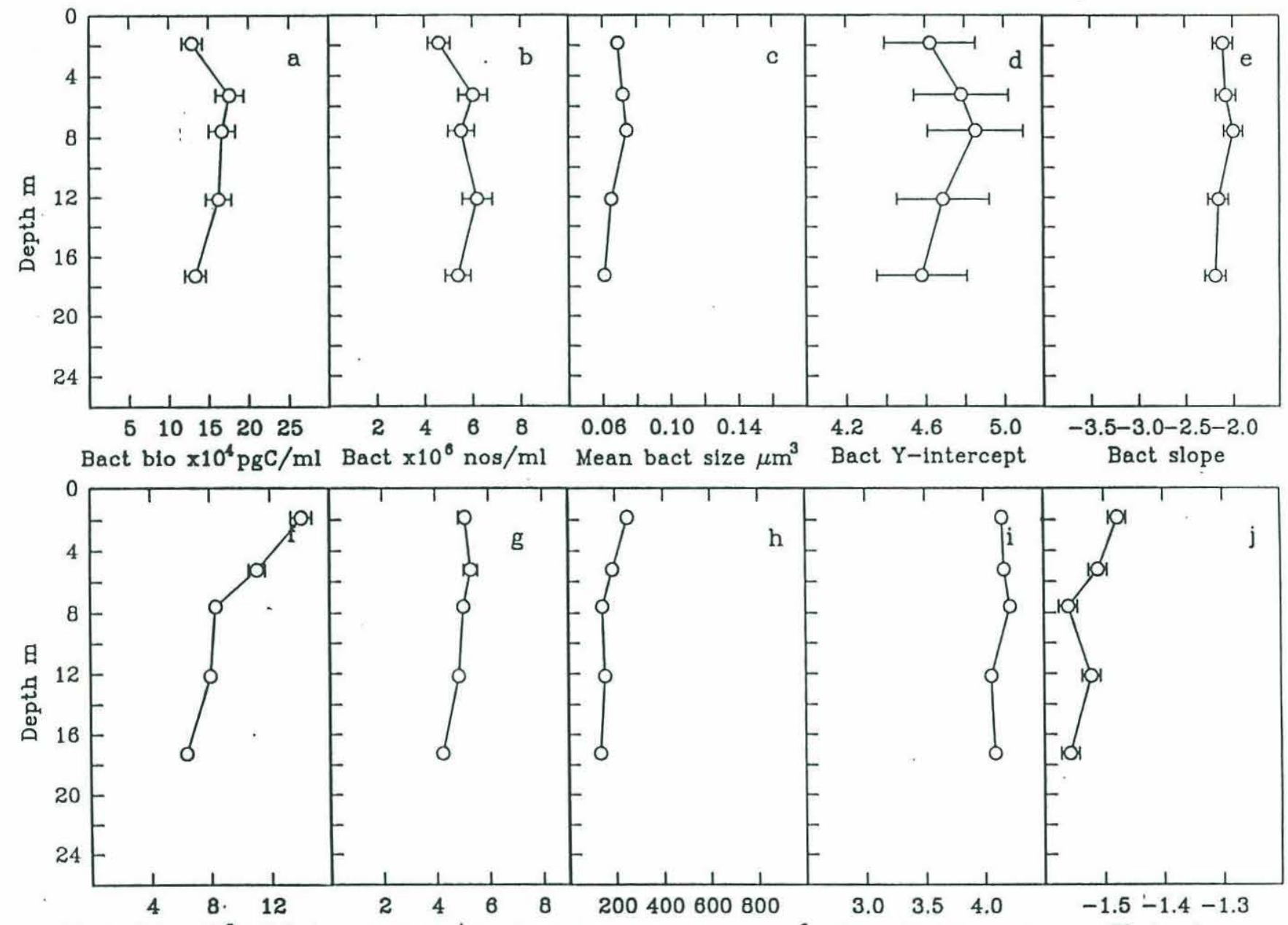

Phyto bio $\times 10^{5} \mathrm{pgC} / \mathrm{ml}$ Phyto $\times 10^{4} \mathrm{nos} / \mathrm{ml}$ Mean phyto size $\mu \mathrm{m}^{3}$ Phyto Y-intercept

Phyto slope

Fig. F8. Depth profiles of size spectral characteristics for Boston Harbour $\left(42^{\circ} 20.4^{\prime} \mathrm{N}, 70^{\circ} 56.5^{\prime} \mathrm{W}\right)$ on June 25,1993 at $0700 \mathrm{hrs}$, corresponding to the size spectra and environmental conditions shown in Fig. F7. 


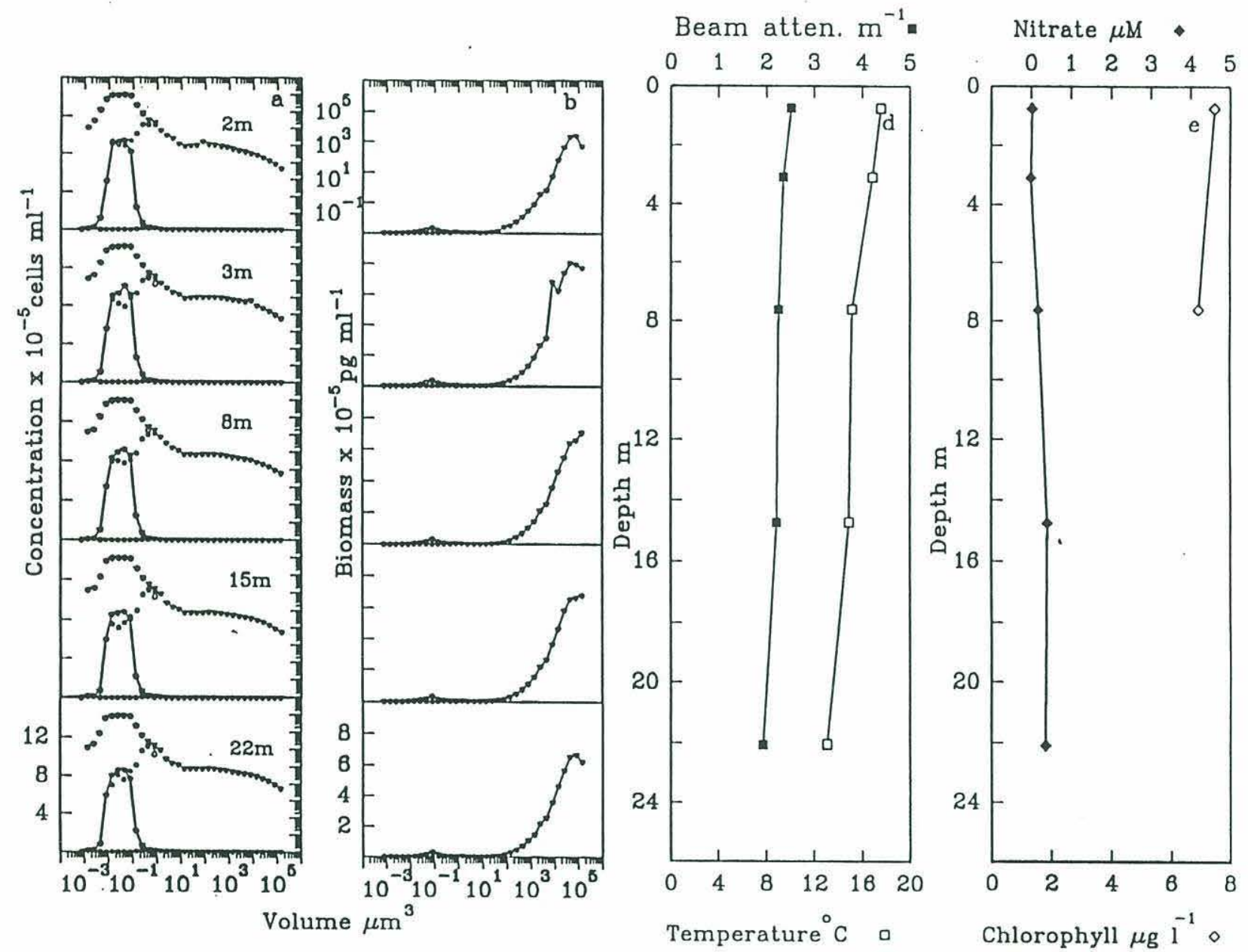

Fig. F9. Depth profiles of flow cytometrically generated size spectra and environmental measurements for the station in Boston Harbour ( $\left.42^{\circ} 20.4^{\prime} \mathrm{N}, 70^{\circ} 56.5^{\prime} \mathrm{W}\right)$ on August 27, 1993 at $0650 \mathrm{hrs}$. Environmental measurements were taken from Kelly et. al., 1994d. 

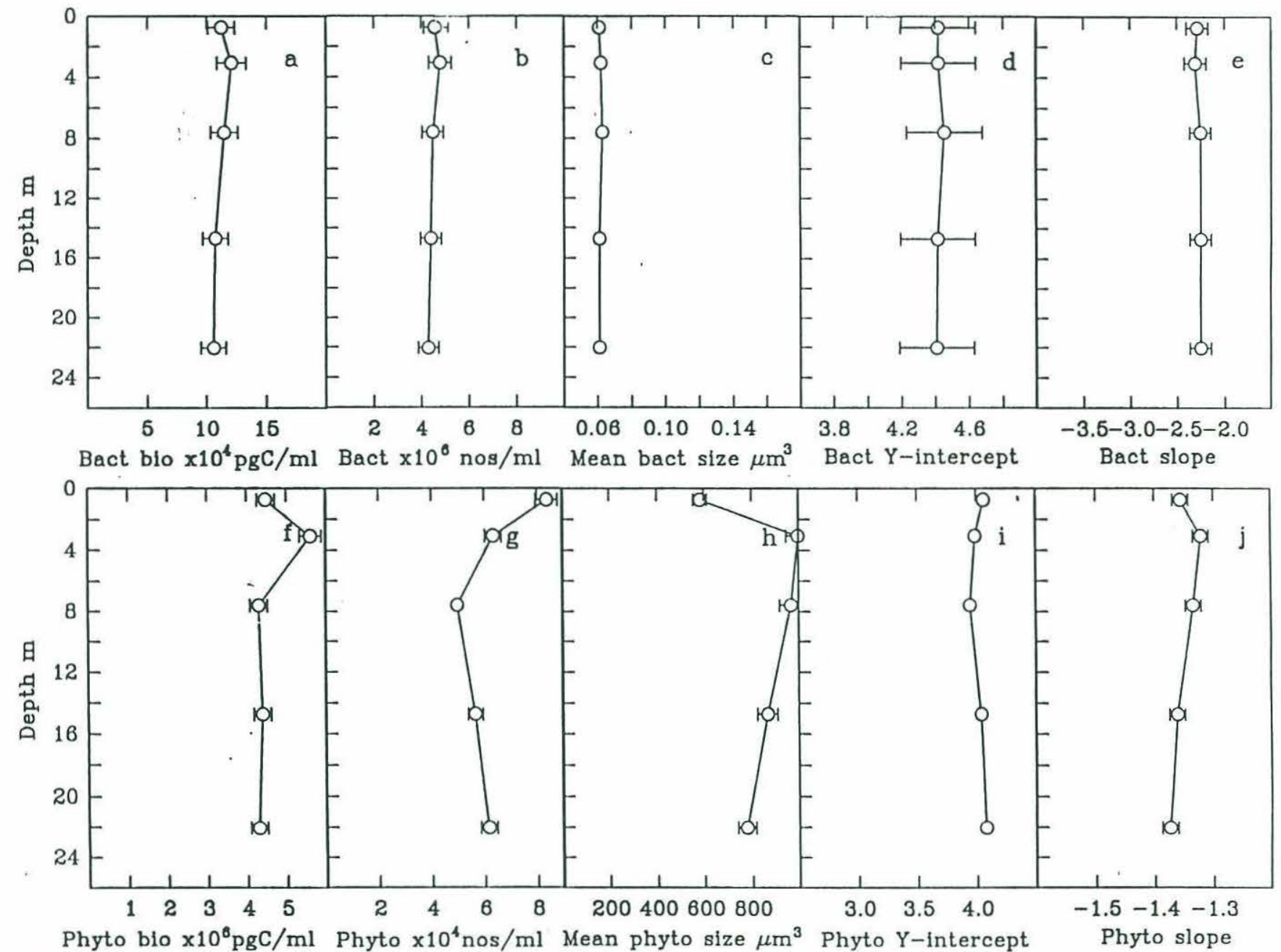

Fig. F10. Depth profiles of size spectral characteristics for Boston Harbour $\left(42^{\circ} 20.4^{\prime} \mathrm{N}, 70^{\circ} 56.5^{\prime} \mathrm{W}\right)$ on August 27,1993 at $0650 \mathrm{hrs}$, corresponding to the size spectra and environmental conditions shown in Fig. F9. 

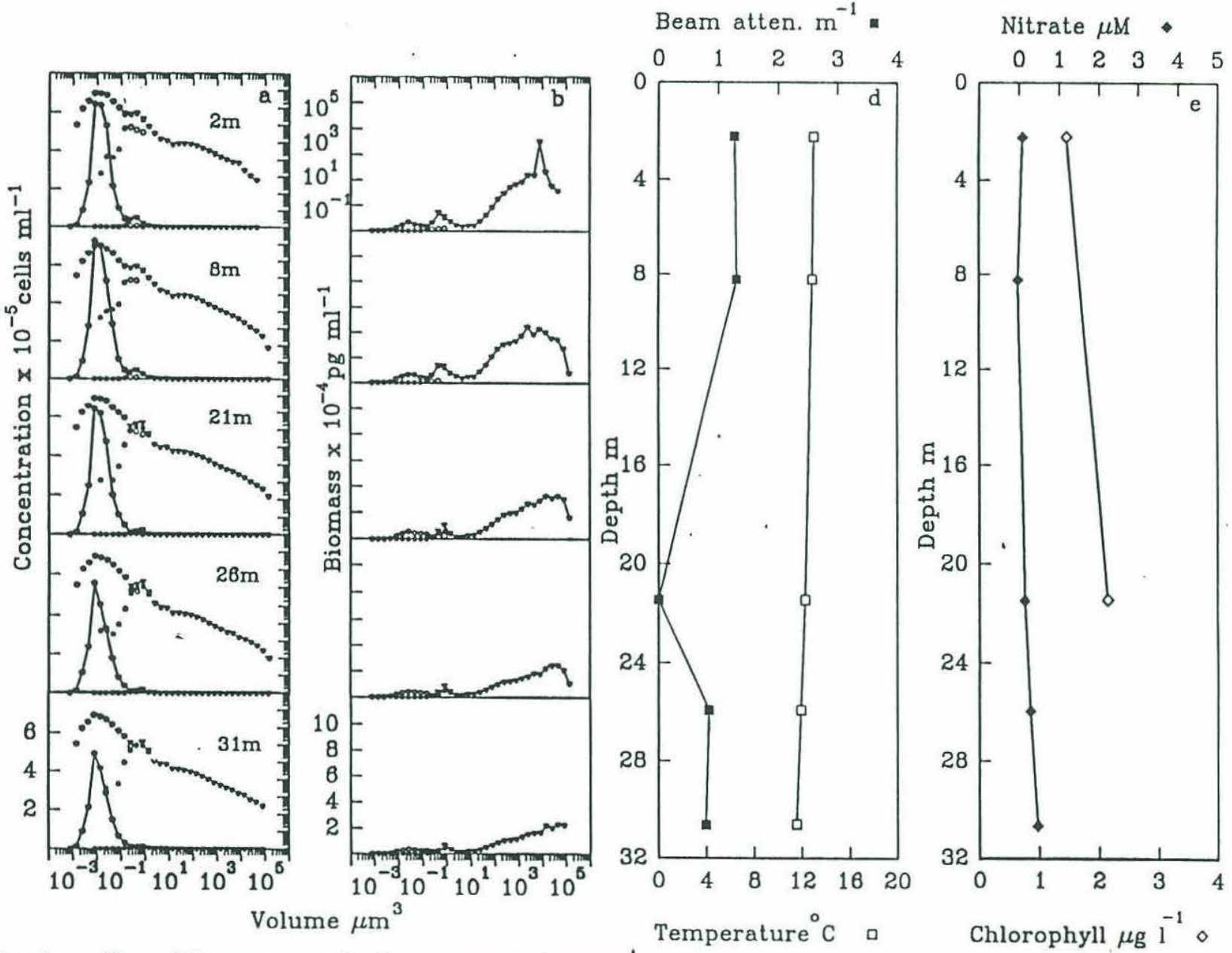

Fig. F11. Depth profiles of flow cytometrically generated size spectra and environmental measurements for the station in Cape Cod Bay $\left(41^{\circ} 54.5^{\prime} \mathrm{N}, 70^{\circ} 13.7^{\prime} \mathrm{W}\right)$ on October 13,1992 . Environmental measurements were taken from Kelly et. al., 1993. 

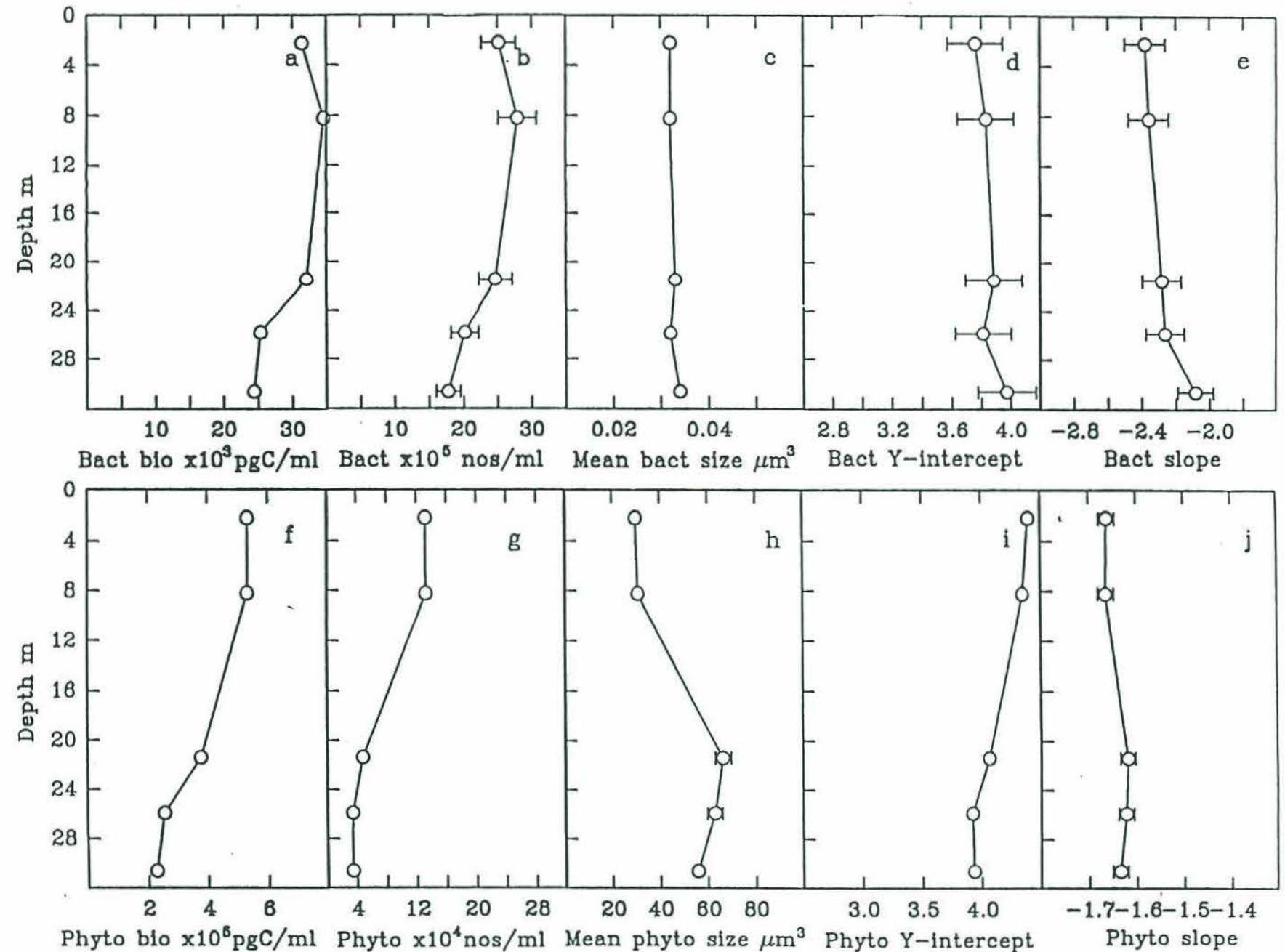

Fig. F12. Depth profiles of size spectral characteristics for Cape Cod Bay $\left(41^{\circ} 54.5^{\prime} \mathrm{N}, 70^{\circ} 13.7^{\prime} \mathrm{W}\right)$ on October 13,1992 , corresponding to the size spectra and environmental conditions shown in Fig. F11. 

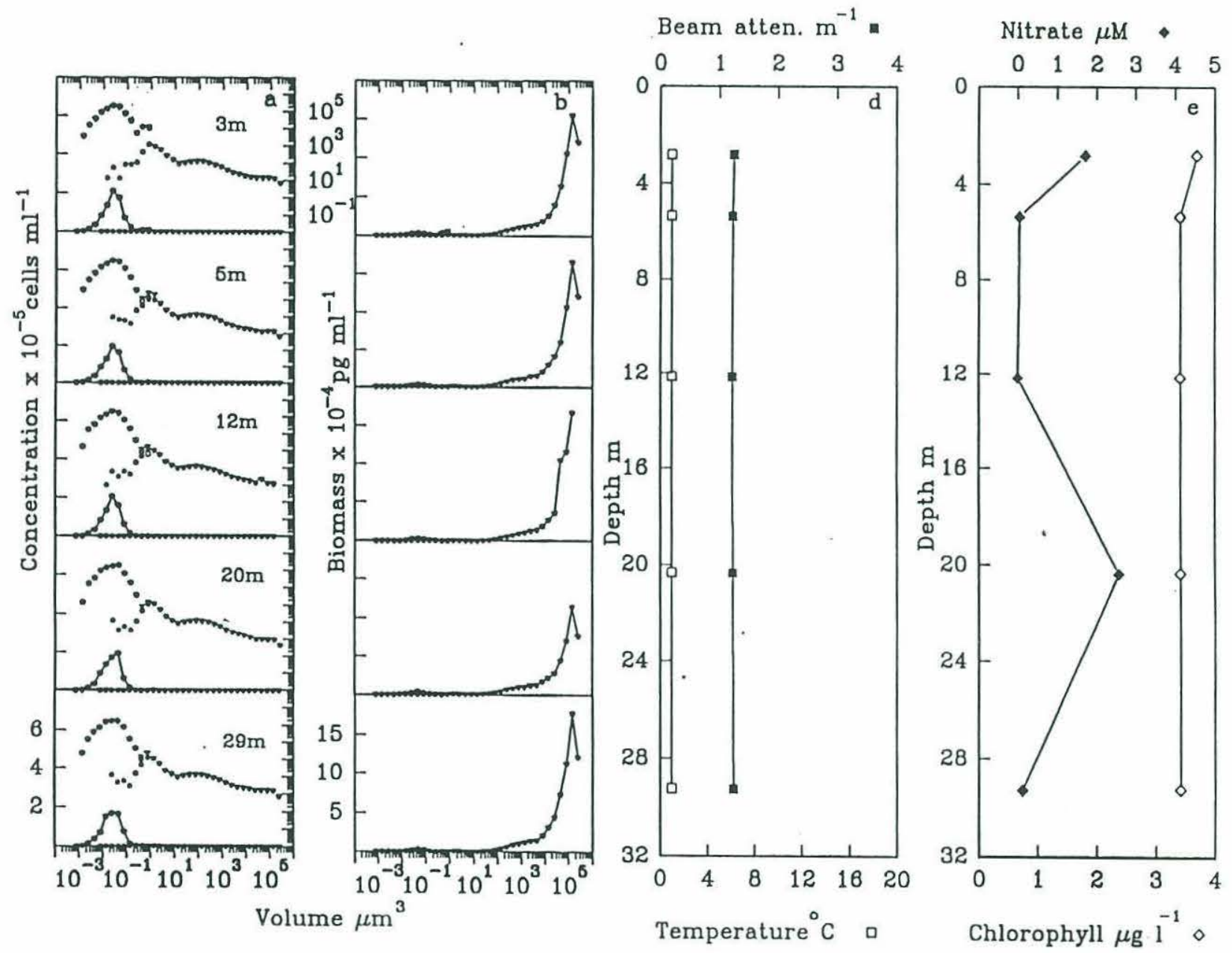

Fig. F13. Depth profiles of flow cytometrically generated size spectra and environmental measurements for the station in Cape Cod Bay $\left(41^{\circ} 54.5^{\prime} \mathrm{N}, 70^{\circ} 13.7^{\prime} \mathrm{W}\right)$ on February 25, 1993 at $1120 \mathrm{hrs.} \mathrm{Environmental} \mathrm{measurements} \mathrm{were} \mathrm{taken} \mathrm{from} \mathrm{Kelly} \mathrm{et.} \mathrm{al.,} \mathrm{1994a.}$ 

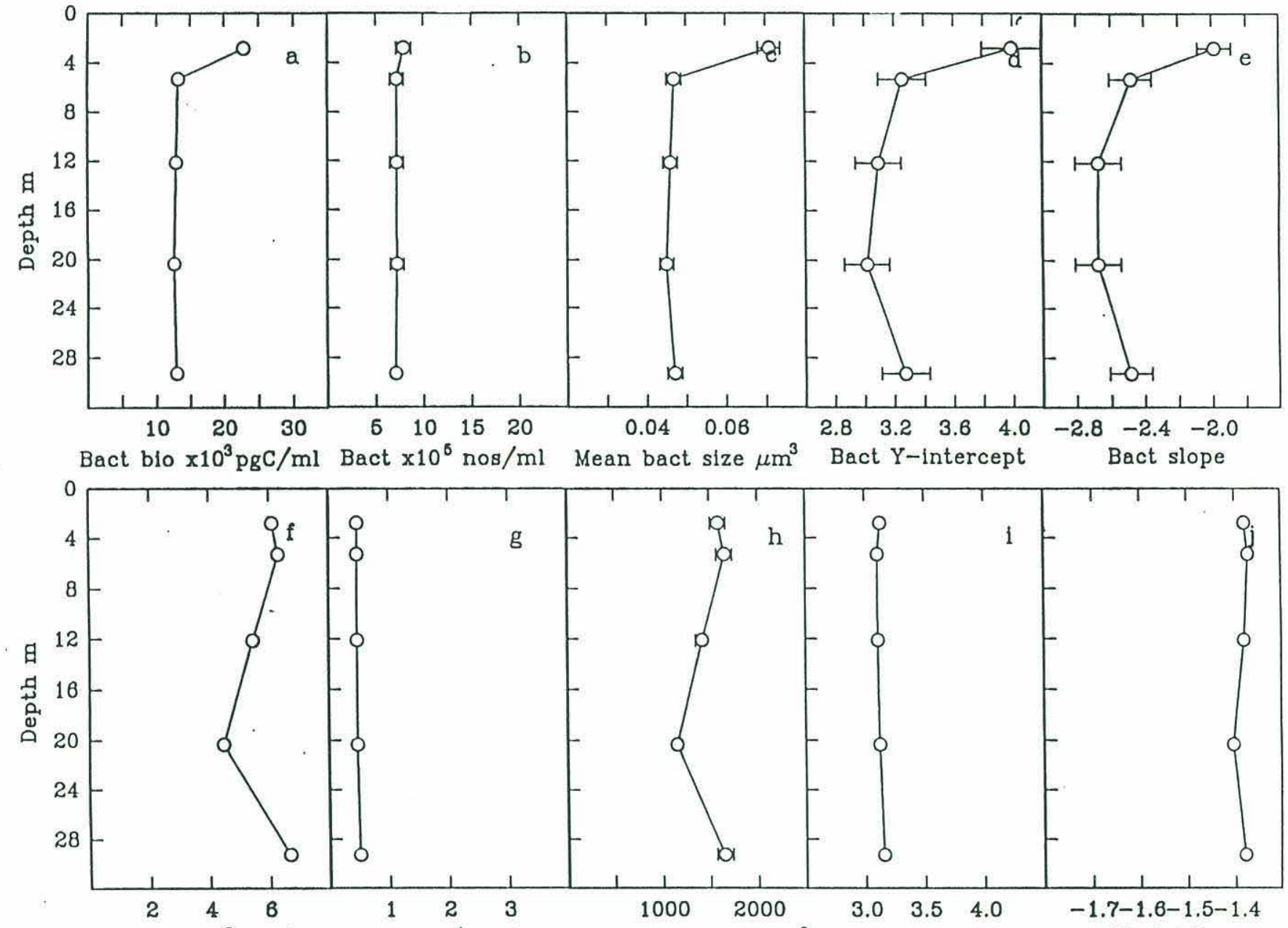

Phyto blo $\times 10^{6} \mathrm{pgC} / \mathrm{ml}$ Phyto $\times 10^{4} \mathrm{nos} / \mathrm{ml}$ Mean phyto size $\mu \mathrm{m}^{3}$ Phyto Y-intercept Phyto slope

Fig. F14. Depth profiles of size spectral characteristics for Cape Cod Bay $\left(41^{\circ} 54.5^{\prime} \mathrm{N}, 70^{\circ} 13.7^{\prime} \mathrm{W}\right)$ on February 25,1993 at $1120 \mathrm{hrs}$, corresponding to the size spectra and environmental conditions shown in Fig. F13. 


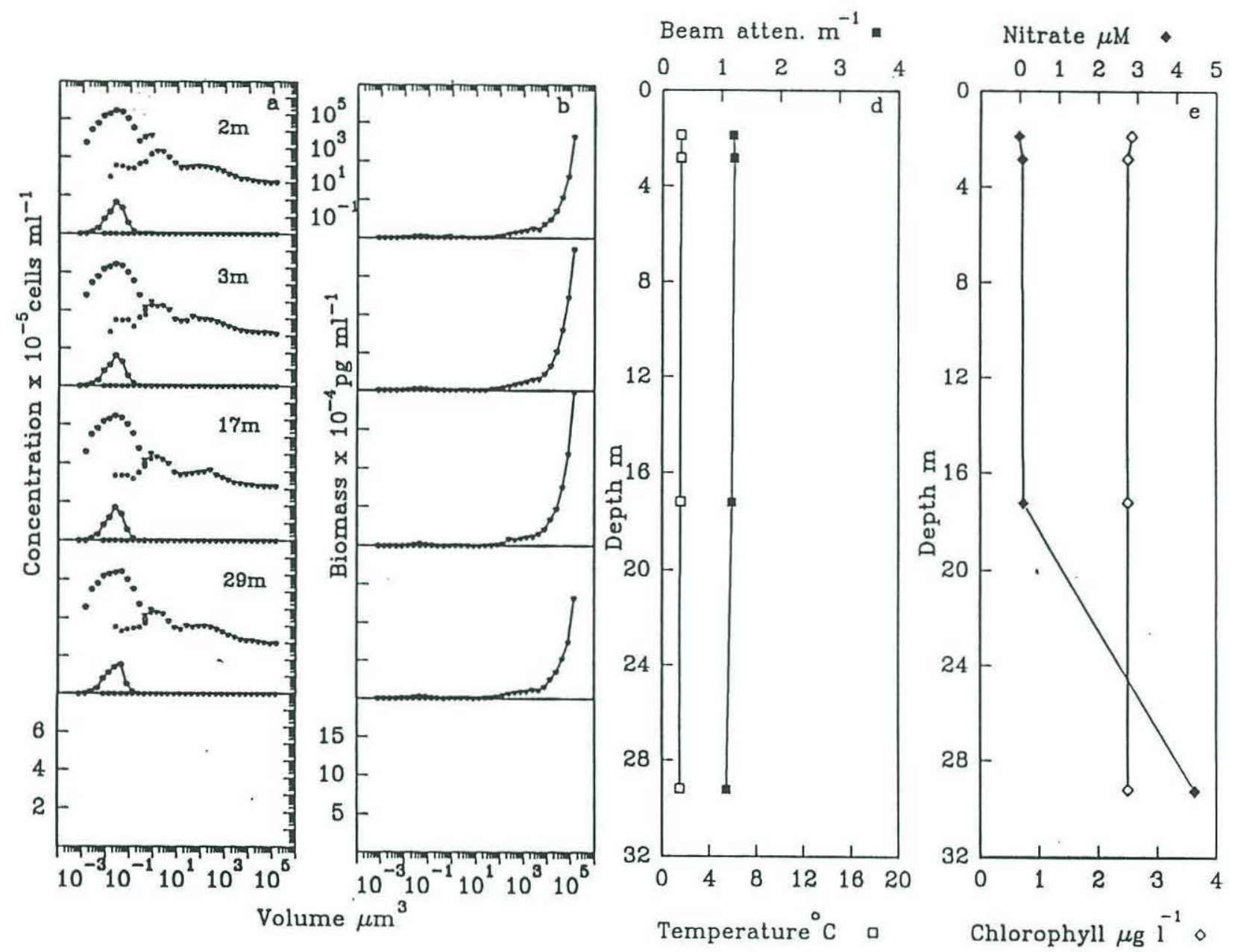

Fig. F15. Depth profiles of flow cytometrically generated size spectra and environmental measurements for the station in Cape Cod Bay $\left(41^{\circ} 54.5^{\prime} \mathrm{N}, 70^{\circ} 13.7^{\prime} \mathrm{W}\right)$ on March 11, 1993 at 1200 hrs. Environmental measurements were taken from Kelly et. al., 1994a. 

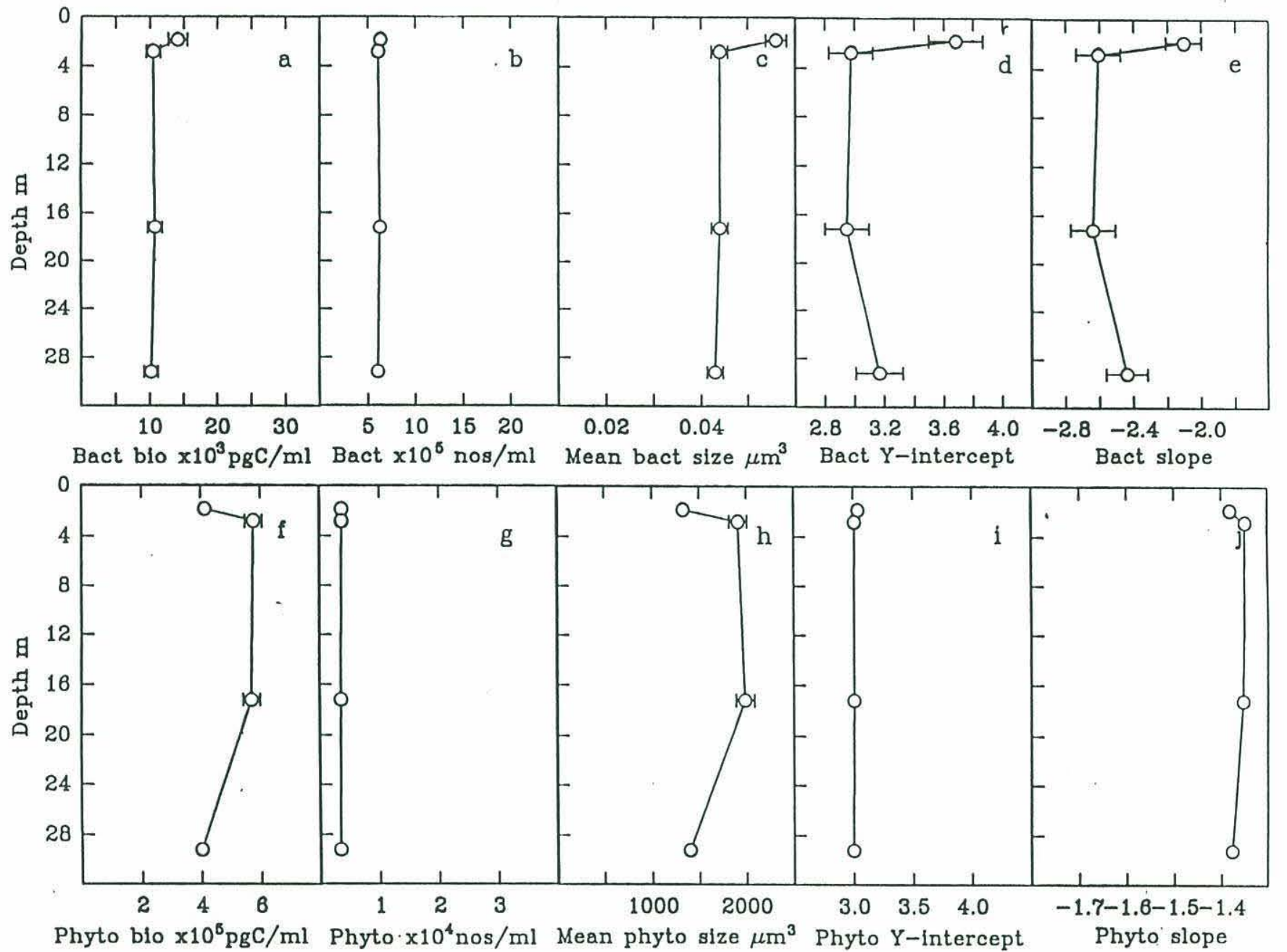

Fig. F16. Depth profiles of size spectral characteristics for Cape Cod Bay ( $41^{\circ} 54.5^{\prime} \mathrm{N}, 70^{\circ} 13.7^{\prime} \mathrm{W}$ ) on March 11,1993 at $1200 \mathrm{hrs}$, corresponding to the size spectra and environmental conditions shown in Fig. F15. 


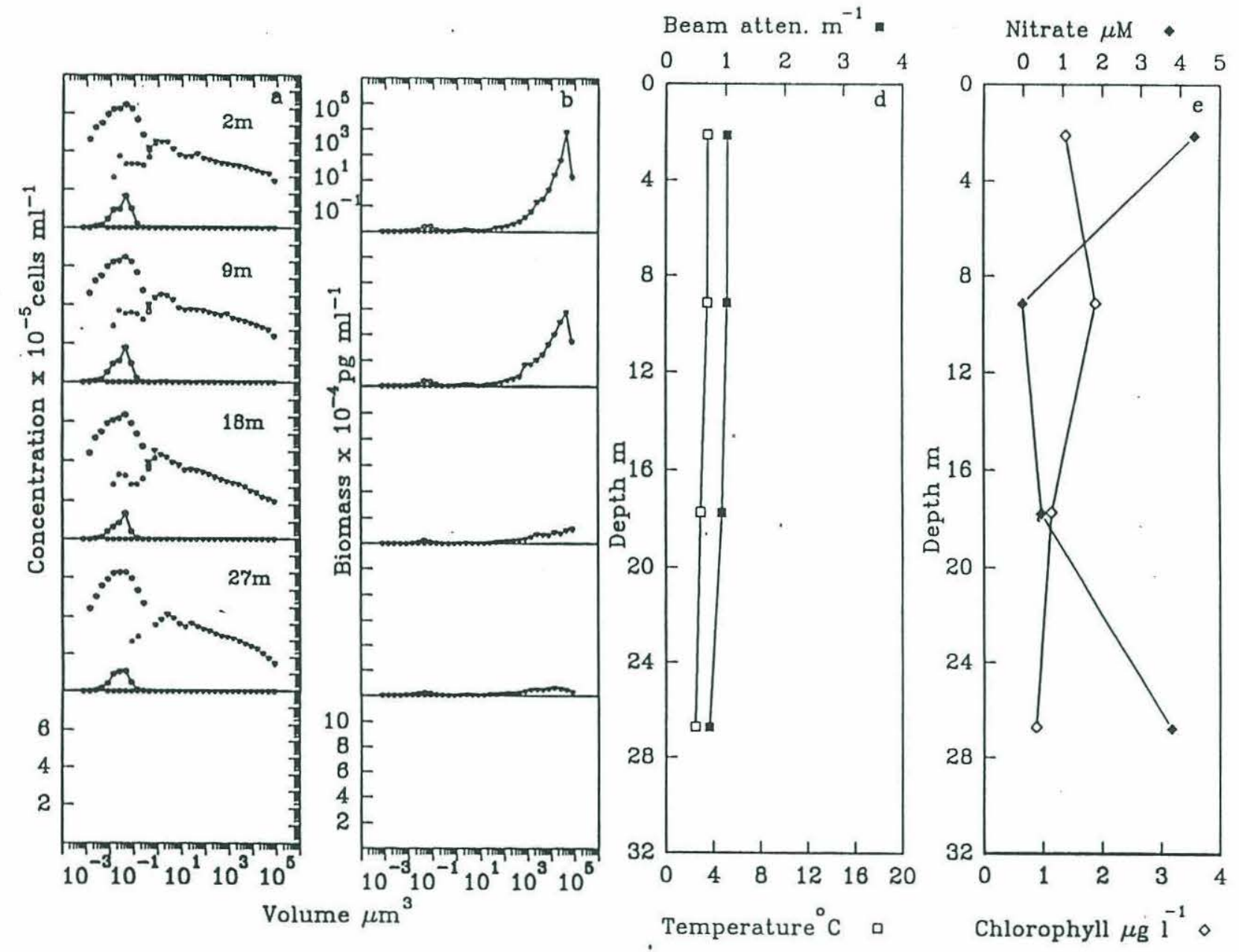

Fig. F17. Depth profiles of flow cytometrically generated size spectra and environmental measurements for the station in Cape Cod Bay ( $41^{\circ} 54.5^{\prime} \mathrm{N}, 70^{\circ} 13.7^{\prime} \mathrm{W}$ ) on April 8, 1993 at 0840 hrs. Environmental measurements were taken from Kelly et. al., 1994b. 

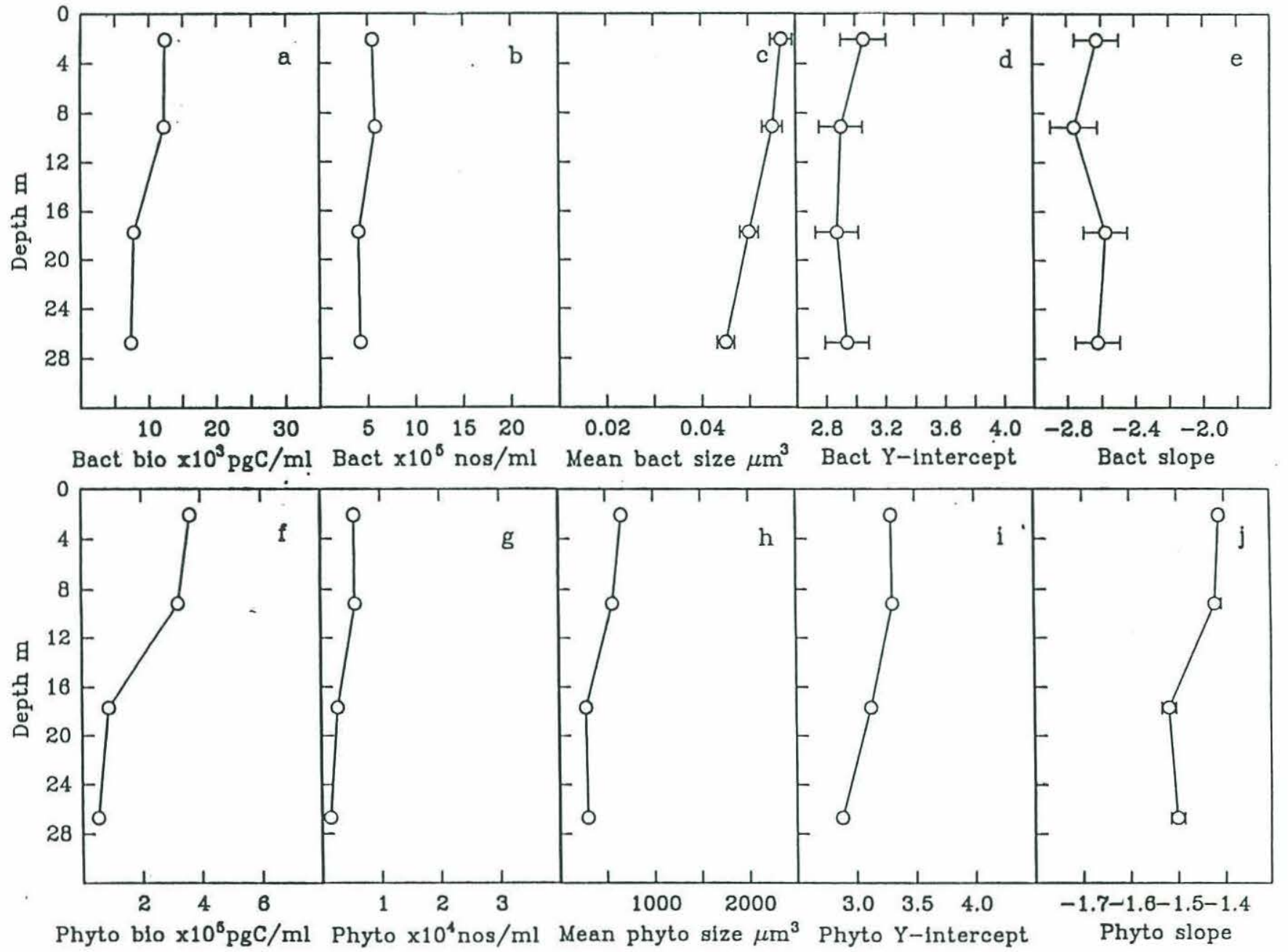

Fig. F18. Depth profiles of size spectral characteristics for Cape Cod Bay $\left(41^{\circ} 54.5^{\prime} \mathrm{N}, 70^{\circ} 13.7^{\prime} \mathrm{W}\right)$ on April 8, 1993 at $0840 \mathrm{hrs}$, corresponding to the size spectra and environmental conditions shown in Fig. F17. 

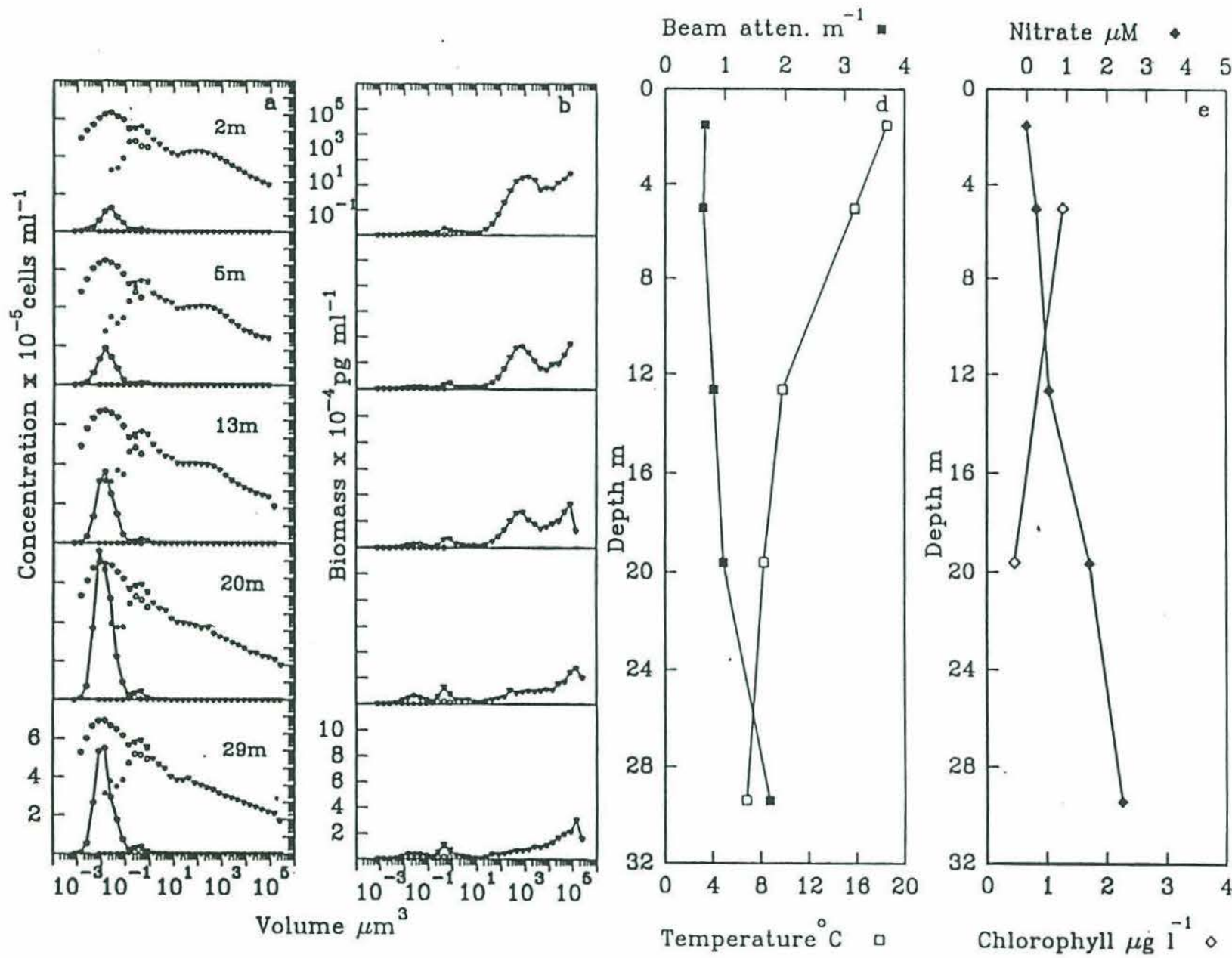

Fig. F19. Depth profiles of flow cytometrically generated size spectra and environmental measurements for the station in Cape Cod Bay $\left(41^{\circ} 54.5^{\prime} \mathrm{N}, 70^{\circ} 13.7^{\prime} \mathrm{W}\right)$ on August 26, 1993 at 0815 hrs. Environmental measurements were taken from Kelly et. al., 1994d. 

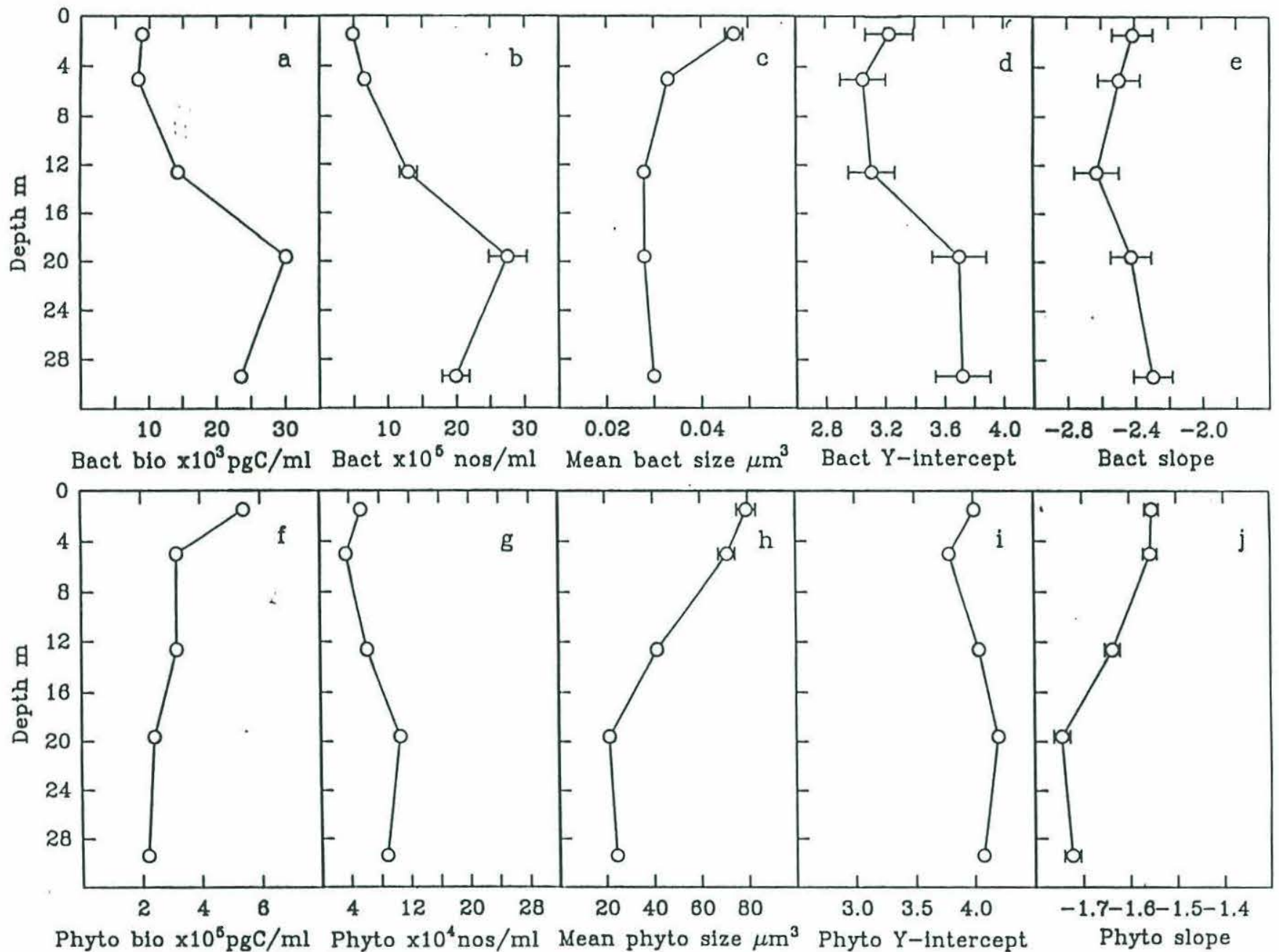

Fig. F20. Depth profiles of size spectral characteristics for Cape Cod Bay ( $\left.41^{\circ} 54.5^{\prime} \mathrm{N}, 70^{\circ} 13.7^{\prime} \mathrm{W}\right)$ on August 26,1993 at $0815 \mathrm{hrs}$, corresponding to the size spectra and environmental conditions shown in Fig. F19. 

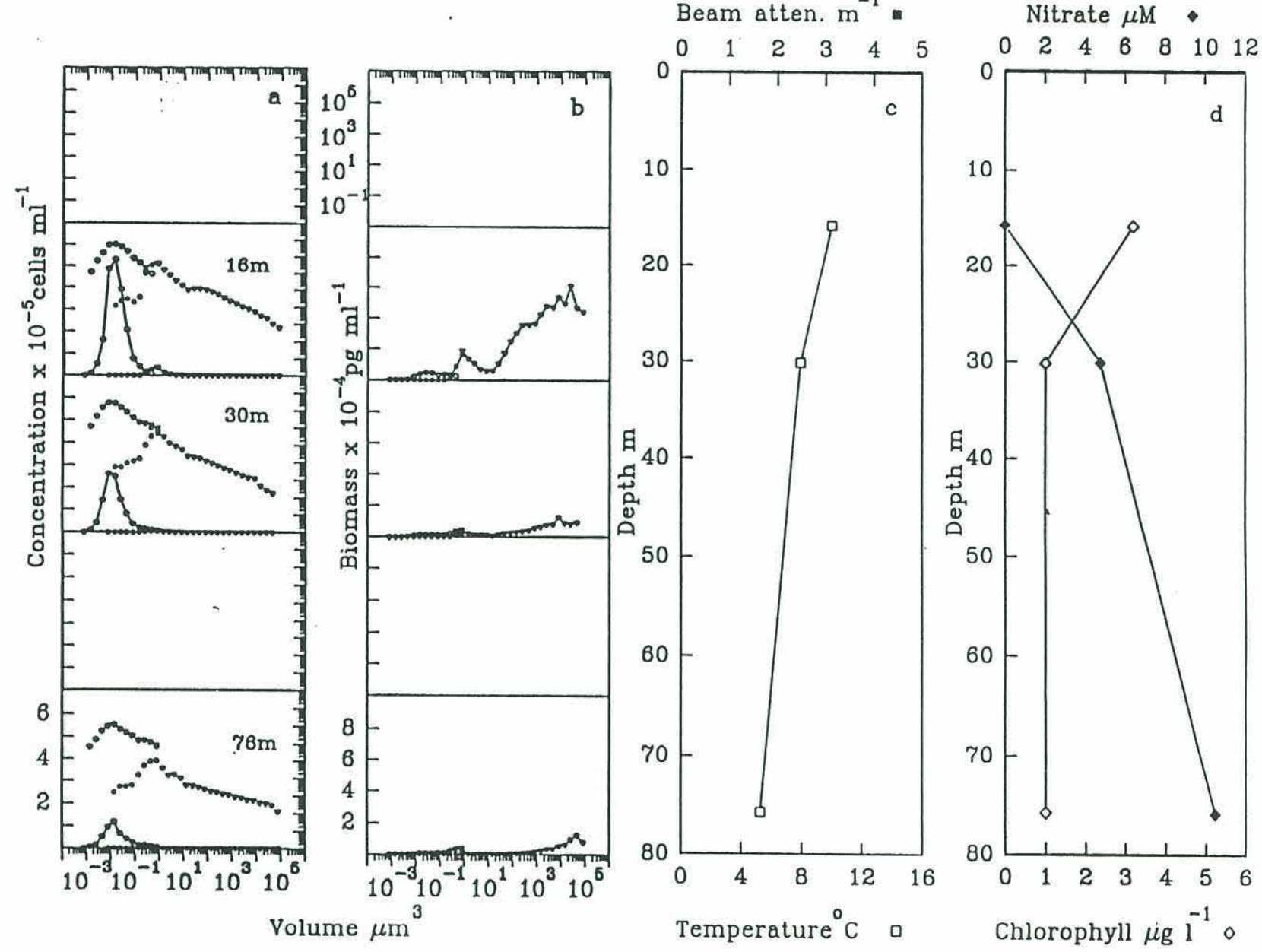

Fig. F21. Depth profiles of flow cytometrically generated size spectra and environmental measurements for the station in Massachusetts Bay $\left(42^{\circ} 28.4^{\prime} \mathrm{N}, 70^{\circ} 37.1^{\prime} \mathrm{W}\right)$ on October 14, 1992. Environmental measurements were taken from Kelly et. al., 1993. 

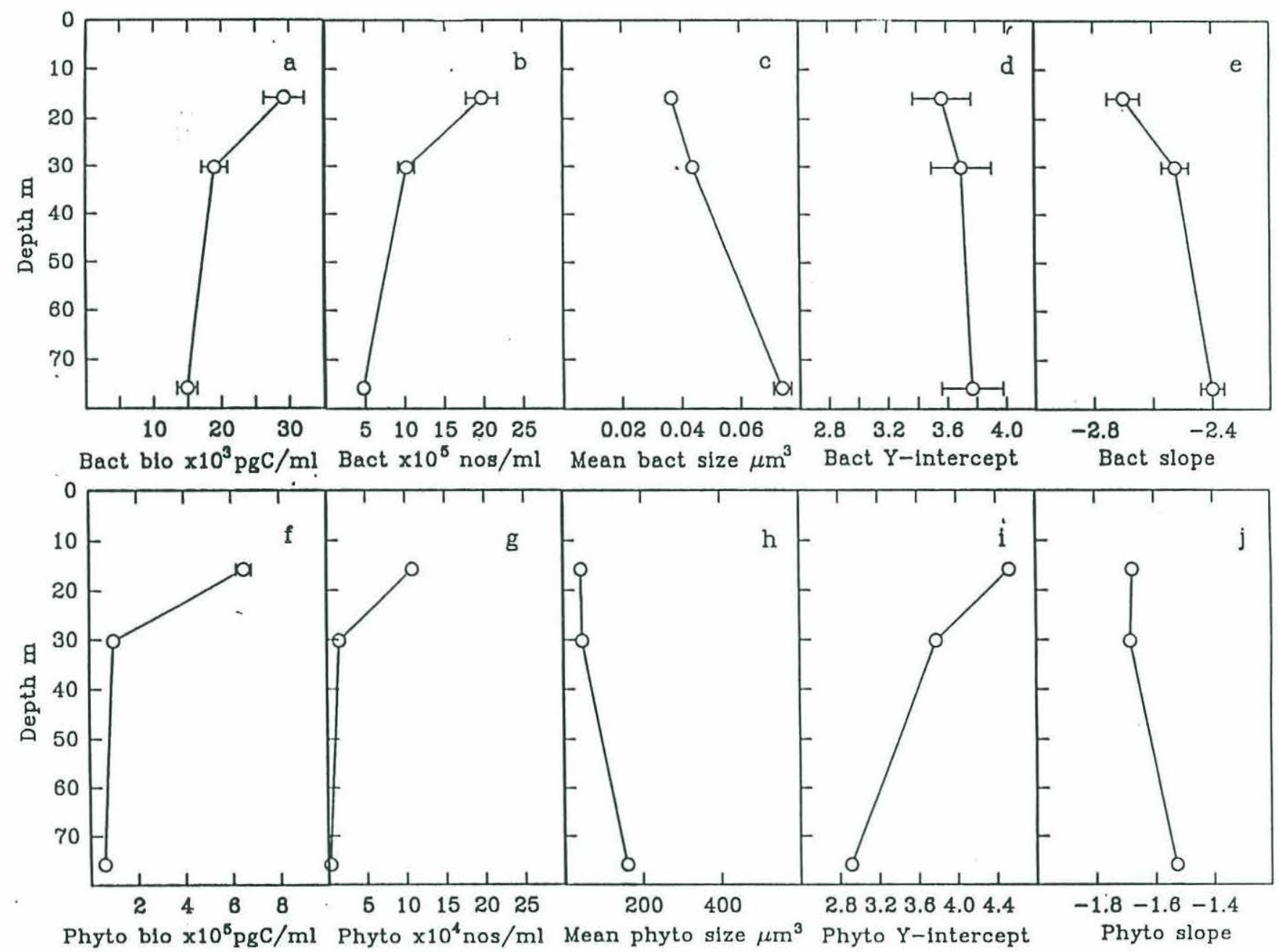

Fig. F22. Depth profiles of size spectral characteristics for Massachusetts Bay $\left(42^{\circ} 28.4^{\prime} \mathrm{N}, 70^{\circ} 37.1^{\prime} \mathrm{W}\right)$ on October 14,1992 , corresponding to the size spectra and environmental conditions shown in Fig. F21. 

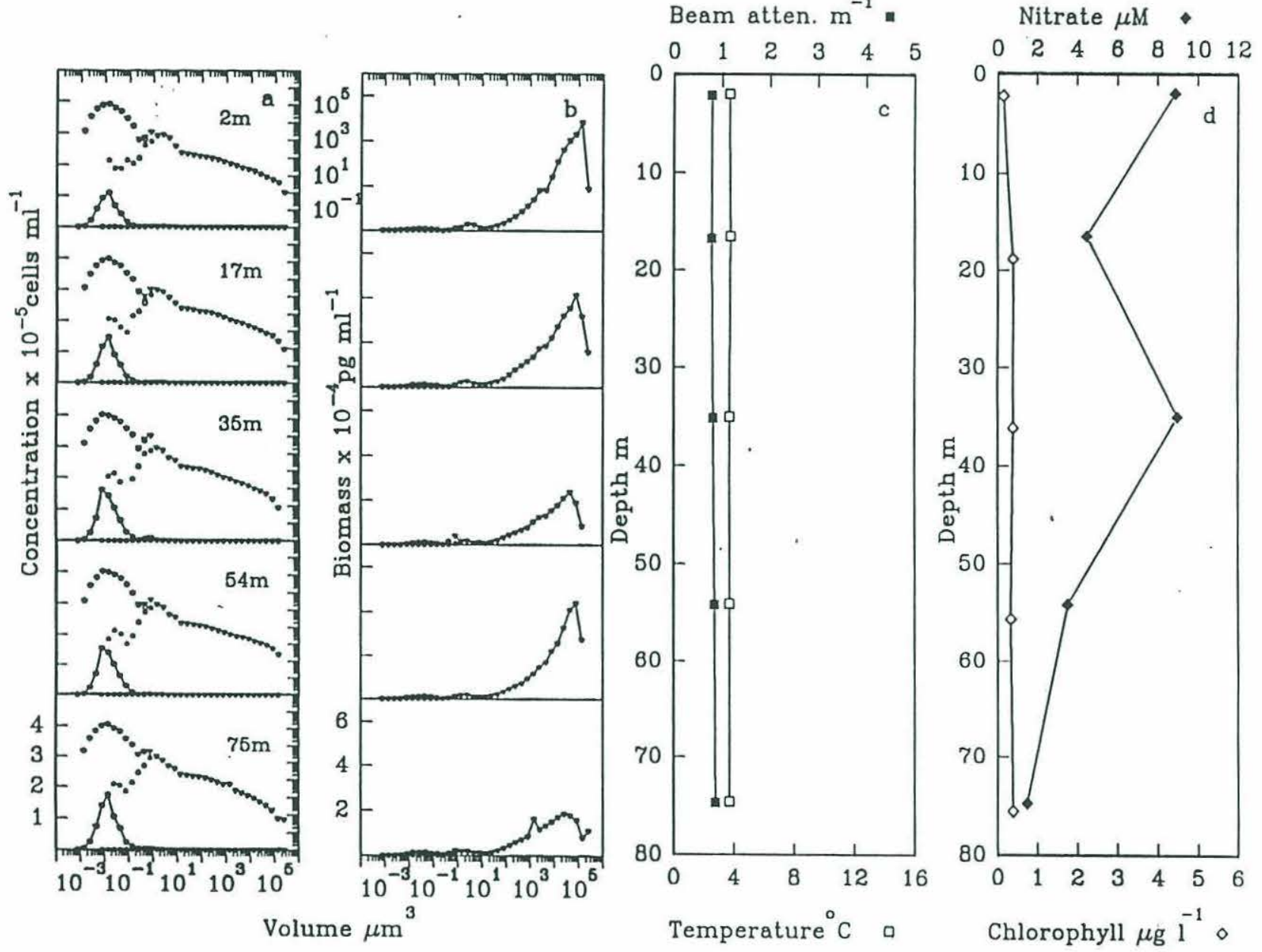

Fig. F23. Depth profiles of flow cytometrically generated size spectra and environmental measurements for the station in Massachusetts Bay $\left(42^{\circ} 28.4^{\prime} \mathrm{N}, 70^{\circ} 37.1^{\prime} \mathrm{W}\right)$ on February 23, 1993 at $1535 \mathrm{hrs}$. Environmental measurements were taken from Kelly et. al., 1994a. 

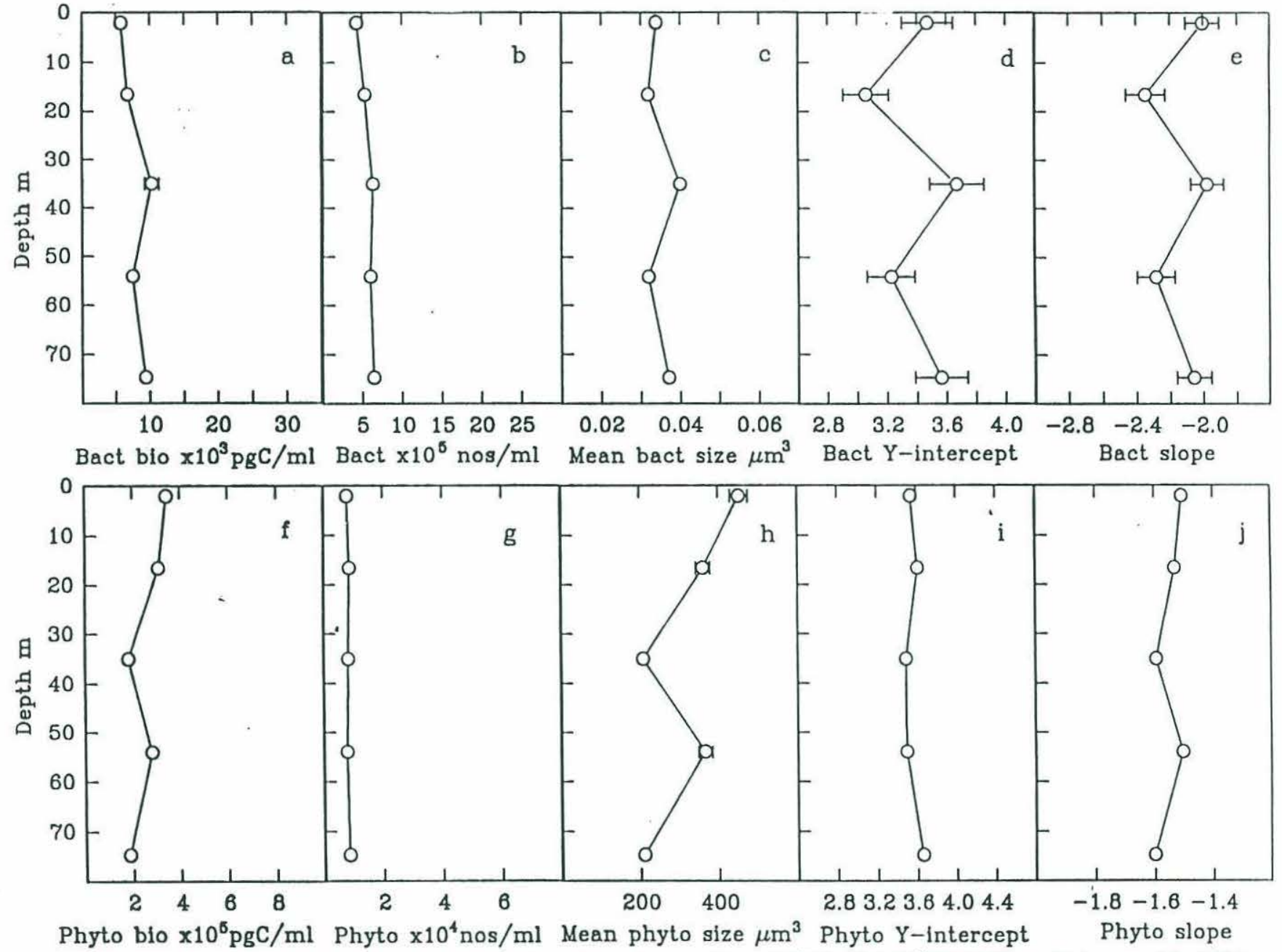

Fig. F24. Depth profiles of size spectral characteristics for Massachusetts Bay $\left(42^{\circ} 28.4^{\prime} \mathrm{N}, 70^{\circ} 37.1^{\prime} \mathrm{W}\right)$ on February 23,1993 at 1535 hrs, corresponding to the size spectra and environmental conditions shown in Fig. F23. 

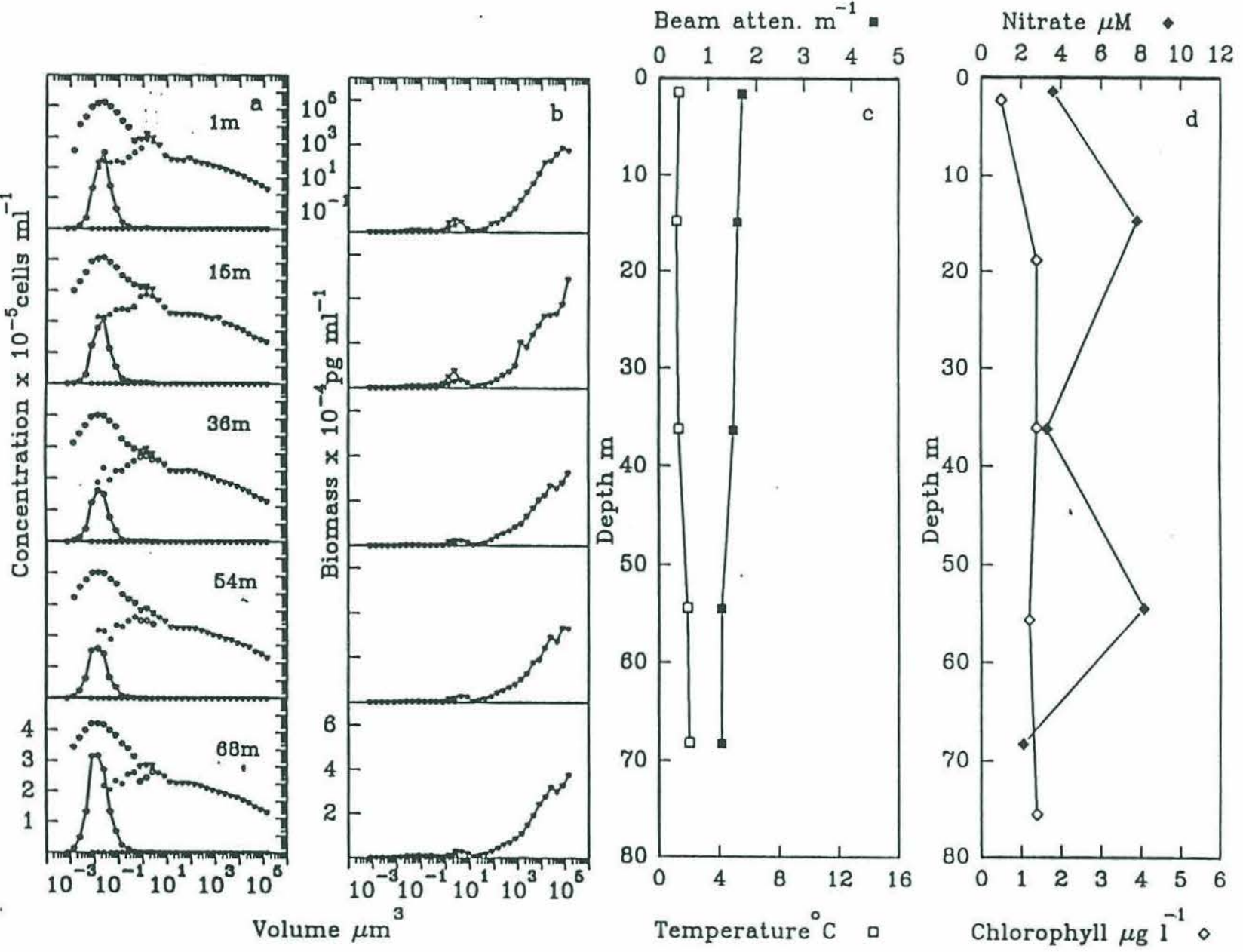

Fig. F25. Depth profiles of flow cytometrically generated size spectra and environmental measurements for the station in Massachusetts Bay $\left(42^{\circ} 28.4^{\prime} \mathrm{N}, 70^{\circ} 37.1^{\prime} \mathrm{W}\right)$ on March 9, 1993 at $1620 \mathrm{hrs}$. Environmental measurements were taken from Kelly et. al., 1994a. 

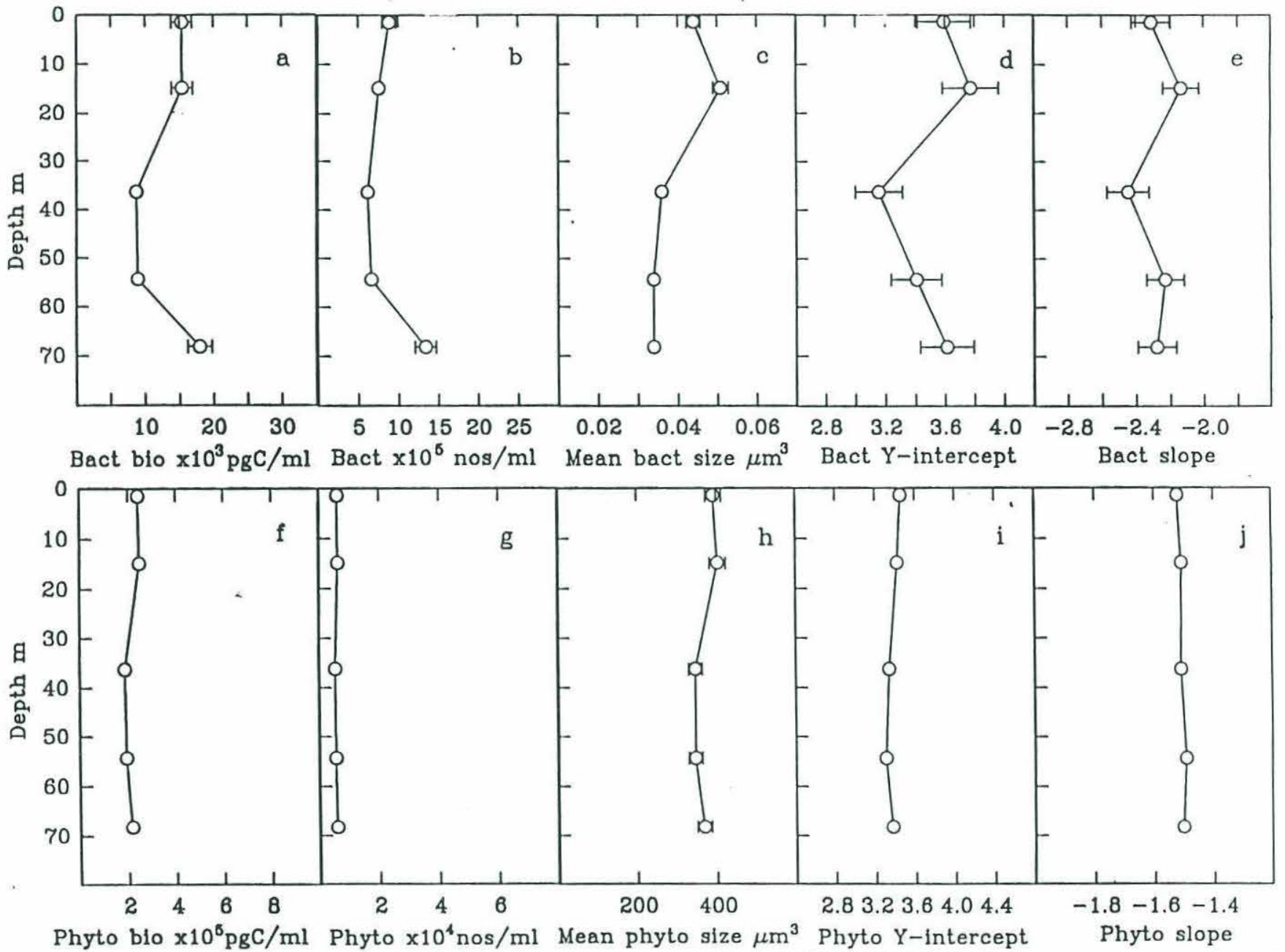

Fig. F26. Depth profiles of size spectral characteristics for Massachusetts Bay $\left(42^{\circ} 28.4^{\prime} \mathrm{N}, 70^{\circ} 37.1^{\prime} \mathrm{W}\right)$ on March 9,1993 at $1620 \mathrm{hrs}$, corresponding to the size spectra and environmental conditions shown in Fig. F25. 


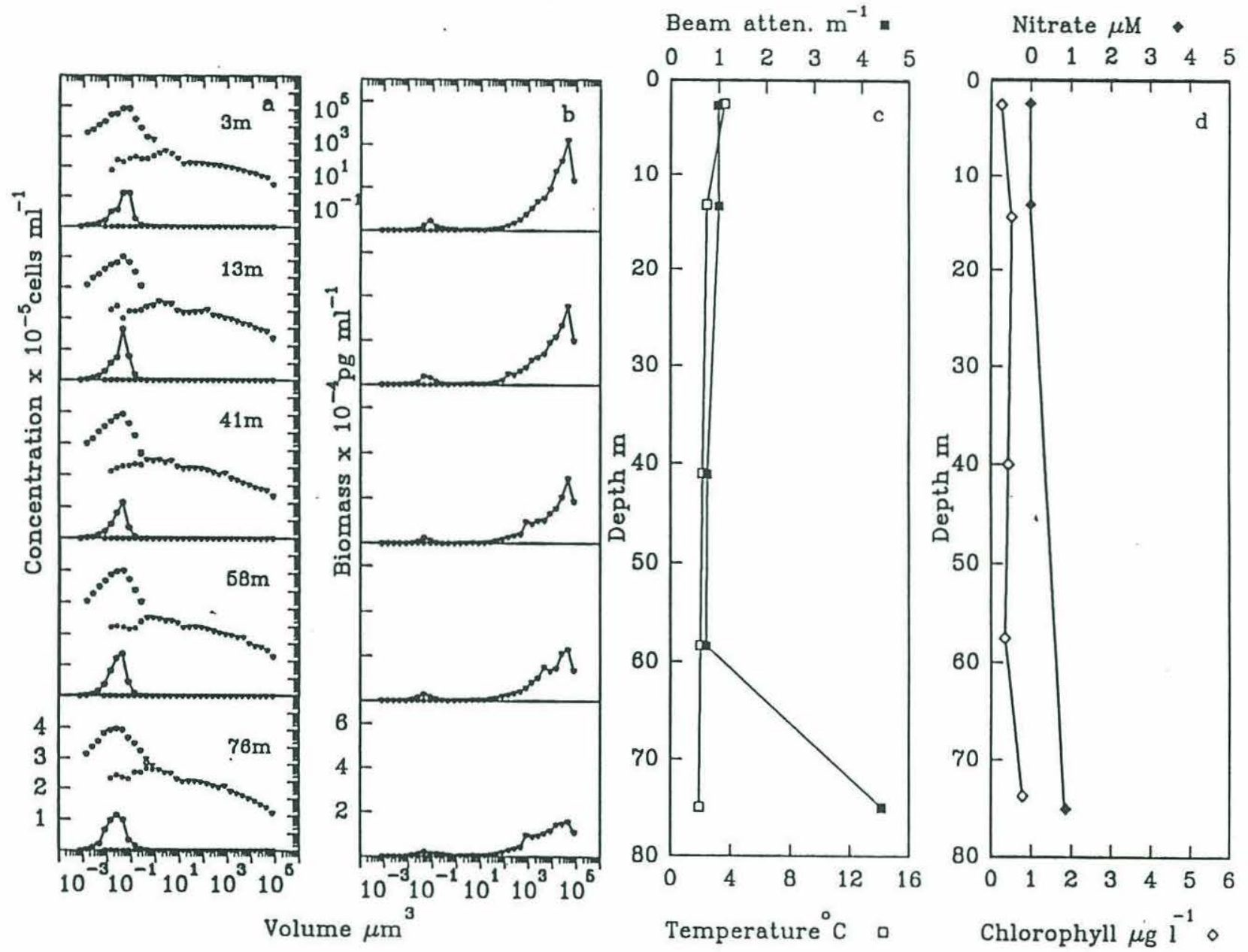

Fig. F27. Depth profiles of flow cytometrically generated size spectra and environmental measurements for the station in Massachusetts Bay ( $\left.42^{\circ} 28.4^{\prime} \mathrm{N}, 70^{\circ} 37.1^{\prime} \mathrm{W}\right)$ on April 6, 1993 at $1520 \mathrm{hrs}$. Environmental measurements were taken from Kelly et. al., 1994b. 

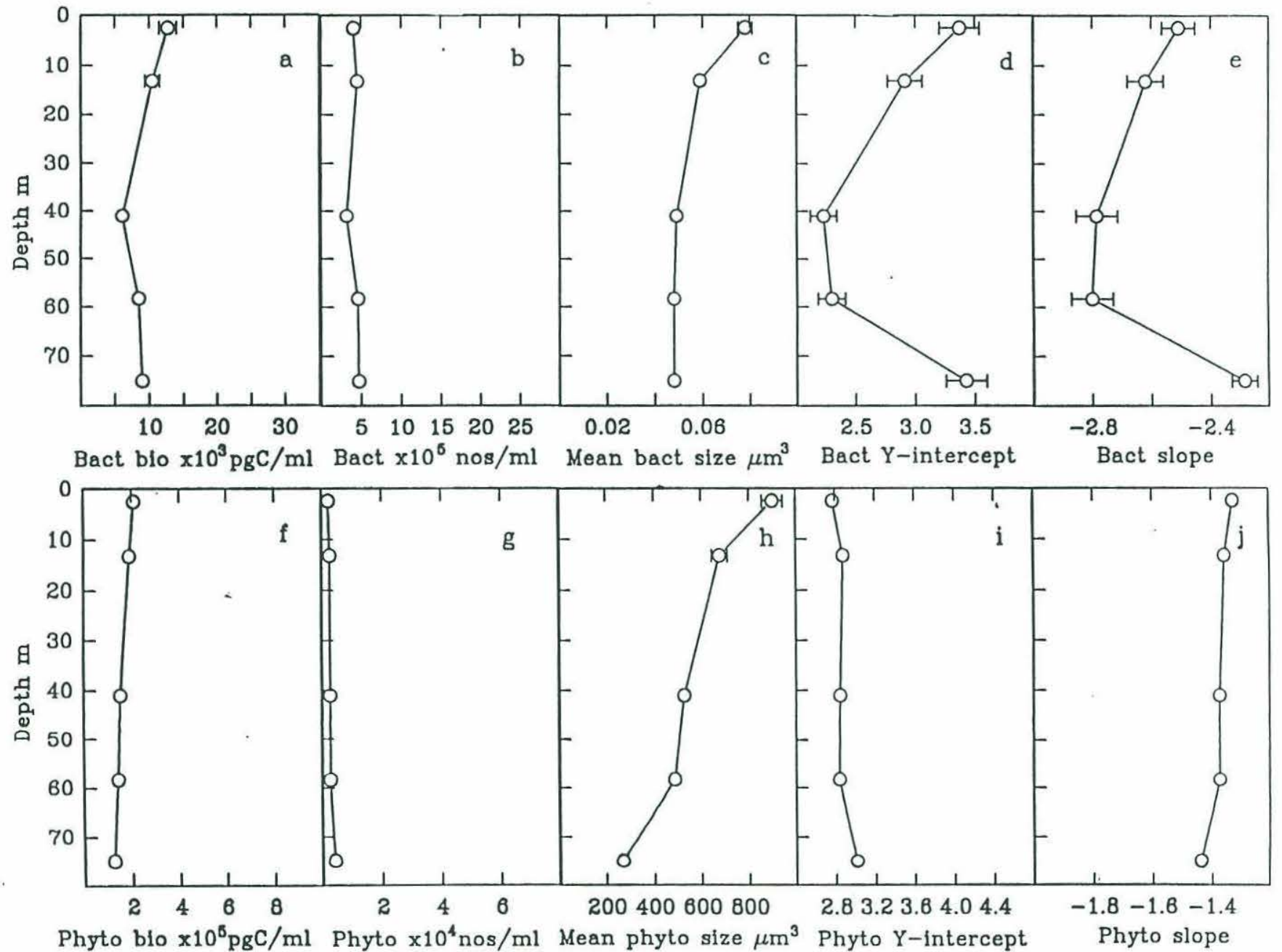

Fig. F28. Depth profiles of size spectral characteristics for Massachusetts Bay $\left(42^{\circ} 28.4^{\prime} \mathrm{N}, 70^{\circ} 37.1^{\prime} \mathrm{W}\right)$ on April 6, $1993 \mathrm{at} 1520 \mathrm{hrs}$, corresponding to the size spectra and environmental conditions shown in Fig. F27. 

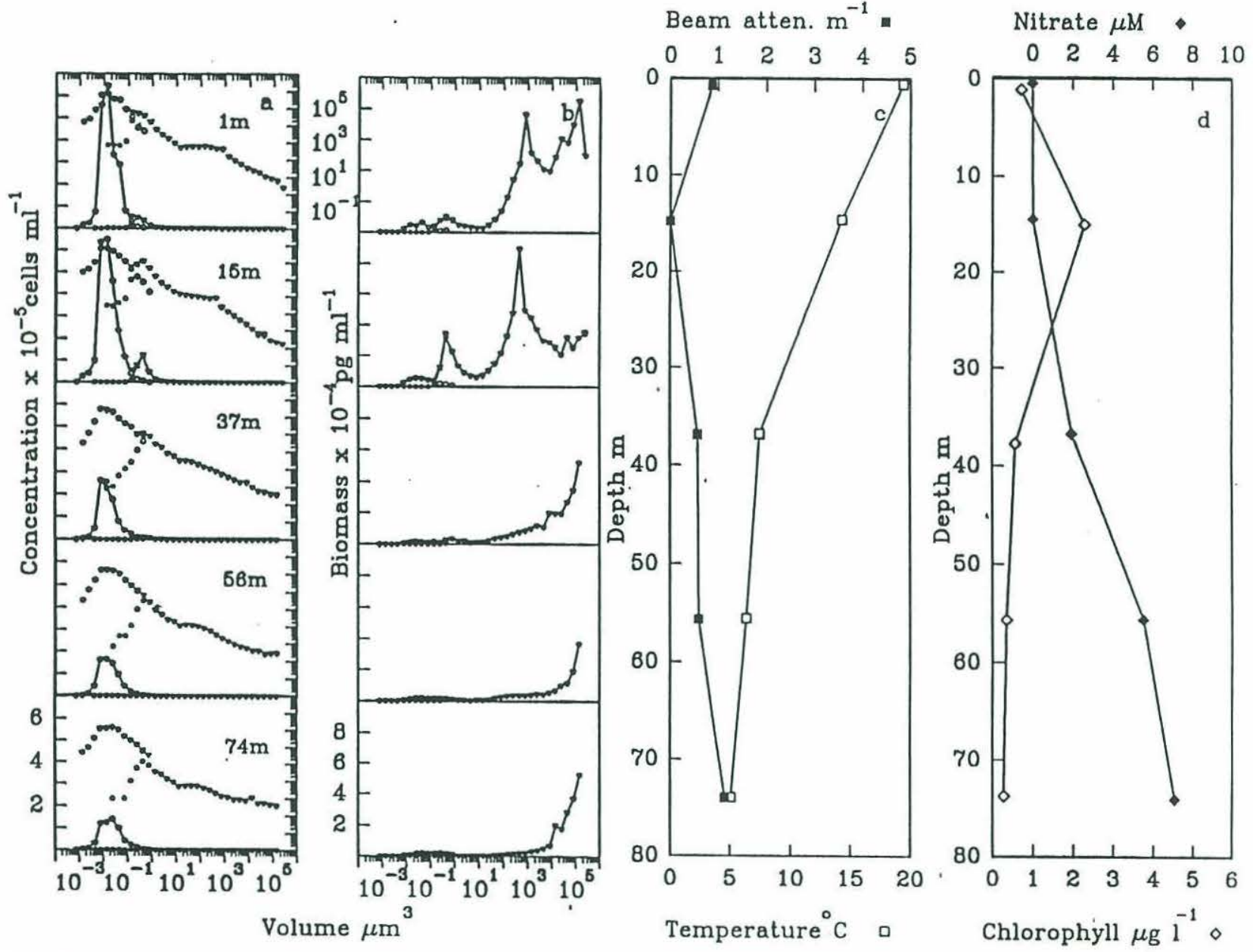

Fig. F29. Depth profiles of flow cytometrically generated size spectra and environmental measurements for the station in Massachusetts Bay $\left(42^{\circ} 28.4^{\prime} \mathrm{N}, 70^{\circ} 37.1^{\prime} \mathrm{W}\right)$ on August 24,1993 at $1425 \mathrm{hrs}$. Environmental measurements were taken from Kelly et. al., 1994d. 

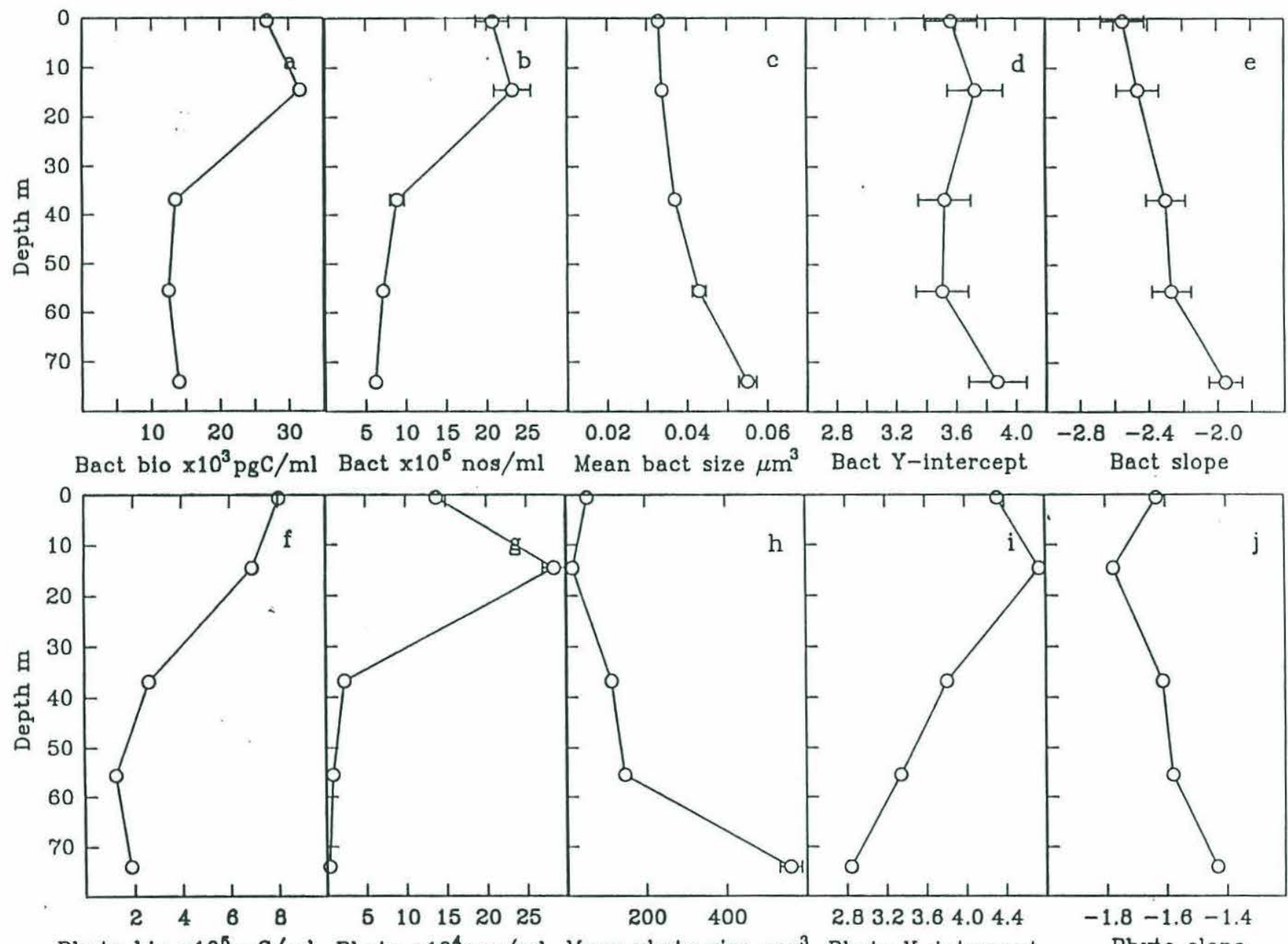

Phyto bio $\times 10^{5} \mathrm{pgC} / \mathrm{ml}$ Phyto $\times 10^{4} \mathrm{nos} / \mathrm{ml}$ Mean phyto size $\mu \mathrm{m}^{3}$ Phyto Y-intercept Phyto slope

Fig. F30. Depth profiles of size spectral characteristics for Massachusetts Bay $\left(42^{\circ} 28.4^{\prime} \mathrm{N}, 70^{\circ} 37.1^{\prime} \mathrm{W}\right)$ on August 24,1993 at 1425 hrs, corresponding to the size spectra and environmental conditions shown in Fig. F29. 
APPENDIX G

ADDITIONAL FIGURES OF MICROBIAL SIZE SPECTRA FROM THE SARGASSO SEA 


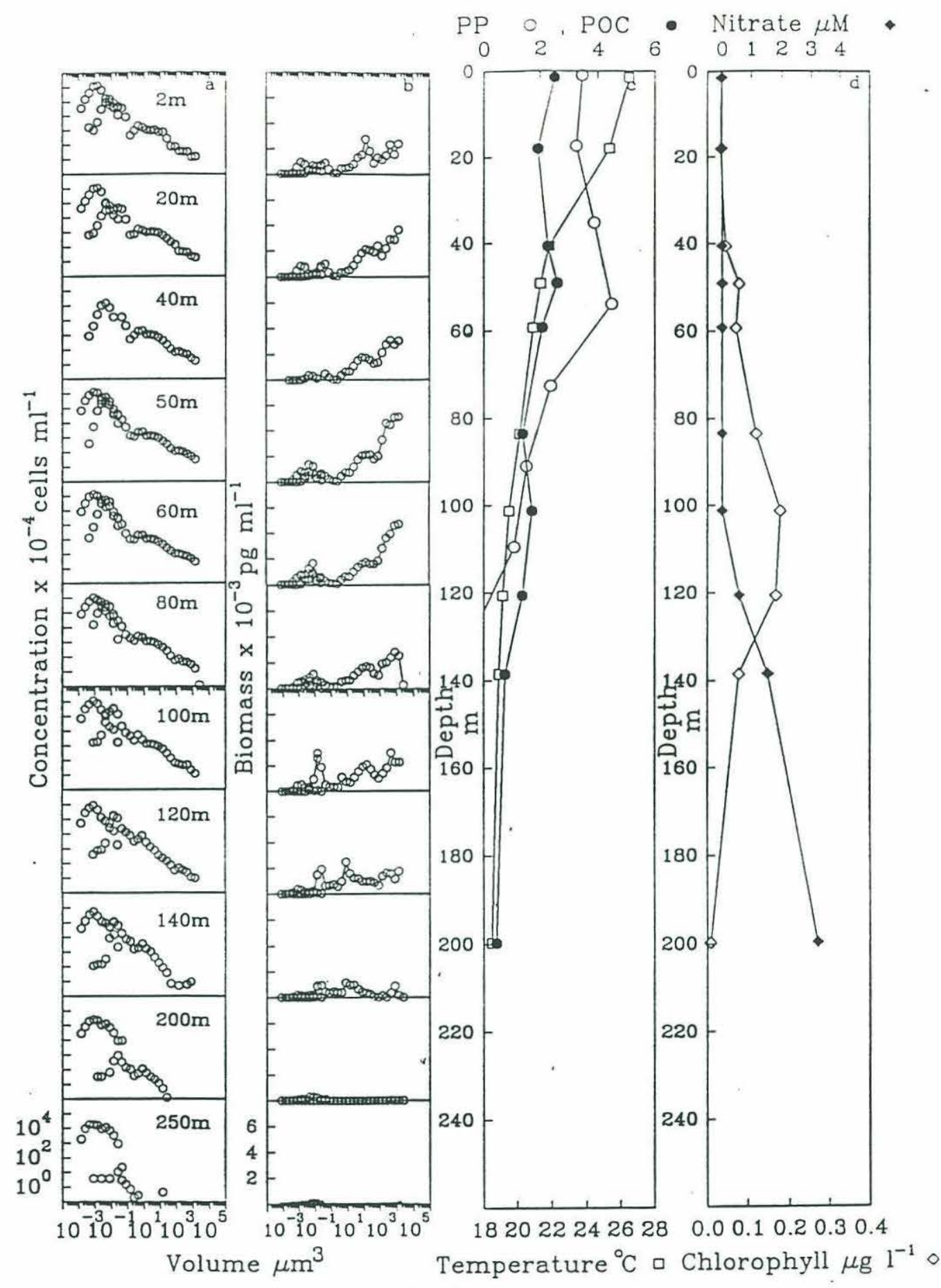

G1. Depth profiles of flow cytometrically generated size spectra and environmental measurements for the BATS station in the Sargasso Sea $\left(31^{\circ} 50^{\prime} \mathrm{N}, 64^{\circ} 10^{\prime} \mathrm{W}\right)$ on July 14, 1992 at 1453 hrs. Environmental measurements were taken from Knapp et. al., 1994. 

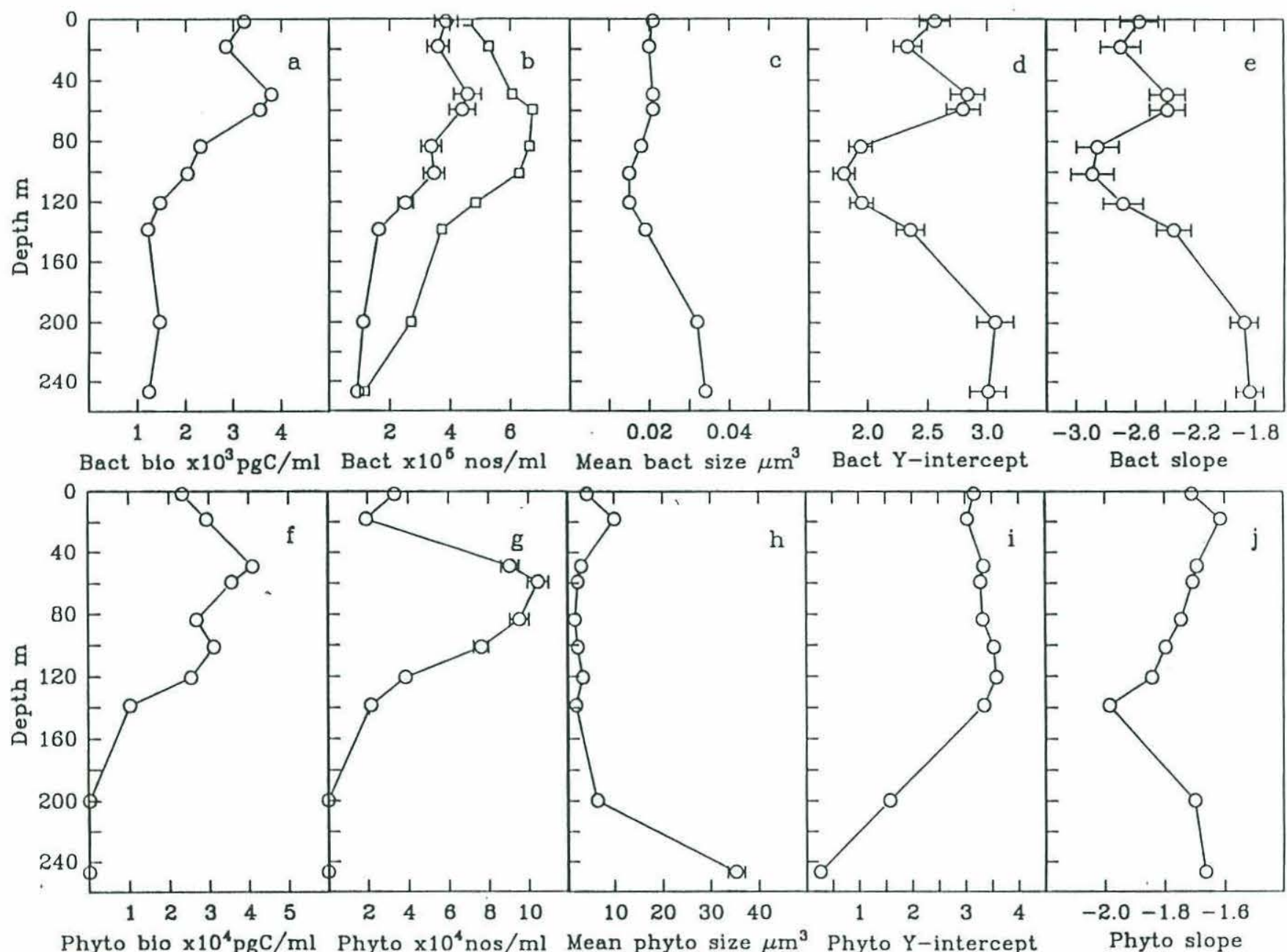

Fig. G2. Depth profiles of size spectral characteristics for the BATS station in the Sargasso Sea on July 14, 1992 at 1453 hrs, corresponding to the size spectra and environmental conditions shown in Fig. G1. 


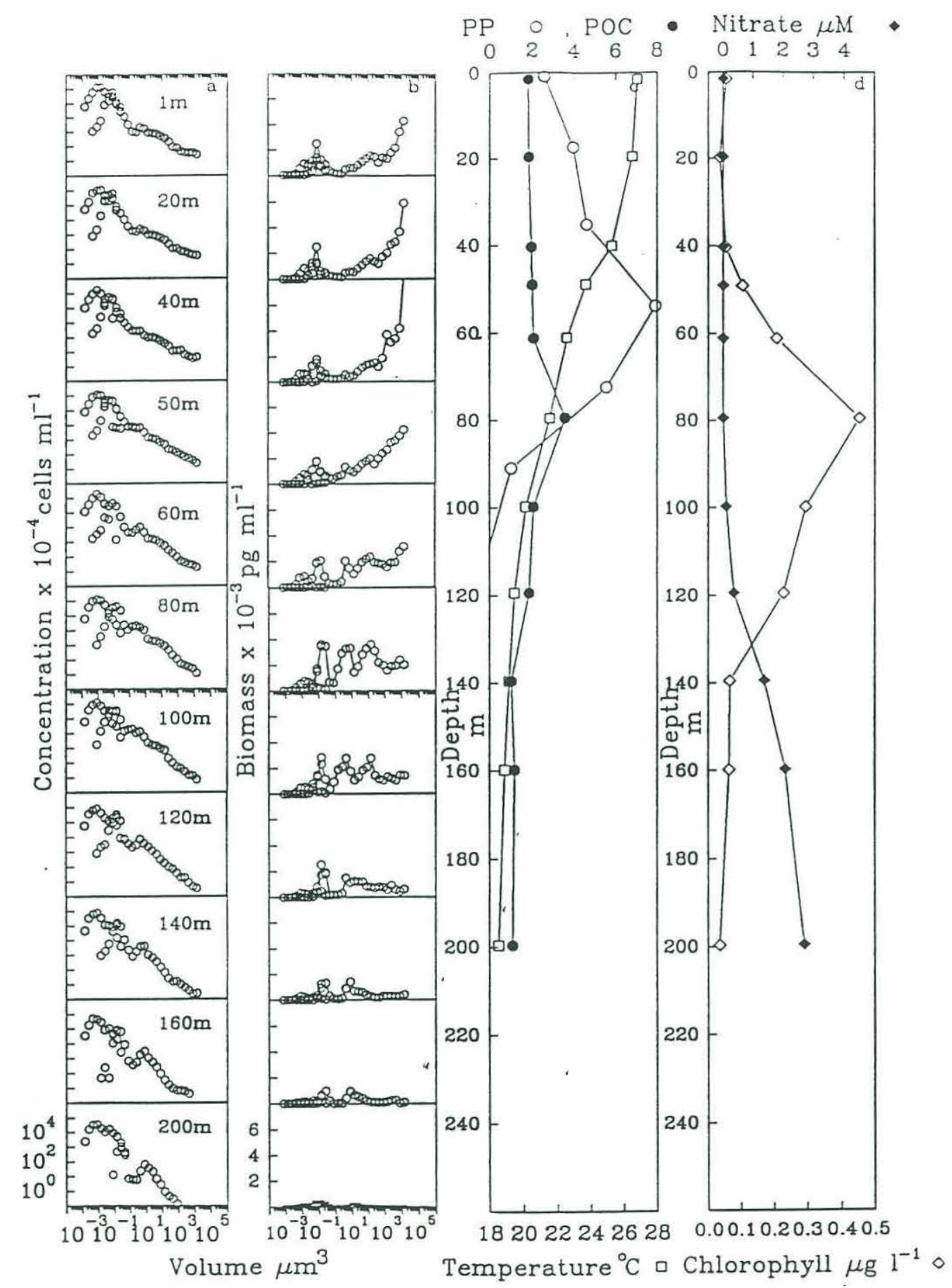

Fig. G3. Depth profiles of flow cytometrically generated size spectra and environmental measurements for the BATS station in the Sargasso Sea ( $31^{\circ} 50^{\prime} \mathrm{N}$, $64^{\circ} 10^{\prime} \mathrm{W}$ ) on September 14, 1992 at $1100 \mathrm{hrs}$. Environmental measurements were taken from Knapp et. al., 1994. 

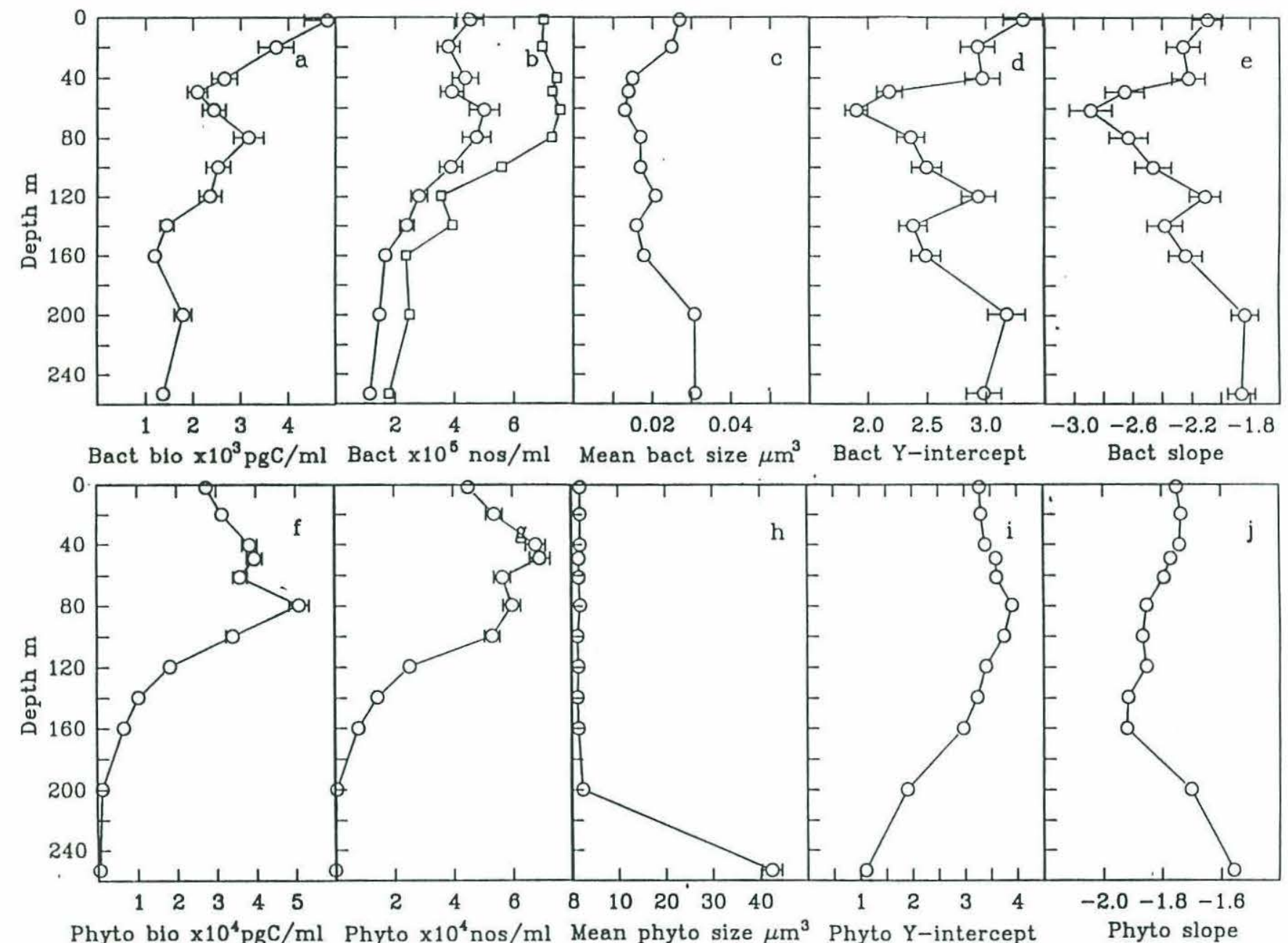

Fig. G4. Depth profiles of size spectral characteristics for the BATS station in the Sargasso Sea on September 14, 1992 at $1100 \mathrm{hrs,}$ corresponding to the size spectra and environmental conditions shown in Fig. G3. 

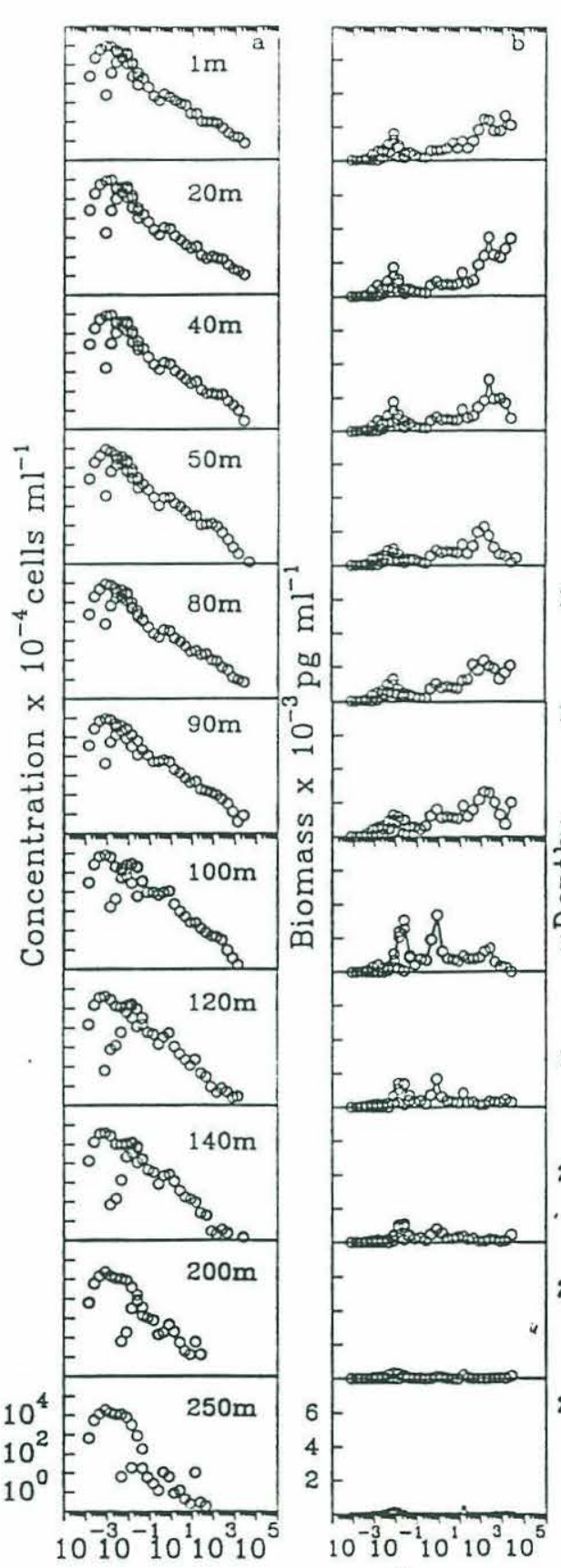

$\begin{array}{cccc}\mathrm{PP} & 0 & \mathrm{POC} \\ 0 & 2 & 4 & 6\end{array}$

- Nitrate $\mu \mathrm{M}$ -

$$
0
$$

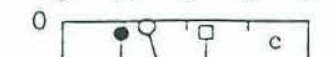

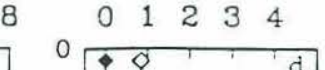

$0 \longdiv { 0 }$

20
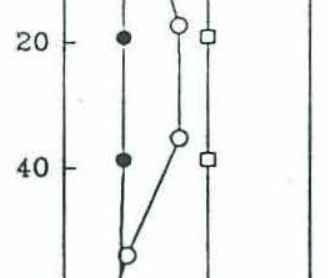

60
80
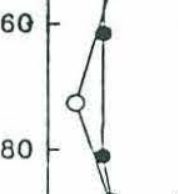

100

120
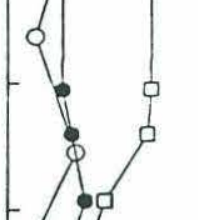

9

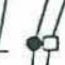

140

蓄

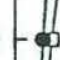

며

160

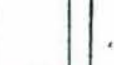

20.
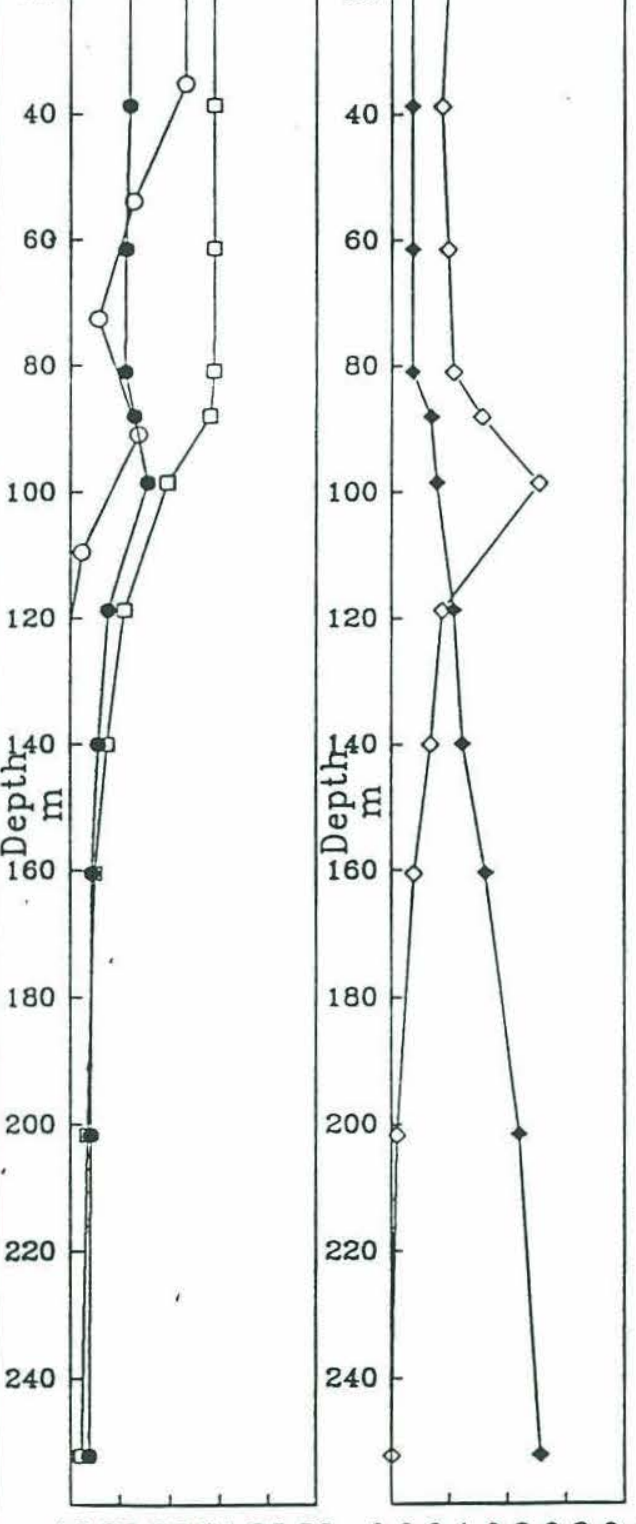

$182022242628 \quad 0.00 .10 .20 .30 .4$

Volume $\mu \mathrm{m}^{3}$

Temperature ${ }^{\circ} \mathrm{C}$ 口 Chlorophyll $\mu \mathrm{g} \mathrm{l}^{-1} \mathrm{C}$

Fig. G5. Depth profiles of flow cytometrically generated size spectra and environmental measurements for the BATS station in the Sargasso Sea $\left(31^{\circ} 50^{\prime} \mathrm{N}\right.$, $64^{\circ} 10^{\prime} \mathrm{W}$ ) on November 12, 1992 at 1245 hrs. Environmental measurements were taken from Knapp et. al., 1995. 

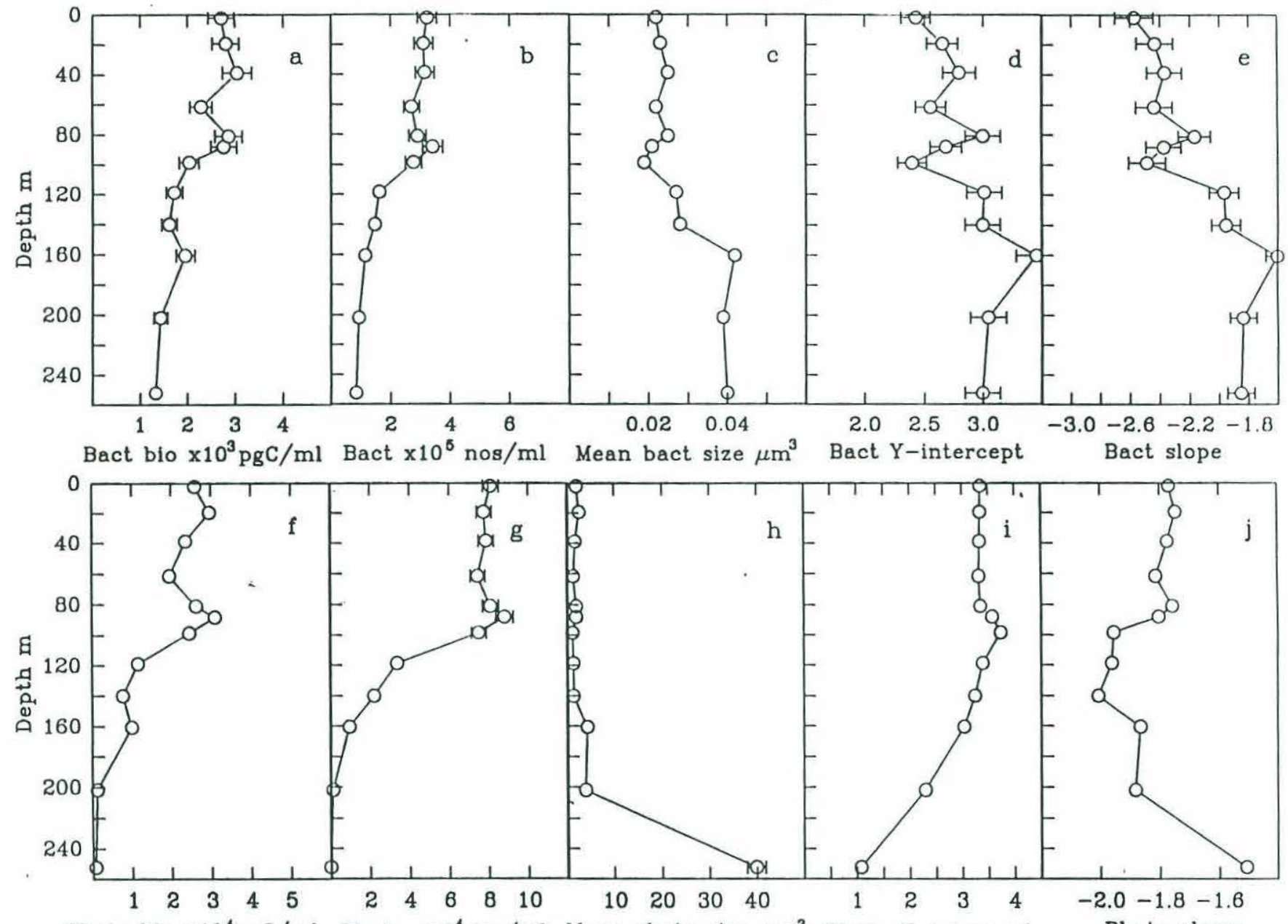

Phyto bio $\times 10^{4} \mathrm{pgC} / \mathrm{ml}$ Phyto $\times 10^{4} \mathrm{nos} / \mathrm{ml}$ Mean phyto size $\mu \mathrm{m}^{3}$ Phyto Y-intercept Phyto slope

Fig. G6. Depth profiles of size spectral characteristics for the BATS station in the Sargasso Sea on November 12, 1992 at 1245 hrs, corresponding to the size spectra and environmental conditions shown in Fig. G5. 


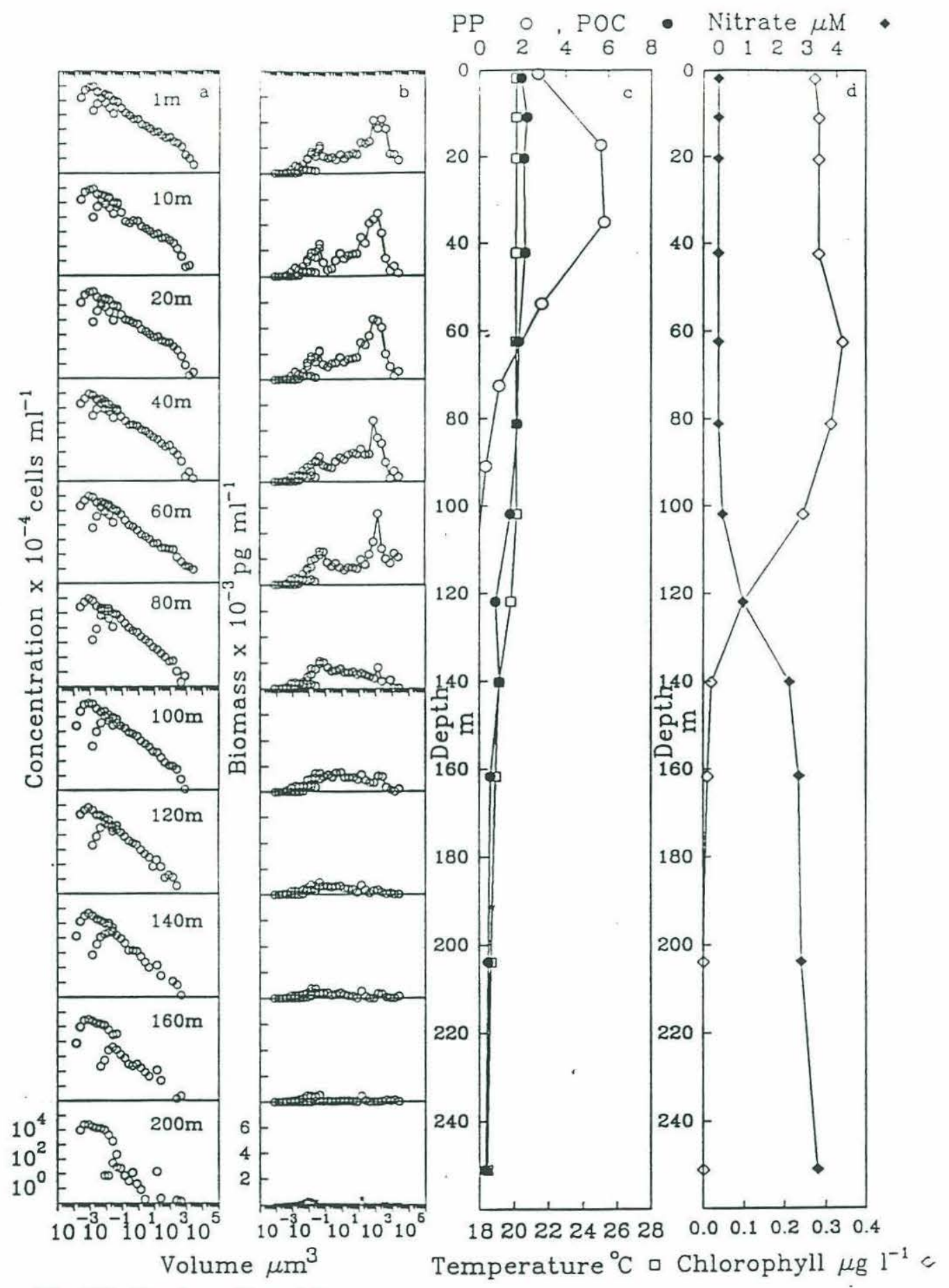

Fig. G7. Depth profiles of flow cytometrically generated size spectra and environmental measurements for the BATS station in the Sargasso Sea ( $31^{\circ} 50^{\prime} \mathrm{N}$, $64^{\circ} 10^{\prime} \mathrm{W}$ ) on February 9, 1993 at 0815 hrs. Environmental measurements were taken from Knapp et. al., 1995. 

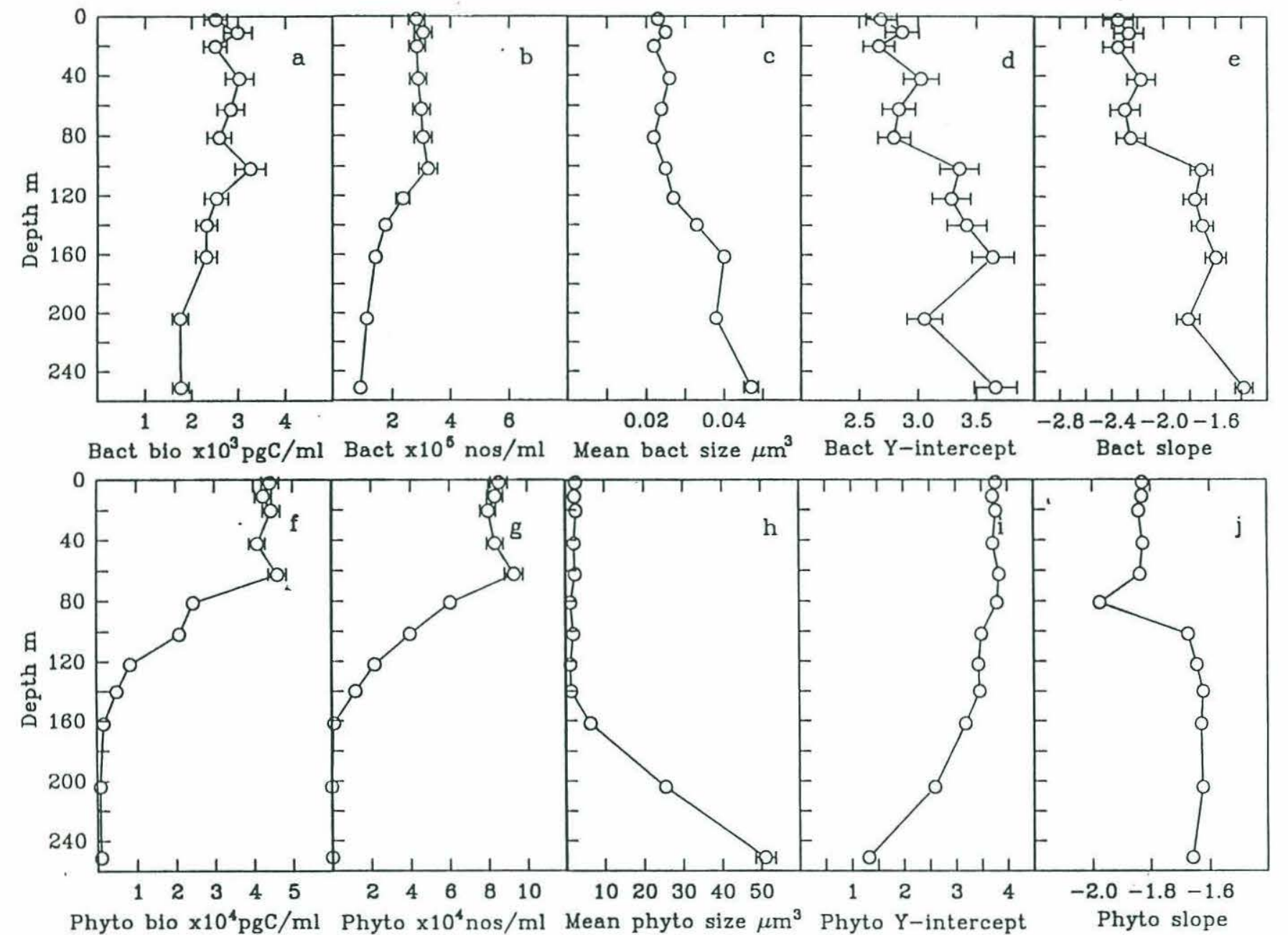

Fig. G8. Depth profiles of size spectral characteristics for the BATS station in the Sargasso Sea on February 9, 1993 at $0815 \mathrm{hrs,}$ corresponding to the size spectra and environmental conditions shown in Fig. G8. 


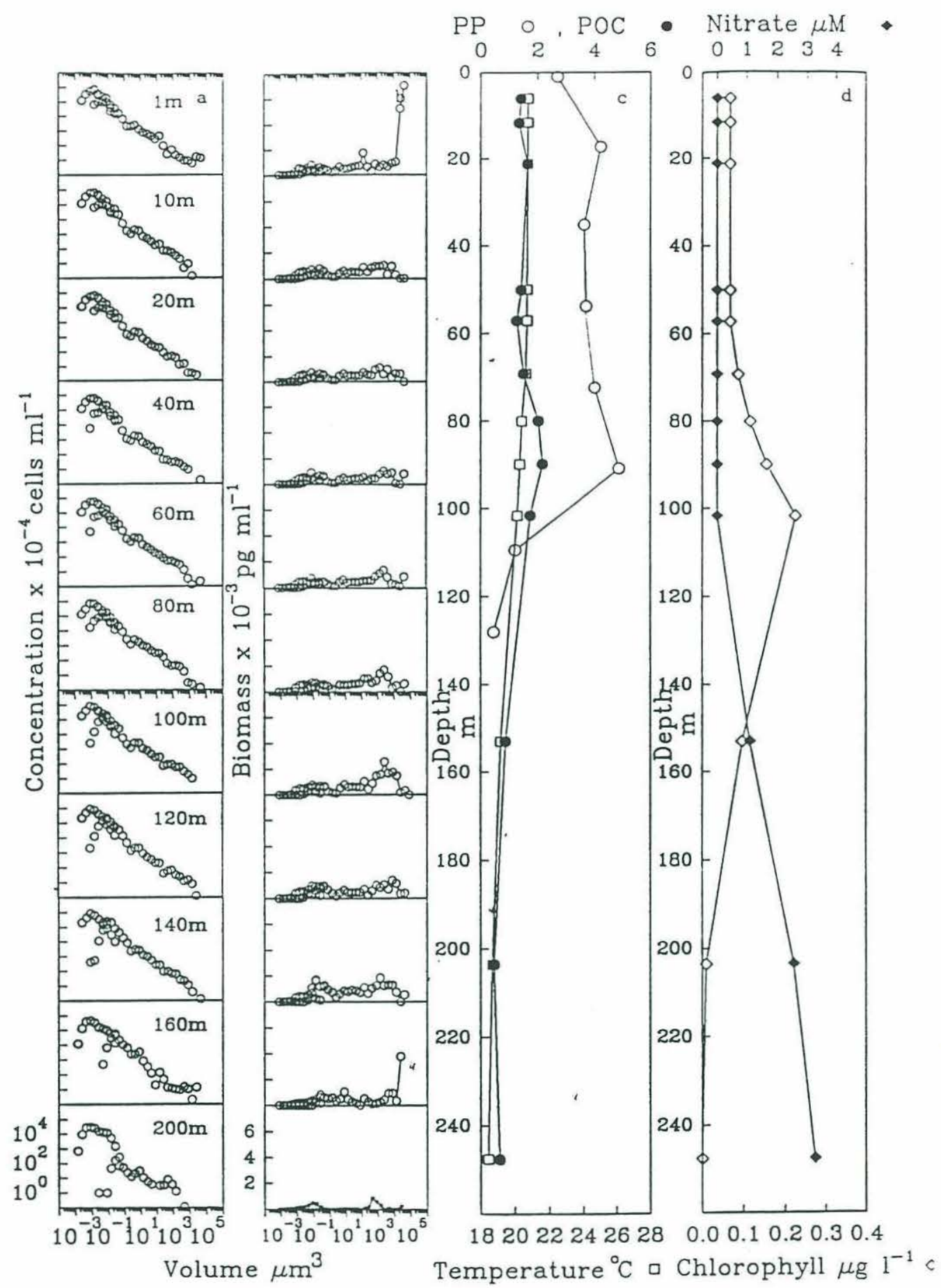

Fig. G9. Depth profiles of flow cytometrically generated size spectra and environmental measurements for the BATS station in the Sargasso Sea $\left(31^{\circ} 50^{\prime} \mathrm{N}\right.$, $64^{\circ} 10^{\prime} \mathrm{W}$ ) on April 14, 1993 at $1400 \mathrm{hrs}$. Environmental measurements were taken from Knapp et. al., 1995. 

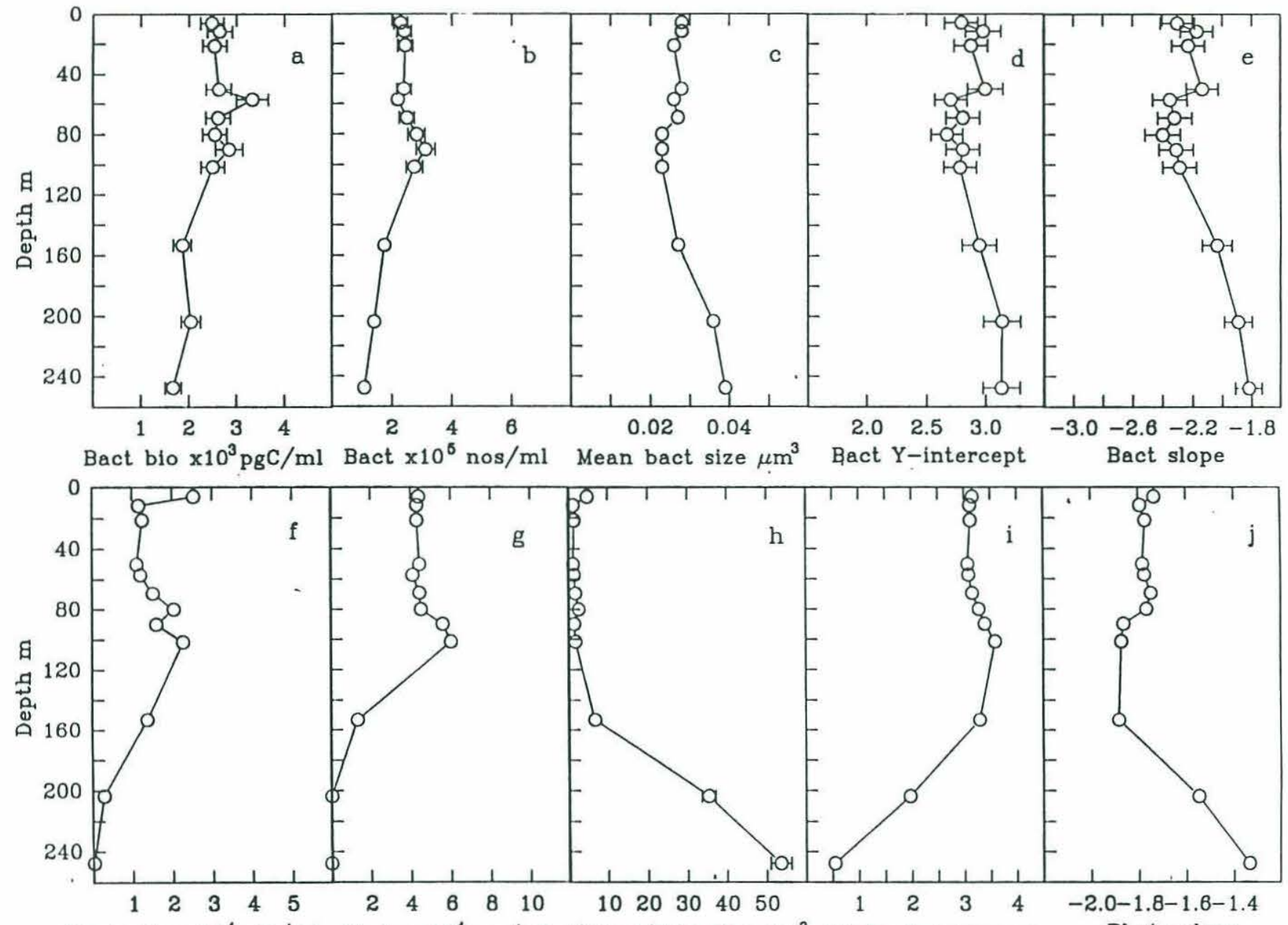

Phyto bio $\times 10^{4} \mathrm{pgC} / \mathrm{ml}$ Phyto $\times 10^{4} \mathrm{nos} / \mathrm{ml}$ Mean phyto size $\mu \mathrm{m}^{3}$ Phyto Y-intercept

Phyto slope

Fig. G10. Depth profiles of size spectral characteristics for the BATS station in the Sargasso Sea on April 14, 1993 at 1400 hrs, corresponding to the size spectra and environmental conditions shown in Fig. G9. 
APPENDIX H

ADDITIONAL FIGURES OF MICROBIAL SIZE SPECTRA FROM THE

EQUATORIAL PACIFIC 


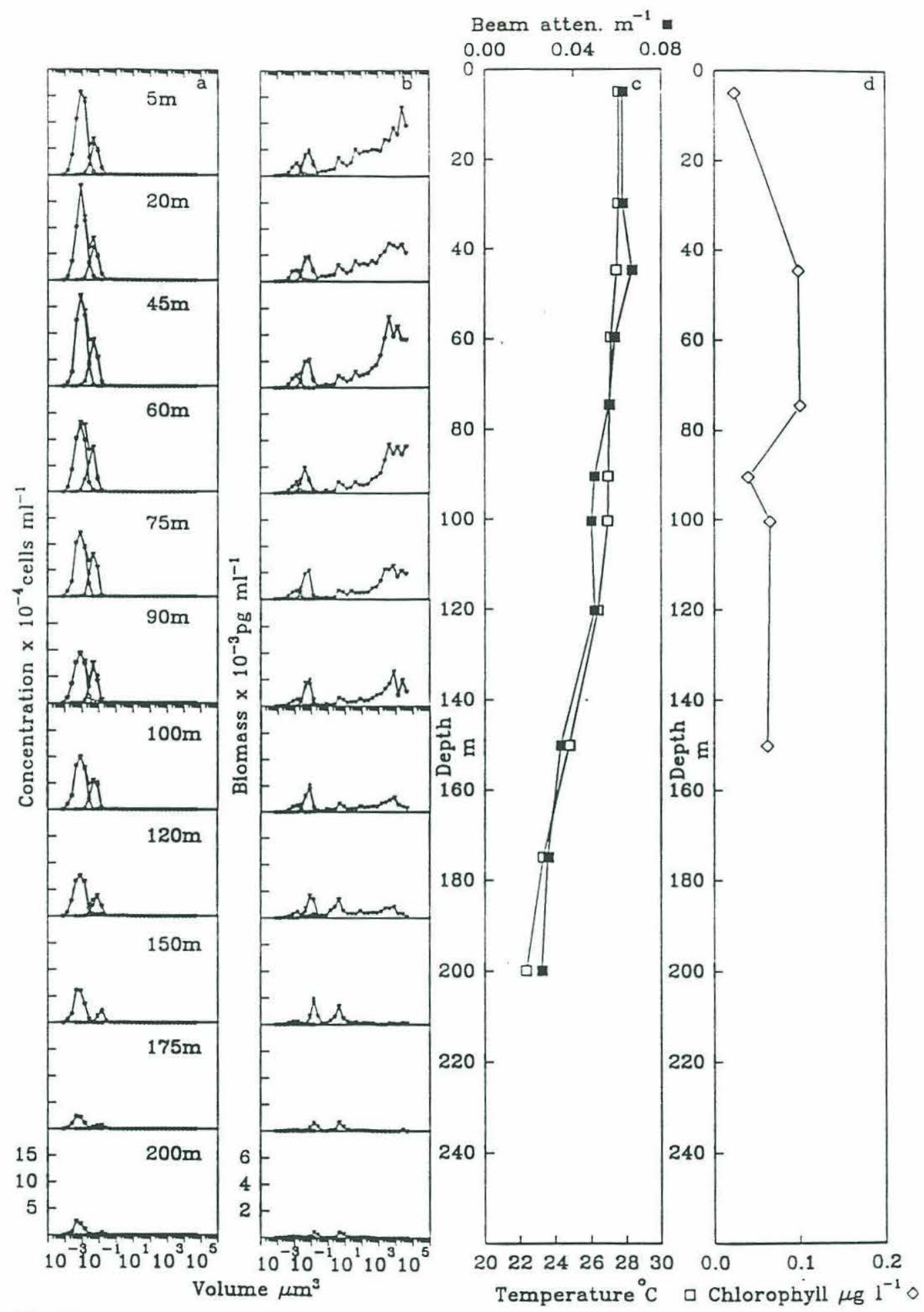

Fig. H1. Depth profiles of flow cytometricaily generated size spectra and environmental measurements for the equatorial Pacific $\left(12^{\circ} \mathrm{S}, 140^{\circ} \mathrm{W}\right)$ on September 25, 1992 at 2130 hrs. Environmental measurements were taken from J. Murray, W. Gardner and R. Bidigare. 

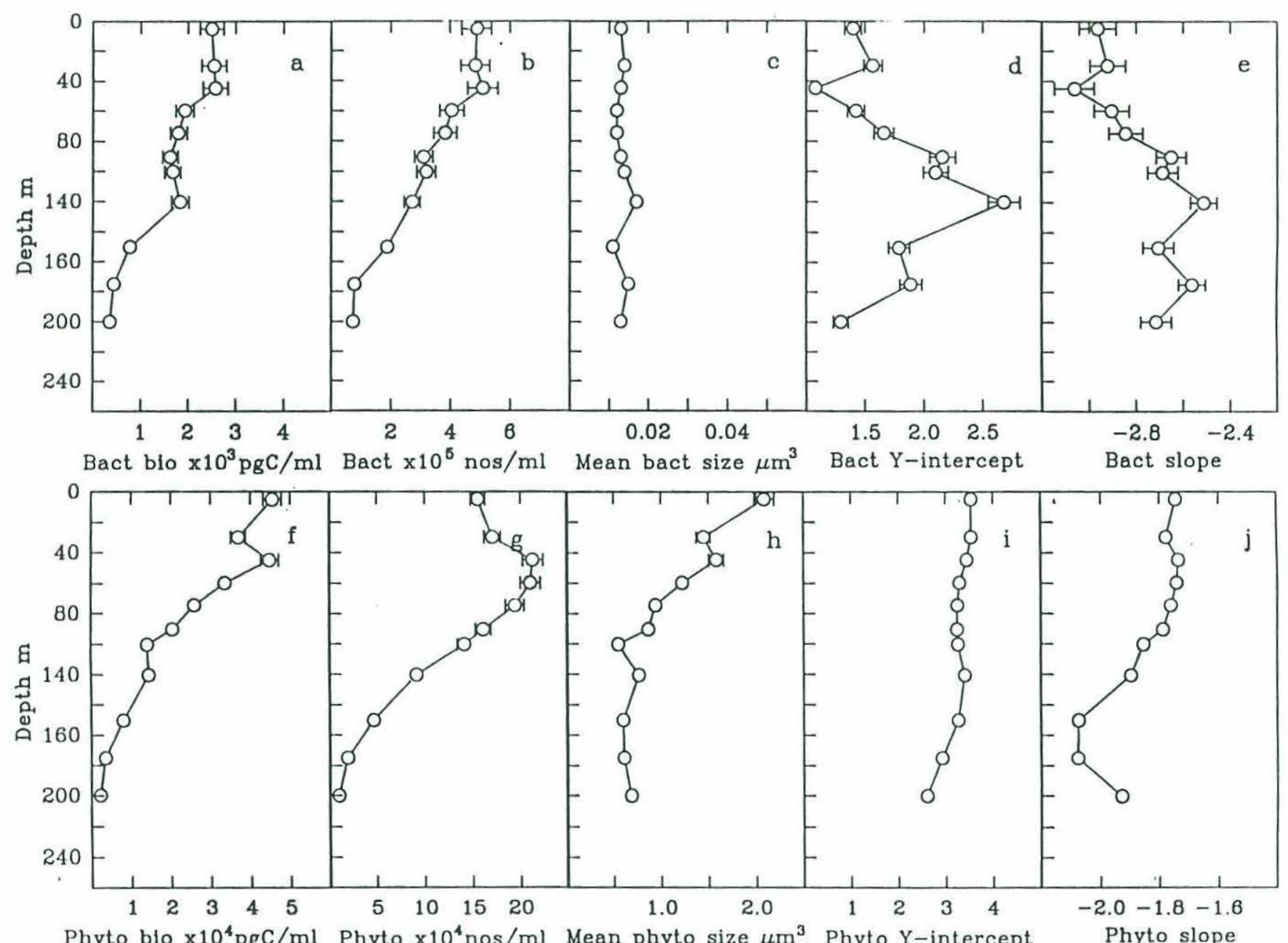

Fig. H2. Depth profiles of size spectral characteristics for the equatorial Pacific $\left(12^{\circ} \mathrm{S}, 140^{\circ} \mathrm{W}\right)$ on September 25,1992 at $2130 \mathrm{hrs}$, corresponding to the size spectra and environmental conditions shown in Fig. H1. 

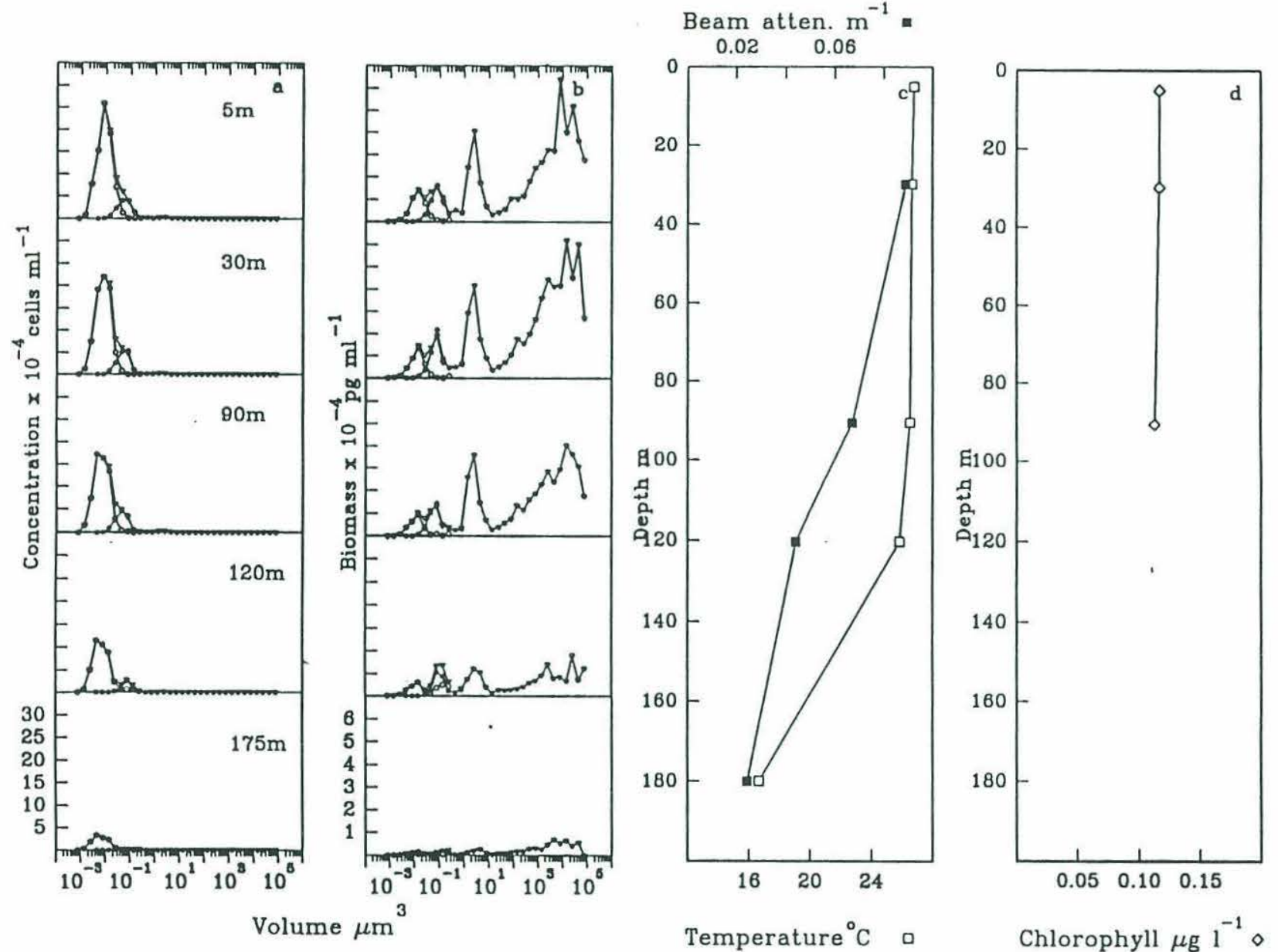

Fig. H3. Depth profiles of flow cytometrically generated size spectra and environmental measurements for the equatorial Pacific $\left(4^{\circ} \mathrm{S}\right.$, $140^{\circ} \mathrm{W}$ ) on September 30, 1992. Environmental measurements were taken from J. Murray, W. Gardner and R. Bidigare. 

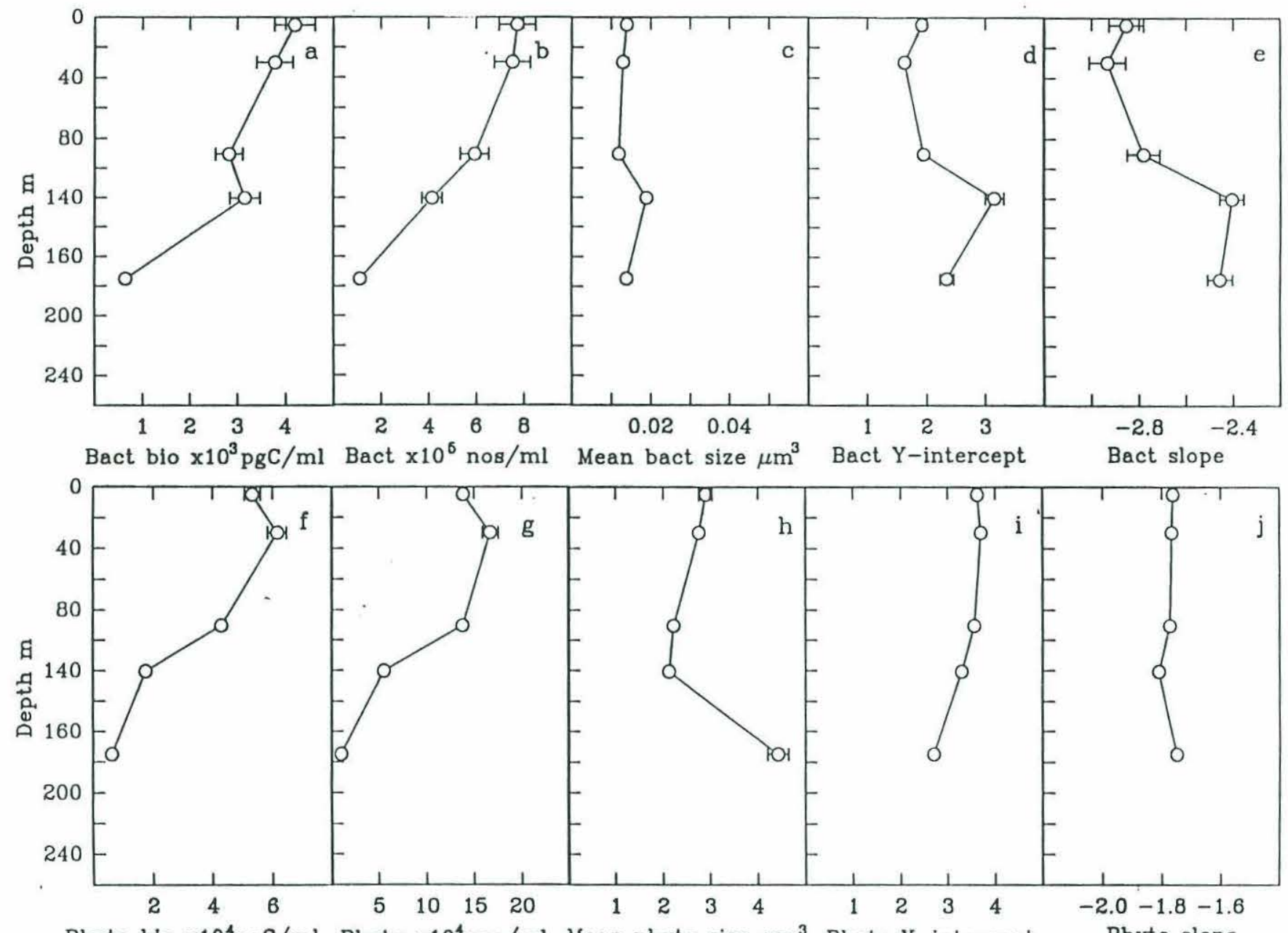

Phyto bio $\times 10^{4} \mathrm{pgC} / \mathrm{ml}$ Phyto $\times 10^{4} \mathrm{nos} / \mathrm{ml}$ Mean phyto size $\mu \mathrm{m}^{3}$ Phyto Y-intercept Phyto slope

Fig. H4. Depth profiles of size spectral characteristics for the equatorial Pacific $\left(4^{\circ} \mathrm{S}, 140^{\circ} \mathrm{W}\right)$ on September 30,1992 , corresponding to the size spectra and environmental conditions shown in Fig. H3. 

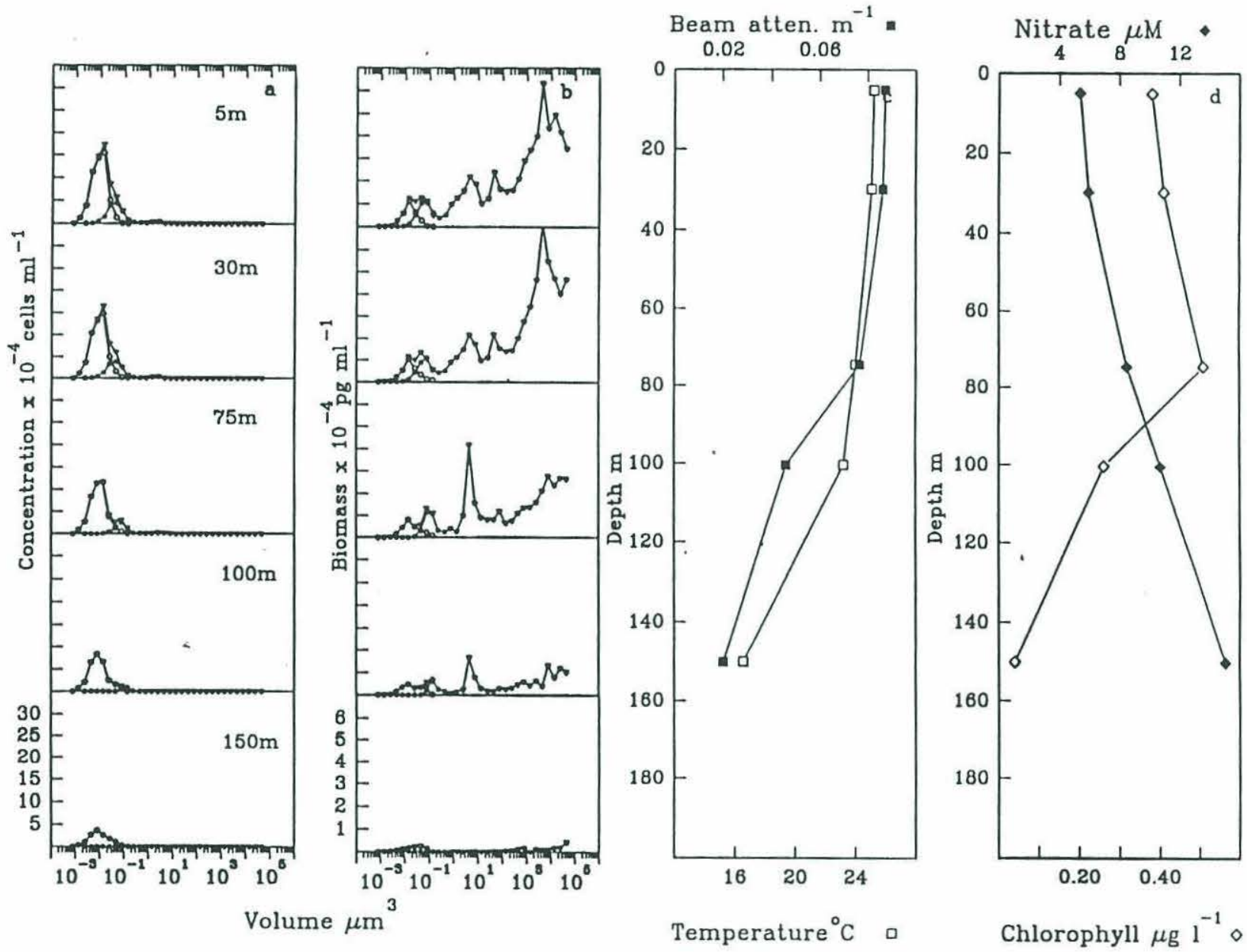

Fig. H5. Depth profiles of flow cytometrically generated size spectra and environmental measurements for the equatorial Pacific $\left(0^{\circ} \mathrm{S}\right.$, $140^{\circ} \mathrm{W}$ ) on October 3, 1992 at 0630 hrs. Environmental measurements were taken from J. Murray, W. Gardner, R. Bidigare and P.
Wheeler. 


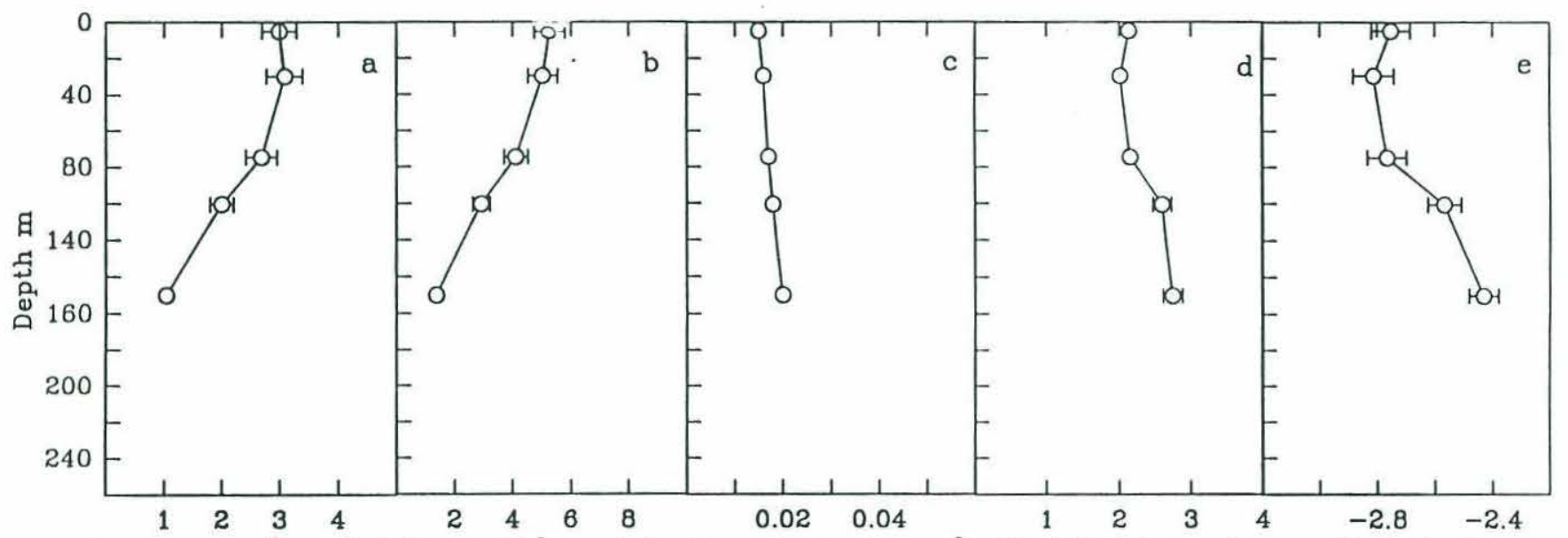

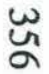

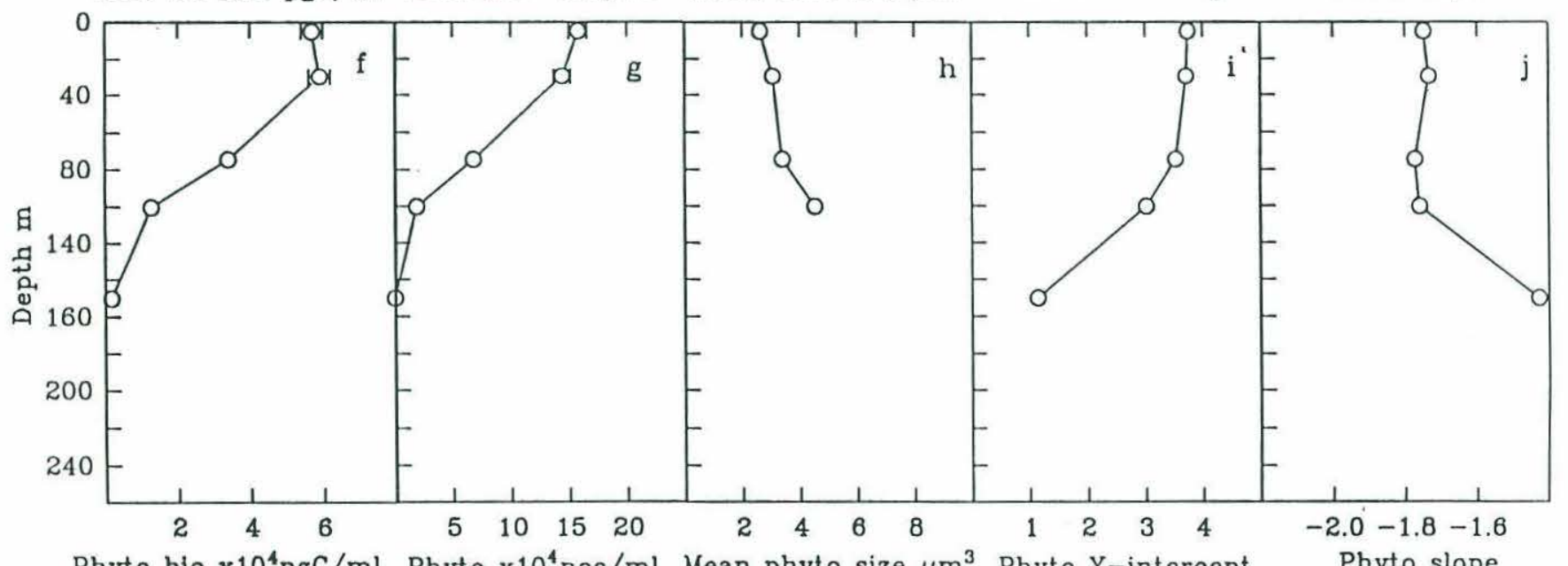

Phyto bio $\times 10^{4} \mathrm{pgC} / \mathrm{ml}$ Phyto $\times 10^{4}$ nos $/ \mathrm{ml}$ Mean phyto size $\mu \mathrm{m}^{3}$ Phyto Y-intercept

Phyto slope

Fig. H6. Depth profiles of size spectral characteristics for the equatorial Pacific $\left(0^{\circ} \mathrm{S}, 140^{\circ} \mathrm{W}\right)$ on October 3,1992 at $0630 \mathrm{hrs}$, corresponding to the size spectra and environmental conditions shown in Fig. H5. 


\section{REFERENCES (Appendices)}

Aref, L., 1996. Forward light scatter and how it relates to phytoplankton size in flow cytometry. MSc thesis, MIT.

Binder, B., Chisholm, S.W., Olson, R.J., Frankel, S.L. and Worden, A.Z., 1996. Dynamics of pico-phytoplankton, ultra-phytoplankton and bacteria in the central equatorial Pacific. Deep Sea Res. (in press).

Campbell, L., Nolla, H.A. and Vaulot, D., 1994. The importance of Prochlorococcus to community structure in the central North Pacific Ocean. Limnol. Oceanogr. 39(4): 954961.

Campillo, A.J. and Shapiro, S.L., 1978. Picosecond fluorescence studies of exciton migration and annihilation in photosynthetic systems. A review. Phytochem Photobiol. 28: 975-1013.

Chisholm, S.W., Olson, R.J., Zettler, E.R, Goericke, R., Waterbury, J. and Welschmeyer, N., 1988. A novel free-living prochlorophyte abundant in the oceanic euphotic zone. Nature 334: 340-343.

DuRand, M.D., 1995. Phytoplankton growth and diel variations in beam attenuation through individual cell analysis. Ph.D. Thesis. MIT/WHOI: 263pp.

Duval, C., 1993. Phototrophic and Heterotrophic Picoplankton in the Equatorial Pacific: Analysis by Flow Cytometry. MSc thesis. MIT: 127pp.

Gaedke, U., 1992. The size distribution of plankton biomass in a large lake and its seasonal variability. Limnol. Oceanogr. 37(6): 1202-1220.

Geider, R.J., Platt, T. and Raven, J.A., 1986. Size dependence of growth and photosynthesis in diatoms. Mar. Ecol. Prog. Ser. 30: 93-104.

Hall, J.A., 1991. Long-term preservation of picophytoplankton for counting by fluorescence microscopy. Brit. Phycol. J. 26: 169-174.

Hopcroft, R.R. and Roff, J.C., 1990. Phytoplankton size fractions in a tropical neritic ecosystem near Kingston, Jamaica. J. Plank. Res. 12: 1069-1088.

Kelly, J., Albro, C., Foster, K., Hennessy, J., Doering, P., Reed, L., Requintina, E., Turner, J. and Borkman, D. 1993. Water quality monitoring in Massachusetts and Cape 
Cod Bays: annual report for 1992. MWRA Enviro. Quality Dept. Tech. Rpt. Series No. 93-16. Massachusetts Water Resources Authority, Boston, MA: 129.

Kelly, J., Albro, C., Hennessy, J., Turner, J., Borkman, D. and Doering, P., 1994a. Water quality monitoring in Massachusetts and Cape Cod Bays: December 1992, February and March 1993. MWRA Enviro. Quality Dept. Tech. Rpt. Series No. 94-2. Massachusetts Water Resources Authority, Boston, MA: 197.

Kelly, J., Albro, C., Hennessy, J., Turner, J., Borkman, D. and Doering, P., 1994b. Water quality monitoring in Massachusetts and Cape Cod Bays: April and May 1993. MWRA Enviro. Quality Dept. Tech. Rpt. Series No. 94-3. Massachusetts Water Resources Authority, Boston, MA: 143.

Kelly, J., Albro, C., Hennessy, J., Turner, J., Borkman, D. and Doering, P., 1994c. Water quality monitoring in Massachusetts and Cape Cod Bays: June and July 1993. MWRA Enviro. Quality Dept. Tech. Rpt. Series No. 94-11. Massachusetts Water Resources Authority, Boston, MA: 152.

Kelly, J., Albro, C., Hennessy, J., Turner, J., Borkman, D. and Doering, P., 1994d. Water quality monitoring in Massachusetts and Cape Cod Bays: August and September 1993. MWRA Enviro. Quality Dept. Tech. Rpt. Series No. 94-12. Massachusetts Water Resources Authority, Boston, MA: 152.

Kiфrboe, T. 1993. Turbulence, phytoplankton cell size and the structure of pelagic food webs. Adv. in Mar. Bio. 29:1-72.

Knapp, A.H., Michaels, A.F., Dow, R.L., Johnson, R.J., Gundersen, K., Sorensen, J.C., Close, A.R., Hammer, M., Knauer, G.A., Lohrenz, S.E., Asper, V.A., Tuel, M., Ducklow, H., Quinby, H., Brewer, P. and Bidigare, R., 1994. Bermuda Atlantic Time-Series Studies : Data Report for BATS 37-48. U.S.JGOFS BATS Data Report B-4: 240pp.

Knapp, A.H., Michaels, A.F., Dow, R.L., Johnson, R.J., Gundersen, K., Sorensen, J.C., Close, A.R., Hammer, M., Knauer, G.A., Lohrenz, S.E., Asper, V.A., Tuel, M., Ducklow, H., Quinby, H., Brewer, P. and Bidigare, R., 1995. Bermuda Atlantic Time-Series Studies : Data Report for BATS 49-60. U.S.JGOFS BATS Data Report B-5: 240pp.

Landry, M., Kirshtein,J. and Monger, B., 1993. Quantitative estimates of paraformaldehyde preserved Prochlorococcus by flow cytometry. Signal Noise 6(1): 3

Li, W.K.W., 1994. Phytoplankton biomass and chlorophyll concentration across the North Atlantic. Sci. Mar. 58(1-2): 67-79. 
Mc Cave, I.N., 1975. Vertical flux of particles in the pelagic ecosystem. Helgol. wiss. Meeresunters 30: 575-581.

Monger, B. C. and Landry, M.R., 1993. Flow Cytometric Analysis of Marine Bacteria Using Hoechst 33342. Appl. Env. Microbiology 59: 905-911.

Neale, P.J., Cullen, J.J. and Yentsch, C. M., 1989. Bio-optical interferences from chlorophyll a fluorescence: What kind of fluorescence is measured in flow cytometry? Limnol. Oceanogr. 34: 1739-1748.

Olson, R.J., Zettler, E.A. and Anderesson, O.K., 1989. Discrimination of eukaryotic phytoplankton cell types from light scatter and autofluorescence properties measured by flow cytometry. Cytometry 10: 636-643.

Olson, R.J., Chisholm, S.W., Zettler, E.R. and Armbrust, E.V., 1990a. Pigments, size and distribution of Synechococcus in the North Atlantic and Pacific Oceans. Limnol. Oceanogr. 35: 45-58.

Raimbult, P., Rodier, M. and Taupier-Letage, I., 1988. Size fraction of phytoplankton in the Ligurian Sea and the Algerian Basin (Mediterranean Sea): Size distribution versus total concentration. Mar. Microb. Food Webs 3:1.

Rodriguez, J. and Mullin, M. 1986. Relation between biomass and body weight of plankton in a steady state oceanic ecosystem. Limnol. Oceanogr. 31 (2): 361-370.

Ruiz, J., Guerrero, V., Rodriguez, V. \& Rodriguez, J., 1992. Chlorophyll and size biomass spectrum of phytoplankton. Analysis of fluctuations in eutrophic, coastal waters. In G. Columbo, I. Ferrari, V.U. Ceccherelli \& R. Rossi (eds), Marine eutrophication and population dynamics. Olsen and Olsen, Denmark: 59-62.

Sheldon, R., Prakash, A. and Sutcliff, W., 1972. The size distribution of particles in the ocean. Limnol. Oceanogr. 17: 327-340.

Sieracki, M. and Cucci, T., 1993. A note on losses of Prochlorococcus cells due to preservation. Signal Noise 6(1): 2

Van De Hulst, H.C., 1957. Light scattering by small particles. John Wiley \& Sons, Inc., New York, 470 pp.

Vaulot, D., Courties, C. and Partensky, F. 1989. A simple method to preserve oceanic phytoplankton for flow cytometry analysis. Cytometry 10: 629-635. 